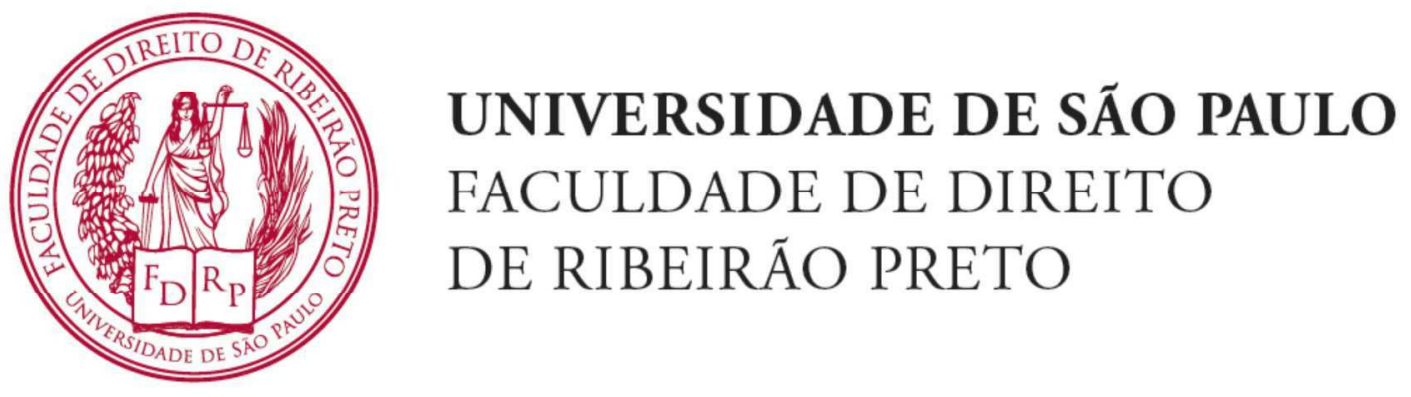

Marta Rodrigues Maffeis Moreira

\title{
CIRURGIA ESTÉTICA EM MENORES: \\ CAPACIDADE DE CONSENTIMENTO
}

\author{
Tese de Livre Docência
}

Ribeirão Preto

2016 
UNIVERSIDADE DE SÃO PAULO

FACULDADE DE DIREITO

DE RIBEIRÁO PRETO

Marta Rodrigues Maffeis Moreira

\section{CIRURGIA ESTÉTICA EM MENORES: \\ CAPACIDADE DE CONSENTIMENTO}

Tese apresentada como requisito parcial para o concurso de livre docência junto ao Departamento de Direito Privado e de Processo Civil - Área de Direito Civil Patrimonial e Existencial (Edital FDRP 29/2016).

\section{RIBEIRÃO PRETO}



Para

César,

Pelo amor incondicional;

Maria Júlia,

Mateus e

Natan,

Para que amem seus estudos. 



\section{RESUMO}

O presente trabalho busca estudar a capacidade de consentimento dos menores nas intervenções médicas, em especial, as cirurgias estéticas. Para tanto, desenvolve um panorama geral sobre a cirurgia estética e sua relação com a Medicina de Desejo, situando o Brasil no cenário mundial. Em se tratando de uma intervenção médica, abordam-se várias questões atinentes ao contrato de tratamento médico, sobretudo em relação ao paciente menor e adentra-se no tema do consentimento. Antes, porém, por se tratar de pressuposto para o consentimento eficaz, apresenta-se o dever de esclarecimento médico e os princípios constitucionais da dignidade da pessoa humana, o direito de autodeterminação e a autonomia. Em seguida, trata do consentimento médico nas intervenções médicas, abordando suas inúmeras discussões. Por fim, do consentimento dos menores capazes e incapazes de consentir e sua relação com o cuidado familiar.

Palavras-chave: cirurgia estética, capacidade de consentimento, menores, dever de esclarecimento, autodeterminação e cuidado familiar. 



\section{ABSTRACT}

The present study aims to investigate the minor's capacity of consenting to medical procedures, especially aesthetic surgeries. To this end, it presents a general scenario about cosmetic surgery and its relationship with the desire-driven medicine, or "medicine of desire", situating Brazil in the world scenario. Regarding medical procedures, several questions related to medical treatment agreements are addressed, mainly about minor patients and then discusses the informed consent issues. Prior to that, however, as it is a presupposition of an effective consent, it presents the responsibility for medical information and the constitutional principles of human dignity, the right of selfdetermination and autonomy. Subsenquently, it approaches the informed consent in medical procedures, approching its inumerous issues. Finally, it focuses on consents of minors capable and incapable of consenting and their relationship with family care.

Keywords: aesthetic surgery, capacity of consenting, minors, responsibility for clarification, self-determination and family care. 



\section{ZUSAMMENFASSUNG}

Die vorliegende Arbeit untersucht die Einwilligungsfähigkeit von Minderjährigen bei chirurgischen Eingriffen, vor allem bei Schönheitsoperationen. Dazu wird ein allgemeiner Überblick über das Gebiet der Schönheitsoperationen (Plastische Chirurgie) im Zusammenhang der sog. Wunschmedizin gegeben. Brasilien wird dabei im internationalen Kontext verortet. $\mathrm{Da}$ es sich um medizinische Eingriffe handelt, werden verschiedene Fragen hinsichtlich des Arzt- und Behandlungsvertrags diskutiert, mit dem Fokus auf den minderjährigen Patienten und der Frage der Einwilligung. Zuvor wird auf die Voraussetzung der wirksamen Einwilligung, d.h. auf die Aufklärungspflicht des Arztes eingegangen, sowie auf die konstituierenden Prinzipien der Menschenwürde, das Recht auf Selbstbestimmung und die Autonomie. Die darauf folgenden Ausführungen behandeln die medizinische Einwilligung bei den Eingriffen und die zahlreichen Diskussionen über diesen Punkt. Zum Schluss geht es um die Einwilligung der einwilligungsfähigen bzw. -unfähigen Minderjährigen und ihrer Beziehung zur elterlichen Sorge. 
Schlüsselwörter: Schönheitsoperation, Einwilligungsfähigkeit, Minderjährige, Aufklärungspflicht, Selbstbestimmung, elterliche Sorge. 


\section{SUMÁRIO}

SUMÁRIO

INTRODUÇÃO......................................................................................................7

CAPÍtUlO 1 - A CIRURGia PlÁSTICA ESTÉtiCA. Aspectos

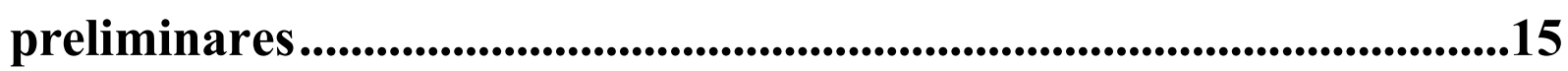

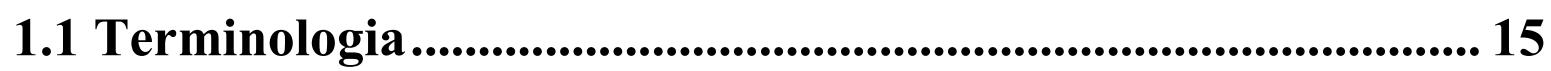

1.20 cirurgião plástico estético ............................................................ 21

1.3 Aspectos históricos ................................................................................. 31

1.4 Posição do Brasil no cenário mundial em relação aos procedimentos e cirurgias estéticas ........................................................ 35

CAPÍTULO 2 - MEDICINA DE DESEJO.............................................67

2.1. A cirurgia estética como medicina de desejo............................. 67

2.2. Indicação ............................................................................................... 78

2.3 Aspectos psíquicos ................................................................................ 93

2.3.1 Aspectos psíquicos e perturbações psíquicas...........................93

2.3.2 Perturbação de dismorfobia corporal.........................................98

CAPÍTULO 3 - O CONTRATO MÉDICO ........................................ 107

3.1 Aspectos preliminares .......................................................................... 107 
3.2. Obrigações de meio e de resultado .

3.3 O paciente menor

3.4. Natureza jurídica do contrato............................................... 150

3.4.1. Estipulação em favor de terceiros ..................................... 150

3.4.1.1 Panorama histórico ....................................................... 156

3.4.1.2 O terceiro (ou beneficiário) ............................................ 160

3.4.1.3 Partes contratuais (promissário e promitente) ................. 164

3.4.1.4 Objeto da estipulação em favor de terceiros e aquisição do

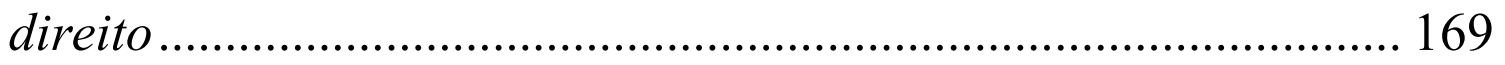

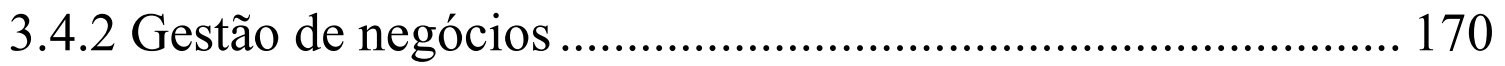

3.4.2.1 Caracterização ............................................................... 174

3.4.2.2 Deveres e responsabilização das partes ........................... 178

3.4.2.3 Ratificação ..................................................................... 183

3.4.2.4 Figuras afins e a morte de uma das partes ...................... 185

3.4.3 Relações contratuais de fato ............................................. 187

3.4.4 Conclusões sobre a natureza jurídica do contrato médico ... 201

CAPÍTULO 4 - DEVER DE ESCLARECIMENTO.......................... 203

4.1 A relação médico-paciente................................................ 203

4.2 A extensão do esclarecimento nas cirurgias estéticas............ 217 
4.3 Objeto do esclarecimento

4.3.1 Aspectos preliminares................................................. 226

4.3.2 Esclarecimento sobre o diagnóstico .................................. 228

4.3.3 Esclarecimento sobre o procedimento................................ 235

4.3.3.1 Quanto à execução da cirurgia ....................................... 236

4.3.3.2 Quanto às alternativas de tratamento ............................ 237

4.3.3.3 Quanto às perspectivas de sucesso ................................. 241

4.3.3.4 Quanto aos prejuízos para a saúde ................................. 246

4.3.4 Esclarecimento sobre os riscos ...................................... 248

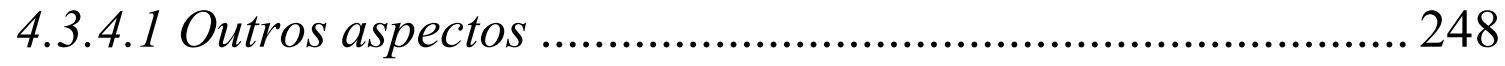

4.3.4.2. A suspeita de risco ....................................................... 252

4.3.5 Outros tipos de esclarecimento........................................ 255

4.3.5.1 Quanto aos efeitos dos medicamentos ............................ 255

4.3.5.2 Quanto a não realização do tratamento .......................... 255

4.3.5.3 Quanto à qualidade .................................................... 256

4.4 Realização do esclarecimento ............................................... 257

4.4.1 A conversa de esclarecimento .......................................... 257

4.4.2 Documentação do esclarecimento ...................................... 261 
4.4.3 Pessoas envolvidas no esclarecimento ............................... 267

CAPÍTULO 5 - CONSENTIMENTO .................................................. 269

5.1. Aspectos genéricos sobre consentimento e vontade.............. 269

5.2 Princípios constitucionais do consentimento ......................... 272

5.2.1 Dignidade da pessoa humana ......................................... 273

5.2.2 Autodeterminação e Autonomia........................................ 282

5.2.2.1 Considerações iniciais................................................... 282

5.2.2.2 Autonomia e autodeterminação nas intervenções médicas287

5.2.2.3 A relação entre autonomia e beneficência: autonomia nas intervenções médicas em crianças e adolescentes ........................ 297

5.3 Contexto Internacional .................................................... 304

5.3.1 Convenção Internacional sobre os Direitos da Criança ....... 304

5.3.2 Convenção de Biomedicina ................................................ 323

CAPÍTULO 6 - O CONSENTIMENTO NAS INTERVENÇÕES MÉDICAS .............................................................................................. 329

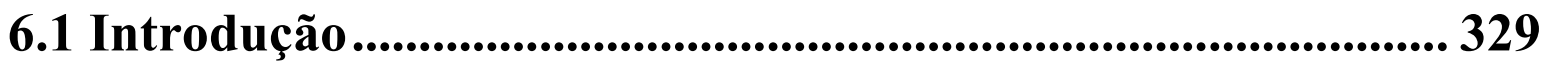

6.2 Natureza jurídica do consentimento nas intervenções

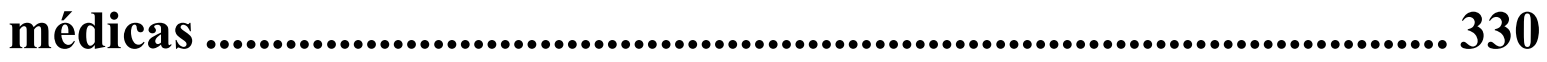

6.3 A capacidade de consentir ......................................................... 337 
6.3.1 Concepções não jurídicas da capacidade de consentir.

6.3.2 Concepção jurídica da capacidade de consentir

6.3.3 Avaliação da capacidade de consentimento no caso concreto.... 368

6.3.4 Parâmetros para avaliar a capacidade de consentimento ..... 391

6.3.4.1 Tipo de tratamento.

6.3.4.2 Racionalidade objetiva 400

CAPÍTULO 7 - O CONSENTIMENTO NAS INTERVENÇÕES MÉDICAS EM MENORES 407

7.1 Os menores incapazes de consentir 407

7.1.1 A concepção do consentimento como cuidado da pessoa.... 407 7.1.2 O consentimento dos pais nos procedimentos médicos como objeto do cuidado familiar 416

7.1.3 Definição e pressupostos da capacidade de veto 429

7.2 Menores capazes de consentir 446 


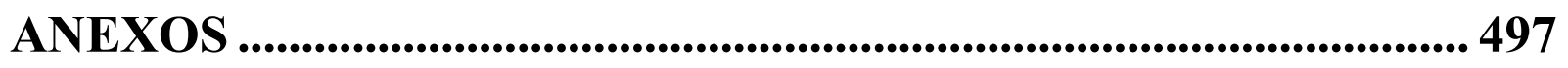

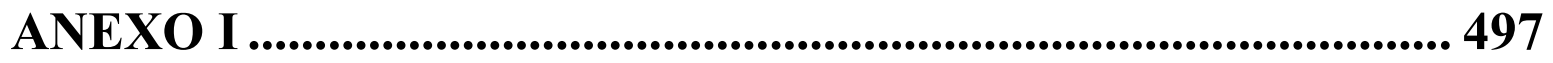

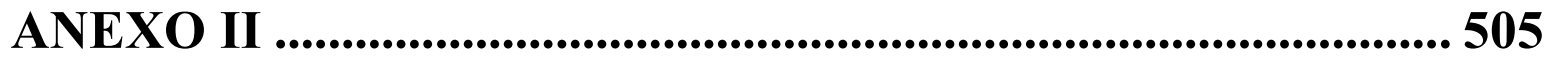

ANEXO III .............................................................................. 533

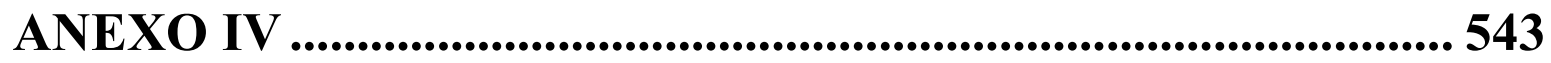

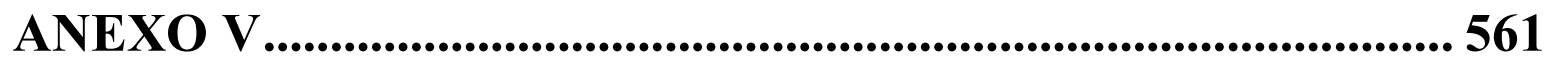

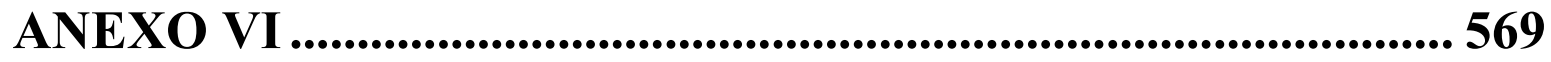

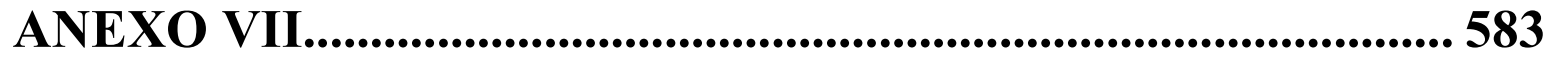

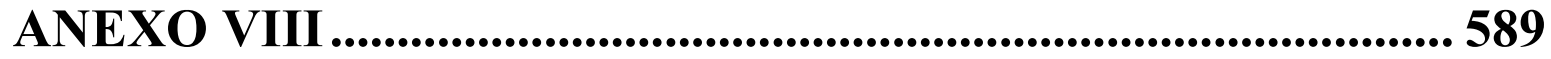




\section{INTRODUÇÃO}

O presente trabalho tem por objetivo analisar a prática da cirurgia plástica estética em menores por considerar esse assunto de grande relevância e repercussão social. Segundo dados da Sociedade Brasileira de Cirurgia Plástica (SBCP), no período de 2008 a 2012 o número de cirurgias aumentou $141 \%$ entre adolescentes de 14 a 18 anos, enquanto no mesmo período essas cirurgias cresceram $38,6 \%$ entre os adultos, o que significa que entre os menores as cirurgias aumentaram 3,5 vezes mais. ${ }^{1}$

O Brasil é um dos países onde mais se realiza esse tipo de intervenção médica, ocupando, em regra, o $2^{\circ}$ lugar no ranking mundial. Em relação ao procedimento de aumento de mama entre adolescentes menores de 18 anos, o país se posiciona em primeiro lugar no mundo, sendo seguido pela Colômbia, conforme estatística internacional que será apresentada no capítulo 1. A ausência de regulamentação específica sobre o tema, aliada à frequência da realização desses procedimentos demonstram a necessidade de se aprofundar o debate e o estudo sobre o tema.

Recentemente, em 25 de julho de 2016, a Colômbia aprovou uma lei proibindo a prática de cirurgias estéticas em menores de idade, excepcionando apenas cirurgias de nariz e orelhas. Segundo noticiário de

${ }^{1}$ Disponível em: $<$ http://www2.cirurgiaplastica.org.br/>. Acesso em: 5 dez. 2016. 
grande circulação daquele país, ${ }^{2}$ a legislação teve por escopo frear o aumento das intervenções estéticas em menores, principalmente mulheres, que buscam alcançar níveis de beleza de forma obsessiva, até mesmo em clínicas clandestinas, submetendo-se a cirurgias e procedimentos estéticos que muitas vezes lhes causam diversas complicações de saúde e, até mesmo, a morte. As cirurgias mais recorrentes são aumento de mama e glúteo e as jovens tomam por modelo de beleza aquele veiculado pela mídia, como por exemplo, a novela "Sin tetas no hay paraíso" de Gustavo Bolívar, que explora a relação entre beleza e narcotráfico.

Segundo a notícia, até o momento esses procedimentos podiam ser feitos de forma livre, sendo necessário apenas o consentimento dos genitores e do médico. Entretanto, pode-se concluir que isso não foi suficiente para coibir a prática exagerada de cirurgias estéticas em menores.

Também na Alemanha, a notícia foi veiculada pelo Frankfurter Allgemeine, ${ }^{3}$ no sentido de que a Colômbia pertence a um dos sete países do mundo onde mais se pratica cirurgia estética e que, em 2015, segundo estatística internacional, foram realizadas na América Latina mais de meio milhão de intervenções cirúrgicas e não cirúrgicas. No país das telenovelas e concurso de misses, a aparência se tornou uma verdadeira obsessão pelas mulheres. Na América Latina, tem sido prática frequente as meninas

2 Disponível em: <http://www.semana.com/nacion/articulo/ley-que-prohibe-cirugiasplasticas-a-menores-de-edad/483487>. Acesso em: 7 dez. 2016.

3 Disponível em: <http://www.faz.net/aktuell/stil/leib-seele/neue-brueste-zum-15geburtstag-14534139.html>. Acesso em: 7 dez. 2016. 
ganharem de presente de quinze anos, ao invés da tradicional festa, uma cirurgia de aumento de mama.

As jovens entrevistadas na notícia narraram que mulheres sofrem forte pressão social pela beleza e que a aparência lhes abre muitas oportunidades, tanto pessoais como profissionais. Contaram que a pressão advém não só dos meios de comunicação, redes sociais e publicidade, mas até mesmo de amigas que já se submeteram a uma operação estética. Muitas delas não desejavam sofrer esse tipo cirurgia, mas, por conta da pressão, deixaram-se operar e sofreram consequências como fortes dores e cicatrizes marcantes.

No Brasil, o cenário não é diferente. Considerando que o país está à frente da Colômbia na prática de cirurgias de aumento de mama entre jovens menores de 18 anos, conforme a referida estatística, é possível ter uma ideia da gravidade do tema no contexto nacional, observando que também é um país onde se dá muito valor à beleza feminina, onde imperam as telenovelas com seus modelos de beleza e onde o narcotráfico possui forte aderência.

Segundo notícia veiculada pela revista Veja, ${ }^{4}$ especialistas são contrários à prática de procedimentos estéticos invasivos em adolescentes, afirmando categoricamente que são contraindicados, uma vez que a adolescência é um período caracterizado por transformações no corpo, o que pode gerar insatisfações com a aparência e levar ao desejo de constantes correções. No Brasil, como não há uma lei proibindo cirurgias estéticas em 4 Disponível em: <http://veja.abril.com.br/saude/kylie-admitiu-ter-preenchido-oslabios-pode/>. Acesso em: 7 dez. 2016. 
menores, a recomendação da Sociedade Brasileira de Cirurgia Plástica é que apenas sejam realizados procedimentos relacionados com problemas de saúde, como correção de lábio leporino, orelha de abano, rinoplastia para melhorar a respiração, além da redução das mamas quando há comprometimento da coluna. Entretanto, a busca nos consultórios pelos menores não é apenas por essas intervenções, mas principalmente para a colocação de próteses de silicone e lipoaspiração.

O tema, entretanto, não pode ser enfrentado sem um olhar sobre os menores e sua capacidade de consentimento para as intervenções médicas. Desse modo, este trabalho se debruçará sobre uma das peculiaridades do Direito Médico, que é a capacidade de consentir dos menores, por meio da qual, menores podem e devem dar seu consentimento para a prática de intervenções médicas, ainda que sejam considerados incapazes para a prática de atos civis conforme as regras de incapacidade do Direito Civil.

Para adentrar no tema propriamente dito é preciso analisar diversas questões, todas elas interligadas com o tema da prática de cirurgias estéticas em menores e sua capacidade de consentimento.

Dessa forma, no capítulo 1, apresenta-se um panorama geral sobre a cirurgia estética, a figura do cirurgião plástico estético e sua formação profissional, bem como questões atinentes à especialidade da Medicina Estética. A seguir, expõe-se um breve histórico sobre a prática da cirurgia estética no Brasil e finaliza-se contextualizando o Brasil no cenário mundial 
em relação à prática da cirurgia estética com vários quadros de pesquisa internacional, que demonstram a posição de destaque do país no cenário mundial.

No capítulo 2, são trazidas várias considerações sobre a Medicina de Desejo, conceito formulado para diferenciar um ramo de tendência na Medicina em contraposição à Medicina Tradicional. Em seguida, aborda-se o conceito de indicação médica e suas peculiaridades em relação à cirurgia estética e, como desdobramento, analisa-se o tema das perturbações psíquicas, não raramente relacionadas à prática dessa cirurgia, em especial a perturbação da dismorfobia corporal.

O capítulo 3 é dedicado ao contrato de tratamento médico. Inicia-se com aspectos gerais desse tipo de contrato, para depois enfrentar a tradicional questão das obrigações de meio e resultado. Prossegue-se com questões específicas do contrato médico com paciente menor, sendo estudado o tema da natureza jurídica do contrato.

O capítulo 4 trata do dever de esclarecimento. Primeiramente, cuida-se da relação médico-paciente para, em seguida, adentrar nas especificidades do dever de esclarecer em seus vários aspectos, quais sejam, a extensão do esclarecimento, seu objeto, riscos e demais aspectos importantes, finalizando com a conversa de esclarecimento e a documentação respectiva.

No capítulo 5, adentra-se no tema do consentimento. Diante da amplitude do tema, de início são apresentadas algumas considerações gerais 
para situar essa temática. Em seguida, abordam-se os princípios constitucionais do consentimento e, por fim, apresenta-se o contexto internacional sobre os direitos das crianças, em especial a Convenção Internacional sobre os Direitos da Criança e a Convenção de Biomedicina, nas quais vários direitos são regulamentados, principalmente o direito de expressão e opinião.

O capítulo 6 trata do consentimento nas intervenções médicas e aborda diversas questões polêmicas. Em primeiro lugar, a natureza jurídica do consentimento em tais intervenções, sua diferença da capacidade de agir e implicações entre ambas. A seguir, cuida-se da capacidade de consentimento, analisando-se concepções não jurídicas e jurídicas da capacidade. Ainda nesse capítulo, é estudada a questão da avaliação da capacidade de consentimento, por meio de parâmetros sugeridos pela doutrina.

O último capítulo cuida do consentimento nas intervenções médicas em menores, considerando, em primeiro lugar, os menores incapazes de consentimento e as implicações do poder familiar, ora tratado por cuidado familiar e, por fim, os menores capazes de consentimento.

O presente trabalho contém abundante literatura e legislação alemã, uma vez que, nesse país, desenvolveu-se, até o momento, significativa pesquisa a respeito do tema ora estudado, enquanto quase nada se encontrou em outros países como Brasil, Itália, França, Portugal e Espanha. Além 
disso, por se tratarem de países, cujos sistemas jurídicos pertencem à tradição romano-germânica (civil law), mostra-se plausível a aplicação e interpretação dos institutos jurídicos no Brasil. 


\section{CAPÍTULO 1 - A CIRURGIA PLÁSTICA ESTÉTICA. Aspectos preliminares}

\subsection{Terminologia}

$\mathrm{O}$ conceito de cirurgia plástica estética refere-se às intervenções médicas que têm por finalidade o embelezamento por meio de mudança da aparência exterior do paciente movida por um desejo seu e para as quais não existe um motivo para a atividade médica. ${ }^{5}$ A atividade médica convencional diz respeito à cura ou alívio de doenças, sofrimentos e demais danos corporais e psíquicos. Entretanto, no caso da cirurgia plástica estética, tal atividade refere-se às intervenções sem o escopo de tratar uma doença ou melhorar as funções fisiológicas. ${ }^{6}$ Nesse ponto, a cirurgia plástica estética diferencia-se da cirurgia plástica reparadora, a qual se ocupa com a eliminação de doenças e correção das mais variadas lesões, que contemplam queimaduras, reconstrução mamária após a cirurgia de câncer de mama, sequelas ocasionadas por acidentes, fratura de ossos da face, lesões causadas por tumores ou cânceres de peles, entre outras. ${ }^{7}$

${ }^{5}$ STOCK, Christof. Die Indikation in der Wunschmedizin. Ein medizinrechtlicher Beitrag zur ethischen Diskussion über "Enhancement". Frankfurt am Main: Peter Lang, 2009. p. 159.

${ }^{6}$ WENZEL, Frank. Handbuch des Fachanwalts Medizinrecht. Köln: Luchterhand, 2007. pp. 30-32.

${ }^{7}$ STOCK, Christof. Die Indikation in der Wunschmedizin. Op. Cit. p. 159. 
Também pertencem ao campo da cirurgia plástica estética intervenções suplementares pelas quais são fornecidos outros serviços a pedido do cliente que vão além do necessário, sob o ponto de vista médico. ${ }^{8}$

No presente trabalho será usada a terminologia abreviada "cirurgia estética" em atenção ao uso pela jurisprudência da expressão "cirurgia plástica estética" e pela literatura médica da expressão "Medicina Estética". São reconhecidos, ainda os termos cirurgia cosmética e cirurgia embelezadora, os quais, por vezes, são encontrados na doutrina, mas que não serão utilizados na presente pesquisa.

À primeira vista, o conceito de cirurgia plástica estética pode parecer compreensível de modo geral. Entretanto, um olhar mais agudo demonstrará que há inúmeras dificuldades em torno do conceito de beleza.

Se a cirurgia estética busca a beleza, pergunta-se, então, o que é a beleza?

O dicionário Oxford explica o conceito de beauty como a qualidade de ser prazeroso aos sentidos ou à mente, ou seja, uma conexão de características que proporcionam alegria para os sentidos. ${ }^{9} \mathrm{O}$ dicionário Aurélio, por sua vez, ${ }^{10}$ traz belo como aquilo que tem formas perfeitas e

${ }^{8}$ Ibidem, p. 159. Por exemplo, uma mulher que irá passar por um procedimento de retirada de nódulo na mama e pede ao médico que coloque implante de silicone.

${ }^{9}$ UNIVERSITY OF OXFORD. Verbete Beauty. In Oxford Advanced Learner's Dictionary. 6 ed. Oxford: University Press, 2004. p. 102.

${ }^{10}$ BUARQUE DE HOLANDA, Aurélio. Verbete Belo. In Novo Dicionário Aurélio da Língua Portuguesa, 2 ed. Rio de Janeiro: Nova Fronteira, 1986. p.246. 
proporções harmônicas; que é agradável aos sentidos. A Brockhaus Enzyklopädie usa o conceito de beleza para descrever o termo estética no sentido da percepção, a teoria que tem por objeto a beleza em ambas as formas, a natural e a artística. ${ }^{11}$

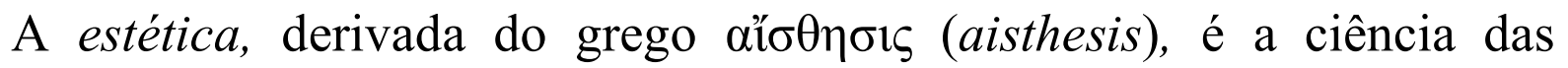
sensações, como a define MORAES SILVA; ${ }^{12}$ é a teoria das artes fundada sobre natureza e gosto. Trata-se da ciência do belo e que estuda as leis gerais da crítica e do gosto, aplicadas à avaliação e apreciação dos produtos da inteligência humana debaixo do ponto de vista artístico. ${ }^{13}$ Cabe ressaltar, no entanto, que algumas fontes filosóficas e literárias gregas de Platão, no

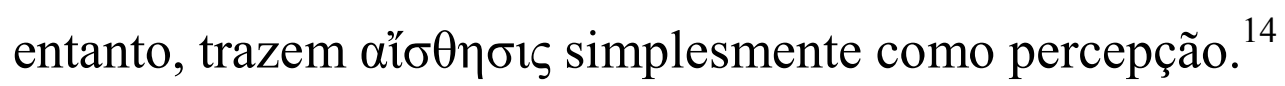

Com isso vê-se que não há uma definição unívoca, mas um reconhecimento de que se trata de um conceito mais complexo do que pode parecer à primeira vista. Poderá a beleza ser conceituada objetivamente, dependerá ela do âmbito cultural no qual a pessoa está inserida ou dependerá da percepção do observador? ${ }^{15}$

${ }^{11}$ Verbete Ästhetik. In Brockhaus Enzyklopädie. v. 2, p. 558.

${ }^{12}$ Verbete Esthètica in Diccionario da língua portugueza. v. 1.8 ed.. Rio de Janeiro: Empreza Litteraria Fluminense, 1890. p. 850.

13 CALDAS AULETE, Francisco Júlio. Verbete Estética in Dicionário contemporâneo da língua portuguesa. v. 2, 3 ed.. Lisboa: Sociedade Industrial de Tipografia, 1948. p. 1153.

${ }_{14}$ Nesse sentido, Theaetetus, 151e; Republ. 6, 507e.

15 LORZ, Sigrid. Arzthaftung bei Schönheitsoperationen. Berlin: Dunckler \& Humblot, 2007. p. 28. 
Na história da filosofia muito se discutiu se a beleza é ou não um conceito objetivamente determinável. No classicismo grego, a beleza era composta por harmonia e simetria. No caso do corpo humano, era importante a congruência proporcional das diferentes partes formando um todo harmônico. Usavam-se, para tanto, fórmulas matemáticas, para cálculos da beleza. Como medida para o corpo ideal calculava-se a equivalência triangular entre ambos os mamilos e o umbigo. ${ }^{16} \mathrm{Na}$ Grécia Antiga, Aristóteles considerava a beleza por meio de ordem e simetria. ${ }^{17}$

No caminhar dos séculos, muitos, principalmente artistas e pintores, chegaram a defender o famoso axioma de que as proporções seriam mais ideais quanto mais se aproximassem da chamada proporção áurea, representada pela letra grega $\varphi$ em homenagem ao grego Fidias, que teria supervisionado as construções do Partenon. ${ }^{18} /{ }^{19} \mathrm{Na}$ época do Renascimento,

16 BREDIN, Hugh; SANTORO-BRIENZA, Liberato. Philosophies of Art and Beauty. Introducing Aesthetics. Edinburgh: Edinburgh University Press, 2000. pp. 22, 27-28.

17 WAGNER, Jörg. Der Begriff des Schönen in der Definition von Platon, Arstoteles und Seneca. Preetz: Bahnsen, 2000. p. 12.

${ }^{18}$ NAINI, Farhad. Facial Aesthetics: Concepts \& Clinical Diagnosis, 2011. Trad. Port. Sílvia Mariângela Spada (et. al.). Estética Facial: Conceitos e diagnósticos clínicos. Rio de Janeiro, Elsevier, 2014. p. 43.

${ }^{19}$ Há quem afirme, inclusive, que o número $\varphi$, obtido pela proporção áurea, algo em torno de 1.61803, o qual é um número irracional, esteja presente em várias obras de

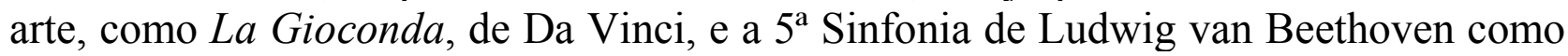
ideia de algo que agrada os sentidos. Nesse Sentido, BELINI, Marcelo Manechine. A razão áurea e a sequência de Fibonacci. Dissertação de mestrado apresentada ao Instituto de Ciências Matemáticas e de Computação da Universidade de São Paulo. Orientador: Prof. Assoc. Márcio Fuzeto Gameiro. São Carlos, 2015. pp. 13-27. 
Leonardo da Vinci também considerava a proporcionalidade dos antigos para sustentar que um rosto belo consiste em três grandes partes simétricas. ${ }^{20}$

Em época mais recente, foram feitas diversas tentativas por meio de pesquisa de atratividade para determinar o conceito de beleza conforme critérios objetivos. Um aspecto ponderado pela pesquisa foi a média de atratividade, de forma que quanto mais um rosto se aproxima ao formato médio de uma certa população, maior será sua atratividade e, por consequência, sua beleza. ${ }^{21}$

Outro aspecto para a determinação objetiva da beleza poderia ser visualizado na funcionalidade eficiente do corpo humano. Por exemplo, pernas longas são vistas em todas as culturas como atraentes porque se pode fugir com mais rapidez, andar mais e, com isso, ter maiores chances de sobrevivência. Ademais, uma característica de beleza seria a simetria de ambas as metades do corpo (esquerda e direita), uma vez que isso demonstraria ausência de defeito genético e, com isso, mais saúde. ${ }^{22}$

Tais perspectivas de determinação objetiva da beleza podem até servir como um ponto de partida, mas não abarcam todo o conceito de beleza em

${ }^{20}$ RÜDIGER, Margit; GROSSHANS, Lore. Schönheitsoperationen, Beauty nach Mass. München: GU, 2003. p. 12.

${ }^{21}$ ETCOFF, Nancy. Nur die Schönsten überleben. Die Ästhetik des Menschen. München: Diederichs, 2001. p. 34.

${ }^{22}$ MÜLLER; SCHUSTER, Was zeichnet ein schönes Gesicht aus?. In: HERGOVICH, Andreas (Coord.). Psychologie des Schönheit. Physische Attraktivität aus wissenschaftlicher Perspektive, Wien, WUV, 2002. p. 205. 
sua complexidade. Ainda que se possa medir o corpo humano pela simetria e proporcionalidade, comparando-o com a média dos demais corpos, a beleza não se deixa reduzir a medidas numéricas. É verdade que a medida média pode ser considerada como medida padrão e base da beleza, mas não a beleza em si mesma, a qual requer muitas outras características. Além disso, tomar um corpo como sendo o ideal e perfeito seria reduzir demais a beleza, que se deixa demostrar por meio de inúmeras formas. ${ }^{23}$

Nesse sentido, a beleza não pode ser determinada apenas por critérios objetivos, mas, sobretudo, por aspectos culturais. Um típico exemplo disso são as ideias de beleza em relação à massa corporal. No período barroco e ainda hoje em muitos países da África, um corpo com bastante gordura sinaliza bem-estar material e, por isso, é considerado belo. De outro lado, na cultura europeia atual um corpo esbelto sinaliza disciplina e força de vontade $^{24}$.

Ainda, ao lado dessa concepção cultural, existe a concepção de tratar a beleza através de critérios subjetivos, pela qual se sustenta que a beleza existe somente através da percepção da mente e cada mente percebe uma

${ }^{23}$ ETCOFF, Nancy. Nur die Schönsten überleben. Op. Cit., p. 15.

${ }^{24}$ POSCH, Waltraud. Körper machen Leute: Der Kult um die Schönheit. Frankfurt: Campus, 1999. pp. 37; 48-49. 
beleza diferente. ${ }^{25}$ Atualmente propaga-se essa concepção de que beleza deveria ser determinada apenas de forma subjetiva e não objetiva. ${ }^{26}$

No contexto da cirurgia estética o conceito de beleza deve der determinado de forma funcional, ou seja, é o paciente que determina a beleza de seu corpo como objetivo da cirurgia conforme sua percepção individual. Evidente que sua percepção pode ser influenciada por critérios objetivos, pela média de beleza de uma certa população ou por critérios culturais, mas decisiva é seu sentimento pessoal. ${ }^{27}$

\section{$1.2 O$ cirurgião plástico estético}

Para o exercício da Medicina não é obrigatória a obtenção do título de especialista. Esse título pode ser obtido após a conclusão de um programa de Residência Médica reconhecido pelo MEC ou por meio de concurso de título da respectiva Sociedade de especialidade médica. Esse concurso consiste em prova elaborada pela Sociedade após o profissional ter realizado um curso de especialização, estágio ou outra forma de capacitação ${ }^{28}$.

25 BRAZDA; HUNEK; KÄMPFER, Der Schönheitsbegriff in der Antike, in: HERGOVICH, Andreas (Coord.). Psychologie der Schönheit. Op. Cit., pp. 15-18. ${ }^{26}$ LIGGETT, Arline. Die Tyrannei des Schönheit, München: Heyne, 1991. p. 168.

${ }^{27}$ LORZ, Sigrid. Arzthaftung bei Schönheitsoperationen. Op. Cit., p. 34.

${ }^{28}$ Disponível em $<$ http://portal.mec.gov.br/residencias-em-saude $>$. Acesso em 18 nov. 2016. 
A Residência Médica foi criada pelo Decreto Federal $\mathrm{n}^{\circ} 80.281$ de 5/9/1977 ${ }^{29}$. Dispõe seu art. $1^{\mathrm{o}}$ :

A Residência em Medicina constitui modalidade do ensino de pósgraduação destinada a médicos, sob a forma de curso de especialização, caracterizada por treinamento em serviço, em regime de dedicação exclusiva, funcionando em Instituições de saúde, universitárias ou não, sob a orientação de profissionais médicos de elevada qualificação ética e profissional.

Segundo o $\mathrm{MEC}^{30}$, a residência médica é considerada o melhor instrumento para a especialização médica e só pode ser empregada para programas que sejam credenciados pela Comissão Nacional de Residência Médica.

A formação de um cirurgião plástico ocorre por etapas. Após os seis anos da graduação na faculdade de medicina, o profissional deve fazer residência em "Cirurgia Geral" por um período de dois anos. Nessa fase, aprende procedimentos de várias especialidades cirúrgicas como Cirurgia do Aparelho Digestivo, Urologia, Cirurgia do Trauma, Traumatologia, Cirurgia Pediátrica, Neurocirurgia e Cirurgia Plástica. Terminada tal etapa, após novo concurso em hospital credenciado junto ao Ministério da Educação e/ou Sociedade Brasileira de Cirurgia Plástica, inicia-se um treinamento

${ }^{29}$ Regulamenta a Residência Médica, cria a Comissão Nacional de Residência Médica e dá outras providências.

${ }^{30}$ Disponível em $<$ http://portal.mec.gov.br/residencias-em-saude $>$. Acesso em 18 nov. 2016. 
focado exclusivamente na Cirurgia Plástica por, no mínimo, 3 anos. Após esse período, o médico se submete a um concurso para adquirir o título de membro da Sociedade Brasileira de Cirurgia Plástica. ${ }^{31}$ Tudo isso garante uma experiência e preparação que oferece maior segurança e melhores resultados para os pacientes. ${ }^{32}$

Essa formação do cirurgião plástico, o qual também adquire conhecimentos e habilidades para cirurgias e procedimentos meramente estéticos, conforme se observa do rol de procedimentos reconhecidos pela Sociedade Brasileira de Cirurgia Plástica, que será apresentado a seguir, é diferente daquela do chamado cirurgião estético.

O cirurgião estético é um médico de qualquer outra especialidade, como cirurgião geral ou ginecologista, que se propõe a executar cirurgias plásticas. $\mathrm{O}$ treinamento não é o mesmo: o médico pode realizar cursos de menor duração que oferecem o conhecimento necessário para realizar procedimentos. Enquanto o cirurgião plástico pode, e deve, se filiar à Sociedade Brasileira de Cirurgia Plástica (SBCP) por conta de sua preparação rigorosa e específica, o estético não pode ${ }^{33}$.

${ }^{31}$ Disponível em $<$ http://www2.cirurgiaplastica.org.br $>$. Acesso em 18 nov. 2016.

${ }^{32}$ Disponível em $<\mathrm{http} / / \mathrm{www} 2$.cirurgiaplastica.org.br/cirurgiao-plastico-x-cirurgiaoestetico-qual-a-diferenca>. Acesso em 18 nov. 2016.

${ }^{33}$ Ibidem. 
Além da diferença na preparação explicada acima, a AMB Associação Médica Brasileira - e o CFM - Conselho Federal de Medicina não reconhecem a atuação dos chamados cirurgiões estéticos. ${ }^{34}$

Em 2002, foi criada a Comissão Mista de Especialidades (CME) por meio de um convênio firmado entre o Conselho Federal de Medicina, a Associação Médica Brasileira (que congrega as sociedades nacionais de especialidades médicas) e a Comissão Nacional de Residência Médica (CNRM). A atribuição da Comissão Mista de Especialidades é, dentre outras, estabelecer os critérios para o reconhecimento e denominação de especialidades médicas e áreas de atuação na Medicina. ${ }^{35}$ Essas entidades decidem conjuntamente a forma de concessão e os registros de títulos de especialista, de acordo com o previsto na cláusula terceira do referido convênio firmado entre CFM, AMB e CNRM. ${ }^{36}$

Em 2016, a CME publicou a Portaria 1/2016 que regulamenta o seu próprio funcionamento. Tal comissão é composta pelo Conselho Federal de Medicina (CFM), pela Associação Médica Brasileira (AMB) e pela

${ }^{34}$ Ibidem.

${ }^{35}$ A CNRM foi criada pelo Decreto $n^{\circ}$. 80.821 de 05 de setembro de 1977 , cuja redação foi alterada no que se refere à CNRM pelo Decreto $\mathrm{n}^{\circ}$. 7.562 de 15 de setembro de 2011. As atribuições da referida comissão são definidas pelo art. $2^{\circ}$, caput, do Decreto $\mathrm{n}^{\circ}$. 7.562/2011: A CNRM é instância colegiada de caráter consultivo e deliberativo do Ministério da Educação e tem a finalidade de regular, supervisionar e avaliar as instituições e os programas de residência médica.

${ }^{36}$ CLÁUSULA TERCEIRA. A Comissão Mista de Especialidades - CME definirá os critérios para criação e reconhecimento de especialidades e áreas de atuação médica, estabelecendo requisitos técnicos e atendendo a demandas sociais. 
Comissão Nacional de Residência Médica (CNRM). A portaria disciplina, também, o reconhecimento e o registro das especialidades médicas e respectivas áreas de atuação no âmbito dos Conselhos de Medicina, além de dar outras providências. Essa portaria foi homologada pela Resolução 2.148/2016 do CFM $^{37}$.

O capítulo I da referida portaria trata das normas orientadoras e regulamentadoras, trazendo em seu art. $1^{\circ}$ o que se entende por especialidade médica e área de atuação. In verbis,

O Conselho Federal de Medicina (CFM), a Associação Médica Brasileira (AMB) e a Comissão Nacional de Residência Médica (CNRM) reconhecerão as mesmas especialidades e áreas de atuação.

$\S 2^{\circ}$. Define-se área de atuação como modalidade de organização do trabalho médico, desenvolvida por profissionais capacitados para exercer ações médicas específicas, sendo derivada e relacionada com uma ou mais especialidades.

$\mathrm{O} \S 3^{\circ}$ dispõe que se reconhecem como especialidades médicas aquelas consideradas raízes e aquelas que preencherem os critérios dispostos na portaria.

A relação das especialidades médicas e áreas de atuação é renovada e republicada periodicamente. A última relação foi aprovada pela Resolução

${ }^{37} \mathrm{Cf}$. anexo I 
CFM 2.149, de 22 de julho de $2016^{38}$, que homologou a Portaria CME ${ }^{\circ}$ 2/2016, a qual contém: a relação das especialidades médicas reconhecidas, num total de 54; a relação das áreas de atuação médicas reconhecidas, num total de 57; titulações de especialidades médicas; Certificações de áreas de atuação.

Dispõe o art. $5^{\circ}$ da portaria $1 / 2015$ da CME que a CME somente reconhecerá especialidade médica com tempo de formação mínimo de dois anos e área de atuação com tempo de formação mínimo de um ano, sendo obrigatória carga horária anual mínima de 2.880 horas.

A CME só analisa propostas de criação de novas especialidades e áreas de atuação mediante solicitação da sociedade de especialidade, no caso, a Sociedade Brasileira de Medicina Estética, via Associação Médica Brasileira. Tal associação emite apenas títulos e certificados que atendam às determinações da Comissão Mista de Especialidades. Os Conselhos Regionais de Medicina registram a informação de títulos de especialidade e certificados de áreas de atuação reconhecidos pela Comissão.

Nos termos do art. 17 do Anexo da Resolução CFM No 2.148/2016: $E$ ́ proibido aos médicos - o que caracteriza infração ética sujeita à punição pelos CRMs - a divulgação e o anúncio de especialidades ou áreas de atuação que não tenham reconhecimento da CME.

${ }^{38} \mathrm{Cf}$. anexo II. 
Diante desse panorama, o Superior Tribunal de Justiça se posicionou negando reconhecimento à Medicina Estética como uma especialidade médica.

$\S 1^{\circ}$. Define-se especialidade médica como núcleo de organização do trabalho médico que aprofunda verticalmente a abordagem teórica e prática de segmentos da dimensão biopsicossocial do indivíduo e da coletividade.

Esse foi o entendimento da Ministra Eliana Calmon ${ }^{39}$, que relatou o recurso especial apreciado pela segunda turma do Superior Tribunal de Justiça no processo movido contra o Conselho Regional de Medicina do Espírito Santo (CRM-ES). A Segunda Turma acompanhou por unanimidade a decisão da relatora, cujo teor foi publicado pelo STJ em 10 de fevereiro de 2010.

A referida ação foi movida por um médico que fez curso de pósgraduação lato sensu em Medicina Estética. Embora o curso realizado fosse reconhecido pela Coordenação de Aprimoramento de Pessoal de Nível Superior (Capes) do Ministério da Educação (MEC), o médico teve seu registro de "especialista" em Medicina Estética negado pelo CRM-ES na via administrativa. O órgão de classe, entretanto, defendeu sua posição, sob o argumento de que a Resolução $\mathrm{n}^{\mathrm{o}} 1.845 / 2008$ do Conselho Federal de

${ }^{39}$ STJ, $2^{\text {a }}$ Turma, REsp. 1038260 / ES. Rel. min. Eliana Calmon. j. 17 dez. 2009, P. DJe. 10 fev. 2010. Disponibilizado na íntegra no anexo III. 
Medicina (CFM), que enumera as especialidades médicas, não faz referência à Medicina Estética. ${ }^{40}$

Diante da negativa do registro de "especialista" em Medicina Estética, o médico impetrou mandado de segurança perante o CRM-ES, para que lhe fosse reconhecido referido título, sendo a ordem concedida em primeira instância. Entretanto, o Tribunal Regional Federal da 2 $2^{\mathrm{a}}$ Região (TRF-2), corte competente para apreciar o apelo em segunda instância, reformou a decisão após recurso de apelação interposto pelo CRM-ES e, posteriormente, em vias de recurso especial, o STJ confirmou a decisão do TRF-2. Em seu voto, a Ministra Eliana Calmon considerou que deve ser levada em conta a competência dos Conselhos de Medicina, não cabendo ao Poder Judiciário invadir essa competência para obrigá-los a conferir o título de especialista a um ramo científico que ainda não foi reconhecido como especialidade médica.

Segundo a Ministra, a Lei $n^{\circ} 3.268 / 57^{41}$ deu aos conselhos o poder de supervisionar, disciplinar e julgar a ética profissional da classe médica. Outrossim, essa norma torna obrigatório o registro para se exercer atividades em qualquer área da Medicina. Aponta ainda que os Conselhos de

\footnotetext{
40 Disponível na íntegra $\quad$ em $<$ http://www.portalmedico.org.br/resolucoes/cfm/2008/1845_2008.htm>. Acesso em 18 nov. 2016. Conforme afirmado supra, atualmente a lista de especialidades homologada pela Resolução 2.149/2016 pelo CFM é aquela da Portaria 2/2016 da CME.

${ }^{41}$ Dispõe sôbre os Conselhos de Medicina, e dá outras providências.
} 
Medicina funcionam como "órgãos delegados do Poder Público para questões de saúde pública e relativas às atividades dos médicos". Diante dessa competência dos conselhos, a Resolução CFM n 1845/2008 traz a lista de especialidades que são reconhecidas e, dentre elas, não consta como especialidade a cirurgia plástica estética.

Para o Superior Tribunal de Justiça, "a simples existência de um curso de pós-graduação não é capaz de fazer surgir, no universo científico, um novo ramo de especialidade médica, conforme regulamentado pelo órgão competente".

A ministra relatora concluiu que, se a "Medicina Estética" não é prevista como especialidade médica pelo CFM, não se pode conceder o título de especialista. Nos termos de seu voto, a ministra conclui: "Entendo não ser possível ao Judiciário invadir a competência dos conselhos de Medicina, para conferir o título de especialista, em ramo ainda não reconhecido como especialidade médica".

Aliás, nesse sentido já havia se posicionado o CREMESP:

A Medicina Estética não é uma especialidade médica reconhecida pelo Conselho Federal de Medicina e Associação Médica Brasileira. A prática da Medicina Estética envolve vários procedimentos reconhecidos em várias 
especialidades. Se os procedimentos médicos forem reconhecidos, e dentro da ética, não existirão sanções e nem ilegalidade. ${ }^{42}$

Diante desse contexto, é mister ressaltar que apenas a cirurgia plástica é reconhecida como especialidade no Brasil e não a Medicina Estética.

Conforme enumera a Sociedade Brasileira de Cirurgia Plástica, os principais procedimentos e cirurgias da Cirurgia Plástica são ${ }^{43}$.

Contorno Corporal: Abdômen, Dermolipectomia abdominal, Contorno Corporal, Lifting de Braço, Lifting de Coxa, Pós Bariátrica, Prótese de Glúteo, Rinoplastia, Lifting de braços, Ritidectomia, Aumento labial, Aumento mandibular, Mentoplastia, Prótese de panturrilha, Ginecomastia, Cirurgia da intimidade, Plástica de pálpebras - blefaroplastia, Redução de orelha - otoplastia, Levantamento de sobrancelha, Inclusão de prótese na região malar, Gastroplastia. Correção de cicatriz: Queiloplastia e Onfaloplastia. Expansão de tecido (face) Minilifting, Bichectomia, Cirurgia de Pálpebra, Implantes Faciais, Lifting Facial, Lifting de Sobrancelhas, Cirurgia de Queixo, Cirurgia de Orelha, Cirurgia de Nariz, Toxina Botulínica, Remoção de marcas de nascença, Peeling químico, Peeling laser, Dermoabrasão, Microdermobrasão ou Peeling de cristal, Injeção de gordura, Lifting Frontal ou Lifting de Testa, Tumores Cutâneos. Cirurgia de lábio

${ }^{42}$ Consulta $\mathrm{n}^{\mathrm{o}}$ 81.920/01 do CREMESP (Conselho Regional de Medicina de São Paulo) - Assunto: Se Medicina Estética é uma especialidade reconhecida. Conselheira Irene Abramovich. Homologado em 21 mai. 2002.

${ }^{43}$ Disponível em: <http://www2.cirurgiaplastica.org.br/\#!/sbcp>. Acesso em 18 nov. 2016. 
leporino. Lipoaspiração: Hidrolipo, Lipoescultura, Remodelamento corporal, Bioplastia. Mama: Redução de Mama, Mamoplastia de Aumento, Mamoplastia Redutora, Lifting de Mama, Reconstrução Mamária, Transplante para correção de assimetria mamária, Revisão do implante de mama, Mamoplastia periareolar. Procedimentos minimamente invasivos: Cirurgia dermatológica, Dermoabrasão, Laser, Peeling Químico, Plasma Rico em Plaquetas, Preenchimento Cutâneo, Toxina Botulínica, Rejuvenescimento das mãos. Rejuvenescimento da pele. Transplante capilar.

\subsection{Aspectos históricos}

A história das práticas cirúrgicas no Brasil ainda é algo pouco explorado e desenvolvido na literatura nacional, no que se refere à cirurgia plástica. Sabe-se, no entanto, que o primeiro trabalho escrito acerca do que podemos entender por cirurgia estética foi Considerações sobre o lábio leporino: suas complicações e tratamento adequado, obra de autoria do médico Joaquim Januário Carneiro, publicado em 1842. Em tal escrito, o referido autor faz alusões às dificuldades de alimentação e fonéticas das pessoas que apresentavam lábios leporinos. Ainda, já preconizava os 
procedimentos cirúrgicos em menores, com idades entre 3 e 6 meses, descrevendo instrumentos e tempos. ${ }^{44}$

Algumas décadas após a publicação do referido trabalho, nos dois primeiros decênios do século XX, despontam novos cursos de medicina no território nacional, além dos já existentes no Rio de Janeiro e na Bahia, a saber: Porto Alegre (1899); Belo Horizonte (1911); Curitiba (1912); São Paulo (1913) e Belém (1919). Com isso, novos trabalhos relativos à cirurgia plástica surgem nas faculdades de medicina, principalmente nas antigas escolas do Rio de Janeiro e da Bahia. Despontam, então, obras como Diagnóstico do agente das queimaduras, de Eurípedes Clementino Aguiar (Bahia-1902) e Dos métodos uretroplásticos empregados no tratamento de hipospádias, escrito por Juscelino Monteiro Junior, (Bahia-1907), dentre outros trabalhos. Neste período histórico, muitos médicos, ainda que não se dedicassem exclusivamente aos procedimentos de cirurgia plástica, buscavam conhecimentos sobre tal tema nas literaturas nacional e estrangeira existentes e disponíveis à época e nos grandes centros médicos, principalmente na Europa. Alguns, tais como Antonio Pires Rebelo, procuravam se dedicar a estética. O mencionado médico, nos anos trinta do século passado, estabeleceu no Rio de Janeiro uma clínica sob o título de

${ }^{44}$ FRANCO, Talita. Princípios em cirurgia plástica. São Paulo: Atheneu, 2002. p. 11. 
Academia Cientifica de Beleza, porém, dedicou-se mais à dermatologia estética, apesar de ter realizado alguns procedimentos cirúrgicos. ${ }^{45}$

Em 1915, o médico José Rebello Netto defende sua tese de doutorado na então Faculdade de Medicina de São Paulo (que depois viria a ser incorporada pela Universidade de São Paulo) ${ }^{46}$ a qual intitulou Cirurgia Estética. No entanto, como no Brasil eram inexistentes os cursos de especialização na referida área cirúrgica, Rebello Neto parte para a Europa, em 1929, onde frequentou renomados cursos de especialização, retornando no ano seguinte como especialista. ${ }^{47}$ De volta a terras bandeirantes, Rebello Neto cria, em 1930, a primeira clínica destinada exclusivamente à cirurgia plástica, na Santa Casa de Misericórdia de São Paulo, o que pode ser considerado como a célula mater dessa especialidade no Brasil. ${ }^{48}$ É importante ressaltar, porém, que alguns anos antes, em 1926, Desidério Stapler publica, também em São Paulo, um artigo a respeito de cirurgia estética, o qual poder ser considerado o primeiro do gênero a ser publicado no Brasil.

Nota-se, no entanto, que Stapler não lança mão do termo cirurgia plástica, usando, entretanto, o termo cirurgia estética. Na obra, Stapler

${ }^{45}$ MARTIRE JUNIOR, Lybio. História da cirurgia plástica brasileira. São Paulo, 2005. Disponível em <http://sbhm.webnode.com.br/products/historia-da-cirurgiaplastica>. Acesso em 27 set. 2016.

${ }^{46}$ Note-se que a tese não foi defendida perante a Universidade de São Paulo, haja vista ela ter sido fundada fundada, apenas, em 1934.

${ }^{47}$ FRANCO, Talita. Princípios em cirurgia plástica. Op. Cit., p. 11.

${ }^{48}$ MARTIRE JUNIOR, Lybio. História da cirurgia plástica brasileira. Op. Cit.. 
apresenta várias imagens de pacientes antes e depois da cirurgia, muitos deles operados de rugas, orelhas e lábios. Também, classifica os defeitos em três grandes categorias, a saber: $1^{a}$ ). De nascença ou adquiridos, que desfiguram o portador e de tal forma que chamam a atenção de todos. $2^{a}$ ) Defeitos que, sem chamarem atenção, enfeiam as pessoas. $3^{a}$ ) Os que não são realmente defeitos, mas são desagradáveis aos portadores. ${ }^{49}$

Um marco de grande importância para a história da cirurgia estética no Brasil é o dia 07 de dezembro de 1948, quando, em São Paulo, Rebello Neto e Antônio Prudente, junto com outros médicos brasileiros, fundam a Sociedade Brasileira de Cirurgia Plástica (a SBCP). ${ }^{50}$ Nessa década, por conta da fundação da Sociedade Brasileira de Cirurgia Plástica e da Sociedade Latino Americana de Cirurgia Plástica, em 1940, o referido ramo da cirurgia viu o start de sua expansão pelo território brasileiro, com destaque para a organização do Serviço de Queimaduras do Hospital das Clínicas da Universidade de São Paulo, em 1947, primeira unidade especializada no tratamento de queimados da América Latina. Em 1956, na cidade de São Paulo, a sociedade organiza o primeiro Congresso Brasileiro de Cirurgia Plástica. ${ }^{51}$

${ }^{49}$ FRANCO, Talita. Princípios em cirurgia plástica. Op. Cit., p. 11.

${ }^{50}$ Ibidem, p. 11.

${ }^{51}$ MARTIRE JUNIOR, Lybio. História da cirurgia plástica brasileira. Op. Cit.. 
Papel de destaque no desenvolvimento da cirurgia plástica brasileira é o de Ivo Pitanguy, falecido em 06 de agosto de $2016,{ }^{52}$ que foi, talvez, o responsável pelo reconhecimento que a cirurgia plástica tem hoje no Brasil e em âmbito internacional. ${ }^{53}$ Foi o responsável pela implementação, no Rio de Janeiro, do serviço de Cirurgia Plástica Reparadora da Santa Casa de Misericórdia, em $1954 .{ }^{54}$ Como professor da Pontifícia Universidade Católica do Rio de Janeiro, Pitanguy foi o responsável pela formação sistematizada de profissionais especialistas em cirurgia plástica. ${ }^{55}$

A partir dos anos 60 e 70, a cirurgia estética brasileira já é dotada de grande renome internacional. Surgem, então, diversos cursos de especialização e hospitais e clínicas específicos para tais procedimentos. ${ }^{56}$

\subsection{Posição do Brasil no cenário mundial em relação aos procedimentos e cirurgias estéticas ${ }^{57}$}

52 Disponível em <http://g1.globo.com/rio-de-janeiro/noticia/2016/08/ivo-pitanguymorre-no-rio-aos-90-anos.html >. Acesso em 24 nov. 2016.

${ }^{53}$ FRANCO, Talita. Princípios em cirurgia plástica, Op. cit., p. 12.

${ }^{54}$ MARTIRE JUNIOR, Lybio. História da cirurgia plástica brasileira. Op. Cit..

${ }^{55}$ FRANCO, Talita. Princípios em cirurgia plástica, Op. cit., p. 12.

${ }_{57}^{56}$ MARTIRE JUNIOR, Lybio. História da cirurgia plástica brasileira. Op. Cit. 57

http://www.isaps.org/Media/Default/global-

statistics/2016\%20ISAPS\%20Results.pdf (acesso em 01/12/2016) 
A International Society of Aesthetic Plastic Surgery (ISAPS Sociedade Internacional de Cirurgia Plástica Estética) foi fundada em 1970 com o compromisso de proporcionar segurança às pessoas que decidem se submeter a uma cirurgia plástica estética, inclusive àquelas que buscam uma intervenção no exterior, o que tem sido cada vez mais comum com o crescimento da indústria do turismo médico.

A cada ano a ISAPS realiza pesquisa com vários países sobre procedimentos cirúrgicos e não cirúrgicos. Em 2015, a referida sociedade convidou aproximadamente 35 mil cirurgiões plásticos para participar do estudo. Além disso, solicitou-se às sociedades nacionais que encorajassem seus membros a participarem da pesquisa.

Essa pesquisa coletou dados de 1.398 cirurgiões plásticos. Os números finais foram projetados em relação às estatísticas internacionais e esses números são exclusivamente baseados no número estimado de cirurgiões plásticos em cada país e na amostra correspondente. Essa pesquisa internacional se concentra apenas em cirurgiões plásticos qualificados oficialmente.

Para ajudar na contagem da estimativa de cirurgiões plásticos no mundo todo, representantes de sociedades nacionais forneceram números de mais de $96 \%$ do total de 40 mil cirurgiões plásticos estimados. Para aqueles casos em que a sociedade nacional não forneceu o total de cirurgiões plásticos de seu respectivo país, foi usada uma simples equação regressiva 
para estimar o número de cirurgiões plásticos no país, baseado no tamanho da população e no PIB.

Todos os dadas citados foram analisados em relação a sua racionalidade estatística.

Essa pesquisa internacional sobre procedimentos estéticos e cosméticos realizada em 2015 foi compilada, tabulada e analisada pela Industry Insights, Inc, uma empresa de pesquisa independente sediada em Columbia, Oklahoma. 


\begin{tabular}{|c|c|c|c|c|c|c|c|c|c|c|}
\hline \multicolumn{11}{|c|}{ International Study on Aesthetic/Cosmetic Procedures Performed in 2015} \\
\hline & $\begin{array}{l}\text { World- } \\
\text { Wide } \\
\text { Totals }\end{array}$ & USA & Brazil & $\begin{array}{l}\text { South } \\
\text { Korea }\end{array}$ & India & Mexico & Germany & Colombia & France & Italy \\
\hline \multicolumn{11}{|c|}{ TOTAL PROCEDURES } \\
\hline \multicolumn{11}{|c|}{ Surgical Procedures } \\
\hline \multicolumn{11}{|c|}{ Face \& Head } \\
\hline Brow Lift & 243,14 & 28,535 & 31,405 & 16,437 & 5,827 & 14,214 & 5,714 & 7,315 & 4,446 & 3,584 \\
\hline Ear Surgery & 252,718 & 16,25 & 42,24 & 6,472 & 18,06 & 10,323 & 10,052 & 7,192 & 6,375 & 4,544 \\
\hline Eyelid Surgery & $1,264,702$ & 141,505 & 143,165 & 101,985 & 29,434 & 48,329 & 54,907 & 27,959 & 35,473 & 19,96 \\
\hline Facelift & 411,529 & 75,92 & 48,84 & 28,116 & 7,783 & 16,585 & 10,801 & 8,503 & 12,474 & 4,544 \\
\hline Facial Bone Contouring & 108,25 & 11,115 & 7,48 & 8,143 & 4,666 & 11,269 & 2,092 & 4,921 & 323 & 2,2 \\
\hline Fat Grafting-face & 591,894 & 49,66 & 51,645 & 63,326 & 27,649 & 27,652 & 21,877 & 15,827 & 11,847 & 11,216 \\
\hline Neck Lift & 232,606 & 32,695 & 31,405 & 7,093 & 7,826 & 16,151 & 7,498 & 8,294 & 7,724 & 2,984 \\
\hline Hair Transplantation & 134,019 & 7,605 & 9,075 & 7,436 & 39,625 & 992 & 1,167 & 3,088 & 2,651 & 984 \\
\hline Rhinoplasty & 730,287 & 49,855 & 65,12 & 72,562 & 44,29 & 39,897 & 12,717 & 24,852 & 20,055 & 9,984 \\
\hline Total Face \& Head Procedures & $3,969,147$ & 413,14 & 430,375 & 311,571 & 185,158 & 185,411 & 126,824 & 107,949 & 101,365 & 60 \\
\hline \multicolumn{11}{|c|}{ Breast } \\
\hline Breast Augmentation - saline & 64,674 & 36,14 & 275 & 3,365 & 366 & 0 & 385 & 171 & 447 & 0 \\
\hline Breast Augmentation-silicone & $1,311,129$ & 255,06 & 158,95 & 44,039 & 23,865 & 57,552 & 46,242 & 44,888 & 37,354 & 21,744 \\
\hline \multicolumn{11}{|l|}{ Breast Augmentation-fat } \\
\hline Transfer & 113,189 & 18,785 & 7,205 & 3,15 & 5,375 & 4,061 & 6,749 & 1,644 & 4,123 & 1,656 \\
\hline Breast Implant Removal & 153,476 & 37,115 & 12,705 & 6,3 & 1,742 & 5,952 & 5,967 & 6,09 & 6,004 & 2,744 \\
\hline Breast Lift & 512,248 & 106,535 & 80,52 & 8,101 & 9,052 & 21,902 & 15,271 & 16,321 & 14,421 & 7,16 \\
\hline Breast Reduction & 423,093 & 67,08 & 72,6 & 5,165 & 16,491 & 14,198 & 17,121 & 11,381 & 18,953 & 3,672 \\
\hline Gynecomastia & 212,328 & 25,545 & 26,4 & 4,757 & 25,091 & 6,96 & 9,876 & 4,142 & 4,351 & 4,216 \\
\hline Total Breast Procedures & $2,790,138$ & 546,26 & 358,655 & 74,876 & 81,98 & 110,624 & 101,611 & 84,636 & 85,652 & 41,192 \\
\hline \multicolumn{11}{|c|}{ Body \& Extremities } \\
\hline Abdominoplasty & 758,59 & 137,605 & 131,12 & 7,993 & 32,401 & 39,634 & 17,682 & 29,317 & 22,924 & 5,384 \\
\hline
\end{tabular}




\begin{tabular}{|c|c|c|c|c|c|c|c|c|c|c|}
\hline \multicolumn{11}{|l|}{$\begin{array}{l}\text { Buttock Augmentation- } \\
\text { implants }\end{array}$} \\
\hline Only & 30,916 & 1,56 & 8,14 & 514 & 710 & 2,945 & 385 & 2,423 & 124 & 344 \\
\hline \multicolumn{11}{|c|}{ Buttock Augmentation-fat } \\
\hline Transfer & 258,107 & 21,255 & 55,605 & 2,572 & 4,752 & 29,528 & 3,336 & 23,038 & 3,021 & 2,344 \\
\hline Buttock Lift & 30,905 & 4,095 & 4,125 & 471 & 1,935 & 2,945 & 848 & 561 & 646 & 360 \\
\hline Liposuction & $1,394,588$ & 240,565 & 182,765 & 39,753 & 88,193 & 70,773 & 40,065 & 51,623 & 29,45 & 20,784 \\
\hline Lower Body Lift & 56,169 & 6,955 & 7,7 & 429 & 3,677 & 3,286 & 2,092 & 2,632 & 2,85 & 728 \\
\hline Penile Enlargement & 11,703 & 325 & 440 & 1,222 & 1,484 & 78 & 319 & 665 & 228 & 440 \\
\hline Thigh Lift & 70,672 & 8,775 & 10,505 & 86 & 2,967 & 3,317 & 3,16 & 2,613 & 3,876 & 1,328 \\
\hline
\end{tabular}


A primeira tabela demonstra que o Brasil foi o país que mais realizou procedimentos cirúrgicos na face e cabeça.

Em relação a procedimentos nas mamas, corpo e extremidades, o Brasil ficou em segundo lugar, perdendo apenas para os Estados Unidos. De qualquer forma, a quantidade de procedimentos cirúrgicos realizada no Brasil é expressiva, ou seja, aproximadamente 1.224 .300 procedimentos cirúrgicos, o que equivale a aproximadamente $12,7 \%$ do total de procedimentos realizados no mundo, contrastando com $14,7 \%$ do primeiro colocado.

Em relação a procedimentos não cirúrgicos o Brasil permaneceu em segundo lugar, considerando procedimentos injetáveis, de rejuvenescimento da face, não injetáveis e outros, num total de 2.323.245 procedimentos não cirúrgicos, o que equivale a $10,7 \%$ do total de procedimentos não cirúrgicos realizados no mundo.

Esses os resultados que se observam nas quatro tabelas a seguir. 


\section{Tabela 1}

\begin{tabular}{|c|c|c|c|c|c|c|c|c|c|c|}
\hline \multicolumn{11}{|c|}{ International Study on Aesthe Cosmetic Procedures Performed in 2015} \\
\hline & $\begin{array}{l}\text { World- Wide } \\
\text { Totals }\end{array}$ & USA & Brazil & $\begin{array}{l}\text { South } \\
\text { Korea }\end{array}$ & India & Mexico & Germany & Colombia & France & Italy \\
\hline Upper Arm Lift & 102,588 & 17,81 & 12,595 & 707 & 5,074 & 5,069 & 4,437 & 2,546 & 5,33 & 2,16 \\
\hline Upper Body Lift & 22,634 & 2,6 & 2,805 & 0 & 1,333 & 1,674 & 1,563 & 1,017 & 124 & 616 \\
\hline Labiaplasty & 95,01 & 10,855 & 12,87 & 2,186 & 3,935 & 3,441 & 5,296 & 3,259 & 3,097 & 1,872 \\
\hline Vaginal Rejuvenation & 50,086 & 2,535 & 6,6 & 2,764 & 6,859 & 2,821 & 639 & 2,508 & 523 & 1,312 \\
\hline \multicolumn{11}{|c|}{ Total Body \& Extremities } \\
\hline Procedures & $2,881,968$ & 454,935 & 435,27 & 58,697 & 153,317 & 165,509 & 79,823 & 122,199 & 72,191 & 37,672 \\
\hline $\begin{array}{ll}\text { Total } & \text { Surgical } \\
\text { Procedures } & \end{array}$ & $9,641,253$ & $1,414,335$ & $1,224,300$ & 445,144 & 420,454 & 461,544 & 308,258 & 314,783 & 259,208 & 138,864 \\
\hline \multicolumn{11}{|l|}{ Non-Surgical Procedures } \\
\hline Injectables & & & & & & & & & & \\
\hline Botulinum Toxin & $4,627,752$ & $1,141,595$ & 359,865 & 279,019 & 85,334 & 161,355 & 148,459 & 76 & 91,751 & 110,4 \\
\hline
\end{tabular}




\begin{tabular}{|c|c|c|c|c|c|c|c|c|c|c|}
\hline Calcium Hydroxylapatite & 173,492 & 59,93 & 13,805 & 4,415 & 215 & 7,208 & 4,833 & 580 & 3,525 & 5,344 \\
\hline Hyaluronic Acid & $2,865,086$ & 580,32 & 195,03 & 198,378 & 60,05 & 86,32 & 129,852 & 41,002 & 92,103 & 109,288 \\
\hline Poly-L-Lactic Acid & 64,134 & 24,05 & 9,35 & 1,672 & 151 & 93 & 1,277 & 0 & 979 & 2,272 \\
\hline Total Injectables & $7,730,464$ & $1,805,895$ & 578,05 & 483,482 & 145,749 & 254,975 & 284,421 & 117,582 & 188,357 & 227,304 \\
\hline \multicolumn{11}{|l|}{ Facial Rejuvenation } \\
\hline Chemical Peel & 489,344 & 101,01 & 86,295 & 7,779 & 58,093 & 8,339 & 2,092 & 5,852 & 5,026 & 12,112 \\
\hline Full Field Ablative & 169,098 & 30,29 & 30,8 & 4,329 & 11,61 & 6,247 & 1,277 & 3,629 & 323 & 5,616 \\
\hline $\begin{array}{l}\text { Micro-Ablative } \\
\text { Resurfacing }\end{array}$ & 217,593 & 45,175 & 25,19 & 22,009 & 16,942 & 5,549 & 0 & 4,142 & 105 & 2,656 \\
\hline Dermabrasion & 51,882 & 8,385 & 2,365 & 1,436 & 3,225 & 2 & 4,085 & 2,119 & 779 & 712 \\
\hline Microdermabrasion & 365,587 & 111,15 & 33,33 & 16,801 & 19,135 & 19,329 & 209 & 14,317 & 0 & 1,744 \\
\hline $\begin{array}{l}\text { Nonsurgical } \quad \text { Skin } \\
\text { Tightening }\end{array}$ & 340,609 & 56,55 & 31,24 & 36,088 & 11,202 & 28,35 & 6 & 6,973 & 6,451 & 3,784 \\
\hline Photo Rejuvenation & 568,672 & 122,85 & 78,155 & 48,86 & 6,816 & 24,521 & 0 & 13,965 & 6,099 & 2,688 \\
\hline Polymethylmethacrylate & 36,017 & 7,605 & 10,89 & 2,722 & 0 & 264 & 0 & 0 & 0 & 0 \\
\hline Total Injectables & $2,238,803$ & 483,015 & 298,265 & 140,024 & 127,022 & 94,597 & 13,663 & 50,996 & 18,782 & 29,312 \\
\hline
\end{tabular}




\begin{tabular}{|l|c|c|c|c|c|c|c|c|c|c|}
\hline \multicolumn{1}{|l}{ Other } \\
\hline Cellulite Treatment & 283,598 & 12,48 & 67,155 & 10,136 & 16,534 & 33,48 & 1,453 & 5,396 & 6,251 & 5,24 \\
\hline Hair Removal & $1,099,053$ & 174,59 & 106,205 & 45,217 & 154,65 & 30,008 & 4,118 & 30,077 & 7,201 & 4,928 \\
\hline $\begin{array}{l}\text { Nonsurgical } \\
\text { Reduction }\end{array}$ & 425,315 & 119,47 & 17,655 & 19,33 & 32,293 & 17,066 & 4,151 & 23,646 & 8,921 & 4,712 \\
\hline Tattoo Removal & 128,218 & 12,74 & 11,77 & 12,772 & 24,209 & 6,696 & 352 & 2,698 & 0 & 1,512 \\
\hline Treatment of Leg Veins & 73,19 & 7,8 & 14,245 & 43 & 9,052 & 2,682 & 66 & 1,492 & 0 & 1,088 \\
\hline Sclerotherapy & 76,778 & 12,285 & 6,6 & 86 & 5,526 & 6,867 & 925 & 1,967 & 0 & 5,8 \\
\hline Total Other & $2,086,152$ & 339,365 & 223,63 & 87,584 & 242,262 & 96,798 & 11,065 & 65,275 & 22,373 & 23,28 \\
\hline $\begin{array}{l}\text { Total Non-Surgical } \\
\text { Procedures }\end{array}$ & $12,055,418$ & $2,628,275$ & $1,099,945$ & 711,09 & 515,033 & 446,369 & 309,15 & 233,852 & 229,511 & 279,896 \\
\hline Total Procedures & $\mathbf{2 1 , 6 9 6 , 6 7 1}$ & $\mathbf{4 , 0 4 2 , 6 1 0}$ & $\mathbf{2 , 3 2 4 , 2 4 5}$ & $\mathbf{1 , 1 5 6 , 2 3 4}$ & $\mathbf{9 3 5 , 4 8 7}$ & $\mathbf{9 0 7 , 9 1 3}$ & $\mathbf{6 1 7 , 4 0 8}$ & $\mathbf{5 4 8 , 6 3 5}$ & $\mathbf{4 8 8 , 7 1 8}$ & $\mathbf{4 1 8 , 7 6}$ \\
\hline
\end{tabular}


Tabela 2

\begin{tabular}{|c|c|c|c|}
\hline \multicolumn{4}{|c|}{ Total Face \& Head Procedures } \\
\hline Rank * & Country: & & \% of World-Wide Total \\
\hline 1 & Brazil & 430,375 & $10.8 \%$ \\
\hline 2 & USA & 413,140 & $10.4 \%$ \\
\hline 3 & South Korea & 311,571 & $7.8 \%$ \\
\hline 4 & Mexico & 185,411 & $4.7 \%$ \\
\hline 5 & India & 185,158 & $4.7 \%$ \\
\hline 6 & Germany & 126,824 & $3.2 \%$ \\
\hline 7 & Colombia & 107,949 & $2.7 \%$ \\
\hline 8 & France & 101,365 & $2.6 \%$ \\
\hline 9 & Italy & 60,000 & $1.5 \%$ \\
\hline \multicolumn{4}{|c|}{ Total Breast Procedures } \\
\hline & & & $\%$ of World-Wide \\
\hline Rank & Country: & & Total \\
\hline 1 & USA & 546,260 & $19.6 \%$ \\
\hline 2 & Brazil & 358,655 & $12.9 \%$ \\
\hline 3 & Mexico & 110,624 & $4.0 \%$ \\
\hline 4 & Germany & 101,611 & $3.6 \%$ \\
\hline 5 & France & 85,652 & $3.1 \%$ \\
\hline 6 & Colombia & 84,636 & $3.0 \%$ \\
\hline 7 & India & 81,980 & $2.9 \%$ \\
\hline 8 & South Korea & 74,876 & $2.7 \%$ \\
\hline 9 & Italy & 41,192 & $1.5 \%$ \\
\hline \multicolumn{4}{|c|}{ Total Body \& Extremities } \\
\hline & & & $\%$ of World-Wide \\
\hline Rank & Country: & & Total \\
\hline 1 & USA & 454,935 & $15.8 \%$ \\
\hline 2 & Brazil & 435,270 & $15.1 \%$ \\
\hline 3 & Mexico & 165,509 & $5.7 \%$ \\
\hline 4 & India & 153,317 & $5.3 \%$ \\
\hline 5 & Colombia & 122,199 & $4.2 \%$ \\
\hline 6 & Germany & 79,823 & $2.8 \%$ \\
\hline 7 & France & 72,191 & $2.5 \%$ \\
\hline 8 & South Korea & 58,697 & $2.0 \%$ \\
\hline 9 & Italy & 37,672 & $1.3 \%$ \\
\hline \multicolumn{4}{|c|}{ Total Surgical Procedures } \\
\hline & & & $\%$ of World-Wide \\
\hline Rank & Country: & & Total \\
\hline 1 & USA & $1,414,335$ & $14.7 \%$ \\
\hline 2 & Brazil & $1,224,300$ & $12.7 \%$ \\
\hline 3 & Mexico & 461,544 & $4.8 \%$ \\
\hline 4 & South Korea & 445,144 & $4.6 \%$ \\
\hline 5 & India & 420,454 & $4.4 \%$ \\
\hline 6 & Colombia & 314,783 & $3.3 \%$ \\
\hline
\end{tabular}




\begin{tabular}{cccc|}
7 & Germany & 308,258 & $3.2 \%$ \\
8 & France & 259,208 & $2.7 \%$ \\
9 & Italy & 138,864 & $1.4 \%$ \\
$*$ & Rankings are based solely on those countries from which a sufficient survey response was \\
and data were considered to be representative. &
\end{tabular}

\section{Tabela 3}

\begin{tabular}{|c|c|c|c|}
\hline \multicolumn{4}{|c|}{ Total Injectibles } \\
\hline Rank* & Country: & & $\%$ of World-Wide Total \\
\hline 1 & USA & $1,805,895$ & $23.4 \%$ \\
\hline 2 & Brazil & 578,050 & $7.5 \%$ \\
\hline 3 & South Korea & 483,482 & $6.3 \%$ \\
\hline 4 & Germany & 284,421 & $3.7 \%$ \\
\hline 5 & Mexico & 254,975 & $3.3 \%$ \\
\hline 6 & Italy & 227,304 & $2.9 \%$ \\
\hline 7 & France & 188,357 & $2.4 \%$ \\
\hline 8 & India & 145,749 & $1.9 \%$ \\
\hline 9 & Colombia & 117,582 & $1.5 \%$ \\
\hline \multicolumn{4}{|c|}{ Total Facial Rejuvenation } \\
\hline Rank* & Country: & & $\%$ of World-Wide Total \\
\hline 1 & USA & 483,015 & $21.6 \%$ \\
\hline 2 & Brazil & 298,265 & $13.3 \%$ \\
\hline 3 & South Korea & 140,024 & $6.3 \%$ \\
\hline 4 & India & 127,022 & $5.7 \%$ \\
\hline 5 & Mexico & 94,597 & $4.2 \%$ \\
\hline 6 & Colombia & 50,996 & $2.3 \%$ \\
\hline 7 & Italy & 29,312 & $1.3 \%$ \\
\hline 8 & France & 18,782 & $0.8 \%$ \\
\hline 9 & Germany & 13,663 & $0.6 \%$ \\
\hline \multicolumn{4}{|c|}{ Total Non-Surgical Procedures } \\
\hline Rank * & Country: & & $\%$ of World-Wide Total \\
\hline 1 & USA & $2,628,275$ & $21.8 \%$ \\
\hline 2 & Brazil & $1,099,945$ & $9.1 \%$ \\
\hline 3 & South Korea & 711,090 & $5.9 \%$ \\
\hline 4 & India & 515,033 & $4.3 \%$ \\
\hline 5 & Mexico & 446,369 & $3.7 \%$ \\
\hline 6 & Germany & 309,150 & $2.6 \%$ \\
\hline 7 & Italy & 279,896 & $2.3 \%$ \\
\hline 8 & Colombia & 233,852 & $1.9 \%$ \\
\hline 9 & France & 229,511 & $1.9 \%$ \\
\hline \multicolumn{4}{|c|}{ Total Other Non-Surgical Procedures } \\
\hline Rank * & Country: & & $\%$ of World-Wide Total \\
\hline 1 & USA & 339,365 & $16.3 \%$ \\
\hline 2 & India & 242,262 & $11.6 \%$ \\
\hline
\end{tabular}




\begin{tabular}{|llll|}
$\mathbf{3}$ & Brazil & 223,630 & $10.7 \%$ \\
$\mathbf{4}$ & Mexico & 96,798 & $4.6 \%$ \\
$\mathbf{5}$ & South Korea & 87,584 & $4.2 \%$ \\
$\mathbf{6}$ & Colombia & 65,275 & $3.1 \%$ \\
$\mathbf{7}$ & Italy & 23,280 & $1.1 \%$ \\
$\mathbf{8}$ & France & 22,373 & $1.1 \%$ \\
$\mathbf{9}$ & Germany & 11,065 & $0.5 \%$ \\
\hline
\end{tabular}

\section{Tabela 4}

\begin{tabular}{|llll|}
\hline \multicolumn{4}{|l|}{ Total Procedures } \\
\hline Rank * & Country: & \% of World-Wide Total \\
\hline $\mathbf{1}$ & USA & $4,042,610$ & $18.6 \%$ \\
$\mathbf{2}$ & Brazil & $2,324,245$ & $10.7 \%$ \\
$\mathbf{3}$ & South Korea & $1,156,234$ & $5.3 \%$ \\
$\mathbf{4}$ & India & 935,487 & $4.3 \%$ \\
$\mathbf{5}$ & Mexico & 907,913 & $4.2 \%$ \\
$\mathbf{6}$ & Germany & 617,408 & $2.8 \%$ \\
$\mathbf{7}$ & Colombia & 548,635 & $2.5 \%$ \\
$\mathbf{8}$ & France & 488,718 & $2.3 \%$ \\
$\mathbf{9}$ & Italy & 418,760 & $1.9 \%$ \\
$*$ & Rankings are based solely on those countries from which a sufficient survey response was \\
received and data were considered to be representative.
\end{tabular}

Em relação à estimativa de cirurgiões plásticos, num ranking de 30 países o Brasil ocupa o segundo lugar, com cerca de 5.500 cirurgiões plásticos, perdendo para os Estados Unidos que contam com cerca de 6.500 . 


\begin{tabular}{|c|c|c|c|}
\hline \multicolumn{4}{|c|}{$\begin{array}{c}\text { Countries Ranked by Estimated Number of } \\
\text { Plastic Surgeons (Top 30) }\end{array}$} \\
\hline Rank & Country & $\begin{array}{l}\text { Plastic } \\
\text { Surgeons }\end{array}$ & $\begin{array}{l}\text { Percent of } \\
\text { Total Plastic } \\
\text { Surgeons }\end{array}$ \\
\hline 1 & USA & 6,5 & $16.0 \%$ \\
\hline 2 & Brazil & 5,5 & $13.5 \%$ \\
\hline 3 & China & 2,8 & $6.9 \%$ \\
\hline 4 & Japan & 2,225 & $5.5 \%$ \\
\hline 5 & South Korea & 2,15 & $5.3 \%$ \\
\hline 6 & India & 2,15 & $5.3 \%$ \\
\hline 7 & Russia & 2 & $4.9 \%$ \\
\hline 8 & Mexico & 1,55 & $3.8 \%$ \\
\hline 9 & Turkey & 1,2 & $2.9 \%$ \\
\hline 10 & Germany & 1,1 & $2.7 \%$ \\
\hline 11 & Colombia & 950 & $2.3 \%$ \\
\hline 12 & France & 950 & $2.3 \%$ \\
\hline 13 & Spain & 945 & $2.3 \%$ \\
\hline 14 & $\begin{array}{l}\text { United } \\
\text { Kingdom }\end{array}$ & 865 & $2.1 \%$ \\
\hline 15 & Italy & 800 & $2.0 \%$ \\
\hline 16 & $\begin{array}{l}\text { Chinese } \\
\text { Taipei }\end{array}$ & 600 & $1.5 \%$ \\
\hline 17 & Canada & 575 & $1.4 \%$ \\
\hline 18 & Venezuela & 500 & $1.2 \%$ \\
\hline 19 & Egypt & 400 & $1.0 \%$ \\
\hline 20 & Peru & 380 & $0.9 \%$ \\
\hline 21 & Argentina & 350 & $0.9 \%$ \\
\hline 22 & Australia & 320 & $0.8 \%$ \\
\hline 23 & Thailand & 320 & $0.8 \%$ \\
\hline 24 & Greece & 275 & $0.7 \%$ \\
\hline 25 & Netherlands & 270 & $0.7 \%$ \\
\hline 26 & South Africa & 265 & $0.7 \%$ \\
\hline 27 & Belgium & 265 & $0.7 \%$ \\
\hline 28 & Iran & 240 & $0.6 \%$ \\
\hline 29 & $\begin{array}{l}\text { Saudi } \\
\text { Arabia }\end{array}$ & 230 & $0.6 \%$ \\
\hline 30 & Poland & 200 & $0.5 \%$ \\
\hline
\end{tabular}


Tabela demonstrativa do total de procedimentos em 2015, cirúrgicos e não cirúrgicos e a posição do Brasil em segundo lugar.

\begin{tabular}{|c|c|c|c|c|c|c|c|}
\hline \multicolumn{8}{|c|}{ Countries by Total Number of Procedures-2015 } \\
\hline Rank* & & $\begin{array}{l}\text { Total Surgical } \\
\text { Procedures }\end{array}$ & $\begin{array}{c}\text { \% of total } \\
\text { surgical } \\
\text { procedures }\end{array}$ & $\begin{array}{c}\text { Total } \\
\text { Nonsurgical } \\
\text { Procedures }\end{array}$ & $\begin{array}{c}\% \text { of total } \\
\text { nonsurgical } \\
\text { procedures }\end{array}$ & $\begin{array}{c}\text { Total } \\
\text { Procedures }\end{array}$ & $\begin{array}{c}\% \text { of total } \\
\text { procedures }\end{array}$ \\
\hline 1 & USA & $1,414,335$ & $14.7 \%$ & $2,628,275$ & $21.8 \%$ & $4,042,610$ & $18.6 \%$ \\
\hline 2 & Brazil & $1,224,300$ & $12.7 \%$ & $1,099,945$ & $9.1 \%$ & $2,324,245$ & $10.7 \%$ \\
\hline 3 & South & 445,144 & $4.6 \%$ & 711,09 & $5.9 \%$ & $1,156,234$ & $5.3 \%$ \\
\hline 4 & India & 420,454 & $4.4 \%$ & 515,033 & $4.3 \%$ & 935,487 & $4.3 \%$ \\
\hline 5 & Mexico & 461,544 & $4.8 \%$ & 446,369 & $3.7 \%$ & 907,913 & $4.2 \%$ \\
\hline 6 & Germany & 308,258 & $3.2 \%$ & 309,15 & $2.6 \%$ & 617,408 & $2.8 \%$ \\
\hline 7 & Colombia & 314,783 & $3.3 \%$ & 233,852 & $1.9 \%$ & 548,635 & $2.5 \%$ \\
\hline \multirow[t]{2}{*}{8} & France & 259,208 & $2.7 \%$ & 229,511 & $1.9 \%$ & 488,718 & $2.3 \%$ \\
\hline & Italy & 138,864 & $1.4 \%$ & 279,896 & $2.3 \%$ & 418,76 & $1.9 \%$ \\
\hline
\end{tabular}

A tabela a seguir demonstra os procedimentos mais realizados em 2015: aumento de mama, lipoaspiração, cirurgia de pálpebras, plástica abdominal, rinoplastia, enxerto de gordura na face, lift de mama, redução de mama, aumento de nádega, cirurgia de orelha, lift de sobrancelha, lift de pescoço, ginecomastia, remoção de implante de mama, transplante de cabelo, contorno do osso facial, lift de braço, plástica labial, lift de queixo, lift de coxa, quadril, costas e abdômem, rejuvenescimento vaginal, lift de nádega, lift da parte superior do corpo, aumento de pênis. 


\begin{tabular}{|c|c|c|c|}
\hline \multicolumn{4}{|c|}{$\begin{array}{l}\text { Number of World-Wide Surgical Procedures Performed by Plastic } \\
\text { Surgeons }\end{array}$} \\
\hline Rank & Surgical Procedure & Total & $\begin{array}{l}\text { Percent of } \\
\text { Total } \\
\text { Surgical } \\
\text { Procedures }\end{array}$ \\
\hline 1 & $\begin{array}{c}\text { Breast } \\
\text { Augmentation }\end{array}$ & $1,488,992$ & $15.4 \%$ \\
\hline 2 & Liposuction & $1,394,588$ & $14.5 \%$ \\
\hline 3 & Eyelid Surgery & $1,264,702$ & $13.1 \%$ \\
\hline 4 & Abdominoplasty & 758,59 & $7.9 \%$ \\
\hline 5 & Rhinoplasty & 730,287 & $7.6 \%$ \\
\hline 6 & Fat Grafting- & 591,894 & $6.1 \%$ \\
\hline 7 & Breast Lift & 512,248 & $5.3 \%$ \\
\hline 8 & Breast & 423,093 & $4.4 \%$ \\
\hline 9 & Facelift & 411,529 & $4.3 \%$ \\
\hline 10 & $\begin{array}{c}\text { Buttock } \\
\text { Augmentation }\end{array}$ & 289,023 & $2.7 \%$ \\
\hline 11 & Ear Surgery & 252,718 & $2.6 \%$ \\
\hline 12 & Brow Lift & 243,14 & $2.5 \%$ \\
\hline 13 & Neck Lift & 232,606 & $2.4 \%$ \\
\hline 14 & Gynecomastia & 212,328 & $2.2 \%$ \\
\hline 15 & $\begin{array}{c}\text { Breast Implant } \\
\text { Removal }\end{array}$ & 153,476 & $1.6 \%$ \\
\hline 16 & $\begin{array}{c}\text { Hair } \\
\text { Transplantation }\end{array}$ & 134,019 & $1.4 \%$ \\
\hline 17 & $\begin{array}{l}\text { Facial Bone } \\
\text { Contouring }\end{array}$ & 108,25 & $1.1 \%$ \\
\hline 18 & Upper Arm Lift & 102,588 & $1.1 \%$ \\
\hline 19 & Labiaplasty & 95,01 & $1.0 \%$ \\
\hline 20 & Thigh Lift & 70,672 & $0.7 \%$ \\
\hline 21 & Lower Body Lift & 56,169 & $0.6 \%$ \\
\hline 22 & $\begin{array}{c}\text { Vaginal } \\
\text { Rejuvenation }\end{array}$ & 50,086 & $0.5 \%$ \\
\hline 23 & Buttock Lift & 30,905 & $0.3 \%$ \\
\hline 24 & Upper Body Lift & 22,634 & $0.2 \%$ \\
\hline \multirow[t]{2}{*}{25} & $\begin{array}{c}\text { Penile } \\
\text { Enlargement }\end{array}$ & 11,703 & $0.1 \%$ \\
\hline & $\begin{array}{l}\text { Total Surgical } \\
\text { Procedures }\end{array}$ & $9,641,253$ & \\
\hline$* * \mathrm{~F}$ & $\begin{array}{l}\text { * Procedure was } \\
\text { een adjusted to }\end{array}$ & in 2014 su & between \\
\hline
\end{tabular}


A tabela a seguir apresenta os procedimentos não cirúrgicos mais comuns. São eles: toxina butolímica, ácido hialurônico, transplante capilar, foto-rejuvenescimento, peeling químico, redução de gordura não cirúrgica, microdermoabrasão, contração de pele não cirúrgica, tratamento de celulite, peeling a laser, hidroxiapatita, peeling a laser com ablação em bloco, remoção de tattoo, terapia de esclerose, tratamento de veias das pernas, ácido poli-L-lático, emoabrasão e polimetilmetacrilato.

\begin{tabular}{|llc|}
\hline \multicolumn{2}{|c|}{ Number of World-Wide Nonsurgical Procedures Performed by } \\
\hline & & $\begin{array}{c}\text { Percent of Total } \\
\text { Nonsurgical Procedures }\end{array}$ \\
\hline Botulinum Toxin & $38.4 \%$ \\
Hyaluronic Acid & $4,627,752$ & $23.8 \%$ \\
Hair Removal & $2,865,086$ & $9.1 \%$ \\
Photo Rejuvenation & $1,099,053$ & $4.7 \%$ \\
Chemical Peel & 568,672 & $4.1 \%$ \\
Nonsurgical Fat Reduction & 489,344 & $3.5 \%$ \\
Microdermabrasion & 425,315 & $3.0 \%$ \\
Nonsurgical Skin Tightening & 365,587 & $2.8 \%$ \\
Cellulite Treatment & 340,609 & $2.4 \%$ \\
Micro-Ablative Resurfacing & 283,598 & $1.8 \%$ \\
Calcium Hydroxylapatite & 217,593 & $1.4 \%$ \\
Full Field Ablative & 173,492 & $1.4 \%$ \\
Tattoo Removal & 169,098 & $1.1 \%$ \\
Sclerotherapy & 128,218 & $0.6 \%$ \\
Treatment of Leg Veins & 76,778 & $0.6 \%$ \\
Poly-L-Lactic Acid & 73,190 & $0.5 \%$ \\
Dermabrasion & 64,134 & $0.4 \%$ \\
Polymethylmethacrylate & 51,882 & $0.3 \%$ \\
Total Nonsurgical Procedures & 36,017 & \\
\hline
\end{tabular}


A tabela a seguir demonstra os países que realizam os procedimentos cirúrgicos mais comuns.

O Brasil ficou em segundo lugar quanto ao aumento de mama, lipoaspiração, plástica abdominal e rinoplastia.

Em relação ao terceiro procedimento cirúrgico mais comum, qual seja, plástica nas pálpebras, o Brasil ficou em primeiro lugar.

\begin{tabular}{|c|c|c|c|}
\hline \multicolumn{4}{|c|}{ Countries Performing Most Popular Surgical Procedures } \\
\hline Rank* & Country & Number & Percentage of Tota \\
\hline \multicolumn{4}{|c|}{ Breast Augmentation } \\
\hline 1 & USA & 309,985 & $20.8 \%$ \\
\hline 2 & Brazil & 166,430 & $11.2 \%$ \\
\hline 3 & Mexico & 61,613 & $4.1 \%$ \\
\hline 4 & Germany & 53,376 & $3.6 \%$ \\
\hline 5 & South Korea & 50,553 & $3.4 \%$ \\
\hline 6 & Colombia & 46,702 & $3.1 \%$ \\
\hline 7 & France & 41,924 & $2.8 \%$ \\
\hline 8 & India & 29,606 & $2.0 \%$ \\
\hline 9 & Italy & 23,400 & $1.6 \%$ \\
\hline \multicolumn{4}{|c|}{ Liposuction } \\
\hline 1 & USA & 240,565 & $17.2 \%$ \\
\hline 2 & Brazil & 182,765 & $13.1 \%$ \\
\hline 3 & India & 88,193 & $6.3 \%$ \\
\hline 4 & Mexico & 70,773 & $5.1 \%$ \\
\hline 5 & Colombia & 51,623 & $3.7 \%$ \\
\hline 6 & Germany & 40,065 & $2.9 \%$ \\
\hline 7 & South Korea & 39,753 & $2.9 \%$ \\
\hline 8 & France & 29,450 & $2.1 \%$ \\
\hline 9 & Italy & 20,784 & $1.5 \%$ \\
\hline \multicolumn{4}{|c|}{ Eyelid Surgery } \\
\hline 1 & Brazil & 143,165 & $11.3 \%$ \\
\hline 2 & USA & 141,505 & $11.2 \%$ \\
\hline 3 & South Korea & 101,985 & $8.1 \%$ \\
\hline 4 & Germany & 54,907 & $4.3 \%$ \\
\hline 5 & Mexico & 48,329 & $3.8 \%$ \\
\hline 6 & France & 35,473 & $2.8 \%$ \\
\hline 7 & India & 29,434 & $2.3 \%$ \\
\hline 8 & Colombia & 27,959 & $2.2 \%$ \\
\hline 9 & Italy & 19,960 & $1.6 \%$ \\
\hline \multicolumn{4}{|c|}{ Abdominoplasty } \\
\hline 1 & USA & 137,605 & $18.1 \%$ \\
\hline
\end{tabular}




\begin{tabular}{|llll|}
2 & Brazil & 131,120 & $17.3 \%$ \\
3 & Mexico & 39,634 & $5.2 \%$ \\
4 & India & 32,401 & $4.3 \%$ \\
5 & Colombia & 29,317 & $3.9 \%$ \\
6 & France & 22,924 & $3.0 \%$ \\
7 & Germany & 17,682 & $2.3 \%$ \\
8 & South Korea & 7,993 & $1.1 \%$ \\
9 & Italy & 5,384 & $0.7 \%$ \\
\hline Rhinoplasty & & & \\
1 & South Korea & 72,562 & $9.9 \%$ \\
2 & Brazil & 65,120 & $8.9 \%$ \\
3 & USA & 49,855 & $6.8 \%$ \\
4 & India & 44,290 & $6.1 \%$ \\
5 & Mexico & 39,897 & $5.5 \%$ \\
6 & Colombia & 24,852 & $3.4 \%$ \\
7 & France & 20,055 & $2.7 \%$ \\
8 & Germany & 12,717 & $1.7 \%$ \\
9 & Italy & 9,984 & $1.4 \%$ \\
\hline
\end{tabular}

As duas tabelas abaixo apresentam os vários procedimentos cirúrgicos e não cirúrgicos realizados por homens e mulheres, sendo que em relação aos procedimentos cirúrgicos, as mulheres representam $84,7 \%$ dos procedimentos, contra $15,3 \%$ dos homens, e, em relação aos procedimentos não cirúrgicos, as mulheres representam $85,6 \%$ contra $14,4 \%$ dos homens, o que demonstra uma alta predominância das mulheres nos procedimentos estéticos.

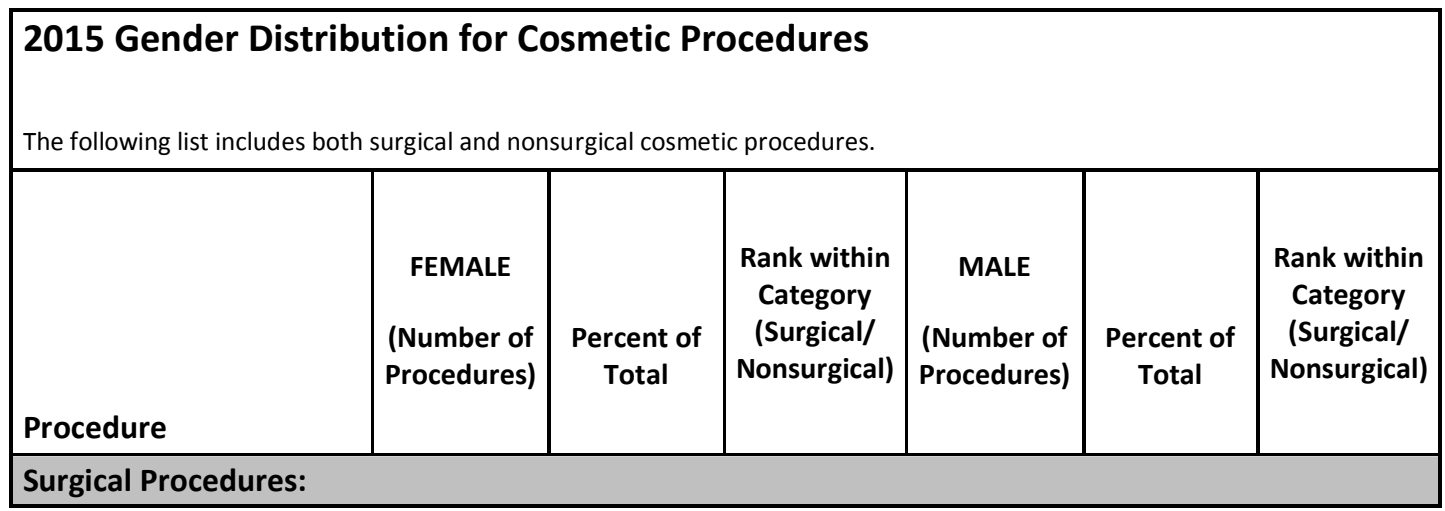




\begin{tabular}{|c|c|c|c|c|c|c|}
\hline Abdominoplasty & 703,361 & $92.7 \%$ & 4 & 55,229 & $7.3 \%$ & 9 \\
\hline $\begin{array}{l}\text { Breast Augmentation- } \\
\text { saline }\end{array}$ & 64,483 & $99.7 \%$ & 20 & 191 & $0.3 \%$ & 24 \\
\hline $\begin{array}{l}\text { Breast Augmentation- } \\
\text { fat transfer }\end{array}$ & 112,222 & $99.1 \%$ & 15 & 967 & $0.9 \%$ & 22 \\
\hline $\begin{array}{l}\text { Breast Augmentation- } \\
\text { silicone }\end{array}$ & $1,299,793$ & $99.1 \%$ & 1 & 11,336 & $0.9 \%$ & 15 \\
\hline Breast Implant Removal & 151,815 & $98.9 \%$ & 14 & 1,661 & $1.1 \%$ & 21 \\
\hline Breast Lift & 512,248 & $100.0 \%$ & 6 & Dna & dna & dna \\
\hline Breast Reduction & 423,093 & $100.0 \%$ & 8 & Dna & dna & dna \\
\hline Brow Lift & 204,622 & $84.2 \%$ & 11 & 38,518 & $15.8 \%$ & 11 \\
\hline $\begin{array}{l}\text { Buttock } \\
\text { Augmentation-fat }\end{array}$ & 246,695 & $95.6 \%$ & 10 & 11,412 & $4.4 \%$ & 14 \\
\hline $\begin{array}{l}\text { Buttock Augmentation- } \\
\text { implants only }\end{array}$ & 30,474 & $98.6 \%$ & 23 & 442 & $1.4 \%$ & 23 \\
\hline Buttock Lift & 28,022 & $90.7 \%$ & 24 & 2,883 & $9.3 \%$ & 20 \\
\hline Ear Surgery & 161,21 & $63.8 \%$ & 13 & 91,508 & $36.2 \%$ & 7 \\
\hline Eyelid Surgery & 988,62 & $78.2 \%$ & 3 & 276,082 & $21.8 \%$ & 1 \\
\hline Facelift & 353,791 & $86.0 \%$ & 9 & 57,738 & $14.0 \%$ & 8 \\
\hline Facial Bone Contouring & 79,646 & $73.6 \%$ & 18 & 28,604 & $26.4 \%$ & 12 \\
\hline Fat Grafting-face & 499,584 & $84.4 \%$ & 7 & 92,311 & $15.6 \%$ & 6 \\
\hline Gynecomastia & dna & Dna & dna & 212,328 & $100.0 \%$ & 3 \\
\hline Hair Transplantation & 26,409 & $19.7 \%$ & 25 & 107,611 & $80.3 \%$ & 5 \\
\hline Labiaplasty & 95,01 & $100.0 \%$ & 17 & dna & dna & dna \\
\hline Liposuction & $1,181,074$ & $84.7 \%$ & 2 & 213,514 & $15.3 \%$ & 2 \\
\hline Lower Body Lift & 47,425 & $84.4 \%$ & 22 & 8,744 & $15.6 \%$ & 16 \\
\hline Neck Lift & 188,39 & $81.0 \%$ & 12 & 44,216 & $19.0 \%$ & 10 \\
\hline Penile Enlargement & dna & Dna & dna & 11,703 & $100.0 \%$ & 13 \\
\hline Rhinoplasty & 534,523 & $73.2 \%$ & 5 & 195,764 & $26.8 \%$ & 4 \\
\hline Thigh Lift & 66,997 & $94.8 \%$ & 19 & 3,675 & $5.2 \%$ & 18 \\
\hline Upper Arm Lift & 99,073 & $96.6 \%$ & 16 & 3,516 & $3.4 \%$ & 19 \\
\hline Upper Body Lift & 18,55 & $82.0 \%$ & 26 & 4,084 & $18.0 \%$ & 17 \\
\hline Vaginal Rejuvenation & 50,086 & $100.0 \%$ & 21 & dna & dna & dna \\
\hline $\begin{array}{ll}\text { Totals - } & \text { Surgical } \\
\text { Procedures } & \\
\end{array}$ & $8,167,217$ & $84.7 \%$ & & $1,474,036$ & $15.3 \%$ & \\
\hline
\end{tabular}

\section{Gender Distribu tion for Cosmetic Procedures}

The following list includes both surgical and nonsurgical cosmetic procedures. 


\begin{tabular}{|c|c|c|c|c|c|c|}
\hline Procedure & \begin{tabular}{|c|} 
FEMALE \\
(Number of \\
Procedures)
\end{tabular} & $\begin{array}{c}\text { Percent of } \\
\text { Total }\end{array}$ & $\begin{array}{c}\text { Rank within } \\
\text { Category } \\
\text { (Surgical/ } \\
\text { Nonsurgical) }\end{array}$ & \begin{tabular}{c|} 
MALE \\
(Number of \\
Procedures)
\end{tabular} & $\begin{array}{c}\text { Percent of } \\
\text { Total }\end{array}$ & $\begin{array}{c}\text { Rank within } \\
\text { Category } \\
\text { (Surgical/ } \\
\text { Nonsurgical) }\end{array}$ \\
\hline \multicolumn{7}{|l|}{ Non-Surgical Procedures: } \\
\hline Botulinum Toxin & $4,003,837$ & $86.5 \%$ & 1 & 623,914 & $13.5 \%$ & 1 \\
\hline Calcium Hydroxylapatite & 152,165 & $87.7 \%$ & 11 & 21,327 & $12.3 \%$ & 13 \\
\hline Cellulite Treatment & 259,515 & $91.5 \%$ & 9 & 24,084 & $8.5 \%$ & 12 \\
\hline Chemical Peel & 431,04 & $88.1 \%$ & 5 & 58,304 & $11.9 \%$ & 6 \\
\hline Dermabrasion & 41,191 & $79.4 \%$ & 17 & 10,691 & $20.6 \%$ & 15 \\
\hline Full Field Ablative & 144,243 & $85.3 \%$ & 12 & 24,855 & $14.7 \%$ & 11 \\
\hline Hair Removal & 928,171 & $84.5 \%$ & 3 & 170,882 & $15.5 \%$ & 3 \\
\hline Hyaluronic Acid & $2,523,631$ & $88.1 \%$ & 2 & 341,454 & $11.9 \%$ & 2 \\
\hline $\begin{array}{l}\text { Micro-Ablative } \\
\text { Resurfacing }\end{array}$ & 181,81 & $83.6 \%$ & 10 & 35,783 & $16.4 \%$ & 10 \\
\hline Microdermabrasion & 311,322 & $85.2 \%$ & 7 & 54,265 & $14.8 \%$ & 7 \\
\hline $\begin{array}{l}\text { Nonsurgical } \quad \text { Fat } \\
\text { Reduction }\end{array}$ & 350,289 & $82.4 \%$ & 6 & 75,025 & $17.6 \%$ & 5 \\
\hline $\begin{array}{l}\text { Nonsurgical } \\
\text { Tightening }\end{array}$ & 297,284 & $87.3 \%$ & 8 & 43,325 & $12.7 \%$ & 9 \\
\hline Photo Rejuvenation & 481,703 & $84.7 \%$ & 4 & 86,968 & $15.3 \%$ & 4 \\
\hline Poly-L-Lactic Acid & 55,275 & $86.2 \%$ & 16 & 8,859 & $13.8 \%$ & 17 \\
\hline Polymethylmethacrylate & 30,4 & $84.4 \%$ & 18 & 5,617 & $15.6 \%$ & 18 \\
\hline Sclerotherapy & 66,444 & $86.5 \%$ & 14 & 10,334 & $13.5 \%$ & 16 \\
\hline Tattoo Removal & 74,312 & $58.0 \%$ & 13 & 53,906 & $42.0 \%$ & 8 \\
\hline Treatment of Leg Veins & 61,659 & $84.2 \%$ & 15 & 11,531 & $15.8 \%$ & 14 \\
\hline $\begin{array}{l}\text { Totals - Non-Surgical } \\
\text { Procedure }\end{array}$ & $10,394,293$ & $86.2 \%$ & & $1,661,126$ & $13.8 \%$ & \\
\hline TOTALS ALL PROCEDURES & $18,561,509$ & $85.6 \%$ & & $3,135,162$ & $14.4 \%$ & \\
\hline
\end{tabular}

As próximas tabelas demonstram os procedimentos mais comuns em cada país.

No Brasil os procedimentos cirúrgicos mais comuns são: lipoaspiração, aumento de mama, cirurgia de pálpebra, plástica abdominal e lifting de mama. 
Já os procedimentos não cirúrgicos mais comuns são: toxina butolínica, ácido hialurônico, transplante capilar, peeling químico e foto-rejuvenescimento.

\begin{tabular}{|c|c|}
\hline \multicolumn{2}{|c|}{ Most Common Procedures by Country } \\
\hline \multicolumn{2}{|l|}{ Total } \\
\hline \multicolumn{2}{|l|}{ USA } \\
\hline \multicolumn{2}{|l|}{ Surgical Procedures } \\
\hline Breast Augmentation & 309,985 \\
\hline Liposuction & 240,565 \\
\hline Eyelid Surgery & 141,505 \\
\hline Abdominoplasty & 137,605 \\
\hline Breast Lift & 106,535 \\
\hline \multicolumn{2}{|l|}{ Non-Surgical Procedures } \\
\hline Botulinum Toxin & $1,141,595$ \\
\hline Hyaluronic Acid & 580,320 \\
\hline Hair Removal & 174,590 \\
\hline Photo Rejuvenation & 122,850 \\
\hline Nonsurgical Fat Reduction & 119,470 \\
\hline \multicolumn{2}{|l|}{ Brazil } \\
\hline \multicolumn{2}{|l|}{ Surgical Procedures } \\
\hline Liposuction & 182,765 \\
\hline Breast Augmentation & 166,340 \\
\hline Eyelid Surgery & 143,165 \\
\hline Abdominoplasty & 131,120 \\
\hline Breast Lift & 80,520 \\
\hline \multicolumn{2}{|l|}{ Non-Surgical Procedures } \\
\hline Botulinum Toxin & 359,865 \\
\hline Hyaluronic Acid & 195,030 \\
\hline Hair Removal & 106,205 \\
\hline Chemical Peel & 86,295 \\
\hline Photo Rejuvenation & 78,155 \\
\hline \multicolumn{2}{|l|}{ South Korea } \\
\hline \multicolumn{2}{|l|}{ Surgical Procedures } \\
\hline Eyelid Surgery & 101,985 \\
\hline Rhinoplasty & 72,562 \\
\hline Fat Grafting-face & 63,326 \\
\hline Breast Augmentation & 50,553 \\
\hline
\end{tabular}


Liposuction

Non-Surgical Procedures

Botulinum Toxin

Hyaluronic Acid

Photo Rejuvenation

48,860

Hair Removal

45,217

Nonsurgical Skin Tightening

36,088

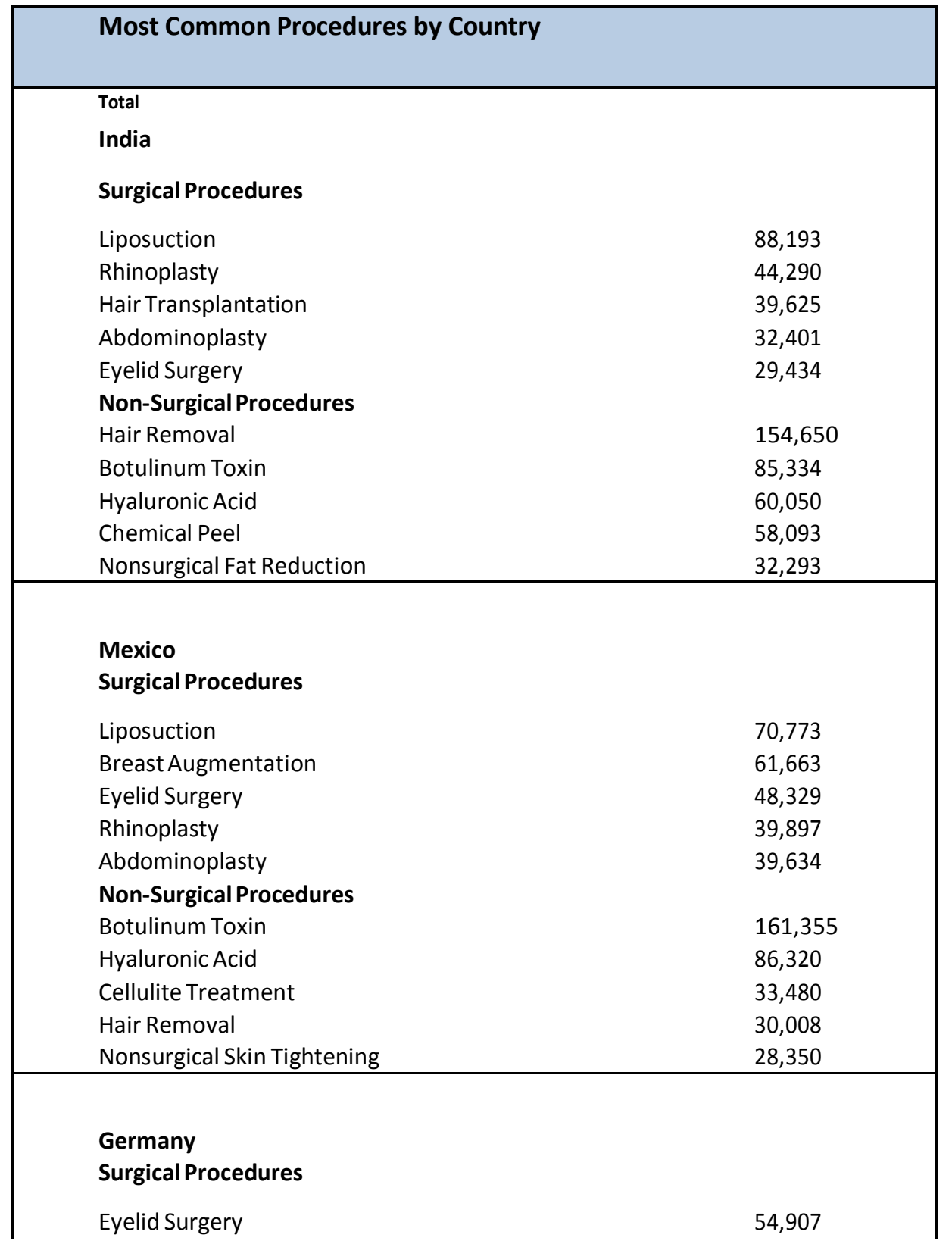


Breast Augmentation

Liposuction

Fat Grafting-face

Abdominoplasty

Non-Surgical Procedures

Botulinum Toxin

Hyaluronic Acid

6,000

Nonsurgical Skin Tightening

4,833

Calcium Hydroxylapatite

4,151

Nonsurgical Fat Reduction

\begin{tabular}{|c|c|}
\hline \multicolumn{2}{|c|}{ Most Common Procedures by Country } \\
\hline \multicolumn{2}{|l|}{ Total } \\
\hline \multicolumn{2}{|l|}{ Colombia } \\
\hline \multicolumn{2}{|l|}{ Surgical Procedures } \\
\hline Liposuction & 51,623 \\
\hline Breast Augmentation & 46,702 \\
\hline Abdominoplasty & 29,317 \\
\hline Eyelid Surgery & 27,959 \\
\hline Rhinoplasty & 24,852 \\
\hline \multicolumn{2}{|l|}{ Non-Surgical Procedures } \\
\hline Botulinum Toxin & 76,000 \\
\hline Hyaluronic Acid & 41,002 \\
\hline Hair Removal & 30,077 \\
\hline Nonsurgical Fat Reduction & 23,646 \\
\hline Microdermabrasion & 14,317 \\
\hline \multicolumn{2}{|l|}{ France } \\
\hline \multicolumn{2}{|l|}{ Surgical Procedures } \\
\hline Breast Augmentation & 41,924 \\
\hline Eyelid Surgery & 35,473 \\
\hline Liposuction & 29,450 \\
\hline Abdominoplasty & 22,924 \\
\hline Rhinoplasty & 20,055 \\
\hline \multicolumn{2}{|l|}{ Non-Surgical Procedures } \\
\hline Hyaluronic Acid & 92,103 \\
\hline Botulinum Toxin & 91,751 \\
\hline Nonsurgical Fat Reduction & 8,921 \\
\hline Hair Removal & 7,201 \\
\hline Nonsurgical Skin Tightening & 6,451 \\
\hline
\end{tabular}




$\begin{array}{ll}\text { Surgical Procedures } & \\ \text { Breast Augmentation } & 23,400 \\ \text { Liposuction } & 20,784 \\ \text { Eyelid Surgery } & 19,960 \\ \text { Fat Grafting-face } & 11,216 \\ \text { Rhinoplasty } & 9,984 \\ \text { Non-Surgical Procedures } & \\ \text { Botulinum Toxin } & 110,400 \\ \text { Hyaluronic Acid } & 109,288 \\ \text { Chemical Peel } & 12,112 \\ \text { Sclerotherapy } & 5,800 \\ \text { Full Field Ablative } & 5,616\end{array}$

Tabela demonstrando os procedimentos não cirúrgicos mais populares em cada país.

$\mathrm{O}$ Brasil fica em $2^{\circ}$ lugar quanto à toxina butolínica, em $3^{\circ}$ quanto ao ácido hialurônico e ao transplante capilar, em $2^{\circ}$ na fotorejuvenescimento e no peeling químico.

\begin{tabular}{|llll|}
\hline \multicolumn{4}{ll}{ Countries Performing Most Popular Non-Surgical Procedures } \\
\hline Rank* & Country & Number of Procedures & Percentage of Total \\
\hline Botulinum Toxin & & & \\
1 & USA & $1,141,595$ & $24.7 \%$ \\
2 & Brazil & O Brsail359,865 & $7.8 \%$ \\
3 & South Korea & 279,019 & $6.0 \%$ \\
4 & Mexico & 161,355 & $3.5 \%$ \\
5 & Germany & 148,459 & $3.2 \%$ \\
6 & Italy & 110,400 & $2.4 \%$ \\
7 & France & 91,751 & $2.0 \%$ \\
8 & India & 85,334 & $1.8 \%$ \\
9 & Colombia & 76,000 & $1.6 \%$ \\
\hline Hyaluronic Acid & & & \\
1 & USA & 580,320 & $20.3 \%$ \\
2 & South Korea & 198,378 & $6.9 \%$ \\
3 & Brazil & 195,030 & $6.8 \%$ \\
\hline
\end{tabular}




\begin{tabular}{|c|c|c|c|}
\hline & & & \\
\hline 4 & Germany & 129,852 & $4.5 \%$ \\
\hline 5 & Italy & 109,288 & $3.8 \%$ \\
\hline 6 & France & 92,103 & $3.2 \%$ \\
\hline 7 & Mexico & 86,320 & $3.0 \%$ \\
\hline 8 & India & 60,050 & $2.1 \%$ \\
\hline 9 & Colombia & 41,002 & $1.4 \%$ \\
\hline \multicolumn{4}{|c|}{ Hair Removal } \\
\hline 1 & USA & 174,590 & $15.9 \%$ \\
\hline 2 & India & 154,650 & $14.1 \%$ \\
\hline 3 & Brazil & 106,205 & $9.7 \%$ \\
\hline 4 & South Korea & 45,217 & $4.1 \%$ \\
\hline 5 & Colombia & 30,077 & $2.7 \%$ \\
\hline 6 & Mexico & 30,008 & $2.7 \%$ \\
\hline 7 & France & 7,201 & $0.7 \%$ \\
\hline 8 & Italy & 4,928 & $0.4 \%$ \\
\hline 9 & Germany & 4,118 & $0.4 \%$ \\
\hline \multicolumn{4}{|c|}{ Photo Rejuvenation } \\
\hline 1 & USA & 122,850 & $21.6 \%$ \\
\hline 2 & Brazil & 78,155 & $13.7 \%$ \\
\hline 3 & South Korea & 48,860 & $8.6 \%$ \\
\hline 4 & Mexico & 24,521 & $4.3 \%$ \\
\hline 5 & Colombia & 13,965 & $2.5 \%$ \\
\hline 6 & India & 6,816 & $1.2 \%$ \\
\hline 7 & France & 6,099 & $1.1 \%$ \\
\hline 8 & Italy & 2,688 & $0.5 \%$ \\
\hline 9 & Germany & 0 & $0.0 \%$ \\
\hline
\end{tabular}

\begin{tabular}{|llll|}
\hline Co & untries & Performing & \multicolumn{2}{l|}{ Popular Non-Surgical Procedures } \\
\hline Rank ${ }^{*}$ & Country & Number of Procedures & Percentage of Total \\
\hline Chemical Peel & & & \\
1 & USA & 101,010 & $20.6 \%$ \\
2 & & & $17.6 \%$ \\
3 & Brazil & 86,295 & $11.9 \%$ \\
4 & India & 58,093 & $2.5 \%$ \\
5 & Italy & 12,112 & $1.7 \%$ \\
6 & Mexico & 8,339 & $1.6 \%$ \\
7 & South Korea & 7,779 & $1.2 \%$ \\
8 & Colombia & 5,852 & $1.0 \%$ \\
9 & France & 5,026 & $0.4 \%$
\end{tabular}


* Rankings are based solely on those countries from which a sufficient survey response was received and data were considered to be representative.

Tabela demonstrando ranking de cada país nos procedimentos cirúrgicos. No Brasil são realizados mais procedimentos de corpo e extremidades, de rosto e cabeça e de mama.

\begin{tabular}{|c|c|c|c|}
\hline \multicolumn{4}{|c|}{ Surgical Procedure Group Ranking by Country } \\
\hline $\mathbf{R}$ & Country & Total & $\%$ of \\
\hline \multicolumn{4}{|c|}{ USA } \\
\hline 1 & Total Breast Procedures & 546,260 & 38.6 \\
\hline 2 & Total Body \& Extremities Procedures & 454,935 & 32.2 \\
\hline 3 & Total Face \& Head Procedures & 413,140 & 29.2 \\
\hline \multicolumn{4}{|c|}{ Brazil } \\
\hline 1 & Total Body \& Extremities Procedures & 435,270 & 35.6 \\
\hline 2 & Total Face \& Head Procedures & 430,375 & 35.2 \\
\hline 3 & Total Breast Procedures & 358,655 & 29.3 \\
\hline \multicolumn{4}{|c|}{ South Korea } \\
\hline 1 & Total Face \& Head Procedures & 311,571 & 70.0 \\
\hline 2 & Total Breast Procedures & 74,876 & 16.8 \\
\hline 3 & Total Body \& Extremities Procedures & 58,697 & 13.2 \\
\hline \multicolumn{4}{|c|}{ India } \\
\hline 1 & Total Face \& Head Procedures & 185,158 & 44.0 \\
\hline 2 & Total Body \& Extremities Procedures & 153,317 & 36.5 \\
\hline 3 & Total Breast Procedures & 81,980 & 19.5 \\
\hline \multicolumn{4}{|c|}{ Mexico } \\
\hline 1 & Total Face \& Head Procedures & 185,411 & 40.2 \\
\hline 2 & Total Body \& Extremities Procedures & 165,509 & 35.9 \\
\hline 3 & Total Breast Procedures & 110,624 & 24.0 \\
\hline \multicolumn{4}{|c|}{ Germany } \\
\hline 1 & Total Face \& Head Procedures & 126,824 & 41.1 \\
\hline 2 & Total Breast Procedures & 101,611 & 33.0 \\
\hline 3 & Total Body \& Extremities Procedures & 79,823 & 25.9 \\
\hline \multicolumn{4}{|c|}{ Colombia } \\
\hline 1 & Total Body \& Extremities Procedures & 122,199 & 38.8 \\
\hline 2 & Total Face \& Head Procedures & 107,949 & 34.3 \\
\hline
\end{tabular}




\begin{tabular}{|c|c|c|c|}
\hline 3 & Total Breast Procedures & 84,636 & 26.9 \\
\hline \multicolumn{4}{|c|}{ France } \\
\hline 1 & Total Face \& Head Procedures & 101,365 & 39.1 \\
\hline 2 & Total Breast Procedures & 85,652 & 33.0 \\
\hline 3 & Total Body \& Extremities Procedures & 72,191 & 27.9 \\
\hline \multicolumn{4}{|c|}{ Italy } \\
\hline 1 & Total Face \& Head Procedures & 60,000 & 43.2 \\
\hline 2 & Total Breast Procedures & 41,192 & 29.7 \\
\hline 3 & Total Body \& Extremities Procedures & 37,672 & 27.1 \\
\hline \multicolumn{4}{|c|}{ * Percentage reflects portion of countries total surgical procedures } \\
\hline
\end{tabular}

Ranking de procedimentos não cirúrgicos. No Brasil são mais realizados procedimentos injetáveis, de rejuvenescimento facial e outros.

\begin{tabular}{|c|c|c|c|}
\hline \multicolumn{4}{|c|}{ Non-Surgical Procedure Group Ranking by Country } \\
\hline $\mathbf{R}$ & Country & Total & $\%$ of \\
\hline \multicolumn{4}{|c|}{ USA } \\
\hline 1 & Total Injectables Procedures & $1,805,895$ & 68.7 \\
\hline 2 & Total Facial Rejuvenation Procedures & 483,015 & 18.4 \\
\hline 3 & Total Other Procedures & 339,365 & 12.9 \\
\hline \multicolumn{4}{|c|}{ Brazil } \\
\hline 1 & Total Injectables Procedures & 578,050 & 52.6 \\
\hline 2 & Total Facial Rejuvenation Procedures & 298,265 & 27.1 \\
\hline 3 & Total Other Procedures & 223,630 & 20.3 \\
\hline \multicolumn{4}{|c|}{ South Korea } \\
\hline 1 & Total Injectables Procedures & 483,482 & 68.0 \\
\hline 2 & Total Facial Rejuvenation Procedures & 140,024 & 19.7 \\
\hline 3 & Total Other Procedures & 87,584 & 12.3 \\
\hline \multicolumn{4}{|c|}{ India } \\
\hline 1 & Total Other Procedures & 242,262 & 47.0 \\
\hline 2 & Total Injectables Procedures & 145,749 & 28.3 \\
\hline 3 & Total Facial Rejuvenation Procedures & 127,022 & 24.7 \\
\hline \multicolumn{4}{|c|}{ Mexico } \\
\hline 1 & Total Injectables Procedures & 254,975 & 57.1 \\
\hline 2 & Total Other Procedures & 96,798 & 21.7 \\
\hline
\end{tabular}


Germany

1 Total Injectables Procedures

2 Total Facial Rejuvenation Procedures

3

Total Other Procedures

Colombia

1 Total Injectables Procedures

France

$1 \quad$ Total Injectables Procedures 188,357

Italy

Quanto à idade das pessoas que se submetem a procedimentos cosméticos.

Observa-se significativa participação de jovens de 18 anos ou menos na prática de aumentos de mama, lipoaspiração, rinoplastia, toxina butolímica e redução de gordura não cirúrgica.

\section{Age Distribution for Certain Cosmetic Procedures}

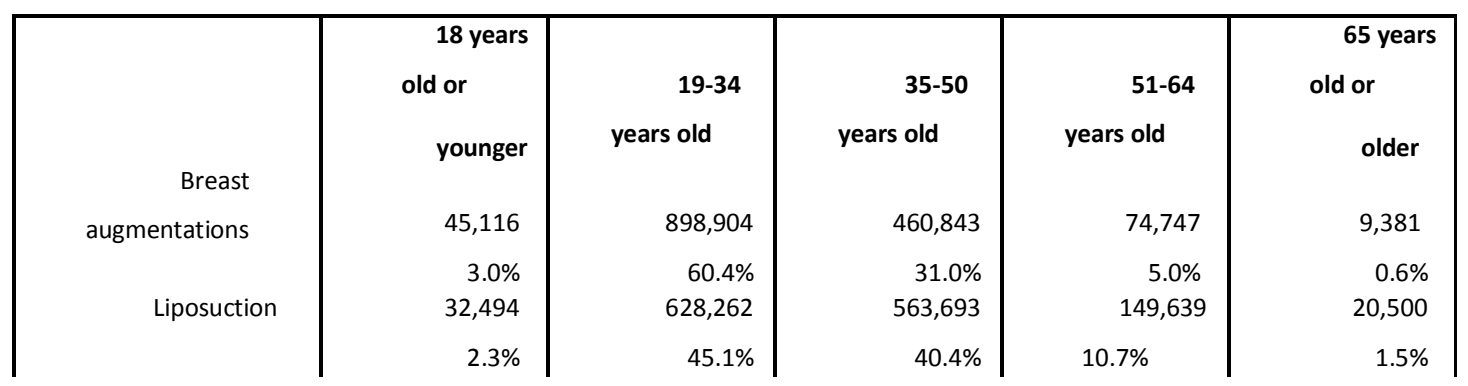




\begin{tabular}{|c|c|c|c|c|c|c|c|}
\hline Rhinoplasty & 55,064 & & 474,686 & & 165,045 & 30,453 & 5,039 \\
\hline & $7.5 \%$ & & $65.0 \%$ & & $22.6 \%$ & $4.2 \%$ & $0.7 \%$ \\
\hline Botulinum & 29,155 & & $1,048,18$ & & $2,312,95$ & $1,027,36$ & 210,100 \\
\hline Toxin & $0.6 \%$ & 6 & $22.7 \%$ & 0 & $50.0 \%$ & $22.2 \%$ & $4.5 \%$ \\
\hline Nonsurgical Fat & 10,633 & & 126,318 & & 176,080 & 89,741 & 22,542 \\
\hline Reduction & $2.5 \%$ & & $29.7 \%$ & & $41.4 \%$ & $21.1 \%$ & $5.3 \%$ \\
\hline
\end{tabular}

Em termos do local onde os procedimentos cosméticos são realizados, no Brasil 56,1\% ocorre em hospitais.

\section{Percent of Cosmetic Procedures by Location}

\begin{tabular}{|c|c|c|c|c|c|c|c|c|c|c|}
\hline & $\begin{array}{l}\text { World- } \\
\text { Wide }\end{array}$ & Brazil & Colombia & France & Germany & India & Italy & Mexico & $\begin{array}{l}\text { South } \\
\text { Korea }\end{array}$ & USA \\
\hline $\begin{array}{c}\text { An office } \\
\text { facility } \\
\text { A hospital }\end{array}$ & $32.7 \%$ & $33.9 \%$ & $20.6 \%$ & $21.4 \%$ & $35.1 \%$ & $24.4 \%$ & $36.3 \%$ & $25.9 \%$ & $60.4 \%$ & $41.6 \%$ \\
$\begin{array}{c}\text { A free- } \\
\text { standing }\end{array}$ & $46.7 \%$ & $56.1 \%$ & $56.3 \%$ & $60.4 \%$ & $53.0 \%$ & $54.4 \%$ & $26.1 \%$ & $54.1 \%$ & $34.0 \%$ & $18.6 \%$ \\
$\begin{array}{c}\text { Surgicenter } \\
\text { Other }\end{array}$ & $19.8 \%$ & $9.8 \%$ & $22.5 \%$ & $18.2 \%$ & $11.9 \%$ & $20.1 \%$ & $37.0 \%$ & $19.9 \%$ & $5.7 \%$ & $39.5 \%$ \\
& $0.8 \%$ & $0.2 \%$ & $0.7 \%$ & $0.0 \%$ & $0.0 \%$ & $1.1 \%$ & $0.6 \%$ & $0.1 \%$ & $0.0 \%$ & $0.3 \%$ \\
\hline
\end{tabular}

Em relação a aumento de mama praticado por mulheres de 17 anos ou menos, o Brasil é o líder mundial, com 19\% do total de procedimentos. Os motivos alegados são síndrome de Poland, assimetria severa, micromastia congênita, mama tubular e outros. Mas o motivo mais alegado é simples aumento bilateral cosmético $(37,9 \%)$. 
Breast Augmentations for Women 17 Years Old or Younger - 2015

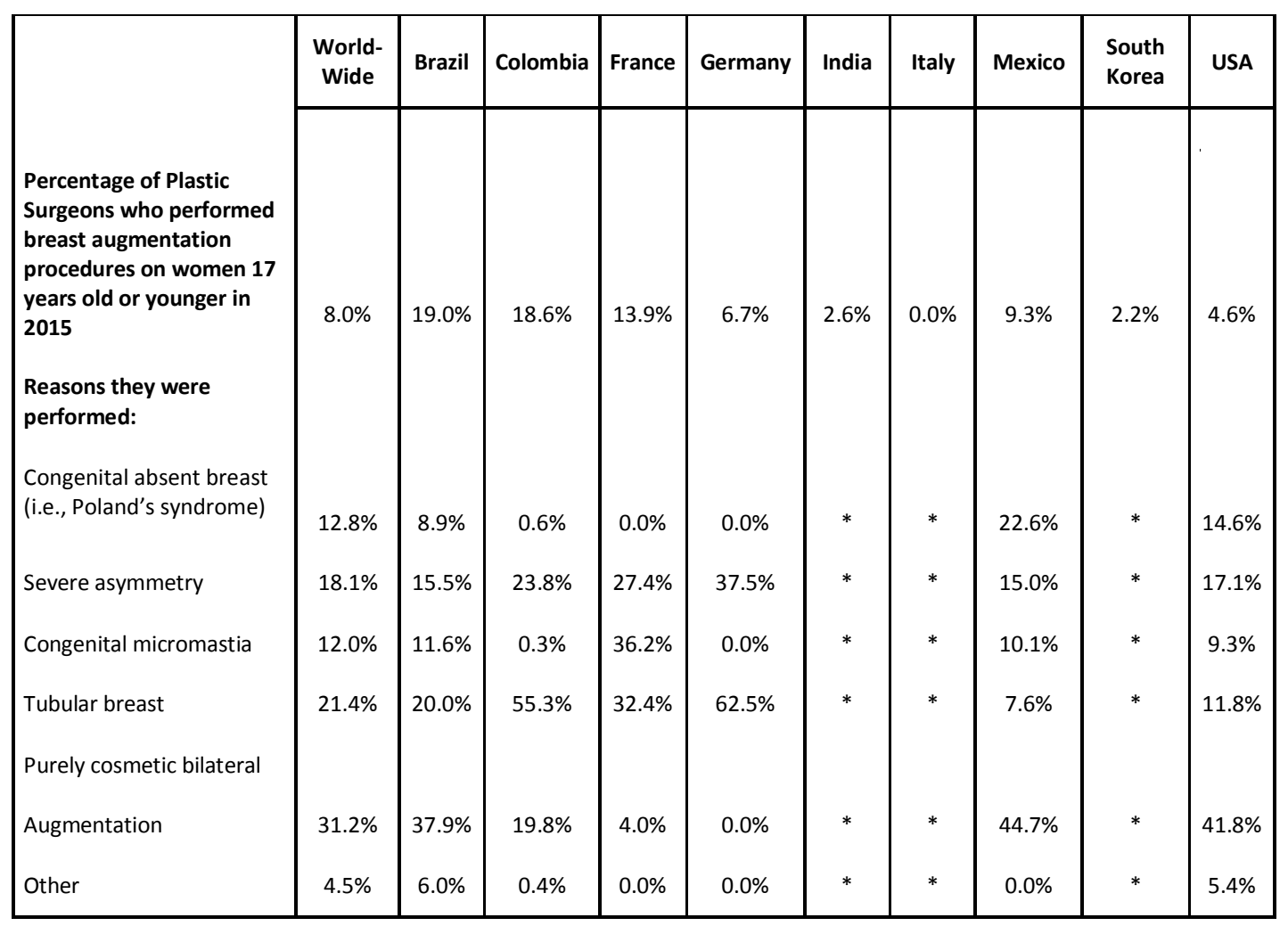

Por fim, demonstra-se que o turismo médico no Brasil para a realização de procedimentos estéticos é irrelevante, comparado com outros países. A tabela a seguir comprova um baixo número de pacientes estrangeiros no Brasil para tais procedimentos. Assim, pode-se concluir que tal questão afeta basicamente a população brasileira, sendo de relevância para o tratamento do tema no país. 


\section{Medical Tourism - 2015}

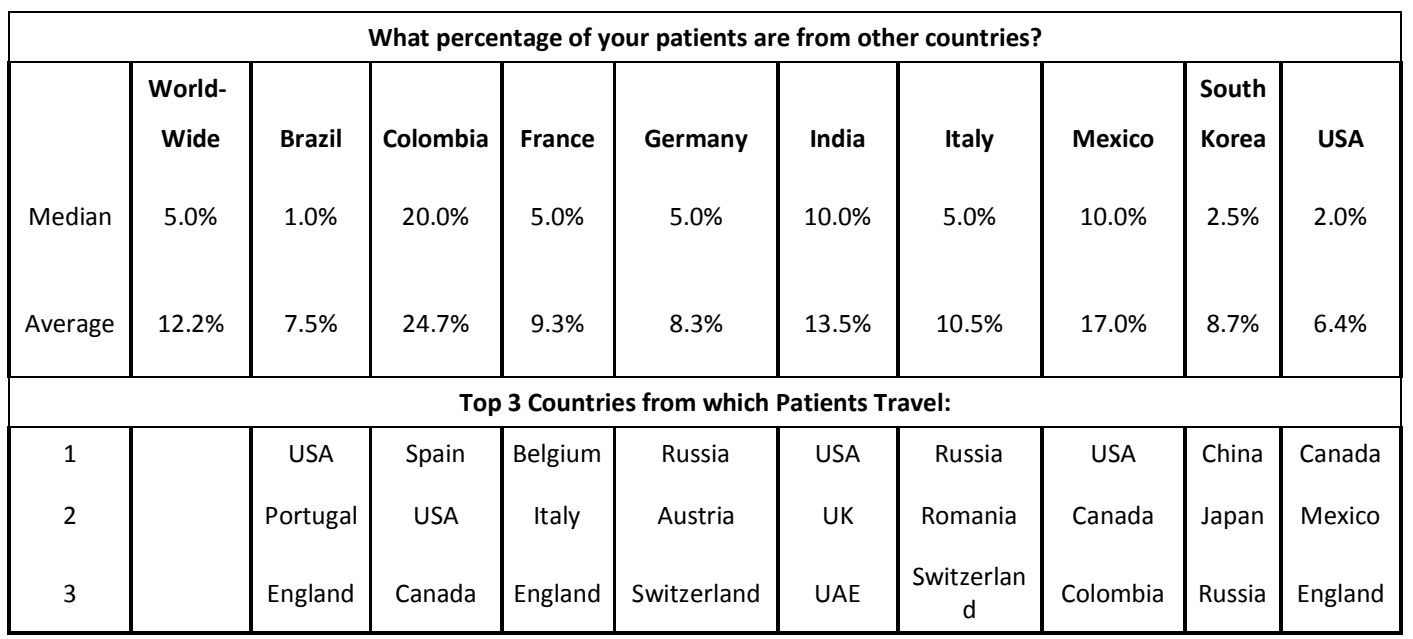




\section{CAPÍTULO 2 - MEDICINA DE DESEJO}

\subsection{A cirurgia estética como medicina de desejo ${ }^{58}$}

A cirurgia estética é um dos principais campos da chamada medicina de desejo. ${ }^{59}$ Esta, ao contrário da medicina tradicional, apresenta-se como uma medicina nova, que coloca à disposição de seus usuários uma grande variedade de tratamentos médicos para melhoramento da aparência e performance pessoal, com finalidade cognitiva (melhor desempenho cognitivo), física (melhor aparência ou desempenho físico em atletas, por exemplo) ou social (melhor colocação na sociedade ou busca por um melhor emprego).

58 Esse termo foi cunhado pela doutrina alemã com a expressão Wunscherfüllende Medizin, cf. KETTNER, Matthias (coord.). Wunscherfüllende Medizin: Ärztliche Behandlung im Dient von Selbstverwirklichung und Lebensplanung. Frankfurt: Campus, 2009. A respeito de uma tentativa de esclarecimento e precisão desse conceito, cf. BUYX, Alena; HUCKLENBROICH, Peter. Wunscherfüllende Medizin und Krankheitsbegriff: Eine medizinische Analyse, in KETTNER, Matthias (coord.). Wunscherfüllende Medizin. Op. Cit., pp. 25-53.

${ }^{59}$ KETTNER, Matthias; JUNKER, Iris, Konsequenzen der wunscherfüllenden Medizin für die Arzt-Patient-Beziehung, in KETTNER, Matthias (coord.). Wunscherfüllende Medizin: Ärztliche Behandlung im Dient von Selbstverwirklichung und Lebensplanung. Op. Cit., p. 62 
A palavra desejo, segundo CALDAS AULETE, ${ }^{60}$ enseja inclinação do espirito humano para alguma coisa cuja posse ou realização lhe causaria prazer. É um instinto que move o homem a procurar fora de si, da sua condição e do seu poder, o gozo ou felicidade. É um anseio, uma veemente aspiração de algo. É uma vontade de se ter, possuir ou conseguir uma determinada coisa, um apetite sem moderação. ${ }^{61}$ Deriva do vocábulo latino desiderium, que significa necessidade física. ${ }^{62}$

A medicina de desejo não lida com pessoas doentes que procuram um tratamento médico para curar uma doença, mas, sim, com clientes ou consumidores em busca de satisfação de necessidades culturalmente interpretadas. ${ }^{63} \mathrm{O}$ cliente da medicina de desejo necessita dos conhecimentos e práticas médicas não para lidar com um estado de sofrimento causado por uma doença, mas para conseguir uma condição corporal necessária e adequada para o estilo de vida desejado (lifestyle). ${ }^{64}$

${ }^{60}$ Verbete Desejo. In Dicionário contemporâneo da língua portuguesa. Op. Cit., p. 810.

${ }^{61}$ MORAES SILVA, António. Verbete Desejo. In Diccionario da língua portugueza. Op. Cit., p. 638.

${ }_{62}$ TORRINHA, Francisco. Dicionário Latino Português. 2 ed. Porto: Gráficos Reunidos, 1942. p. 246.

${ }^{63}$ KETTNER, Matthias; JUNKER, Iris. Konsequenzen der wunscherfüllenden Medizin für die Arzt-Patient-Beziehung, in KETTNER, Matthias (coord.), Wunscherfüllende Medizin. Op. Cit., p. 55.

${ }^{64}$ Ibidem, p. 66. 
Para melhor ilustrar as diferenças entre ambas as medicinas, apresenta-se o quadro abaixo: ${ }^{65}$

\begin{tabular}{|c|c|}
\hline Medicina tradicional & Medicina de desejo \\
\hline doença & necessidade \\
\hline saúde & SAÚDE \\
\hline pathogenese & salutogenese \\
\hline indicação & contraindicação \\
\hline papel de doente & papel de cliente \\
\hline imperativa & optativa \\
\hline autonomia & derregulação \\
\hline medicina tradicional & medicina alternativa \\
\hline
\end{tabular}

Enquanto a medicina de desejo se dedica às necessidades, no sentido de necessidades interpretadas culturalmente, a medicina tradicional se orienta pela doença. ${ }^{66}$ Nesta, o conceito de saúde é entendido, estruturalmente, por uma dupla negação: saúde é a ausência de algo negativo (doença) e o tratamento médico leva, numa situação ideal, ao estado anterior de saúde. Por isso no quadro

${ }^{65}$ Ibidem, p. 67.

${ }^{66}$ Ibidem, p. 67. 
acima "saúde" aparece em letras minúsculas. ${ }^{67}$ Já para a medicina de desejo, saúde deve ser escrita com letras maiúsculas, haja vista que ela deve ser pensada como uma qualidade complexa, positiva, social, biológica e psíquica, que sempre pode ser melhorada. ${ }^{68}$

Nesse sentido, enquanto a preocupação no que se refere à "saúde", como não existência de uma doença que necessita de tratamento, apresenta-se como um processo delimitado, cuja finalidade é atacar o estado de enfermidade, a preocupação em relação à "SAÚDE" é um processo tendencialmente indefinível, uma vez que o cliente sempre terá a possibilidade de melhorar algum aspecto de sua saúde, seja a aparência corporal, o bem-estar, a capacidade profissional, etc. ${ }^{69}$

É certo que a definição de saúde é algo muito difícil, pois sua definição possui implicações legais, sociais e econômicas dos estados de saúde e doença. A definição mais difundida é a encontrada no preâmbulo da Constituição da Organização Mundial da Saúde, pela qual saúde é um estado de completo bem-estar físico, mental e social, e não apenas a ausência de doenças. Há críticas em relação a esse conceito, principalmente no que tange ao termo "completo" que leva à ideia de ser a saúde algo idealizado e

\footnotetext{
${ }^{67}$ Ibidem, p. 67.

${ }^{68}$ Ibidem, p. 67.

${ }^{69}$ Ibidem, p. 67.
} 
impossível de ser alcançado. ${ }^{70}$ Entretanto, essa definição já contém a transição de "saúde" para "SAÚDE", já que afirma que saúde é o bem-estar corporal, espiritual e social completo e não somente estar livre de doenças e deficiências. ${ }^{71}$

O segundo aspecto que o quadro acima ressalta é que, na medicina tradicional, a preocupação é explicar o porquê de o organismo ficar doente (pathogênese), enquanto a medicina de desejo se preocupa mais com o surgimento da saúde e como ela pode ser mantida. A esse respeito, cite-se o neologismo formulado por Antonovsky de "salutogênese". ${ }^{72}$ 73 $^{73}$

70 SEGRE, Marco, O conceito de saúde. Disponível em $<$ http://www.scielo.br/scielo.php?script=sci_arttext\&pid=S003489101997000600016>. Acesso em 09 set. 2016.

${ }^{71}$ KETTNER, Matthias; JUNKER, Iris, Konsequenzen der wunscherfüllenden Medizin für die Arzt-Patient-Beziehung, in KETTNER, Matthias (coord.). Wunscherfüllende Medizin. Op. Cit., pp. 67-68.

${ }^{72}$ Ibidem, pp. 68-69.

${ }^{73} \mathrm{O}$ termo salutogênese foi cunhado pelo médico e sociólogo Aaron Antonovsky após a Segunda Guerra Mundial como forma de se determinar a procura dos motivos que levam uma pessoa a estar saudável, em contraposição com a busca das razões que levam a pessoa a ficar doente, que é a patogênese. Assim, a salutogênese questiona o que fazer para que a pessoa continue sadia, sem, no entanto, se tratar de uma busca pela felicidade inconsciente. Como centro da salutogênese, Antonovsky propõe um senso de coerência, o qual se resume numa maneira na qual o indivíduo encontra de resolver seus problemas de maneira satisfatória sem que para isso sucumba a eles. Nesse sentido: MORAES, Wesley Aragão de. Salutogênese e caminhos iniciáticos: A espiritualidade como item de saúde in Arte Médica Ampliada, v. 34. n. 4. São Paulo: Associação Brasileira de Medicina Antroposófica, 2014. pp. 156163. 
Nessa esteira, a medicina tradicional lida com o paciente como a pessoa que tem direito a um bom tratamento garantido institucionalmente; cabe ao médico informa-lo sobre os métodos e alternativas, quando houver, de tratamentos possíveis. A medicina de desejo, ao contrário, lida não com um paciente, mas com um cliente, que traz ao médico suas aspirações e espera dele o êxito da conduta médica. $^{74}$

O termo paciente pode ser compreendido em sentido estrito e em sentido amplo. ${ }^{75}$ Stricto sensu, paciente se refere à pessoa doente ou que se sente como doente. Paciente é aquele que é tomado de uma "infelicidade", de modo que deve suportar essa situação de forma sofrida e com paciência. Lato sensu, entretanto, paciente é toda pessoa que usa o serviço de saúde, que é tratada por algum médico ou algum profissional da área de saúde. Nesse sentido, a gestante é uma paciente, sem que isso signifique que ela esteja doente ou se sinta como uma pessoa doente. Tal sentido amplo, então, abrangeria a ideia de cliente, que é a pessoa que usa o serviço de saúde, mas com outra finalidade que não a de tratar uma doença.

${ }^{74}$ KETTNER, Matthias; JUNKER, Iris, Konsequenzen der wunscherfüllenden Medizin für die Arzt-Patient-Beziehung, in KETTNER, Matthias (coord.), Wunscherfüllende Medizin. Op. Cit., p. 69.

${ }^{75}$ PANAGOPOULOU-KOUTNATZI, Fereniki. Die Selbstbestimmung des Patienten. Berlin: Duncker \& Humblot, 2009. pp. 24-25. 
Outra diferença apontada no quadro acima é que, diante do quadro de doença, a medicina tradicional apresenta-se como sendo imperativa, na medida em que seu tratamento se impõe para restabelecer a saúde, desde que conte com o consentimento do paciente, ao passo que a medicina de desejo é optativa, já que não existe um quadro de doença a ser combatido. ${ }^{76}$ Disso decorre que as medidas médicas, na medicina tradicional, devem ser indicadas para combater um determinado estado patológico. Em outras palavras, o médico parte do diagnóstico de um determinado quadro patológico, verifica seu prognóstico e busca a terapia adequada ao caso concreto. Ao contrário, na medicina de desejo, a qual não tem por finalidade combater uma doença, afirma-se que suas medidas são contraindicadas. $^{77}$

$\mathrm{Na}$ medicina tradicional fala-se em autonomia, que enseja a autonomia do médico de conduzir as ofertas de tratamento segundo os conhecimentos médicos e sob sua responsabilidade. Ou seja, o médico responsável pelo tratamento de uma determinada doença oferece ao paciente os tratamentos disponíveis pela ciência médica e conforme seus conhecimentos médicos. $\mathrm{Na}$ medicina de desejo, a oferta de tratamento não depende dos conhecimentos médicos, mas, ${ }^{76}$ KETTNER, Matthias; JUNKER, Iris, Konsequenzen der wunscherfüllenden Medizin für die Arzt-Patient-Beziehung, in KETTNER, Matthias (coord.). Wunscherfüllende Medizin. Op. Cit., p. 68.

${ }^{77}$ Ibidem, p. 69. 
sim, da procura do mercado por determinados tratamentos. Por isso se fala que a medicina de desejo atende necessidades interpretadas culturalmente $^{78}$.

A medicina de desejo ainda se relaciona com o aperfeiçoamento da pessoa. Esse conceito, também conhecido pelo termo enhancement, significa a tentativa de melhoramento, por meio de técnica, das características normais de uma pessoa saudável através de intervenções em seu corpo. Isso pode começar com as cirurgias estéticas e terminar com as quimeras. Pode-se imaginar a alteração de pessoas pela técnica genética, operações e preparados químicos. ${ }^{79}$

No entanto, aquilo que é considerado um melhoramento, pode se transformar, ao contrário, em danos à mente e ao corpo. ${ }^{80}$ Temese que o enhancement da pessoa a prejudique fortemente. Citam-se, principalmente, danos na personalidade, perda de autodeterminação e perda da vontade de viver. ${ }^{81}$ A questão que se coloca é se os desejos das pessoas, os quais elas acreditam serem essenciais para alcançar a felicidade, devem ser satisfeitos sob quaisquer circunstâncias.

${ }^{78}$ Ibidem , pp. 69-70.

${ }^{79}$ GESANG, Bernward. Perfektionierung des Menschen. Berlin: Walter de Gruyter, 2007. pp. 3-4.

${ }^{80}$ Ibidem, p. 10.

${ }^{81}$ Ibidem, p. 82. 
Conforme uma posição dita conservadora, as pessoas seriam mais felizes ao final quando seus desejos de se melhorar fossem realizados espontaneamente. A longo prazo, entretanto, elas perceberiam que se prejudicaram enquanto buscavam uma melhora. Trata-se aqui de se indagar sobre o bem-estar das pessoas no futuro. ${ }^{82}$

Diferentemente, a posição liberal sustenta que o bem-estar duradouro das pessoas também se refere a seus desejos. Tais desejos poderiam ser movidos por simples capricho ou falsas informações, o que tornaria as pessoas infelizes caso os realizassem. ${ }^{83}$ Cita-se um exemplo dado por um cirurgião plástico suíço: uma intervenção aplicada de forma errônea pode alterar a personalidade de forma prejudicial ou causar danos à saúde. Porém, alguns pacientes se esquecem disso, quando eles se dirigem ao cirurgião estético portando uma revista.

Por isso, a posição liberal afirma que apenas os desejos esclarecidos devem ser atendidos. Desejos têm uma finalidade, a qual deve ser avaliada antes de serem realizados. Quando essa avaliação e a finalidade estão em conformidade com uma satisfação alcançável de forma realista, então esses desejos valem como esclarecidos.

${ }^{82}$ Ibidem, p. 83.

${ }^{83}$ Ibidem, p. 83. 
Diante desse contexto, o avanço da medicina de desejo e com ela o incentivo do melhoramento das pessoas deve ser ponderado com cautela pelas pessoas que desejam fazer uso de suas medidas médicas.

Há algum tempo, o Conselho Federal de Medicina alemão formou uma coalizão de forças políticas e sociais para fazer resistência contra a pressão da indústria de beleza. A finalidade foi formar uma oposição a esse mercado, que busca seduzir sistematicamente as pessoas para suas práticas, através de um forte e amplo esclarecimento para evitar que jovens considerem a sua aparência como uma falha humana que somente pode ser eliminada através de cirurgia. $^{84}$

Fala-se que a medicina de embelezamento, via de regra a medicina de melhoramento estético, é uma moda bem-sucedida. Para esse sucesso colaboram muitas forças baseadas em projeções e ilusões, dentre elas o desejo de influenciar a mudança da aparência decorrente da idade e outras insuficiências estéticas. ${ }^{85}$

Esse é um desejo bastante antigo das pessoas, mas parece que hoje é passível de ser realizado e é considerado de grande importância para o sucesso pessoal. As chances e as possibilidades ${ }^{84}$ KETTNER, Matthias; JUNKER, Iris, Konsequenzen der wunscherfüllenden Medizin für die Arzt-Patient-Beziehung, in KETTNER, Matthias (coord.). Wunscherfüllende Medizin. Op. Cit., p. 62.

${ }^{85}$ Ibidem, p. 62. 
de fazer progresso dependem, hoje, entre outras coisas, para a pessoa, em muitas áreas sociais, de uma aparência atrativa. Atualmente, também se verifica outro fenômeno: as pessoas ainda em idade avançada querem continuar ativas profissional e socialmente. $^{86}$

O culto ao corpo, ou seja, o corpo desempenhando o papel de um objeto afetivo que dá sentido à vida, aparece em muitas práticas corporais atuais. No entanto, é preciso questionar: quando o culto ao corpo se transforma numa mania de corpo, o culto de beleza se transforma numa mania de beleza e o culto à juventude, numa mania de juventude? O conceito de mania leva à área da psicopatologia e é carregado de conotação moralista.

A questão é saber qual o limite do moralmente aceitável quando a tematização do corpo ganha formas de mania: a modelo que passa fome e chega a morrer de anorexia, o halterofilista que por causa de sua massa muscular não pode mais andar, mulheres de 70 anos que não param de fazer lifting, homens de 50 que fazem transplante capilar e se submeter a cirurgias de aumento de pênis. ${ }^{87}$

Quem fala de mania ou loucura deve conhecer as regras da normalidade. Mas o que na área de estética, considerando suas conotações históricas e contemporâneas é normal ou anormal? As ${ }^{86}$ Ibidem, p. 62.

${ }^{87}$ Ibidem, p. 63. 
possibilidades técnicas e econômicas abrem em sociedades liberais um amplo espaço para preferências e desejos particulares, o que torna difícil formular linhas normativas. Isso somente é possível nos poucos casos graves de dano próprio ou alheio. ${ }^{88}$

Os riscos de danos irreversíveis ou de difícil reversibilidade, como aqueles que prejudicam a saúde, a autodeterminação e a personalidade, existem. No entanto, as técnicas de melhoramento da pessoa, que buscam satisfazer seus desejos, foram concebidas de modo a promover aqueles mesmos bens jurídicos, proporcionando à pessoa um maior bem-estar.

\subsection{Indicação}

A intervenção de cura pressupõe uma indicação. Medidas médicas de tratamento sem indicação não configuram intervenções de cura e podem induzir um erro médico de tratamento. Afirma-se que um tratamento de cura é indicado do ponto de vista médico quando ele traz consigo a razão para uma prescrição de um determinado procedimento diagnóstico ou terapêutico, razão essa

${ }^{88}$ Ibidem, p. 63. 
que justifica a utilização de uma medida médica. ${ }^{89} \mathrm{~A}$ indicação é uma das condições fundamentais para que a prestação médica se desenvolva conforme as normas jurídicas, ao lado do consentimento informado e da execução da medida lege artis. ${ }^{90}$

Com efeito, o entendimento tradicional da atividade médica baseia-se no princípio "nenhuma intervenção sem indicação", o qual enseja que todo procedimento médico tem que apresentar uma indicação. ${ }^{91}$

A medicina tradicional parte da compreensão básica de que a aplicação de seus meios serve para um determinado tratamento. Em outras palavras, a atividade médica relaciona-se com a cura ou alívio de doenças, sofrimentos ou danos corporais nas pessoas. Nesses

${ }^{89}$ BÖHMKER, Daniela. Die Entscheidungskompetenz des minderjährigen Patienten in der medizinischen Behandlung. Frankfurt: Peter Lang, 2014. p. 91.

${ }^{90}$ LAUFS, Adolf. $\S 6$ Grundbegriffe des Arztrechts, §6, 1, in LAUFS, Adolf; UHLENBRUCK, Wilhelm, Handbuch des Azrtrechts. 3. ed. München: Beck, 2002, p. 60. STEFFEN, Erich; DRESSLER, Wolf-Dieter, Arzthaftungsrecht. 9 ed. Köln: RWS, 2002. p. 163; ROUKA, Stella. Das Selbstbestimmungsrecht des Minderjährigen bei ärztlichen Eingriffen. Frankfurt: Peter Lang, 1994. p. 81; BÖHMKER, Daniela. Die Entscheidungskompetenz. Op. Cit., pp. 91-92. Esse trabalho não analisará o aspecto da execução da medida médica conforme as regras técnicas, porque ele permanece inalterado em todas as áreas da medicina, diferentemente da indicação e do consentimento informado que sofrem alterações, principalmente no que toca à medicina estética.

${ }^{91}$ STOCK, Christof, Die Indikation in der Wunscherfüllende Medizin. Op. Cit., pp. 87; 90. 
casos, a necessidade do tratamento médico é evidente, o que leva à afirmação de que existe uma indicação médica para o tratamento. ${ }^{92}$

O conceito médico de indicação encontra-se em harmonia com o conceito geral de indicação dado pelo direito penal. Partindo do $\S$ 218 do Código Penal alemão, uma intervenção é indicada do ponto de vista penal: wenn er nach den Erkentnissen und Erfahrungen der Heilkunde geeignet und nach den Grundsätzen eines gewissenhaften Arztes notwendig ist, Leben, Gesundheit und Wohlbefinden des Patienten zu erhalten oder herzustellen bzw. Störungen zu lindern..$^{93}$ Nesse sentido, uma intervenção médica não será considerada lesão corporal quando ela se mostrar necessária e, portanto, indicada, para manter ou restabelecer a vida, a saúde ou o bem-estar do paciente, conforme os conhecimentos, princípios e experiências da ciência médica.

A indicação tem como pré-condição uma tendência objetiva de conservar, assegurar ou restituir a saúde humana, ${ }^{94}$ podendo ser compreendida sob diferentes prismas. Num primeiro momento, ela

92 SCHWENZFEIER, Katja. Die kollisionsrechtliche Anknüpfung des Behandlungsverhältnisses im Rahmen einen kosmetischen Operation. Der Patient als Verbraucher?. Hamburg: D. Kovac, 2011. p. 17.

93 "Quando ele é apto segundo os conhecimentos e a experiência da ciência médica e segundo os princípios de um médico competente é necessário, a fim de preservar ou restabelecer a vida, a saúde e o bem-estar do paciente ou, ainda, amenizar sofrimentos" (tradução própria).

${ }^{94}$ KATZENMEIER, Christian. Arzthaftung. München: Beck, 2002. p. 38 
se refere ao motivo ou à causa para a realização de um determinado processo diagnóstico ou terapêutico; a indicação justifica a medida médica a ser executada concretamente, tanto o diagnóstico, como a terapia têm como condição a indicação. Aqui há referência à necessidade do tratamento em relação ao benefício proporcionado à saúde do paciente. ${ }^{95}$ Nesse sentido, a indicação pode ser classificada em vital, absoluta, relativa e sem indicação.

Observa-se que a doutrina não é unânime quanto à compreensão dessa classificação. Segundo a opinião tradicional ${ }^{96}$ fala-se em indicação vital quando a medida médica é essencial para a cura de uma doença de alto risco de vida do paciente. Indicação absoluta, entretanto, significa que o tratamento é necessário para curar uma insuficiência média da saúde e indicação relativa quando o tratamento é apropriado para a restituição da saúde, mas não necessário e, por fim, não existe qualquer indicação médica nos casos em que o tratamento médico não se mostra necessário a proporcionar benefício à saúde do paciente.

STOCK, ${ }^{97}$ quando trata da indicação na medicina tradicional, pondera que se fala em indicação absoluta quando a atuação médica

${ }^{95}$ STOCK, Christof, Die Indikation in der Wunscherfüllende Medizin. Op. Cit., pp. 87-88; LORZ, Sigrid. Arzthaftung bei Schönheitsoperationen. Berlin: Dunckler \& Humblot, 2007. p. 97.

${ }^{96}$ Nesse sentido, cf. as citações das notas $85,86,87,88$ e 89 supra.

${ }^{97}$ Die Indikation in der wunscherfüllende Medizin. Op. Cit., pp. 88-89. 
é absolutamente necessária para combater um dano à saúde do paciente, como por exemplo, uma cirurgia em caso de apendicite aguda, ou sob certas circunstâncias, quando a terapia deve ser executada imediatamente antes que se tenha um diagnóstico conclusivo. Se houver prejuízo à vida do paciente, fala-se, então, em indicação vital, hipótese em que não haverá sequer tempo de tomar o consentimento do paciente. Ou seja, o autor trata da indicação absoluta como gênero, da qual a indicação vital seria uma espécie em caso de perigo de vida.

No que se refere à indicação relativa, STOCK $^{98}$ tem um entendimento mais abrangente. Em primeiro lugar, sustenta o autor que a indicação relativa existe somente quando há um perigo relativo à saúde do paciente, mesmo entendimento sustentado pela doutrina tradicional. Mas um segundo aspecto é que, para ele, existe indicação relativa se um procedimento de cura tem possibilidade apenas relativa de alcançar sucesso. Esse é um outro ponto de vista apresentado pelo autor, que leva em consideração a chance de sucesso da intervenção. Nesse caso, o médico conta com a alternativa de agir ou agir de maneira diferente.

Segundo o autor, um exemplo possível de indicação relativa que se encontra na literatura é a cirurgia cesariana indicada pelo médico

${ }^{98}$ Ibidem, p. 89. 
como conveniente à sua agenda ou da paciente e à organização de seu pessoal ou da clínica/hospital em que atua. Entretanto, o autor refuta que nesse caso haveria indicação, ainda que relativa, porque esta deve se relacionar unicamente com o estado de saúde do paciente e não com outros aspectos. ${ }^{99}$ Aliás, o exemplo da cesariana é citado para ilustrar hipóteses de indicação absoluta, relativa e nenhuma indicação, sendo que nesse último caso tampouco se observa alguma predisposição jurídica de proibição. ${ }^{100}$

Conforme o entendimento de STOCK $^{101}$, a medicina de desejo e, por consequência, a cirurgia estética, relacionam-se, exclusivamente, com indicações relativas, no sentido de possibilidade relativa de se alcançar sucesso. Isso porque sempre existe a alternativa de não tomar uma medida, ou seja, de nada fazer.

Entretanto, outros doutrinadores discordam dessa posição, pois partem da necessidade da intervenção. Para eles, a característica das cirurgias estéticas é que elas não se referem a intervenções médicas necessárias. Trata-se de intervenções que têm por finalidade aumentar a qualidade de vida e, em regra, alcançar a melhora da aparência, da autoconfiança e da autoestima, além de aumentar a

${ }^{99}$ Ibidem, p. 90.

${ }^{100}$ SPICKHOFF, Andreas. Die Eingriffsindikation im Wandel der Zeit aus der Sicht eines Juristen, Life-style Medizin - von der medizinischen Indikation zum modischen Trend. Heidelberg: Springer, 2012. p. 13. ${ }^{101}$ Die Indikation in der wunscherfüllende Medizin. Op. Cit., p. 101. 
atratividade. Nessas hipóteses não se cogita afastar um sofrimento ou um problema de saúde no sentido médico. Nesse sentido, as cirurgias estéticas são consideradas intervenções sem indicação. ${ }^{102}$

Ainda segundo STOCK, ${ }^{103}$ entende-se como contraindicação absoluta uma circunstância que proíbe em qualquer caso a aplicação de um procedimento diagnóstico ou terapêutico ${ }^{104}$. De outro lado, na contraindicação relativa, há um aspecto que é contrário à medida médica, mas não a exclui totalmente. ${ }^{105}$

Essa concepção de indicação como "motivo" e "justificação" da utilização de um determinado procedimento diagnóstico ou

${ }^{102}$ SPICKHOFF, Andreas. Die Eingriffsindikation im Wandel der Zeit. Op. Cit., p. 13; HENNIG, Lysann. Tattoos, Piercings, Schönheitsoperationen. Halle, Universitätsverlag Halle-Wittnberg, 2012, pp. 69-70.

${ }^{103}$ Die Indikation in der wunscherfüllende Medizin, Op. Cit., p. 102.

${ }^{104} \mathrm{O}$ aspecto da proibição leva à conclusão que se trata de algo ilícito, proibido pela lei, considerando o legislador que seria algo maléfico à saúde. Por exemplo, o aborto no Brasil, que em regra é proibido, sendo permitido apenas nas hipóteses do art. 128 do Código Penal. Nos termos do referido diploma normativo: "Art. 128. Não se pune o aborto praticado por médico: I se não há outro meio de salvar a vida da gestante; II - se a gravidez resulta de estupro e o aborto é precedido de consentimento da gestante ou, quando incapaz, de seu representante legal."

105 Por exemplo, as cirurgias estéticas realizadas pelas asiáticas de ocidentalização do rosto, pelas quais tornam os olhos mais arredondados e o rosto mais ovalado; e pelos asiáticos de aumento de tamanho, quebrando a perna em várias partes para colocação de prótese para alongamento. 
terapêutico no tratamento de uma doença, toma como ponto de partida critérios objetivos da ciência médica. ${ }^{106}$

Segundo FRANCKE, ${ }^{107}$ a profissão médica desenvolve padrões de tratamento diagnóstico e terapêutico conforme os fundamentos da ciência médica e da experiência profissional. Para tanto, pressupõese a existência de um quadro patológico definido, o que torna tais padrões de tratamento indicados. Cabe ao médico escolher dentre os métodos de tratamento definidos e executá-los conforme as regras técnicas. Dessa forma, a indicação tem seu fundamento na ciência médica e na relação de causalidade de seus efeitos. ${ }^{108}$

A determinação da indicação não se relaciona com a autodeterminação do paciente e a decisão sobre a execução do tratamento conforme aquela determinação da indicação não é da esfera de competência profissional do médico. Com isso existe uma diferença essencial entre os campos da indicação e da decisão,

106 DAMM, Reinhard. Informed consent zwischen Indikations- und Wunschmedizin: Eine medizinrechtliche Betrachtung, in KETTNER, Matthias (coord.), Wunscherfüllende Medizin. Op. Cit., p. 185.

107 Ärztliche Berufsfreiheit und Patientenrechte: eine Untersuchung zu den verfassungsrechtlichen Grundlagen des ärztlichen Berufsrechts und des Patientenschutz. Stuttgart: Enke, 1994. p. 42.

${ }^{108}$ DAMM, Informed consent zwischen Indikations- und Wunschmedizin. Op. Cit., pp. 185-186. 
diferença essa de importância central para a medicina enquanto ciência, e para o Direito Médico. ${ }^{109}$

Diante desse panorama, observa-se que a indicação é um pressuposto fundamental para uma intervenção médica no paciente. Entretanto, pode-se constatar, em relação a essas normas, tendências atuais de problematização e relatividade desse conceito. ${ }^{110}$ Isso está em relação direta com o crescimento da importância da medicina de desejo moderna, induzido pela técnica e mudanças sociais, que provocaram uma relatividade da indicação médica tradicional. ${ }^{11}$

Mais atingidos por essa evolução são os conceitos de indicação e o princípio do consentimento informado. ${ }^{112}$ À primeira vista parece haver um paradoxo, no sentido de que, de um lado, se verifica uma expansão de prestações oferecidas pela medicina de desejo e subjetivismo ${ }^{113}$ dos motivos de tratamento médico em tempos de escassez e, de outro lado, uma objetivização da medicina diante do desenvolvimento de provas cada vez mais rígidas de eficiência e evidência. Problemas fundamentais resultam da circunstância de que a medicina pode cada vez mais interferir no

${ }^{109}$ Ibidem, p. 186.

${ }^{110}$ Ibidem, p. 183.

111 Ibidem, p. 183.

${ }_{112}^{112}$ Sobre consentimento informado, cf. capítulo 4.

113 Aqui no sentido de teoria segundo a qual os julgamentos estéticos exprimem apenas gostos individuais. 
estado e na situação das pessoas, sem qualquer relação com o binômio tradicional doença/saúde, como ocorre com as cirurgias estéticas. $^{114}$

Com isso DAMM sugere novas orientações acerca do conceito de indicação médica, o qual permanece, assim como entendido pela medicina tradicional, como um dos princípios norteadores que fundamenta as intervenções médicas. $\mathrm{O}$ autor toma como ponto de partida o conceito de indicação como conceito de legitimação. Por conta de sua perplexidade, existem tendências de recusar uma indicação médica pela medicina de desejo. No entanto, essa "perda" de indicação nos tratamentos da moderna medicina de desejo deve ser compensada com um maior rigor no esclarecimento a ser prestado pelo médico. O dever de informar, nesses casos, é mais rigoroso. ${ }^{115}$ No mesmo sentido, SPICKHOFF sustenta que as intervenções médicas sem indicação têm como pressuposto altas exigências de esclarecimento, sustentando que nos casos das cirurgias puramente estéticas, deve vigorar um esclarecimento franco e impiedoso. ${ }^{116}$

114 DAMM, Reinhard. Informed consent zwischen Indikations- und Wunschmedizin. Op. Cit., p. 183.

${ }^{115}$ A esse respeito se tratará no capítulo 4, item 4.2.

${ }^{116}$ Die Eingriffsindikation im Wandel der Zeit, in Life-style Medizin. Op. Cit., p. 15. Essa relação entre indicação e consentimento informado será abordada no item 4.2 do Capítulo 4. 
KERN $^{117}$ mostra-se avesso a essa tendência de relativização do conceito de indicação para justificar a existência de indicação em tratamentos autênticos da medicina de desejo. Para ele o conceito de indicação é claro e não deve ser abrandado, ainda que por motivos jurídicos de responsabilidade médica para proteção do paciente. A par dessa posição apresentada por Kern, não se pode fechar os olhos diante desse contexto de problematização e relativização do conceito de indicação, bem como das novas tendências trazidas pela medicina de desejo.

Nesse sentido, STOCK formula uma concepção de indicação a partir do desejo do paciente. Segundo o autor, observando-se de forma mais exata o desejo do cliente, deve-se diferenciar se, também, há como exigir uma decisão médica específica para a realização do tratamento, de modo que isso poderia ser considerado indicação por parte do médico. ${ }^{118}$

No caso de um desejo absoluto do cliente (imperativo de tratamento absoluto), o tratamento médico é exigido sem qualquer necessidade médica, decisão médica ou objetivo terapêutico. Aqui o

117 KERN, §49, Rn. 10. In LAUFS, Adolf; KERN, Handbuch des Arztrechts. 4 ed. München: Beck, 2010.

${ }^{118}$ STOCK, Christof. Die Indikation in der Wunschmedizin. Op. Cit., p. 95. O autor usa o termo "cliente" ao invés de "paciente" para constrastar a situação de ausência de doença e busca por uma melhora da aparência e aumento da autoestima. Esse aspecto será abordado no capítulo 3 item 3.1. 
desejo do cliente é o critério exclusivo e, dessa forma, realmente não haveria indicação para o procedimento. ${ }^{119}$

Entretanto, no caso de um desejo relativo, levam-se em consideração tanto interesses médicos como outros interesses externos. É o exemplo da cesariana desejada pela cliente, que, ao lado de fatores externos, como conveniência do procedimento e escolha de data, também considera aspectos médicos, como por exemplo, o posicionamento do feto, que não estaria em posição adequada para parto normal, sendo arriscado qualquer método de remanejamento de sua posição. ${ }^{120}$

No caso da cirurgia estética, o desejo do cliente corresponde a um imperativo relativo, porque, quando deseja a execução da operação, ele demonstra confiança na avalição do médico. Desse modo, este deverá decidir pelo procedimento, desde que as razões médicas baseadas no conhecimento científico não sejam contrárias à medida e que pareça possível o sucesso do tratamento. ${ }^{121}$ Ou seja, os critérios médicos não são secundários em relação ao desejo do cliente, ao contrário, eles são levados em consideração e ponderados

${ }^{119}$ STOCK, Christof. Die Indikation in der Wunschmedizin. Op. Cit., p. 96.

${ }^{120}$ Ibidem, p. 96.

${ }^{121}$ Ibidem, p. 96. 
na decisão médica, sopesando-se quais aspectos são a favor ou contra a execução do tratamento desejado. ${ }^{122}$

Embora seja o desejo do cliente que desencadeie a atividade do médico, não se abre mão da justificação da atividade médica. Nesse sentido, a indicação não é somente o fundamento do agir médico, mas também o processo pelo qual o médico pondera e decide sobre os benefícios e riscos da medida. ${ }^{123}$

Essa compreensão conceitual da indicação também se aplica à medicina tradicional, mas muda de perspectiva na medicina de desejo. Assim, na medicina tradicional o médico deve, primeiramente, verificar o estado de saúde do paciente e depois decidir quais medidas diagnósticas e terapêuticas deve tomar. Quanto maior o perigo de uma piora no estado de saúde, mais cedo o médico deve intervir, e quanto menor for o perigo de tal piora, mais a intervenção médica deve ser justificada. ${ }^{124}$

No caso da cirurgia estética (medicina de desejo), por outro lado, o médico tem o dever de ponderar de maneira precisa e decidir se e como sua atividade deve ser justificada. Nessa avaliação, um dos fatores a ser ponderado é se a intervenção é apta para alcançar o

\footnotetext{
122 Ibidem, pp. 96-98, 159-161.

123 Ibidem, p. 98, 159-161.

${ }^{124}$ Ibidem, p. 98.
} 
êxito desejado pelo cliente. ${ }^{125}$ Por consequência, o dever de cuidado na medicina de desejo deve ser maior. ${ }^{126}$

A existência de uma indicação para um tratamento médico não decorre de uma simples conclusão de leis científicas ou de um elo entre diagnóstico e terapia. Ao contrário, depende, sim, de uma decisão valorativa, na qual são considerados a necessidade do tratamento, seu êxito, riscos, efeitos colaterais e efeitos a longo prazo, ou seja, diversos aspectos da vida do paciente. Interesses diferentes devem integrar a avaliação do risco-benefício no processo de ponderação e decisão para as medidas estéticas. ${ }^{127}$

Segundo STOCK, existe uma indicação quando todos os aspectos importantes, sobretudo os aspectos médicos, ao lado de outros, como psíquicos, sociais, éticos e jurídicos estão integrados na decisão do médico e são ponderados de maneira adequada. Ao contrário, uma medida médica não é indicada quando aspectos médicos e outros não foram integrados no processo de indicação ou não o foram de maneira suficiente. ${ }^{128}$

${ }^{125}$ Ibidem, pp. 93, 97 e 159-160.

${ }^{126}$ Ibidem, p. 98.

${ }^{127}$ FRANCKE, Robert. Ärztliche Berufsfreiheit. Op. Cit., pp. 42-43.

${ }^{128}$ STOCK, Christof. Die Indikation in der Wunschmedizin. Op. Cit., p. 99. 
Tanto na medicina tradicional, como na medicina de desejo, a medida é considerada indicada quando puder garantir o êxito da terapia. $^{129}$

Assim, a indicação médica não se direciona apenas pelo aspecto da existência de um motivo ou necessidade para o agir médico, mas, também pelo êxito desejado, conforme o diagnóstico e os conhecimentos médicos no momento do tratamento. ${ }^{130}$

Essa orientação conceitual da indicação pelo resultado do tratamento ocorre, sobretudo, na medicina de desejo. A título exemplificativo, no caso de uma cirurgia de nariz ou de mama, se existirem os pressupostos médicos para a realização do desejo do cliente, pode-se falar que existe indicação para a atividade médica $^{131}$.

A medicina de desejo sempre foi entendida como uma medicina para a qual não se podia estabelecer uma indicação médica, pois era motivada basicamente pelo desejo do cliente. Entretanto, segundo

${ }^{129}$ STOCK, Christof. Die Indikation in der Wunschmedizin. Op. Cit., p. 99. $\mathrm{O}$ autor observa que na medicina tradicional o êxito da terapia não significa necessariamente a cura da doença, sendo suficiente que ela contribua para melhorar o quadro patológico, diminuir sofrimento ou evitar sua piora.

${ }^{130}$ STOCK, Christof. Die Indikation in der Wunschmedizin. Op. Cit., pp. 99-100.

${ }^{131}$ Ibidem, p. 94. 
essa outra perspectiva, é até possível dizer que falta para a medicina de desejo um motivo médico, mas não uma indicação ${ }^{132}$.

\subsection{Aspectos psíquicos}

\subsubsection{Aspectos psíquicos e perturbações psíquicas}

Uma discussão importante é a da influência da medicina de desejo na psique, em relação à execução de cirurgias estéticas. ${ }^{133} \mathrm{~A}$ psique é o conjunto das funções psíquicas formada por consciência, vivência, pensamento, ação, expressão, comportamento e modo de como a pessoa lida consigo mesma, com outras pessoas e com as coisas e acontecimentos do seu ambiente ${ }^{134}$.

Aspectos psíquicos são aqueles que, ao contrário dos aspectos fisiológicos, atingem os sentimentos e a experiência mentais e psíquicos, entendendo-se aqui como todas as maneiras de comportamento que podem ser relevantes para a medicina de desejo. Em primeiro lugar pode-se citar o comportamento em relação à

${ }^{132}$ Ibidem, p. 100.

133 Ibidem, p. 162.

134 KINDT, Hildburg. Verbete Psychotherapie. In ESER, Albin; LUTTEROTTI, Markus von; SPORKEN, Paul (coord.). Lexikon Medizin, Ethik, Recht. Freiburg: Herder, 1989. p. 861. 
própria aparência, que se expressa pelo desejo de se submeter a uma medida que não é necessária do ponto de vista médico. ${ }^{135}$

Tal desejo pode ser apresentado pela pessoa de várias maneiras, ou seja, de forma insistente ou hesitante, espontânea ou refletida, oral ou por escrito. Decisivo é que esse desejo, por qualquer forma que se expresse, demonstra a importância dessas intervenções estéticas para o estado geral psíquico-mental da pessoa. ${ }^{136}$

Devem-se diferenciar os aspectos psíquicos da existência de uma doença psíquica ou, como é denominado na psicoterapia e na psiquiatria, perturbação psíquica, transtorno, disfunção ou distúrbio. ${ }^{137}$ A perturbação psíquica refere-se a uma síndrome de comportamento psíquico clínico importante. Essa síndrome é ligada a um sofrimento ou deficiência de capacidade de conseguir resolver tarefas quotidianas e leva a um risco maior de suicídio. ${ }^{138}$

A existência de doenças ligadas à saúde mental é evidente no dia-a-dia do século XXI. Prova disso é a sua presença na vida de cerca de 700 milhões de pessoas $(13 \%$ de todas as doenças do mundo), o que representa um terço do total dos casos de doenças

${ }^{135}$ STOCK, Christof. Die Indikation in der Wunschmedizin. Op. Cit., p. 162.

${ }_{137}^{136}$ Ibidem, p. 162.

137 PERREZ, Meinrad. BAUMANN, Urs (Coord.). Lehrbuch klinische Psychologie: Psychotherapie. 5 ed., Bern: Huber, 2011, pp. 32-36.

${ }^{138}$ STOCK, Christof. Die Indikation in der Wunschmedizin. Op. Cit., p. 163. 
não transmissíveis, conforme dados da Organização Mundial da Saúde. ${ }^{139}$

Nesse contexto surgiu a necessidade da formulação de um Plano de Ação para a Saúde Mental (2013-2020) com o intuito de conferir tratamento específico para tais situações. Segundo a Organização Mundial da Saúde,

Saúde mental é a capacidade do indivíduo, do grupo, do meio ambiente, de interagir uns com os outros de modo a promover o bem-estar subjetivo, o desenvolvimento e o uso otimizados das capacidades mentais (cognitiva, afetiva e relacional), a conquista de metas individuais e coletivas consistentes com justiça e realização e preservação das condições de igualdade fundamental. (tradução nossa $)^{140}$

${ }^{139}$ Disponível em: $<$ http://memoria.ebc.com.br/agenciabrasil/noticia/2013-0520/oms-doencas-mentais-e-neurologicas-atingem-cerca-de-700-milhoes-depessoas-alerta-oms $>$. Acesso em 12 set. 2016.

140 Mental health is the capacity of the individual, the group and the environment to interact with one another in ways that promote subjective well-being, the optimal development and use of mental abilities (cognitive, affective and relational), the achievement of individual and collective goals consistent with justice and the attainment and preservation of conditions of fundamental equality. WORLD HEALTH ORGANIZATION. Women's Mental Health: An Evidence Based Review. Geneva, 2000. p.11. Disponível em:

http://apps.who.int/iris/bitstream/10665/66539/1/WHO_MSD_MDP_00.1.pdf >. Acesso em: 12 set. 2016. 
Com esse Plano de Ação, a Organização Mundial da Saúde busca trazer à tona a situação de particular vulnerabilidade à qual estão acometidas as pessoas com esse tipo de enfermidade. Apresenta-se como meio para novas modalidades de compreensão das perturbações mentais, uma vez que essas perturbações envolvem alterações no modo de pensar assim como nas emoções, o que gera falhas no bem-estar da pessoa.

Assim, apesar da ausência de uma lista universalmente aceita das patologias psíquicas, a Organização Mundial da Saúde publicou uma Classificação Internacional de Doenças e Problemas relacionados à saúde (CID $10^{141}$ ). Essa classificação apresenta o intuito de promover maior padronização dos problemas por meio do estabelecimento de códigos, considerando os sinais, sintomas, aspectos anormais, queixas, circunstâncias sociais e causas externadas recorrentes em cada uma das patologias.

Conforme o Relatório Mundial da Saúde: ${ }^{142}$

A Classificação das Perturbações Mentais e Comportamentais ICD-10: Descrições Clínicas e Normas de Diagnóstico contém uma

141 Disponível em: $<$ http://enfermagem.bvs.br/vhl/colecao-de-fontes-deinformacao/terminologia/cid-classificacoes-internacionais-de-doencas/>. Acesso em 12 set. 2016. Cf. anexo IV

$142 \quad$ Disponível em: $\quad<$ http://psiquiatriabh.com.br/wp/wpcontent/uploads/2015/01/Relatorio-OMS-da-saude-mental-no-mundo2001.pdf $>$. Acesso em 12 set. 2016. 
lista completa de todas as perturbações mentais e comportamentais. Critérios de diagnóstico adicionais para a investigação estão também disponíveis, para uma definição mais precisa dessas perturbações. Toda a classificação de perturbações mentais diz respeito a síndromes e condições, mas não a indivíduos. Estes podem sofrer de uma ou mais perturbações durante um ou mais períodos da vida, mas nunca um indivíduo deve ser rotulado por um diagnóstico qualquer. Ninguém deve ser equiparado a uma perturbação, física ou mental.

No seu capítulo V serão apresentados os transtornos mentais e comportamentais, o que corresponde aos códigos F00 a F99, cuja íntegra se apresenta no anexo III do presente trabalho.

As perturbações psíquicas podem ser caracterizadas ou reconhecidas de forma mais ou menos clara, no entanto, os limites da necessidade de tratamento não são facilmente definidos. Quando faltam parâmetros biológicos de medição, a decisão pelo tratamento depende de uma percepção intensiva e avaliação profunda. ${ }^{143}$ Muitas vezes tais perturbações só podem ser diagnosticadas por meio de equipe multiprofissional que, no caso dos menores, seria formada por pediatras, psiquiatras, psicoterapeutas e neurologistas de

${ }^{143}$ STOCK, Christof. Die Indikation in der Wunschmedizin. Op. Cit., p. 164. 
crianças e adolescentes, além de outros profissionais necessários ao caso concreto. $^{144}$

O progresso da física médica levou ao ponto de que perturbações psíquicas não são mais tratadas apenas de maneira psicoterapêutica e farmacológica, mas também por meio de cirurgias. Por exemplo, depressões relacionadas a tumor no cérebro podem ser curadas por cirurgias no cérebro.

$\mathrm{Na}$ medicina de desejo, pergunta-se se e quando o método de cirurgia estética é adequado para melhorar a situação psíquica.

\subsubsection{Perturbação de dismorfobia corporal}

Dentre as várias perturbações psíquicas, aponta-se a dismorfobia ou dismorfia como uma das causas que poderia levar o paciente à opção pelo tratamento via cirurgia estética. ${ }^{145} \mathrm{~A}$ imagem corporal é a imagem formada pela mente de como as pessoas pensam e sentem seu corpo. Essa representação se inicia com o desenvolvimento neural da criança e acompanha o ser humano durante seu desenvolvimento. Na formação da imagem corporal contribuem tanto aspectos objetivos, como tamanho, forma e superfície, como também mecanismos de percepção, como visão,

${ }^{144}$ Ibidem, p. 164.

${ }^{145}$ Ibidem, pp. 169-170. 
tato, forma, espaço. Todos esses aspectos são importantes para interpretar o conhecimento do corpo, inclusive sob os pontos de vista emocionais e afetivos. Alguns transtornos psíquicos prejudicam essa percepção, contribuindo para interpretações distorcidas das sensações e da imagem do corpo. ${ }^{146}$

O transtorno dismórfico corporal (TDC), conhecido inicialmente pelo termo dismorfofobia, hoje simplificado para dismorfobia ou simplesmente dismorfia, ${ }^{147}$ é uma perturbação psiquiátrica caracterizada por uma intensa preocupação da pessoa quanto a um defeito imaginário ou mínimo em sua aparência. ${ }^{148}$ Esse

146 KADUNC, Bogdana; PALERMO, Eliandre; ADDOR, Flavia (et. al.). Tratado de cirurgia dermatológica, cosmiatria e laser da Sociedade Brasileira de Dermatologia. Rio de Janeiro: Elvesier, 2013. p. 83.

${ }^{147}$ BERRIOS, German E. The History of Mental Symptons: Descriptive Psychopathology Since Nineteenth Century. Cambridge: Cambridge University Press, 1996. p. 227. (Disponível em: $<$ https://books.google.com.br/books?id=XSD_ucVR3E8C\&pg=PA277\&redir _esc $=\mathrm{y} \# \mathrm{v}=$ onepage $\& \mathrm{q} \& \mathrm{f}=$ false $>$ ). Relata o autor que foi considerado também o termo "complexo de Thersites", pois Thersites era extremamente feio e odiado. Segundo a Ilíada de Homero, Thersites fez parte do exército grego na guerra de Tróia, representando na mitologia grega um lutador comum do povo. Ainda segundo o autor, também foi considerado o termo "complexo de Quasimodo", em referência ao célebre personagem da obra "O Corcunda de Notre-Dame", do escritor francês Victor Hugo. Mas coube a Enrico Morselli, em 1886, dar ao distúrbio o nome de "dismorfofobia", em referência a Dysmorfia, que se relata tendo sido a mulher mais feia de Esparta.

${ }_{148}$ BJORNSSON, Andri S., DIDIE, Elizabeth R., PHILLIPS, Katharine A., Body dysmorphic disorder. Dialogues in Clinical Neuroscience, Paris, $\mathrm{n}$. 12(2), pp. 221-232, jun. 2010. Disponível em: $<$ https://www.ncbi.nlm.nih.gov/pmc/articles/PMC3181960/pdf/DialoguesClin 
transtorno requer a existência tanto de pensamentos obsessivos a respeito de suspostos defeitos quanto comportamentos compulsivos que se desenvolvem em resposta a esses pensamentos. Em muitos casos, existem outras doenças psíquicas encobertas pela dismorfobia. $^{149}$

Pacientes que possuem esse transtorno relatam ao médico extrema insatisfação com sua aparência ou confessam que pensam no seu defeito por longas horas do dia, não conseguindo "pensar em outra coisa". ${ }^{150}$ Além disso, os ideais de beleza promovidos pela mídia levam a uma interiorização desse pensamento, o que reforça a doença. $^{151}$ Tanto assim que alguns revelam sua insatisfação

Neurosci-12-221.pdf $>$. Acesso em 23 set. 2016; LORZ, Sigrid. Azrthaftung bei Schönhetitsoperationen. Op. Cit., p. 111.

149 BLACK, Donald W.; GRANT, Jon E., DSM-5 Guidenbok, 2014. Trad. Port. Janisa S. Antoniazzi, Evelyn Tesche, Gabriel Rios Borges (et. all). Guia para o DSM-5: complemento essencial para o manual diagnóstico e estatístico de transtornos mentais. Disponível em $<$ http://books.google.com/books?id=PJs7BgAAQBAJ\&pg=PA153 $>$. Acesso em: 23 set. 2016; LORZ, Sigrid, Azrthaftung bei Schönhetitsoperationen. Op. Cit., p. 111.

150 KADUNC, PALERMO, ADDOR e outros, Tratado de cirurgia dermatológica. Op. Cit., p. 85; BJORNSSON, Andri S., DIDIE, Elizabeth R., PHILLIPS, Katharine A., Body dysmorphic disorder. Op. Cit., pp. 221-232. Narrando que pacientes chegam a se olhar de 6 a 8 horas por dia no espelho; que aproximadamente $40 \%$ dos pacientes pensam de 3 a 8 horas por dia na parte do corpo que não gostam, e $25 \%$ reportaram que pensam nisso mais de 8 horas por dia.

${ }^{151}$ STOCK, Christof. Die Indikation in der Wunschmedizin. Op. Cit., p. 167. 
mostrando ao médico fotos de celebridades ou modelos com as características desejadas. Outros fazem foto de si mesmos e fazem as alterações desejadas com caneta ou computador. ${ }^{152}$

Esse transtorno causa significativo incômodo no dia-a-dia da pessoa, levando o indivíduo a sofrimentos nas áreas social, profissional e outras clinicamente importantes. Algumas perguntas feitas a pacientes sobre o impacto de sua aparência nas atividades quotidianas revelam que, para muitos, sua aparência não permite que se mantenham em um emprego ou se relacionem afetivamente, bem como que não conseguem desempenhar tarefas que normalmente seriam desempenhadas sem grandes dificuldades pelas pessoas que não pensam de forma compulsiva em sua aparência. ${ }^{153}$ Narra-se que no convício social, os pacientes usam "disfarces", como chapéus, lenços e mangas longas para encobrir o "defeito", e posicionam o corpo de maneira a esconder a parte indesejada. ${ }^{154}$ Apontou-se, também, a menor probabilidade de que pessoas portadoras do

152 KADUNC, Bogdana; PALERMO, Eliandre; ADDOR, Flavia (et. al.). Tratado de cirurgia dermatológica, cosmiatria e laser da Sociedade Brasileira de Dermatologia. Op. Cit., pp. 85-86.

${ }^{153}$ Ibidem, p. 85. STOCK, Christof. Die Indikation in der Wunschmedizin. Op. Cit., p. 167.

${ }^{154}$ KADUNC, Bogdana; PALERMO, Eliandre; ADDOR, Flavia (et. al.). Tratado de cirurgia dermatológica, cosmiatria e laser da Sociedade Brasileira de Dermatologia. Op. Cit., p. 86; BJORNSSON, Andri S., DIDIE, Elizabeth R., PHILLIPS, Katharine A., Body dysmorphic disorder. Op. Cit., pp. 221-232. 
distúrbio permaneçam casadas, havendo uma propensão a se divorciarem, bem como que são significativamente mais propensas a estarem desempregadas que a população em geral. ${ }^{155}$

É um transtorno mental bastante comum, o qual afeta cerca de $0,7 \%$ a $2,4 \%$ da população, sendo mais comum que a esquizofrenia e a anorexia nervosa. Alguns estudos chegam a indicar de 2\% a $13 \%$. $^{156}$

A dismorfobia é geralmente diagnosticada em consultas clínicas. Estudos apontaram que entre 9\% e 12\% dos casos, o problema é diagnosticado em consulta dermatológica e entre 3\% e $5 \%$ em consulta de cirurgia estética. Estudos com pacientes adolescentes indicou que 4,8\% deles possuía o transtorno. ${ }^{157}$

O diagnóstico é caracterizado, sobretudo, pela forte discrepância entre a deformação diagnosticada pelo médico e aquela vivenciada pelo paciente. ${ }^{158}$ Há referências ${ }^{159}$ de que o transtorno aparece tanto

${ }^{155}$ BJORNSSON, Andri S., DIDIE, Elizabeth R., PHILLIPS, Katharine A., Body dysmorphic disorder. Op. Cit., pp. 221-232.

${ }^{156}$ Ibidem, pp. 221-232.

157 KADUNC, Bogdana; PALERMO, Eliandre; ADDOR, Flavia (et. al.). Tratado de cirurgia dermatológica, cosmiatria e laser da Sociedade Brasileira de Dermatologia. Op. Cit., pp. 84-85; BJORNSSON, Andri S., DIDIE, Elizabeth R., PHILLIPS, Katharine A., Body dysmorphic disorder. Op. Cit., pp. 221-232.

${ }^{158}$ STOCK, Christof. Die Indikation in der Wunschmedizin. Op. Cit., p. 167. 
em crianças de 5 anos como em adultos de 80. Ainda, embora os estudos apontem uma primazia de mulheres, aparece em homens da mesma forma, em relação aos quais pode ocorrer o subtipo muscular, que significa perceber o corpo como muito pequeno. ${ }^{160}$

A dismorfobia geralmente aparece na adolecência, com dois estudos reportando a idade de 16 anos como aquela em que o transtorno desponta. ${ }^{161}$ Mesmo se iniciando antes dos 18 anos, apenas alguns estudos se ocuparam em examinar as características clínicas do transtorno na juventude. Da mesma forma que os adultos, também se revelaram os aspectos do sofrimento e do consumo de horas por dia com preocupações com a aparência, assim como

159 PHILLIPS, Katharine A.; MENARD, William; FAY, Christina; RISA, Weisberg. Demographic Characteristics, Phenomenology, Comorbidity, and Family History in 200 Individuals With Body Dysmorphic Disorder. Psychosomatics, n. 46(4), pp. 317-325, 2005. Disponível em: $<$ https://www.ncbi.nlm.nih.gov/pmc/articles/PMC1351257/>. Acesso em: 23 set. 2016.

${ }^{160}$ PHILLIPS, Katharine A. Understanding Body Dysmorphic Disorder: An Essencial Guide. New York: Oxford University Press, 2009. pp. 50-51. Disponível em: $<$ https://books.google.com.br/books?id=uRTcOYgWj9cC\&pg=PA50\&dq=mu scle + dysmorphia\&redir_esc $=\mathrm{y} \# \mathrm{v}=$ onepage $\& \mathrm{q}=$ muscle $\% 20$ dysmorphia $\& \mathrm{f}=$ fal se>. Acesso em: 24 set. 2016.

161 PHILLIPS, Katharine A.; MENARD, William; FAY, Christina; WEISBERG, Risa B. Demographic Characteristics, Phenomenology, Comorbidity, and Family History in 200 Individuals With Body Dysmorphic Disorder. Op. Cit., pp. 317-325. 
comportamentos compulsivos. ${ }^{162}$ Num estudo com 33 crianças e adolescentes, $18 \%$ desistiu da escola por causa dos sintomas da dismorfobia ${ }^{163}$ e num estudo com 36 jovens, $22 \%$ desistiu dos estudos pela mesma causa. ${ }^{164}$

Outro estudo assinalou que adolescentes possuem crença mais desiludida sobre sua aparência e são mais propensos à tentativa de suicídio. ${ }^{165}$ A maioria dos pacientes com dismorfobia deseja (71\% a $76 \%)$ e recebe $(64 \%$ a $66 \%)$ tratamento estético, dentre eles, dermatológico e cirúrgico. ${ }^{166}$

${ }^{162}$ ALBERTINI, Ralph S., PHILLIPS, Katharine A. Thirty-three cases of body dysmorphic disorder in children and adolescents. Journal of the American Academy of Child \& Adolescent Psychiatry's, n. 38 (4), pp. 453-459, abril de 1999.

163 PHILLIPS, Katharine A.; MENARD, William; FAY, Christina; WEISBERG, Risa B. Clinical features of body dysmorphic disorder in adolescents and adults. Psychiatry Research, n. 141(3), pp. 305-314, março de 2006.

Disponívelem: $<$ https://www.ncbi.nlm.nih.gov/pmc/articles/PMC1592052/pdf/nihms9381.pdf $>$. Acesso em: 23 set. 2016.

164 ALBERTINI, Ralph S., PHILLIPS, Katharine A. Thirty-three cases of body dysmorphic disorder in children and adolescents. Op. Cit., pp. 453459.

165 PHILLIPS, Katharine A.; MENARD, William; FAY, Christina; WEISBERG, Risa B. Clinical features of body dysmorphic disorder in adolescents and adults. Op. Cit., pp. 305-314; CULL John G.; GILL, Wayne S. Suicide Probability Scale. Los Angesles: Western Psychological Services (WPS). 1982.

166 CRERAND, Canice E.; PHILLIPS, Katharine A.; MENARD, William; FAY, Christina. Nonpsychiatric Medical Treatment of Body Dysmorphic Disorder. Psychosomatics, n. 46(4), pp. 549-555, 2005. Disponível em: 
Um estudo com uma parte da população na Alemanha demonstrou que $7,2 \%$ dos pacientes que receberam cirurgia estética eram portadores de dismorfobia, enquanto apenas 2,8\% deles não possuía o transtorno. Entretanto, a cirurgia estética raramente contribui para a melhora dos sintomas da dismorfobia. Um estudo envolvendo 200 pacientes demonstrou que apenas 3,6\% dos tratamentos estéticos, dentre eles o cirúrgico, resultou numa melhora geral; ${ }^{167}$ outro estudo, dessa vez com 250 pacientes, revelou que 7\% dos tratamentos levaram a essa melhora. ${ }^{168}$

Existe uma dificuldade significativa de tratamento com pacientes portadores da dismorfobia porque geralmente eles têm mais de uma queixa, já se consultaram com vários especialistas e passaram por inúmeros tratamentos. Também ocorre mudanças de insatisfação, já que "agora que resolvemos um problema, vamos partir para outro". Em regra, ficam insatisfeitos com os tratamentos realizados, têm mais problemas pós-operatórios e mostram-se

$<$ http://www.psychosomaticsjournal.com/article/S0033-3182(05)700402/pdf>. Acesso em: 23 set. 2016.

${ }^{167}$ Ibidem, pp. 549-555.

168 PHILLIPS, Katharine A.; GRANT, Jon; SINISCALCHI, Jason; ALBERTINI, Ralph S. Surgical and Nonpsychiatric Medical Treatment of Patients With Body Dysmorphic Disorder. Psychosomatics, n. 42(6), pp. 504510, novembro-dezembro de 2001. Disponível em: $<$ https://www.ncbi.nlm.nih.gov/pubmed/11815686>. Acesso em 23 set. 2016. 
extremamente vulneráveis para passarem por inúmeros outros procedimentos estéticos que costumam piorar os sintomas. ${ }^{169}$

Intervenções cirúrgicas ou aplicações de medicamentos a longo prazo podem reforçar as perturbações e ter como consequência a falta de sucesso de outros tratamentos. Estudos apontaram que pessoas que se submeteram a intervenções cirúrgicas continuaram descontentes e que mulheres, após implantes cosméticos, tiveram uma maior taxa de suicídio. ${ }^{170}$

Nesse contexto, sustenta-se que o tratamento mais adequado para a dismorfobia é a terapia cognitiva comportamental, ${ }^{171}$ não se podendo considerar a cirurgia estética como um tratamento plausível com possibilidade de sucesso de cura. ${ }^{172} \mathrm{Em}$ tal situação fática, não há indicação médica de cirurgia estética para tratar pessoas portadoras de dismorfobia.

169 KADUNC, PALERMO, ADDOR e outros, Tratado de cirurgia dermatológica. Op. Cit., p. 86.

${ }^{170}$ STOCK, Christof. Die Indikation in der Wunschmedizin. Op. Cit., p. 169.

${ }^{171}$ PHILLIPS, Katharina A.; DIDIE, Elizabeth (et. all). Body Dysmorphic Disorder: Treating an Underrecognized. The American Journal of Psychiatry, n. 165(9), pp. 1111-1118, setembro de 2008. Disponível em: $<$ https://www.ncbi.nlm.nih.gov/pmc/articles/PMC2716131>. Acesso em 23 set. 2016. No mesmo sentido, STOCK, Christof. Die Indikation in der Wunschmedizin. Op. Cit., p. 169.

${ }^{172}$ STOCK, Christof. Die Indikation in der Wunschmedizin. Op. Cit., p. 169. 


\section{CAPÍTULO 3 - O CONTRATO MÉDICO}

\subsection{Aspectos preliminares}

O tratamento do paciente pelo médico ocorre numa relação jurídica geralmente representada por um contrato médico. ${ }^{173} \mathrm{O}$ direito brasileiro não contempla no Código Civil uma figura contratual própria para esse contrato, ao contrário do direito alemão, que reconhece o contrato de tratamento médico em seus $\S \S 630 \mathrm{a}$ 630h do BGB (Bürgerliches Gesetzbuch). ${ }^{174}$

173 DEUTSCH, Erwin; SPICKHOFF, Andreas. Medizinrecht. Azrtrecht, Arzneimittelrecht, Medizinproduktrecht und Transfusionsrecht. 7 ed. Heidelberg: Springer, 2014. p. 77.

${ }^{174} \S 630 \mathrm{a}$ Vertragstypische Pflichten beim Behandlungsvertrag

(1) Durch den Behandlungsvertrag wird derjenige, welcher die medizinische Behandlung eines Patienten zusagt (Behandelnder), zur Leistung der versprochenen Behandlung, der andere Teil (Patient) zur Gewährung der vereinbarten Vergütung verpflichtet, soweit nicht ein Dritter zur Zahlung verpflichtet ist.

(2) Die Behandlung hat nach den zum Zeitpunkt der Behandlung bestehenden, allgemein anerkannten fachlichen Standards zu erfolgen, soweit nicht etwas anderes vereinbart ist.

$\S 630$ b Anwendbare Vorschriften

Auf das Behandlungsverhältnis sind die Vorschriften über das Dienstverhältnis, das kein Arbeitsverhältnis im Sinne des §622 ist, anzuwenden, soweit nicht in diesem Untertitel etwas anderes bestimmt ist. \$630c Mitwirkung der Vertragsparteien; Informationspflichten

(1) Behandelnder und Patient sollen zur Durchführung der Behandlung zusammenwirken. 
(2) Der Behandelnde ist verpflichtet, dem Patienten in verständlicher Weise zu Beginn der Behandlung und, soweit erforderlich, in deren Verlauf sämtliche für die Behandlung wesentlichen Umstände zu erläutern, insbesondere die Diagnose, die voraussichtliche gesundheitliche Entwicklung, die Therapie und die zu und nach der Therapie zu ergreifenden Maßnahmen. Sind für den Behandelnden Umstände erkennbar, die die Annahme eines Behandlungsfehlers begründen, hat er den Patienten über diese auf Nachfrage oder zur Abwendung gesundheitlicher Gefahren zu informieren. Ist dem Behandelnden oder einem seiner in $\S 52$ Absatz 1 der Strafprozessordnung bezeichneten Angehörigen ein Behandlungsfehler unterlaufen, darf die Information nach Satz 2 zu Beweiszwecken in einem gegen den Behandelnden oder gegen seinen Angehörigen geführten Straf- oder Bußgeldverfahren nur mit Zustimmung des Behandelnden verwendet werden.

(3) Weiß der Behandelnde, dass eine vollständige Übernahme der Behandlungskosten durch einen Dritten nicht gesichert ist oder ergeben sich nach den Umständen hierfür hinreichende Anhaltspunkte, muss er den Patienten vor Beginn der Behandlung über die voraussichtlichen Kosten der Behandlung in Textform informieren. Weitergehende Formanforderungen aus anderen Vorschriften bleiben unberührt.

(4) Der Information des Patienten bedarf es nicht, soweit diese ausnahmsweise aufgrund besonderer Umstände entbehrlich ist, insbesondere wenn die Behandlung unaufschiebbar ist oder der Patient auf die Information ausdrücklich verzichtet hat.

$\S 630 d$ Einwilligung

(1) Vor Durchführung einer medizinischen Maßnahme, insbesondere eines Eingriffs in den Körper oder die Gesundheit, ist der Behandelnde verpflichtet, die Einwilligung des Patienten einzuholen. Ist der Patient einwilligungsunfähig, ist die Einwilligung eines hierzu Berechtigten einzuholen, soweit nicht eine Patientenverfügung nach $\S 1901$ a Absatz 1 Satz 1 die Maßnahme gestattet oder untersagt. Weitergehende Anforderungen an die Einwilligung aus anderen Vorschriften bleiben unberührt. Kann eine Einwilligung für eine unaufschiebbare Maßnahme nicht rechtzeitig eingeholt werden, darf sie ohne Einwilligung durchgeführt werden, wenn sie dem mutmaßlichen Willen des Patienten entspricht.

(2) Die Wirksamkeit der Einwilligung setzt voraus, dass der Patient oder im Fall des Absatzes 1 Satz 2 der zur Einwilligung Berechtigte vor der Einwilligung nach Maßgabe von $\S 630$ e Absatz 1 bis 4 aufgeklärt worden ist. 
(3) Die Einwilligung kann jederzeit und ohne Angabe von Gründen formlos widerrufen werd $\S 630$ e Aufklärungspflichten

(1) Der Behandelnde ist verpflichtet, den Patienten über sämtliche für die Einwilligung wesentlichen Umstände aufzuklären. Dazu gehören insbesondere Art, Umfang, Durchführung, zu erwartende Folgen und Risiken der Maßnahme sowie ihre Notwendigkeit, Dringlichkeit, Eignung und Erfolgsaussichten im Hinblick auf die Diagnose oder die Therapie. Bei der Aufklärung ist auch auf Alternativen zur Maßnahme hinzuweisen, wenn mehrere medizinisch gleichermaßen indizierte und übliche Methoden zu wesentlich unterschiedlichen Belastungen, Risiken oder Heilungschancen führen können.

(2) Die Aufklärung muss

1. mündlich durch den Behandelnden oder durch eine Person erfolgen, die über die zur Durchführung der Maßnahme notwendige Ausbildung verfügt; ergänzend kann auch auf Unterlagen Bezug genommen werden, die der Patient in Textform erhält,

2. so rechtzeitig erfolgen, dass der Patient seine Entscheidung über die Einwilligung wohlüberlegt treffen kann,

3. für den Patienten verständlich sein.

Dem Patienten sind Abschriften von Unterlagen, die er im Zusammenhang mit der Aufklärung oder Einwilligung unterzeichnet hat, auszuhändigen.

(3) Der Aufklärung des Patienten bedarf es nicht, soweit diese ausnahmsweise aufgrund besonderer Umstände entbehrlich ist, insbesondere wenn die Maßnahme unaufschiebbar ist oder der Patient auf die Aufklärung ausdrücklich verzichtet hat.

(4) Ist nach $\S 630 d$ Absatz 1 Satz 2 die Einwilligung eines hierzu Berechtigten einzuholen, ist dieser nach Maßgabe der Absätze 1 bis 3 aufzuklären.

(5) Im Fall des $\S 630$ d Absatz 1 Satz 2 sind die wesentlichen Umstände nach Absatz 1 auch dem Patienten entsprechend seinem Verständnis zu erläutern, soweit dieser aufgrund seines Entwicklungsstandes und seiner Verständnismöglichkeiten in der Lage ist, die Erläuterung aufzunehmen, und soweit dies seinem Wohl nicht zuwiderläuft. Absatz 3 gilt entsprechend.

§630f Dokumentation der Behandlung

(1) Der Behandelnde ist verpflichtet, zum Zweck der Dokumentation in unmittelbarem zeitlichen Zusammenhang mit der Behandlung eine Patientenakte in Papierform oder elektronisch zu führen. Berichtigungen und 
Änderungen von Eintragungen in der Patientenakte sind nur zulässig, wenn neben dem ursprünglichen Inhalt erkennbar bleibt, wann sie vorgenommen worden sind. Dies ist auch für elektronisch geführte Patientenakten sicherzustellen.

(2) Der Behandelnde ist verpflichtet, in der Patientenakte sämtliche aus fachlicher Sicht für die derzeitige und künftige Behandlung wesentlichen Maßnahmen und deren Ergebnisse aufzuzeichnen, insbesondere die Anamnese, Diagnosen, Untersuchungen, Untersuchungsergebnisse, Befunde, Therapien und ihre Wirkungen, Eingriffe und ihre Wirkungen, Einwilligungen und Aufklärungen. Arztbriefe sind in die Patientenakte aufzunehmen.

(3) Der Behandelnde hat die Patientenakte für die Dauer von zehn Jahren nach Abschluss der Behandlung aufzubewahren, soweit nicht nach anderen Vorschriften andere Aufbewahrungsfristen bestehen.

Vorschrift eingefügt durch das Gesetz zur Verbesserung der Rechte von Patientinnen und Patienten $v$

$\S 630 \mathrm{~g}$ Einsichtnahme in die Patientenakte

(1) Dem Patienten ist auf Verlangen unverzüglich Einsicht in die vollständige, ihn betreffende Patientenakte zu gewähren, soweit der Einsichtnahme nicht erhebliche therapeutische Gründe oder sonstige erhebliche Rechte Dritter entgegenstehen. Die Ablehnung der Einsichtnahme ist zu begründen. § 811 ist entsprechend anzuwenden.

(2) Der Patient kann auch elektronische Abschriften von der Patientenakte verlangen. Er hat dem Behandelnden die entstandenen Kosten zu erstatten.

(3) Im Fall des Todes des Patienten stehen die Rechte aus den Absätzen 1 und 2 zur Wahrnehmung der vermögensrechtlichen Interessen seinen Erben zu. Gleiches gilt für die nächsten Angehörigen des Patienten, soweit sie immaterielle Interessen geltend machen. Die Rechte sind ausgeschlossen, soweit der Einsichtnahme der ausdrückliche oder mutmaßliche Wille des Patienten entgegensteht.

§630h Beweislast bei Haftung für Behandlungs- und Aufklärungsfehler

(1) Ein Fehler des Behandelnden wird vermutet, wenn sich ein allgemeines Behandlungsrisiko verwirklicht hat, das für den Behandelnden voll beherrschbar war und das zur Verletzung des Lebens, des Körpers oder der Gesundheit des Patienten geführt hat.

(2) Der Behandelnde hat $\mathrm{zu}$ beweisen, dass er eine Einwilligung gemäß $\S 630 \mathrm{~d}$ eingeholt und entsprechend den Anforderungen des $\S 630 \mathrm{e}$ aufgeklärt hat. Genügt die Aufklärung nicht den Anforderungen des $\S 630 \mathrm{e}$, kann der 
A introdução dos $\S \S 630 \mathrm{a}-630 \mathrm{~h}$ no BGB ocorreu pela Lei dos Direitos dos Pacientes (Patientenrechtegesetz), aprovada em $1^{\circ}$ de fevereiro de 2013, que entrou em vigor em dos mesmos mês e ano. ${ }^{175}$ Antes dessa reforma legislativa, a doutrina tratava o contrato de tratamento médicos sob as prescrições do contrato de prestação de serviço e, eventualmente, do contrato de obra. ${ }^{176}$

Entretanto, nessa reforma legislativa, no campo do Direito Médico, o legislador não se referiu expressamente ao paciente

Behandelnde sich darauf berufen, dass der Patient auch im Fall einer ordnungsgemäßen Aufklärung in die Maßnahme eingewilligt hätte.

(3) Hat der Behandelnde eine medizinisch gebotene wesentliche Maßnahme und ihr Ergebnis entgegen $\S 630 \mathrm{f}$ Absatz 1 oder Absatz 2 nicht in der Patientenakte aufgezeichnet oder hat er die Patientenakte entgegen $\S 630$ f Absatz 3 nicht aufbewahrt, wird vermutet, dass er diese Maßnahme nicht getroffen hat.

(4) War ein Behandelnder für die von ihm vorgenommene Behandlung nicht befähigt, wird vermutet, dass die mangelnde Befähigung für den Eintritt der Verletzung des Lebens, des Körpers oder der Gesundheit ursächlich war.

(5) Liegt ein grober Behandlungsfehler vor und ist dieser grundsätzlich geeignet, eine Verletzung des Lebens, des Körpers oder der Gesundheit der tatsächlich eingetretenen Art herbeizuführen, wird vermutet, dass der Behandlungsfehler für diese Verletzung ursächlich war. Dies gilt auch dann, wenn es der Behandelnde unterlassen hat, einen medizinisch gebotenen Befund rechtzeitig $\mathrm{zu}$ erheben oder $\mathrm{zu}$ sichern, soweit der Befund mit hinreichender Wahrscheinlichkeit ein Ergebnis erbracht hätte, das Anlass zu weiteren Maßnahmen gegeben hätte, und wenn das Unterlassen solcher Maßnahmen grob fehlerhaft gewesen wäre.

${ }^{175}$ Sobre o desenvolvimento histórico da Patientenrechtegesetz: SPICKHOFF, Andreas. Medizinrecht. 2 ed. München: Beck, 2014. pp. 420-421.

${ }^{176}$ Ibidem, pp. 421-423. 
menor. ${ }^{177}$ A finalidade da lei foi trazer maior transparência e segurança jurídica para pacientes e médicos e conferir aos pacientes mais direitos em caso de erro médico. ${ }^{178}$

Foram trazidas para o corpo do texto legislativo decisões consolidadas pela jurisprudência. De início, uma alteração festejada pela doutrina foi a tipificação do contrato de tratamento médico, o qual, ainda que inserido no capítulo que trata do direito de prestação de serviço, dele se diferencia em diversos e peculiares aspectos.

Em seu conteúdo essencial estão a regulamentação legal dos deveres médico de esclarecimento ( $\$ 630 \mathrm{e}$ BGB), informação (\$630c BGB) e documentação ( $\$ 630 \mathrm{~h} \mathrm{BGB).} \mathrm{Houve} \mathrm{um} \mathrm{fortalecimento} \mathrm{dos}$ direitos do paciente com a inversão do ônus da prova em caso de erro grosseiro ( $\$ 630 \mathrm{~h}$ Abs. 5 BGB) e uma nova regulamentação do consentimento do paciente (§630d BGB), que atribui ao médico a obrigação de toma-lo antes da execução de qualquer procedimento médico. Em caso de paciente menor, deve-se tomar o consentimento de seus representantes legais ( $§ 630 \mathrm{~d}$ Abs. 1 Satz 1 BGB). ${ }^{179}$

177 BRÜCKNER, Sarah. Das medizinische Selbstbestimmungsrecht Minderjähriger. Marburg: Tectum, 2014. p. 2.

${ }^{178}$ GLEIXNER-EBERLE, Elisabeth. Die Einwilligung in die medizinische Behandlung Minderjähriger. Frankfurt: Springer, 2014. p. 244 Sobre um estudo mais aprofundado sobre a Patientenrechtgesetz: . KUBELLA, Kathrin. Patientenrechtegesetz. London: New York Springer, 2011.

${ }^{179}$ GLEIXNER-EBERLE, Elisabeth. Die Einwilligung in die medizinische Behandlung Minderjähriger. Op. Cit., p. 244. 
A lei, entretanto, nada falou a respeito da capacidade de consentimento dos menores, nem ao menos forneceu uma definição de capacidade de consentimento. ${ }^{180}$ Algumas regras importantes do projeto de lei não foram aprovadas, dentre elas aquela que proibia cirurgia estética em menores. ${ }^{181}$

No direito brasileiro as regras sobre o contrato médico são extraídas da doutrina e da jurisprudência, uma vez que os artigos 593 e seguintes do Código Civil, que tratam do contrato de prestação de serviço, não se mostram adequadas para regulamentar a relação médico-paciente. $\mathrm{O}$ contrato de tratamento médico se realiza entre duas partes. De um lado está o paciente e, especificamente no caso do presente trabalho, o paciente menor. ${ }^{182}$ De outro, está o profissional, que pode ser o médico sozinho, uma clínica ou hospital. A própria Lei de Direitos do Paciente da Alemanha não deixou claro quem estaria do lado da parte que se compromete à prestação do tratamento médico. ${ }^{183}$

Não há necessidade de qualquer formalidade para a formação do referido contrato, sendo suficiente o consentimento das partes sobre

${ }^{180}$ Ibidem, p. 245.

${ }^{181}$ DEUTSCH, Erwin; SPICKHOFF, Andreas. Medizinrecht. Azrtrecht, Arzneimittelrecht, Medizinproduktrecht und Transfusionsrecht. Op. Cit., p. 77.

${ }^{182}$ Sobre o paciente menor, item 3.3 infra.

${ }^{183}$ SPICKHOFF, Andreas. Medizinrecht. Op. Cit., pp. 424-426. 
seu objeto, no caso, a cirurgia estética, bem como sobre os deveres e direitos de ambas as partes. ${ }^{184}$ Constitui tal contrato um organismo que possui começo e fim, desenvolvendo-se por meio de deveres principais e acessórios necessários para promover a saúde do paciente. Com base na autonomia privada, o contrato médico permite a formação da relação jurídica entre as partes, tendo por fim, na pior das hipóteses, a responsabilidade civil do profissional. ${ }^{185}$

O referido contrato é caracterizado de forma especial pelo elemento da confiança, a qual tanto médico como paciente depositam um no outro. ${ }^{186}$ Como pressuposto, o contrato apresenta a capacidade de agir das partes. ${ }^{187}$

\subsection{Obrigações de meio e de resultado}

Ao se discorrer acerca da relação jurídica obrigacional, mostrase necessário, ainda que de maneira sucinta, trazer à baila o conceito de obrigação. No direito romano, as Institutas de Justiniano definem a obligatio como iuris vinculum, quo necessitate adstringimur

${ }^{184}$ DEUTSCH, Erwin; SPICKHOFF, Andreas. Medizinrecht. Azrtrecht, Arzneimittelrecht, Medizinproduktrecht und Transfusionsrecht. Op. Cit., p. 91 .

${ }^{185}$ Ibidem, p. 77.

${ }^{186}$ Ibidem, p. 77.

${ }^{187}$ Ibidem, p. 93. Sobre a capacidade de agir nos contratos de tratamento médico com pacientes menores, cf. capítulo 7.2 infra. 
alicuius solvendae rei secundum nostrae civitatis iura. ${ }^{188}$ Ou seja, como ensina DERNBURG, ${ }^{189}$ as obrigações são vínculos jurídicos que consistem no dever de uma prestação, dotada de conteúdo patrimonial, pelo devedor ao credor. Parece bastante claro o conceito trazido por VOLTERRA, ${ }^{190}$ segundo o qual a obrigação consiste na faculdade de um sujeito (credor) em pretender uma conduta positiva ou negativa a ser desempenhada por outro sujeito, o qual se denomina devedor, com base em um vínculo existente entre eles. Em outras palavras, o objeto dos direitos obrigacionais é uma determinada ação ou omissão que o sujeito integrante do polo passivo da relação jurídica obrigacional deve desempenhar em satisfação ao interesse daquele que ocupa o polo ativo da referida relação.

Tal conduta positiva (ação) ou negativa (omissão) recebe o nome de prestação e, para que esta ação constitua, de fato, uma prestação, deve ser dotada de caráter patrimonial. ${ }^{191}$ A prestação vem a ser, então, aquilo que o credor tem o direito de exigir do

${ }^{188}$ I. 3, 13.

${ }^{189}$ DERNBURG, Heinrich. Pandekten. v. 3.6 ed., 1900. Trad. It. F. B. Cicala. Diritto delle Obrigazioni. Torino: Fratelli Bocca, 1903. p. 1.

${ }^{190}$ Istituzioni di Diritto Privato Romano. Roma: La Sapienza, 1988. p. 439.

${ }^{191}$ GOMES, Orlando. Obrigações. 17 ed. Rio de Janeiro: Forense, 2008. p. 23. 
devedor. ${ }^{192}$ Nesse sentido, cabe ressaltar, como defende ORLANDO GOMES, ${ }^{193}$ que o interesse do credor não precisa ser necessariamente econômico, mas o objeto da prestação deve apresentar conteúdo patrimonial.

Desse modo, é interessante ressaltar, ainda que não seja o objetivo do presente trabalho, que se vê, já de plano, uma primeira diferença dos chamados direitos obrigacionais (ou direitos pessoais) em relação aos direitos reais, haja vista que enquanto nestes o titular tira proveito econômico de uma coisa, o titular de um direito obrigacional obtém tal proveito da própria conduta a ser desempenhada pelo devedor, quando esta for de conteúdo patrimonial. ${ }^{194}$ LAFAYETTE $^{195}$ ensina que os direitos pessoais (ou obrigacionais) têm como objeto imediato, não coisas corpóreas, mas atos ou prestações de pessoas determinadas, muito embora grande parte dessas condutas, quando realizadas, resulte em um direito real ou conduzam ao exercício desse direito.

Feito esse presente excurso inicial acerca das obrigações de maneira genérica, passa-se, pois, à análise das chamadas obrigações

${ }^{192}$ SERPA LOPES, Miguel Maria de. Curso de direito Civil. v. 2. $3^{\mathrm{a}}$ ed. Rio de Janeiro: Freitas Bastos, 1961. p. 68.

${ }^{193}$ Obrigações. Op. Cit., p. 24

${ }^{194}$ VOLTERRA, Edoardo. Istituzioni di Diritto Privato Romano. Op. Cit., p. 440.

${ }^{195}$ Direito das Cousas. Rio de Janeiro: Baptista de Souza, 1922. p. 2. 
de meio e de resultado. Note-se que em relação às obrigações de meio, também se encontra na doutrina, como sinônimo, a expressão obrigações de diligência. ${ }^{196}$ Esta distinção entre obrigações de meio e de resultado se faz necessária frente à definição das responsabilidades do devedor, em função analógica com delitos formais e materiais, como imaginado por Demogue $;{ }^{197}$ é uma forma de se agrupar obrigações tradicionalmente classificadas em certos planos, à vista do problema da apuração da responsabilidade civil. ${ }^{198}$

Primeiramente, cabe ressaltar que toda obrigação é composta de um elemento objetivo e um subjetivo. O primeiro se perfaz no bem ou resultado esperado na relação jurídica obrigacional, ao passo que o segundo elemento trata do comportamento do devedor em relação ao resultado esperado pelo credor. Dessa maneira, o resultado final pode ou não compor o vínculo jurídico que liga credor e devedor, assim, se por causa da natureza da prestação a ser desempenhada

\footnotetext{
${ }^{196}$ Nesse sentido, TUNC, André. La distinction des obligations de résultat et des obliations de diligence. In Jalons - Dits et Écrits d'André Tunc, 1991. Trad. port. V. J. de Fradera. A distinção entre obrigações de resultado e obrigações de diligência. RT. São Paulo: Revista dos Tribunais, n. 778, p. $755,2000$.

${ }^{197}$ SERPA LOPES, Miguel Maria de. Curso de direito Civil. Op. Cit., p. 37; PEREIRA, Caio Mário da Silva. Instituições de direito civil. v. 2. 25 ed. Rio de Janeiro: Forense, 2012. p. 47

${ }^{198}$ Ibidem, pp. 47-48.
} 
pelo devedor o resultado depender de fatores externos à sua vontade, estar-se-á diante de uma obrigação de resultado. ${ }^{199}$

Segundo COMPARATO, ${ }^{200}$ a distinção entre obrigações de meio e de resultado foi proposta por Demogue quando tratou do problema relativo à repartição do ônus da prova em matéria de obrigações ex contracto e ex delicto, entretanto, segundo MENGONI, ${ }^{201}$ a distinção entre obrigações de meio e de resultado é dos juristas alemães e Demogue apenas criou a denominação. Para COMPARATO,${ }^{202}$ um exemplo da distinção entre uma obrigação de meio e de resultado, no Direito Romano, é a diferenciação existente entre as figuras da locatio operarum e da locatio operis faciendi. A distinção que há entre uma e outra figura, segundo FERRINI, ${ }^{203}$ consiste no fato de que, enquanto com a locatio operarum há uma prestação de serviço em favor do tomador, na locatio operis faciendi

${ }^{199}$ COMPARATO, Fábio Konder. Obrigações de meios, de resultado e de garantia. In TEPEDINO, Gustavo, FACHIN, Luiz Edson (org.). Doutrinas essenciais: Obrigações e contratos. v. 1. São Paulo: Revista dos Tribunais, 2011.p. 768.

${ }^{200}$ Ibidem, p. 763.

201 Obbligazioni 'di risultato' e obbligazioni 'di mezzi' - Studio critico. Estratto dalla Rivista del Diritto Commerciale. 52, n. 5-6, 7-8, 9-10, parte I. Milano: Francesco Vallardi. p. 1, nt. 2. 1954.

${ }^{202}$ Obrigações de meios, de resultado e de garantia. Op. Cit., p. 765.

${ }^{203}$ Manuale di Pandette. 3 ed. Milano: Società Editrice Libraria, 1908. p. 696. 
o devedor se obriga à execução de uma obra. ${ }^{204}$ Desse modo, nesta se objetiva o resultado final do trabalho do conductor ao invés do serviço propriamente dito, ao passo que na primeira figura o objeto é o trabalho como tal, pouco importando o resultado. ${ }^{205}$ Tendo em mente essa divisão, as obrigações de meio encontram-se bastante ligadas à locatio operarum enquanto as obrigações de resultado se espelham na locatio operis faciendi. Ressalte-se, porém, como já se disse supra, que no Direito Romano inexistia a terminologia obrigações de meio e de resultado, a qual se deve, como dito, a Demogue. Nesse sentido, PONTES DE MIRANDA ${ }^{206}$ defende que aquele que promete serviço, ou trabalho, deve a atividade mesma, enquanto o que se obriga à execução de uma obra deve ao credor o resultado.

As obrigações de resultado, segundo GIOSTRI, ${ }^{207}$ ensejam que o devedor, por um determinado ato ou procedimento, obrigar-se-ia a atingir um resultado preciso que fora previamente avençado entre as ${ }^{204}$ Paul. 2 ad ed. D. 50, 16, 5, 1: "Opere locato conducto": his verbis Labeo

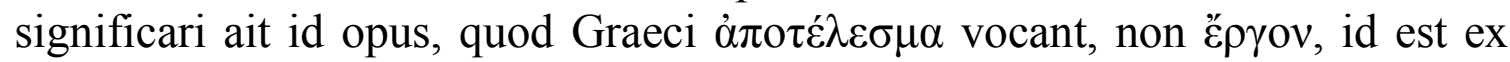
opere facto corpus aliquod perfectum.

205 Também nesse sentido: CORREA, Alexandre; SCIASCIA, Gaetano. Manual de direito romano. v. 1. 1 ed. São Paulo: Saraiva, 1949. p. 260.

206 Tratado de Direito Privado: Parte Especial - Direito das Obrigações: Contrato de locação de Serviços. Contrato de trabalho. t. 47. 3 ed. Rio de Janeiro: Borsoi, 1972. p. 10.

${ }^{207}$ Algumas reflexões sobre as obrigações de meio e de resultado na avaliação da responsabilidade médica. Revista Trimestral de Direito Civil. Rio de Janeiro: Instituto Brasileiro de Direito Civil. v. 5. p. 103, 2001. 
partes da relação jurídica obrigacional, como nas obrigações de pagar determinada quantia in pecuniam. Exige-se, em tal categoria obrigacional, que o resultado seja útil ao credor e, não sendo atingido, estará configurada uma situação de inadimplemento. $\mathrm{Ou}$ seja, o devedor de uma obrigação de resultado deveria estabelecer de forma efetiva a execução daquilo que produziu a sua desoneração. ${ }^{208}$ Desse modo, para que se pleiteasse em juízo uma indenização mediante ação própria para tal fim, bastaria a prova de que o resultado esperado pelo credor não foi atingido, cabendo ao devedor provar em sentido contrário. Em outros termos, o bem jurídico desejado pelo credor é a essência de uma obrigação de resultado. ${ }^{209}$

Nas obrigações de meio, em sentido oposto, ocorre que o devedor se compromete em desenvolver um determinado comportamento empregando, assim, todos os meios apropriados para alcançar um dado resultado, porém, não se vincula à sua obtenção. Há, nesse conjunto, obrigações relativas a uma norma de comportamento do devedor. ${ }^{210}$ Note-se, como defende TUNC, ${ }^{211}$ o

208 TUNC, André. La distinction des obligations de résultat et des obliations de diligence. Op. Cit., p. 756.

${ }^{209}$ PEREIRA, Caio Mário da Silva. Instituições de direito civil. Op. Cit., p. 48.

${ }^{210}$ CHAVES, Antônio. Tratado de Direito Civil. v. 2. t. I. 3 ed. São Paulo: Revista dos Tribunais, 1984. p. 48.

${ }^{211}$ La distinction des obligations de résultat et des obliations de diligence. Op. Cit., p. 756. 
comportamento diligente do devedor durante a execução de uma obrigação de meio, no mais das vezes, atingirá o seu objetivo.

São situações nas quais o devedor deve observar e desempenhar o comportamento do bonus paterfamilias e ao credor cabe, se assim julgar necessário, o ônus de provar que o ocupante do polo passivo da relação jurídica obrigacional não agiu de tal forma. ${ }^{212}$ Nelas, o devedor se vincula ao emprego de toda a diligência, prudência e perícia para atingir um fim acordado com a parte, mas, o adimplemento desta está no comportamento do devedor para atingir uma meta, a cujo êxito não está adstrito o devedor. Tem-se, como exemplos, o trabalho do médico que se obriga a tratar um determinado paciente, sem que esteja vinculado a curar-lhe, bem como do advogado, que se obriga a agir da melhor forma em interesse de seu cliente, mas não se obriga a obter o sucesso em determinada ação. ${ }^{213}$

Segundo TRABUCCHI, ${ }^{214}$ o objeto deste tipo de obrigações é um dever preciso de se cumprir o convencionado entre as partes enquanto é possível ao devedor, critério normalmente característico

${ }^{212}$ COMPARATO, Fábio Konder. Obrigações de meios, de resultado e de garantia. Op. Cit., p. 763.

${ }^{213}$ GIOSTRI, Hildegard Taggesel. Algumas reflexões sobre as obrigações de meio e de resultado na avaliação da responsabilidade médica. Op. Cit., pp. 102-103.

${ }^{214}$ Istituzioni di diritto civile. 43 ed. Padova: Cedan, 2007. p. 631. 
das obrigações de fazer. Desse modo, verifica-se que a obrigação, quando é de meio, é adimplida quando o devedor, ao desempenhar sua conduta, emprega a diligência que se espera do bonus paterfamilias. $^{215}$ Ao invés do devedor prometer ao credor uma prestação da qual se espera um determinado resultado, aquele é obrigado por convenção ou ex vi lege a tomar determinadas medidas e a empregar alguns meios, apesar de que, possivelmente, tendam a, naturalmente, produzir um determinado resultado. ${ }^{216}$

A intensa discussão que surge em torno da relação jurídica existente entre médico e seu paciente não é recente ${ }^{217}$ no direito brasileiro e perdura até os dias presentes, ${ }^{218}$ principalmente no que se refere à responsabilidade civil dos médicos, sobre a qual já se versaram discussões se seria de natureza contratual ou extracontratual. $^{219}$ Entende boa parte da doutrina nacional e
${ }^{215}$ Ibidem, p. 631.
${ }^{216}$ SERPA LOPES, Miguel Maria de. Curso de direito Civil. Op. Cit., p. 37.
${ }^{217}$ Já no Direito Romano, Ulpiano defendia a exclusão da responsabilidade do médico pela morte do paciente, da mesma forma como deve a este ser imputado se o cometeu por imperícia. Nesse sentido, Ulp. 1 opin. D. 1, 18, 6, 7: Sicuti medico imputari eventus mortalitatis non debet, ita quod per imperitiam commisit, imputari ei debet: praetextu humanae fragilitatis delictum decipientis in periculo homines innoxium esse non debet.
${ }^{218}$ MAFFEIS MOREIRA, Marta Rodrigues. Contribuição ao estudo da responsabilidade civil do médico à luz do Direito Romano. São Paulo: Quartier Latin, 2016. p. 55.
${ }^{219}$ ANDRIGHI, Fátima Nancy. Responsabilidade civil na cirurgia estética. Brasília, 2006.
p.
1.
Disponível
em: 
estrangeira $^{220}$ que tais profissionais celebram com seus pacientes um contrato de prestação de serviços. Segundo PONTES DE MIRANDA, ${ }^{221}$ o médico não se obriga a alcançar o resultado, que é a cura, muito embora esta seja desejada tanto pelo paciente quanto pelo profissional contratado. Entretanto, o médico promete toda a atividade técnica com fins, certamente, de alcançar a cura. $\mathrm{O}$ termo

$<$ http://bdjur.stj.jus.br/jspui/bitstream/2011/2278/Responsabilidade_Civil_Cir urgia.pdf $>$. Acesso em: 13 out. 2016. A ministra defende que a discussão em torno da natureza contratual ou extracontratual da responsabilidade do médico se dava em razão do antigo art. 1.545 do Código Bevilaqua, que determinava o dever de reparação do dano causado pelo médico (e por outros profissionais da saúde), o qual não se encontrava no capítulo que versava sobre a responsabilidade contratual, mas junto ao capítulo II do título VIII ( $d a$ liquidação das obrigações resultantes de atos ilícitos). Dizia o art. 1.545: Os médicos, cirurgiões, farmacêuticos, parteiras e dentistas são obrigados a satisfazer o dano, sempre que da imprudência, negligência, ou imperícia, em atos profissionais, resultar morte, inabilitarão de servir, ou ferimento. No entanto, com o advento do Código de 2002, a responsabilidade passou a ser entendida como de natureza contratual, salvo em alguns casos, como acidentes e demais casos em que o médico deve prestar atendimento antes de qualquer ajuste negocial com o paciente.

${ }^{220}$ Nesse sentido, TRABUCCHI, Alberto. Istituzioni di diritto civile. Op. Cit., p. 631; GOMES, Orlando. Obrigações. Op. Cit., p. 24; BEVILAQUA, Clóvis. Código Civil dos Estados Unidos do Brasil comentado. v. 4. Rio de Janeiro: Francisco Alves, 1958. p. 321; LOPEZ, Teresa Ancona. Das várias espécies de contratos - da locação de coisas; do empréstimo, da prestação de serviços; da empreitada; do depósito. In AZEVEDO, Antônio Junqueira (coord.). Comentários ao Código Civil. v. 7. São Paulo: Saraiva, 2003. p. 202; THEODORO JR., Humberto. Aspectos processuais da ação de responsabilidade por erro médico. RT. São Paulo: Revista dos Tribunais. v. 760, p. 42, fevereiro de 1999.

221 Tratado de Direito Privado: Parte Especial - Direito das Obrigações: Contrato de locação de Serviços. Contrato de trabalho. t. 47. Op. Cit., p. 11. 
usado pelo autor é locação de serviços, tal qual utilizado pelo Código Beviláqua, ${ }^{222}$ expressão bem mais próxima do termo romano do referido contrato.

O Código Civil de 2002, no entanto, optou por nomeá-lo contrato de prestação de serviços, ao regulá-lo entre os arts. 593 e 609, o que seria mais adequado para os dias atuais, na visão de ANCONA LOPES. ${ }^{223}$ Para a autora, o termo locação, na sociedade contemporânea enseja, apenas, a locação de coisas, a conhecida locatio rei do Direito Romano, haja vista que, dado o respeito ao princípio da dignidade da pessoa humana - valor fundante do ordenamento jurídico pátrio positivado no art. $1^{\circ}$, III, da Constituição Federal de 1988 - essa denominação não é mais cabível dentro da ordem jurídica nacional. Isto porque, a expressão locatio surge num contexto social no qual a escravidão era um fato social e as pessoas escravizadas apresentavam tratamento jurídico de res. Não se alugam pessoas nem seus serviços, haja vista que elas, sejam físicas ou jurídicas, prestam-nos se assim o quiserem e da forma que melhor lhes aprouver.

Em uma comparação entre os ordenamentos jurídicos brasileiro e português, verifica-se que o contrato de prestação de serviços ${ }^{222}$ O regramento do contrato de locação de serviços, no Código Civil de 1916 encontra-se nos arts. 1.216 a 1.236 .

${ }^{223}$ Das várias espécies de contratos - da locação de coisas; do empréstimo, da prestação de serviços; da empreitada; do depósito. Op. Cit., p. 189. 
existente no Brasil não se confunde com o tipificado no art. 1.154 do Código Civil luso. Isto porque, nos termos do referido dispositivo, $o$ contrato de prestação de serviços é aquele em que uma das partes se obriga a proporcionar à outra certo resultado de seu trabalho intelectual ou manual, com ou sem retribuição (grifo nosso). Notese que pela simples leitura do dispositivo, verifica-se que o contrato de prestação de serviços naquele ordenamento jurídico enseja uma obrigação de resultado, haja vista que o referido contrato tem como objeto o resultado do trabalho realizado pela parte, e não a atividade laborativa do devedor. ${ }^{224}$ Justifica-se, ainda, pois que a empreitada também é modalidade de prestação de serviços, como se lê no art. 1.155 da lei civil substantiva de Portugal. ${ }^{225}$

No ordenamento jurídico brasileiro, o contrato de prestação de serviços é aquele no qual o devedor se obriga a oferecer determinados serviços ao credor, mediante remuneração que este lhe deve, ${ }^{226}$ devendo executá-lo com independência técnica e sem uma

${ }^{224}$ PIRES DE LIMA, Fernando Andrade; ANTUNES VARELA, João de Matos. Código Civil Anotado. v. 2. 4 ed. Coimbra: Coimbra, 2011. p. 783.

${ }^{225} O$ Mandato, o depósito e a empreitada, regulados nos capítulos subsequentes, são modalidades do contrato de prestação de serviços.

${ }^{226}$ BEVILAQUA, Clóvis. Código Civil dos Estados Unidos do Brasil comentado. Op. Cit., p. 321. Note-se que embora a definição pareça tautológica, o autor ainda o define de acordo com a antiga definição de locação de serviços. 
relação de subordinação. ${ }^{227} / 228 \mathrm{~A}$ independência técnica do prestador enseja que este realize a atividade devida ao tomador de forma que não esteja vinculado à escolha dos métodos e processos pelo credor, ou seja, é o próprio devedor quem escolhe a forma como melhor lhe aprouver para a execução da prestação devida, devendo agir, no entanto, de maneira proba e diligente, como o bonus paterfamilias. Desse modo, ORLANDO GOMES ${ }^{229}$ exemplifica a independência técnica com a figura do médico cirurgião, o qual age da forma como melhor entender para realizar uma cirurgia, não é o paciente que lhe determina o método a ser seguido para a intervenção. Ressalte-se, também, que a insubordinação é caráter do contrato de prestação de serviços, haja vista que, se houvesse uma relação de subordinação jurídica entre prestador e tomador, a hipótese seria de um contrato de trabalho.

Segundo MELLO FRANCO, ${ }^{230}$ é um contrato consensual, bilateral, oneroso, comutativo e não solene; além disso, o contrato pode ou não ser de execução continuada, ou por prazo determinado.

${ }^{227}$ GOMES, Orlando. Contratos. 26 ed. Rio de Janeiro: Forense, 2008. p. 354.

${ }^{228}$ No Código Civil de 2002: Art. 593. A prestação de serviço, que não estiver sujeita às leis trabalhistas ou à lei especial, reger-se-á pelas disposições deste Capitulo.

${ }^{229}$ Contratos. Op. Cit., p. 355.

${ }^{230}$ Contratos - Direito Civil e Empresarial. 2 ed. São Paulo: Revista dos Tribunais, 2011. pp. 127-128. 
Também, pode ou não ser um contrato intuito personae, haja vista que se contrata um prestador, em regra, em intenção do contratante e da pessoa contratada, salvo se houver disposição em contrário para substituição, como se lê no art. 605 do Código Civil. ${ }^{231}$ Seu objeto é a própria atividade desenvolvida pelo prestador, seja ela de natureza material ou imaterial, como aquele prestado por um técnico em informática e pelo advogado, respectivamente. ${ }^{232}$ Outro elemento essencial do contrato de prestação de serviços é a remuneração do prestador, a qual recebe o título de honorários, ${ }^{233}$ haja vista que não há presunção de prestação gratuita de serviços. Isso não impede, no entanto, que o prestador o faça gratuitamente, com escopo de liberalidade, porém, a gratuidade deve ser declarada de forma expressa pelo prestador. ${ }^{234}$

Como se viu, há diversas vozes na doutrina que classificam o contrato celebrado entre médico e paciente como um contrato de prestação de serviços no qual o profissional se obriga a empregar

${ }^{231}$ Art. 605. Nem aquele a quem os serviços são prestados, poderá transferir a outrem o direito aos serviços ajustados, nem o prestador de serviços, sem aprazimento da outra parte, dar substituto que os preste.

${ }^{232}$ LOPEZ, Teresa Ancona. Das várias espécies de contratos - da locação de coisas; do empréstimo, da prestação de serviços; da empreitada; do depósito. Op. Cit., p. 203.

${ }^{233}$ GOMES, Orlando. Contratos. Op. Cit., p. 355.

${ }^{234}$ LOPEZ, Teresa Ancona. Das várias espécies de contratos - da locação de coisas; do empréstimo, da prestação de serviços; da empreitada; do depósito. Op. Cit., pp. 203-204. 
todas as técnicas que melhor lhe aprouver e as quais julgar mais adequadas para o tratamento do paciente. Desse modo, pela própria natureza do contrato de prestação de serviços em si, a obrigação que vincula o médico ao paciente se enquadraria como uma obrigação de meio, haja vista que, se a obrigação fosse de resultado, o profissional estaria obrigado a alcançar a cura do paciente. Discute-se, no entanto, se toda atividade médica corresponde a uma obrigação de meio.

Segundo TUNC, ${ }^{235}$ a obrigação do médico frente ao seu paciente é obrigação de meio (ou de diligência, segundo a terminologia da qual o referido autor lança mão). Isto porque o vinculum iuris que liga o médico ao paciente, em termos civis, consiste em propiciar a este cuidados conscienciosos e com a devida atenção, de acordo com o que melhor determinar a ciência e a literatura médicas para o caso específico, pois não pode o profissional da saúde prometer ao enfermo a cura de sua enfermidade, haja vista que esta não depende, apenas, do médico. Desse modo, em caso de um desfecho trágico gerado pela moléstia, a responsabilidade do médico não seria exigida de ipso iure, tampouco este deveria provar, a princípio, que agiu de maneira adequada no caso, aplicando os cuidados indicados de acordo com ${ }^{235}$ La distinction des obligations de résultat et des obliations de diligence. Op. Cit., p. 756. 
dados científicos. Ao contrário, compete ao interessado provar que o profissional não agiu de forma correta para que ficasse caracterizado o inadimplemento do médico: faz-se necessário que a parte interessada prove a culpa determinada do profissional. Isto se deve ao fato de que, nas obrigações de meio, cabe ao credor o onus probandi de provar a inexecução ou que o devedor (o médico, no caso) agiu com culpa determinada durante a execução do tratamento. ${ }^{236}$

Também COMPARATO ${ }^{237}$ defende que o médico está adstrito ao paciente através de uma obrigação de meio. $\mathrm{O}$ paciente procura $\mathrm{o}$ profissional com o escopo de ver sua enfermidade curada, no entanto, apesar de tal desejo ser a causa da essência do referido contrato, não é o objeto pactuado. Isto porque o paciente pode exigir que o médico empregue, como se falou supra, todos os métodos para um melhor tratamento, de acordo com os ditames da medicina. No entanto, o paciente não pode exigir que o médico seja infalível em sua ação, de modo a, de qualquer jeito, obter-lhe a cura para a enfermidade, também o médico não pode promete-la de forma certa, uma vez que, segundo o autor, estaria o médico incidindo no delito

${ }^{236}$ Também nesse sentido, LOPEZ, Teresa Ancona. Dano estético. $2^{\mathrm{a}}$ ed. São Paulo: Revista dos Tribunais, 1999. p. 54.

${ }^{237}$ Obrigações de meios, de resultado e de garantia. Op. Cit., pp. 765-766. 
de charlatanismo, ${ }^{238}$ sendo concebível sua responsabilização nos termos do Código Penal. ${ }^{239}$ É importante ressaltar, no entanto, como defende COUTO E SILVA, ${ }^{240}$ que embora o médico assuma, de fato, uma obrigação de meio, haja vista que o dever deste consiste, como já se ressaltou no presente trabalho, dispensar ao paciente os devidos cuidados de acordo com a técnica que as ciências médicas lhe colocam à disposição, o fim não deixa de integrar o processo das obrigações de meio. Desse modo, destaca o autor, a finalidade é, também, indissociável do contrato realizado com o médico.

Um dos argumentos que surgem na defesa de que a obrigação do médico é de meio se perfaz na existência de um risco ao paciente, há um fator álea nos procedimentos médicos, sejam eles de natureza clínica ou cirúrgica. ${ }^{241}$ Para LOPEZ, ${ }^{242}$ álea enseja um acontecimento que é impossível de se evitar, geralmente

${ }^{238} \mathrm{O}$ autor comete um equívoco, no texto, ao dizer que o delito seria de curandeirismo, previsto no art. 284 da lei penal substantiva (apesar de indicar o artigo 283 da referida lei). No entanto, o tipo penal adequado é o charlatanismo, tipificado no referido art. 283.

${ }^{239}$ Art. 283. Inculcar ou anunciar cura por meio secreto ou infalível: Pena detenção, de três meses a um ano, e multa.

${ }^{240}$ A obrigação como processo. Rio de Janeiro: FGV, 2006. p. 64.

${ }^{241}$ GIOSTRI, Hildegard Taggesel. Algumas reflexões sobre as obrigações de meio e de resultado na avaliação da responsabilidade médica. Op. Cit., pp. 104-105.

${ }^{242}$ Princípio da precaução e evolução da responsabilidade civil. São Paulo: Quartier Latin, 2010. p. 24. 
imprevisível. Assim, para alguns autores, tais quais COMPARATO, ${ }^{243}$ a responsabilidade será, sempre, de meio.

No que se refere à cirurgia estética, surge uma dúvida quanto à natureza da obrigação do médico cirurgião. COMPARATO, ${ }^{244}$ ensina que a obrigação do médico sempre será de meio, pois ainda que este se comprometa a realizar uma determinada operação, ainda assim não promete um resultado, não respondendo pelo seu insucesso.

Também AGUIAR JR. ${ }^{245}$ afirma que se trata de uma obrigação de meio, haja vista que ainda há a presença do fator álea numa cirurgia estética, o que traz riscos imprevisíveis ao procedimento cirúrgico, principalmente no que diz respeito à reação do organismo do paciente à intervenção. Assim, o dano causado e a insatisfação do paciente frente às expectativas com o embelezamento através do procedimento cirúrgico devem ser analisados de acordo com os princípios norteadores das obrigações de meio, não de resultado.

A este entendimento contribuem GIOSTRI ${ }^{246}$ e FOSTER. $^{247} \mathrm{~A}$ primeira autora defende a inaplicabilidade do conceito de obrigação

${ }^{243}$ Obrigações de meios, de resultado e de garantia. Op. Cit., p. 766.

${ }^{244}$ Ibidem, p. 766.

${ }^{245}$ Responsabilidade civil do médico. RT. São Paulo: Revista dos Tribunais. n. 718, p. 40, agosto de 1995 .

246 Algumas reflexões sobre as obrigações de meio e de resultado na avaliação da responsabilidade médica. Op. Cit., p. 107. 
de meio ao procedimento cirúrgico estético devido, também, ao fator álea, haja vista que o próprio organismo humano é o que há de mais aleatório, tanto em aspectos físicos quanto psíquicos. O segundo, nesse mesmo sentido, defende que o médico não pode controlar todos os fatores que podem incidir no procedimento cirúrgico, assim, não pode o profissional assegurar ao paciente que o procedimento não deixará qualquer vestígio, v.g. a formação de um queloide.

Ainda nessa linha defensiva, $\mathrm{LORZ}^{248}$ afirma que o alcance do sucesso é o ponto central da questão de saber se o médico é obrigado a oferecer somente o tratamento correto e zeloso ou também alcançar o sucesso estético. Pondera a autora que o sucesso das cirurgias de cura em geral depende de inúmeros fatores, como o estado físico e psíquico do paciente, em relação ao qual a influência do médico tem seus limites. Esses fatores não são completamente domináveis, mesmo sob condições máximas e conforme o atual estado da medicina, na medida em que a cirurgia é apenas uma parte na cadeia de inúmeras condições referentes ao sucesso da cura.

${ }^{247}$ Cirurgia plástica estética: obrigação de resultado ou obrigação de meios?. RT. São Paulo: Revista dos Tribunais. n. 738, p. 85, 1997.

${ }^{248}$ Arzthaftung bei Schönheitsoperationen. Op. Cit., pp. 73-75. 
Assim, a classificação do contrato de um tratamento de cura seria somente na forma de um contato de serviço. ${ }^{249}$

Sustenta LORZ que o mesmo raciocínio deve ser utilizado no caso das cirurgias estéticas, pois as imponderabilidades do corpo humano existem independentemente da cirurgia, qualquer que seja sua finalidade, de cura ou estética. O risco de um insucesso das cirurgias em geral certamente não pode ser dominado pelo médico, haja vista que o sucesso dela não depende única e exclusivamente das capacidades físicas e psíquicas do paciente. ${ }^{250}$

Dessa forma, a autora defende uma repartição de riscos entre paciente e médico, de modo a solucionar a questão da falta de sucesso em uma cirurgia estética. Assim, quando uma cirurgia estética não levar ao resultado estético desejado, apesar de sua execução zelosa e correta pelo médico, a causa para isso se encontra na esfera do paciente. Entretanto, se o sucesso estético não se realizar por causa de um erro do médico, então a causa estará na esfera deste. ${ }^{251} \mathrm{O}$ médico pode evitar o erro de tratamento seguindo o zelo e cuidado necessários, mas de fato, ele não pode alcançar o

${ }^{249}$ Ibidem, p. 73. Conforme citação anterior, essa obra foi publicada em 2007, antes, portanto, da aprovação da Lei dos Direitos dos Pacientes, que introduziu os $\S \S 630 \mathrm{a} / 630 \mathrm{~h}$ no BGB.

${ }^{250}$ Arzthaftung bei Schönheitsoperationen. Op. Cit., p. 74.

${ }^{251}$ Ibidem, p. 74. 
sucesso estético em face das imponderabilidades do organismo humano. $^{252}$

De outro lado, o médico poderia se responsabilizar pelo sucesso estético e assumir a responsabilidade civil pela sua não ocorrência, quando a probabilidade de sucesso é alta, sobretudo nas intervenções de rotina, onde o risco de fracasso é pequeno. Porém, LORZ também afasta essa solução, argumentando que esse risco de insucesso, ainda que pequeno, existe, e não seria justo atribui-lo ao médico. $^{253}$

Mesmo havendo uma expectativa do paciente pelo resultado estético desejado, isso nada muda na distribuição de risco. Isso vale principalmente quando o paciente foi corretamente informado pelo médico sobre os riscos da cirurgia. Mesmo em caso de omissão de informação, pode-se presumir que ele tem conhecimento geral que cirurgias sempre estão relacionadas com complicações e nem sempre levam ao resultado desejado. ${ }^{254}$ Segundo a autora, o paciente saudável não vai moldar sua decisão de realizar uma cirurgia estética por causa da promessa de sucesso, mas, sim, pela possibilidade de alcançar o embelezamento, dependendo da força de seu desejo em se submeter a uma cirurgia estética e assumir os riscos a ela inerentes.

${ }^{252}$ Arzthaftung bei Schönheitsoperationen (cit.), p. 74.

${ }^{253}$ Arzthaftung bei Schönheitsoperationen. Op. Cit., p. 75.

${ }^{254}$ Ibidem, pp. 76-79. 
Não se trata de proteger uma expectativa de sucesso seguro. A confiança que o paciente deposita no médico somente é legítima no que toca à execução correta e zelosa da intervenção. ${ }^{255}$

No entanto, o entendimento que parece mais acertado é o que segue no sentido de considerar que na cirurgia estética, assim como em outros procedimentos de baixa complexidade, tais como exames de raio-x, o que há é uma obrigação de resultado que vincula o profissional. ${ }^{256}$ Nesse sentido, ANCONA LOPEZ ${ }^{257}$ afirma que é obrigação de resultado, haja vista que, em se tratando de cirurgia estética, o paciente não sofre de uma moléstia, então procura o médico para a obtenção de um resultado específico que é melhorar algum aspecto de seu corpo que lhe causa incômodo. Assim, caso não atinja tal resultado, presume-se a culpa do profissional. ${ }^{258}$

BENACCHIO $^{259}$ defende, também, que há uma obrigação de resultado do médico, caso este for omisso quanto ao dever de

${ }^{255}$ Ibidem, pp. 73-75.

${ }^{256}$ Cabe ressaltar, aqui, que em trabalho anterior [Contribuição ao estudo da responsabilidade civil do médico à luz do Direito Romano. Op. Cit., p. 58] seguíamos o entendimento oposto, de que a obrigação é de meio.

${ }^{257}$ Dano estético. Op. Cit., p. 91.

258 ANCONA LOPEZ, Teresa. Responsabilidade civil dos médicos. In CAHALI, Yussef Said (coord.), Responsabilidade civil: doutrina e jurisprudência. 2 ed., São Paulo: Saraiva, 1988. p. 321.

${ }_{259}$ Responsabilidade civil do médico. In NERY, Rosa Maria de Andrade; DONNINI, Rogério (coord.). Responsabilidade civil: Estudos em homenagem ao professor Rui Geraldo Camargo Viana. São Paulo: Revista dos Tribunais, 2009. p. 331. 
informar o paciente, uma vez que se presume que este busca o tratamento estético com o escopo de embelezamento, que é um resultado específico. ${ }^{260}$

Tal dever, segundo afirma ANDRIGHI, ${ }^{261}$ ocupa um lugar central na relação médico-paciente, principalmente no que se refere à cirurgia estética, o que obriga ao profissional a informar o paciente sobre todos os riscos e possíveis variações no resultado, e essa preocupação não pode, jamais, ser "sonegada" pelo profissional. ${ }^{262}$

Para ORLANDO GOMES, ${ }^{263}$ o médico, nas cirurgias estéticas, não age de modo a salvaguardar a vida ou a saúde do paciente, mas para melhorar a aparência das pessoas e, em busca dessa melhora é que as pessoas buscam o profissional; assim, o médico comprometese a um resultado.

${ }^{260} \mathrm{O}$ autor defende que a referida presunção só é afastada se o profissional deixar claro ao paciente todos os riscos e incertezas do procedimento, fazendo com que a obrigação se torne de meio.

${ }^{261}$ Responsabilidade civil na cirurgia estética. Op. Cit., pp. 7-8.

${ }^{262}$ Segundo HIRONAKA, Giselda Maria Fernandes Novaes. Cirurgia plástica e responsabilidade civil do médico: para uma análise jurídica da culpa do cirurgião plástico. Revista do Instituto de Estudos e Pesquisa (Divisão Jurídica). Bauru: ITE. n. 39, pp. 508-512, 2004, embora defenda que o médico assuma uma obrigação de meio na cirurgia estética, este deve verificar, nos exames prévios, as condições do paciente, sendo obrigado a esclarecê-lo sobre eventuais riscos, assim, não se obrigará a garantir um resultado específico. Mas se não o fizer ou se garanti-lo, não se livrará de uma obrigação de resultado.

${ }^{263}$ Questões de direito civil. 5 ed. São Paulo: Saraiva, 1988. p. 450. 
Ainda na linha defensiva de que a obrigação do médico na cirurgia estética é de resultado e não de meio, VERGAMINI LUNA e GIMENES ARCAS ${ }^{264}$ defendem que é o médico quem aconselha que o paciente se submeta ou não ao procedimento cirúrgico estético, desse modo, garante um resultado a ser alcançado, presumindo-se a culpa caso este não seja observado.

Também STOCCO ${ }^{265}$ segue o mesmo entendimento de uma obrigação de resultado, uma vez que, ao contrário da medicina tradicional, na cirurgia estética o médico assume um resultado previsto, antecipado e anunciado, invertendo-se, então, o onus probandi em desfavor do profissional o qual deve provar que não agiu de maneira culposa e que o resultado não foi alcançado por causas excludentes de responsabilidade, as quais estariam alheias à vontade do médico.

Além dos aqui citados, vários outros autores, como KFORI NETO ${ }^{266}$ e SANTARELLI ZULIANI ${ }^{267}$ seguem nessa mesma linha,

${ }^{264}$ Responsabilidade civil do Estado e a atividade médica. in HIRONAKA, Giselda Maria Fernandes Novaes, DIAZ FALAVIGNA, Maria Clara Osuna, (coord.). Ensaios sobre responsabilidade civil na pós modernidade. 1 ed. Porto Alegre: Magister, 2007. p. 20.

265 Tratado de responsabilidade civil. 8 ed. São Paulo: Revista dos Tribunais, 2011. p. 629.

${ }^{266}$ A responsabilidade civil do médico. In NERY JR., Nelson; NERY, Rosa Maria de Andrade (org.). Doutrinas essenciais: Responsabilidade civil. v. 5, São Paulo: Revista dos Tribunais, 2010. p. 623. O autor traz a cirurgia estética como exemplo de obrigação de resultado imputada ao profissional médico, 
considerando de resultado a obrigação do cirurgião plástico, opinião que nos parece ser a mais acertada, com dissemos supra. Também na França, há entendimento nesse sentido, como defendem CHAMMARD e MONZEIN. $^{268}$

Nesse diapasão, também segue o entendimento jurisprudencial brasileiro. Há no Superior Tribunal de Justiça, precedentes no sentido de se considerar a cirurgia estética como obrigação de resultado. $\mathrm{O}$ tribunal já se pronunciou da seguinte forma em diversos julgados:

Vale dizer, numa cirurgia estética e reparadora, a responsabilidade do médico será de resultado em relação à parcela estética da intervenção e de meio em relação à sua parcela reparadora. (...). Acrescente-se, por oportuno, que o uso da técnica adequada na cirurgia não é suficiente para isentar o recorrente da culpa pelo não cumprimento de sua obrigação. Se, mesmo

havendo, então, a culpa presumida deste em não se alcançando o fim determinado.

${ }^{267}$ Inversão do ônus da prova na ação de responsabilidade civil fundada em erro médico. RT. São Paulo: Revista dos Tribunais. n. 811, p. 49, maio de 2003.

${ }^{268}$ La responsabilité medicale. Paris: Presses Universitaires de France, 1974. p. 85. Nas palavras dos autores: En matière de chirurgie esthétique et plastique, l'obligation du chirurgion est de résustat quant á l'aspect chirurcical de son action et de moyen quant á l'aspect esthétique 
utilizando-se do procedimento apropriado, o recorrente não alcançou os resultados dele esperados, há a obrigação de indenizar. ${ }^{269}$

A obrigação assumida pelo médico, normalmente, é obrigação de meios, posto que objeto do contrato estabelecido com o paciente não é a cura assegurada, mas sim o compromisso do profissional no sentido de uma prestação de cuidados precisos e em consonância com a ciência médica na busca pela cura. Apesar de abalizada doutrina em sentido contrário, este Superior Tribunal de Justiça tem entendido que a situação é distinta, todavia, quando o médico se compromete com o paciente a alcançar um determinado resultado, o que ocorre no caso da cirurgia plástica meramente estética. Nesta hipótese, segundo o entendimento nesta Corte Superior, o que se tem é uma obrigação de resultados e não de meios. ${ }^{270}$

Um caso tido como precedente no referido tribunal e que merece destaque, foi relatado pelo ministro Waldemar Zveiter julgado pela terceira turma da corte em $1999 .{ }^{271}$ Segundo o relator, a obrigação de resultado fica configurada num procedimento estético, onde se busca, como objeto, obter uma certa imagem ou

${ }^{269}$ STJ, $3^{\text {a }}$ Turma. REsp 1097955/MG, rel. Nancy Andrighi. j. 27 set. 2011. P.DJe. 03 out. 2011.

${ }^{270}$ STJ, 4 ${ }^{\mathrm{a}}$ Turma. REsp 236708 / MG, rel. Carlos Fernando Mathias (juiz convocado do TRF-1). j. 10 fev. 2009. P.DJe. 18 mai. 2009.

${ }^{271}$ STJ, $3^{\text {a }}$ Turma. REsp. 81101 / PR, rel. Waldemar Zveiter. j. 13 abr. 1999. P.DJ. 31 mai. 1999. 
configuração. No referido caso, restou vencido o ministro Carlos Alberto Menezes Direito, o qual, em seu voto vista, defendeu a classificação em obrigação de meio, uma vez que, dada a natureza de qualquer procedimento cirúrgico, independentemente de sua especialidade, há uma expectativa de melhor resultado possível, apesar de haver a possibilidade de se obter um resultado bom ou ruim, ainda que não haja negligência, imprudência ou imperícia do profissional. Isso se deve a fatores alheios, como o metabolismo do paciente.

Diante desse contexto, é muito difícil definir a obrigação de resultado nos tratamentos médicos em geral, inclusive na cirurgia estética. Afinal, há as imponderabilidades do organismo humano. Entretanto, em virtude das particularidades da cirurgia estética, em que há uma maior previsibilidade de sucesso, tendemos (assim como o Superior Tribunal de Justiça) em considerar as cirurgias estéticas como obrigações de resultado. Não se pode, por outro lado, ignorar situações em que mesmo nessas cirurgias seria mais condizente falar de uma obrigação de meio, especialmente para os casos em que há um maior risco no procedimento cirúrgico, dificultando a previsão do sucesso. 


\subsection{O paciente menor}

O tratamento médico de menores, assim como o de adultos, também ocorre normalmente por meio de um contrato. ${ }^{272}$ Quando crianças e adolescentes são os pacientes na relação com o médico, apresenta-se a questão de saber quem, afinal, é a parte contratual ao lado do médico.

O Estatuto da Criança e do Adolescente ${ }^{273}$ definiu, em seu art. $2^{\circ}$, criança como a pessoa até 12 anos de idade incompletos e adolescente, aquela entre 12 e 18 anos. Em nível internacional, a Convenção sobre os Direitos da Criança define, em seu artigo $1^{\circ}$, criança como sendo o ser humano que ainda não completou 18 anos, salvo se o direito nacional estipulou de forma diferente o início da maioridade.

No que se refere à capacidade de agir, o art. $3^{\circ}$ do Código Civil brasileiro, dispõe que são absolutamente incapazes de exercer os atos da vida civil os menores de 16 anos. Por eles devem agir seus representantes legais, como determina o art. 1.634, $\mathrm{V}$ da mesma lei civil substantiva. Disso não difere muito a situação dos relativamente incapazes, ou seja, dos menores entre 16 e 18 anos

${ }^{272}$ BÖHMKER, Daniela. Die Entscheidungskompetenz des minderjährigen Patienten in der medizinischen Behandlung. Op. Cit., p. 36.

${ }^{273}$ Lei $n^{\circ} 8.069 / 90$. 
ainda não completos, pois também necessitam da concordância de seus pais, ainda que estes atuem na forma de assistência, ex vi dos arts. $4^{\circ}$ e $1.634, \mathrm{~V}$ do Código Civil.

A ligação dos absolutamente incapazes com a vida jurídica é indireta, por meio do instituto da representação. ${ }^{274}$ Quanto aos relativamente incapazes, podem exercer seus direitos, porém o ordenamento jurídico reconhece que lhes falta algumas qualidades que permitam a total liberdade de ação para procederem com autonomia, exigindo que sejam assistidos ${ }^{275}$. Para N. NERY e R. NERY, a representação e assistência são os dois institutos jurídicos que garantem a igualdade e a liberdade negocial da pessoa natural absolutamente ou relativamente incapaz. ${ }^{276}$ AMARAL pontua que a ordem jurídica protege os incapazes estabelecendo mecanismos destinados a possibilitar-lhes o exercício dos direitos, dentre os quais a representação e a assistência. ${ }^{277}$ Os direitos das pessoas incapazes se exercem, sem prejuízo para o comércio jurídico, através dos institutos da representação, da assistência e da autorização. ${ }^{278}$

${ }^{274}$ PEREIRA, Caio Mário da Silva. Instituições de Direito Civil. v. 1. 24 ed. Rio de Janeiro: Forense, 2011. p. 229

${ }^{275}$ Ibidem, p. 236.

${ }^{276}$ Código Civil Comentado. Op. Cit.,. p. 299.

${ }^{277}$ Direito Civil: Introdução. 7 ed. Rio de Janeiro: Renovar, 2008. p. 269.

${ }^{278}$ GOMES, Orlando. Introdução ao Direito Civil. 20 ed. Rio de Janeiro: Forense, 2010. p. 134. 
Partindo do princípio da autonomia da vontade, o Código Civil concede aos sujeitos de direito uma autorização para regulamentarem seus negócios por si mesmos. Isso pressupõe uma determinada capacidade e maturidade daqueles que agem sobre seus assuntos. A capacidade de agir, então, pode ser definida como a capacidade de uma pessoa física praticar negócios jurídicos de forma eficaz por si mesma ou por meio de representantes legais. ${ }^{279}$

Sobre esse ponto é importante ressaltar o aspecto da eficácia da declaração de vontade. O Código Civil parte do entendimento de que todas as pessoas são capazes de agir, ressalvadas algumas exceções. Dessa forma o Direito Civil estabelece alguns patamares de idade por meio dos quais diferencia entre incapazes $\mathrm{e}$ relativamente incapazes de agir. ${ }^{280}$

Nesse contexto, o menor incapaz não pode agir sozinho para celebrar um contrato médico, independentemente do seu desenvolvimento mental no caso concreto. ${ }^{281}$ Os pais, representantes

${ }^{279}$ BÖHMKER, Daniela. Die Entscheidungskompetenz des minderjährigen Patienten in der medizinischen Behandlung. Op. Cit., p. 44.

${ }^{280}$ Ibidem, p. 44.

${ }^{281}$ DEUTSCH, Erwin; SPICKHOFF, Andreas. Medizinrecht. Azrtrecht, Arzneimittelrecht, Medizinproduktrecht und Transfusionsrecht. Op. Cit., pp. 93-94; GLEIXNER-EBERLE, Die Einwilligung (cit.), p. 374; KERN, §39 Die Parteien des Arztvertrages, Rn. 24. In LAUFS, Adolf; KERN, BerndRüdiger (coord.). Handbuch des Arztrechts. Op.Cit.; RUMETSCH, Virgilia. Medizinische Eingriffe bei Minderjährigen. Eine rechtsvergleichende 
legais em regra, podem celebrar o contrato em seu próprio nome ou como representantes em nome da criança ou do adolescente. ${ }^{282}$ Em se tratando de relativamente incapazes, o menor pode dar seu consentimento, mas para eficácia da celebração do contrato faz-se necessária também a concordância de seus genitores. ${ }^{283}$ Poderia o relativamente incapaz celebrar o contrato sozinho nos casos em que apenas auferisse vantagens com o negócio. ${ }^{284}$ Porém, isso não se aplica ao caso do contrato de cirurgia estética, em que existe a contraprestação do pagamento dos honorários médicos, que representam uma desvantagem jurídica e econômica para o menor. $^{285}$

Untersuchung zum Schweizer und deutschen Recht. Helbing Lichtenhahn: Basel, 2013. p. 9.

${ }^{282}$ KERN, $\$ 39$ Die Parteien des Arztvertrages, Rn. 24. In LAUFS, Adolf; KERN, Bernd-Rüdiger (coord.). Handbuch des Arztrechts. Op. Cit.; BÖHMKER, Daniela. Die Entscheidungskompetenz des minderjährigen Patienten in der medizinischen Behandlung. Op. Cit., pp. 44-45.

${ }^{283}$ DÖLL, Erman. Bürgerliches Gesetzbuch. v. 1, 14 ed. Köln: Dr. Otto Schmidt, 2014. §1626, Rn. 16b; RUMETSCH, Virgilia. Medizinische Eingriffe bei Minderjährigen. Op. Cit., p. 11; BÖHMKER, Daniela. Die Entscheidungskompetenz des minderjährigen Patienten in der medizinischen Behandlung. Op. Cit., p. 45.

${ }^{284}$ SPICKHOFF, Andreas. Medizinrecht. Op. Cit., pp. 426-427; BÖHMKER, Daniela. Die Entscheidungskompetenz des minderjährigen Patienten in der medizinischen Behandlung. Op. Cit., pp. 46-47.

${ }^{285}$ KERN, $\$ 39$ Die Parteien des Arztvertrages, Rn. 24. In LAUFS, Adolf; KERN, Bernd-Rüdiger (coord.). Handbuch des Arztrechts. Op. Cit.,; BÖHMKER, Daniela. Die Entscheidungskompetenz des minderjährigen Patienten in der medizinischen Behandlung. Op. Cit., pp. 45-47. 
Dessa forma, um menor necessita sempre do consentimento de seus pais para a celebração do contrato de tratamento médico. Se o contrato for celebrado sem o consentimento de seus genitores, não será eficaz. A eficácia do contrato depende, portanto, da concordância dos pais. ${ }^{286}$

Entretanto, mesmo que os pais sejam os parceiros contratuais, a criança e o adolescente recebem a necessária proteção contratual, pois, na qualidade de pacientes, serão eles que sofrerão o procedimento médico. Dessa forma, é garantido a eles o direito de ajuizar uma ação contra o médico em caso de erro médico ou qualquer fato atribuível ao profissional que enseje alguma reparação civil. $^{287}$

Para a celebração do contrato os pais não precisam necessariamente agir de forma simultânea. Os doutrinadores DEUTSCH e SPICKHOFF esclarecem como as situações podem ser solucionadas. ${ }^{288}$ Normalmente o que ocorre é que apenas um dos genitores acompanha o filho ao médico. Nesse caso, explicam os

${ }^{286}$ DEUTSCH, Erwin; SPICKHOFF, Andreas. Medizinrecht. Azrtrecht, Arzneimittelrecht, Medizinproduktrecht und Transfusionsrecht. Op. Cit., p. 739.

${ }^{287}$ Ibidem, pp. 94 e 739; KERN, §39 Die Parteien des Arztvertrages, Rn. 30. In LAUFS, Adolf; KERN, Bernd-Rüdiger (coord.). Handbuch des Arztrechts. Op. Cit.

${ }^{288}$ Medizinrecht. Azrtrecht, Arzneimittelrecht, Medizinproduktrecht und Transfusionsrecht. Op. Cit., p. 743. 
autores, entende-se que o genitor ausente autorizou o outro a agir por ambos. O médico, então, conforme a concordância daquele que se faz presente, não precisa se certificar se o outro está ou não de acordo com o procedimento a ser realizado. Essa solução parece adequada nos casos de procedimentos simples e sem maiores riscos ou consequências para a saúde da criança ou adolescente. ${ }^{289}$

Entretanto, em casos de procedimentos graves ou com riscos à saúde do menor, essa solução não se mostra adequada. Dessa forma, a doutrina alemã extraiu de um julgamento do Bundesgerichtshof, datado de 28 de junho de 1988, três grupos diferentes de procedimentos, conforme a gravidade da intervenção médica e a necessidade do consentimento de ambos os pais. ${ }^{290}$

No primeiro grupo inserem-se os procedimentos graves ou com possíveis consequências graves. Nesse caso, ambos os pais devem ser informados e questionados sobre seu consentimento. Se eles não estiverem de acordo, a questão deverá ser resolvida perante o Poder Judiciário, desde que não se trate de caso urgente.

${ }^{289}$ Ibidem, p. 743.

${ }^{290}$ Ibidem, p. 744; BÖHMKER, Daniela. Die Entscheidungskompetenz des minderjährigen Patienten in der medizinischen Behandlung. Op. Cit., pp. 39-41; ULSENHEIMER, § 139 Die fahrlässige Körperverletzung, Rn. 31. In LAUFS, Adolf; UHLENBRUCK, Wilhelm, Handbuch des Arztrechts, $3^{\mathrm{a}}$ ed., München: Beck, 2002, pp. 1250-1251. 
No segundo grupo inserem-se os procedimentos medianamente graves, com consequências não muito significativas. Nesse caso, o médico deve sugerir ao genitor presente que questione o outro sobre sua concordância. Em princípio, basta o consentimento daquele que está presente, desde que o médico possa confiar na sua informação, no sentido de que ele está autorizado a agir também pelo outro.

Por fim, no terceiro grupo inserem-se os procedimentos simples, de riscos leves, sendo suficiente o consentimento apenas do genitor presente. Nessa situação pode-se presumir que o pai ausente autorizou o outro a agir por ambos.

Em caso de separação, divórcio ou morte de um dos pais, a competência para dar o consentimento para uma intervenção médica em favor do menor caberá ao genitor que detém a guarda. ${ }^{291} \mathrm{Se}$, no entanto, a hipótese for de guarda compartilhada ${ }^{292}$, ambos possuirão a guarda do filho e, por consequência, valerão as mesmas regras expostas acima como se fossem casados ou vivessem em união estável.

Ainda sobre o atendimento médico a menores, o Conselho Regional de Medicina do Estado de São Paulo (CREMESP) já se manifestou no sentido de que, em se tratando de atendimento de ${ }^{291}$ DEUTSCH, Erwin; SPICKHOFF, Andreas. Medizinrecht. Azrtrecht, Arzneimittelrecht, Medizinproduktrecht und Transfusionsrecht. Op. Cit., p. 744 .

${ }^{292}$ Arts. 1.583 e 1.584 do Código Civil. 
urgência/emergência, deve-se realizar o atendimento de modo a se preservar a maior segurança que se puder ao paciente, devendo os médicos comunicar aos pais e responsáveis o mais breve possível. Atente-se, no entanto, que, em se tratando de pré-adolescente em condição de comparecimento, realizar-se-á o atendimento e comunicar-se-á, simultaneamente, aos pais. ${ }^{293}$

Mesmo quando o menor procura atendimento desacompanhado, o CREMESP entende que deve ser prestado o atendimento sem restrições ao paciente. No entanto, deve-se observar que este deve apresentar capacidade de entendimento dos seus problemas e possa, por seus próprios meios, resolvê-los. ${ }^{294}$ Ainda, ex vi do art. 74 do Código de Ética Médica ${ }^{295}$ (Resolução CFM nº. 1.931/2009), o médico não pode revelar o sigilo profissional no que se refere a tal atendimento, ainda que aos pais do paciente, desde que, como já dito, o menor atendido tenha capacidade de discernimento especificamente em relação ao fato sobre o qual o sigilo possa

293 CONSELHO REGIONAL DE MEDICINA DO ESTADO DE SÃO PAULO. Consulta $n^{\circ}$. 40/13-CFM. rel. Celso Murad. Emitido em: 18 set. 2013.

294 CONSELHO REGIONAL DE MEDICINA DO ESTADO DE SÃO PAULO. Consulta ${ }^{\circ}$. 15.633/94. rel. Luiz Fernando Carneiro. Aprovado em: 16 ago. 1994.

${ }^{295}$ Art. 74. [É vedado ao médico] Revelar sigilo profissional relacionado a paciente menor de idade, inclusive a seus pais ou representantes legais, desde que o menor tenha capacidade de discernimento, salvo quando a não revelação possa acarretar dano ao paciente. 
recair. ${ }^{296}$ Ressalte-se que a recusa no atendimento pode configurar negligência do profissional, incorrendo este em infrações administrativas e, até mesmo, penais (caso se configure omissão de socorro). ${ }^{297}$

Muito se tenta apegar à idade do paciente para se definir se este deve ou não ser atendido, considerando-se que, de acordo com entendimento internacional, estes já são maduros no que se refere ao entendimento de orientações que lhes são fornecidas. Entretanto, o conceito de adolescente é bastante fluido e, assim, não deve o profissional ficar preso à faixa etária do paciente, devendo analisar o caso concreto. $^{298}$

Merece atenção, da mesma forma, o que se refere a informações prestadas aos genitores quando estes forem separados e apenas um exercer a guarda do menor. Segundo entendimento do referido Conselho, na situação que citamos, deve-se fornecer as informações, apenas, ao genitor (ou genitora) guardião do menor. O que não detém a guarda, contudo, se quiser as informações, deve requerê-las

296 DANTAS, Eduardo; COLTRI, Marcos Vinícius. Comentários ao Código de Ética Médica. Rio de Janeiro: GZ, 2010. pp. 288-292.

297 CONSELHO REGIONAL DE MEDICINA DO ESTADO DE SÃO PAULO. Consulta no . 15.996/94. rel. Adriana T. M. Brisolla Pezzotti. Emitido em: 28 jul. 1994.

298 CONSELHO REGIONAL DE MEDICINA DO ESTADO DE SÃO PAULO. Consulta $n^{\circ}$. 40/13-CFM. rel. Celso Murad. Emitido em: 18 set. 2013. 
ao Poder Judiciário. Assim, quando houver ordem do Estado-juiz para que as informações sejam fornecidas, isso deverá ser feito observando o disposto no art. $89, \S^{\circ}$, do referido Código. ${ }^{299} \beta^{300}$

\subsection{Natureza jurídica do contrato}

Não se tratará nessa oportunidade da natureza jurídica dos contratos em geral, mas apenas em relação ao contrato médico de cirurgia estética com o paciente menor. A respeito do assunto existem várias opiniões divergentes.

\subsubsection{Estipulação em favor de terceiros}

Quando o contrato é firmado entre o médico e os representantes legais do paciente menor, alguns sustentam que ele toma a forma de um contrato ou estipulação em favor de terceiro que, no caso, é o menor. ${ }^{301}$ Os doutrinadores que defendem essa figura contratual

${ }^{299} \S 1^{\circ}$ Quando requisitado judicialmente o prontuário será disponibilizado ao perito médico nomeado pelo juiz.

${ }^{300}$ CONSELHO REGIONAL DE MEDICINA DO ESTADO DE SÃO PAULO. Consulta $n^{\circ}$. 154.805/11. rel. Laide Helena Casemiro Pereira. Emitido em: 13 dez. 2011.

${ }^{301}$ KERN, §39 Die Parteien des Arztvertrages, Rn. 24. In LAUFS, Adolf; KERN, Bernd-Rüdiger (coord.). Handbuch des Arztrechts. Op. Cit.; UHLENBRUCK, LAUFS, §40 Die Parteien des Arlztvertrages, Rn. 8. In LAUFS, Adolf; UHLENBRUCK, Wilhelm (coord.), Handbuch des Arztreht. Op. Cit., p. 393; BÖHMKER, Daniela. Die 
argumentam que frequentemente pode acontecer de o menor ir sozinho ao médico. Nesse caso, o menor atua como mensageiro da declaração de vontade dos pais, e o contrato se forma entre os pais e o médico, quando este aceita aquela declaração transmitida. Nessa configuração, o menor é o terceiro a favor de quem o contrato é estipulado.

UHLENBRUCK e LAUFS ${ }^{302}$ argumentam que quando um dos pais celebra um contrato que também produz eficácia vinculante ao outro genitor, em favor do filho de ambos, na dúvida, também o menor se torna parte contratual. No caso concreto pode-se estabelecer, por interpretação, se se trata de um contrato com efeito de proteção sobre um terceiro ou de um autêntico contrato em favor de terceiro.

BÖHMKER ${ }^{303}$ defende que se trata de contrato em favor de terceiro e que, no mínimo, deveria se reconhecer um contrato com efeito de proteção em favor de terceiro. Essa figura contratual seria configurada pelo seu conteúdo, quando o médico/devedor não

Entscheidungskompetenz des minderjährigen Patienten in der medizinischen Behandlung. Op. Cit., p. 94; RUMETSCH, Virgilia. Medizinische Eingriffe bei Minderjährigen. Op. Cit., pp. 9-10.

$302 \S 40$ Die Parteien des Arztvertrages, Rn. 8. In LAUFS, Adolf; UHLENBRUCK, Wilhelm (coord.), Handbuch des Arztrechts. Op. Cit, p. 399.

${ }^{303}$ Die Entscheidungskompetenz des minderjährigen Patienten in der medizinischen Behandlung. Op. Cit., pp. 37-38. 
estiver limitado ao âmbito de proteção do outro parceiro contratual, mas sim, de um terceiro, em relação ao qual o médico se obriga a prestar cuidado e proteção.

Enquanto no contrato em favor de terceiro o menor é incluído juridicamente como parte contratual, e, independentemente da questão da capacidade de agir, possui um direito de exigência próprio, no contrato com efeito de proteção em favor de terceiro, ele é incluído nos deveres contratuais de proteção e cuidado, cuja violação lhe autoriza um direito de indenização próprio. ${ }^{304}$

No caso de tratamento médico de menor, a jurisprudência alemã afirma que se trata de autêntico contrato em favor de terceiro, pelo qual se reconhece ao menor um direito próprio ao tratamento cuidadoso e zeloso devido pelo médico. ${ }^{305}$ No caso concreto deverá ser analisado se os pais quiseram atribuir ao filho o direito imediato à prestação principal. Na dúvida, deve-se partir do pressuposto de que o menor recebeu esse direito, situação que configurará um contrato em favor de terceiro, já que o menor possui direito de ação

${ }^{304}$ Die Entscheidungskompetenz des minderjährigen Patienten in der medizinischen Behandlung. Op. Cit., p. 38.

305 UHLENBRUCK,Wilhelm; LAUFS, Adolf. $\S 40$ Die Parteien des Arztvertrages, Rn. 8. In LAUFS, Adolf; UHLENBRUCK, Wilhelm (coord.), Handbuch des Arztrechts. Op. Cit, p. 393. 
própria e direito de exigir a prestação contratual, mas não se obrigando ao pagamento do honorário médico. ${ }^{306}$

Estipulação é termo que advém de stipulatio, com o significado de ajuste; contrato; promessa; proposta. ${ }^{307}$ Conceitua-se tal figura como um contrato entre duas partes no qual se estabelece que o benefício dele decorrente, no todo ou em parte, será revertido a um terceiro que é totalmente estranho ao acordo feito. ${ }^{308}$

Muito se discute na doutrina a propósito da caracterização jurídica desse contrato, dada a sua estrutura particularmente diferente daquela de um negócio jurídico ordinário, tendo em vista que há duas declarações de vontade na celebração de um ajuste com o benefício a um estranho à relação jurídica. Mais complexo se torna pela admissão que este terceiro, ainda que não participe da formação do contrato, adquire as qualidades de sujeito da relação obrigacional. ${ }^{309}$

${ }^{306}$ Além disso, segundo GLEIXNER-EBERLE, Elisabeth. Die Einwilligung in die medizinische Behandlung Minderjähriger. Op. Cit., p. 376, em caso de tratamento de menores absolutamente incapazes, seria possível concluir pelas circunstâncias que o menor deverá ser incluído apenas no âmbito de proteção do contrato, cabendo-lhe apenas uma ação de indenização em caso de erro médico.

${ }^{307}$ PAPALEO, João Cesar Guaspari. Contrato a Favor de Terceiro. Rio de Janeiro: Renovar, 2002. p. 42.

${ }^{308}$ SERPA LOPES, Miguel Maria de. Curso de direito civil. v. 3.3 ed. Rio de Janeiro: Freitas Bastos, 1960. p. 126.

${ }^{309}$ PEREIRA, Caio Mario da Silva. Instituições de Direito Civil. v. 3. 17 ed. Rio de Janeiro: Forense, 2014. p. 93. 
A estipulação em favor de terceiros decorre daquilo que os portugueses chamam de contrato em que um dos contraentes atribui por conta e à ordem de outro, uma vantagem a terceiro estranho à relação contratual. ${ }^{310}$ A estipulação, portanto, decorre de um contrato em que alguém estipulou e outrem se obrigou a realizar a tal prestação que atribui direito próprio a um terceiro.

Nas palavras de PONTES DE MIRANDA ${ }^{311}$, a estipulação em favor de terceiro é a atribuição de eficácia, a favor de terceiro, ao negócio jurídico bilateral, inclusive a acordo de transmissão ou constituição. Não se trata simplesmente de promessa, repelindo o autor a opinião daqueles que consideram não ser possível estipulação em favor de terceiro para acordos de transmissão de posse ou propriedade.

As partes do contrato que gera a obrigação são: o promitente (o que se obriga a prestar) e o promissário, ou estipulante (o que atribui o direito ao terceiro). O terceiro, que não é parte no contrato, é o beneficiário. $^{312}$ PONTES DE MIRANDA explica a estipulação em favor de terceiros com a metáfora da bi-ramificação do negócio

${ }^{310}$ ANTUNES VARELA, João de Matos. Das obrigações em geral. v. 1.10 ed. Coimbra: Almedina, 2008. p. 410.

311 Tratado de Direito Privado: Parte Especial - Direito das Obrigações. t. 26. $3^{\text {a }}$ ed. Rio de Janeiro: Borsoi, 1971. pp. 218-219.

312 NERY JR, Nelson; NERY, Rosa Maria de Andrade. Código Civil Comentado [versão E-book].11 ed. São Paulo: Revista dos Tribunais, 2014. p. 1207. 
jurídico, há um negócio jurídico formado por dois galhos ao invés de um galho só, como seria no caso de representação do terceiro pelo estipulante. $\mathrm{O}$ promitente promete ao promissário e vincula-se a esse e ao terceiro. ${ }^{313}$

Em sua base, a estipulação compreende dois polos contratantes, mas, nos resultados do contrato, alcança quem só participa da relação após a sua formação (o beneficiário). Alguns juristas não concebem um vínculo obrigacional para quem não manifestou vontade, porém SERPA LOPES ${ }^{314}$ aponta que a impossibilidade reside apenas em uma relação de débito contra a vontade do devedor, nada impede uma relação de crédito em que o credor não manifestou vontade na formação do vínculo.

Conforme lembra o citado doutrinador ${ }^{315}$, o princípio geral da teoria contratual é o da relatividade dos efeitos do contrato, os seus benefícios e as suas obrigações somente abrangem, diretamente, as partes que dele participam, excluídos os terceiros. Percebe-se, porém, que a estipulação em favor de terceiros constitui em exceção ao referido princípio, dado que os efeitos do contrato se irradiam

${ }^{313}$ Tratado de Direito Privado: Parte Especial - Direito das Obrigações. t. 26. Op. Cit., pp. 221.

${ }^{314}$ SERPA LOPES, Miguel Maria de. Curso de direito civil. v. 3. Op. Cit., p. 126.

${ }^{315}$ Ibidem, p. 121. 
para além das partes, há terceiros estranhos à formação do contrato que posteriormente dele adquirem vantagem. ${ }^{316}$

\subsubsection{Panorama histórico}

Inicialmente, partindo-se das considerações de PONTES DE MIRANDA $^{317}$, observa-se que a estipulação em favor de terceiros, no direito antigo, não era algo muito bem desenvolvido. A aquisição para outrem tinha que ser para alguém que fosse ligado ao adquirente, entrando, juridicamente, no patrimônio deste. Quando discorre sobre o direito romano clássico, afirma o autor que este negava a possibilidade de estipulação em favor de terceiros, conforme o princípio Alteri stipulari nemo potest. A resistência devia-se à concepção de que não poderiam as partes estipular eficácia contratual para além delas mesmas. É discutido na doutrina se o referido princípio sofreu uma atenuação no direito clássico ou pós-clássico, sendo certo que no direito justinianeu já se admitia, ainda que com restrições, a estipulação em favor de terceiros como algo juridicamente vinculante, tendo o terceiro ação contra a parte

${ }^{316}$ GOMES, Orlando. Contratos. Op. Cit., p. 196.

${ }^{317}$ Tratado de Direito Privado: Parte Especial - Direito das Obrigações. t. 26. Op. Cit., p. 208. O autor faz referência a alguns livros do Digesto e do Codex que exemplificam a impossibilidade da estipulação em favor de terceiros no direito romano, quais sejam: D. L. 11, 44, 7; D. L. 38, § 17, 45, 1 e C. L. 26, 5, 11 
contratante para compeli-la a cumprir o contrato de que se beneficiaria. ${ }^{318}$ Exemplos das hipóteses excepcionais de admissão da estipulação em favor de terceiro seriam um contrato em favor do próprio herdeiro e quando o pai constituía dote para a própria filha estabelecendo que, dissolvido o casamento, o dote seria restituído à filha ou aos netos. ${ }^{319}$

No direito medieval, continuou sendo excepcional a admissão da estipulação em favor de terceiros, assim permanecendo até as Codificações do século XIX. ${ }^{320}$ Sustenta-se ${ }^{321}$ que mudanças nesse paradigma só ocorreram motivadas por três fatores: necessidade do comércio jurídico (surgimento de figuras contratais como o transporte e o seguro) ${ }^{322}$; a evolução do direito alemão no século XIX e o deslocamento, por parte dos ordenamentos jurídicos, de uma perspectiva individualista para uma concepção social, a qual se mostra mais preocupada com o interesse geral. PONTES DE

${ }^{318}$ MOREIRA ALVES, José Carlos. Direito Romano. 16 ed. Rio de Janeiro: Forense, 2012. p. 474.

${ }^{319}$ WALD, Arnold. Direito Civil: Direito das Obrigações e Teoria Geral dos Contratos. v. 2. 20 ed., São Paulo: Saraiva, 2011. p. 316.

${ }^{320}$ PAPALEO, João Cesar Guaspari. Contrato a Favor de Terceiro. Op. Cit., p. 87.

${ }^{321}$ Ibidem, pp. 87-92.

${ }^{322}$ Orlando Gomes aponta que a estipulação em favor de terceiros configurase em vários contratos, citando como exemplos o de seguro de vida; constituição de renda e transporte de objetos para terceiros destinatários. Nesse sentido, Contratos. Op. Cit., p. 196. 
MIRANDA $^{323}$ observa que o Código Civil Francês, copiado por muitos outros códigos civis de diversos outros ordenamentos jurídicos, em profundo apego ao princípio romano referido no parágrafo anterior, proibia a estipulação em favor de terceiros. Diversas teorias foram criadas pela doutrina francesa em uma tentativa de contornar a proibição anacrônica codificada, resultando em confusão quanto à caracterização do instituto.

A referida confusão fez com que diversos autores brasileiros discorressem sobre as teorias relativas à natureza jurídica da estipulação em favor de terceiros. ${ }^{324}$ A doutrina discute se seria: I Oferta, de modo que até a aceitação do terceiro não haveria contrato, apenas oferta; II - Gestão de Negócios, empreendida pelo estipulante no interesse do terceiro; III - Obrigação unilateral, por haver uma suposta declaração unilateral de vontade por parte do estipulante, algo difícil de defender se se considera haver também a manifestação de vontade do promitente; IV - Exceção à regra dos efeitos contratuais apenas entre as partes, ainda sem uma

${ }^{323}$ Tratado de Direito Privado: Parte Especial - Direito das Obrigações. t. 26. Op. Cit., pp. 214-216.

${ }^{324}$ SERPA LOPES, Miguel Maria de. Curso de direito civil. v. 3. Op. Cit., pp. 127-129. 
estruturação e, por fim, $\mathrm{V}$ - Contrato, que é a teoria mais aceita na doutrina brasileira. ${ }^{325}$

No direito alemão, o princípio romano Alteri stipulari nemo potest foi considerado egoísta. Argumentava-se que a Alemanha deveria repelir o individualismo romano e primar pela solidariedade. Sendo o querer das partes bastante para produção de efeitos jurídicos, defendia-se que deveria ser protegida a vontade quando uma determinada pessoa quisesse contratar a favor de um terceiro. Assim, o que era exceção foi adquirindo maior amplitude ${ }^{326}$. A admissão da estipulação em favor de terceiro como figura autônoma com regulamentação própria foi cunhada no Código Civil Alemão, servindo de inspiração aos Códigos Civis brasileiros de 1916 e de $2002^{327}$, este último praticamente uma cópia do anterior no que se refere à regulação desta figura jurídica ${ }^{328}$

${ }^{325}$ PEREIRA, Caio Mario da Silva. Instituições de Direito Civil. v. 3. Op. Cit., pp. 93-94.

${ }^{326}$ PAPALEO, João Cesar Guaspari. Contrato a Favor de Terceiro. Op. Cit., pp. 89-91.

${ }^{327}$ WALD, Arnold. Direito Civil: Direito das Obrigações e Teoria Geral dos Contratos. Op. Cit., p. 316.

${ }^{328}$ Nesse sentido, a doutrina aponta que o Código Civil de 2002 não trouxe qualquer mudança substancial na disciplina da estipulação em favor de terceiros, de modo que os artigos que tratam do assunto, arts. 436, 437 e 438, são reprodução dos seus equivalentes no Código Civil de 1916, apenas com alterações de ordem formal. Nesse sentido, TEPEDINO, Gustavo; MORAES, Maria Celina Bodin de; BARBOZA, Heloisa Helena. Código Civil 


\subsubsection{O terceiro (ou beneficiário)}

Modernamente, superado o princípio romano a que se referiu supra, a eficácia da estipulação em favor de terceiro consiste em este adquirir o direito e a pretensão que um dos figurantes da relação jurídica prometeu. No entanto, não se faz necessário que a prestação vá do promitente ao promissário e deste ao terceiro, a prestação passa diretamente do promitente ao terceiro. ${ }^{329}$

No direito português, a estipulação em favor de terceiro é classificada, quanto à sua eficácia, em real; obrigacional e liberatória, diferenciando-se, nesse ponto, do direito brasileiro, que não permite a eficácia real do referido contrato. Para que fique claro, a estipulação tem carácter meramente obrigacional no Brasil. A eficácia liberatória do direito português não deixa de ser obrigacional, tem por virtude permitir, no patrimônio de terceiro, a liberação de uma dívida. ${ }^{330}$

Ao terceiro (ou beneficiário) só há a posição de credor da relação obrigacional, inexistindo qualquer contraprestação,

Interpretado conforme a Constituição da República. t. 2. Rio de Janeiro : Renovar, 2006. p. 52.

${ }^{329}$ PONTES DE MIRANDA, Francisco Cavalcanti. Tratado de Direito Privado: Parte Especial - Direito das Obrigações. t. 26. Op. Cit., p. 217.

${ }^{330}$ NERY JR, Nelson; NERY, Rosa Maria de Andrade. Código Civil Comentado. Op. Cit., p. 1202-1203. 
conforme afirma parte da doutrina. ${ }^{331}$ Para outros, é possível estipulação acompanhada de um encargo imposto ao terceiro, inclusive tendo o estipulante a faculdade de exigir o cumprimento ou revogar a estipulação por inexecução do encargo. ${ }^{332}$ Além disso, no momento da celebração do contrato, não precisa o terceiro ser conhecido, basta que seja determinável, pode inclusive ainda nem ter nascido. $^{333}$ Somente a indeterminação absoluta do terceiro invalida o contrato. ${ }^{334}$

Parte da doutrina argumenta que os direitos e deveres oriundos da estipulação surgem, via de regra, independentemente da aceitação do terceiro. No entanto, em certos casos, a sua aceitação obsta que as partes contratuais realizem um distrato ou modifiquem o conteúdo contratual sem a prévia concordância do beneficiário. ${ }^{335}$ Para outros, a aceitação do terceiro é necessária para que o direito que for adquirir possa ingressar em seu patrimônio, o efeito do contrato não se realiza sem a sua vontade, ainda que essa em nada 331 Rosenvald, Nelson. In PeluzO, Cezar. (Coord.). Código Civil Comentado: doutrina e jurisprudência. 7 ed. Barueri: Manole, 2013. p. 491. Também nesse sentido GOMES, Orlando. Contratos. Op. Cit., p. 196.

${ }^{332}$ PEREIRA, Caio Mario da Silva. Instituições de Direito Civil. v. 3. Op. Cit., p. 93.

333 PONTES DE MIRANDA, Francisco Cavalcanti. Tratado de Direito Privado: Parte Especial - Direito das Obrigações. t. 26. Op. Cit., p. 224

${ }^{334}$ PEREIRA, Caio Mario da Silva. Instituições de Direito Civil. v. 3. Op. Cit., p. 96.

${ }^{335}$ WALD, Arnold. Direito Civil: Direito das Obrigações e Teoria Geral dos Contratos. Op. Cit., p. 317. 
interfira na validade do que fora pactuado entre promitente e promissário. $^{336}$

O terceiro adquire não só o direito que lhe implica uma vantagem, também pode pleitear a execução da prestação devida pelo promitente, tem direito e pretensão ao que fora estipulado. ${ }^{337} \mathrm{~A}$ execução movida pelo terceiro fica adstrita às normas e condições estabelecidas no contrato, excluída a situação em que o estipulante (promissário) reserva-se o direito de substituir o terceiro. ${ }^{338}$ A leitura dos artigos 436 e 438 do Código Civil basta para concluir o exposto neste parágrafo. ${ }^{339}$ Quanto à possibilidade de execução da prestação pelo terceiro, consolidado é o entendimento da jurisprudência pelo

${ }^{336}$ Nesse sentido: GOMES, Orlando. Contratos. Op. Cit., p. 197 e também PEREIRA, Caio Mario da Silva. Instituições de Direito Civil. v. 3. Op. Cit., p. 99 .

337 PONTES DE MIRANDA, Francisco Cavalcanti. Tratado de Direito Privado: Parte Especial - Direito das Obrigações. t. 26. Op. Cit., p. 218.

${ }^{338}$ GOMES, Orlando. Contratos. Op. Cit., p. 197.

${ }^{339}$ Art. 436. O que estipula em favor de terceiro pode exigir o cumprimento da obrigação.

Parágrafo único. Ao terceiro, em favor de quem se estipulou a obrigação, também é permitido exigi-la, ficando, todavia, sujeito às condições e normas do contrato, se a ele anuir, e o estipulante não o inovar nos termos do art. 438. Art. 438. O estipulante pode reservar-se o direito de substituir o terceiro designado no contrato, independentemente da sua anuência e da do outro contratante. 
seu cabimento, conforme ementa de acórdão do Superior Tribunal de Justiça: ${ }^{340}$

CIVIL E PROCESSUAL CIVIL. CONTRATO DE SEGURO. AÇÃO AJUIZADA PELA VÍTIMA CONTRA A SEGURADORA. LEGITIMIDADE PASSIVA AD CAUSAM. ESTIPULAÇÃO EM FAVOR DE TERCEIRO. DOUTRINA E PRECEDENTES. RECURSO PROVIDO.

I - As relações jurídicas oriundas de um contrato de seguro não se encerram entre as partes contratantes, podendo atingir terceiro beneficiário, como ocorre com os seguros de vida ou de acidentes pessoais, exemplos clássicos apontados pela doutrina.

II - Nas estipulações em favor de terceiro, este pode ser pessoa futura e indeterminada, bastando que seja determinável, como no caso do seguro, em que se identifica o beneficiário no momento do sinistro.

III - O terceiro beneficiário, ainda que não tenha feito parte do contrato, tem legitimidade para ajuizar ação direta contra a seguradora, para cobrar a indenização contratual prevista em seu favor.

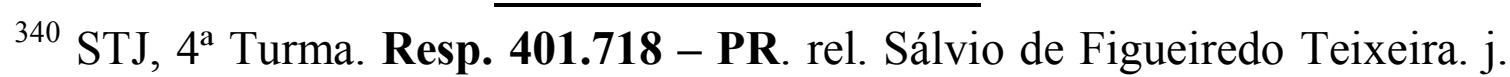
03 set. 2002. P. D.J. 24 mar. 2003. 


\subsubsection{Partes contratuais (promissário e promitente)}

Deve-se observar que é essencial às partes do contrato (o que não inclui o terceiro, por óbvio, já que este não é parte) agir de modo a deixar clara a intenção de atribuir uma vantagem ao beneficiário. ${ }^{341}$ Grande interesse tem a doutrina italiana na intenção do estipulante, inclusive colocando-a como requisito intrínseco de validade do contrato que estipula em favor de terceiro. ${ }^{342}$

O estipulante pode revogar o que estipulou antes da aceitação do terceiro. No entanto, a estipulação torna-se irrevogável, segundo a doutrina $^{343}$, após a aceitação, uma vez que a manifestação de vontade do terceiro em querer a vantagem leva prejuízo a este com a revogação. ${ }^{344}$ Esta é uma faculdade reconhecida ao estipulante que exonera o promitente da prestação ao terceiro, passando a prestação a ser devida ao estipulante, salvo se contrária for a vontade das partes, a natureza do contrato não permitir ou a prestação ao terceiro ser personalíssima, o que é algo raramente verificado. Por não ser matéria de ordem pública, pode o estipulante estabelecer no contrato ${ }^{341}$ ANTUNES VARELA, João de Matos. Das obrigações em geral. Op. Cit., p. 410.

${ }^{342}$ GIRINO, Franco. Studi in Tema di Stipulazione a Favore di Terzi. Milano: Giuffrè, 1965. pp. 33-34.

${ }^{343}$ SERPA LOPES, Miguel Maria de. Curso de direito civil. v. 3. Op. Cit., p. 130.

${ }^{344}$ A lei estabelece, no art. 437 do Código Civil, que se no contrato ficar estabelecido que o terceiro pode reclamar a execução, não pode o estipulante exonerar o promitente. 
que a estipulação é irrevogável, está no campo da autonomia das partes contratuais. $^{345}$

Não se ignora que, caso previsto no contrato, pode o promissário substituir o terceiro designado, exercer um poder formativo modificativo $^{346}$, independentemente da anuência deste ou do promitente. É uma razoável prerrogativa permitir ao promissário alterar o beneficiário em um contrato do qual não extrairá qualquer vantagem jurídica. ${ }^{347} \mathrm{O}$ terceiro, ao aceitar o benefício, aceita também o risco de ser substituído na forma e nos termos contratualmente previstos. ${ }^{348}$ A substituição do terceiro não implica em contradição com a impossibilidade de revogação após a

${ }^{345}$ PEREIRA, Caio Mario da Silva. Instituições de Direito Civil. v. 3. Op. Cit., p. 98.

346 PENTEADO, Luciano de Camargo. Doação com Encargo e causa contratual. 2 ed. São Paulo: Revista dos Tribunais, 2013. p. 333.

${ }^{347}$ É importante observar que, em caso de beneficiário de seguro de vida, também pode ocorrer substituição do terceiro por parte do estipulante, porém o Código Civil, no art. 791 parágrafo único, dispõe que a seguradora (promitente) precisa ser notificada na substituição. Em não sendo notificada, desobriga-se pagando ao antigo beneficiário. Em caso de seguro contra acidentes de trabalho, é comum a substituição do beneficiário, dado que este é o empregado de determinada empresa que firmou o seguro, perdurando sua posição de beneficiário enquanto perdura a relação de trabalho.

${ }^{348}$ TEPEDINO, Gustavo; MORAES, Maria Celina Bodin de; BARBOZA, Heloisa Helena. Código Civil Interpretado conforme a Constituição da República. t. 2. Op. Cit., p. 56. 
aceitação, dado que a referida irrevogabilidade compreende apenas o benefício em si, não a posição de terceiro. ${ }^{349}$

O promissário tem a faculdade, como é esperado por ser parte contratual, de exigir judicialmente que o promitente cumpra sua parte no contrato. Porém, conforme já dito, esse direito também cabe ao beneficiário. Mais do que isso, é importante frisar que o beneficiário tem direito de ação autônomo com relação ao promissário, estão em mesmo grau de importância na possibilidade de exigir do promitente o cumprimento da sua prestação, ${ }^{350}$ conforme é o entendimento firmado em acórdão do Superior Tribunal de Justiça: ${ }^{351}$

$\mathrm{Na}$ estipulação em favor de terceiro, tanto o estipulante quanto o beneficiário podem exigir do devedor o cumprimento da obrigação (art. 436, par. único, do $\mathrm{CCO} 2$ ou art. 1.098, par. único, do CC/1916). Com isso, o terceiro, até então estranho à relação obrigacional originária, com ela consente e passa efetivamente a ter direito material à prestação que lhe foi prometida. Nessas situações

349 PONTES DE MIRANDA, Francisco Cavalcanti. Tratado de Direito Privado: Parte Especial - Direito das Obrigações. t. 26. Op. Cit., p. 235.

${ }^{350}$ PENTENADO, Luciano de Camargo. Doação com Encargo e causa contratual. Op. Cit., p. 333.

${ }^{351}$ STJ, $3^{\text {a }}$ Turma. Resp. 1.086.989 - RS. rel. Nancy Andrighi. j. 23 fev. 2010. P. D. J. 05 mar. 2010. 
nem mesmo o estipulante pode lhe retirar o direito de pleitear a execução do contrato (art. 437 do CC02).

Na hipótese específica dos autos, entende-se que a recorrente (promitente) não teria o direito de pleitear a resolução do contrato, mesmo que a empresa (estipulante) não tenha cumprido a sua parte na convenção, pelas seguintes razões: a) a recorrida (beneficiário) consentiu e aderiu de boa-fé à relação obrigacional; b) com a adesão, a recorrida adquiriu o direito material à prestação prometida; c) a recorrida possui um direito de ação próprio, autônomo, podendo exigir diretamente do promitente a prestação, sem a necessidade de interferência do estipulante; d) com a adesão da recorrida (beneficiário), o promitente não tem a faculdade de privá-la do seu direito, o que ocorreria por via indireta se admitida a resolução do contrato; e e) a resolução do contrato tornaria sem efeito o direito do beneficiário já incorporado ao seu patrimônio jurídico (...)

PONTES DE MIRANDA ${ }^{352}$ pontua que a estipulação em favor de terceiros é celebrada em nome próprio do promissário, e, salvo a eficácia de criar um direito de crédito ao terceiro, todos os demais efeitos se limitam às partes. $\mathrm{O}$ promissário não atua como representante do terceiro, ainda que haja uma relação jurídica entre

352 Tratado de Direito Privado: Parte Especial - Direito das Obrigações. t. 26. Op. Cit., p. 225. 
eles. Essa é a fundamental diferença da estipulação em favor de terceiros de outros institutos similares, como o mandato. Neste contrato, aquele que estipula algo em favor de outrem age com poderes especiais para isso, age a mando desse outrem, do mandante. ${ }^{353}$

Também é importante não confundir a estipulação em favor de terceiros, realizada através de vontade negocial, com os contratos com eficácia protetora para terceiros, cujos efeitos vantajosos transcendem as partes e atingem terceiros, como no exemplo de um contrato de locação firmado entre A e B e que também beneficia os membros da família de A que vivem com ele. ${ }^{354}$ Nesse caso, a vantagem ao terceiro advém de disposição legal, não é a eficácia principal de um contrato atribuir-lhe vantagem, há apenas uma eficácia lateral. ${ }^{355}$

${ }^{353}$ SERPA LOPES, Miguel Maria de. Curso de direito civil. v. 3. Op. Cit., p. 129.

${ }^{354}$ TEPEDINO, Gustavo; MORAES, Maria Celina Bodin de; BARBOZA, Heloisa Helena. Código Civil Interpretado conforme a Constituição da República. t. 2. Op. Cit., p. 53.

355 A eficácia lateral também é chamada de eficácia anexa. Mais sobre o assunto em: BERNARDES DE MELLO, Marcos. Teoria do Fato Jurídico: Plano da Eficácia. 5 ed. São Paulo: Saraiva, 2009. p. 53. 
3.4.1.4 Objeto da estipulação em favor de terceiros e aquisição do direito

Para PONTES DE MIRANDA a prestação do promitente ao terceiro pode ser patrimonial ou não ${ }^{356}$, opinião diversa daquela exposta por ORLANDO GOMES, para quem a prestação precisa ser patrimonial e gratuita. $^{357}$

A aquisição do direito, por parte do terceiro, opera desde logo, ficando diferida para após a aceitação apenas o seu exercício. ${ }^{358} \mathrm{Ou}$ seja, celebrado o contrato, o direito do terceiro já passa a existir, tornando-se irrevogável e definitivo com a aceitação. ${ }^{359} \mathrm{Se}$ o promissário se reserva o direito de substituir o terceiro, o direito existe até o momento da substituição, passando ao substituto. Pode ocorrer que a aquisição da vantagem não seja observada desde logo, porém não se presume, é preciso que haja uma de duas situações: ou que esteja explicitada no contrato, através da existência de uma condição ou termo ao direito a ser adquirido pelo terceiro, ou que

${ }^{356}$ Tratado de Direito Privado: Parte Especial - Direito das Obrigações. t. 26. Op. Cit., p. 225.

${ }^{357}$ GOMES, Orlando. Contratos. Op. Cit., p. 197

${ }^{358}$ SERPA LOPES, Miguel Maria de. Curso de direito civil. v. 3. Op. Cit., p. 133.

${ }^{359}$ PEREIRA, Caio Mario da Silva. Instituições de Direito Civil. v. 3. Op. Cit., p. 96. 
pela própria natureza do contrato, como no caso de seguro de vida em que não se designou o beneficiário. ${ }^{360}$

Em caso de seguro de vida, até a ocorrência do evento morte, o terceiro tem apenas direito expectativo, só após a morte que passa a ter pretensão e pode exigir a prestação do promitente. Se ainda não há nenhum direito, ainda que expectativo, podem os figurantes do contrato modificá-lo, caso haja reserva no contrato permitindo isso. $^{361}$

\subsubsection{Gestão de negócios}

Prosseguindo na discussão sobre a natureza jurídica do contrato de tratamento médico, tendo por paciente um menor, parte da doutrina sustenta ser plausível aplicar as regras da gestão de negócios. ${ }^{362}$ Segundo esses doutrinadores, a declaração de vontade dos absolutamente incapazes é ineficaz, assim como a declaração dos relativamente incapazes, se não houver a concordância de seus

${ }^{360}$ PONTES DE MIRANDA, Francisco Cavalcanti. Tratado de Direito Privado: Parte Especial - Direito das Obrigações. t. 26. Op. Cit., p. 242. ${ }^{361}$ Ibidem, p. 243.

362 DEUTSCH, Erwin; SPICKHOFF, Andreas. Medizinrecht. Azrtrecht, Arzneimittelrecht, Medizinproduktrecht und Transfusionsrecht. Op. Cit., p. 95; UHLENBRUCK, Wilhelm; LAUFS, Adlf. $\$ 40$ Die Parteien des Arztrechts, Rn. 8. In LAUFS, Adolf; UHLENBRUCK, Wilhelm (coord.), Handbuch des Arztrechts. Op. Cit, pp. 392-393. 
representantes legais. O contrato firmado entre os pais e o médico assemelha-se, por isso, a uma gestão de negócios.

ORLANDO GOMES ${ }^{363}$ inicia seu estudo sobre a gestão de negócios pontuando que se trata de figura que parte da noção romana, já superada, de quase-contrato. Este, ${ }^{364}$ de acordo com o que consta nas Institutas, ${ }^{365}$ assim é denominado por não haver, no caso, o consenso entre as partes, peculiar aos contratos, nem a violação da lei, característica dos delitos. ${ }^{366}$ Essa definição é complementada, afirmando-se que são recordados, nas Institutas, os vínculos que já no direito clássico eram fontes geradoras de obrigação, baseados não numa conventio entre as partes (e, portanto, não classificáveis entre os contratos), mas em um ato unilateral. A

${ }^{363}$ Obrigações. Op. Cit., p. 289.

364 NERY JR, Nelson; NERY, Rosa Maria de Andrade. Código Civil Comentado. Op. Cit., p. 1665. Ao tratar da gestão de negócios no direito romano e sua configuração atual, discorrem os autores: "A figura da gestão de negócios alheios sem outorga, no dizer claríssimo de Labeão, consubstancia atitude realizada sem palavras (gestum rem significare sine verbis factam Ulp. $11 a d$ ed. D. 50, 16, 19). Em matéria de gestão de negócios forma-se sociedade ex lege quando os interesses do gestor e do gerido são comuns. $\mathrm{Ou}$ seja: quando alguém gere interesses alheios que apresentam afinidade temática, de conteúdo, com interesses próprios, quer pela natureza deles, quer pela finalidade, quer ainda pela maneira como estejam organizados, considerase sócio do titular dos interesses geridos. Constitui-se, desta maneira, relação jurídica de sociedade sem contrato de sociedade, por força de lei, organizandose, plurilateralmente, a atividade em torno do fim".

${ }^{365}$ I. 3,27

${ }^{366}$ WALD, Arnoldo. Direito Civil: Direito das Obrigações e Teoria Geral dos Contratos. Op. Cit., p. 93. 
esse juntam-se outros vínculos, também estes provenientes de um ato unilateral, aos quais os pós-clássicos atribuíram a eficácia de surgir uma obrigação (é o caso da gestão de negócios). ${ }^{367}$

Abordando a caracterização da gestão de negócios no direito romano (negotiorum gestio), observa-se que para sua ocorrência, ao menos nos direitos pós-clássico e justinianeu, deveriam ser preenchidos os requisitos que a seguir serão descritos. $\mathrm{O}$ primeiro deles (A) era a gestão de negócio alheio (elemento objetivo), podendo consistir em simples atos, ou mesmo negócios jurídicos. $\mathrm{O}$ negócio ser alheio implicava em o instituto não ficar caracterizado na gestão de negócio próprio, ainda que com proveito de terceiro, em caso, por exemplo, de serem o gestor e o terceiro sócios ou coerdeiros. Outro requisito (B) era o animus negotia aliena gerendi (elemento subjetivo), bastava que o gestor quisesse, com sua atividade, resultar em proveito para o terceiro dono do negócio, ainda que sequer o conhecesse. $\mathrm{O}$ terceiro requisito (C) era $\mathrm{o}$ negotium utiliter coeptum, a atividade do gestor deveria trazer alguma utilidade ao dono do negócio (dominus negotii), aferida objetivamente por meio da análise de a gestão ter corrido igual a que um indivíduo normal, na mesma situação, realizaria em proveito próprio. O quarto e último requisito (D) seria a espontaneidade da ${ }^{367}$ VOLTERRA, Edoardo. Instituzioni di Diritto Privato Romano. Op. Cit., p. 543. 
gestão, não poderia ser realizada em cumprimento de uma obrigação, como seria no caso de existência de um mandato expresso ou tácito. ${ }^{368}$

Uma abordagem muito interessante é trazida por SERPA LOPES ${ }^{369}$ para quem a gestão de negócios representa o choque entre dois conceitos, um individual, proibitivo da interferência de alguém na esfera jurídica de outrem e, outro social que justificaria, em determinadas circunstâncias, uma intervenção. A problemática é justamente saber até que ponto a pessoa tem sua esfera jurídica livre de interferências externas, bem como os limites para uma intromissão ser considerada lícita. PONTES DE MIRANDA ${ }^{370}$ enfrenta esse choque de conceito pontuando que os limites da gestão, em regra, são aqueles dados pela vontade do dono do negócio, havendo uma forte responsabilização do gestor por gerir negócio contra a vontade manifesta ou presumível do dono, ao que se depreende do art. 1332 do Código Civil de 1916, com correspondência legislativa no art. 862 do atual Código Civil. ${ }^{371}$

${ }^{368}$ MOREIRA ALVES, José Carlos. Direito Romano. Op. Cit., pp. 571-572.

${ }^{369}$ Curso de direito civil. v. 5.3 ed. Rio de Janeiro: Freitas Bastos, 1961. p. 20.

${ }^{370}$ Tratado de Direito Privado: Parte Especial - Direito das Obrigações. t. 43. 3 ed. Rio de Janeiro: Borsoi, 1971. p. 197.

${ }^{371}$ Art. 862. Se a gestão foi iniciada contra a vontade manifesta ou presumível do interessado, responderá o gestor até pelos casos fortuitos, não provando que teriam sobrevindo, ainda quando se houvesse abatido. 


\subsubsection{Caracterização}

Os apontamentos quanto à caracterização do instituto da gestão de negócios no direito romano são importantes, visando-se à problemática que persiste nos dias atuais quanto a alguns de seus elementos, que são essenciais para sua ocorrência. Conforme a doutrina aponta na definição do instituto atualmente, nas palavras de WALD ${ }^{372}$ a gestão de negócios ocorre quando (...) alguém administra, sem procuração, os bens alheios, surgindo obrigações entre o proprietário dos bens administrados e o gestor de negócios. Aquele que é o sujeito ativo da gestão é chamado de gestor de negócios, enquanto aquele que tem os negócios geridos é chamado de dono (ou a já referida expressão, ainda hoje usada por alguns autores, dominus negotti ou ainda, simplesmente dominus).

Para N. NERY JR e R. NERY ${ }^{373}$ a gestão de negócios tem natureza jurídica de negócio jurídico unilateral. PONTES DE MIRANDA $^{374}$ traz opinião diversa quanto à natureza jurídica, não aceitando que seja enquadrada como um negócio jurídico, sendo

372 Direito Civil: Direito das Obrigações e Teoria Geral dos Contratos. Op. Cit., p. 93.

${ }^{373}$ Código Civil Comentado. Op. Cit., p. 1660.

374 Tratado de Direito Privado: Parte Especial - Direito das Obrigações. t. 43. Op. Cit., p. 178 
para ele um ato jurídico stricto sensu, ${ }^{375}$ ao menos em uma situação de não contrariedade à vontade do dono. Se a pessoa gere contra a vontade manifesta ou presumível do dominus negotii (dono do negócio), haveria ato-fato ilícito. Há que ser observado também a gestão de negócios ser "sem procuração", se há relação jurídica que imponha ou permita ao gestor gerir os negócios de alguém, essa situação não é a figura jurídica da gestão de negócios. Há um caráter de negócio de representação, os efeitos da gestão vinculam ativa e passivamente o dono, a pessoa em cujo nome os atos de gestão são praticados.

Assim, para que fique configurada a gestão de negócios, em síntese, é necessário: (I) que o negócio seja alheio, isto é, que envolva o patrimônio de outra pessoa que não o do gestor $;^{376}$ (II) que o gestor exerça a atividade de gestão conforme os interesses do dono, que sua gerência lhe seja útil; por fim, (III) que o gestor tenha

${ }^{375}$ Também é a opinião de Marcos Bernardes de Mello que a gestão de negócio é ato jurídico stricto sensu, classificada por este como um ato jurídico stricto sensu compósito, formado pela junção de uma manifestação de vontade relevante e um ato de efetiva gestão. Nesse sentido: BERNARDES DE MELLO, Marcos. Teoria do Fato Jurídico: Plano da Existência. 14 ed. São Paulo: Saraiva, 2007. pp. 164-165.

${ }^{376}$ A palavra negócio não é usada aqui no sentido técnico-jurídico, mas no amplo sentido de interesse ou assunto. Nesse sentido, ALMEIDA COSTA, Mário Júlio. Direito das Obrigações. 7 ed. Coimbra: Almedina, 1999. p. 409. 
a intenção de gerir de forma útil ao dono do negócio, é necessário o animus negotia aliena geranti. ${ }^{377}$

Esse último requisito, apontado como necessário por ORLANDO GOMES, é controverso na doutrina, havendo aqueles que pensam ser a vontade do gestor irrelevante para a eficácia jurídica do ato de gestão. ${ }^{378}$ Conforme é perceptível, todos os atuais requisitos para a configuração da gestão de negócios são os mesmo apontados supra como aqueles presentes no direito romano. $\mathrm{O}$ requisito romano da espontaneidade da gestão, ainda não referido como atual, é posteriormente explicitado por ORLANDO GOMES, ${ }^{379}$ no sentido de que o gestor não pode estar autorizado a agir nem obrigado a administrar os interesses do dominus, ou seja, não pode ter autorização representativa e nem a administração dos bens por força de uma obrigação, como é o caso do tutor. Conjuntamente com a espontaneidade da gestão o autor sublinha o

377 GOMES, Orlando. Obrigações. Op. Cit., p. 290. Pontes de Miranda considera a volição do gestor muito importante, defendendo o requisito do animus negotia aliena gerendi, pois, nas palavras do autor "inicia-se situação jurídica que independe da vontade superveniente do gestor, vinculo, por lei, à continuação; se não houver aquele animus, falta o elemento subjetivo, que livraria o ato de ser ato ilício absoluto". PONTES DE MIRANDA, Francisco Cavalcanti. Tratado de Direito Privado: Parte Especial - Direito das Obrigações. t. 43. Op. Cit., p. 203.

378 TEPEDINO, Gustavo; MORAES, Maria Celina Bodin de; BARBOZA, Heloisa Helena. Código Civil Interpretado conforme a Constituição da República. t. 2. Op. Cit., pp. 709-711.

${ }^{379}$ GOMES, Orlando. Obrigações. Op. Cit., pp. 290-291. 
propósito de obrigar, de modo que a gestão não ficaria configurada por mero ato de liberalidade do gestor, de certa forma redundando no requisito (III). Tais são os requisitos, em sua visão, para a configuração do contrato de gestão (lembrando que é controversa a natureza jurídica da gestão de negócios, conforme observado no parágrafo anterior, entendendo ORLANDO GOMES que a gestão de negócios é contrato). Por fim, o autor ainda coloca como requisito o desconhecimento do dominus da gestão do negócio, porque caso tenha conhecimento, trata-se de mandato tácito, desconfigurando o instituto, conforme já apontado.

Como já dito, não há consenso quanto aos requisitos necessários para a caracterização da gestão de negócios. CAIO MARIO ${ }^{380}$ aponta os mesmos requisitos que ORLANDO GOMES, ainda que nada diga quanto ao propósito de obrigar e ao desconhecimento do dominus da gestão do negócio, inserindo um requisito diverso de limitar a ação do gestor a atos de natureza patrimonial, dado que, para o autor, atos de outra natureza exigiriam sempre a outorga de poderes.

Esta também é a opinião de ALMEIDA COSTA, ${ }^{381}$ para quem o negócio a ser gerido tem que ser suscetível de ser realizado por

380 PEREIRA, Caio Mario da Silva. Instituições de Direito Civil. v. 3. Op. Cit., p. 386

${ }^{381}$ Direito das Obrigações. Op. Cit., p. 409. 
pessoa diversa do dono ou titular, além da não contrariedade à lei, à ordem pública e aos bons costumes. Assim, ficariam excluídos de serem praticados pelo gestor atos de natureza pessoal, não patrimonial, como a adoção, o divórcio, o testamento e etc.

Outra opinião ainda é a de PONTES DE MIRANDA, ${ }^{382}$ para quem é possível ao gestor praticar atos positivos ou negativos não apenas patrimoniais, mas também atos de afastamento de perigo à vida ou à saúde do dono do negócio, sua família e seus animais. $\mathrm{O}$ autor cita como exemplo a cooperação para a extinção de um incêndio ou a ajuda para evitar as consequências de um inundação como atos passíveis de serem configurados como gestão de negócios.

\subsubsection{Deveres e responsabilização das partes}

No Código Civil de 1916 a gestão de negócios era tratada como contrato, passando no atual Código Civil a constar no Título referente aos Atos Unilaterais, localização mais apropriada na visão de CAIO MARIO. ${ }^{383}$

382 Tratado de Direito Privado: Parte Especial - Direito das Obrigações. t. 43. Op. Cit., p. 179.

${ }^{383}$ Instituições de Direito Civil. v. 3. Op. Cit., p. 385. O autor considera que a gestão de negócios não pode ser contrato porque faltaria o acordo prévio de vontades. 
Tal figura, bem como seus pressupostos e efeitos, estão disciplinados pelos arts. 861 a 875 do Código Civil de 2002. Quanto aos deveres do gestor, há o de atuar de acordo com o interesse e vontade real ou presumível do dono do negócio, apreciados segundo critérios objetivos. $^{384}$

Outro é o dever de avisar ao dono do negócio, tão logo seja possível, que assumiu a gestão, conforme dispõe o art. $864 .{ }^{385}$ Pelo já exposto, a visão de ORLANDO GOMES de que é requisito da gestão o desconhecimento do dominus da gestão de negócios não parece guardar coerência com o texto legal, ainda que o próprio autor reconheça como dever do gestor comunicar ao dono do negócio a gestão que assumiu. ${ }^{386}$

Outros deveres são os de continuar a gestão começada e levá-la a termo em caso de perigo, além de prestar contas da gestão.

Quanto ao dever de continuar a gestão, PONTES DE MIRANDA $^{387}$ pontua que a vinculação entre o gestor e o dominus é ex lege, a vontade do gestor só é considerada no momento em que

${ }^{384}$ ALMEIDA COSTA, Mário Júlio. Direito das Obrigações. Op. Cit., p. 414.

${ }^{385}$ Art. 864. Tanto quanto possa, comunicará o gestor ao dono do negócio a gestão que assumiu, aguardando-lhe a resposta, se da espera resultar perigo.

${ }_{386}$ GOMES, Orlando. Obrigações. Op. Cit., p. 291.

${ }^{387}$ Tratado de Direito Privado: Parte Especial - Direito das Obrigações. t. 43. Op. Cit., p. 204. 
começa a gerir, exigindo a lei a continuidade, desde que continuem presentes os requisitos já elencados.

Por fim, o dever de prestar contas da gestão se subdivide em dever de ressarcir todos os danos eventualmente da gestão resultantes e dever de restituir qualquer proveito retirado da gestão (lucros). Antes de abordar os deveres do dominus, cumpre entender porque este fica obrigado perante as obrigações contraídos pelo gestor.

Conforme exposto no parágrafo anterior, a vinculação entre as partes é ex lege, ou seja, não é decorrência de nenhuma declaração de vontade do dominus. A posição de obrigado decorre, conforme N. NERY JR e R. NERY ${ }^{388}$, (...) da circunstância mesma do conteúdo da obra do gestor, toda ela realizada à guisa de benefício do patrimônio e da pessoa do dono do negócio.

Observando-se propriamente os deveres do dominus, nota-se que consistem em: dever de cumprir com todas as obrigações contraídas em seu nome e dever de reembolsar o gestor as despesas necessárias ou úteis que este último houver feito. ${ }^{389} \mathrm{O}$ negócio ser

\footnotetext{
${ }^{388}$ Código Civil Comentado. Op. Cit., p. 1662.

389 Conforme dispõe o art. 869: "Se o negócio for utilmente administrado, cumprirá ao dono as obrigações contraídas em seu nome, reembolsando ao gestor as despesas necessárias ou úteis que houver feito, com os juros legais, desde o desembolso, respondendo ainda pelos prejuízos que este houver sofrido por causa da gestão.
} 
regido utilmente é questão de fato, ficando o ônus da prova para o gestor. Nas palavras de PONTES DE MIRANDA, ${ }^{390}$ para observar se a gestão foi útil é preciso saber (...) se foi proveitosa, o que acrescentou na esfera jurídica do dono do negócio, ou pelo menos o que evitou que se perdesse, ou diminuísse. A utilidade da gestão é o que vincula o dono do negócio a cumprir as obrigações contraídas em seu nome.

$\mathrm{O}$ art. 869 do Código Civil, que trata dos deveres do dominus, em seu parágrafo segundo, dispõe que vigora o disposto nesse artigo, ainda quando o gestor, em erro quanto ao dono do negócio, der a outra pessoa as contas da gestão. É interessante notar que tal artigo implica em um dever de lealdade do gestor, a lei não lhe impõe nenhuma restrição de direito ainda que erre quanto ao dono do negócio. A boa-fé objetiva e o seu decorrente dever de lealdade aqui presente por si só já bastam para o reconhecimento do dever de prestar contas ao dono do negócio. ${ }^{391}$

Há um tratamento legislativo muito claro quanto à responsabilidade do gestor, o qual responde até por caso fortuito quando realiza operações arriscadas; quando inicia a gestão contra a vontade manifesta ou presumível do dono e quando preterir ${ }^{390}$ Tratado de Direito Privado: Parte Especial - Direito das Obrigações. t. 43. Op. Cit., p. 221.

${ }^{391}$ NERY JR., Nelson; NERY, Rosa Maria de Andrade. Código Civil Comentado. Op. Cit., p. 1663. 
interesses do dono do negócio para privilegiar interesses próprios. ${ }^{392}$ Nesse último caso, se o gestor tem interesses contrários ou concorrentes com os do dono do negócio deve ter muito cuidado para não colocar seus interesse pessoais à frente. Nada impede, porém, que seja o maior credor do dominus, por exemplo, e a útil gestão também lhe aproveite. ${ }^{393}$

Além dos deveres já expostos, o gestor é obrigado a indenizar o dominus (dono) em diversas hipóteses, a começar pela (a) quando não dirigir o negócio segundo o interesse e vontade presumível do dono e (b) não empenhar toda a diligência habitual na administração do negócio. Se a gestão ocorre com a diligência habitual do gestor e conforme os interesses e a vontade presumível do dono, o mau êxito desta não torna indenizável o dano. ${ }^{394}$ Também são hipóteses indenizáveis: (c) interromper a gestão, sabendo que, da interrupção, resultarão danos ao dono; (d) se fizer substituir e o substituto

${ }^{392}$ Art. 868. O gestor responde pelo caso fortuito quando fizer operações arriscadas, ainda que o dono costumasse fazê-las, ou quando preterir interesse deste em proveito de interesses seus.

Parágrafo único. Querendo o dono aproveitar-se da gestão, será obrigado a indenizar o gestor das despesas necessárias, que tiver feito, e dos prejuízos, que por motivo da gestão, houver sofrido.

393 PONTES DE MIRANDA, Francisco Cavalcanti. Tratado de Direito Privado: Parte Especial - Direito das Obrigações. t. 43. Op. Cit., p. 209. ${ }^{394}$ Ibidem, p. 222. 
cometer faltas, ainda que seja pessoa idônea; (e) se os prejuízos da gestão excederem seu proveito. ${ }^{395}$

Conforme fica evidente, a responsabilidade do gestor é ampla e rigorosa, baseada, segundo CAIO MARIO, ${ }^{396}$ na ideia de que ninguém é obrigado a iniciar gestão de negócios alheios e, em assim procedendo, deve agir com a máxima diligência para que não cause prejuízo por sua intromissão na esfera jurídica do outro.

\subsubsection{Ratificação}

A ratificação da gestão de negócios pelo dominus negotti já era conhecida no direito romano, sendo debatido se configuraria um mandato posterior. A resposta aqui adotada é negativa, pois haveria mandato apenas na situação de o gestor precisar cobrar o dominus negotti por eventuais despesas realizadas na gestão, através da chamada actio mandati contraria. ${ }^{397}$ Atualmente, o dominus pode, por meio de uma declaração unilateral de vontade e após ocorridos os atos de gestão, dar autorização representativa ao gestor. Tal declaração consiste em ratificação, que retroage ao dia do começo dos atos de gestão e produz todos os efeitos da outorga de poderes,

${ }^{395}$ GOMES, Orlando. Obrigações. Op. Cit., p. 293.

${ }^{396}$ Instituições de Direito Civil. v. 3. Op. Cit., p. 388.

${ }^{397}$ MOREIRA ALVES, José Carlos. Direito Romano. Op. Cit., p. 572. 
ficando confirmado que o gestor obedeceu à vontade do dono. ${ }^{398} \mathrm{~A}$ natureza jurídica da ratificação é apontada pela doutrina como de negócio jurídico unilateral que tem em sua essência o caráter irrevogável e retroativo. ${ }^{399}$

O contrário, a desaprovação dos atos de gestão, é possível quando estes são contra o interesse do dono. Porém, há algumas exceções, algumas situações em que não é possível a desaprovação, como quando a gestão se proponha a acudir prejuízos iminentes e quando redunde em proveito do dono do negócio, conforme dispõe o art. 874 do Código Civil.

Com relação aos elementos integrantes da ratificação, observase que ela consiste em elemento pessoal e elementos reais e formais. ${ }^{400} \mathrm{O}$ pessoal seria a declaração de vontade receptícia, pois destina a produzir efeitos perante terceiros com os quais o gestor estabeleceu relações jurídicas através de seus atos de gestão. Os reais seriam as limitações quanto aos atos e gestão que podem ser objeto de ratificação, porém, apenas aqueles que podem ser objeto de representação, ficando excluídos o testamento e a emancipação, por exemplo. Por fim, quanto à forma, seria livre por não haver a lei

398 PONTES DE MIRANDA, Francisco Cavalcanti. Tratado de Direito Privado: Parte Especial - Direito das Obrigações. t. 43. Op. Cit., p. 201. ${ }^{399}$ SERPA LOPES, Miguel Maria de. Curso de direito civil. v. 5. Op. Cit., p. 55 .

${ }^{400}$ Ibidem, p. 57. 
imposto qualquer restrição, desde que a forma de manifestação de vontade escolhida seja suficiente para indicar o propósito do dominus de ratificar os atos de gestão.

Importante observar que a ratificação pura e simples produzir todos os efeitos do mandato, conforme é o texto legal, ${ }^{401}$ não significa que a gestão de negócios passa a ser um mandato, pois não se trata de uma questão que está no plano da existência do fato jurídico, mas sim, é atinente ao plano da eficácia, havendo retroatividade com a característica de coincidência com a eficácia do mandato. $^{402}$

\subsubsection{Figuras afins e a morte de uma das partes}

Pelo que se depreende do exposto, a gestão de negócios não se confunde com o instituto jurídico do contrato de mandato, dado que aquela é realizada sem outorga de poderes, diferentemente deste. Também não se confunde com a estipulação em favor de terceiro, pois, ainda que haja em ambas as figuras jurídicas a aquisição de direitos por terceiros sem a intervenção destes, a estruturação jurídica de ambas em muito se diferencia.

${ }^{401}$ Art. 873. A ratificação pura e simples do dono do negócio retroage ao dia do começo da gestão, e produz todos os efeitos do mandato.

${ }^{402}$ PONTES DE MIRANDA, Francisco Cavalcanti. Tratado de Direito Privado: Parte Especial - Direito das Obrigações. t. 43. Op. Cit., p. 215. 
O promitente pode revogar ou modificar a estipulação em determinadas situações, algo não possível ao gestor, responsável pelos prejuízos que causar com a injustificada interrupção dos atos de gestão. ${ }^{403} \mathrm{Na}$ estipulação em favor de terceiros, além disso, pode o beneficiário aceitar ou recursar o que fora estipulado, algo que também não é possível ao dominus negotti se a gestão lhe tenha sido útil. $^{404}$

A morte do gestor faz cessar a gestão de negócios, salvo se o gestor atuava como profissional, ${ }^{405}$ havendo sucessão na gestão. Quanto à este último ponto, SERPA LOPES ${ }^{406}$ afirma que os herdeiros devem avisar ao dono do negócio do falecimento do gestor, prestando contas se a gestão não estiver terminada ou se o gestor não o fez antes de morrer. Não têm os herdeiros, e parece claro pela própria configuração do instituto jurídico da gestão de negócios, a obrigação em prosseguir com a gestão caso não tenham

${ }^{403}$ Nas palavras de PEREIRA, Caio Mario da Silva. Instituições de Direito Civil. v. 3. Op. Cit., p. 387: "Esta obrigação de continuar a gestão começada tem por objetivo evitar que o zelo intermitente do gestor e a sua falta de perseverança causem dano ao dominus".

404 ALMEIDA COSTA, Mário Júlio. Direito das Obrigações. Op. Cit., p. 413.

${ }^{405}$ Atuação como profissional ocorre quando o gestor assume a gestão detendo conhecimentos técnicos para a prática dos atos, como é o caso do gestor médico, advogado, fabricante de ferros para pontes, eletricista, etc. Nesse sentido: PONTES DE MIRANDA, Francisco Cavalcanti. Tratado de Direito Privado: Parte Especial - Direito das Obrigações. t. 43. Op. Cit., p. 224.

${ }^{406}$ Curso de direito civil. v. 5. Op. Cit., pp. 50-51. 
interesse, dado o caráter voluntário que respalda os atos do gestor. A morte do dono no negócio não faz cessar a gestão, assim como não tem qualquer repercussão na gestão a sua interdição, com a exceção de perder a titularidade do bem ou se for nomeado representante legal para gerir o negócio. A morte do gestor não encerra a gestão e é justamente uma característica apontada pela doutrina como critério de diferenciação entre a gestão de negócios e o mandato, dado que este último é pautado por uma relação de confiança em que a morte do mandante põe termo final ao mandato, ${ }^{407}$ não há essa relação de confiança na gestão de negócios. Outras forma de encerrar a gestão é o dono ou terceiro com outorga assumir a gestão. ${ }^{408}$

\subsubsection{Relações contratuais de fato}

Quanto às relações contratuais de fato, não se poderia dizer que elas efetivamente integram uma das posições da doutrina na caracterização da natureza jurídica dos contratos de tratamento médicos de menores. Isso porque, as referências encontradas sempre são no sentido de crítica a essa categoria, de forma a afastá-la como uma das formas possíveis desses contratos.

${ }^{407}$ SERPA LOPES, Miguel Maria de. Curso de direito civil. v. 5. Op. Cit., p. 50.

${ }^{408}$ PONTES DE MIRANDA, Francisco Cavalcanti. Tratado de Direito Privado: Parte Especial - Direito das Obrigações. t. 43. Op. Cit., p. 225. 
Nesse sentido, afirmam DEUTSCH e SPICKHOFF ${ }^{409}$ que se deve rechaçar o instituto jurídico dos contratos de fato, que não seria adequado à natureza da prestação médica. Em primeiro lugar, porque não se deve reconhecer a categoria dos contratos de fato em si mesma; em segundo, porque ainda que se aceitasse essa categoria, ela se limitaria ao âmbito dos negócios de massa, o que não se coaduna com a relação médico - paciente.

Entretanto, mesmo com esse sentido negativo dos contatos de fato em relação aos contratos de tratamento médicos de menores, optou-se por trazer à baila algumas considerações a respeito, pois a eles a doutrina faz alguma referência, ainda que para não admitir sua natureza jurídica para os contratos de tratamento médico em menores.

Como resposta à circulação massiva de bens que se observa na modernidade, surge a teoria das relações contratuais de fato. A doutrina alemã dos séculos XIX e XX, baseada no que já discorreram os pandectistas, entendia que o conceito de negócio

${ }^{409}$ Medizinrecht. Azrtrecht, Arzneimittelrecht, Medizinproduktrecht und Transfusionsrecht. Op. Cit., p. 95. Concorda com essa posição, GLEIXNEREBERLE, Elisabeth. Die Einwilligung in die medizinische Behandlung Minderjähriger. Op. Cit., p. 376. 
jurídico então existente não era capaz de comportar os fenômenos de direito contratual que se observava à época. ${ }^{410}$

Faz-se necessário, ao principiar o tema, a busca de um conceito de negócio jurídico para que se possa afirmar que este é insuficiente para ser aplicado aos fenômenos que se observa no direito contratual. Para TRABUCCHI, ${ }^{411}$ negócio jurídico é a manifestação de vontade voltada a um fim prático o qual consiste na constituição, modificação ou extinção de uma determinada situação jurídica passível de tutela do ordenamento jurídico vigente. De maneira um tanto quanto distinta, ORLANDO GOMES ${ }^{412}$ o define como toda declaração de vontade destinada a produzir efeitos jurídicos correspondentes ao intento prático do declarante, se reconhecido e garantido por lei. ${ }^{413}$ Note-se que, embora sejam díspares em alguns termos, as definições trazidas têm a vontade das partes como elemento central do conceito de negócio jurídico.

410 HIRATA, Alessandro. Relações contratuais fáticas (faktische Vertragsverhältnisse). Tese. São Paulo: Universidade de São Paulo, 2011. pp. 2-3.

${ }^{411}$ Istituzioni di diritto civile. Op. Cit., p. 98.

${ }^{412}$ Introdução ao direito civil. Op. Cit., p. 213.

${ }^{413}$ Também nesse sentido, SERPA LOPES, Miguel Maria de. Curso de direito civil. v. 1.3 ed. Rio de Janeiro: Freitas Bastos, 1960. p. 404 define negócio jurídico como um negócio de declaração de vontade por força do qual se declara querer a produção de um determinado efeito jurídico, incumbindo à ordem jurídica fazer com que este efeito jurídico se realize, por ser ele querido pelo autor. 
Segundo ANTUNES VARELA, ${ }^{414}$ a doutrina a que se referiu supra traz o acordo de vontades entre duas partes como o elemento essencial da relação contratual. No entanto, há algumas situações jurídicas que não apresentam como base essa declaração de vontade dos contraentes, ainda que a elas sejam aplicadas as normas do regime contratual. Ou seja, defende-se a existência de relações contratuais e obrigacionais que não derivam da declaração de vontade do negócio jurídico, ${ }^{415}$ uma vez que existe a obrigação da parte, não obstante falte ou venha a faltar a vontade ou a consciência da declaração e, até mesmo, a vontade de ação. ${ }^{416}$ Assim, demostram-se as relações contratuais de fato, as quais não nascem do negócio jurídico, mas de puras situações de fato.

Segundo MESSINEO, ${ }^{417}$ nas hipóteses de relações contratuais de fato (ou, nos termos usados pelo autor, nos contratti di fato ou irregolari), os efeitos que são determinados, por uma via excepcional, demonstram que o ordenamento jurídico disciplina situações contratuais, que a rigor parece que deve ignorar. São relações às quais se pode classificar como praeter legem, uma vez

${ }^{414}$ Das obrigações em geral. v. 1. Op. Cit., p. 220.

${ }^{415}$ EHRLICH, Eugen. Die stillschweigende Willenserklärung. Berlin, 1983. p. 160.

416 MOTA PINTO, Carlos Alberto da. Cessão do contrato. São Paulo: Saraiva, 1985. p. 215, nt. 37.

${ }^{417}$ Verbete Contratto irregolare (di fatto) e ad effetto irregolare. Enciclopedia del diritto. v. 10. Milano: Giuffrè, 1962. p. 111. 
que não se enquadram nos requisitos prescritos pela lei. No entanto, não é por esse motivo que escapam da disciplina legal, uma vez que essas relações, não obstante a invalidade, são, em regra, executadas pelas partes, dando origem aos efeitos jurídicos logo em sequência.

Nesse sentido, HAUPT ${ }^{418}$ apresenta a teoria das relações contratuais de fato, as quais, segundo ele, poderiam surgir independentemente do acordo de vontades das partes contratantes, mas através de uma simples efetivação de elementos fáticos, o que afasta a antiga teoria que defendia o acordo de vontades como elemento central da relação contratual. É uma particularidade da circulação massiva de bens, as quais o ordenamento jurídico não pode ignorar e, desse modo, deve aplicar as regras jurídicas dos contratos, ainda que esteja ausente o elemento acordo de vontades, característico do direito contratual tradicional. ${ }^{419} / 420$

Note-se, no entanto, que, em sentido oposto há quem defenda que não é necessário abrir mão do conceito de declaração de vontade

418 Über faktischen Vertragsverhältnisse. In Festschrift der Leipziger Juristenfakultät für Dr. Heinrich Siber zum 10. April 1940 II. Leipzig, 1943. pp. 5 e ss.

419 HIRATA, Alessandro. Relações contratuais fáticas (faktische Vertragsverhältnisse). Op. Cit., pp. 3-4.

${ }^{420}$ Em sentido oposto, MESSINEO, Francesco.Verbete Contratto irregolare (di fatto) e ad effetto irregolare. Op. Cit., pp. 111-112 defende que não se deve aplicar a disciplina idêntica à do contrato correspondente. 
ou acordo negocial para se explicar a ideia de relação contratual de fato. $^{421}$

Posteriormente, LARENZ ${ }^{422}$ aprimorou o conceito de Haupt ao criar a ideia de comportamento socialmente típico. Note-se, segundo defende ALMEIDA COSTA, ${ }^{423}$ que a doutrina não é pacífica em utilizar a expressão faktische Vertragsverhältnisse, muitos, como Larenz, preferem a expressão sozialtypische Verhalten, ou seja, comportamento social típico. Isso porque esta não induz a uma conclusão equivocada de que se trata de processos extrajurídicos e, simultaneamente, salienta o aspecto de atribuição de que a relevância jurídica a tais situações resulta de uma valoração objetiva e não propriamente da vontade negocial.

$\mathrm{Na}$ doutrina brasileira, COUTO E SILVA ${ }^{424}$ dá o nome de atos existenciais ao chamado comportamento social típico. Segundo o autor, são tipos existentes à margem dos tipos legais, denominados sociais em virtude de suas obras e práticas reiteradas, os quais ainda

421 Nesse sentido, ALARCÃO, Rui de. A confirmação dos negócios anuláveis. Coimbra: Atlântida, 1971, p. 82, nt. 111.

${ }^{422}$ Die Begründung von Schuldverhältnissen durch sozialtypisches Verhalten, 1956. Trad. port. de A. Hirata. O estabelecimento das relações obrigacionais por meio de comportamento social típico. Revista Direito GV. São Paulo: FGV. v. 3. n. 1, pp. 55-63, 2006.

${ }^{423}$ Direito das obrigações. 9 ed., Coimbra: Almedina, 2001. p. 201.

${ }^{424}$ A obrigação como processo. Op. Cit., pp. 77-78. 
não foram recebidos e regulados de forma convencional pelo ordenamento jurídico.

Para LARENZ, ${ }^{425}$ ao criar a expressão relações contratuais de fato, Haupt englobou nela três grupos de fatos típicos que são as relações contratuais fáticas "em virtude de contatos sociais", as "coletividades fáticas", e as chamadas "relações contratuais fáticas em virtude de uma obrigação de prestar social". As categorias englobadas pela expressão, apesar de distintas, apresentam a característica comum de que, não havendo um acordo negocial válido, as relações contratuais surgiam através de uma fatispécie social vinculante para os envolvidos que se realiza conforme a praxe cotidiana. Desse modo, critica Larenz, trata-se de uma reunião infeliz haja vista que são manifestações bem diversas.

A ideia de relações contratuais de fato se baseia, principalmente, na concepção de que na atual sociedade de massas, algumas condutas geram vínculos obrigacionais sem que, para tal, haja uma declaração de vontade, mas que derivam de ofertas e aceitações de fato. ${ }^{426} \mathrm{Ou}$ seja, em virtude de um significado social típico, bens e serviços de utilização massificada ocasionam comportamentos de seus usuários, os quais produzem as mesmas consequências jurídicas

${ }^{425}$ Die Begründung von Schuldverhältnissen durch sozialtypisches Verhalten. Op. Cit., p. 57.

${ }^{426}$ MENEZES CORDEIRO, António Manuel da Rocha e. Da boa fé no direito civil. v. 1. Coimbra: Almedina, 2007. p. 555. 
de uma atuação verdadeiramente negocial, mas são distintos desta. $^{427}$

As relações fáticas são promotoras de mudanças significativas na disciplina das fontes de obrigações. ${ }^{428}$ Isso porque as partes se vinculam por meio de seus comportamentos sociais típicos, segundo a terminologia de Larenz. ${ }^{429}$

Haupt parte do ponto de vista de que, na circulação massiva de bens, há uma oferta pública de uma prestação da qual qualquer pessoa que o desejar pode dela fazer uso. Porém, nessa situação não há uma conclusão prévia do contrato, ou, ainda, um acordo de forma expressa ou não acerca da prestação e de seu preço. Desse modo, havendo a prestação de um serviço mediante remuneração, espera-se que o usuário de tal serviço, de fato, seja obrigado a realizar a remuneração, ainda que, para tal, não tenha declarado sua vontade. $^{430}$

Passa-se, pois ao estudo dos três grupos de contratos de fato.

${ }^{427}$ ALMEIDA COSTA, Mário Júlio. Direito das obrigações, 2001. Op. Cit., p. 202.

${ }^{428}$ Essa alteração nas fontes nas obrigações pode ser observada, entre nós, em COUTO E SILVA, Clóvis Veríssimo do. A obrigação como processo. Op. Cit., p. 77, o qual classifica os atos existenciais como verdadeiras fontes de obrigações.

429 HIRATA, Alessandro. Relações contratuais fáticas (faktische Vertragsverhältnisse). Op. Cit., p. 5.

430 LARENZ, Karl. Die Begründung von Schuldverhältnissen durch sozialtypisches Verhalten. Op. Cit., p. 58. 
O primeiro grupo é aquele que nasce de meros contatos sociais (aus sozialem Kontakt), no qual HAUPT ${ }^{431}$ traz à baila alguns casos em que figura a culpa na conclusão do contrato. Nesse grupo, há o contrato sem o emprego da declaração de vontade, ou seja, a parte se vincula independentemente da celebração de um negócio jurídico, ou, até mesmo, antes desta. ${ }^{432}$

Por contato social, segundo MENEZES CORDEIRO, ${ }^{433}$ entendem-se aqueles relacionamentos nos quais há uma relação entre algumas pessoas que colaboram para determinados fins e, para tal, não se estabelece uma previsão contratual. Segundo LARENZ, ${ }^{434}$ nesse grupo se incluem os deveres de cuidado $e$ consideração "pré-contratuais". Nesta primeira categoria, também, encontra-se a figura da culpa in contrahendo. Segundo HIRATA, ${ }^{435}$ a expressão relações contratuais fáticas por meio de contato social é criticada pela doutrina, haja vista que se trata de um conceito

${ }^{431}$ Über faktische Vertragsverhältnisse. Op. Cit., pp. 9 e ss.

${ }^{432}$ Nesse sentido, MESSINEO, Francesco. Verbete Contratto irregolare (di fatto) e ad effetto irregolare, Op. Cit., p. 112; ALMEIDA COSTA, Mário Júlio, Direito das obrigações, 2001. Op. Cit., p. 204; ANTUNES VARELA, João de Matos. Das obrigações em geral. Op. Cit., pp. 220-221

${ }^{433}$ Da boa fé no direito civil. Op. Cit., p. 555.

434 Die Begründung von Schuldverhältnissen durch sozialtypisches Verhalten. Op. Cit., p. 57.

${ }^{435}$ Relações contratuais fáticas (faktische Vertragsverhältnisse). Op. Cit., p. 36, nt. 126. 
bastante vago para que seja usado de modo a indicar uma determinada categoria de relações jurídicas.

No segundo grupo, o das coletividades fáticas, há situações em que o elemento constitutivo encontra-se na inserção em uma relação de comunhão, ${ }^{436}$ ou seja, postula-se a inclusão de um determinado sujeito numa situação comunitária. ${ }^{437}$ Nessa categoria, inserem-se a sociedade de fato e o contrato de trabalho de fato. Nestes casos, a relação se estabelece através de uma prestação de fato, ainda que os contratos sejam nulos desde sua origem. ${ }^{438 / 439}$

Por fim, há o grupo das relações contratuais fáticas em virtude de uma obrigação de prestação social, as quais se fundam, como se pode depreender da própria denominação, em uma relação social. ${ }^{440}$ Para ANTUNES VARELA, ${ }^{441}$ trata-se da categoria mais importante

${ }^{436}$ MESSINEO, Francesco. Verbete Contratto irregolare (di fatto) e ad effetto irregolare, Op. Cit., p. 112.

437 MENEZES CORDEIRO, António Manuel da Rocha e. Da boa fé no direito civil. Op. Cit., p. 556; HIRATA, Alessandro. Relações contratuais fáticas (faktische Vertragsverhältnisse). Op. Cit., p. 39.

438 LARENZ, Karl. Die Begründung von Schuldverhältnissen durch sozialtypisches Verhalten. Op. Cit., p. 57; Relações contratuais fáticas (faktische Vertragsverhältnisse). Op. Cit., p. 39; AZEVEDO, Antônio Junqueira de. Estudos e pareceres de direito privado. São Paulo: Saraiva, 2004. p. 30.

${ }^{439}$ Note-se, porém, que ANTUNES VARELA. Das obrigações em geral. Op. Cit., p. 221 não fala em nulidade, mas em ineficácia dos referidos contratos.

${ }^{440}$ MESSINEO, Francesco. Verbete Contratto irregolare (di fatto) e ad effetto irregolare, Op. Cit., p. 112.

${ }^{441}$ Das obrigações em geral. Op. Cit., p. 221. 
dentre as consideradas, haja vista que sua abrangência alcança casos nos quais se observa atos reveladores da vontade de negociar, mas que não se enquadram nos moldes do tradicional mutuo consenso. Nesse sentido, também HIRATA ${ }^{442}$ entende que essa categoria é aquela que fundamenta toda a teoria das relações contratuais de fato.

Nesta categoria, segundo HIRATA, ${ }^{443}$ encontram-se os negócios de economia de massa ${ }^{444}$ e as prestações de subsistência social. Caso exemplificativo dessa categoria é a utilização de transportes públicos, como ônibus, trens, bondes, dentre outros. São casos em que não há uma declaração de vontade expressa do usuário do serviço, propriamente dita. A relação jurídica configura-se com o próprio ato de se adentrar no meio de transporte. Nesse campo, as partes não têm nenhuma possibilidade de escolha em celebrar ou não o referido contrato para o transporte do usuário, como no exemplo. Este necessita do transporte para a sua locomoção, de acordo com suas necessidades pessoais, ao passo que a concessionária responsável pela prestação do serviço de transportes público está obrigada a atendê-lo. Desse modo, há uma necessidade de contratar

${ }^{442}$ Relações contratuais fáticas (faktische Vertragsverhältnisse). Op. Cit., p. 41.

${ }^{443}$ Ibidem, p. 41.

${ }^{444}$ ANTUNES VARELA. Das obrigações em geral. Op. Cit., p. 221. - O autor traz o termo tráfico jurídico de massas. 
que se traduz num dever de prestação social por parte da empresa prestadora do serviço de transporte. ${ }^{445}$

A teoria das relações contratuais de fato encontra críticas na doutrina. A própria doutrina alemã, desde a década de 1970, já não a respalda mais. Isso porque, há entendimento no sentido de que se acolhida fosse nos exatos parâmetros fixados por Haupt, haveria uma quebra no sistema de direito privado como um todo e, desse modo, tornar-se-ia desnecessária para atingir os resultados almejados, os quais já estariam atendidos por outras figuras, tal qual a do enriquecimento sem causa. ${ }^{446} \mathrm{O}$ próprio LARENZ $^{447}$ abandona o termo por ele cunhado, ao longo do tempo. Segundo HIRATA, ${ }^{448}$ a partir dos anos 70 do século passado, observou-se na doutrina alemã o abandono da teoria das relações contratuais de fato. Segundo o autor, tal abandono é fruto de um desenvolvimento histórico, haja vista que esta foi criada e sustentada por juristas da escola de Kiel, os quais foram apoiadores e deram sustento em nível intelectual ao nazismo, na Segunda Guerra mundial.

445 HIRATA, Alessandro. Relações contratuais fáticas (faktische Vertragsverhältnisse). Op. Cit., pp. 42-43.

${ }_{446}$ HIRATA, Alessandro. Relações contratuais fáticas (faktische Vertragsverhältnisse). Op. Cit., p. 86.

${ }^{447}$ Allgemeiner Teil des deutschen Bürgerlichen Rechts. 7 ed. München: Beck, 1989. pp. 534-536.

${ }^{448}$ Relações contratuais fáticas (faktische Vertragsverhältnisse). Op. Cit., pp. $4 ; 114$. 
ANTUNES VARELA ${ }^{449}$ entende ser desnecessário recorrer à teoria das faktische Vertragsverhältnisse. Segundo o autor, no que se refere à categoria das relações contratuais fáticas por meio de contato social, basta que se observe o princípio da boa-fé durante a fase de formação e de preparação do contrato e não apenas no momento da execução do contrato. Também ALARCÃO, ${ }^{450}$ como já se referiu supra, não vê a necessidade de se socorrer der uma categoria dogmática distinta da declaração negocial e do acordo de vontades, uma vez que, em qualquer das categorias já apontadas, a teoria das faktische Vertragsverhältnisse traz o flanco a objeções graves, porventura acentuadas fora do "clima legislativo" germânico.

No Brasil, a doutrina pouco se debruçou acerca do tema das relações contratuais de fato, ainda que seja uma figura bastante útil, principalmente, no que se refere à circulação de bens em massa. Isso porque, segundo a teoria apresentada, há uma fonte de obrigações que vai além do conceito de contrato, o qual se baseia, unicamente, no acordo de vontades estabelecido entre as partes contratantes. ${ }^{451}$

${ }^{449}$ Das obrigações em geral. Op. Cit., p. 222.

${ }_{451}^{450}$ A confirmação dos negócios anuláveis. Op. Cit., p. 82.

451 HIRATA, Alessandro. Relações contratuais fáticas (faktische Vertragsverhältnisse). Op. Cit., pp. 114-115. 
Entre nós, destaque merece a alusão às relações contratuais de fato feita por C. COUTO E SILVA, ${ }^{452}$ à qual já se fez referência supra. Também AMARAL, ${ }^{453}$ na doutrina nacional, se referiu sobre o tema, ao afirmar que, principalmente por construção jurisprudencial, o direito pátrio reconhece a juridicidade das relações de fato, tais quais as relações contratuais, união estável e filiação, separação e sociedades de fato. HIRATA, ${ }^{454}$ também no Brasil, recentemente se debruçou exaustivamente sobre a teoria das faktische Vertragsverhältnisse.

Também na jurisprudência, há uma aplicação exígua da referida teoria, principalmente no que se refere ao Superior Tribunal de Justiça. Em um passado não muito distante, o referido Tribunal aplicou a teoria ao julgar o recurso especial $\mathrm{n}^{\circ} 915.322$ - MG:

Ora, o Tribunal de Justiça de Minas Gerais, como bem destacado no voto-vista do Min. Herman Benjamin, reconheceu que não houve dolo ou culpa em relação à lesividade ao erário, porquanto houve prestação de serviços. E, corretamente, não poderia ser de outro modo. Afinal, como expus, a doutrina das relações contratuais de fato resolve bem o problema: o servidor de fato prestou serviços e, com sua força de trabalho, contribuiu para o 452 A obrigação como processo. Op. Cit., pp. 77-78.

${ }^{453}$ Direito Civil: Introdução. Op. Cit., pp. 219-220.

${ }^{454}$ Relações contratuais fáticas (faktische Vertragsverhältnisse). Op. Cit., pp. 1-115. 
desempenho das funções do Município. Rigorosamente, será hipótese raríssima aquela na qual se extrairá dano ao erário de uma relação paracontratual como a vertente nos autos. Ter-se-ia, por exemplo, uma situação na qual o servidor aparente não trabalhou, violando o sinalagma e o deslocamento patrimonial ${ }^{455}$.

Anteriormente, o STJ já aplicou a teoria em outros casos julgados pela corte. Nesse sentido, há os Recursos Especiais n ${ }^{\circ}$. 57$712-8 / \mathrm{RJ}^{456}$ e $\mathrm{n}^{\mathrm{o}} .120719-\mathrm{SP}^{457}$ e no Agravo Regimental no Agravo de Instrumento $n^{\circ} .47 .901-3 / \mathrm{SP}^{458}$ todos relatados pelo ministro Ruy Rosado de Aguiar.

\subsubsection{Conclusões sobre a natureza jurídica do contrato médico}

Após a explanação sobre as diversas teorias a respeito da natureza jurídica do contrato médico com o paciente menor, especialmente no direito alemão, uma vez que essa doutrina foi a

${ }^{455}$ STJ, $2^{\mathrm{a}}$ Turma. REsp 915.322 - MG. rel. Humberto Martins. j. 23 set. 2008. P. DJ. 27 nov. 2008.

${ }^{456}$ STJ, $4^{\text {a }}$ Turma. REsp. $\mathbf{n}^{\mathbf{0}}$. 57-712-8/RJ. rel. Ruy Rosado de Aguiar, j. 11 abr.1995, P. DJ. 29 mai. 1995.

${ }^{457}$ STJ, $4^{\text {a }}$ Turma. REsp. $\mathbf{n}^{\mathbf{0}}$. 120719-SP. rel. Ruy Rosado de Aguiar, j. 22 out. 1997, P. DJ. 12 abr. 1999.

${ }^{458}$ STJ, $4^{\text {a }}$ Turma. Ar.Ag. $\mathbf{n}^{\mathbf{0}}$. 47.901-3/SP. rel. Ruy Rosado de Aguiar, j. 12 set. 1994, P. DJ. 31 out. 1994. 
que mais se debruçou sobre o tema, cabe tecer algumas considerações conclusivas sobre a questão.

É possível reconhecer que todas as teorias (estipulação em favor de terceiros, gestão de negócios e relações contratuais fáticas) apresentam pontos de acerto, possibilitando identificar o contrato médico com qualquer uma delas. Contudo, de outro lado, não é possível excluir nenhuma dessas teorias ou mesmo, acolher categoricamente uma delas.

A discussão sobre a natureza jurídica de um contrato sempre revela aspectos interessantes para uma melhor compreensão da figura estudada. Não é diferente nesse caso, apresentando todas as teorias argumentos que auxiliam no estudo e na análise do contrato médico com paciente menor. Assim, pode-se concluir que essa análise da natureza jurídica desse contrato médico, mesmo que não se decida por uma das teorias apresentadas, é fundamental para o melhor entendimento dele. Além disso, por fim, cabe ressaltar que a doutrina alemã inclina-se por reconhecer no contrato médico uma estipulação em favor de terceiro, o que provavelmente melhor trata dos interesses do paciente menor. 


\section{CAPÍTULO 4 - DEVER DE ESCLARECIMENTO}

\subsection{A relação médico-paciente}

Nos últimos séculos a conduta médica orientou-se, sobretudo, pelo princípio da assistência, segundo o qual o bem-estar do paciente era determinado pelos médicos e cuidadores de saúde. O respeito pela autonomia do paciente teve um papel claramente secundário. Até o final do século XX, a relação médico-paciente foi marcada por uma visão paternalista, a qual decorria do famoso Juramento de Hipócrates e predominou nos códigos de conduta médica, não se fazendo qualquer referência à vontade de paciente. ${ }^{459}$

$\mathrm{O}$ esclarecimento e o esforço para obter o consentimento do paciente serviam mais para convencer o paciente sobre a necessidade da terapia proposta pelo médico do que possibilitar uma decisão autodeterminada pelo paciente. A função do esclarecimento era, basicamente, motivar o paciente a se submeter à medida médica

459 SIMON, Alfred; NAUCK, Friedemann. Patientenautonomie in der klinischen Praxis. In WIESERMANN, Claudia; SIMON, Alfred (coord.). Patientenautonomie. Theoretische Grundlagen. Praktische Anwendungen. Münster: Mentis, 2013. p. 167. 
e, com isso, assegurar o sucesso do tratamento. ${ }^{460}$ A chamada "mentira piedosa", pela qual o médico não apresentava um diagnóstico e um prognóstico ruim com a boa intenção de não tirar a esperança do paciente foi considerada como eticamente aceitável. Mais que isso, era considerada uma orientação de conduta ${ }^{461}$.

Narram DEUTSCH e SPICKHOFF ${ }^{462}$ que esclarecimento e consentimento surgiram na segunda metade do século XIX e no decorrer dos anos se desenvolveram como primeiros mandamentos para o paciente. Segundo os autores, o caso se passou na presença de Bismarck. No final de maio de 1887, o sucessor do trono, que futuramente viria a ser o Imperador Friedrich III, padecia de câncer na laringe e os médicos que tratavam dele estavam decididos a torná-lo inconsciente para extirpar a laringe sem comunicá-lo sobre essa decisão. Bismarck protestou e exigiu que não poderiam prosseguir sem o consentimento do paciente e, ademais, como se tratava do sucessor do trono, também deveria haver a concordância do chefe da família. O Kaiser comunicou que a operação não deveria ser realizada sem o consentimento de seu filho. Embora esse fato tenha se passado no século XIX, é certo que esse panorama de fortalecimento do dever de esclarecimento por parte dos médicos se

${ }^{460}$ Ibidem, p. 167.

${ }^{462}$ Medizinrecht. Op. Cit., pp. 264-266. 
alterou profundamente nas últimas décadas. Tendo em vista as mudanças de valores na sociedade no sentido de valorizar mais a individualidade e responsabilidade própria, o direito de autodeterminação ganhou nitidamente em importância. ${ }^{463}$

$\mathrm{Na}$ atualidade, aceita-se como evidente o fato de que o paciente não deve somente ser esclarecido sobre sua doença, mas também ser integrado ativamente nas decisões de tratamento para que possa tomar uma decisão autodeterminada. ${ }^{464}$

A respeito dessa inter-relação entre o esclarecimento e participação do paciente no processo de decisão, EMANUEL e EMANUEL $^{465}$ apresentam quatro modelos de relação médicopaciente, pelos quais contrapõem os desejos do paciente com os deveres do médico. De cada tipo respectivo, os autores direcionam as concepções de autonomia do paciente e papel do médico.

Passa-se a descrever esses modelos, pois eles podem apontar alguma solução para a configuração da relação médico-paciente. Não se trata de apresentar argumentos para concluir pelo modelo "certo" ou "melhor", mas sim, de apresentar argumentos para cada

463 SIMON, Alfred; NAUCK, Friedemann. Patientenautonomie in der klinischen Praxis. Op. Cit., p. 167.

${ }^{464}$ Ibidem, pp. 167-168.

465 EMANUEL, Ezekiel J.; EMANUEL, Linda L. Four Models of the Physician-Patient-Relationship. Journal of the American Medical Association. v. 267, pp. 2221-2226, abril de 1992. 
contexto de situação prática, no qual um modelo se mostra mais adequado do que outro. ${ }^{466}$

O primeiro modelo apresentado por EMANUEL e EMANUEL é o paternalista. Nesse modelo, o paciente se apresenta como necessitado da intervenção médica e incapaz de decisão. Seu bemestar de saúde é considerado um valor objetivo e, nessa medida, passível de ser compartilhado. Nessa relação, o médico paternalista é a parte ativa, protetora e que decide sozinho, na medida em que sua tarefa é promover o bem-estar do paciente de forma independente das preferências pessoais deste, atuando no sentido de uma "tutela paterna". Autonomia do paciente, esclarecimento e participação têm importância secundária. A relação é, portanto, assimétrica. Um sucesso de terapia já pode ser esperado por conta de uma relação de confiança positiva. O médico atua de forma autoritária, pressupondo o consentimento do paciente e sem consideração às suas reais preferências. É certo que em situações de necessidade, a ação do médico sem consentimento do paciente é até legítima e plausível. Mas a questão que se coloca é saber quando o paciente pode e deve subordinar suas decisões para um médico que

466 KETTNER, Matthias; JUNKER, Iris. Konsequenzen der wunscherfüllenden Medizin für die Arzt-Patient-Beziehung. In KETTNER, Matthias (coord.). Wunscherfüllende Medizin: Ärztliche Behandlung im Dient von Selbstverwirklichung und Lebensplanung. Op. Cit., p. 70. 
se apresenta ao mesmo tempo como competente do ponto de vista profissional, bem como totalmente paternalista. ${ }^{467}$

O segundo modelo apresentado pelos autores é o modelo informativo. Aqui, a relação médico-paciente é marcada pela experiência técnica e científica do médico. $\mathrm{O}$ médico que informa o paciente apresenta-lhe todos os fatos médicos relevantes e lhe informa sobre o seu estado, diagnóstico, alternativas de terapia, riscos e vantagens de todas as medidas médicas desejadas pelo paciente. Cabe ao paciente decidir, após ser amplamente informado. Aqui o bem-estar do paciente não é um valor objetivo, pois é o paciente que o define, que julga e decide conforme suas próprias ideias. Nesse modelo a autonomia do paciente tem valor máximo. ${ }^{468}$ Segundo KETTNER e JUNKER, ${ }^{469}$ esse modelo se mostra apropriado para situações de fornecimento de serviço, em que o médico se apresenta como um provedor de serviço, atuando de forma competente e especializada e informando o paciente/cliente sobre as possibilidades que podem ser realizadas. Nesse modelo o médico não dá conselhos ao paciente, no sentido de aumentar sua

467 EMANUEL, Ezekiel J.; EMANUEL, Linda L. Four Models of the Physician-Patient-Relationship. Op. Cit., p. 2221.

${ }^{468}$ Ibidem, pp. 2221-2222.

${ }^{469}$ Konsequenzen der wunscherfüllenden Medizin für die Arzt-PatientBeziehung. Op. Cit., p. 71. 
capacidade crítica de decisão, pois a autonomia do paciente tem valor máximo. O paciente é soberano.

SIMON e NAUCK ${ }^{470}$ chamam-no de modelo de cliente, pois o paciente desempenha papel de cliente que solicita serviços individuais de saúde e melhores serviços de hospedagem. Na relação entre cliente e prestador de serviço de saúde, a antiga assimetria da relação médico-paciente se dissolve, de modo que esse tipo de modelo apenas se aplica para um campo limitado de prestação de serviço de saúde, como por exemplo, aconselhamento e cuidados médicos para viagens, prevenção e alívio de perturbações do estado psíquico-mental não graves e intervenções de melhora sem relação com doença.

O terceiro modelo é o modelo de interpretação. Em tal modelo, o médico age como um conselheiro. Ele coloca à disposição do paciente todas as informações relevantes e participa com ele no processo de decisão, ou seja, o médico ajuda o paciente a encontrar a solução mais adequada. Aqui o médico aconselha o paciente e ampara seu processo de decisão e compreensão, mas a decisão final sobre o tratamento cabe ao paciente. Nesse modelo a autonomia do paciente também tem um valor alto, mas como conselheiro competente, o médico também pode questionar os desejos e a

${ }^{470}$ Patientenautonomie in der klinischen Praxis. Op. Cit., p. 176. 
compreensão do paciente sem que isso signifique uma intromissão ilegítima. $^{471}$

Esse modelo é tratado pelos doutrinadores SIMON e $\mathrm{NAUCK}^{472}$ como um modelo de parceria, pelo qual a figura do paciente doente se dissolve para dar lugar a um paciente parceiro. É um modelo fundamentado na experiência de que a prevenção, limitação ou melhora da doença e do sofrimento não são apenas tarefas do médico, mas que também devem contar com a participação do paciente. Na qualidade de um "expert participativo", o paciente age de forma ativa e se torna corresponsável pelo resultado. Esse modelo não nega a assimetria entre médico e paciente, mas torna digno de respeito o conhecimento do paciente e sua responsabilidade pela sua doença.

Por fim, o modelo deliberativo é aquele em que o médico age como um amigo. O diálogo com o paciente é caracterizado por uma troca de argumentos de igual para igual. $O$ médico informa o paciente e, junto com ele, elabora uma concepção de bem-estar bem refletida. Aqui o médico não está limitado aos desejos e interesses particulares do paciente, pois o bem-estar pode ser considerado também em um sentido público, como por exemplo, a questão de o

471 EMANUEL, Ezekiel J.; EMANUEL, Linda L. Four Models of the Physician-Patient-Relationship. Op. Cit., p. 2222.

${ }^{472}$ Patientenautonomie in der klinischen Praxis. Op. Cit., p. 176. 
paciente querer participar de um estudo clínico. Doença e saúde não são aceitas apenas como assuntos particulares do paciente, mas estão integrados na perspectiva de uma comunidade solidária. A autonomia do paciente também tem um alto valor e é integrada ao mesmo tempo moral e socialmente. ${ }^{473}$

Quando se trata de uma situação de doença, os quatro modelos se mostram apropriados, uma vez que fazem referência à necessidade do paciente, sua confiança e autonomia, a vantagem de conhecimento do médico, e o objetivo conjunto de cura ou alívio de sofrimento. Mas se a situação for de saúde, caso em que a intenção ou desejo do paciente for o melhoramento de sua saúde, então o modelo paternalista se afasta por completo.

Numa cultura liberal a promoção da saúde anda de mãos dadas com o aumento da autonomia do paciente e com uma pluralidade de valores. O conceito positivo de saúde deve ser considerado à luz das diferentes perspectivas do significado de se ter uma vida saudável. Diante de um amplo campo de prestações de serviço, para as quais a garantia de transparência e de responsabilidade pelos produtos poderia proteger os consumidores, o modelo de informação teria maior relevância. Mas em um campo de prestações mais complexas, cuja expansão se antevê desde logo, sustenta-se que o modelo 473 EMANUEL, Ezekiel J.; EMANUEL, Linda L. Four Models of the Physician-Patient-Relationship. Op. Cit., p. 2222. 
interpretativo ou de parceria seria bastante adequado, desde que não haja grandes riscos de irreversibilidade, como por exemplo, as cirurgias estéticas com intervenções de grau baixo a médio. No modelo de informação exige-se muito do paciente, pois a decisão deve ser tomada por ele sozinho, sem contar com o auxílio de um profissional com mais experiência e com olhar técnico. O médico apenas the presta as informações necessárias, sem qualquer conselho. O modelo deliberativo, de outra parte, coloca um peso maior não na relação médico-paciente propriamente dita, mas no sistema de saúde e na política de saúde. ${ }^{474}$

Os modelos apresentados, principalmente os três primeiros, não se excluem. Ao contrário, se complementam, considerando as circunstâncias de cada situação concreta. Por exemplo, quando uma gestante procura uma clínica para fazer o parto, age conforme o modelo de cliente ou informativo, ou seja, ela compara as ofertas e decide por uma clínica, cujas condições correspondem mais aos seus desejos. $\mathrm{Na}$ conversa preparatória para o parto e durante tal procedimento, mostra-se adequado o modelo interpretativo ou de parceria. A participação de cada um - mulher, médico, parteira, ou doula - é importante nas tarefas e responsabilidades. Se durante o

${ }^{474}$ KETTNER, Matthias; JUNKER, Iris. Konsequenzen der wunscherfüllenden Medizin für die Arzt-Patient-Beziehung. Op. Cit., pp. 72-73. 
parto ocorrerem complicações, tais como a necessidade de uma Cesária, então a parturiente coloca-se num papel muito mais passivo, no qual ela se deixa confiar pela competência técnica da equipe médica. ${ }^{475}$

Diante desse contexto, fica evidente que a autonomia do paciente é de suma importância na relação médico-paciente quando se está à frente de uma escolha por uma intervenção médica em prol do melhoramento da saúde, como ocorre na cirurgia estética e, por consequência, do bem-estar do paciente. A medicina moderna, da qual a cirurgia estética faz parte, levou a necessidade de maior participação do paciente, que não deve apenas sancionar de forma passiva as propostas de tratamento oferecidas pelo médico. Deve haver um diálogo entre as partes, que também deve ser conduzido de maneira responsável pelo paciente. Trata-se assim de uma relação de parceria. $^{476}$

Ainda que na medicina de desejo esteja afastado o tratamento de uma doença, isso não afasta o desafio da ajuda médica e a necessidade de um acompanhamento científico. Médico e paciente se encontram, aqui, como parceiros de autorresponsabilidade. $\mathrm{O}$ médico como representante da competência e conhecimentos 475 SIMON, Alfred; NAUCK, Friedemann. Patientenautonomie in der klinischen Praxis. Op. Cit., p. 176.

${ }^{476}$ STOCK, Christof. Die Indikation in der Wunschmedizin. Op. Cit., pp. 114-115. 
científicos e o paciente como titular do direito de autodeterminação, decidindo a favor ou contra uma medida médica. ${ }^{477}$

$\mathrm{Na}$ prática clínica a autonomia do paciente se expressa principalmente no consentimento informado ${ }^{478}$. A necessidade de consentimento foi uma exigência jurídica que surgiu em primeiro lugar na área da pesquisa com seres humanos, conforme se observa no Código de Nurembergue de 1947 e se ampliou na segunda metade do século XX na medicina inteira como padrão. ${ }^{479}$

$\mathrm{O}$ consentimento informado parte do princípio salus et voluntas aegroti suprema lex e significa que toda intervenção médica deve ser justificada pelo consentimento do paciente após ser devidamente esclarecido. ${ }^{480}$ Pode-se entender o consentimento informado como derivado da proteção da integridade física e psíquica do paciente,

${ }^{477}$ STOCK, Christof. Die Indikation in der Wunschmedizin. Op. Cit., pp. 114-115.

478 SIMON, Alfred; NAUCK, Friedemann. Patientenautonomie in der klinischen Praxis. Op. Cit., p. 169.

479 ALDERSON, Priscilla. Die Autonomie des Kindes - über die Selbstbestimmungsfähigkeit von Kindern in der Meidizin. In WIESEMANN, Claudia; DÖRRIES, Andrea; WOLFSLAST, Gabriele; SIMON, Alfred (Coord.). Das Kind als Patient - Ethische Konflikte zwischen Kindeswohl und Kindeswille. Frankfurt: Campus, 2003. p. 28; SIMON, Alfred, Patientenautonomie (cit.), pp. 169.

${ }^{480}$ A literatura sobre consentimento esclarecido é bastante vasta. Cita-se aqui DEUTSCH, Erwin; SPICKHOFF, Andreas. Medizinrecht. Azrtrecht, Arzneimittelrecht, Medizinproduktrecht und Transfusionsrecht. Op. Cit., p. 747; SIMON, Alfred; NAUCK, Friedemann. Patientenautonomie in der klinischen Praxis. Op. Cit., p. 169. 
bem como do exercício de sua liberdade, os quais são manifestações de um direito geral de personalidade. ${ }^{481}$

A responsabilidade civil do médico pode decorrer de dois fundamentos centrais: execução de uma intervenção sem o consentimento eficaz do paciente ou sem observância das regras técnicas do standard médico. ${ }^{482} / 483$ A ausência ou ineficácia do consentimento do paciente ou de seu representante legal, em caso de incapacidade daquele, leva ao entendimento de que a intervenção médica, ainda que executada lege artis, poderia configurar uma lesão corporal, ${ }^{484}$ podendo, ainda, incorrer nas penas do art. 129 do Código Penal. ${ }^{485}$ Trata-se de um tratamento médico arbitrário, que

${ }^{481}$ VAZ RODRIGUES, João. O Consentimento Informado para o Acto Médico no Ordenamento Jurídico Português: Elementos para o estudo da manifestação de vontade do paciente. Coimbra: Coimbra Editora, 2001. p. 198.

${ }^{482}$ LORZ, Sigrid. Arzthaftung bei Schönheitsoperationen. Op. Cit., p. 90.

483 A respeito dos padrões de conduta médico e responsabilidade civil decorrente de erro médico. Nesse sentido, MAFFEIS MOREIRA, Marta Rodrigues. Contribuição para o Estudo da Responsabilidade Civil do Médico à luz do Direito Romano. Op. Cit., pp. 71-113 e 147-167.

484 SIMON, Alfred; NAUCK, Friedemann. Patientenautonomie in der klinischen Praxis. Op. Cit., p. 169.

485 Art. 129. Ofender a integridade corporal ou a saúde de outrem:

Pena - detenção, de três meses a um ano.

$\S 1^{\circ}$ Se resulta: I - Incapacidade para as ocupações habituais, por mais de trinta dias; II - perigo de vida; III - debilidade permanente de membro, sentido ou função; IV - aceleração de parto:

Pena - reclusão, de um a cinco anos. 
além de violar bens jurídicos como a vida, o corpo e a saúde, viola também os direitos da personalidade da liberdade e autodeterminação. ${ }^{486}$

O esclarecimento, portanto, é pressuposto para o consentimento e contém uma renúncia à proteção absoluta do corpo em relação a lesões e, por consequência, à proteção da intimidade. ${ }^{487}$ Nesse sentido, o esclarecimento preenche o conteúdo do consentimento. ${ }^{488}$ Esclarecimento por parte do médico e consentimento por parte do paciente são deveres contratuais, conforme preceitua o $§ 630 \mathrm{~d}, 1$ do $\mathrm{BGB}^{489}$ e a partir desse agir conjunto, a vontade do paciente se realiza. ${ }^{490}$

O esclarecimento serve ao exercício do direito de autodeterminação do paciente, que se baseia na garantia $\S 2^{\circ}$ Se resulta: I - Incapacidade permanente para o trabalho; II - enfermidade incurável; III perda ou inutilização do membro, sentido ou função; IV deformidade permanente; $\mathrm{V}$ - aborto:

Pena - reclusão, de dois a oito anos.

$\S 3^{\circ}$ Se resulta morte e as circunstâncias evidenciam que o agente não quis o resultado, nem assumiu o risco de produzi-lo:

Pena - reclusão, de quatro a doze anos.

${ }^{486}$ DEUTSCH, Erwin; SPICKHOFF, Andreas. Medizinrecht. Azrtrecht, Arzneimittelrecht, Medizinproduktrecht und Transfusionsrecht. Op. Cit., p. 91 .

${ }^{487}$ Ibidem, pp. 264 e 279.

${ }^{488}$ LORZ, Sigrid. Arzthaftung bei Schönheitsoperationen. Op. Cit., p. 91.

${ }^{489}$ Cf. nota 170.

490 DEUTSCH, Erwin; SPICKHOFF, Andreas. Medizinrecht. Azrtrecht, Arzneimittelrecht, Medizinproduktrecht und Transfusionsrecht. Op. Cit., p. 265. 
constitucional do livre desenvolvimento da personalidade. ${ }^{491}$ Nesse contexto do direito à vida e à inviolabilidade corporal, o direito de autodeterminação ganha um conteúdo especial. ${ }^{492}$ Esse esclarecimento deve possibilitar a decisão livre e responsável do paciente e colocá-lo em posição de avaliar as vantagens e desvantagens de sua decisão e sobre esse fundamento, tomar uma decisão esclarecida e autorresponsável. ${ }^{493}$ É o paciente que tem que tomar uma decisão autodeterminada sobre seu corpo e o que acontece com ele. $^{494}$

Isso também abrange o direito do paciente autodeterminar sua aparência como parte da sua personalidade. ${ }^{495} \mathrm{O}$ direito de autodeterminação demonstra que o paciente não deve ser

${ }^{491}$ LORZ, Sigrid. Arzthaftung bei Schönheitsoperationen. Op. Cit., p. 91. A respeito da autodeterminação como livre desenvolvimento da personalidade, cf. Art. 2 (1) GG: Art. 2 (1) Jeder hat das Recht auf die freie Entfaltung seiner Persönlichkeit, soweit er nicht die Rechte anderer verletzt und nicht gegen die verfassungsmäßige Ordnung oder das Sittengesetz verstößt.

492 (2) Jeder hat das Recht auf Leben und körperliche Unversehrtheit.

493 TAUPITZ, Jochen. Empfehlen sich zivilrechtliche Regelungen zu Absicherung der Patientenautonomie am Ende des Lebens? (Gutachten A für den 63. Deutschen Juristentag), München: Beck, 2000, A 28.

494 GIESEN, Dieter. Arzthaftungsrecht: Die zivilrechtliche Verantwortlichkeit des Arztes in rechtsvergleichender Sicht. Bielefeld: Gieseking, 1981, p. 112.

495 SCHUCK, Martin. Strafrechtliche Bedeutung der Verletzung der ärztlichen Aufklärungslast unter besonderer Berücksichtigung der kosmetischen Chirurgie. Dissertação. München, 1980. p. 11. 
considerado um mero objeto, mas sujeito do tratamento. ${ }^{496}$ Somente por meio de um esclarecimento correto pelo médico, o qual dispõe de conhecimentos maiores e melhores sobre todas as circunstâncias que envolvem a medida médica, o paciente poderá decidir se ele quer assumir o ônus e os riscos de uma cirurgia com finalidade de embelezamento. Isso significa tomar uma decisão de responsabilidade própria. ${ }^{497}$

\subsection{A extensão do esclarecimento nas cirurgias estéticas}

O esclarecimento médico deve abranger a essência, importância e extensão do tratamento. ${ }^{498}$ No caso das cirurgias estéticas, a extensão do esclarecimento é de importância central para a responsabilidade civil do médico. ${ }^{499}$ A esse respeito, parte-se da questão de saber se o médico deve informar o paciente de maneira geral, oferecendo a ele uma impressão genérica ou se o esclarecimento do médico tem que ser intensivo e abrangente. ${ }^{500}$

${ }^{496}$ STEFFEN, Erich; DRESSLER, Wolf-Dieter. Arzthaftungsrecht. Op. Cit., pp. 162-163, Rn. 321.

${ }^{497}$ LAUFS, Adolf; KATZENMEIER, Christian; LIPP, Volker. Arzthaftung. 6a edição, München: Beck, 2009.

${ }^{498}$ LORZ, Sigrid. Arzthaftung bei Schönheitsoperationen. Op. Cit., p. 91.

${ }^{499}$ Ibidem, p. 96.

${ }^{500}$ Ibidem, p. 96. 
Visto sob o aspecto ético-social, o médico deve saber a disposição do paciente para ser informado sobre sua situação de forma total ou apenas parcial. $^{501} \mathrm{~A}$ maior parte da doutrina sustenta que no caso das cirurgias estéticas o esclarecimento deve ser exaustivo e impiedoso, com a maior abrangência possível e sem poupar o paciente de todos os aspectos, principalmente aqueles relacionados aos riscos da intervenção. ${ }^{502}$ Essa posição decorre da relação entre indicação e esclarecimento, os quais, mais do que conceitos normativos de per si, devem ser considerados em estreita conexão. $^{503}$

O Direito Médico, ademais, nas palavras de LAUFS ${ }^{504}$ referese, além dessa íntima relação entre ambos os conceitos, a uma fórmula de relação recíproca entre indicação e dever de 501 DEUTSCH, Erwin; SPICKHOFF, Andreas. Medizinrecht. Azrtrecht, Arzneimittelrecht, Medizinproduktrecht und Transfusionsrecht. Op. Cit., p. 266.

${ }^{502}$ SPICKHOFF, A., Die Eingriffsindikation im Wandel der Zeit. Op. Cit., pp. 15-16; DAMM, Reinhard. Informed consent zwischen Indikations- und Wunschmedizin. Op. Cit., pp. 186-187; LAUFS, Adolf. $\$ 64$ Die Risikoaufklärung im besonderem, in LAUFS, Adolf; UHLENBRUCK, Wilhelm (coord.). Handbuch des Arztrechts. Op. Cit., p. 517; STEFFEN, Erich; DRESSLER, Wolf-Dieter, Arzthaftungsrecht. Op. Cit., p. 200; DEUTSCH, Erwin; SPICKHOFF, Andreas. Medizinrecht. Azrtrecht, Arzneimittelrecht, Medizinproduktrecht und Transfusionsrecht. Op. Cit., p. 295.

503 DAMM, Reinhard. Informed consent zwischen Indikations- und Wunschmedizin. Op. Cit., p. 186.

$504 \$ 63$ Die Selbstbestimmungsaufklärung. In LAUFS, Adolf; UHLENBRUCK, Handbuch des Arztrechts Op. Cit., p. 508. 
esclarecimento, no sentido de que quanto mais urgente for a indicação, quanto mais necessária for a intervenção, mais suave será a obrigação de esclarecer. Ao contrário, quanto menos urgente for a intervenção conforme a indicação médica e a perspectiva de cura, considerando o momento da intervenção e o estágio da ciência médica, mais intenso deve ser o esclarecimento. ${ }^{505}$

$\mathrm{DAMM}^{506}$ chama a atenção para a primeira regra de que, em caso de urgência, o dever de esclarecimento é mais leve apenas por causa do fator tempo, pois, diante da situação concreta mostra-se plausível uma limitação na extensão do esclarecimento. Disso decorre que, em caso de indicação vital, o esclarecimento médico não pode ser relativizado, sendo possível apenas uma simplificação.

Essa fórmula foi desenvolvida pela doutrina, ${ }^{507}$ que se orientou pelo benefício à saúde que a intervenção médica pode proporcionar para estabelecer a extensão do esclarecimento. Dessa forma, no caso de uma indicação vital, ${ }^{508}$ ou seja, quando o tratamento é essencial para a cura de uma doença de alto risco à vida do paciente, as exigências e abrangência do esclarecimento são menores.

${ }^{505}$ KATZENMEIER, Christian. Arzthaftung. Op. Cit., p. 328.

${ }^{506}$ Informed consent zwischen Indikations- und Wunschmedizin: Eine medizinische Betrachtung. Op. Cit., p. 187.

${ }^{507}$ LORZ, Sigrid. Arzthaftung bei Schönheitsoperationen. Op. Cit., p. 328.

${ }^{508}$ Sobre a falta de uniformidade na doutrina quanto ao termo indicação, cf. capítulo 2, item 2.2. 
No caso de uma indicação absoluta, na qual o tratamento é necessário para curar uma insuficiência média da saúde, o médico deve esclarecer o paciente em termos gerais e dar a ele uma impressão genérica. Na existência de uma indicação relativa, isto é, quando o tratamento é apropriado para a restituição da saúde, mas não é necessário, o esclarecimento deve acontecer de maneira mais detalhada. Por fim, quando não houver indicação médica, o esclarecimento deve se pautar por exigências bastante rígidas. Nesse passo, sobretudo no contexto das cirurgias estéticas como medidas médicas sem indicação, as exigências do esclarecimento como pressuposto de um consentimento eficaz são maiores. ${ }^{509}$

Por isso, SPICKHOFF ${ }^{510}$ acentua que a doutrina em geral aponta para um esclarecimento com uma clareza e dureza que não poupam o paciente, sendo que até mesmo complicações mais remotas devem ser esclarecidas, a não ser que não exista conhecimento médico cientificamente comprovado sobre o risco. ${ }^{511}$ Assevera ainda o doutrinador que a jurisprudência alemã, no que é acompanhada também pela austríaca, decide nesse sentido. No contexto do esclarecimento e do consentimento ainda que pouca

${ }^{509}$ LORZ, Sigrid. Arzthaftung bei Schönheitsoperationen. Op. Cit., p. 98; LAUFS, Adolf. §63 Die ärztliche Aufsklärungspflicht. Op. Cit., p. 508.

${ }^{510}$ Die Eingriffsindikation im Wandel der Zeit. Op. Cit., pp. 15-16.

${ }^{511} \mathrm{O}$ esclarecimento de riscos remotos será tratado mais à frente (cf. item 4.4.4 infra). 
referência se faça à rígida categorização da indicação em indicação absoluta, relativa e ausência de indicação, os julgamentos consideram que quanto maior for o cuidado para uma decisão realmente refletida do paciente, tanto mais rigorosas serão as exigências do dever de esclarecer. ${ }^{512}$

O paciente deve decidir de maneira ponderada e realista se quer colocar realmente sua saúde em risco para tentar uma melhora da sua aparência, melhora essa que, sob certas circunstâncias, pode até ser duvidosa. ${ }^{513}$ Disso decorre que o médico deve esclarecer as vantagens e desvantagens com todas as consequências de maneira clara e compreensível para que o paciente possa ponderar se ele quer assumir o risco de um possível insucesso, alterações físicas, sejam elas temporárias ou permanentes, ou restrições à saúde, ainda quando essas consequências sejam remotas. ${ }^{514}$

A razão para um esclarecimento abrangente e "impiedoso" seria o fato que as cirurgias estéticas são executadas para atingir um determinado sucesso estético. Como tais procedimentos não servem para a cura de um sofrimento corporal mas para uma necessidade estética do paciente, afirma-se que o risco de prejuízo não tem um

\footnotetext{
${ }^{512}$ SPICKHOFF, Andreas. Die Eingriffsindikation im Wandel der Zeit. Op. Cit., pp. 15-16.

${ }^{513}$ LORZ, Sigrid. Arzthaftung bei Schönheitsoperationen. Op. Cit., p. 98.

514 LAUFS, Andreas.; KATZENMEIER, Christian. Arzthaftungsrecht. München: Beck, 2015. Rn. 199.
} 
correspondente benefício para a saúde. Por isso o esclarecimento não deve poupar o paciente de nenhuma circunstância, ainda que inflija nele um medo maior diante das complicações. ${ }^{515}$

Também em outros ordenamentos jurídicos são estabelecidas exigências altas na extensão de esclarecimento das cirurgias estéticas diante da ausência de necessidade de intervenção médica. $\mathrm{Na}$ Áustria ${ }^{516}$ e na Suíça ${ }^{517}$ o esclarecimento com finalidade somente estética deve ocorrer de forma absolutamente clara e sem poupar o paciente. Também na Holanda o esclarecimento deve ser detalhado. ${ }^{518} \mathrm{Na}$ França o médico tem o dever de esclarecer as circunstâncias ao paciente de maneira completa, entendendo-se os riscos atípicos e raros. ${ }^{519} \mathrm{Na}$ Itália, cirurgias que servem apenas para promover o embelezamento, exigem um esclarecimento mais

${ }^{515}$ LORZ, Sigrid. Arzthaftung bei Schönheitsoperationen. Op. Cit., p. 99.

516 JUEN, Thomas. Arzthaftungsrecht. Die zivilrechtliche Haftung des Arztes für den Behandlungsfehler - der Arzthaftungsprozess in Österreich. 2 ed. Wien: Manz, 2005. p. 60.

${ }^{517}$ EISNER, Beate. Die Aufklärungspflicht des Arztes im schweizerischen Recht mit Hinweisen auf das Deutsche und amerikanische Recht. In KOTZUR, Joachim; NOACK, Herbert; WEBER, Ulrich (Coord.). Jahrbuch Junger Zivilrechtswissenschaftler. München: Hannover, 1991. p. 201.

${ }^{518}$ DUTE, Jos. Landesbericht Niederlande. In FISCHER, Gerfried; LILIE, Hans (Coord.). Ärztliche Verantwortung im europäischen Rechtsvergleich. Köln: Verlag, 1999. p. 281.

${ }^{519}$ LE TOURNEAU, Philippe; CADIET, Loïc. Droit de la responsabilité et des contrats. Paris: Dalloz, 2002. Rn. 1912. 
abrangente do que nos tratamentos de cura em geral. ${ }^{520}$ Por fim, o Court of Appeal da Inglaterra menciona que a extensão do esclarecimento nas cirurgias estéticas deveria ser maior por causa da ausência de necessidade médica. ${ }^{521}$

Segundo LORZ, ${ }^{522}$ por trás das altas exigências da extensão do esclarecimento nas cirurgias estéticas, está a questão de que a saúde, no sentido de restabelecimento, seria a única utilidade de um tratamento médico. Entretanto, a autora questiona se essa orientação do esclarecimento apenas em face da saúde do paciente seria a mais adequada para promover e garantir o direito de autodeterminação do paciente. Para LORZ, a doutrina que defende um esclarecimento impiedoso para as cirurgias estéticas considera que esse tipo de cirurgia não tem qualquer finalidade para a saúde do paciente, sendo executada apenas por razões beleza. Com isso, para a autora, o termo "esclarecimento impiedoso" leva a impressão de que o esclarecimento deveria mais conduzir o paciente para uma determinada direção, talvez de desistência da cirurgia e menos capacitá-lo para uma decisão autodeterminada. Um esclarecimento duro e impiedoso não garante a autodeterminação do paciente.

520 DWYER-HOLIGHAUS. Axel. Die Aufklärungspflicht des Arztes im Rechtsvergleich zwischen Deutschland und Italien. Leipzig: Leipziger Juristische Studien, 2005. 34; 93.

${ }^{521}$ LORZ, Sigrid. Arzthaftung bei Schönheitsoperationen. Op. Cit., p. 100. ${ }^{522}$ Ibidem, p. 100. 
LORZ $^{523}$ contrapõe-se a essa posição, asseverando que o esclarecimento não é uma mera transferência de informações, mas deve melhorar a competência de decisão do paciente e habilitá-lo a se posicionar de forma autodeterminada. Conforme a melhor doutrina, ora representada por LAUFS, é preciso observar o sentido e a finalidade do esclarecimento: possibilitar ao paciente uma decisão livre e responsável. ${ }^{524}$

Nesse sentido, o médico deve colocar à disposição do paciente tantas informações quantas sejam necessárias para que este possa decidir com responsabilidade própria se aceita ou não a realização de uma cirurgia estética. Dessa forma, o esclarecimento oferece aos pacientes, como leigos do ponto de vista médico, a base para decidir de modo qualificado entre as vantagens e desvantagens de uma cirurgia. Sob outro ângulo, o esclarecimento não deve transmitir ao paciente conhecimentos profissionais específicos, mas possibilitar a ele explicações plausíveis sobre o que a cirurgia estética pode significar para a sua situação pessoal. ${ }^{525}$

${ }^{523}$ Ibidem, p. 101.

${ }^{524}$ LAUFS, Adolf. $\S 63$ Die Selbstbestimmungsaufklärung. In: LAUFS, Adolf; UHLENBRUCK, Wilhelm, Handbuch des Arztrechts. Op. Cit., p. 509.

${ }^{525}$ LAUFS, Adolf; KATZENMEIER, Christian; LIPP, Volker. Arzthaftung. Op. Cit., p. 327. 
É verdade que pode surgir alguma dificuldade para o médico no que se refere a encontrar a medida certa de informações que ajudem o paciente na sua tomada de decisão responsável. Um esclarecimento superficial demais não fornece ao paciente informações suficientes e impede uma decisão ponderada, porque esta parte de pré-condições distorcidas. Entretanto, um esclarecimento muito detalhado pode sobrecarregar o paciente e, ao invés de facilitar sua decisão autodeterminada, acaba por dificultála. ${ }^{526}$ Por consequência, o sentido e a finalidade do esclarecimento podem ter efeito contrário, ou seja, ao invés de promover uma decisão autodeterminada do paciente, ele afastaria a construção de um relacionamento de confiança e parceria entre médico e paciente e se dirigiria a uma proteção paternalista do paciente de si mesmo. Em relação às cirurgias estéticas, isso levaria a um maior valor do princípio salus aegroti suprema lex frente ao princípio voluntas aegroti suprema lex. ${ }^{527}$

Porém, argumenta LORZ, ${ }^{528}$ também nas cirurgias estéticas deve-se manter a função do esclarecimento como instrumento de promoção da autodeterminação, ponderando o possível dano da cirurgia de um lado e o benefício pessoal de outro, representado,

\footnotetext{
${ }^{526}$ Ibidem, p. 337

${ }^{527}$ LORZ, Sigrid. Arzthaftung bei Schönheitsoperationen. Op. Cit., p. 101. ${ }^{528}$ Ibidem, p. 101.
} 
sobretudo, pela diminuição de sofrimento, fortalecimento da autoestima, reconhecimento social ou carreira profissional.

Por isso, o paciente não pode receber pouco esclarecimento, nem em demasia. É certo que os riscos e efeitos colaterais não devem ser negligenciados, mas também não precisam ser apresentados de maneira assustadora. Um esclarecimento exagerado pode causar insegurança no paciente e quando este não está em condições de avaliar os ônus e riscos de maneira realista e comparar com o possível benefício, o esclarecimento, ao invés de promover, impedirá uma decisão autodeterminada. ${ }^{529}$

Conclui LORZ que o critério decisivo para a determinação da extensão da obrigação do esclarecimento não é o benefício de saúde passível de ser alcançado pela cirurgia, mas sim o grau de capacitação do paciente para tomar uma decisão autodeterminada. ${ }^{530}$

\subsection{Objeto do esclarecimento}

\subsubsection{Aspectos preliminares}

O dever de esclarecimento possui diversos aspectos que dificultam o estabelecimento de regras casuísticas ou gerais. Porém, não se pode, jamais, desconsiderar-se seu escopo e sentido. Ou seja,

${ }^{529}$ Ibidem, pp. 101-102.

${ }^{530}$ Ibidem, p. 102. 
que o esclarecimento deve possibilitar uma decisão livre e responsável da pessoa, a fim de que esta possa realizar seu direito de autodeterminação. ${ }^{531}$

O paciente deve ser esclarecido de forma ampla sobre diversas circunstâncias, principalmente sobre o tipo de intervenção, sua extensão (da qual se expôs supra), execução, consequências esperadas, riscos, necessidade, urgência, perspectivas de êxito em relação ao diagnóstico e à terapia. Após isso, devem ser informadas as alternativas de tratamento, em caso de haver vários métodos médicos igualmente indicados que puderem levar a diferentes incômodos, riscos e chances de cura. ${ }^{532} \mathrm{O}$ principal campo refere-se ao esclarecimento dos riscos, mas o esclarecimento não se esgota neste, ainda que o risco esteja em primeiro plano. ${ }^{533}$ Os diferentes tipos de esclarecimento não configuram categorias rígidas, pois pode haver certa simbiose entre eles. ${ }^{534}$

${ }^{531}$ LAUFS, Adolf. $\$ 63$ Die Selbstbestimmungsaufklärung. In LAUFS, Adolf; UHLENBRUCK, Wilhelm. Handbuch des Arztrechts. Op. Cit., p. 509.

${ }^{532}$ DEUTSCH, Erwin; SPICKHOFF, Andreas. Medizinrecht. Azrtrecht, Arzneimittelrecht, Medizinproduktrecht und Transfusionsrecht. Op. Cit., pp. 279-280. SIMON, Alfred; NAUCK, Friedemann. Patientenautonomie in der klinischen Praxis. Op. Cit., p. 169

${ }^{533}$ LAUFS, Adolf. §63 Die Selbstbestimmungsaufklärung. In LAUFS, Adolf; UHLENBRUCK, Wilhelm. Handbuch des Arztrechts. Op. Cit., p. 509.

${ }^{534}$ Ibidem, p. 509. 


\subsubsection{Esclarecimento sobre o diagnóstico}

Significa informar ao paciente sobre o diagnóstico médico. O paciente deve saber que ele está doente de qual doença se trata. ${ }^{535}$ Em casos de doenças graves, mortais ou em que não há possibilidade de tratamento, o médico não precisa comunicar o diagnóstico de forma total. Nesse caso, a não informação ocorre a favor do paciente, uma vez que o conhecimento do diagnóstico pode comprometer seu estado psicológico e levar a uma piora de seu estado de saúde. ${ }^{536}$ Nesse caso, seria suficiente a comunicação do diagnóstico em termos genéricos. ${ }^{537}$ Entretanto, ainda assim, o médico deve informar o paciente sobre uma intervenção planejada. ${ }^{538}$

${ }^{535}$ Ibidem, p. 509; KATZENMEIER, Christian. Arzthaftung. Op. Cit., p. 326.

${ }^{536}$ LAUFS, Adolf. $§ 63$ Die Selbstbestimmungsaufklärung. In: LAUFS, Adolf; UHLENBRUCK, Wilhelm, Handbuch des Arztrechts. Op. Cit., p. 509; DEUTSCH, Erwin; SPICKHOFF, Andreas. Medizinrecht. Azrtrecht, Arzneimittelrecht, Medizinproduktrecht und Transfusionsrecht. Op. Cit., pp. $280-281$.

${ }_{537}$ LAUFS, Adolf. § 63 Die Selbstbestimmungsaufklärung. In: LAUFS, Adolf; UHLENBRUCK, Wilhelm, Handbuch des Arztrechts. Op. Cit., p. 509, p. 509; DEUTSCH, Erwin; SPICKHOFF, Andreas. Medizinrecht. Azrtrecht, Arzneimittelrecht, Medizinproduktrecht und Transfusionsrecht. Op. Cit., pp. 280-281.

${ }^{538}$ LAUFS, Adolf. $§ 63$ Die Selbstbestimmungsaufklärung. In: LAUFS, Adolf; UHLENBRUCK, Wilhelm, Handbuch des Arztrechts. Op. Cit., p. 509 . 
No esclarecimento ao paciente, o médico tem sempre a liberdade de usar as expressões que entender mais oportunas, evitando, por exemplo, as palavras "carcinoma" e "câncer". ${ }^{539}$ É importante pontuar que o profissional não deve transmitir ao paciente um diagnóstico inseguro, ainda não provado, ou presumido. ${ }^{540}$

O esclarecimento do diagnóstico pode ser parte do cumprimento de um contrato, quando se tratar de um puro contrato de diagnóstico, a chamada "segunda opinião" ${ }^{541}$ Nos casos normais de tratamento, esse esclarecimento deverá ocorrer quando o conhecimento do diagnostico for essencial para a decisão do paciente, o que, geralmente, ocorre.

Essas considerações iniciais sobre o esclarecimento de diagnóstico direcionado a tratamentos de saúde na medicina tradicional são importantes para alertar que elas não podem ser facilmente transferidas para as cirurgias estéticas, já que estas têm como objetivo não a cura de uma doença, mas o embelezamento da aparência. ${ }^{542}$

${ }^{539}$ Ibidem, p. 510.

${ }_{540}^{540}$ Ibidem, p. 509.

${ }^{541}$ DEUTSCH, Erwin; SPICKHOFF, Andreas. Medizinrecht. Azrtrecht, Arzneimittelrecht, Medizinproduktrecht und Transfusionsrecht. Op. Cit., p. 280.

${ }^{542}$ LORZ, Sigrid. Arzthaftung bei Schönheitsoperationen. Op. Cit., p. 109. 
A respeito das cirurgias estéticas, duas questões são apontadas em especial: ${ }^{543}$ deve o médico esclarecer o paciente que sua aparência atual já corresponde aos padrões de beleza atuais e com isso não seria necessária uma cirurgia estética? Em segundo lugar, deve o profissional esclarecer o paciente sobre outras falhas de beleza, cuja correção o paciente até o momento não demonstrou intenção de corrigir?

Para responder essas perguntas é importante considerar que a informação a ser prestada pelo médico deve ser apropriada para influenciar o resultado do seu processo de decisão. ${ }^{544}$

LORZ $^{545}$ afasta esse tipo de informação a ser prestado pelo médico. Argumenta a autora que, ao ponderar as várias circunstâncias que permeiam as cirurgias estéticas, importa menos os ideais de beleza atuais, pois o valor da beleza é algo subjetivo e altamente pessoal. É evidente que esse sentimento pode ser influenciado pelos padrões de beleza, muitas vezes lançados pela mídia e meios de comunicação, mas decisiva é a avaliação individual da beleza própria e a insatisfação com a aparência. Prossegue a autora dizendo que o considerado por muitos como

543 Ibidem, p. 109.

544 DEUTSCH, Erwin; SPICKHOFF, Andreas. Medizinrecht. Azrtrecht, Arzneimittelrecht, Medizinproduktrecht und Transfusionsrecht. Op. Cit., p. 266 .

${ }^{545}$ Arzthaftung bei Schönheitsoperationen. Op. Cit., p. 110. 
normal e aceitável pode ser desagradável para uma determinada pessoa e incomodá-la. Além disso, existe a dificuldade prática de avaliar os ideais de beleza em vigor e compará-los com a aparência do paciente, porque o conceito de beleza não encontra uma definição consensual, apesar de inúmeras tentativas de definição. Por consequência, a informação do médico no sentido de que o paciente já corresponde aos ideais de beleza, não necessitando de qualquer cirurgia estética, não ajuda muito.

Essa situação seria diferente daquela em que o paciente dá muito valor para que sua aparência corresponda ao ideal de beleza atual e, de fato, o médico observa que já existe tal correspondência. Nessa situação, cabe ao profissional informar o paciente que talvez uma cirurgia estética não fosse necessária, sendo certo que a decisão final caberá ao paciente. ${ }^{546}$

Outra situação interessante levantada pela doutrinadora LORZ é se o médico deve esclarecer eventuais "falhas de beleza" do paciente.

Fazendo-se um paralelo com o diagnóstico em caso de doença, quando o paciente doente procura o médico, isso se dá ou porque ele deseja alguma medida de prevenção, ou porque já se manifestaram alguns sintomas, cujo diagnóstico ele deseja. Nesse passo, espera-se

${ }^{546}$ Ibidem, p. 110. 
um diagnóstico preciso diante dos conhecimentos profissionais do médico.

Entretanto, no caso de um paciente saudável, que procura um cirurgião estético para a realização de uma cirurgia, em regra, o paciente já tem ideias claras sobre quais partes do corpo pretende operar. Não se cogita que o paciente espere do médico um diagnóstico sobre eventuais "falhas de beleza"... Até porque a avaliação da beleza própria é de natureza personalíssima e o paciente não precisa, para isso, da avaliação do médico.

De outra parte, quando o paciente está contente com a aparência de outras regiões do corpo, também não existe obrigação do médico de apontar alguma "falha de beleza" que pudesse ser considerada um “desvio" dos ideais de beleza vigentes. Tal obrigação levaria à perplexidade de que o médico poderia provocar a insatisfação do paciente com partes do corpo que antes eram por ele bem aceitos e, desse modo, induzi-lo à prática de uma cirurgia estética adicional. Isso não é absolutamente tarefa do médico, pois a realização de uma cirurgia estética adicional não corresponde à vontade original do paciente, nem tampouco ao seu bem-estar, em face dos incômodos e riscos existentes em toda e qualquer intervenção, principalmente cirúrgica. $^{547}$

${ }^{547}$ Ibidem, p. 111. 
Ainda, outra questão importante no que se refere ao esclarecimento sobre o diagnóstico é a da perturbação de dismorfia corporal. Como visto no capítulo 2, item 2.3.2, a dismorfia corporal é uma perturbação psiquiátrica caracterizada por uma intensa preocupação da pessoa quanto a um defeito imaginário ou mínimo em sua aparência, levando o paciente a um forte sofrimento e restrições nas áreas social e profissional. Tais anomalias, mesmo sendo apenas imaginadas, são vivenciadas de maneira real pelo paciente, o qual procura curar através de medidas obsessivas, dentre elas a cirurgia estética.

Entretanto, como visto supra, a cirurgia não é uma medida indicada, uma vez que com frequência o paciente se sente pior do que antes de realizá-la. Pode acontecer de o paciente não ter conhecimento de ser portador dessa perturbação psíquica. Por isso, um esclarecimento adequado, que informa o paciente sobre sua doença, abre a ele a possibilidade para se decidir por uma psicoterapia ou um tratamento medicamentoso, que são os mais indicados. Esse esclarecimento é importante para que o paciente decida se, realmente, quer submeter-se a uma cirurgia estética para alcançar a beleza almejada. ${ }^{548}$

548 GRÜNDEL, Mirko. Einwilligung und Aufklärung bei psychotherapeutischen Behandlungsmassnahmen. NJW 2002, p. 2987. 
Contudo, uma obrigação do médico no sentido de esclarecer o paciente sobre a existência de uma perturbação psíquica somente existirá quando for possível a ele identificar a perturbação de dismorfobia corporal. Um indício pode ser um desejo incomum ou extravagante do paciente como, por exemplo, falha de simetria mínima e praticamente imperceptível nas mamas, até porque não se observa de forma objetiva qualquer distorção em relação aos padrões de beleza atuais. Outro indício é o paciente já ter se submetido a várias cirurgias estéticas. ${ }^{549}$

Em havendo indícios da doença de dismorfobia, é dever do médico conduzir a anamnese de forma mais profunda do que em casos padrão de cirurgia estética. Ou seja, o médico deve inquirir mais o paciente e buscar o apoio de psicólogos e/ou psiquiatras. Quando o médico conclui que o paciente sofre de dismorfobia, ele tem que comunicar o paciente sobre esse diagnóstico e esclarecê-lo que uma psicoterapia ou tratamento com medicamentos é mais indicado para alcançar a satisfação com sua aparência, ao invés de uma cirurgia estética. Nessa situação, a relação médico-paciente se expressa na parceria que deve haver entra ambos, a fim de o médico

549 Segundo LORZ, Sigrid. Arzthaftung bei Schönheitsoperationen. Op. Cit., p. 113, o Tribunal de Düsseldorf acenou que duas ou três cirurgias não configuram a perturbação de dismorfia. Mas como observado no item 2.3.2. há pessoas que se deixaram operar dezenas de vezes, o que pode caracterizar sim a dismorfia corporal. 
conseguir convencer o paciente que ele sofre dessa doença e que deve buscar outra alternativa de tratamento. ${ }^{550}$

\subsubsection{Esclarecimento sobre o procedimento}

Esse esclarecimento refere-se ao tipo, extensão e execução do procedimento. ${ }^{551} \mathrm{O}$ paciente deve ter conhecimento sobre a terapia proposta. O médico deve comunicar-lhe como a terapia se desenvolverá e qual será a evolução do seu estado de saúde, isto é, antes de receber o tratamento e após recebê-lo, diante das perspectivas dos efeitos a serem causados. ${ }^{552}$

$\mathrm{O}$ esclarecimento do processo de tratamento pode se limitar a perspectivas essenciais e a previsões como, por exemplo, a possibilidade de um dano duradouro. Somente esse esclarecimento permite ao paciente comparar as várias possibilidades e decidir junto com o médico por um tipo de tratamento ${ }^{553}$.

No caso da cirurgia estética, o médico deve comunicar ao paciente sobre a gravidade da intervenção e quais incômodos ele

${ }^{550}$ Ibidem, p. 113.

${ }^{551}$ LAUFS, Adolf. $\$ 63$ Die Selbstbestimmungsaufklärung. In: LAUFS, Adolf; UHLENBRUCK, Wilhelm, Handbuch des Arztrechts. Op. Cit., p. 281.

${ }^{552}$ DEUTSCH, Erwin; SPICKHOFF, Andreas. Medizinrecht. Azrtrecht, Arzneimittelrecht, Medizinproduktrecht und Transfusionsrecht. Op. Cit., p. 281.

${ }^{553}$ Ibidem, p. 281. 
pode esperar na vida futura. ${ }^{554} \mathrm{O}$ esclarecimento sobre o procedimento abrange a) a execução da cirurgia estética planejada, b) as alternativas possíveis de tratamento, c) as perspectivas de sucesso do tratamento e d) as restrições de saúde que ocorrem com frequência.

\subsubsection{Quanto à execução da cirurgia}

O fundamento do esclarecimento do médico sobre a execução da cirurgia planejada é deixar claro ao paciente o que vai acontecer com ele. Somente quando o paciente tem uma ideia adequada sobre o decorrer completo da cirurgia, ele pode tomar uma decisão autodeterminada. $^{555}$

Não se trata de comunicar ao paciente conhecimentos médicos profissionais, mas, sim, fornecer-lhe informação sobre a extensão, gravidade e duração da cirurgia. Devem ser esclarecidas, principalmente, todas as mudanças planejadas em relação à sua aparência. ${ }^{556}$ Em nome dos princípios da dignidade da pessoa humana e da autodeterminação, apenas o paciente pode determinar

${ }^{554}$ LORZ, Sigrid. Arzthaftung bei Schönheitsoperationen. Op. Cit., pp. 113-114.

${ }^{555}$ KATZENMEIER, Christian. Arzthaftung. Op. Cit., p. 326.

${ }^{556}$ Ibidem, p. 327. 
sua aparência. Vale aqui sua vontade como máxima suprema do agir médico (voluntas aegroti suprema lex). ${ }^{557}$

\subsubsection{Quanto às alternativas de tratamento}

A escolha pelo método de tratamento é assunto do médico, que poderá escolher o método de operação que corresponda à sua formação profissional, experiência e prática. Ele não precisa apresentar ao paciente todas as alternativas teoricamente existentes, nem explicar suas vantagens e desvantagens. ${ }^{558}$

Pode acontecer, do ponto de vista médico, que uma possibilidade de tratamento não represente uma alternativa real para o paciente, porque ela não é indicada no caso concreto, já que leva a um risco bem maior e as chances de cura são consideravelmente menores. Nesse caso fala-se que há apenas possibilidades teóricas de tratamento, sobre as quais o médico não precisa esclarecer. ${ }^{559}$

No caso de haver várias alternativas de tratamento que são igualmente indicadas, mas que levam a transtornos, riscos ou chances de sucesso essencialmente diferentes, incide o dever médico de esclarecer. Por exemplo, pode ocorrer uma alternativa entre um

${ }^{557}$ LORZ, Sigrid. Arzthaftung bei Schönheitsoperationen. Op. Cit., p. 114. ${ }^{558}$ KATZENMEIER, Christian. Arzthaftung. Op. Cit., p. 331.

${ }^{559}$ DEUTSCH, Erwin; SPICKHOFF, Andreas. Medizinrecht. Azrtrecht, Arzneimittelrecht, Medizinproduktrecht und Transfusionsrecht. Op. Cit., p. 281 . 
método conservativo e cirúrgico, entre um método que usa medicamentos e outro de exposição à radiação. ${ }^{560}$

O princípio de liberdade médica de escolha do método de tratamento vale enquanto não existir uma alternativa de tratamento autêntica para o paciente e, com isso, não for atingido seu direito de autodeterminação. Uma alternativa autêntica existirá quando entre os vários métodos, houver chances comparáveis e riscos diferentes, o que levará a uma possibilidade de escolha. Isso vale, sobretudo, para casos em que o método alternativo aponta as mesmas perspectivas de sucesso e riscos menores ou quando o método alternativo apontar os mesmos riscos, mas perspectivas de sucesso maiores. ${ }^{561}$ Quando existem duas alternativas e uma dessas tem riscos muito maiores, então, em geral, falta uma alternativa autêntica que necessita esclarecimento. ${ }^{562}$

Por isso existe uma obrigação de esclarecimento sobre métodos de tratamento alternativos com espectro de risco diferente somente no caso em que se tratar, por exemplo, de métodos de cirurgia diferentes, mas que tem, em princípio, o mesmo valor e eficiência. ${ }^{563}$

${ }^{560}$ Ibidem, p. 281.

561 KATZENMEIER, Christian. Arzthaftung. Op. Cit., p. 331; DEUTSCH, Erwin; SPICKHOFF, Andreas. Medizinrecht. Azrtrecht, Arzneimittelrecht, Medizinproduktrecht und Transfusionsrecht. Op. Cit., p. 282.

562 SPICKHOFF, Andreas. Medizinrecht. Azrtrecht, Arzneimittelrecht, Medizinproduktrecht und Transfusionsrecht. Op. Cit., p. 282.

563 Ibidem, (cit.), p. 282. 
Sobre métodos alternativos de cirurgia, deve-se esclarecer também quando nenhum dos dois métodos, no caso concreto, mostrarem vantagens claras ou quando várias possibilidades de tratamento de igual eficiência estão à disposição. ${ }^{564} \mathrm{O}$ médico não precisa esclarecer sobre métodos alternativos que ainda estão em fase de experimentação e ainda não pertencem ao padrão médico, especialmente em se tratando de métodos novos, cuja execução o cirurgião em concreto não tem experiência e conhecimento suficientes, de modo que os riscos da cirurgia são maiores. ${ }^{565}$

No caso de alternativas de tratamento, o esclarecimento não tem como pré-condição que a discussão científica sobre certos riscos já esteja concluída. Basta que vozes sérias da ciência médica indiquem os riscos ligados a determinados tratamentos. ${ }^{566} \mathrm{Em}$ se tratando de uma mudança a curto prazo de um método de cirurgia, a intervenção não é coberta pelo consentimento na cirurgia com a utilização de um outro método (o médico não pode mudar o método a curto prazo).

Também aspectos econômicos podem causar a obrigação de esclarecimento sobre alternativas de tratamento (mas só dentro dos ${ }_{565}^{564}$ Ibidem, p. 282.

${ }^{565}$ Ibidem, p. 284. Os autores comentam que métodos experimentais seriam apenas admissíveis quando o tratamento tradicional se mostrou totalmente ineficaz no caso concreto.

${ }^{566}$ DEUTSCH, Erwin; SPICKHOFF, Andreas. Medizinrecht. Azrtrecht, Arzneimittelrecht, Medizinproduktrecht und Transfusionsrecht. Op. Cit., p. 284; KATZENMEIER, Christian. Arzthaftung. Op. Cit., p. 332. 
limites que são exigidos a um médico no assim chamado "esclarecimento econômico"), quando conforme a alternativa disponível os custos a serem arcados pelo paciente são diferentes. Caso existam alternativas de tratamento, o médico pode, depois da informação sobre as alternativas, dar uma recomendação concreta. Essa recomendação não deve superar a dimensão adequada, ele vai dar conselho, mas não persuadir o paciente haja vista que sobre alternativas de tratamento não indicadas e não adequadas, não se deve esclarecer.

Diferente pode acontecer numa situação específica, por exemplo, quando se trata da alternativa de doação de sangue e substituição de sangue em relação às Testemunhas de Jeová. Também aqui o médico não pode abandonar os padrões médicos de tratamento os quais, na Alemanha, são formulados no $§ 630 \mathrm{a}, 2$ do BGB. Quando existe a ameaça de uma situação desse tipo, ainda resta ao médico, recusar talvez, antecipadamente, o tratamento. Quando a alternativa não tem sentido porque o resultado desejado (por exemplo, um diagnóstico) não pode ser obtido através dessa alternativa, não há também uma alternativa de tratamento com obrigação de esclarecimento. 


\subsubsection{Quanto às perspectivas de sucesso}

As perspectivas de sucesso do tratamento devem ser consideradas no processo de decisão do paciente, pois são de suma importância nas cirurgias estéticas, que se direcionam pela possibilidade de alcance de êxito do procedimento. ${ }^{567}$

A questão que se apresenta, agora, é saber se o desejo do paciente pode ser alcançado com o método desejado. ${ }^{568}$

Considerando que a sensibilidade estética é altamente pessoal, uma vez que não existem parâmetros fisionômicos objetivos, o médico precisa avaliar as ideias do paciente, ou seja, aquilo que na opinião dele seria um sucesso de tratamento. A decisão médica pela execução do procedimento deve se basear no desejo pessoal do paciente e naquilo que pode ser realizado dentro das possibilidades da ciência médica. ${ }^{569}$ A propósito, essa é a grande dificuldade: entender corretamente o desejo do paciente e verificar se tal desejo pode ser realizado conforme as técnicas científicas que estejam à disposição no momento da cirurgia. ${ }^{570}$

${ }^{567}$ STOCK, Christof. Die Indikation in der Wunschmedizin. Op. Cit., p. 257; LORZ, Sigrid. Arzthaftung bei Schönheitsoperationen. Op. Cit., p. 117.

${ }^{568}$ STOCK, Christof. Die Indikation in der Wunschmedizin. Op. Cit., p. 257.

${ }^{569}$ Ibidem, p. 257.

${ }^{570}$ Ibidem, p. 272. 
Em outras palavras, a questão do alcance do êxito do tratamento orienta-se pela possibilidade médica objetiva. $\mathrm{Na}$ medicina tradicional, parte-se da necessidade do tratamento conforme o diagnóstico para verificar se é ou não justificável. O método de tratamento deve estar à disposição e ser capaz de curar ou diminuir uma doença ou evitar sua piora. Na cirurgia estética, entretanto, falta a necessidade médica do procedimento, uma vez que não existe um motivo para o agir médico. Por isso deve ser verificado se a situação concreta do cliente pode ou não ser melhorada considerando um ponto de vista objetivo. ${ }^{571}$

O médico tem, por isso, obrigação de esclarecer o paciente sobre as perspectivas de sucesso que a cirurgia pode alcançar, considerando o desejo do paciente. $^{572} \mathrm{E}$, por ser dotado de conhecimento profissional e experiência, confere-se a ele uma dimensão razoável de liberdade de decisão, se a medida escolhida é adequada para alcançar o resultado, conforme os parâmetros da especialidade da medicina estética. Ademais, é isso que o paciente pode esperar: que o médico se oriente pelo padrão da ciência médica para alcançar o desejo por ele expressado. ${ }^{573}$

${ }^{571}$ Ibidem, p. 258.

${ }^{572}$ LORZ, Sigrid. Arzthaftung bei Schönheitsoperationen. Op. Cit., p. 117.

${ }^{573}$ STOCK, Christof. Die Indikation in der Wunschmedizin. Op. Cit., p. 257. 
Depois de o médico formar uma ideia sobre o processo do tratamento e do resultado a ser alcançado, deve ele transmitir ao paciente um quadro realista quanto ao êxito do tratamento para obter seu consentimento, o que pode se dar por meio de fotos e simulações de computador. ${ }^{574}$ Deve o médico, ainda, ponderar e informar ao paciente qual o melhor resultado possível a ser esperado na melhor das hipóteses e qual resultado infausto eventualmente pode ocorrer, na pior das hipóteses. ${ }^{575}$

Isso abrange, também, a possibilidade de sucesso total ou apenas parcial da cirurgia, apesar de um tratamento zeloso e correto por causa de imponderabilidades do organismo humano. Em qualquer situação, o paciente deve ter o conhecimento se o embelezamento desejado da sua aparência pode ser realizado completamente ou apenas em parte. ${ }^{576}$ A conduta do profissional será passível de responsabilidade civil quando a medida não for

${ }^{574}$ Ibidem, p. 257.

${ }^{575}$ LORZ, Sigrid. Arzthaftung bei Schönheitsoperationen. Op. Cit., p. 117.

${ }^{576}$ Ibidem, pp. 117-118. Essa questão remete ao item 3.2 do capítulo 3, quando se tratou das obrigações de meio e resultado. Conforme lá exposto, apesar da dificuldade em se delimitar essa categoria nas cirurgias estéticas, em caso de cirurgias de alta complexidade, é plausível que o sucesso total não seja possível de ser alcançado apesar de todo esforço médico empreendido. Nesse caso, poder-se-ia cogitar de um sucesso parcial. 
apropriada do ponto de vista profissional para levar ao êxito desejado pelo cliente. ${ }^{577}$

Ao lado do sucesso da cirurgia, mesmo com procedimentos adequados, muitas vezes o desejo do cliente só se realiza por meio de efeitos colaterais que caracterizam danos fisiológicos, os quais podem ser permanentes ou passageiros. Um dano passageiro e inevitável é a cirurgia em si mesma. Dano permanente é a formação de cicatrizes pós-operatórias, por exemplo, que podem ser mais ou menos duradouras, ou a perda de um osso, ${ }^{578}$ como no caso de retirada de uma costela no procedimento estético de diminuição de cintura, ou em outros órgãos, bem como cortes de nervos. ${ }^{579}$ Sobretudo a questão das cicatrizes deve ser esclarecida com detalhes: tamanho, tipo, largura, se poderão ser cobertas com roupas ou disfarçadas com penteados, se forem na cabeça. ${ }^{580}$

Ainda é necessário esclarecer o paciente sobre a durabilidade limitada de um sucesso estético. Para uma decisão autodeterminada, o paciente precisa saber se o embelezamento de sua aparência é duradouro ou se serão necessárias novas intervenções de tempos em

${ }^{577}$ STOCK, Christof. Die Indikation in der Wunschmedizin. Op. Cit., pp. 261-262.

${ }_{579}^{578}$ Ibidem, p. 118.

579 SPICKHOFF, Andreas. Medizinrecht. Azrtrecht, Arzneimittelrecht, Medizinproduktrecht und Transfusionsrecht. Op. Cit., p. 287.

${ }^{580}$ LORZ, Sigrid. Arzthaftung bei Schönheitsoperationen. Op. Cit., pp. 118-119. 
tempos, com novos riscos e incômodos. Por exemplo, para a redução de rugas através de injeção de Botulinum toxin deve haver uma repetição a cada seis meses; implantes de silicone gel devem ser trocados a cada 10 ou 15 anos. ${ }^{581}$

Ainda a respeito das perspectivas de sucesso das cirurgias estéticas, afirma-se que podem ser considerados dois tipos de sucesso, quais sejam, o direto, que se refere justamente ao embelezamento, e o indireto, que diz respeito à diminuição do sofrimento por causa da aparência própria, o fortalecimento da estima pessoal, o reconhecimento social e o progresso na carreira profissional. Todas essas são perspectivas de sucesso muitas vezes almejadas pelos pacientes de cirurgias estéticas. Fazendo-se um paralelo com a medicina tradicional, enquanto a finalidade do tratamento de cura geralmente se esgota na restituição da saúde, na cirurgia estética, por trás da finalidade direta de beleza, pode estar também as finalidades indiretas. A esse respeito, argumenta-se que o médico não é obrigado a esclarecer sobre essas perspectivas de sucesso indireto, pois elas não fazem parte da área médica e não estão no âmbito da profissionalismo e cientificidade médicos. $\mathrm{Na}$ verdade, o sucesso indireto que se pode alcançar com o êxito da

${ }^{581}$ KARCHER, Eva. Methoden und Techniken von A-Z. In TASCHEN, Angelika (Coord.). Schönheitschirurgie. Köln: Verlag, 2005. p. 312. 
cirurgia estética faz parte da esfera privada ou profissional do paciente. $^{582}$

\subsubsection{Quanto aos prejuizos para a saúde}

Além da utilidade da cirurgia estética, é de grande importância conhecer eventuais prejuízos à saúde decorrentes da cirurgia, pois somente quando o paciente conhece esses prejuízos, pode ele compará-los com o sucesso esperado e tomar uma decisão autodeterminada. Via de regra, também deve ser informada a necessidade de uma intervenção subsequente para afastar algum prejuízo sofrido pela primeira cirurgia, por exemplo, para evitar a formação de tecido de gordura decorrente de um aumento de mama. ${ }^{53}$

O médico deve, por isso, avaliar corretamente a vantagem possível, configurada na realização do resultado esperado, e a possibilidade de dano. Se o profissional avaliar esses prejuízos à saúde de forma errônea, de forma que o paciente não recebe os esclarecimentos de forma adequada, seu consentimento será

${ }^{582}$ LAUFS, Adolf. $§ 63$ Die Selbstbestimmungsaufklärung. In: LAUFS, Adolf; UHLENBRUCK, Wilhelm, Handbuch des Arztrechts. Op. Cit., p. 511.

${ }^{583}$ Ibidem, p. 287. 
considerado ineficaz e a conduta do médico poderá ser objeto de responsabilidade. ${ }^{584}$

Às vezes, o paciente manifesta um desejo que somente seria alcançado mediante um grande prejuízo à sua saúde, superando o resultado positivo esperado. Mesmo que o paciente insista na realização de seu desejo, o médico não pode colocar sua saúde sob grave risco de dano. Deve ser feita uma delimitação clara entre o desejo do paciente e os riscos admitidos. Trata-se de um campo de tensão entre voluntas e salus. ${ }^{585}$ Do ponto de vista médico, quando ele e o paciente partirem de uma medida que pode trazer dano à saúde e nenhum ou pouco efeito benéfico, essa medida é considerada contraindicada. Do ponto de vista jurídico, poderá ser hipótese de responsabilidade civil. ${ }^{586}$

Nesse passo, o conflito entre salus e voluntas leva à questão de saber quanto da autonomia do paciente o médico deve aceitar. Seria justificável uma conduta médica que se subjuga a tal exigência? Parece que não. Na qualidade de profissional, o médico não está

${ }^{584}$ STOCK, Christof. Die Indikation in der Wunschmedizin. Op. Cit., pp. 260-261.

${ }^{585}$ Ibidem, pp. 101 e 260 . Assevera o autor que por voluntas se entende a vontade ou desejo do paciente, que vem expresso por meio de sua autodeterminação; salus refere-se à saúde ou bem-estar do paciente, que pode ser proporcionado por um padrão da prática médica; é algo que se refere ao conhecimento técnico e científico do médico.

${ }^{586}$ Ibidem, p. 262. 
obrigado a ceder à vontade do paciente que almeja realizar seu desejo a qualquer custo e submetê-lo a um procedimento de grave risco à sua saúde. ${ }^{587}$

A distribuição dos papéis parece clara: somente o médico pode decidir quanto à realização ou não da intervenção por conta da sua competência profissional. Considerando que nenhuma intervenção médica pode ser executada sem o consentimento do paciente, nesse caso, mesmo diante de seu consentimento, a intervenção não deverá ser realizada se for evidentemente prejudicial. ${ }^{588}$

\subsubsection{Esclarecimento sobre os riscos}

\subsubsection{Outros aspectos}

Conquanto nos itens anteriores vários aspectos do esclarecimento sobre o risco já foram abordados, passa-se a tecer algumas derradeiras considerações.

O esclarecimento dos riscos deve transmitir informações sobre os perigos de uma intervenção médica, a saber, efeitos colaterais duradouros ou passageiros, mas que não se deixam afastar mesmo

${ }^{587}$ Ibidem, pp. 261-262.

${ }^{588}$ Ibidem, p. 260-261. 
mediante uma execução correta e cuidadosa, sem qualquer tipo de erro. Trata-se de riscos não evitáveis. ${ }^{589}$

Como já mencionado supra, as exigências do esclarecimento em relação às cirurgias estéticas são mais rigorosas, por se tratarem de intervenções que almejam somente o embelezamento da aparência. Primeiramente, há que se esclarecer sobre os riscos típicos, que são aqueles vinculados à própria intervenção, independentemente da ocorrência de qualquer complicação. ${ }^{590}$

Mas, também, os riscos atípicos, também chamados remotos, estatisticamente comprovados por terem uma baixa ocorrência, devem ser esclarecidos. Riscos atípicos são aqueles cuja ocorrência pode prejudicar gravemente a vida futura do paciente. Apesar de sua raridade na intervenção específica, podem surpreender o paciente leigo. ${ }^{591}$ Alguns afirmam que se o risco for excepcional e raro, a

${ }^{589}$ LAUFS, Adolf. §64 Die Risikoaufklärung im besonderen. In LAUFS, Adolf; UHLENBRUCK, Wilhelm. Handbuch des Arztrechts. Op. Cit., p. 512.

${ }^{590}$ LAUFS, Adolf. $\S 64$ Die Risikoaufklärung im besonderen. In LAUFS, Adolf; UHLENBRUCK, Wilhelm. Handbuch des Arztrechts. Op. Cit., p. 513; KATZENMEIER, Christian. Arzthaftung. Op. Cit., p. 329. Os autores citam como exemplos de riscos típicos, dores na nuca e garganta após a remoção de dobras sob o queixo ou em caso de redução de mama, o médico foi considerado obrigado a esclarecer não apenas sobre riscos estéticos de assimetrias, mas também sobre riscos relacionados à saúde, como complicações de circulação e dores de tensão.

${ }^{591}$ LAUFS, Adolf. $\$ 64$ Die Risikoaufklärung im besonderen. In LAUFS, Adolf; UHLENBRUCK, Wilhelm. Handbuch des Arztrechts. Op. Cit., p. 
ponto de não ter qualquer influência sobre a decisão autodeterminada do paciente, então, fica dispensado um esclarecimento a respeito deste. ${ }^{592}$

Essa posição isolada na doutrina não parece ser a mais pertinente. No caso das cirurgias estéticas, as estatísticas de risco ficam em segundo plano, quando se trata de capacitar o paciente para uma decisão de responsabilidade própria. Decisiva é a dimensão do prejuízo para sua vida, de modo que mesmo sendo muito baixa a probabilidade de dano, existe o dever de esclarecimento. $^{593}$

O médico não tem obrigação de informar o paciente sobre riscos gerais normalmente ligados às cirurgias, como trombose, embolias, dores nas lesões, infecções, sangramentos pós-operatórios, rupturas de cicatrizes, porque esses riscos são considerados como sendo de conhecimento geral. Entretanto, quando for possível identificar que o paciente não conhece esses riscos ou quando as complicações puderem se desenvolver de forma surpreendente para a pessoa leiga

513; KATZENMEIER, Christian. Arzthaftung. Op. Cit., p. 329. Como exemplos de riscos atípicos, citam-se, naquele mesmo caso de redução de mama, que uma necrose de uma ferida poderia causar a perda do mamilo, bem como perturbações na sensibilidade.

${ }^{592}$ Nesse diapasão, WAGNER, Jörg. Münchner Kommentar. Op. Cit., § 823, Rn. 704.

${ }^{593}$ LAUFS, Adolf. $\S 64$ Die Risikoaufklärung im besonderen. In LAUFS, Adolf; UHLENBRUCK, Wilhelm. Handbuch des Arztrechts. Op. Cit., p. 513; KATZENMEIER, Christian. Arzthaftung. Op. Cit., pp. 329-330. 
e forem especialmente graves para o paciente concreto, então incide o dever de esclarecimento. ${ }^{594}$ Identificar um risco como sendo geral ou específico depende da situação física concreta do paciente. Por exemplo, o risco de trombose numa cirurgia de lipoaspiração, embora em regra seja considerado basicamente um risco genérico, em circunstâncias especiais, como obesidade, pode ser mais elevado e estar especificamente vinculado à intervenção. ${ }^{595}$

O dever de esclarecimento não se reporta, evidentemente, ao risco de um dano estético ou à saúde decorrente de má execução da cirurgia. $\mathrm{O}$ paciente espera do médico um tratamento cuidadoso e correto sob o ponto de vista da ciência médica e, nesse caso, responderá o médico pelo erro de tratamento. ${ }^{596 / 597}$

${ }^{594}$ KATZENMEIER, Christian. Arzthaftung. Op. Cit., p. 330.

${ }^{595}$ LORZ, S., Arzthaftung bei Schönheitsoperationen (cit.), p. 123.

${ }^{596}$ LAUFS, A dolf. $\$ 62$ Die therapeutische Aufklärung. In LAUFS, Adolf; UHLENBRUCK, Wilhelm. Handbuch des Arztrechts. Op. Cit., p. 501; DEUTSCH, Erwin; SPICKHOFF, Andreas. Medizinrecht. Azrtrecht, Arzneimittelrecht, Medizinproduktrecht und Transfusionsrecht. Op. Cit., p. 270.

597 A respeito de erro de tratamento, cf. MAFFEIS MOREIRA, Marta Rodrigues. Contribuição ao Estudo da Responsabilidade Civil do Médico à Luz do Direito Romano. Op. Cit., pp. 91-113; 147-161. 
Por fim, se o risco do procedimento planejado já for conhecido pelo paciente, de forma que ele não necessita de esclarecimento a respeito, então este pode deixar de ser dado. ${ }^{598}$

\subsubsection{A suspeita de risco}

LORZ $^{599}$ chama a atenção para um aspecto importante que surge no dever de esclarecer sobre os riscos, que se refere à mera suspeita de risco. A característica de um risco é sua possibilidade de realização. Ao lado dos danos certos e do risco de dano, existe uma terceira categoria, que é a da suspeita de risco.

$\mathrm{Na}$ suspeita de risco, prossegue a autora, é incerto se a cirurgia já o traz consigo, ou seja, se existe uma relação de causalidade entre cirurgia e dano. Aqui, há mera presunção de que o risco possa ocorrer, pois não existem provas científicas. Por isso, é duvidoso se existe um dever médico de esclarecimento sobre essa suspeita de risco. ${ }^{600}$

O exemplo dado para se questionar sobre esse dever de esclarecimento é do silicone gel usado nos implantes de mama que se deu no início dos anos 1990, sobretudo nos Estados Unidos, onde

598 DEUTSCH, Erwin; SPICKHOFF, Andreas. Medizinrecht. Azrtrecht, Arzneimittelrecht, Medizinproduktrecht und Transfusionsrecht. Op. Cit., p. 299.

599 Arzthaftung bei Schönheitsoperationen. Op. Cit., p. 124.

${ }^{600}$ Ibidem, p. 124. 
surgiram doenças do sistema imunológico em diversas mulheres após a cirurgia de implante de silicone nas mamas. Após esse fato, cerca de doze mil mulheres ajuizaram ações contra a empresa líder Dow Corning, que foi obrigada a pagar indenização às mulheres prejudicadas num montante de 4,2 bilhões de dólares. Em abril de 1992, a Food and Drug Administration (FDA) tirou dos Estados Unidos a permissão para cirurgias estéticas de implantes de mama com silicone gel, muito embora os fabricantes de implantes de silicone gel não tenham podido provar a inofensividade do produto. Permitiu-se, então, o uso de determinados implantes de silicone gel em ramos de estudos clínicos controlados apenas para reconstrução de mama em caso de amputação por tumor. Apenas em abril de 2005 a $F D A$ retirou a proibição e permitiu cirurgias estéticas com implantes de silicone gel sob rígida regulamentação. ${ }^{601}$

Diferentemente, na Alemanha, àquela época, esses implantes continuaram a ser admitidos, pois o Bundesinstituts für Arzneimittel und Medizinprodukte (BfArM) não decretou uma proibição nesse caso. $^{602}$

${ }^{601}$ LORZ, Sigrid. Arzthaftung bei Schönheitsoperationen. Op. Cit., pp. 124-125.

${ }^{602}$ Ibidem, p. 125. A autora comenta que esse entendimento foi compartilhado pela Comissão da nião Européia, pois até o ano de 2007, data de seu trabalho, não pode ser provado um processo científico de causa e efeito entre o implante de silicone e as doenças do sistema imunológico. 
Diante desse contexto, LORZ ${ }^{603}$ defende que a suspeita de risco também deve ser informada pelo médico para que o paciente possa tomar uma decisão com responsabilidade e autodeterminada.

Embora as pesquisas científicas não tenham demonstrado algo sobre a possibilidade real da ocorrência de um dano, ainda que remota, a suspeita também deve ser informada, pois capacita o paciente no seu processo de decisão. Dessa forma, sendo amplamente esclarecido, o paciente poderá decidir com responsabilidade própria. ${ }^{604}$

DEUTSCH e SPICKHOFF sustentam que a jurisprudência diverge nesse ponto. No caso de risco de um efeito corporal nocivo causado pelo silicone na cirurgia de aumento de mama, há julgamento no sentido de que tal risco não deve ser esclarecido, quando não houver confirmação científica a respeito, sendo apenas duvidoso. Porém, há outros julgamentos defendendo que, em casos de medidas médicas não indicadas, exige-se um esclarecimento bastante rigoroso e impiedoso, razão pela qual haveria, sim, o dever de informar. ${ }^{605}$

${ }^{603}$ Ibidem, p. 128.

${ }^{604}$ Ibidem, pp. 127-128.

${ }^{605}$ Medizinrecht. Azrtrecht, Arzneimittelrecht, Medizinproduktrecht und Transfusionsrecht. Op. Cit., pp. 295-297. 


\subsubsection{Outros tipos de esclarecimento}

\subsubsection{Quanto aos efeitos dos medicamentos}

Quando o médico aplica o medicamento no paciente, como no caso de uma infusão, ele está obrigado ao esclarecimento. Mas em se tratado de medicamento que o próprio paciente deve tomar, o dever de esclarecer recai tanto sobre o médico como sobre o fabricante. $\mathrm{O}$ médico deve esclarecer o paciente principalmente sobre os efeitos graves e frequentes, além daquelas que constam na bula. Mais importante que a frequência das complicações é a extensão dos possíveis transtornos. ${ }^{606}$

\subsubsection{Quanto a não realização do tratamento}

O médico deve uma informação maior sobre o risco de não se realizar o tratamento. Por exemplo, a ameaça de um problema cardíaco, caso o paciente deixe de fazer a diálise, ou paciente que se recusa a fazer um raio-X após a quebra da mão, o médico tem que informar de forma abrangente sobre o risco dessa recusa. Quando uma cesariana é indicada e a grávida a recusa, então o médico tem

${ }^{606}$ Ibidem, pp. 287-288. 
que indicar claramente os riscos relacionados a essa decisão da gestante ou parturiente. ${ }^{607}$

Esse tipo de esclarecimento tem importância nos casos de tratamento de cura da medicina tradicional, quando a ausência do tratamento puder causar prejuízos à saúde do paciente. No caso das cirurgias estéticas, ausente sua necessidade do ponto de vista médico, e considerando todas as características mencionadas supra no item 2.1 do capítulo 2 sobre a medicina de desejo, não se vislumbra maior importância em aprofundar esse tema.

\subsubsection{Quanto à qualidade}

Nos últimos tempos, aumentou-se a discussão sobre esse tipo de esclarecimento. Ou seja, se existe um dever de informar sobre tratamentos que poderiam ser executados com qualidade superior por outro médico ou clínica. ${ }^{608}$

Não há dúvida de que um tratamento executado abaixo do standard médico é passível de responsabilidade civil. Reconhece-se, também, que o parâmetro de cuidado objetivo pode levar a

${ }^{607}$ Ibidem, pp. 288-289.

${ }^{608}$ Ibidem, p. 291. Os autores afirmam que esse tipo de esclarecimento tem sido admitido pela jurisprudência alemã de forma ainda muito tímida. 
diferentes standards de responsabilidade dentre as diferentes categorias de clínicas e especialistas. ${ }^{609}$

Duvidoso é, apenas, se o médico que está executando o tratamento, pode ser responsabilizado pela omissão de uma referência e a correspondente informação no sentido de que a execução do tratamento poderia ter uma melhor qualidade em outro local. Esse mais alto nível pode se referir à qualificação pessoal do cirurgião ou do equipamento disponível. $\mathrm{O}$ fundamento desse esclarecimento é o direito de autodeterminação do paciente em relação à sua integridade corporal e sua concretização, pois a realização do tratamento em outro local pode significar maiores chances de cura ou de êxito no tratamento. ${ }^{610}$

\subsection{Realização do esclarecimento}

\subsubsection{A conversa de esclarecimento}

$\mathrm{O}$ esclarecimento deve ocorrer numa conversa individual com o paciente, oportunidade em que o médico deve esclarecer o paciente

${ }^{609}$ Sobre standard médico e responsabilidade civil, cf. MAFFEIS MOREIRA, Marta Rodrigues. Contribuição ao Estudo da Responsabilidade Civil do Médico à luz do Direito Romano. Op. Cit. pp. 102-113.

${ }^{610}$ DEUTSCH, Erwin; SPICKHOFF, Andreas. Medizinrecht. Azrtrecht, Arzneimittelrecht, Medizinproduktrecht und Transfusionsrecht. Op. Cit., p. 291; LORZ, Sigrid. Arzthaftung bei Schönheitsoperationen. Op. Cit., pp. 128-133. 
de forma objetiva, clara e em linguagem acessível à capacidade intelectual dele, considerando que normalmente se trata de pessoa leiga. A conversa de esclarecimento deve capacitar o paciente a tomar uma decisão autônoma e consciente. ${ }^{611}$

É certo que em algumas situações não há necessidade de novo e exaustivo esclarecimento por parte do médico como, por exemplo, no caso de exame de sangue repetitivo, ou informar apenas algum aspecto diferente que não tenha sido informado anteriormente. Mais importante é aproveitar a conversa de esclarecimento para dar oportunidade ao paciente de dizer se possui alguma dúvida. ${ }^{612}$

Sustenta a doutrina ${ }^{613}$ que o esclarecimento deve ser compreensível para o paciente. Em caso de pacientes estrangeiros, apesar das dificuldades de compressão, ele deve ter uma ideia adequada da gravidade e da amplitude de risco concreto. Nesse caso, em não havendo tempo para se buscar um tradutor, pode-se recorrer

611 DEUTSCH, Erwin; SPICKHOFF, Andreas. Medizinrecht. Azrtrecht, Arzneimittelrecht, Medizinproduktrecht und Transfusionsrecht. Op. Cit., pp. 266-267; KAZTENMEIER, Christian. Arzthaftung. Op. Cit., pp. 324, 327.

${ }^{612}$ DEUTSCH, Erwin; SPICKHOFF, Andreas. Medizinrecht. Azrtrecht, Arzneimittelrecht, Medizinproduktrecht und Transfusionsrecht. Op. Cit., p. 267.

${ }^{613}$ Ibidem, pp. 300-301; STEFFEN, Erich; DRESSLER, Wolf-Dieter. Arzthaftungsrecht. Op. Cit., p. 205. 
à linguagem corporal por gestos. Mas para isso deve haver uma urgência. ${ }^{614}$

Nem sempre é fácil para o médico avaliar se o paciente entendeu o esclarecimento dado. Isso não vale somente para pacientes de língua estrangeira, mas também em casos de pacientes com dificuldade de audição, de raciocínio e diferença de linguagem regional. Se o paciente recebe passivamente um esclarecimento que foi dado de forma correta sem sinalizar que não o entendeu, não há uma violação do dever de esclarecer, a não ser que o médico tivesse condições de perceber claramente essa falta de compreensão. ${ }^{615}$ Ademais, por meio da conversa de esclarecimento, o médico tem a oportunidade de sondar o horizonte de compreensão do paciente, identificar suas expectativas e medos. Esse é o momento para expor ao paciente todos os aspectos mencionados supra. ${ }^{616}$

Quando a intervenção não é urgente, sustenta a doutrina que deve ser dado ao paciente tempo para reflexão. ${ }^{617}$ Esse é o caso das cirurgias estéticas, em que não há urgência na sua execução. ${ }^{618}$

${ }^{614}$ DEUTSCH, Erwin; SPICKHOFF, Andreas. Medizinrecht. Azrtrecht, Arzneimittelrecht, Medizinproduktrecht und Transfusionsrecht. Op. Cit., pp. 301-302.

${ }^{615}$ Ibidem, p. 303.

${ }^{616}$ Ibidem, pp. 300-301.

617 LAUFS, Adolf. \$66 Die Art und Weise der Aufklärung. Aufklärungsformulare. In LAUFS, Adolf; UHLENBRUCK, Wilhelm. Handbuch des Arztrechts. Op. Cit., pp. 528-529; DEUTSCH, Erwin; 
Nesse sentido, a Lei de Cirurgias e Tratamentos Estéticos da Áustria ${ }^{619}$ estabelece, em seu §7. (5), que um tratamento ou operação numa pessoa que já completou 16 anos, mas ainda não completou 18 deve ser executado, pelo menos, depois de quatro semanas após ter sido dado o consentimento. Esse prazo é considerado prazo para reflexão, justamente para dar oportunidade ao paciente de ponderar todos os aspectos que o médico lhe esclareceu e decidir se realmente deseja se submeter a uma intervenção estética. Por isso mesmo, não se admite o chamado "esclarecimento de véspera" em caso de cirurgia estética, sobretudo quando o paciente se confrontar pela primeira vez com consequências significativas como, por exemplo, o aumento visível de cicatrizes ou possíveis danos duradouros à saúde. ${ }^{620}$

SPICKHOFF, Andreas. Medizinrecht. Azrtrecht, Arzneimittelrecht, Medizinproduktrecht und Transfusionsrecht. Op. Cit., pp. 310-311.

${ }^{618}$ DEUTSCH, Erwin; SPICKHOFF, Andreas. Medizinrecht. Azrtrecht, Arzneimittelrecht, Medizinproduktrecht und Transfusionsrecht. Op. Cit., pp. 310-311.

${ }^{619} \mathrm{Cf}$. anexo $\mathrm{V}$.

${ }^{620}$ SPICKHOFF, Andreas. Die Eingriffsindikation im Wandel der Zeit. Op. Cit., pp. 15-16; DEUTSCH, Erwin; SPICKHOFF, Andreas. Medizinrecht. Azrtrecht, Arzneimittelrecht, Medizinproduktrecht und Transfusionsrecht. Op. Cit.,, pp. 310-311. 


\subsubsection{Documentação do esclarecimento}

A conversa entre médico e paciente deve ser livre de qualquer formalismo, não havendo necessidade da forma escrita. É verdade que documentos escritos e assinados pelo paciente servem de prova para o médico demonstrar que cumpriu sua obrigação contratual, dando-lhe maior segurança. Mas, ainda que o médico utilize documentos escritos para esclarecer o paciente, esta não pode ser a única forma de esclarecer, sendo fundamental a conversa de esclarecimento. $^{621}$

É desejável que o consentimento seja expresso nessa oportunidade, após o médico esclarecer todos os aspectos pertinentes à cirurgia estética. Nada impede, entretanto, que seja marcada mais uma consulta para novos esclarecimentos, se necessário. Contudo, alguns doutrinadores sustentam que não podem ser feitas exigências exageradas em relação às provas do cumprimento do dever de informar. ${ }^{622}$

${ }^{621}$ DEUTSCH, Erwin; SPICKHOFF, Andreas. Medizinrecht. Azrtrecht, Arzneimittelrecht, Medizinproduktrecht und Transfusionsrecht. Op. Cit., pp. 307-309 e 313; LAUFS, Adolf. §66 Die Art und Weise der Aufklärung. Aufsklärungsformulare. In LAUFS, Adolf; UHLENBRUCK, Wilhelm. Handbuch des Arztrechts. Op. Cit., p. 531.

${ }^{622}$ DEUTSCH, Erwin; SPICKHOFF, Andreas. Medizinrecht. Azrtrecht, Arzneimittelrecht, Medizinproduktrecht und Transfusionsrecht. Op. Cit., p. 313. Observam os autores que se faltar um consentimento por escrito, a presunção de que o esclarecimento foi dado milita a favor do médico, quando 
Documentos escritos e assinados pelo paciente dando seu consentimento são úteis como meio de prova de que o esclarecimento foi dado de forma adequada. Porém, além do aspecto da utilidade como meio de prova, o Código Civil alemão, em seu §630f (2) (1) estabelece que a documentação de consentimento e esclarecimento é necessária ao cumprimento da obrigação contratual. Se não houver uma documentação suficiente, presume-se que o consentimento e o esclarecimento não aconteceram. A documentação é essencial no protocolo de responsabilidade civil do médico. ${ }^{623}$

Contudo, mesmo assim, entende-se que o médico pode provar que tanto o esclarecimento quanto o consentimento se deram de forma adequada, não somente com a ajuda de um formulário, mas por outros meios de prova. Cabe ao médico o ônus da prova de que ele deu ao paciente a possibilidade de fazer outras perguntas e que explicou o formulário de esclarecimento em seus aspectos gerais. $\mathrm{O}$ que não se admite é a realização do esclarecimento apenas por meio de formulários, pois eles somente são um indício de que aconteceu uma conversa de esclarecimento. ${ }^{624}$

ele puder provar que o esclarecimento foi dado de forma adequada em outros casos semelhantes.

${ }^{623}$ Ibidem, p. 313.

${ }^{624}$ DEUTSCH, Erwin; SPICKHOFF, Andreas. Medizinrecht. Azrtrecht, Arzneimittelrecht, Medizinproduktrecht und Transfusionsrecht. Op. Cit., 
Aliás, se fosse admitido que o paciente restasse esclarecido apenas por meio de formulários e demais materiais de esclarecimento, como estatísticas de graus de complicação, porcentagens de prognósticos, fotos de doenças ou modelos - no caso das cirurgias estéticas - então, seria possível "programar" o resultado do consentimento, que seria tratado como um cálculo quase matemático e o paciente seria reduzido a um robô. ${ }^{625}$

Quanto ao modelo de formulário, existem aqui duas possibilidades. ${ }^{626} \mathrm{O}$ formulário abstrato, que contém o consentimento do paciente para uma cirurgia, representa, de resto, um blanckett (papel em branco) no qual o médico preenche a intervenção e seus riscos. Esse documento tem a vantagem de ser preenchido em relação ao paciente em concreto e, exatamente por causa da sua abstração inicial, documenta um cuidado específico para o paciente individual. ${ }^{627}$

p. 313; LAUFS, Adolf. §66 Die Art und Weise der Aufklärung. Aufsklärungsformulare. In LAUFS, Adolf; UHLENBRUCK, Wilhelm. Handbuch des Arztrechts. Op. Cit., pp. 531-532.

${ }^{625}$ ROTHÄRMEL, Sonja. Einwilligung, Veto, Mitbestimmung. BadenBaden: Nomos, 2004. p. 205.

${ }^{626}$ DEUTSCH, Erwin; SPICKHOFF, Andreas. Medizinrecht. Azrtrecht, Arzneimittelrecht, Medizinproduktrecht und Transfusionsrecht. Op. Cit., p. 313; LAUFS, Adolf. \$66 Die Art und Weise der Aufklärung. Aufsklärungsformulare. In LAUFS, Adolf; UHLENBRUCK, Wilhelm. Handbuch des Arztrechts. Op. Cit., pp. 531-532.

${ }^{627}$ DEUTSCH, Erwin; SPICKHOFF, Andreas. Medizinrecht. Azrtrecht, Arzneimittelrecht, Medizinproduktrecht und Transfusionsrecht. Op. Cit., 
De outro lado, o formulário concreto é uma brochura préformulada, configurada para o tratamento específico, que vem a ser entregue ao paciente, o qual assina um exemplar para finalidade de prova e recebe outro que muitas vezes fica nos seus pertences. Esse último tipo de formulário deveria somente servir para a orientação do médico e apoio do esclarecimento oral. Entretanto, a sua entrega é problemática: corre-se o perigo de se anular sua finalidade de prova, uma vez que é produzida de forma unilateral. ${ }^{628}$

A utilização dessas brochuras pode conter para alguns pacientes o esclarecimento necessário, mas, para outros, pode significar ou um exagero ou uma informação completamente insuficiente. Além disso, outra crítica que se faz a esses esclarecimentos préformulados é o perigo de falta de organização: pode ocorrer de a brochura não ser entregue pelo médico, mas pela secretária ou enfermeira antes de qualquer conversa entre as partes. Com isso, não atingir sua finalidade de realmente esclarecer e possibilitar ao paciente uma decisão autodeterminada. Ou, ainda, podem ser

p. 314; LAUFS, Adolf. §66 Die Art und Weise der Aufklärung. Aufsklärungsformulare. In LAUFS, Adolf; UHLENBRUCK, Wilhelm. Handbuch des Arztrechts. Op. Cit., pp. 531-532.

${ }_{228}$ DEUTSCH, Erwin; SPICKHOFF, Andreas. Medizinrecht. Azrtrecht, Arzneimittelrecht, Medizinproduktrecht und Transfusionsrecht. Op. Cit., p. 314; LAUFS, Adolf. §66 Die Art und Weise der Aufklärung. Aufsklärungsformulare. In LAUFS, Adolf; UHLENBRUCK, Wilhelm. Handbuch des Arztrechts. Op. Cit., pp. 531-532. 
entregues formulários falsos e, por causa da confusão, o esclarecimento foi falho. Ademais, também se aponta como problemático que um esclarecimento de risco possa ser ineficaz e enganoso quando forem entregues ao paciente folhas de informações que não estão em conformidade com a intervenção planejada; ou quando houver lacunas no formulário pode-se inferir que também houve lacunas na conversa de esclarecimento. ${ }^{629}$

$\mathrm{Na}$ conversa de esclarecimento é possível que o paciente manifeste seu desejo de não ser esclarecido. Trata-se de um direito do paciente, o de renunciar às informações sobre risco de uma intervenção planejada. Nessa hipótese, o paciente considera o médico uma autoridade essencial, cujas orientações apenas deseja obedecer. Encontra-se na esfera de autodeterminação do paciente o seu desejo de depositar toda sua confiança nas mãos do médico.

Entretanto, não se admite uma renúncia total e geral. O paciente deve ser informado sobre a necessidade da intervenção, seu tipo, extensão e riscos. Ele pode renunciar apenas a detalhes do procedimento e dos riscos. Da mesma forma, nega-se ao médico tomar um consentimento genérico do paciente, devendo esclarecê-lo

${ }^{629}$ DEUTSCH, Erwin; SPICKHOFF, Andreas. Medizinrecht. Azrtrecht, Arzneimittelrecht, Medizinproduktrecht und Transfusionsrecht. Op. Cit., p. 314; LAUFS, Adolf. §66 Die Art und Weise der Aufklärung. Aufsklärungsformulare. In LAUFS, Adolf; UHLENBRUCK, Wilhelm. Handbuch des Arztrechts. Op. Cit., pp. 531-532. 
também quando o risco da intervenção sai da esfera de previsão de um leigo sensato, ou mesmo quando esse risco puder ser previsto e reconhecido do ponto de vista médico.

Quando o paciente quiser que sua renúncia ao esclarecimento tenha validade, deve deixar expresso que se deixa conduzir por confiança pelo médico.

Excepcionalmente, por motivos terapêuticos, o médico pode ser dispensado do dever de esclarecer. Isso ocorre quando houver a possibilidade de prejuízos ao paciente, que pode sofrer significativos danos psíquicos e corporais. Nesse caso, afirma-se que o esclarecimento é contraindicado. Em nenhum outro momento o princípio voluntas aut salus aegroti suprema lex se apresenta tão urgente. Duvidosos, entretanto, são os pressupostos para que essa dispensa ao esclarecimento seja reconhecida, pois a doutrina não é unânime a respeito e o Bundesgerichtshof já julgou que tais pressupostos devem ser muito rigorosos e limitados ${ }^{630}$.

Diante desse contexto, a melhor posição é não admitir a renúncia ao esclarecimento nas cirurgias estéticas. Considerando que a doutrina majoritária defende um maior rigorismo no dever de 630 LAUFS, Adolf. $\$ 66$ Die Art und Weise der Aufklärung. Aufsklärungsformulare. In LAUFS, Adolf; UHLENBRUCK, Wilhelm. Handbuch des Arztrechts. Op. Cit., pp. 531-532. 
esclarecimento que, como já exposto, deve ser rígido e impiedoso, reconhecer ao paciente uma renúncia a tal direito, seria contraditório com os aspectos da cirurgia estética como medicina de desejo e, portanto, como uma intervenção desejada.

\subsubsection{Pessoas envolvidas no esclarecimento}

Em primeiro lugar quem está obrigado a esclarecer é o médico escolhido pelo paciente para executar a cirurgia estética. Ao lado dele podem participar outros profissionais, como o anestesista. Cada um deles é competente para esclarecer sobre seu âmbito de atuação. Uma transferência da obrigação de esclarecer a outro médico somente é possível quando este dispuser do conhecimento especial necessário. Eventuais falhas no esclarecimento serão atribuídas ao médico competente para dá-las diante de sua posição de garante assumida pela obrigação de esclarecer. ${ }^{631}$

O esclarecimento é considerado uma atividade que faz parte do campo profissional médico, de modo que a transferência para cuidadores e demais profissionais da saúde que não sejam médicos

631 LAUFS, Adolf. $\$ 66$ Die Art und Weise der Aufklärung. Aufsklärungsformulare. In LAUFS, Adolf; UHLENBRUCK, Wilhelm. Handbuch des Arztrechts. Op. Cit., p. 527; KATZENMEIER, Christian. Artzhaftung. Op. Cit., p. 327; DEUTSCH, Erwin; SPICKHOFF, Andreas. Medizinrecht. Azrtrecht, Arzneimittelrecht, Medizinproduktrecht und Transfusionsrecht. Op. Cit., pp. 305-306; LORZ, Sigrid. Arzthaftung bei Schönheitsoperationen. Op. Cit., pp. 133-134. 
não é admissível. Via de regra, somente o profissional médico dispõe do conhecimento técnico necessário para transmitir todos os aspectos que circundam o esclarecimento e responder as dúvidas postas pelo paciente. ${ }^{632}$

Do lado do paciente o esclarecimento e o consentimento sofrem nuances nas hipóteses de o paciente ser maior ou menor de idade. Considerando que o presente trabalho se ocupa das intervenções médicas, consistentes nas cirurgias estéticas em menores, a esse respeito passa-se a discorrer nos capítulos seguintes.

632 KATZENMEIER, Christian. Artzhaftung. Op. Cit., pp. 337-338; DEUTSCH, Erwin; SPICKHOFF, Andreas. Medizinrecht. Azrtrecht, Arzneimittelrecht, Medizinproduktrecht und Transfusionsrecht. Op. Cit., pp. 305-306. 


\section{CAPÍTULO 5 - CONSENTIMENTO}

\subsection{Aspectos genéricos sobre consentimento e vontade}

Na tradição romano-germânica, a vontade ocupa um lugar de destaque no campo do direito privado. Isso se deve ao princípio da autonomia da vontade, bastante caro ao direito privado tanto que, no direito francês, o consentimento é colocado como a primeira das quatro condições de validade dos contratos. ${ }^{633}$

Segundo o conceito trazido pelos dicionários, consentimento é aquiescência, aprovação. É concordância de ideias, acordo, consenso. ${ }^{634}$ Assim, a palavra consentimento, em seu sentido básico e objetivo, importa aprovação, declaração ou manifestação de vontade, o que não se diferencia de um sentido jurídico.

Consentimento, no direito privado, está intimamente ligado à capacidade do sujeito-parte de uma relação jurídica obrigacional.

${ }^{633}$ AZEVEDO, Antônio Junqueira de. Negócio Jurídico: existência, validade e eficácia. 4 ed. São Paulo: Saraiva, 2010. p. 76.

${ }^{634}$ CALDAS AULETE, Francisco Júlio. Verbete Consentimento. In Dicionário contemporâneo da língua portuguesa. v. 1. 3 ed. Lisboa: Sociedade Industrial de Tipografia, 1948. p. 639. 
Isto porque, segundo LORENZETTI, ${ }^{635}$ a capacidade é uma condição para que uma determinada pessoa emita uma declaração de vontade válida e, portanto, é um pressuposto do consentimento, pois sem capacidade não há consentimento. A capacidade a que o autor se refere é a capacidade de agir, ou negocial, que é a capacidade de manifestar vontade que entre no mundo jurídico como negócio jurídico. ${ }^{636}$

Conforme MELLO, ${ }^{637}$ a exteriorização consciente de vontade por um indivíduo é o cerne do suporte fático de um ato jurídico, a qual apresenta um caráter finalístico, ou seja, tem como objeto a obtenção de um determinado resultado possível, protegido pelo ordenamento jurídico ou não proibido por ele. Nesse sentido, o consentimento é um elemento constitutivo do ato jurídico, pois se trata de uma conduta que resulta na exteriorização da vontade do indivíduo o qual, de uma forma simples, declara-a ou a manifesta, constituindo, assim, uma conduta relevante aos olhos da ordem jurídica. Nessa linha de raciocínio, a vontade deve ser manifestada com o intuito de realizar aquela conduta juridicamente relevante.

${ }^{635}$ Tratado de los contratos. t. 1. 2. ed. Buenos Aires: Rubinzal-Culzoni, 2007. p. 233.

${ }^{636}$ PONTES DE MIRANDA, Francisco Cavalcanti. Tratado de Direito Privado: Parte Geral - Introdução. Pessoas Físicas e Jurídicas. t. 1. 3 ed. Rio de Janeiro: Borsoi, 1970. p. 157.

${ }^{637}$ Teoria do fato jurídico: plano da existência. Op. Cit. p. 143. 
Nas palavras de PONTES DE MIRANDA, ${ }^{638}$ o conteúdo da vontade é, na ordinariedade dos casos, o que constitui o suporte fáctico sôbre o qual a regra jurídica incide.

No entanto, para o Direito, a vontade deve ser exteriorizada para que produza efeitos, o que é, de certa forma óbvio, pois deve ser, de algum modo, apreendida por alguém. Assim, a declaração de vontade, segundo BETTI, ${ }^{639}$ caracteriza-se como um fenômeno em que o pensamento sai de dentro do indivíduo, objetiva-se a vontade dando-lhe vida própria de modo a torná-la comunicável e apreensível no mundo social. Vê-se, então, que a declaração de vontade deve ser destinada a outras pessoas e isso é o que caracteriza, suficientemente, a natureza da declaração de vontade. ${ }^{640}$ Nesse sentido, em se tratando do direito contratual, LARENZ ${ }^{641}$ afirma que não é decisiva a chamada vontade "interna", não declarada, das partes contratuais, mas sim a vontade objetivada que se manifesta na declaração, cujo conteúdo, como significado imputável da declaração, pode ser objetivamente determinado.

${ }^{638}$ Tratado de Direito Privado: Parte Geral - Introdução. Pessoas Físicas e Jurídicas. t. 1. Op. Cit., p. 81.

${ }^{639}$ Teoria generale del negozio giuridico. 2 ed. Torino: UTET, 1960. p. 12.

${ }^{640}$ BETTI, Emilio. Teoria generale del negozio giuridico. Op. Cit., p. 13.

${ }^{641}$ Die Begründung von Schuldverhältnissen durch sozialtypisches. Op. Cit., p. 59. 


\subsection{Princípios constitucionais do consentimento}

Segundo KOPPERNOCK ${ }^{642}$, os direitos gerais da personalidade são deduzidos a partir de dois princípios norteadores que são o princípio da dignidade da pessoa humana ${ }^{643}$ e o princípio do livre desenvolvimento da personalidade, que também se traduz no princípio da liberdade de agir, desde que não se viole direito de outrem, a ordem pública e os bons costumes. ${ }^{644}$

O princípio da liberdade geral de agir garante que toda pessoa recorra a ele em caso de intervenção em sua liberdade pelo poder público. Esse princípio abarca o direito de não ser molestado por uma pressão estatal prejudicial, que não esteja fundamentada na ordem constitucional. Ou seja, proíbe-se intervenção do Estado que não seja lícita juridicamente. Sua proteção vale em qualquer

${ }^{642}$ KOPPENOCK, Martin. Das Grundrecht auf bioetische Selbstbestimmung. Nomos: Baden-Baden, 1997. p.18.

${ }^{643}$ Constituição Federal alemã: Art. 1(1) Die Würde des Menschen ist unantastbar. Na Constituição Federal brasileira o princípio da dignidade da pessoa humana vem descrito no art. $1^{\circ}$, III.

${ }^{644}$ Constituição Federal alemã: Art. 2(1) Jeder hat das Recht auf die freie Entfaltung seiner Persönlichkeit, soweit er nicht die Rechte anderer verletzt und nicht gegen die verfassungsmäßige Ordnung oder das Sittengesetz verstößt. 
circunstância, qualquer que seja o peso da interferência na formação da personalidade. ${ }^{645}$

Ambos os princípios devem ser relacionados, como aliás o faz a jurisprudência alemã, embora faça referência apenas à dignidade da pessoa humana, conforme pontua o autor. Nesse sentido, a dignidade da pessoa humana serve de fundamento para a formação da personalidade da pessoa, entendida como um ser intelectual e moral, que se vale da liberdade para se desenvolver e se autodeterminar. Atribui-se à proteção da integridade da pessoa humana em seu âmbito intelectual-moral um alto e especial valor. ${ }^{646}$

\subsubsection{Dignidade da pessoa humana ${ }^{647}$}

A dignidade da pessoa humana surge como um valor bastante importante à ordem jurídica mundial no período que se sucedeu à II Guerra Mundial. Isto porque o regime nazista na Alemanha, responsável por mostrar o Estado como um grande violador de direitos fundamentais, foi marcado por aquilo que se pode chamar

645 KOPPENOCK, Martin. Das Grundrecht auf bioetische Selbstbestimmung. Op. Cit., p. 28.

${ }^{646}$ Ibidem, p. 18.

${ }^{647} \mathrm{O}$ presente trabalho não tem por escopo aprofundar esse tema, que é bastante vasto e por si só merecedor de um amplo debate. Aqui serão trazidas apenas algumas considerações que se julgam importantes para fundamentar outros aspectos dos fundamentos constitucionais do consentimento nas intervenções médicas. 
de descartabilidade da pessoa humana, levando a um saldo terrível de milhões de mortes. ${ }^{648}$ Nesse contexto pós guerra, os Estados se organizam num movimento de internacionalização dos direitos humanos, como significado de sua reconstrução. ${ }^{649}$ Esse movimento resultou, em 1948, na promulgação da Declaração Universal dos Direitos Humanos, trazendo já no primeiro dos consideranda do preâmbulo a dignidade da pessoa humana como fundamento da justiça, liberdade e paz. A mesma declaração, em seu artigo $1^{\circ}$, consagra tal princípio como direito de todo o ser humano. In verbis:

Considerando que o reconhecimento da dignidade inerente a todos os membros da família humana e de seus direitos iguais e inalienáveis é o fundamento da liberdade, da justiça e da paz no mundo [...] Artigo I. Todos os seres humanos nascem livres e iguais em dignidade e direitos. São dotados de razão e consciência e devem agir em relação uns aos outros com espírito de fraternidade.

No âmbito do direito interno, o princípio da dignidade da pessoa humana, como se pode extrair da leitura do art. $1^{\circ}$, III, da Constituição Federal de 1988, é um dos valores fundantes do ordenamento jurídico brasileiro e do próprio Estado Brasileiro,

${ }^{648}$ PIOVESAN, Flávia. Direitos humanos, o princípio da dignidade humana e a Constituição de 1988. In PIOVESAN, Flávia; GARCIA, Márcia (org.). Doutrinas essenciais: Direitos humanos. v. 1. São Paulo: Revista dos Tribunais, 2011. p. 307.

${ }^{649}$ Ibidem, p. 307. 
constituído como Estado Democrático de Direito. ${ }^{650} \mathrm{O}$ Constituinte dá à dignidade da pessoa humana um status de valor essencial, o que reveste a Constituição Federal de 1988 com uma roupagem de característica especial. $^{651}$

No entanto, vê-se que tal princípio, tão importante na forma de Estado eleita pelo Constituinte, é usado, não raras vezes, de forma indiscriminada, levando à sua vulgarização e, de certa forma, seu esvaziamento. A jurisprudência brasileira, tal qual aponta DOLINGER, ${ }^{652}$ resta influenciada por uma falsa aplicação da dignidade humana e, dessa forma, ao invés de fortalecer os direitos humanos, acaba por feri-los. Seu uso ambíguo pode se referir ora ao direito da pessoa que sofreu alguma violação jurídica e ora ao aspecto independente de direitos subjetivos e interesses. ${ }^{653}$ Fenômeno parecido ocorre com os direitos fundamentais. A

${ }^{650}$ Art. 1. ${ }^{\text {o }}$ A República Federativa do Brasil, formada pela união indissolúvel dos Estados e Municípios e do Distrito Federal, constitui-se em Estado Democrático de Direito e tem como fundamentos: (...)III - a dignidade da pessoa humana.

651 PIOVESAN, Flávia. Direitos humanos e o direito constitucional internacional. 9 ed. São Paulo: Saraiva, 2008. p. 28.

${ }^{652}$ Dignidade: o mais antigo valor da humanidade. In PIOVESAN, Flávia; GARCIA, Márcia (org.). Doutrinas essenciais: Direitos humanos. v. 1. São Paulo: Revista dos Tribunais, 2011. p. 496.

653 KOPPERNOCK, Martin. Das Grundrecht auf bioethische Selbstbestimmung. Op. Cit., p. 18. 
proliferação destes, como defende FERREIRA FILHO, ${ }^{654}$ desvaloriza os verdadeiros direitos fundamentais $\mathrm{e}$, consequentemente, leva à perda de seu sentido essencial que, segundo o referido autor, é ser expressão da eminente dignidade humana.

É importante ressaltar que a pessoa nunca pode ser vista com um olhar teleológico, ou seja considerada como um meio para se alcançar um determinado fim; deve, sim, ser considerada e tratada como um fim em si mesmo. No entanto, não apenas é nisso em que consiste a dignidade da pessoa, como destaca COMPARATO. ${ }^{655}$ Ela também brota do fato de que, pela sua vontade racional, só a pessoa vive em condições de autonomia, isto é, como ser capaz de guiar-se pelas leis que ela própria edita.

Quanto à natureza da dignidade humana frente à ordem jurídica implementada pela Constituição Federal, é importante destacar que a dignidade da pessoa humana foi eleita pelo constituinte originário de 1988 como um princípio, tal como se ressaltou quando da referência ao art. $1^{\circ}$, III, da Carta de 1988. Assim, faz-se necessário buscar um conceito para a palavra princípio, ainda que não seja este o escopo

${ }^{654}$ Princípios fundamentais do direito constitucional, São Paulo: Saraiva, 2009. p. 91.

${ }^{655}$ A afirmação histórica dos direitos humanos. 8 ed. São Paulo: Saraiva, 2013. p. 34. 
principal do presente estudo. Entre nós, ÁVILA ${ }^{656}$ assim define os princípios:

(...) são normas imediatamente finalísticas, primariamente prospectivas e com pretensão de complementariedade e de parcialidade, para cuja aplicação se demanda uma avaliação da correlação entre o estado de coisas a ser promovido e os efeitos decorrentes da conduta havida como necessária à sua promoção.

Segundo VIEIRA DE ANDRADE, ${ }^{657}$ o princípio da dignidade da pessoa humana é o limitador em caráter absoluto ${ }^{658}$ e a própria base do conteúdo essencial dos direitos fundamentais. Ou seja, havendo princípios e valores que deem uma justificativa para a restrição eventual de alguns direitos, a dignidade da pessoa humana assim como a ideia de liberdade individual funcionam como limites do poder de restrição que o Estado detém. ${ }^{659}$

${ }^{656}$ Teoria dos princípios: Da definição à aplicação dos princípios jurídicos. 4 ed. São Paulo: Malheiros, 2005. p. 70.

${ }^{657}$ Os direitos fundamentais na constituição portuguesa de 1976. 3 ed. Coimbra: Almedina, 2004. p. 306.

${ }^{658} \mathrm{O}$ autor refere-se ao art. 18, $\mathrm{n}^{\circ} .3$ da Constituição Portuguesa de 1976, in verbis: As leis restritivas de direitos, liberdades e garantias têm de revestir carácter geral e abstracto e não podem ter efeito retroactivo nem diminuir a extensão e o alcance do conteúdo essencial dos preceitos constitucionais.

${ }^{659}$ Note-se que o Constituinte Português de 1976 também elegeu a dignidade da pessoa humana como valor-base daquele Estado. Nos termos do art. $1^{\circ}$, Portugal é uma República soberana, baseada na dignidade da pessoa humana e na vontade popular e empenhada na construção de uma sociedade livre, justa e solidária. 
V. A. SILVA, ${ }^{660}$ no entanto, traz uma crítica ao ponto de vista defendido pelo referido doutrinador português. Segundo o autor pátrio, se a dignidade da pessoa humana for o conteúdo essencial absoluto de todos os direitos fundamentais, apenas o referido princípio apresentaria um conteúdo essencial absoluto, enquanto os demais direitos seriam dotados de um conteúdo relativo. Ainda, haveria, segundo suas palavras, uma hipertrofia da dignidade e da consequente absolutização de todos os direitos fundamentais. ${ }^{661}$

Não há dúvidas, porém, que o princípio da dignidade da pessoa humana não é um princípio isolado. Ao contrário, gera reflexos em vários outros direitos fundamentais, como a liberdade de expressão, direito fundamental que integra os chamados direitos fundamentais de primeira geração, ou liberdades públicas, ${ }^{662}$ servindo-lhes de elemento limitador e balizador. Nesse sentido, verbis gratia, extraise do famoso Caso Ellwanger, julgado pelo Supremo Tribunal Federal em 2003:

As liberdades públicas não são incondicionais, por isso devem ser exercidas de maneira harmônica, observados os limites definidos

${ }^{660}$ Direitos fundamentais: Conteúdo essencial, restrições e eficácia. 2 ed. São Paulo: Malheiros, 2014. p. 192.

${ }^{661}$ SILVA, Virgílio Afonso. Direitos fundamentais: Conteúdo essencial, restrições e eficácia. Op. Cit., p. 193.

${ }^{662}$ FERREIRA FILHO, Manoel Gonçalves. Princípios fundamentais do direito constitucional. Op. Cit., p. 92. 
na própria Constituição Federal. $O$ preceito fundamental da liberdade de expressão não consagra o "direito à incitação ao racismo", dado que um direito fundamental não pode constituir-se em salvaguarda de condutas ilícitas, como sucede com os delitos contra a honra. Prevalência dos princípios da dignidade da pessoa humana e da igualdade jurídica. (grifo nosso) ${ }^{663}$

A dignidade da pessoa humana, segundo J. A. SILVA, ${ }^{664}$ é um valor supremo que atrai o conteúdo de todos os direitos fundamentais do homem, desde o direito à vida. É um valor de tamanha importância na Constituição de 1988, que dele decorrem o comando para que a ordem econômica garanta a todos uma existência digna, ${ }^{665}$ que a ordem social promova a promova a justiça social, conforme o art. 193, ${ }^{666}$ tudo não como enunciados meramente formais, mas, nas palavras do referido autor, como indicadores do conteúdo normativo eficaz da dignidade da pessoa humana.

${ }^{663}$ STF, Pleno. HC 82.424-2. rel. Min. Moreira Alves, rel. p. acórdão Min. Maurício Corrêa. j. 17 set. 2003. P. DJ. 19 mar. 2004.

${ }^{664}$ Curso de Direito Constitucional Positivo. 38 ed. São Paulo: Malheiros, 2015. p. 107.

${ }^{665}$ Art. 170. A ordem econômica, fundada na valorização do trabalho humano e na livre iniciativa, tem por fim assegurar a todos existência digna, conforme os ditames da justiça social [...] (grifo nosso).

${ }^{666}$ Art. 193. A ordem social tem como base o primado do trabalho, e como objetivo o bem-estar e a justiça sociais. 
Para PIOVESAN, ${ }^{667}$ o status de extrema precedência que se dá à dignidade humana, na óptica jurídica, trata-se se uma de uma resposta à crise experimentada pelo positivismo jurídico, decorrente da derrota dos regimes totalitários na Alemanha e na Itália na década de 1940. Tais regimes se firmaram nos referidos Estados com base no ordenamento jurídico e geraram um rastro de destruição e mortes que são conhecidos por todos, como a morte de milhões de judeus, ciganos, pessoas com deficiência física, dentre outros grupos sociais vítimas de tais políticas de Estado.

Nesse sentido, ALEXY ${ }^{668}$ defende a existência de duas normas da dignidade humana, sendo que, na sua concepção, há um princípio da dignidade humana e uma regra da dignidade humana, sendo que o conteúdo desta é determinado por uma relação de preferência entre o referido princípio e os demais princípios quando é sopesado em relação a estes. Desse modo, a regra é que se mostra absoluta, não o princípio, uma vez que não há necessidade de se limitar a regra quando de alguma relação de preferência relevante, em virtude da abertura semântica que uma regra apresenta. Assim, em algumas condições, o princípio em questão se mostrará com precedência ${ }^{667}$ Direitos humanos, o princípio da dignidade humana e a Constituição de 1988. Op. Cit., p. 313.

${ }^{668}$ Theorie der grundrechte, 1986. Trad. esp. C. B. Pulido. Teoría de los derechos fundamentales. 2 ed. Madrid: Centro de Estudios Políticos y Constitucionales, 2014. pp. 88-89. 
frente a outros princípios. Isto, no entanto, não lhe dá natureza absoluta, mas, apenas, faz com que nessas condições haja razões de ordem jurídica e constitucional tão fortes, quase totalmente inafastáveis que justifiquem a prevalência do princípio da dignidade da pessoa humana.

Segundo HESSE, ${ }^{669}$ o homem não é partícula isolada em uma sociedade e, muito menos, desprovido da realidade de massa moderna. No entanto, recebe o status de pessoa e assim deve ser entendido, com um valor próprio indisponível, destinado ao livre desenvolvimento. Também, simultaneamente, deve ser entendido numa dimensão coletiva, como membro de diversas instituições da sociedade contemporânea, tais quais comunidades, de matrimônio, de igrejas, grupos sociais e políticos, não em último lugar, também do Estado, com isso, situado nas relações inter-humanas mais diversas, essencialmente moldado por essas relações em sua individualidade concreta, mas também chamado a co-configurar responsavelmente a convivência humana.

Em conclusão, entende-se que a dignidade da pessoa humana é, além de tudo que se expôs supra, condição para o desenvolvimento

${ }^{669}$ Grundzüge des Verfassungsrechts der Bundesrepublik Deutschland, 1995. Trad. port. L. A. Heck. Elementos de Direito Constitucional da República Federal Alemã. Porto Alegre: Sergio Antonio Fabris, 1998. p. 110. 
do Estado de Direito, modelo escolhido pelo constituinte de $1988 .^{670}$ O Estado de Direito é guardião de direitos, pois existe para servir às pessoas, assegurando-lhe o pleno exercício de seus direitos subjetivos e liberdades. ${ }^{671}$ Assim, como defende GOFFREDO TELLES JÚNIOR ${ }^{672}$ ainda que sem citar expressamente o termo dignidade da pessoa, os Estados somente progridem, somente se aprimoram, quando tendem a satisfazer ansiedades do coração humano, assegurando a fruição de valores espirituais, de que a importância da vida individual depende.

\subsubsection{Autodeterminação e Autonomia}

\subsubsection{Considerações iniciais}

Autodeterminação e autonomia são dois conceitos que se misturam na prática diante de suas semelhanças. Doutrinadores observam que o direito de autodeterminação amparado

${ }^{670}$ Art. $1^{\circ}$ A República Federativa do Brasil, formada pela união indissolúvel dos Estados e Municípios e do Distrito Federal, constitui-se em Estado Democrático de Direito e tem como fundamentos (...). (grifo nosso)

${ }^{671}$ TELLES JÚNIOR, Goffredo. Carta aos Brasileiros. In PIOVESAN, Flávia; GARCIA, Márcia (org.). Doutrinas essenciais: Direitos humanos. v. 1. São Paulo: Revista dos Tribunais, 2011. p. 1115.

${ }^{672}$ Carta aos Brasileiros. Op. Cit., p. 1119. 
juridicamente corresponde muitas vezes ao princípio bioético de autonomia do paciente. ${ }^{673}$

Os dicionários trazem autonomia como sinônimo de independência. ${ }^{674}$ Assim, autônomo é aquele que se governa de acordo com suas próprias leis. ${ }^{675}$ A palavra autonomia deriva do

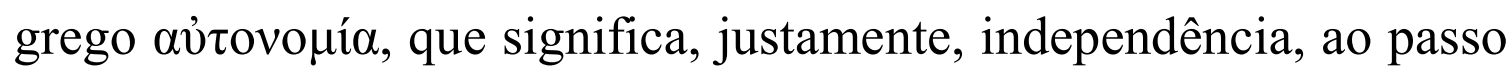
que av̉ióvouos (autônomo) enseja aquele que age livremente, de acordo com suas próprias vontades. ${ }^{676 / 677}$

O significado de autonomia do paciente está marcado em sua essência pelo entendimento de Kant ${ }^{678}$, mesmo que não seja objetivo desse trabalho estudar sua obra. Para ele, a dignidade humana encontra assento na autonomia e deve ser atribuida a todos os

${ }^{673}$ GAUL, Charly. Kann Autonomie "fremdvertreten"werden?Philosophische, medizinische und juristische Überlegungen zur Einstellung lebenserhaltender Therapie bei Schwerstkranken unter Wahrung der Autonomie der Betroffenen. Ethik in der Medizin. n. 14, pp. 160/165, 2002; GUILLOD, Olivier. Die Entscheidungsfreiheit des Patienten. Einige rechtliche Aspekte. In KERN, Gerson; MAZAL, Wolfgang (Coord.). Die Grenzen der Selbstbestimmung. Wien: Verlag, 2003. pp. 27/30.

${ }^{674}$ CALDAS AULETE, Francisco Júlio. Verbete Autonomia. In Dicionário contemporâneo da língua portuguesa. v. 1. Op. Cit., p. 340.

675 MORAES SILVA. Verbete Autônomo. Diccionario da língua portugueza. v. 1. Op. Cit., p. 288.

${ }^{676}$ MALHADAS, Daisi, CONSOLIN DEZOTTI, Maria Celeste, MOURA NEVES, Maria Helena de (et. al.). Dicionário grego-português. Cotia: Ateliê Editorial, 2006. p. 148.

${ }^{677}$ Nesse sentido, Heródoto, Hist. 1, 96.

678 MICHEL, Margot. Rechte von Kindern in medizinischen Heilbehandlungen. Basel: Helbing Lichtenhahn, 2009. pp. 12-13. 
agentes morais. ${ }^{679}$ Ressalte-se, também, que a lei fundamental alemã e o Tribunal Constitucional daquele país acolheram a noção kantiana de dignidade. $^{680}$

O filósofo parte do sentido etimológico da palavra como "regulamentação própria" (auto + nomos) e define autonomia como autodeterminação da vontade moral por meio da pura razão prática, ${ }^{681}$ a qual é uma verdadeira condição necessária de atribuição de dignidade, segundo o citado filósofo prussiano. ${ }^{682}$ Kant não concorda com a comum definição de liberdade como a inexistência de barreiras que impeçam ou dificultem o indivíduo de fazer o que bem entende. Segundo ele, quando nós procuramos aquilo que nos causa prazer ou fugimos da dor, não o fazemos agindo de maneira livre, mas, como animais que somos, agimos como escravos de nossas paixões e desejos. Explica-se: toda vez que assim agimos, o fazemos voltados a uma finalidade que está além de nós, ou seja, de acordo com uma determinação exterior. Para Kant,

${ }^{679}$ ALVES, Gláucia Correa R. Barcelos. Sobre a dignidade da pessoa. In MARTINS-COSTA, Judith (org.). A reconstrução do direito privado. São Paulo: Revista dos Tribunais, 2002. p. 222.

${ }^{680}$ Ibidem, p. 223.

681 BARTMANN, Peter. Selbstbestimmung und Selbsvertretung im Gesundheitswesen. In BARTMANN, Peter; HÜBNER, Ingolf (Coord.). Patientenselbsbestimmung. Paradigmenwechsel und Herausforderung in Gesundheitswesen. Neukirchen-Vluyn, 2002. pp. 13-15.

${ }^{682}$ ALVES, Gláucia Correa R. Barcelos. Sobre a dignidade da pessoa. Op. Cit., p. 227. 
a autonomia é requisito para que o indivíduo aja de maneira livre. Assim, para se agir de tal forma, o indivíduo age conforme uma lei que ele mesmo se impõe e não como animal, ou seja, sem a determinação de fatores externos, tais quais as forças da natureza ou convenções sociais. Kant coloca o conceito de autonomia em confronto com seu antônimo, heteronomia, a qual leva o indivíduo a agir de acordo com determinações feitas por elementos ou forças exteriores a ele. Dessa forma, a ausência de autonomia em determinada ação isenta a imputação de uma responsabilidade moral. Desse modo, para Kant, agir de maneira autônoma não enseja a eleição dos melhores meios para se atingir um determinado fim, de acordo com uma visão teleológica. Ao contrário, é escolher o fim em $s i$, o que é próprio dos seres humanos. ${ }^{683}$

Entretanto, no contexto do direito médico, a concepção de autonomia de Kant sofre críticas. Isso porque ela surge como um processo puramente cognitivo, independente das emoções e sensações e estabelece exigências tão altas que quase todos os pacientes adultos poderiam ser considerados não autônomos e, por

${ }^{683}$ SANDEL, Michael. Justice, 2009. Trad. port. H. Matias e M. A. Máximo. Justiça: O que é fazer a coisa certa. 6 ed. Rio de Janeiro: Civilização Brasileira, 2012. pp. 140-142. A respeito de um entendimento abrangente sobre autonomia para Kant como fundamento do direito de autodeterminação, cf. KERN, Gerson. Vernunft - Gewissen - Heilbehandlung. In KERN, Gerson; WOLFGANG, Mazal (Coord.). Die Grenzen der Selbstbestimmung. Op. Cit. 
consequência, incapazes de consentimento. ${ }^{684}$ Ademais, um entendimento de autonomia puramente racional também negligencia a vivência e o ambiente psicossocial em que está inserido o paciente e, como será abordado adiante, decisões sobre tratamentos médicos não são tomadas de forma puramente racionais, mas são impregnadas por elementos emotivos. ${ }^{685}$

Como muitos conceitos éticos, SIMON e NAUCK observam que autonomia é um conceito polissêmico. ${ }^{686}$ Segundo os autores, como conceito descritivo, autonomia se refere à capacidade para a autodeterminação moral, ou seja, a capacidade de decidir e agir com base nos valores e convicções morais próprios. Essa capacidade é uma característica do ser humano que merece respeito, ainda quando a capacidade de autodeterminação for restrita em certas situações ou até mesmo anulada. Disso decorre um segundo significado de autonomia, que segundo os mesmos autores, é um significado normativo. Isto é, o direito de cada ser humano ser reconhecido como um ser capaz de autodeterminação moral. Esse respeito mútuo implica em duas consequências: de um lado, a proibição de obstruir

684 ALDERSON, Priscila. Die Autonomie des Kindes - über die Selbstbestimmungsfähigkeit von Kindern in der Medizin. Op. Cit., pp. 28, 30-32.

${ }^{685}$ MICHEL, Margot. Rechte von Kindern in medizinischen Heilbehandlungen. Op. Cit., p. 14.

${ }^{686}$ Patientenautonomie in der klinischen Praxis. In WIESEMANN, Claudia; SIMON, Alfred. Patientenautonomie. Münster: Mentis, 2013, p. 169. 
decisões e ações autodeterminadas das outras pessoas e, de outro, a exigência de incentivar essas decisões, fornecendo, um esclarecimento adequado.

\subsubsection{Autonomia e autodeterminação nas intervenções} médicas

No centro dos direitos da personalidade do paciente está o direito de autodeterminação como o direito de a pessoa decidir sobre intervenções em seu próprio corpo, após ser adequadamente

esclarecida e prestar seu consentimento. ${ }^{687}$ Conforme se expôs no item 2.1 do capítulo 2 (relação médico-paciente), no passado a conduta médica tinha por referência o princípio da beneficência e a autonomia do paciente era considerada um aspecto secundário. Essa perspectiva se alterou profundamente nas últimas décadas, quando a autonomia do paciente passou a ser valorizada e ocupar lugar de destaque na relação médico-paciente.

De acordo com o princípio do paternalismo, a integridade corporal é tratada como um valor em si mesmo, que deve ser protegida mesmo contra a vontade de seu titular, quando este toma

687 MICHEL, Margot. Rechte von Kindern in medizinischen Heilbehandlungen. Op. Cit., p. 11; DUTTGE. Gunnar. Patientenautonomie und Einwilligungsfähigkeit. In WIESEMANN, Claudia; SIMON, Alfred. Patientenautonomie. Münster: Mentis, 2013. p. 77. 
uma decisão que contraria sua saúde do ponto de vista objetivo. ${ }^{68} \mathrm{O}$ princípio da beneficência, que faz parte da essência do paternalismo, estabelece ao médico uma regra de conduta no sentido de promover o bem-estar do paciente e não lhe causar nenhum dano, conforme o ensinamento fundamental salus aegroti suprema lex et primum non nocere. $^{689}$

Ao contrário, o princípio da autonomia considera como prioritário o direito do paciente de decidir sobre intervenções em seu corpo de forma livre, ${ }^{690}$ estando em primeiro plano o direito de autodeterminação. ${ }^{691}$ Sustenta a doutrina dominante que o direito de autodeterminação forma a essência dos direitos dos pacientes capazes de consentir e protege a dignidade e valor da pessoa. ${ }^{692}$

688 MICHEL, Margot. Rechte von Kindern in medizinischen Heilbehandlungen. Op. Cit., pp. 12-13.

689 BEAUCHAMP, Tom L.; CHILDRESS, James F. Principles of Biomedical Ethics. 5 ed. New York: Oxford University Press, 2001, pp. 176177; HILDT, Elisabeth. Prädikative genetische Diagnostik bei Kindern im Konflikt zwischen Autonomie und Fürsorge. In WIESEMANN, Claudia; DÖRRIES, Andrea; WOLFSLAST, Gabriele; SIMON, Alfred (coord.). Das Kind als Patient. Ethische Konflikte zwischen Kindeswohl und Kindeswille. Op. Cit., pp. 234-236.

${ }^{690}$ MICHEL, Margot. Rechte von Kindern in medizinischen Heilbehandlungen. Op. Cit.,, p. 12.

${ }^{691}$ GAUL, Charly. Kann Autonomie "fremdvertreten" werden? Op. Cit., pp. 160 e 165.

${ }_{692}$ BUCHER, Eugen. Die Ausübung der Persönlichkeitsrecht, insbesondere: Die Persönlichkeitsrechte des Patienten als Schranken der ärztlichen Tätigkeit. Zürich: Diss, 1956. p. 125, WIEGAND, Wolfgang. Die Aufklärungpflicht und die Folgen ihrer Verletzung. In HONSELL, Heinrich 
No contexto de tratamento médico, vários doutrinadores apresentam suas concepções sobre o direito de autodeterminação. Ora é definido como liberdade de disposição sobre o bem jurídico da integridade corporal, seja física, como psíquica, ${ }^{693}$ ora como liberdade de disposição sobre o próprio corpo e a própria vida. ${ }^{694}$ Ainda, é visto como o direito do paciente em decidir de forma livre sobre toda intervenção em seu próprio corpo, seja de natureza diagnóstica ou terapêutica, ${ }^{695}$ ou também o direito de aceitar ou recusar um determinado procedimento, inclusive quando este for essencial para garantir o direito à vida. ${ }^{696}$

(Coord.). Handbuch des Arztrechts. Zürich: Schulthess Polygraphischer Verlag 1994. p. 119-121.

${ }^{693}$ WIEGAND, Wolfgang. Die Aufklärungpflicht und die Folgen ihrer Verletzung. Op. Cit., pp. 119-121.

${ }^{694}$ SCHWEIZER, Rainer J. Kommentierung von Art. 8, Art. 10 und Art. 13 BV. In: EHRENZELLER, Bernard; MASTRONARDI, Philippe; SCHWEIZER, Rainer J.; VALLERDER, Klaus A. (Coord.). Die schweizerische Bundesverfassung. Kommentar. 2 ed. Zürich: Genf, 2008. n. 26.

${ }^{695}$ RAMER, Paul; RENNHARD, Josef. Patientenrecht. Ein Ratgeber aus der Beobachterpraxis. 2 ed. Zürich: Beobachter-Buchverlag, 1998. p. 32; WIEGAND, Wolfgang. Die Aufklärungpflicht und die Folgen ihrer Verletzung. Op. Cit., pp. 119-121; DUTTGE, Gunnar. Patientenautonomie und Einwilligungsfähigkeit. Op. Cit., p. 78.

${ }^{696}$ ARZT, Gunther. Die Aufklärungspflicht des Arztes aus strafrechtlicher Sicht, In WIEGAND, Wolfgang (Coord.). Arzt und Recht. Bern: BJTP, 1985. pp. 49-51. 
Diante desse panorama, vê-se que o direito de autodeterminação abrange dois conteúdos essenciais: a liberdade de decisão e a liberdade de disposição. ${ }^{697}$

O Código Civil brasileiro também seguiu essa linha de pensamento, ao dispor em seu art. 15 que: "Ninguém pode ser constrangido a submeter-se, com risco de vida, a tratamento médico ou a intervenção cirúrgica".

Porém, é certo que o legislador faltou com certa precisão técnica, pois o tratamento médico ou a intervenção cirúrgica devem sempre contar com o consentimento informado do paciente. Caso o paciente, após ser corretamente informado, não quiser se submeter a uma intervenção médica, essa recusa deverá ser respeitada em reconhecimento à sua dignidade humana ${ }^{698}$.

Segundo BEAUCHAMP e CHILDRESS a renúncia do paciente de sua incolumidade corporal tem como pressuposto uma medida suficiente de liberdade de disposição interna e externa. Sob o ponto de vista externo, essa liberdade é demonstrada por meio de uma

${ }^{697}$ RIEDER, Heike. Genetische Untersuchungen und Persönlichkeitsrecht. Eine Auseinandersetzung mit dem Bundesgesetz über genetische Untersuchungen beim Menschen im medizinischen Bereich, München: Genf, 2006. pp. 54-56.

698 TEPEDINO, Gustavo; BARBOZA, Heloísa Helena; BODIN DE MORAES, Maria Celina. Código Civil Interpretado conforme a Constituição da República. Vol. I. Parte Geral e Obrigações. 2 ed., Rio de Janeiro: Renovar, 2007, pp. 42-43. 
decisão voluntária, isto é, ausente de qualquer pressão externa. Sob o ponto de vista interno, pressupõe a necessária competência como fundamento de um entendimento abrangente da situação e de todas as possíveis consequências da decisão encontrada. ${ }^{699}$

$\mathrm{Na}$ atualidade, observa-se que a crescente importância do direito de autodeterminação dos pacientes apresenta novos desafios, que podem levar a situações complicadas na prática, como, por exemplo, a recusa do paciente a um tratamento indicado pelo médico como de necessidade vital. $^{700}$ A solução desses conflitos exige uma ponderação zelosa entre autonomia e beneficência na situação concreta, além de levar em consideração uma alta medida de competência ética e comunicativa. ${ }^{701}$

Uma discussão que se observa na doutrina é aquela que se refere a decisões tomadas por pacientes que parecem ser contrárias ao seu bem-estar. Num primeiro momento, surge a dúvida se tais decisões realmente são fruto de uma reflexão crítica e autodeterminada, de modo a questionar se elas não seriam um indício de ausência ou limitação da autodeterminação do paciente. ${ }^{702}$

${ }^{699}$ Principles of Biomedical Ethics. Op. Cit., p. 178.

700 SIMON, Alfred; NAUCK, Friedemann. Patientenautonomie in der klinischen Praxis. In WIESEMANN, Claudia; SIMON, Alfred. Patientenautonomie. Op. Cit., pp. 168-169.

${ }^{701}$ Ibidem, p. 168.

${ }^{702}$ Ibidem, pp. 168-169. 
DWORKIN $^{703}$ abre essa discussão, questionando se é possível que pessoas tomem decisões contra seus interesses fundamentais e ainda assim sejam consideradas autônomas. ${ }^{704}$ Para responder a essa questão, o filósofo considera como objetivo da autonomia, segundo um critério comprobatório, o respeito das decisões tomadas pelas pessoas ainda que contrárias aos seus interesses fundamentais. Em outras palavras, deve-se reconhecer um direito amplo e geral de autonomia, pelo respeito das decisões que as pessoas tomam por si mesmas, ainda que se considere que agem de forma imprudente. Isso seria melhor ao invés de interferir na esfera privada de cada um, julgando que a pessoa está errada e não decidiu de forma a proteger seu interesse fundamental. Segundo esse critério, cada pessoa sabe o que para ela representam seus interesses fundamentais e, em última instância, seu bem-estar.

Entretanto, DWORKIN defende que o objetivo da autonomia deve ser independente da afirmação de que uma pessoa sabe o que é melhor para ela e que age sempre em prol de seu bem-estar. $\mathrm{Na}$ verdade, para ele, o objetivo da autonomia deve ser a integridade.

${ }^{703}$ Life's dominion: An Argument about Abortion, Euthanasia, and Individual Freedom. New York: Vintage, 1994. pp. 222-229.

${ }^{704} \mathrm{O}$ autor cita os exemplos das Testemunhas de Jeová que se recusam a receber uma transfusão de sangue que pode lhe salvar a vida por causa de suas convicções religiosas; ou do paciente que somente pode ser salvo se amputar as pernas, mas afirma preferir morrer a ficar sem as pernas. 
Segundo essa concepção, a autonomia deriva da capacidade das pessoas em expressar seu caráter, com seus valores, compromissos, convicções e interesses críticos e experienciais. Ou seja, a autonomia se expressa no reconhecimento de que cada pessoa é responsável pela configuração de vida que pretende formar, conforme sua personalidade e seus próprios valores. ${ }^{705}$

Prossegue o filósofo afirmando que essa concepção de autonomia não pressupõe que as pessoas capazes decidam sempre de maneira coerente e tenham uma vida estruturada e baseada sempre na reflexão, de modo a sempre tomarem as melhores decisões. Ao contrário, reconhece que essas pessoas fazem escolhas que representam insegurança, fraqueza, capricho ou mera irracionalidade. Há uma diferença entre o objetivo geral da autonomia e suas consequências para uma determinada pessoa numa situação específica. Assim, a autonomia estimula e protege as decisões tomadas pelas pessoas em conformidade com seu sistema de valores e convicções pessoais. É verdade que talvez o principal valor dessa capacidade somente se concretize quando as decisões forem congruentes com o valor do bem-estar da pessoa, no que se diz também serem autênticas. Porém, esse direito de autonomia deve

${ }^{705}$ Nos exemplos mencionados supra, respeitam-se as decisões da pessoa morrer ao invés de amputar as pernas ou sofrer uma transfusão de sangue porque se reconhece que ela age conforme seu sistema pessoal de valores. 
ser protegido em qualquer circunstância, garantindo que as pessoas realizem seu objetivo da maneira que julgarem melhor.

Para ilustrar essa concepção de autonomia DWORKIN toma a situação das pessoas com deficiência mental. A análise feita para auferir se essas pessoas têm ou não direito à autonomia depende do grau de sua capacidade geral para conduzir sua vida dessa maneira. Em caso de paciente com demência moderada, comparam-se as escolhas feitas agora em que se desenvolve a doença, com aquelas tomadas quando estava são. Se houver coerência com o caráter geral de sua vida anterior ou se forem eventualmente incoerentes e autodestrutivas como seriam as escolhas de pessoas consideradas plenamente competentes, então esse paciente ainda consegue se comportar conforme seu sistema de valores e, dessa forma, deve-se reconhecer que tem direito à autonomia. Mas, de outro lado, se suas escolhas se contradizem entre si, seja de modo sistemático ou aleatório, então se pode concluir que esse paciente não age mais de forma coerente e perdeu a capacidade que a autonomia lhe confere, que é conduzir sua vida de maneira responsável. Nessa hipótese, ele perdeu o direito de decidir contrariamente a seus interesses, e não se pode permitir que uma pessoa agisse dessa forma em nome da proteção de uma capacidade que ela não tem mais. 
Vários doutrinadores comungam desse entendimento apresentado por DWORKIN. Sustentam que o paciente dotado de autodeterminação não está obrigado a uma decisão racional do ponto de vista objetivo, mas é livre para decidir em harmonia com seu sistema de valores, mesmo que sua decisão aos olhos do médico e de terceiros não pareça razoável e contrarie seus interesses em relação à sua saúde. $^{706}$

Isso ocorre porque nem sempre os valores do paciente coincidirão com o critério profissional do médico e conduzirão às mesmas decisões sobre questões relacionadas à saúde ou doença. Isso porque esses valores são resultado da configuração da personalidade que cada pessoa desenha para si, considerando suas convicções e interesses. ${ }^{707}$ É até mesmo possível que as pessoas mudem seus próprios valores e concepções. ${ }^{708}$

Decisivo, para o bem-estar do paciente, é sua vontade e não aquilo que o médico indica ou propõe em interesse do paciente, o que significa que este pode até mesmo recusar um tratamento ${ }^{706}$ BECHER, Eugen. Der Persönlichkeitsschutz beim ärztlichen Handeln. In WIEGAND, Wolfgang (Coord.). Arzt und Recht. Op. Cit., pp. 124-126; WIEGAND, Wolfgang. Die Aufklärungpflicht und die Folgen ihrer Verletzung. Op. Cit., pp, 119 e 171.

707 MICHEL, Margot. Rechte von Kindern in medizinischen Heilbehandlungen. Op. Cit., p. 12.

708 SIMON, Alfred; NAUCK, Friedemann. Patientenautonomie in der klinischen Praxis. In WIESEMANN, Claudia; SIMON, Alfred. Patientenautonomie. Op. Cit., p. 168. 
sugerido. Trata-se da primazia do princípio da vontade do paciente e, por consequência, de seu direito de autodeterminação. ${ }^{709} \mathrm{~A}$ vontade, aqui, deve ser entendida na capacidade da pessoa conduzir sua própria vida, e empregar seus conhecimentos de forma livre de influências externas, tais como pressão, violência, fraude ou qualquer outra forma de convencimento sobre seu discernimento. ${ }^{710}$

Quando se mantém de maneira rígida a exigência de autenticidade, corre-se o risco de refutar precipitadamente decisões não convencionais como não autodeterminadas. Uma possível solução para esse impasse poderia ser a discussão com o paciente de decisões aparentemente incoerentes, ou seja, refletir com ele de maneira crítica acerca de tais decisões, mas depois aceitá-las como autodeterminadas, independentemente do resultado dessa reflexão. $^{711}$

Nesse contexto, a autonomia deriva da capacidade da pessoa se posicionar conforme suas convicções pessoais e a configuração da 709 MICHEL, Margot. Rechte von Kindern in medizinischen Heilbehandlungen. Op. Cit., p. 12.

710 ALDERSON, Priscila. Die Autonomie des Kindes - über die Selbstbestimmungsfähigkeit von Kindern in der Medizin. Op. Cit., p. 29; DUTTGE, Gunnar, Patientenautonomie und Einwilligungsfähigkeit, p. 78; SIMON, Alfred; NAUCK, Friedemann. Patientenautonomie in der klinischen Praxis. In WIESEMANN, Claudia; SIMON, Alfred. Patientenautonomie. Op. Cit., p. 168.

711 SIMON, Alfred; NAUCK, Friedemann. Patientenautonomie in der klinischen Praxis. In WIESEMANN, Claudia; SIMON, Alfred. Patientenautonomie. Op. Cit., p. 169. 
personalidade que autocriou, e significa auto-regulamentação e autodeterminação. A pessoa dotada de autonomia apresenta capacidade para fazer escolhas livres por meio de seu consentimento após ser devidamente esclarecida. ${ }^{712}$

5.2.2.3 A relação entre autonomia e beneficência: autonomia nas intervenções médicas em crianças e adolescentes

Diante desse contexto, apresenta-se a questão de saber se é possível às pessoas menores alcançarem tal grau de autonomia. ${ }^{713}$

Considerando a prevalência do princípio da autonomia nos tratamentos médicos, poder-se-ia concluir pela existência de uma tensão entre autonomia e beneficência. Entretanto, deve ser questionado se, na verdade, não se deveria buscar certa simbiose entre eles, sobretudo nos tratamentos de pacientes incapazes de discernimento, nos quais o princípio da beneficência ainda tem grande peso. ${ }^{714}$

712 ALDERSON, Priscila. Die Autonomie des Kindes - über die Selbstbestimmungsfähigkeit von Kindern in der Medizin. Op. Cit., p. 28; DUTTGE, Gunnar. Patientenautonomie und Einwilligungsfähigkeit. In WIESEMANN, Claudia; SIMON, Alfred. Patientenautonomie. Op. Cit. p. 78.

${ }^{713}$ ALDERSON, Priscila. Die Autonomie des Kindes - über die Selbstbestimmungsfähigkeit von Kindern in der Medizin. Op. Cit., p. 49. ${ }^{714}$ Ibidem, p. 30. 
ALDERSON pretende solucionar o conflito entre autonomia e beneficência relacionando ambos os princípios e defendendo um modelo de relação médico-paciente participativo, em que ambos atuam conjuntamente no processo de decisão de forma harmônica. ${ }^{715}$ Argumenta a autora que todos os pacientes, por mais independentes que sejam, dependem da assistência do pessoal que lhes presta cuidados à sua saúde e apresenta competência técnica e conhecimentos. Essa assistência pode promover a autonomia, a autoconfiança e a possibilidade de escolhas do paciente. Um atendimento frio, ainda que eficiente, não basta. Pacientes necessitam de uma relação confortável e pessoal com a equipe médica para se sentirem à vontade. ${ }^{716}$

Essa relação é claramente observada no contexto médico de crianças e adolescentes, haja vista que, além da necessidade de cuidados da equipe médica, eles estão muito mais ligados às relações e valores familiares e culturais, dos quais não podem se livrar de forma fácil e rápida, principalmente em situação de necessidade de tratamento. Essa dependência praticamente exclui

715 Ibidem, pp. 28-30; HÜBNER, Karin. Der Patient als Partner - Geteilte Verantwortung. In BARTMANN, Peter. HÜBNER, Ingolf (coord.). Patientenselbstbestimmung. Paradgmenwechsel und Herausforderung im Gesundheitswesen. Neukirchen: Vluyn, 2002, pp. 132-133.

${ }^{716}$ ALDERSON, Priscila. Die Autonomie des Kindes - über die Selbstbestimmungsfähigkeit von Kindern in der Medizin. Op. Cit., pp. 2930. 
ou, ao menos, limita a liberdade de decisão. ${ }^{717}$ Uma criança ou adolescente com pais muito autoritários, por exemplo, certamente receberá menos estímulo para desenvolver um comportamento baseado na autonomia. $^{718}$

É verdade ainda que a autonomia de qualquer paciente, seja criança ou adulto, é limitada quando as informações prestadas pelo médico são novas e complexas. Principalmente quando estão diante de um quadro de doença, que às vezes é dolorosa, com transtornos que os abalam, devendo se submeter a tratamentos indesejados, por vezes até arriscados, essa capacidade de autonomia fica prejudicada. Sua esfera de liberdade se reduz, pois autonomia significa uma vida como agente, justamente o contrário de paciente, que apenas sofre e tolera. $^{719}$

No mesmo sentido, defendem SIMON e NAUCK ${ }^{720}$ que, no modelo de parceria entre médico e paciente, a autonomia do paciente e a beneficência do médico se complementam num

717 MICHEL, Margot. Rechte von Kindern in medizinischen Heilbehandlungen. Op. Cit., p. 14.

${ }^{718}$ ALDERSON, Priscila. Die Autonomie des Kindes - über die Selbstbestimmungsfähigkeit von Kindern in der Medizin. Op. Cit., p. 49.

719 ALDERSON, Priscila. Die Autonomie des Kindes - über die Selbstbestimmungsfähigkeit von Kindern in der Medizin. Op. Cit., p. 49, ROTHÄRMEL, Sonja, Einwilligung, Veto, Mitbestimmung. Op. Cit., p. 207.

${ }^{720}$ Patientenautonomie in der klinischen Praxis. In WIESEMANN, Claudia; SIMON, Alfred. Patientenautonomie. Op. Cit., p. 176. 
processo de tomada de decisão conjunta. Afirmam os doutrinadores que esse processo não se esgota no consentimento informado, tampouco mesmo o consentimento se limita a uma assinatura em formulários. $\mathrm{Na}$ verdade, ele representa um processo que abrange a coleta de informações, sua avaliação e consideração segundo um sistema subjetivo de valores ${ }^{721}$ e se prolonga por toda a duração da relação terapêutica, desde a determinação da finalidade da terapia, da anamnese, diagnóstico e prognóstico, da decisão por uma determinada opção de tratamento, até a execução e evolução da terapia e, em caso de não se alcançar o êxito desejado ou em momento anterior, com a ocorrência de efeitos colaterais prejudiciais, por exemplo, pode-se chegar a um acordo quanto à alteração da terapia ou de seu objetivo. ${ }^{722}$

As decisões sobre tratamentos médicos não são tomadas de forma puramente racional, mas são impregnadas por elementos emotivos. Além disso, não são tomadas de maneiras isolada, pois as pessoas vivem em uma relação de troca, o que fica bem delineado na relação médico-paciente, na qual o médico tem o dever de prestar os esclarecimentos necessários ao paciente, para possibilitar a este

${ }^{721}$ ALDERSON, Priscila. Die Autonomie des Kindes - über die Selbstbestimmungsfähigkeit von Kindern in der Medizin. Op. Cit., p. 49.

722 SIMON, Alfred; NAUCK, Friedemann. Patientenautonomie in der klinischen Praxis. In WIESEMANN, Claudia; SIMON, Alfred. Patientenautonomie. Op. Cit., p. 176. 
tomar uma decisão consciente das circunstâncias e riscos em que o tratamento se desenvolverá. ${ }^{723}$

Percebe-se, dessa forma, que o consentimento percorre um processo tanto emocional como racional, passando primeiro pelo medo diante da doença e pela recusa inicial ao tratamento proposto, diante do fato de ser doloroso, mutilante ou de grave risco, para depois superar as dúvidas e fortalecer os vínculos de confiança com o médico e sua equipe e aceitar os procedimentos propostos para só depois se conceder o consentimento para dar início ao tratamento. ${ }^{724}$ Ademais, o princípio da autonomia atribui ao médico um papel fundamental. Ele é visto como o primeiro transmissor dos conhecimentos sobre o quadro de saúde do paciente, de modo que deve fornecer a ele todos os fundamentos para que o paciente encontre uma decisão, mas sem influenciá-la. ${ }^{725}$

Essa é a tendência atual, na qual, diante da limitação natural de todo ser humano, assistência e autonomia se complementam. O dever de esclarecimento do médico apenas confirma o pensamento de que autonomia implica, necessariamente, assistência. Admitir

${ }^{723}$ ROTHÄRMEL, Sonja. Einwilligung, Veto, Mitbestimmung. Op. Cit., p. 147.

724 ALDERSON, Priscila. Die Autonomie des Kindes - über die Selbstbestimmungsfähigkeit von Kindern in der Medizin. Op. Cit., p. 59. ${ }^{725}$ ROTHÄRMEL, Sonja. Einwilligung, Veto, Mitbestimmung. Op. Cit., p. 207. 
puramente a autonomia poderia significar que o direito de atenção e respeito do paciente são tão lesados como no caso da tutela paternalista, por deixa-lo completamente sozinho na sua liberdade de agir e decidir. ${ }^{726}$

No entanto, um modelo participativo não deve enfraquecer o direito de autodeterminação do paciente. Mesmo que este decida contrariamente ao conselho do médico sobre o tratamento sugerido, mas, com toda consciência sobre os riscos e consequências relacionadas com essa decisão, sua vontade deve ser respeitada. ${ }^{727}$

Dessa forma, o conceito kantiano de autonomia com ênfase na independência e na não interferência em assuntos alheios não se mostra adequada para pacientes que dependem de relações mais estreitas com médicos e pessoal da saúde. ${ }^{728}$ Assistência ou beneficência significa respeito e cuidado em relação ao outro evitando coerção e pressão. Às vezes, para promover a autonomia será necessário buscar compromissos, cooperação e compreensão recíproca, sempre que possível. ${ }^{729}$

${ }^{726}$ DUTTGE, G., Patientenautonomie und Recht. In: WIESEMANN, Claudia; SIMON, Alfred. Patientenautonomie. Op. Cit., pp. 86-88.

727 MICHEL, Margot. Rechte von Kindern in medizinischen Heilbehandlungen. Op. Cit., p. 14.

728 ALDERSON, Priscila. Die Autonomie des Kindes - über die Selbstbestimmungsfähigkeit von Kindern in der Medizin. Op. Cit., pp. 2930.

${ }^{729}$ Ibidem, pp. 29-30. 
Crianças e adolescentes encontram-se numa situação bastante especial. Nascidos como completamente dependentes, eles necessitam de cuidado e proteção dos adultos no decorrer de seu desenvolvimento até adquirirem autonomia e compreensão para o seu ambiente. Com a conclusão de 18 anos, passam a ser tratados como pessoas completamente autônomas do ponto de vista jurídico $^{730}$.

Sobretudo nos primeiros anos de vida, a criança se encontra, via de regra, numa relação de dependência muito forte com seus pais. Essa situação de dependência aliada à vulnerabilidade específica de crianças e adolescentes necessita de uma proteção jurídica especial. $^{731}$

Segundo MICHEL ${ }^{732}$, há doutrinadores que sustentam que a desigualdade das crianças leva a um ponto no qual não basta conceder à criança os mesmos direitos que os de adulto. Os direitos das crianças não necessitam somente de respeito, mas, justamente por causa de sua situação específica de vulnerabilidade, seus direitos devem ser protegidos. Isso não significa afastar de forma automática

730 MICHEL, Margot. Rechte von Kindern in medizinischen Heilbehandlungen. Op. Cit., p. 54.

${ }^{731}$ Ibidem, p. 54.

${ }^{732}$ HÄNNI, Peter; BESLER, Eva Maria. Die Rechte der Kinder. Zu den Grundrechten Minderjähriger und der Schwierigkeit ihrer rechtlichen Durchsetzung. AJP 1998. pp. 139-140, apud MICHEL, Margot. Rechte von Kindern in medizinischen Heilbehandlungen. Op. Cit., pp. 55-56. 
o direito de autodeterminação às pessoas menores e, com isso, o direito de tomarem decisões que gerem efeitos em sua esfera de personalidade. Conforme será exposto, em muitas situações, deve-se reconhecer tal direito, tratando os menores como seres que agem de forma responsável e autodeterminada. Ainda que assim não seja, por causa de sua total incapacidade de discernimento, seu direito fundamental de serem ouvidas permanece. Sua vontade e opinião devem ser integradas no processo de decisão daqueles que lhes representam legalmente, garantindo-lhes, assim, a concretização de seus interesses fundamentais e de seu bem-estar.

\subsection{Contexto Internacional}

\section{$\underline{\text { 5.3.1 Convenção Internacional sobre os Direitos da Criança }}$}

A primeira referência a "direitos da criança" que se observa em um documento jurídico internacional surge em 1923 e encontra-se na Declaração de Genebra sobre Direitos da Criança, endossada pela Assembleia Geral da então Liga das Nações em 1924. A Declaração é obra do Conselho da União Internacional de Proteção à Infância (Save the Children International Union), uma organização não governamental, e determina a proteção da criança em âmbito internacional, sem quaisquer discriminações de raça, religião ou 
nacionalidade. A criança, nesses termos, deve ser alimentada, tratada, auxiliada e reeducada para, assim, desenvolver-se normalmente em todos os aspectos. ${ }^{733} /{ }^{734}$ Em 1959, a Organização das Nações Unidas profere uma nova Declaração, a qual passa a tratar a criança, de fato, como sujeito de direitos, e não mais como um sujeito passivo, ou seja, mero receptador de decisões e ações realizadas em seu favor. ${ }^{735}$

O tratado internacional mais importante para assegurar os direitos das crianças é a Convenção internacional sobre os direitos da criança, de 1989. Tal tratado significa uma importante concretização dos direitos humanos para as crianças. Foi ratificado por todos os países, com exceção de Estados Unidos e Somália. No Brasil, a Convenção foi incorporada ao ordenamento jurídico interno pelo Decreto $n^{\circ} .99 .710$ de 21 de novembro de $1990 .{ }^{736}$

${ }^{733}$ ALBUQUERQUE, Catarina. Os Direitos da Criança: as Nações Unidas, a Convenção e o Comité. In Boletim Documentação e Direito Comparado. nn. 83/84. Lisboa, Gabinete de Documentação e Direito Comparado, p. 27, 2000 .

734 Mais sobre o desenvolvimento histórico dos direitos da criança: MEIRELLES, Rose M. Venceslau. O Princípio do melhor interesse da criança. In BODIN DE MORAES, Maria Celina (coord.). Princípios do direito civil contemporâneo. Rio de Janeiro: Renovar, 2006. pp. 459-467.

${ }^{735}$ MÔNACO, Gustavo Ferraz de Campos. A proteção da criança no cenário internacional. Belo Horizonte: Del Rey, 2005. p. 128.

${ }^{736}$ Art. $1^{\circ}$ A Convenção sobre os Direitos da Criança, apensa por cópia ao presente Decreto, será executada e cumprida tão inteiramente como nela se contém. 
Embora não seja o escopo deste trabalho, quando se depara com um tratado internacional de direitos humanos de tal magnitude, como a referida Convenção, é quase impossível não dedicar algumas linhas sobre a hierarquia dos tratados internacionais de direitos humanos frente ao ordenamento jurídico nacional. Por muito tempo, considerou-se que os referidos tratados, como todos os demais acordos internacionais, encontravam-se no patamar da legislação ordinária $^{737} /^{738}$

No entanto, quanto a isso, há uma quebra de paradigmas com a mudança de entendimento da corte ao analisar o Recurso Extraordinário $n^{\circ}$. 466.343. ${ }^{739}$ Discute-se a questão da posição dos tratados assinados antes do advento da emenda constitucional $n^{\circ} .45$ de 2004. A referida emenda acrescentou o $\$ 3^{\circ}$ no art. $5^{\circ}$ da Constituição Federal de 1988. A leitura do texto contido no referido

${ }^{737}$ Nesse sentido, STF, Pleno. HC 72131/RJ. rel. p. acórdão Moreira Alves. j. 23 nov. 1995. P. DJ. 01 ago. 2003.

${ }^{738}$ Nesse sentido, FERREIRA FILHO, Manoel Gonçalves. Direitos humanos fundamentais. 11 ed. São Paulo: Saraiva, 2009. pp. 102-104.

${ }^{739}$ Ressalte-se, entretanto, que o referido julgado não trata especificamente da Convenção sobre os Direitos da Criança, tampouco sobre direitos da criança. Ao contrário, assim como o case citado em nota supra, o referido julgado traz à baila a questão da prisão civil do depositário infiel. Porém, há que se entender que toda a discussão dogmática acerca da posição hierárquica dos tratados e convenções internacionais de direitos humanos se aplica também à presente Convenção. 
parágrafo $^{740}$ leva a crer que os tratados de direitos humanos incorporados após a vigência da emenda apresentam força constitucional, haja vista que, para sua incorporação no ordenamento jurídico pátrio, segue-se o mesmo rito para a aprovação de emendas constitucionais, como previsto no art. $60, \S 2^{\circ}$, da Carta de $1988 .^{741} /^{742}$

No julgamento do referido caso, ${ }^{743}$ o ministro Gilmar Mendes entendeu, em seu voto, que os tratados internacionais de direitos humanos ratificados anteriormente à vigência da emenda constitucional 45 apresentam caráter supralegal, mas infraconstitucional. O que desperta atenção é o voto-vista do ministro Celso de Mello, segundo o qual as Declarações de Direitos representaram, sempre, um poderoso instrumento de tutela e de salvaguarda dos direitos e garantias individuais. No voto, o ministro reconhece que cláusulas inscritas em tratados que versem sobre direitos humanos apresentam-se com primazia frente à ${ }^{740} \S 3^{\circ}$. Os tratados e convenções internacionais sobre direitos humanos que forem aprovados, em cada Casa do Congresso Nacional, em dois turnos, por três quintos dos votos dos respectivos membros, serão equivalentes às emendas constitucionais.

${ }^{741} \S 2^{\circ}$ A proposta será discutida e votada em cada Casa do Congresso Nacional, em dois turnos, considerando-se aprovada se obtiver, em ambos, três quintos dos votos dos respectivos membros.

${ }^{742}$ Nesse sentido, FERREIRA FILHO, Manoel Gonçalves. Direitos humanos fundamentais. Op. Cit., p. 102.

${ }^{743}$ STF, Pleno. RE $\mathbf{n}^{\mathbf{0}}$. 466343/SP. rel. Cezar Peluso. j. 03 dez. 2008. P. DJe. 05 jun.2009. 
legislação infraconstitucional, se houver antinomia entre o direito interno e internacional, concordando com o voto do ministro Gilmar Mendes. Estando em condição de supralegalidade, os tratados e convenções que versem sobre direitos humanos estão em um patamar intermediário, ou seja, colocam-se acima da legislação infraconstitucional, mas submetem-se aos ditames da Constituição Federal.

No entanto, o ministro avança em seu entendimento, aceitando a orientação de se atribuir natureza constitucional às convenções internacionais de direitos humanos. Estes são revestidos de caráter materialmente constitucional, haja vista que tal qualificação de hierarquia jurídica lhes é transmitida por efeito de sua inclusão no chamado bloco de constitucionalidade.

O ministro não é voz única a seguir tal entendimento. Para LAFER, ${ }^{744}$ os tratados incorporados entre a vigência da Constituição de 1988 e o advento da emenda constitucional 45 são materialmente constitucionais, pois assim foram recepcionados ex $v i$ do art. $5^{\circ}, \S 2^{\circ}$, da Constituição. ${ }^{745}$ Assim, os direitos advindos de tais diplomas, tais como a Convenção sobre Direitos da Criança a qual, como visto, foi

\footnotetext{
${ }^{744}$ A Internacionalização dos Direitos Humanos: Constituição, Racismo e Relações Internacionais. Barueri: Manole, 2005. pp. 16-18.

${ }^{745}$ Os direitos e garantias expressos nesta Constituição não excluem outros decorrentes do regime e dos princípios por ela adotados, ou dos tratados internacionais em que a República Federativa do Brasil seja parte.
} 
incorporada em 1990, encontram-se no bloco da constitucionalidade, o qual, segundo o autor, consiste na somatória daquilo que se adiciona à Constituição escrita, em função dos valores e princípios nela consagrados. ${ }^{746}$

Embora seja um tratado internacional de direitos humanos, MÔNACO ${ }^{747}$ entende que o tratado foi recebido com força de lei ordinária, com potencial, inclusive, para revogar o Estatuto da Criança e do Adolescente. No entanto, não há antinomias entre os dois diplomas normativos, ao contrário, eles se mostram em relação de complementariedade, fazendo com que ambos convivam no ordenamento jurídico pátrio. ${ }^{748}$

A convenção define criança como sendo o ser humano que ainda não completou 18 anos, salvo se o direito nacional estipulou

746 Também nesse sentido, CANÇADO TRINDADE, Antônio Augusto. Tratado de direito internacional dos Direitos Humanos. v. 1. 2 ed. Porto Alegre; Fabris, 2003. p. 513 e PIOVESAN, Flávia. Direitos Humanos e o Direito Constitucional Internacional. Op. Cit., pp. 51-85.

${ }^{747}$ A proteção da criança no cenário internacional. Op. Cit., p. 131.

${ }^{748}$ No mesmo sentido ELIAS, Roberto João. Comentários ao Estatuto da Criança e do Adolescente. 4 ed. São Paulo: Saraiva, 2010. p. 12, observa que o Estatuto da Criança e do Adolescente está em conformidade com a convenção internacional, garantindo a proteção integral dos menores, a qual deve abranger todas as necessidades de pessoa em estágio de desenvolvimento. 
de forma diferente o início da maioridade. ${ }^{749}$ No Brasil, conforme já assinalado, criança é toda pessoa até 12 anos incompletos e, adolescente, a pessoa de 12 a 18 anos. ${ }^{750} \mathrm{O}$ ordenamento jurídico nacional, portanto, também adota a mesma idade limite de 18 anos para separar as pessoas absolutamente capazes juridicamente, daquelas ainda incapazes, ainda que de forma relativa, como aqueles que apresentam idade entre 16 e 18 anos incompletos, como se lê nos arts. $3^{\circ}$ e $4^{\circ}$ do Código Civil Brasileiro de 2002. ${ }^{751}$

Os princípios diretivos da convenção são a proteção da dignidade da criança ${ }^{752}$ e o best interest of the child ou l'intérêt

749 Artigo 1. Para efeitos da presente Convenção considera-se como criança todo ser humano com menos de dezoito anos de idade, a não ser que, em conformidade com a lei aplicável à criança, a maioridade seja alcançada antes. ${ }^{750}$ Nesses termos, define a Lei $\mathrm{n}^{\circ}$. 8.069/1990 (Estatuto da Criança e do Adolescente): Art. $2^{\circ}$. Considera-se criança, para os efeitos desta Lei, a pessoa até doze anos de idade incompletos, e adolescente aquela entre doze e dezoito anos de idade.

${ }^{751}$ Art. $3^{\circ}$. São absolutamente incapazes de exercer pessoalmente os atos da vida civil os menores de 16 (dezesseis) anos.

Art. $4^{\circ}$. São incapazes, relativamente a certos atos ou à maneira de os exercer: I - os maiores de dezesseis e menores de dezoito anos (...).

${ }^{752}$ Preâmbulo da Convenção: Considerando que, de acordo com os princípios proclamados na Carta das Nações Unidas, a liberdade, a justiça e a paz no mundo se fundamentam no reconhecimento da dignidade inerente e dos direitos iguais e inalienáveis de todos os membros da família humana; Tendo em conta que os povos das Nações Unidas reafirmaram na carta sua fé nos direitos fundamentais do homem e na dignidade e no valor da pessoa humana e que decidiram promover o progresso social e a elevação do nível de vida com mais liberdade; (...). 
supérieur de l'enfant, ${ }^{753}$ o qual será traduzido como o melhor interesse da criança, ${ }^{754}$ nos termos usados pela versão oficial brasileira do referido tratado em seus artigos 37 , "c" e 40, 2, "b", III. ${ }^{755}$ Note-se, no entanto, que o referido tratado, no art. $3^{\circ}$, também traz a tradução do princípio como maior interesse, o que é uma impropriedade, haja vista que não se deve analisar o princípio de forma quantitativa, como leva a entender a palavra maior, mas de

${ }^{753}$ Art. $3^{\circ}$. 1: Todas as ações relativas às crianças, levadas a efeito por instituições públicas ou privadas de bem-estar social, tribunais, autoridades administrativas ou órgãos legislativos, devem considerar, primordialmente, o interesse maior da criança.

${ }^{754}$ Embora a tradução alemã se refira a "Kindeswohl" (bem-estar da criança), o conceito de "best interests of the child" não pode ser igualado automaticamente com aquele. Nesse sentido, cf. MICHEL, Margot. Rechte von Kindern in medizinischen Heilbehandlungen. Op. Cit., p. 56.

${ }^{755}$ Artigo 37. Os Estados Partes zelarão para que: (...)c) toda criança privada da liberdade seja tratada com a humanidade e o respeito que merece a dignidade inerente à pessoa humana, e levando-se em consideração as necessidades de uma pessoa de sua idade. Em especial, toda criança privada de sua liberdade ficará separada dos adultos, a não ser que tal fato seja considerado contrário aos melhores interesses da criança, e terá direito a manter contato com sua família por meio de correspondência ou de visitas, salvo em circunstâncias excepcionais (...).

Artigo 40. 2. Nesse sentido, e de acordo com as disposições pertinentes dos instrumentos internacionais, os Estados Partes assegurarão, em particular: (...) b) que toda criança de quem se alegue ter infringido as leis penais ou a quem se acuse de ter infringido essas leis goze, pelo menos, das seguintes garantias: (...) III) ter a causa decidida sem demora por autoridade ou órgão judicial competente, independente e imparcial, em audiência justa conforme a lei, com assistência jurídica ou outra assistência e, a não ser que seja considerado contrário aos melhores interesses da criança, levando em consideração especialmente sua idade ou situação e a de seus pais ou representantes legais (...). (Grifos nossos) 
forma qualitativa, como enseja o termo melhor, usado, também, pelo referido tratado. ${ }^{756}$

O referido princípio não surge com a Convenção. Há vozes no sentido de que este teria se originado na figura do parens patriae do direito inglês, a qual visava a proteção de incapazes, principalmente no que se refere a suas propriedades. ${ }^{757}$ A Declaração dos Direitos da Criança de 1959 dá força ao princípio, trazendo-o expressamente em seu texto, ${ }^{758}$ dando início à sua efetiva aplicação. ${ }^{759}$ Trata-se de

756 MÔNACO, Gustavo Ferraz de Campos. A proteção da criança no cenário internacional. Op. Cit., p. 181.

${ }^{757}$ MEIRELLES, Rose M. Venceslau. O Princípio do melhor interesse da criança. Op. Cit., pp. 462-463; COLUCCI, Camila Fernanda Pinsinato. Princípio do melhor interesse da criança: construção teórica e aplicação prática no direito brasileiro. Dissertação de mestrado (Orientador: Eduardo Tomasevicius Filho). São Paulo: Faculdade de Direito da Universidade de São Paulo, 2014. p. 25.

${ }^{758}$ Princípio 2. A criança gozará proteção social e ser-lhe-ão proporcionadas oportunidades e facilidades, por lei e por outros meios, a fim de lhe facultar o desenvolvimento físico, mental, moral, espiritual e social, de forma sadia e normal e em condições de liberdade e dignidade. $\mathrm{Na}$ instituição das leis visando este objetivo levar-se-ão em conta sobretudo, os melhores interesses da criança. (Grifo nosso)

Princípio 7. A criança terá direito a receber educação, que será gratuita e compulsória pelo menos no grau primário. Ser-lhe-á propiciada uma educação capaz de promover a sua cultura geral e capacitá-la a, em condições de iguais oportunidades, desenvolver as suas aptidões, sua capacidade de emitir juízo e seu senso de responsabilidade moral e social, e a tornar-se um membro útil da sociedade. Os melhores interesses da criança serão a diretriz a nortear os responsáveis pela sua educação e orientação; esta responsabilidade cabe, em primeiro lugar, aos pais. A criança terá ampla oportunidade para brincar e divertir-se, visando os propósitos mesmos da sua educação; a sociedade e as 
conceito bastante vago, cujo significado na Convenção é ainda muito impreciso, pois não foram apontados fatores que deveriam ser considerados na avaliação do melhor interesse da criança. ${ }^{760}$

Conforme o art. $3^{\circ}$ da Convenção todas as medidas nos âmbitos público e privado devem considerar o melhor interesse da criança de maneira prioritária. ${ }^{761}$ Trata-se de uma formulação que deixa em aberto a ponderação de interesses, sejam eles, por exemplo, públicos ou paternos. ${ }^{762}$

Segundo WYTTEMBACH, ${ }^{763}$ o conteúdo essencial do conceito de melhor interesse da criança tanto nessa Convenção da ONU como em outros tratados de direitos humanos, o direito à vida, a proibição de tratamento desumano, cruel ou humilhante e a proibição de discriminação. Também o direito de ser ouvido faz parte do melhor interesse da criança. $^{764}$ Importa ressaltar, ainda, que o referido

autoridades públicas empenhar-se-ão em promover o gozo deste direito. (Grifo nosso)

${ }^{759}$ MÔNACO, Gustavo Ferraz de Campos. A proteção da criança no cenário internacional. Op. Cit., p. 128.

760 WYTTENBACH, Judith. Grund- und Menschenrechtskonflikte zwischen Eltern, Kind und Sttat. Schutzpflichten des Staates gegenüber Kindern und Jugendlichen aus dem internationalen Menschenrechtsschutz und der Bundesverfassung (Art. 11 BV). München: Genf, 2006. p. 137.

${ }^{761}$ Ibidem, p. 138.

${ }^{762}$ Ibidem, p. 138.

${ }^{763}$ Ibidem, p. 136.

${ }^{764}$ Nesse sentido, lê-se o artigo 12 da Convenção. 
princípio se baseia na condição da criança enquanto pessoa humana. Além disso, faz com que ela seja alvo de especial proteção dada sua posição especial de ser humano em desenvolvimento. ${ }^{765}$

A abertura do conceito de melhor interesse da criança leva a uma dependência do contexto, podendo ser bem diferente conforme as ideias e valores de cada cultura. Por conta dessa imprecisão, é de importância fundamental reconhecer a quem cabe a competência de definir o melhor interesse no caso concreto. Ainda, segundo MÔNACO, ${ }^{766}$ o princípio do melhor interesse da criança serviria como fiel da balança quando, diante de um eventual conflito de direitos os quais necessitam de um eventual sopesamento em um caso concreto, o princípio serviria de modo a estabelecer critérios para qual dos direitos conflitantes será privilegiado.

Para MÔNACO,${ }^{767}$ o princípio do melhor interesse da criança se desdobra em um campo objetivo e subjetivo. O primeiro faz com que tal princípio seja considerado como um dos primordiais pelo Estado quando da elaboração de políticas públicas e não necessariamente como o primordial. Em seu aspecto subjetivo, o melhor interesse da criança se desdobra em prescrições ao Estado-

${ }^{765}$ MEIRELLES, Rose M. Venceslau. O Princípio do melhor interesse da criança. Op. Cit., pp. 466-467; ELIAS, Roberto João. Direitos Fundamentais da criança e do Adolescente. São Paulo: Saraiva, 2005, pp. 1-6.

${ }^{766}$ A proteção da criança no cenário internacional. Op. Cit., p. 184.

${ }^{767}$ Ibidem, pp. 181-183. 
legislador, ao Estado-juiz e ao Estado-administração. Ao Estado enquanto legislador, faz com que este, quando em sua atividade de produzir normas (leis), preveja, sempre, diante de mais de uma situação, aquela que gere melhores consequências à criança. Para o Estado-juiz, em função de intérprete autêntico das normas jurídicas, o princípio determina que a aplicação das normas previstas no ordenamento jurídico seja feita de tal modo a ser consentânea com as necessidades reais da criança. Por fim, ao Estado-administrador, o princípio prescreve que quando da elaboração e efetiva execução de políticas públicas, o administrador, havendo pluralidade de opções, deve optar por aquela que melhor efetivar o referido princípio na sociedade, dando-lhe plena aplicação.

Segundo o art. $5^{\circ}$ da convenção cabe aos pais, prioritariamente, conservar os direitos de seu filho. ${ }^{768}$ Os países que assinaram essa convenção são obrigados a apoiar os pais nessa tarefa, nos termos do art. 18 da mesma convenção. ${ }^{769} \mathrm{E}$, conforme art. $3^{\circ} .2$ devem garantir à criança a proteção e o cuidado necessários para seu bem-estar. ${ }^{770}$

${ }^{768}$ Artigo $5^{\circ}$. Os Estados Partes respeitarão as responsabilidades, os direitos e os deveres dos pais ou, onde for o caso, dos membros da família ampliada ou da comunidade, conforme determinem os costumes locais, dos tutores ou de outras pessoas legalmente responsáveis, de proporcionar à criança instrução e orientação adequadas e acordes com a evolução de sua capacidade no exercício dos direitos reconhecidos na presente convenção.

${ }^{769}$ Artigo 18. 1. Os Estados Partes envidarão os seus melhores esforços a fim de assegurar o reconhecimento do princípio de que ambos os pais têm 
A comunidade internacional olha com cuidado o exercício do poder/dever familiar em relação às crianças, impondo vedações ao exercício de maneira desregrada e sem limites. ${ }^{771}$ Nesse sentido, a convenção tem o aspecto louvável de não apresentar uma ótica paternalista das crianças através da fixação pura e simples de obrigações de proteção e cuidado. Mas trata as crianças como sujeitos com personalidade e direitos próprios. A infância não deve ser considerada como uma fase de transição, na qual as crianças são

obrigações comuns com relação à educação e ao desenvolvimento da criança. Caberá aos pais ou, quando for o caso, aos representantes legais, a responsabilidade primordial pela educação e pelo desenvolvimento da criança. Sua preocupação fundamental visará ao interesse maior da criança.

2. A fim de garantir e promover os direitos enunciados na presente convenção, os Estados Partes prestarão assistência adequada aos pais e aos representantes legais para o desempenho de suas funções no que tange à educação da criança e assegurarão a criação de instituições, instalações e serviços para o cuidado das crianças.

3. Os Estados Partes adotarão todas as medidas apropriadas a fim de que as crianças cujos pais trabalhem tenham direito a beneficiar-se dos serviços de assistência social e creches a que fazem jus.

${ }^{770}$ 2. Os Estados Partes se comprometem a assegurar à criança a proteção e o cuidado que sejam necessários para seu bem-estar, levando em consideração os direitos e deveres de seus pais, tutores ou outras pessoas responsáveis por ela perante a lei e, com essa finalidade, tomarão todas as medidas legislativas e administrativas adequadas.

771 MÔNACO, Gustavo Ferraz de Campos. A proteção da criança no cenário internacional. Op. Cit., p. 164. 
preparadas para a vida adulta, mas como uma época com qualidade própria e uma finalidade independente da vida posterior. ${ }^{772}$

As crianças têm liberdade de opinião e de expressão. Como bem ensina G. F. C. MÔNACO, ${ }^{773}$ a liberdade de expressão é a exteriorização da liberdade de opinião que a criança apresenta, as quais se completam com as liberdades de pensamento e consciência. Ainda segundo o autor,

(...) as crianças devem ter a liberdade de pensar e formar a sua própria opinião a respeito dos assuntos que as circundam, incumbindo aos pais e à família de forma geral e mais amplamente também à comunidade prover as informações necessárias ao pleno conhecimento dos fatos, bem como educar as crianças para o pleno desenvolvimento de suas capacidades mentais. ${ }^{774}$

Assim, as crianças não devem mais ser percebidas somente como seres em desenvolvimento e transição, mas como seres de existência plena. $\mathrm{O}$ fundamento dessa mudança de paradigma é a dignidade humana, o respeito diante das crianças como seres humanos. ${ }^{775}$

772 MICHEL, Margot. Rechte von Kindern in medizinischen Heilbehandlungen. Op. Cit., pp. 57-58.

${ }^{773}$ A proteção da criança no cenário internacional. Op. Cit., p. 176.

${ }_{775}^{774}$ Ibidem, p. 176.

775 MICHEL, Margot. Rechte von Kindern in medizinischen Heilbehandlungen. Op. Cit., p. 58. 
A convenção da ONU considera as crianças não somente como membros de uma família, mas sobretudo como pessoas autônomas com direitos subjetivos próprios, os assim chamados direitos das crianças. ${ }^{776}$ Por isso se diz que a Convenção de Direitos da Criança se tornou uma pedra angular no tratamento das crianças e da infância. ${ }^{777}$ Em vista dessa mudança de paradigma e da necessidade de proteção especial da criança, a convenção da ONU estabelece uma série de determinações em prol da defesa de seus direitos.

No contexto do tratamento médico são importantes os arts. 6 (direito à vida), ${ }^{778} 12$ (direito amplo de participação), 13 (liberdade de opinião e informação) e 16 (proteção da vida privada e familiar). ${ }^{779} /{ }^{780}$ Outrossim, deve ser apontado o artigo 24 que

${ }^{776}$ Ibidem, p. 58.

777 HAUSMANN, Christina. Einleitung. In GERBER, Jeni Regula; HAUSMANN, Christina (coord.). Die Rechte des Kindes: Das ONUÜbereinkommen und seine Auswirkungen auf die Schweiz. München: Genf, 2001. pp. 1-2.

${ }^{778}$ Art. 6. 1. Os Estados Partes reconhecem que toda criança tem o direito inerente à vida. 2. Os Estados Partes assegurarão ao máximo a sobrevivência e o desenvolvimento da criança.

779 1. Nenhuma criança será objeto de interferências arbitrárias ou ilegais em sua vida particular, sua família, seu domicílio ou sua correspondência, nem de atentados ilegais a sua honra e a sua reputação.

2. A criança tem direito à proteção da lei contra essas interferências ou atentados.

${ }^{780}$ Afirma-se que o art. 12, que formula direitos amplos de participação, representa uma determinação central no contexto da mudança de visão da criança e da infância. Dele irradiariam os demais direitos de participação. 
assegura à criança o mais alto grau possível de ser alcançado de saúde e o direito de poder usar instituições para o tratamento de doenças e o restabelecimento da saúde. ${ }^{781}$

Nesse sentido, MICHEL, Margot. Rechte von Kindern in medizinischen Heilbehandlungen. Op. Cit., p. 58.

${ }^{781}$ 1. Os Estados Partes reconhecem o direito da criança de gozar do melhor padrão possível de saúde e dos serviços destinados ao tratamento das doenças e à recuperação da saúde. Os Estados Partes envidarão esforços no sentido de assegurar que nenhuma criança se veja privada de seu direito de usufruir desses serviços sanitários.

2. Os Estados Partes garantirão a plena aplicação desse direito e, em especial, adotarão as medidas apropriadas com vistas a:

a) reduzir a mortalidade infantil;

b) assegurar a prestação de assistência médica e cuidados sanitários necessários a todas as crianças, dando ênfase aos cuidados básicos de saúde;

c) combater as doenças e a desnutrição dentro do contexto dos cuidados básicos de saúde mediante, inter alia, a aplicação de tecnologia disponível e o fornecimento de alimentos nutritivos e de água potável, tendo em vista os perigos e riscos da poluição ambiental;

d) assegurar às mães adequada assistência pré-natal e pós-natal;

e) assegurar que todos os setores da sociedade, e em especial os pais e as crianças, conheçam os princípios básicos de saúde e nutrição das crianças, as vantagens da amamentação, da higiene e do saneamento ambiental e das medidas de prevenção de acidentes, e tenham acesso à educação pertinente e recebam apoio para a aplicação desses conhecimentos;

f) desenvolver a assistência médica preventiva, a orientação aos pais e a educação e serviços de planejamento familiar.

3. Os Estados Partes adotarão todas as medidas eficazes e adequadas para abolir práticas tradicionais que sejam prejudicais à saúde da criança.

4. Os Estados Partes se comprometem a promover e incentivar a cooperação internacional com vistas a lograr, progressivamente, a plena efetivação do direito reconhecido no presente artigo. Nesse sentido, será dada atenção especial às necessidades dos países em desenvolvimento. 
Em caso de tratamento forçado de crianças e adolescentes, ${ }^{782} \mathrm{o}$ artigo 25 fornece a eles o direito de que seu tratamento e todas as circunstâncias relevantes para sua internação sejam constantemente verificados.

No que se refere ao direito de autodeterminação da criança, o artigo 12 deve ser ressaltado, pois garante à criança capaz formação de opinião, direito de expressá-la livremente em todas as questões que lhe dizem respeito e consideração de sua opinião de acordo com sua idade e maturidade. In verbis,

1. Os Estados Partes assegurarão à criança que estiver capacitada a formular seus próprios juízos o direito de expressar suas opiniões livremente sobre todos os assuntos relacionados com a criança, levando-se devidamente em consideração essas opiniões, em função da idade e maturidade da criança.

2. Com tal propósito, se proporcionará à criança, em particular, a oportunidade de ser ouvida em todo processo judicial ou administrativo que afete a mesma, quer diretamente quer por intermédio de um representante ou órgão apropriado, em conformidade com as regras processuais da legislação nacional.

782 Por exemplo, internação numa clínica psiquiátrica para tratamento de anorexia. O exemplo é de MICHEL, Margot. Rechte von Kindern in medizinischen Heilbehandlungen. Op. Cit., p. 58. 
No mesmo sentido, cite-se o artigo 13, que cuida da liberdade de informação:

1. A criança terá direito à liberdade de expressão. Esse direito incluirá a liberdade de procurar, receber e divulgar informações e idéias de todo tipo, independentemente de fronteiras, de forma oral, escrita ou impressa, por meio das artes ou por qualquer outro meio escolhido pela criança.

2. O exercício de tal direito poderá estar sujeito a determinadas restrições, que serão unicamente as previstas pela lei e consideradas necessárias:

a) para o respeito dos direitos ou da reputação dos demais, ou

b) para a proteção da segurança nacional ou da ordem pública, ou para proteger a saúde e a moral públicas.

A convenção da ONU não estabelece um limite de idade, apenas trata de um modo geral a capacidade da criança de ter uma opinião e expressá-la. ${ }^{783}$ De fundamental importância, sustenta-se que o art. 12 possui aplicabilidade direta. Assim como este, também possuem aplicabilidade direta os artigos $3,7^{784}$ e $25{ }^{785}$ além de outros que cuidam dos direitos clássicos de liberdade. ${ }^{786}$

783 ALDERSON, Priscila. Die Autonomie des Kindes - über die Selbstbestimmungsfähigkeit von Kindern in der Medizin. Op. Cit., p. 35

${ }^{784}$ 1. A criança será registrada imediatamente após seu nascimento e terá direito, desde o momento em que nasce, a um nome, a uma nacionalidade e, na medida do possível, a conhecer seus pais e a ser cuidada por eles. 
A Convenção de Direitos da Criança da ONU não determinou quem seria competente para a concretização dos direitos da criança, ou seja, se ela mesma poderia realizar seus direitos ou necessitaria do consentimento de seus pais e se esse consentimento ainda seria necessário mesmo que a criança fosse capaz de discernimento. Cabe a cada país, por meio de seus poderes legislativo, executivo e judiciário, interpretar as determinações internacionais e realizar os direitos da criança. A Convenção apenas aponta linhas gerais sobre como lidar com a relação de tensão entre direito de autonomia e necessidade de proteção da criança, o que pode se tornar mais evidente no tema dos tratamentos médicos. ${ }^{787}$

Não se discute a constitucionalidade da Convenção, nem é o objetivo do presente trabalho. No entanto, pode-se dizer, como

2. Os Estados Partes zelarão pela aplicação desses direitos de acordo com sua legislação nacional e com as obrigações que tenham assumido em virtude dos instrumentos internacionais pertinentes, sobretudo se, de outro modo, a criança se tornaria apátrida.

${ }^{785}$ Os Estados Partes reconhecem o direito de uma criança que tenha sido internada em um estabelecimento pelas autoridades competentes para fins de atendimento, proteção ou tratamento de saúde física ou mental a um exame periódico de avaliação do tratamento ao qual está sendo submetida e de todos os demais aspectos relativos à sua internação.

786 MICHEL, Margot. Rechte von Kindern in medizinischen Heilbehandlungen. Op. Cit., p. 59.

${ }^{787}$ Ibidem, p. 59. 
defende PIOVESAN, ${ }^{788}$ que a Convenção está em plena conformidade com a Carta de 1988, haja vista que a primeira concebe a criança como sujeito de direitos a qual deve ser centro de especial proteção e prioridade, o que também fica consubstanciado no art. 227 da Constituição Federal, de acordo com a redação dada pela Emenda Constitucional no ${ }^{\circ} .65$ de $2010 .{ }^{789}$

\subsubsection{Convenção de Biomedicina}

A primeira convenção do Conselho da Europa sobre Biomedicina foi a Convenção Europeia de Proteção aos Direitos Humanos e Dignidade da Pessoa Humana face às aplicações da Biologia e da Medicina, a chamada Convenção de Biomedicina ou Bioética, de 04 de abril de 1997, que teve lugar em Oviedo. A Convenção entrou em vigor no dia $1^{\circ}$ de dezembro de 1999, depois que o número necessário de Estados a ratificou. Até hoje, vinte e um Estados ratificaram a convenção, treze assinaram, mas não ratificaram e o Brasil sequer assinou o documento.

${ }^{788}$ Direitos Humanos e o Direito Constitucional Internacional. Op. Cit., p. 217.

${ }^{789}$ É dever da família, da sociedade e do Estado assegurar à criança, ao adolescente e ao jovem, com absoluta prioridade, o direito à vida, à saúde, à alimentação, à educação, ao lazer, à profissionalização, à cultura, à dignidade, ao respeito, à liberdade e à convivência familiar e comunitária, além de colocá-los a salvo de toda forma de negligência, discriminação, exploração, violência, crueldade e opressão. 
A Convenção de Biomedicina faz uma diferenciação principal entre pessoas capazes e incapazes de consentimento. ${ }^{790}$ Os menores não são tratados, de forma genérica, como incapazes, pois cabe ao direito nacional dizer se eles possuem ou não a capacidade de consentimento. Se eles forem considerados capazes de consentimento de acordo com seu direito nacional, então será aplicável o art. 5 da Convenção, segundo o qual, uma intervenção no âmbito da saúde apenas será legítima, após o paciente menor ter sido amplamente esclarecido e prestado livremente seu consentimento. ${ }^{791}$

$\mathrm{O}$ art. 6 se dedica especialmente às pessoas incapazes de consentimento, sendo importantes os itens 1, 2, 4 e 5. In verbis:

Artigo 6. ${ }^{\circ}$

Protecção das pessoas que careçam de capacidade para prestar o seu consentimento

1 - Sem prejuízo dos artigos $17 .^{\circ}$ e $20 .^{\circ}$, qualquer intervenção sobre uma pessoa que careça de capacidade para prestar o seu consentimento apenas poderá ser efectuada em seu benefício directo.

2 - Sempre que, nos termos da lei, um menor careça de capacidade para consentir numa intervenção, esta não poderá ser

790 MICHEL, Margot. Rechte von Kindern in medizinischen Heilbehandlungen. Op. Cit., p. 60.

${ }^{791}$ Ibidem, p. 60. 
efectuada sem a autorização do seu representante, de uma autoridade ou de uma pessoa ou instância designada pela lei.

A opinião do menor é tomada em consideração como um factor cada vez mais determinante, em função da sua idade e do seu grau de maturidade.

4 - O representante, a autoridade, a pessoa ou a instância mencionados nos $n^{0}$ s. 2 e 3 recebem, nas mesmas condições, a informação citada no artigo $5 .^{\circ}$

5 - A autorização referida nos $n^{0} \mathrm{~s}$. 2 e 3 pode, em qualquer momento, ser retirada no interesse da pessoa em questão. ${ }^{792}$

$\mathrm{O}$ art. $6^{\circ}(1)$ estabelece que apenas intervenções que tragam benefícios diretos às pessoas incapazes de consentir devem ser realizadas, nos termos do art. 17, que trata de pesquisas clínicas e do art. 20 que cuida de transplantes de órgãos e tecidos.

Conforme o art. 6 da Convenção, o qual se transcreveu supra, pessoas incapazes de consentimento não podem decidir sobre intervenções médicas, pois elas não têm direito de autodeterminação no sentido próprio. ${ }^{793}$

Entretanto, a Convenção de Biomedicina determina expressamente que a opinião do menor deve ser levada em ${ }^{792}$ Como o Brasil não é parte da referida convenção, havemos por bem trazer a tradução portuguesa do referido documento.

793 MICHEL, Margot. Rechte von Kindern in medizinischen Heilbehandlungen. Op. Cit., p. 61. 
consideração e mais, que ela tem um peso decisivo conforme sua maturidade e idade crescentes. Trata-se de uma forma de efetiva participação do menor no processo de decisão. ${ }^{794}$

Do art. 6 (2) da Convenção pode-se extrair que, em determinadas intervenções, o consentimento de um menor deveria ser imprescindível ou pelo menos suficiente. ${ }^{795} \mathrm{O}$ consentimento fornecido pelo representante do menor seria admitido apenas em alguns casos. Para tanto, o critério, fornecido pelo art. $6^{\circ}$ (1) é o benefício direto para o paciente. Dessa forma, o parâmetro é um critério objetivo, mas que também não esclarece se o benefício direto deve ser avaliado apenas sob o ponto de vista médico ou se outros fatores também deveriam ser considerados. Segundo o art. $6^{\circ}$ (4) destinatário do esclarecimento é aquele que concede o consentimento. Nesse sentido, a Convenção de Biomedicina não vê um direito especial do incapaz de consentimento em relação ao consentimento. $^{796}$

Em contrapartida, o art. 10, que garante a cada pessoa o direito de esfera privada e o direito de informação, não faz diferença entre pessoas capazes e incapazes de consentimento. Dessa forma se reconhece também aos menores os direitos de esfera privada, de

\footnotetext{
${ }^{794}$ Ibidem, p. 61.

${ }^{795}$ Ibidem, p. 61.

${ }^{796}$ Ibidem, p. 61.
} 
informação e de não saber. ${ }^{797} \mathrm{O}$ art. $10^{\circ}$ (3) contém previsão do privilégio terapêutico. Nos termos do referido dispositivo:

Artigo $100^{\circ}$

Vida privada e direito à informação

1 - Qualquer pessoa tem direito ao respeito da sua vida privada no que toca a informações relacionadas com a sua saúde.

2 - Qualquer pessoa tem o direito de conhecer toda a informação recolhida sobre a sua saúde. Todavia, a vontade expressa por uma pessoa de não ser informada deve ser respeitada.

3 - A título excepcional, a lei pode prever, no interesse do paciente, restrições ao exercício dos direitos mencionados no n. ${ }^{\circ} 2$.

${ }^{797}$ ROTHÄRMEL, Sonja. Einwilligung, Veto, Mitbestimmung. Op. Cit., pp. 31 e 38 . 


\section{CAPÍTULO 6 - O CONSENTIMENTO NAS INTERVENÇÕES MÉDICAS}

\subsection{Introdução}

O tema do consentimento nas intervenções médicas e seus pressupostos representam um ponto essencial no Direito Médico, uma vez que o consentimento constitui pressuposto de legitimidade para toda ação médica. Conforme visto supra, do ponto de vista do paciente, a exigência do consentimento representa a realização e a defesa de seu direito de autodeterminação. Do ponto de vista do médico, por sua vez, a ausência do consentimento ou sua ineficácia pode acarretar responsabilidade civil e/ou criminal, mesmo em caso de tratamento realizado conforme as normas técnicas e sem acarretar qualquer dano corporal ao paciente.

Tal temática também apresenta relevância prática em casos de intervenções médicas em menores, trazendo ainda uma questão bastante importante, que é a da capacidade para consentir. Quando o procedimento médico tiver por paciente um menor, deve-se questionar quem deve ser informado antes do procedimento e quem deve dar o consentimento para que o tratamento possa ser executado. 
No Brasil assim como em outros países, como, por exemplo, a Alemanha, não existe uma regulamentação legal esclarecendo sobre o consentimento para procedimentos médicos em menores. $\mathrm{O}$ Código Civil brasileiro contém, apenas, regras sobre a capacidade de agir para os negócios jurídicos em geral, mas nada em relação à capacidade de ação em assuntos que se refiram aos direitos da personalidade.

\subsection{Natureza jurídica do consentimento nas intervenções} médicas

De início, a questão já se mostra tormentosa no que se refere à natureza jurídica do consentimento no Direito Médico. Sobre esse ponto a doutrina não é unânime. Alguns sustentam que o consentimento é declaração de vontade negocial, aplicando-se a ele as normas do Código Civil que tratam da capacidade de agir (arts. $3^{\circ}$ e $4^{\circ}$ ). A eficácia do consentimento, portanto, vincula-se à capacidade de agir. ${ }^{798}$

798 ENNECERUS, Ludwig; NIPPERDEY, Hans Carl. Lehrbuch des bürgerlichen Rechts, Allgemeinet Teil des bürgerlichen Rechts; Zweiter Halbband: Entstehung, Untergang und Veränderung der Rechte, Ansprüche und Einreden, Ausübung und Sicherung der Rechte. 15 ed. Tübingen: Mohr, 1960. p. 933, §151 II 1e, Fn. 11, p. 1315, §212 II 3. 
Outros, entretanto, argumentam que o consentimento do paciente na intervenção médica não é uma declaração negocial da vontade, de modo que os limites de idade da capacidade de agir disciplinados nos artigos do Código Civil não são aplicáveis. ${ }^{799}$ Ao invés disso, é necessário em cada caso concreto verificar e determinar se o paciente, em decorrência de seu direito de autodeterminação, é capaz de entender, ainda que de forma genérica, a essência, significado, necessidade e extensão do procedimento médico e decidir de forma autônoma a favor ou contra tal procedimento. $^{800}$

799 DEUTSCH, Erwin; SPICKHOFF, Andreas. Medizinrecht. Azrtrecht, Arzneimittelrecht, Medizinproduktrecht und Transfusionsrecht. Op. Cit., p. 270; DUTTGE, Gunnar. Patientenautonomie und Einwilligungsfähigkeit. In: WIESERMANN, Claudia; SIMON, Nauck. Patientenautonomie. Op. Cit., p. 78; HUBER, Peter. In Münchener Kommentar zum Bürgerlichen Gesetzbuch. v. 8. München: Beck, 2008. Rn. 40; HEIDE, Jochen. Medizinische Zwangsbehandlung, Rechtsgrundlagen und verfassungsrechtliche Grenzen der Heilbehandlung gegen den Willen des Betroffenen. Berlin: Duncker \& Humbolt, 2001. pp. 141-143; WÖLK, Florian. Der minderjährige Patient in der ärztliche Behandlung. Frankfurt: Springer, 2001, pp. 80-81; ULSENHEIMER, Klaus. §139 Die fahrlässige Körperverletzung. In LAUFS, Adolf; UHLENBRUCK, Wilhelm. Handbuch des Arztrechts. Op. Cit., Rn. 27, p. 1249.

800 DEUTSCH, Erwin; SPICKHOFF, Andreas. Medizinrecht. Azrtrecht, Arzneimittelrecht, Medizinproduktrecht und Transfusionsrecht. Op. Cit., pp. 271 e 648; ULSENHEIMER, Klaus. \$139 Die fahrlässige Körperverletzung. In LAUFS, Adolf; UHLENBRUCK, Wilhelm. Handbuch des Arztrechts. Op. Cit., 27, p. 1249. 
$\mathrm{Na}$ Alemanha o Bundesgerichtshof (BGH) decidiu um caso emblemático em 05 de dezembro de 1958, pelo qual valorizou o consentimento do menor de forma diferente a uma declaração de vontade meramente negocial. ${ }^{801}$ Nesse caso narra-se que um jovem de 20 anos (à época menor, de acordo com a lei vigente, pela qual a maioridade se dava aos 21 anos) consentiu em uma operação de tireoide. Não houve consentimento dos pais. Aliás, o paciente pediu ao médico que não tomasse o consentimento de seus pais, que viviam na Alemanha Oriental, pois estes tinham medo de sofrer algum tipo de repressão pelo fato do filho ter fugido para a Alemanha Ocidental. Em consequência da operação, o jovem sofreu uma paralisia na corda vocal, que levou à perda da voz de modo irreversível. Como não foi possível provar o erro médico, o paciente alegou que o procedimento médico fora ilícito porque faltou o consentimento de seus representantes legais. O Tribunal alemão indeferiu o pedido do jovem, a par de fundamentar o indeferimento no princípio do venire contra factum proprio, também se valeu da capacidade de consentir. Sustentou o Tribunal que o consentimento do menor no procedimento médico não era declaração de vontade, mas sim permissão para a realização de negócios de fato. ${ }^{802}$

${ }^{801}$ GLEIXNER-EBERLE, Elisabeth. Die Einwilligung in die medizinische Behandlung Minderjähriger. Op. Cit., pp. 274-275.

${ }^{802}$ BGH, Urt. v. 5.12.1958 - VI ZR 266/57 = BGHZ 29, 33, 36. Cf. anexo V. 
De acordo com esse entendimento, afirmou a Corte alemã que, no caso concreto do consentimento para a realização de uma medida médica, não se deve considerar a capacidade de agir do paciente menor, mas, sim, se ele "de acordo com sua maturidade intelectual e moral consegue avaliar o significado e a extensão do procedimento, bem como sua permissão". ${ }^{803}$

$\mathrm{Na}$ Alemanha, tanto a doutrina penal como a civil se apegaram a esse entendimento. Entretanto, ainda existe resistência em se reconhecer que, do ponto de vista dogmático, o consentimento não representa uma declaração de vontade negocial. ${ }^{804}$

Nesse contexto, como a discussão dogmática sobre a natureza do consentimento ainda não foi resolvida, surge a questão de saber se as regras de direito civil que tratam da capacidade de agir, podem ser utilizadas ao menos por analogia para o consentimento de menores em procedimentos médicos. ${ }^{805}$ A polêmica permanece.

Alguns defendem que o consentimento realmente não é uma declaração de vontade negocial, mas, sim, uma declaração de vontade que objetiva um efeito prático, concluindo, com isso, pela

${ }^{803} B G H$, Urt. v. 5.12.1958 - VI ZR 266/57 = BGHZ 29, 33, 36.

${ }^{804}$ HEIDE, Jochen. Medizinische Zwangsbehandlung, Rechtsgrundlagen und verfassungsrechtliche Grenzen der Heilbehandlung gegen den Willen des Betroffenen. Op. Cit., pp. 141-142.

${ }^{805}$ GLEIXNER-EBERLE, Elisabeth. Die Einwilligung in die medizinische Behandlung Minderjähriger. Op. Cit., p. 275. 
utilização das normas da capacidade de agir. ${ }^{806}$ Já outros afirmam que, em princípio, se podem utilizar as regras da capacidade de agir por analogia, mas no campo de disposição de direitos fundamentais deve-se fazer uma exceção para se tomar a capacidade de discernimento e julgamento. ${ }^{807}$

Outros, ainda, sustentam que mesmo diante de direitos fundamentais, poder-se-ia utilizar as regras da capacidade de agir por analogia. ${ }^{808}$ Os fundamentos para isso são vários. Afirma-se que o consentimento se assemelha a uma declaração de vontade negocial, uma vez que aquele que o presta terá à sua disposição uma ação de indenização, cujo objeto é um bem patrimonial. ${ }^{809}$

Ademais, que as normas da capacidade de agir têm como objetivo a proteção do menor, a garantia da segurança jurídica e a segurança do direito dos pais de criar seus filhos. Disso decorre que para a eficácia do consentimento do menor é necessária a ${ }^{806}$ WENDTLAND, Holger. In BAMBERGER, Heinz Georg; ROTH, Herbert (Coord.). Kommentar zum Bürgerlichen Gesetzbuch. v. 1. München: Beck, 2012. §107, Rn. 2.

${ }^{807}$ GERNHUBER, Joachim; COESTER-WALTJEN, Dagmar. Familienrecht. 6 ed. München: Beck, 2010. p. 697.

${ }^{808}$ WENDTLAND, Holger. In BAMBERGER, Heinz Georg; ROTH, Herbert (Coord.). Kommentar zum Bürgerlichen Gesetzbuch. Op. Cit., §107, Rn. 2. $\mathrm{O}$ autor sustenta que, no caso dos menores absolutamente incapazes de agir, apenas o representante legal poderia consentir de forma eficaz, enquanto para os relativamente incapazes, bastaria uma concordância dos representantes. ${ }^{809}$ GLEIXNER-EBERLE, Elisabeth. Die Einwilligung in die medizinische Behandlung Minderjähriger. Op. Cit., p. 277. 
concordância dos seus representantes legais. ${ }^{810}$ Entretanto, esses argumentos podem ser refutados, de modo que as regras da capacidade de agir não devem ser aplicadas ao consentimento para procedimentos médicos em menores nem de forma direta, nem por analogia. $^{811}$

As normas sobre capacidade de agir têm como finalidade incidir principalmente sobre interesses de tráfego nos negócios contratuais e de negócios de massa. A relação médico-paciente, entretanto, referese a bens jurídicos personalíssimos e tem por fundamento $\mathrm{o}$ consentimento esclarecido, afastando-se por completo da noção contratualista que a capacidade de agir abarca. ${ }^{812}$

Em relação à necessidade de proteção aos menores, é verdade que a proteção deve ocorrer também no campo dos tratamentos médicos. Mas, mesmo assim, é justificável afastar o tratamento médico do campo dos negócios jurídicos, tendo em vista as diferenças essenciais entre ambos. As regras da capacidade de agir

810 SCHMITT, Jochem. In Münchener Kommentar zum Bürgerlichen Gesetzbuch - §105 BGB. v. 1. München: Beck, 2008. Rn. 22.

${ }^{811}$ BÖHMKER, Daniela. Die Entscheidungskompetenz des minderjährigen Patienten in der medizinischen Behandlung. Op. Cit., pp. 95-96; GLEIXNER-EBERLE, Elisabeth. Die Einwilligung in die medizinische Behandlung Minderjähriger. Op. Cit., p. 277; REIPSCHLÄGER, Christiane. Die Einwilligung Minderjähriger in ärztliche Heileingriffe und die elterliche Personensorge. Frankfurt: Peter Lang, 2004. p. 40.

${ }^{812}$ GLEIXNER-EBERLE, Elisabeth. Die Einwilligung in die medizinische Behandlung Minderjähriger. Op. Cit., p. 279. 
não levam em conta a crescente capacidade de autodeterminação dos menores. Enquanto se mostra aceitável a determinação alheia por meio dos pais nos negócios jurídicos em geral, no consentimento em relação a bens jurídicos personalíssimos há que se atentar, de forma especial e diferenciada, para a autodeterminação crescente do menor. Trata-se de decisões que tocam diretamente a personalidade do menor, o qual deve ser chamado a participar conforme seu desenvolvimento. ${ }^{813}$

Os problemas específicos, relacionados com o consentimento nos procedimentos que atingem a integridade corporal, não podem ser resolvidos por meio dos limites de idade da capacidade de agir. Parece claro que a declaração de vontade negocial e o consentimento em procedimentos médicos dizem respeito a bens jurídicos da mais alta diferença qualificativa. ${ }^{814}$

No campo do tratamento médico existe uma íntima relação com o direito de personalidade do menor, o que não ocorre no âmbito dos negócios jurídicos. ${ }^{815}$ Os limites rígidos da capacidade de agir não são adequados para sustentar um consentimento para procedimentos

813 REIPSCHLÄGER, Christiane. Die Einwilligung Minderjähriger in ärztliche Heileingriffe und die elterliche Personensorge. Op. Cit., p. 40. 814 LINK, Ihna. Schwangerschaftsabbruch bei Minderjährigen. Eine vergleichende Untersuchung des deutschen und englischen Rechts. Frankfurt: Peter Lang, 2002. p. 91.

815 WÖLK, Florian. Der minderjährige Patient in der ärztlichen Behandlung. Op. Cit., pp. 80, 82. 
médicos, diante das diferentes exigências que estes podem apresentar. Assim é que, quanto mais complexo for um determinado tratamento, maiores serão as exigências para a capacidade de consentir. ${ }^{816}$ Entretanto, os limites de idade da capacidade de agir podem oferecer um ponto de partida para a avaliação da capacidade de consentir, mas não a substituir no caso em apreço. ${ }^{817}$

O cerne da questão é analisar se e em que medida o menor tem capacidade de decisão sobre tratamentos médicos, tendo-se em vista sua necessidade de proteção de um lado, e seu direito de autodeterminação de outro. ${ }^{818}$

\subsection{A capacidade de consentir}

Os ordenamentos jurídicos em geral prescrevem pressupostos pelos quais o Direito reconhece as manifestações de vontade. Abstraindo dos limites objetivos da liberdade de decisão, de

816 ULSENHEIMER, Klaus. §139 Die fahrlässige Körperverletzung. In LAUFS, Adolf; UHLENBRUCK, Wilhelm. Handbuch des Arztrechts. Op. Cit., Rn. 27-29, pp. 1249-1250.

817 DEUTSCH, Erwin; SPICKHOFF, Andreas. Medizinrecht. Azrtrecht, Arzneimittelrecht, Medizinproduktrecht und Transfusionsrecht. Op. Cit., p. 271.

${ }^{818}$ GLEIXNER-EBERLE, Elisabeth. Die Einwilligung in die medizinische Behandlung Minderjähriger. Op. Cit., p. 276. 
prescrições formais etc., isso diz respeito à "capacidade de consentimento". 819

Com o alcance da maioridade, a pessoa passa a ser reconhecida como apta a tomar decisões e participar dos negócios jurídicos. Essa autorização para participar dos negócios jurídicos abrange todas as formas, com as quais a pessoa pode configurar suas relações jurídicas com autorresponsabilidade. Nesse sentido, também se reconhece ao indivíduo uma capacidade geral para a autodeterminação, falando-se, então, em direito à autodeterminação. $^{820}$

Quando uma pessoa é admitida no tráfego jurídico, põe-se a questão (negativa) de saber se em relação a alguns negócios, tendo em vista sua condição pessoal, esse reconhecimento jurídico pode ser negado. Quando se trata de pessoa maior de idade, não se fala em capacidade de consentimento, uma vez que, em princípio, ela a tem, mas de ausência da capacidade de consentimento como uma forma específica de incapacidade para os negócios. Porém, no caso dos menores, a permissão para participar do tráfego jurídico ora discutido depende de sua capacidade de consentimento e deve ser determinada de forma positiva. Ou seja, será analisado se, para 819 TAUPITZ, Jochen. Empfehlen sich zivilrechtliche Regelungen zu Absicherung der Patientenautonomie am Ende des Lebens?, A 52 D. 820 TAUPITZ, Jochen. Empfehlen sich zivilrechtliche Regelungen zu Absicherung der Patientenautonomie am Ende des Lebens?, A 52 D. 
algumas relações jurídicas, o menor terá capacidade de consentimento. ${ }^{821}$

O tema da capacidade de consentimento de menores nos tratamentos médicos não tem sido estudado apenas pelo Direito. Também a sociologia, a educação, a bioética, a psicologia, e a própria medicina, por meio da psiquiatria e da pediatria, dentre outras, se ocupam dessa temática.

A importância de estudos sobre o tema em áreas afins à jurídica é evidente. Segundo ENGISCH, o direito é um elemento essencial da sociedade. ${ }^{822}$ Assim sendo, não se separa das demais ciências, com as quais guarda estreito vínculo. O jurista é, no mais das vezes, um generalista no sentido de que não é especializado em vários campos do conhecimento, quando muito em um ou alguns. Desse modo, para adequar a norma jurídica às vicissitudes do caso concreto, o direito reclamará o estudo de áreas que lhe são afins, fazendo com que o intérprete da norma mergulhe por áreas desconhecidas de modo a compreendê-las de forma mais profunda para assegurar a melhor aplicação do direito ao caso concreto.

821 TAUPITZ, Jochen. Empfehlen sich zivilrechtliche Regelungen zu Absicherung der Patientenautonomie am Ende des Lebens?, A 52 D. ${ }^{822}$ ENGISCH, Karl. Einführung in das juristische Denken, 1983. Trad. Port. J. Baptista Machado. Introdução ao pensamento jurídico. 6 ed. Lisboa: Calouste Gulbenkian, 1988. p. 12. 
A propósito, no Direito Romano, Ulpiano já dizia Iuris prudentia est divinarum atque humanarum rerum notitia, iusti atque iniusti scientia, ou seja, que a jurisprudência é o conhecimento das coisas divinas e humanas, a ciência do justo e do injusto. ${ }^{823}$ Por ciência do direito, $\mathrm{LARENZ}^{824}$ entende a ciência que se confronta com a solução de questões jurídicas no contexto e com base em um ordenamento jurídico determinado, historicamente constituído, ou seja, a tradicionalmente denominada Jurisprudência. Note-se, porém, que jurisprudência, tanto como usado pelo jurista Romano quanto por Larenz não enseja, nesse contexto, o conjunto de decisões de determinado tribunal, como o termo é usado amplamente no Brasil. Ao contrário, enseja a própria ciência do direito, cuja interpretação deve ser feita à luz não só de elementos jurídicos, mas também da interdisciplinariedade, a fím de garantir uma visão mais ampla dos conflitos que surgem no contexto social.

Nesse sentido, a seguir passa-se a tratar de algumas concepções não jurídicas da capacidade de consentimento, as quais, em conjunto com a concepção ou concepções jurídicas, possibilitarão um conhecimento mais amplo e completo sobre essa temática.

${ }_{823}^{823}$ Ulp. 1 reg. D. 1, 1, 10, 2.

${ }^{824}$ Methodenlehre der Rechtswissenschaft, 1991. Trad. Port. J. Lamego. Metodologia da ciência do direito. 3 ed. Lisboa: Calouste Gulbenkian, 1997. p. 1. 
Lembrando-se, ainda, que não se trata de tema central desse trabalho.

\subsubsection{Concepções não jurídicas da capacidade de consentir}

Essas concepções têm como pressuposto que crianças sempre têm uma alta capacidade de discernimento a qual deve ser averiguada de maneira adequada por meio de diferentes análises sobre o consentimento. ${ }^{825}$

Uma contribuição básica em relação ao consentimento de crianças parte da teoria de Piaget, o qual toma por base os estágios do desenvolvimento moral e cognitivo. Piaget desenvolve a partir desses estágios uma concepção de consentimento que abrange capacidade de julgamento, compreensão e voluntariedade. ${ }^{826}$

Argumenta-se que a teoria do desenvolvimento humano de Piaget $^{827}$ se desponta como inovadora em relação às demais teorias

${ }^{825}$ ALDERSON, Priscila. Die Autonomie des Kindes - über die Selbstbestimmungsfähigkeit von Kindern in der Medizin. Op. Cit., pp. 2829.

${ }^{826}$ DÖRRIES, Andrea. Zustimmung und Veto. Aspekte der Selbstbestimmung im Kindesalter. In WIESEMANN, Claudia; SIMON, Alfred. Patientenautonomie. Op. Cit., p. 181.

${ }^{827}$ O psicólogo suíço Jean Piaget (1896-1980) marcou fortemente a psicologia do desenvolvimento no campo do desenvolvimento cognitivo. Em várias pesquisas seus conhecimentos teóricos e empíricos foram provados, corrigidos e complementados. Nesse sentido, BÖHMKER, Daniela. Die Entscheidungskompetenz des minderjährigen Patienten in der medizinischen Behandlung. Op. Cit., p. 67, nt. 214. 
do desenvolvimento ao apresentar uma linha interacionista. Esta marca uma terceira visão a qual surge como uma tentativa de se juntar posições dicotômicas do materialismo mecanicista e do idealismo. Essas posições são marcadas pela ideia de que há um antagonismo impassível de conciliação entre seus dogmas que colocam de forma separada o físico e o psíquico. ${ }^{828}$

Segundo a teoria piagetiana, o desenvolvimento da criança se daria em fases ou etapas. A primeira delas é chamada de estágio sensório-motor, pois a pequena criança não apresenta, ainda, pensamentos ou afetividades que se ligam a representações as quais permitiriam evocações a pessoas ou objetos, quando estas se fizerem ausentes. A principal característica dessa fase é a noção de permanência do objeto. A segunda fase, por sua vez, é chamada de estágio pré-operatório, no qual a criança desenvolve a capacidade simbólica de formas diferentes, como a linguagem, imitação postergada, entre outras, o que torna a criança livre da dependência única de seus movimentos e sensações. Esta vê o mundo unicamente a partir de sua própria perspectiva e não pensa haver outras perspectivas possíveis. O terceiro estágio é a fase de operações concretas, haja vista que esta não profere enunciados verbais; aqui, 828 TERRA, Márcia Regina. O desenvolvimento humano na teoria de Piaget. Campinas, [s.d.], Disponível em: $<$ http://www.unicamp.br/iel/site/alunos/publicacoes/textos/d00005.htm>. Acesso em: 07 nov. 2016. 
aquilo que a criança faz está preso à realidade concreta. Por fim, há uma fase denominada estágio operatório-formal, no qual há a diferenciação entre o real e o possível. Nesse estágio, não mais a criança, mas o adolescente, já tem capacidade $^{829}$ para formular hipóteses e coloca-las à prova de forma sistemática, independentemente da verdade factual. ${ }^{830}$

Pela teoria de Piaget, afirma-se que a recusa das crianças a um determinado tratamento médico é considerada tão vinculante quanto a concordância destas, quando as causas que deram origem a esse comportamento de recusa puderem ser afastadas. Cabe aos pais a tarefa de criar um clima de comunicação, onde a criança possa perceber e compreender que pais e médicos zelam pelo seu bemestar. $^{831}$

Entretanto, a teoria de Piaget encontra fortes objeções. O Comitê de Bioética da American Academy of Pediatrics (AAP) comparou, em 1995, as concepções de informed consent, consent by proxy, parental permission e patient assente. ${ }^{832}$ Segundo

${ }^{829}$ Não se usa, aqui, capacidade em seu sentido jurídico.

${ }^{830}$ PALANGANA, Isilda Campaner. Desenvolvimento e aprendizagem em Piaget e Vigotsi: A relevância social [e-book]. 6 ed. São Paulo: Summus, 2015. pp, 16-19.

831 DÖRRIES, Andrea. Zustimmung und Veto. Aspekte der Selbstbestimmung im Kindesalter. Op. Cit., p. 181.

${ }^{832}$ Committee on Bioethics. Informed consent, parental permission, and assent in pediatric practice. Pediatrics. v. 95, pp. 314-317, fevereiro de 1995. 
entendimento desse Comitê, a doutrina do informed consent tem uma aplicação direta limitada na pediatria, pois apenas pacientes que têm uma capacidade apropriada de decisão e empoderamento legal podem dar seu consentimento informado. Em outras situações, nas quais menores são os pacientes fazem-se necessárias a informed permission dos pais e o assent do menor, nos casos apropriados.

Quanto ao consent by proxy, ou seja, o consentimento dado pelos pais do menor, o Comitê também entende que não é adequado e útil para os casos de pediatria. Conforme o próprio termo indica, consent significa literalmente "to feel or sense with" e expressa algo que é para si mesmo. A pessoa que consente o faz baseada em suas próprias crenças, valores e objetivos pessoais. Diante desse contexto, o Comitê de Bioética da AAP propôs como processo padrão o parental permission and shared responsability, pelo qual o processo de decisão envolvendo tratamento médico de menores deve derivar de uma responsabilidade compartilhada entre pais e médicos. Em geral a parental permission se relaciona com o bem-estar do menor.

Por fim, nos processos de decisão envolvendo tratamento médico de crianças mais velhas e adolescentes, deve-se considerar o assent of patient, assim como a participação dos pais e médicos. Nesse caso, pediatras não devem tratar crianças como seres racionais 
e autônomos automaticamente, mas devem considerar neles a capacidade em desenvolvimento para participar de decisões.

Dessa forma, o assent deve abranger uma informação adequada para a idade sobre a doença e as medidas planejadas. Conforme as crianças se desenvolvem, elas devem se tornar as primeiras guardiãs de sua saúde e parceiras no processo de tomada de decisão, assumindo, assim, as responsabilidades de seus pais. Se houver conflito com os pais, destaca-se de forma expressa que o processo de comunicação e a decisão consensual devem estar em primeiro plano.

Por fim, importante considerar que o Comitê de Bioética da AAP não fixa um limite de idade para considerar a capacidade dos menores no processo de decisão.

O Grupo de Ética da Confederation of European Specialists in Paediatrics (CESP) também se declarou a favor da concepção do informed assente. ${ }^{833}$ Sustentou que por informed consent deve-se entender a aprovação ou recusa pelos representantes legais da criança ou pela criança competente de uma medida médica.

Informed assent significa a concordância da criança, ou a recusa, com procedimentos médicos em casos em que ela não é apta legalmente a dar seu consentimento ou não possui capacidade para ${ }^{833}$ LEVY, Maria de Lourdes; LARCHER, Victor; KURZ, Ronald. Informed consent/assent in children. Statement of the Ethics Working Group of the Confederation of European Specialists in Paediatrics (CESP). European Journal of Pediatrics. v. 162, pp. 629-633, setembro de 2003. 
tanto. Mesmo em casos de crianças que não tenham capacidade de consentimento, os médicos devem ouvir suas opiniões e desejos. Todas as crianças têm o direito de receber informações compatíveis com seu entendimento e expressar sua concordância ou recusa. Esse processo de consentimento ou assentimento deve proteger a dignidade da criança e de sua família.

Essa concepção acentua a atitude de parceria, compreensão mútua, respeito e confiança como um processo contínuo de esclarecimento. Seu fundamento é o respeito da autonomia, considerada uma "regra de ouro", assim como o princípio da não maleficência e direito de participação. Entretanto, afirma-se que não se deve aceitar uma recusa da criança diante de uma medida médica indicada, quando o estado de saúde for grave e houver ameaça à vida, em nome do seu bem-estar. Eventuais conflitos com os pais devem ser esclarecidos em várias conversas e ser levados ao Poder Judiciário apenas em casos excepcionais. Essa concepção aceita os limites de idade dos regulamentos nacionais de cada país, mas chama a atenção para o fato de que a doença da criança pode desempenhar um papel fundamental.

$\mathrm{Na}$ Alemanha, a Deutsche Akademie für Kinder- und Jugendmedizin (Academia Alemã para Medicina de Crianças e Adolescentes) ainda não tratou da concepção do consentimento da 
criança de forma mais profunda. Nesse artigo, que trata da tomada de posição na limitação de terapia, a Deutsche Akademie considerou assent como aceitação de um procedimento proposto, que deve ser aplicado tanto para crianças como seus pais, quando estes não quiserem tomar uma decisão em casos de terminalidade de medidas que mantém a vida do filho. Essa concordância deve ser respeitada, mas devidamente documentada. ${ }^{834}$

O Conselho Federal de Medicina alemão, ao tratar dos princípios da morte assistida por um médico, sustenta que crianças devem ser esclarecidas de forma verdadeira e adequada à sua idade e devem ser integradas regularmente nos processos de decisão que as atingem, conforme seu grau de desenvolvimento, na medida em que isso for desejado por elas. O Conselho pondera que crianças gravemente doentes desenvolvem a capacidade de discernimento desde cedo, o que deve ser levado em consideração no processo de tomada de decisão. ${ }^{835}$

Outras concepções, conhecidas por relacionais, possuem um processo de decisão orientado na família. ${ }^{836}$ Elas não fazem

${ }^{834}$ Begrenzung lebenserhaltender Therapie im Kindes- und Jugendalter. Disponível em: <http://www.dakj.de>. Acesso em: 17 out. 2016.

${ }^{835}$ Bundesärztekammer, Grundsätze der Bundesärztekammer zur ärztlichen Sterbebegleitung, in: Deutsche Ärzteblatt 108, 2011, A346-A348.

${ }^{836}$ FOREMAN, David M. The family rule: a framework for obtaining ethical consent for medical interventions from children. Journal of Medical Ethics. v. 25 (6), pp. 491-500, dezembro de 1999. 
referência à capacidade de consentimento dos menores, nem tratam das diferenças entre concordância e consentimento, as quais se tornam praticamente irrelevantes. Informed consent com menores deve ser compartilhado tanto com a criança como seus pais, havendo uma verdadeira "regra de família". O consentimento por um determinado procedimento médico deve observar a situação e rotina de ambos, criança e família.

Em parte, essas concepções relacionam-se a determinadas medidas de cautela, como, por exemplo, atenção quanto à pressão dos pais contra a criança e aos sinais de recusa da criança. Elas atribuem importância à integração consciente da criança no processo de decisão. Nesse modelo, os membros da família não têm objetivos singulares diferentes, mas os objetivos são vistos em conjunto, de forma que decisões para um de seus membros, no caso, a criança, atingem a família como um todo. Seus fundamentos são a observação e o respeito da autodeterminação da criança, o respeito diante das necessidades familiares e o princípio da não maleficência para a criança.

Outra concepção relacional exige, ao invés do apoio da autonomia da criança, o respeito diante da autonomia da família. Essa concepção leva em consideração a família em sua integralidade e não exclusivamente o bem-estar da criança, embora continue a 
protegê-la. Os pais são obrigados a criar um ambiente para as crianças que permita o crescimento delas para se formarem adultos autodeterminados. O Estado somente pode limitar a autonomia dos pais através de regulamentos legais, por exemplo, reconhecendo direitos de participação da criança e deve punir casos de negligência, maus tratos e exploração. ${ }^{837}$

Por fim, ALDERSON ${ }^{838}$ traz outro entendimento sobre capacidade de consentimento nas crianças. Afastando-se do conceito de assent, a autora formulou uma concepção de consentimento da criança baseada no consent a partir de um estudo empírico por ela realizado no período de 1989 a 1991 com 120 crianças de 8 a 15 anos. $^{839}$

${ }^{837}$ ROSS, Lainie Friedman. Children, families, and health care decisionmaking. Oxford: Clarendon, 1998.

${ }^{838}$ Priscilla Alderson é professora de estudos da infância da Social Science Research Unit, Institute of Education da University of London. Em suas pesquisas realizadas com crianças, Alderson considera-as como coprodutoras dos dados obtidos. Nesse sentido, Research with children: perspectives and practices, 2000. Trad. Port. A. François e F. Müller. As crianças como pesquisadoras: os efeitos dos direitos de participação sobre a metodologia de pesquisa. In Educação \& Sociedade. v. 26, n. 91. Campinas: Centro de Estudos Educação e Sociedade, p. 419, 2005. Dentre seus outros escritos, encontram-se: Children's consent to surgery. Buckingham: Open University Press, 1993; Listening to children: ethics and social research. Barkingside: Barnardo's, 1995, entre outros.

${ }^{839}$ Die Autonomie des Kindes - über die Selbstbestimmungsfähigkeit von Kindern in der Medizin. Op. Cit., p. 28. 
A autora defende a opinião que a competência e capacidade de autodeterminação das crianças no processo de tratamento se desenvolvem, principalmente, por meio das experiências prévias, relacionadas principalmente com seu quadro de doença, vivenciadas por essas crianças. A capacidade de consentimento, portanto, não deriva da idade e da capacidade intelectual, pode oscilar, assim como para os adultos, e depende do contexto.

Nesse sentido, ALDERSON critica os testes de competência geralmente aplicados por médicos para avaliar a capacidade de consentimento da criança. ${ }^{840}$ Em primeiro lugar, porque os resultados desses testes demostram apenas conhecimentos gerais, muitas vezes irrelevantes, e o grau de instrução que a criança recebeu. Também testes de leitura e cálculo ajudam pouco. No estudo realizado, uma das conclusões a que se chegou, foi que, embora as crianças tivessem perdido muitos meses de escola e algumas tivessem uma leitura fraca, o nível de conhecimento que apresentavam era bem alto em relação ao problema de saúde que tinham e ao seu tratamento. Concluiu-se, assim, que o aprendizado é mais eficiente quando tem importância imediata para aquele que aprende. $^{841}$

${ }^{840}$ Ibidem, p. 28.

${ }^{841}$ Ibidem, p. 31. 
Além disso, os testes de competência não abrangem o conhecimento pessoal altamente especializado, que seria mais relevante para o procedimento; muitas crianças, assim como adultos, não têm conhecimento médico geral, por isso há perigo de os testes minimizarem o verdadeiro conhecimento da criança. Quando uma criança não sabe uma resposta, esses testes levam à conclusão de que ela também não entenderá essa resposta quando lhe for explicada mais tarde - trata-se de um raciocínio ilógico e sem fundamento. Os testes tratam competência e consentimento como simples entendimento; entretanto, a competência também abrange um conhecimento aprofundado de como a doença e o tratamento incidirão sobre a vida futura da criança. Essas capacidades não dependem da idade, inteligência ou formação geral do paciente. Ao submeter um paciente a esses testes, seja ele adulto ou criança, um aspecto essencial fica oculto, qual seja, o apoio e a atenção que ele precisa sentir nessa relação que se constrói em torno da confiança. ${ }^{842}$

Após indicar as influências negativas dos testes de competência para a comunicação na relação médico-paciente, a autora, partindo dos resultados obtidos por sua pesquisa empírica, observa que, ao contrário do preconizado pela literatura, no sentido de que crianças geralmente são descritas como difíceis de serem tratadas, por se ${ }^{842}$ Ibidem, p. 31. 
recusarem ao tratamento, revela o contrário, ou seja, que crianças demonstram capacidade de reflexão, são responsáveis e atendem aos conselhos do médico. Em média, as crianças observadas no estudo já haviam passado por quatro cirurgias; uma menina, por quarenta. E, mesmo depois de um tratamento que não tinha surtido o efeito esperado, elas estavam dispostas para mais uma tentativa. Muitas delas tiveram que suportar dores fortes, mas se queixavam pouco, sobretudo para poupar seus pais do verdadeiro alcance do sofrimento infligido.

Também no que diz respeito à linguagem e cognição, ALDERSON argumenta que funcionários de unidades neonatais sabem que bebês, na fase anterior ao desenvolvimento da linguagem, podem ser muito acalmados pela fala, sobretudo pela voz dos pais, que a criança reconhece a partir da experiência prénatal. Aos poucos, a criança aprende a usar a linguagem e a reconhecer determinados significados e sentidos emocionais das palavras. Há diversos exemplos que demostram que crianças pequenas compreendem as informações que lhes são transmitidas e expressam um consentimento eficaz para a realização do tratamento médico.

Nesse sentido, quando se conta a crianças de dois anos sobre a "história" de seu tratamento e a possibilidade de irem para casa após 
os procedimentos médicos, elas compreendem tão bem os procedimentos desagradáveis relacionados a seu tratamento de câncer, por exemplo, que cooperam com eles. Na idade entre 3 e 4 anos, crianças conseguem compreender que uma biópsia de fígado é um procedimento, não um tratamento. Crianças diabéticas bem pequenas entendem que a insulina é que transforma o açúcar em energia e que sua doença ficaria bem pior sem o tratamento. Somente dessa forma conseguem se habituar às injeções quotidianas, das quais sua saúde depende, superando o stress e os incômodos. Entendem, ainda, que devem recusar doces oferecidos por amigos, enfim, crianças que têm experiência de meses ou anos com sua doença, demonstram, muitas vezes, conhecimentos suficientes para que sua opinião seja sopesada e admitida. ${ }^{843}$

A autora sustenta que a teoria das fases de desenvolvimento de Piaget não se mostra adequada a essas crianças, pois elas tiram conhecimento e sentido de responsabilidade de suas experiências quotidianas, em medidas muito superiores ao que se considerava possível. Dessa forma, para considerar uma criança capaz de consentimento, esta precisa ter capacidade de se concentrar e escolher entre muitas alternativas de tratamento, o que significa uma complexidade cognitiva. Além disso, precisam apresentar

${ }^{843}$ Ibidem, pp. 37-38. 
capacidade de abstrair riscos e alternativas ainda não existentes, o que significa serem capazes de usar pensamento indutivo e dedutivo na solução dos problemas. Em relação à afirmativa de que crianças pequenas têm valores instáveis e nenhuma percepção real do bom, da morte ou do futuro, ALDERSON afirma que crianças que têm experiência com sua doença há meses ou anos não necessitam dessas capacidades abstratas, pois conseguem entender totalmente, por sua experiência pessoal direta, sua situação e possibilidades de tratamento. Uma criança que tenha sido submetida à cirurgia por várias vezes tem um conhecimento muito maior que a maioria dos adultos.

A autora afirma que, geralmente, a capacidade de consentimento é estimada à luz de fatores próprios da criança, como, por exemplo, idade, sexo, grupo étnico, capacidade de desenvolvimento intelectual, maturidade, experiência pessoal, esperanças, medos, planos, valores, temperamento e grau de independência, de autoconsciência e disponibilidade de correr riscos. ${ }^{844}$ Evidentemente, também, são importantes fatores externos que cercam a criança, como, por exemplo, o apoio dado pelos pais, o ambiente doméstico, a família, a escola, se a criança se sente fortalecida ao tomar parte nas informações e decisões, se o hospital

${ }^{844}$ Ibidem, p. 38 
que a acolhe tem suas instalações e pessoal preparado para acolhê-la bem, a situação de saúde da criança, o diagnóstico, se há risco de morte ou graves mudanças de vida, quais são os tratamentos à disposição, qual a utilidade, riscos, efeitos colaterais, como foi o esclarecimento dos adultos, quando esse esclarecimento ocorreu, se as informações levaram em conta a criança, se a decisão é urgente, complexa, difícil, arriscada, de resultado imprevisível ou controvertido. $^{845}$

Existem também "macrofatores" que se referem ao contínuo desenvolvimento da ciência médica e dos métodos de tratamento. Os meios de comunicação que apresentam pacientes crianças ora como pobres vítimas e ora como corajosos mocinhos. Tudo isso exerce influência sobre a maneira como adultos e crianças compartilham conhecimentos e decisões e como suas expectativas aumentam ou diminuem.

Diante desse contexto, ALDERSON sugere um modelo de quatro estágios para avaliar a capacidade de consentimento de crianças em tratamentos médicos. São eles: 1 - esclarecimento da criança, 2 - manifestação da opinião da criança, 3 - influência de decisão da criança, 4 - a criança como protagonista da decisão. Mesmo que não se reconheça a capacidade da criança para tomar a ${ }^{845}$ Ibidem, p. 38 
decisão, o que corresponde ao estágio 4 , os três primeiros estágios deveriam ser considerados em relação a todas elas.

A idade a partir da qual a criança deveria participar dos três níveis não se deixa estabelecer de forma rígida. Isso porque, conforme se viu dos casos estudados, crianças podem apresentar um grau de conhecimento e vivência sobre sua história de vida que lhes capacita para participarem do processo de tomada de decisão.

Os resultados mais importantes a que chegou ALDERSON foram que competência e autonomia das crianças em geral não dependem da idade ou capacidade intelectual, mas, sim, da experiência pessoal direta. Esses casos demonstram que crianças podem ter um grau de percepção e inteligência que confrontam a teoria do desenvolvimento baseada na idade.

Assim como adultos, a autonomia em todo paciente é limitada de certa forma e dependente da assistência proporcionada pelo médico e equipe de saúde. Nas crianças, essa simbiose entre autonomia e assistência é mais clara, mas, nem por isso, deve-se deixar de reconhecer a capacidade destas em se posicionarem diante da necessidade de um tratamento médico. A cooperação esclarecida e consentida da criança pode ser alcançada por adultos capazes e é sempre eficaz para alcançar o melhor resultado do tratamento. Paulatinamente, pais e médicos passam a ouvir mais esses pacientes 
menores e, com isso, a lhes proporcionar um efetivo cuidado de seus interesses fundamentais e bem-estar.

\subsubsection{Concepção jurídica da capacidade de consentir}

O acórdão do Bundesgerichtshof (BGH) de 1958 é considerado um marco sobre a compreensão da capacidade de consentimento, pois desprendeu a capacidade de consentimento da capacidade de agir e tentou construir um conceito por meio de uma fórmula de julgamento. ${ }^{846}$ Nos termos do julgamento pelo referido Tribunal, para a capacidade de consentir importa se o paciente, no caso concreto, "possui maturidade intelectual e moral para aferir o significado e a extensão do procedimento e sua autorização". 847

${ }^{846}$ ROTHÄRMEL, Sonja. Einwilligung, Veto, Mitbestimmung. Op. Cit., p. 75; BÖHMKER, Daniela. Die Entscheidungskompetenz des minderjährigen Patienten in der medizinischen Behandlung. Op. Cit., pp. 98-99; RUMETSCH, Virgilia. Medizinische Eingriffe bei Minderjährigen. Op. Cit., p. 62; BRÜCKNER, Sarah. Das medizinische Selbstbestimmungsrecht Minderjähriger. Op. Cit., p. 69.

847 "Nach seiner geistigen und sittlichen Reife die Bedeutung und Tragweite des Eingriffs und seiner Gestattung zu ermessen vermag". Nesse sentido, cf. DEUTSCH, Erwin; SPICKHOFF, Andreas. Medizinrecht. Azrtrecht, Arzneimittelrecht, Medizinproduktrecht und Transfusionsrecht. Op. Cit., pp. 271; 648; ULSENHEIMER, Klaus. \$139 Die fahrlässige Körperverletzung. In LAUFS, Adolf; UHLENBRUCK, Wilhelm. Handbuch des Arztrechts. Op. Cit., Rn. 27, p. 1249. 
Embora essa fórmula tenha tido ampla aceitação perante a doutrina alemã, ${ }^{848}$ ao mesmo tempo ela sofreu críticas por ser considerada vaga, como se coubesse a ela trazer um verdadeiro conteúdo de informação. ${ }^{849}$

Em relação à terminologia, na doutrina vê-se também a expressão "capacidade de discernimento e julgamento" daquele que presta o consentimento. ${ }^{850}$ Capacidade de discernimento significa a capacidade de entender e obter o necessário conhecimento sobre um fato para se chegar a um julgamento, pois o conhecimento do fato é a base para toda decisão valorativa. ${ }^{851}$ Ela se relaciona com um aspecto cognitivo, pois a pessoa que expressa seu consentimento

${ }^{848}$ Além das referências citadas na nota supra, cf.: LAUFS, Adolf. §66 Die Weise und Art der Aufklärung. Aufklärungsformulare. In LAUFS, Adolf; UHLENBRUCK, Wilhelm. Handbuch des Arztrechts. Op. Cit., p. 529; ULSENHEIMER, Klaus. §139 Die fahrlässige Körperverletzung. In LAUFS, Adolf; UHLENBRUCK, Wilhelm. Handbuch des Arztrechts. Op. Cit., p. 1249, Rn. 27; TAUPITZ, Jochen. Empfehlen sich zivilrechtliche Regelungen zu Absicherung der Patientenautonomie am Ende des Lebens?, A 58 e A 63; GLEIXNER-EBERLE, Elisabeth. Die Einwilligung in die medizinische Behandlung Minderjähriger. Op. Cit., p. 281; BRÜCKNER, Sarah. Das medizinische Selbstbestimmungsrecht Minderjähriger. Op. Cit., pp. 75-76.

${ }^{849}$ ROTHÄRMEL, Sonja. Einwilligung, Veto, Mitbestimmung. Op. Cit., p. 76; LINK, Ihna. Schwangerschaftsabbruch bei Minderjährigen. Op. Cit., p. 185.

${ }^{850}$ KUHLMANN, Jens-Michael. Einwilligung in die Heilbehandlung alter Menschen. Frankfurt: Peter Lang, 1996. p. 24.

${ }^{851}$ HEIDE, Jochen. Medizinische Zwangsbehandlung, Rechtsgrundlagen und verfassungsrechtliche Grenzen der Heilbehandlung gegen den Willen des Betroffenen. Op. Cit., p. 147. 
deve observar o bem jurídico que será atingido, as possíveis alternativas e consequências de sua decisão e trabalhar todos esses aspectos num processo de raciocínio lógico. ${ }^{852}$ Já a capacidade de julgamento, por sua vez, significa a capacidade de aferir as consequências mediatas e imediatas do procedimento em relação ao seu corpo e saúde. ${ }^{853}$ Essa capacidade, portanto, também se refere a elementos cognitivos. $^{854}$

Conforme se verifica, a fórmula do BGH limitou-se ao elemento intelectual. $^{855}$

Os ordenamentos jurídicos da Áustria e Suíça trazem uma definição de capacidade de consentimento em que se observa, além do elemento cognitivo, também um elemento que se refere à vontade. No direito austríaco, o $\$ 173^{856}$ do Allgemeines

${ }^{852}$ ODENWALD, Steffen. Die Einwilligunsfähigkeit im Strafrecht unter besonderer Hervorhebung ärztlichen Handels. Frankfurt: Peter Lang, 2004. p. 50 .

${ }^{853}$ HEIDE, Jochen. Medizinische Zwangsbehandlung, Rechtsgrundlagen und verfassungsrechtliche Grenzen der Heilbehandlung gegen den Willen des Betroffenen. Op. Cit., p. 148.

${ }^{854}$ GLEIXNER-EBERLE, Elisabeth. Die Einwilligung in die medizinische Behandlung Minderjähriger. Op. Cit., p. 282.

${ }_{856}^{855}$ Ibidem, p. 281.

856 § 173. (1) Einwilligungen in medizinische Behandlungen kann das einsichts- und urteilsfähige Kind nur selbst erteilen; im Zweifel wird das Vorliegen dieser Einsichts- und Urteilsfähigkeit bei mündigen Minderjährigen vermutet. Mangelt es an der notwendigen Einsichts- und Urteilsfähigkeit, so ist die Zustimmung der Person erforderlich, die mit der gesetzlichen Vertretung bei Pflege und Erziehung betraut ist. 
Bürgerliches Gestezbuch (ABGB) se refere à capacidade de consentimento como capacidade de discernimento e julgamento, mas não explica em que consiste. Apesar da lei não definir o que se entende por capacidade de discernimento e julgamento, a doutrina é pacífica em aceitar que, segundo as exigências do §173 do ABGB, percebe-se nitidamente a referência tanto ao elemento cognitivo como ao elemento da vontade. ${ }^{857}$

Esse entendimento decorre da justificação apresentada pelo legislador na Reforma dos Direitos da Criança de 2001, ${ }^{858}$ na qual ficou expresso que a capacidade de consentimento deve ser reconhecida quando o menor compreende o diagnóstico, as possibilidades terapêuticas, suas alternativas, chances e riscos, bem como compreende o valor dos bens jurídicos que serão atingidos por

(2) Willigt ein einsichts- und urteilsfähiges minderjähriges Kind in eine Behandlung ein, die gewöhnlich mit einer schweren oder nachhaltigen Beeinträchtigung der körperlichen Unversehrtheit oder der Persönlichkeit verbunden ist, so darf die Behandlung nur vorgenommen werden, wenn auch die Person zustimmt, die mit der gesetzlichen Vertretung bei Pflege und Erziehung betraut ist.

(3) Die Einwilligung des einsichts- und urteilsfähigen Kindes sowie die Zustimmung der Person, die mit Pflege und Erziehung betraut ist, sind nicht erforderlich, wenn die Behandlung so dringend notwendig ist, dass der mit der Einholung der Einwilligung oder der Zustimmung verbundene Aufschub das Leben des Kindes gefährden würde oder mit der Gefahr einer schweren Schädigung der Gesundheit verbunden wäre.

${ }^{857}$ GLEIXNER-EBERLE, Elisabeth. Die Einwilligung in die medizinische Behandlung Minderjähriger. Op. Cit., p. 46.

${ }^{858}$ Kindschaftsrechts-Änderungsgesetz (KindR $\left.\ddot{A} G\right) 2001$. 
sua decisão e tem condições de direcionar sua conduta de acordo com esse entendimento.

De acordo com esse posicionamento do legislador austríaco, para averiguar se um paciente menor possui capacidade de consentimento, há que se analisar, no caso concreto, se ele tem capacidade de compreender o motivo, o significado e os efeitos do tratamento, o que se refere ao elemento cognitivo. Em relação ao menor, são decisivos os fatores da idade, maturidade e personalidade, assim como tipo e gravidade do procedimento, além dos riscos e possíveis alternativas relacionadas à execução ou não do procedimento. Percebe-se, aqui, a capacidade de discernimento e julgamento. A par dessa capacidade, o legislador aponta a vontade como a capacidade de se conduzir conforme esse entendimento, o que se refere ao elemento subjetivo da vontade.

$\mathrm{O}$ direito suíço também permite extrair o entendimento de que a capacidade de consentimento se molda pelos elementos intelectual e da vontade.

O Art. 16, "d" do ZGB ${ }^{859}$ dispõe que capacidade de julgamento é a capacidade de agir de forma consciente. A formulação da norma demonstra que a capacidade de julgamento corresponde ao que se ${ }^{859}$ Art. 16, d. Urteilsfähigkeit : Urteilsfähig im Sinne dieses Gesetzes ist jede Person, der nicht wegen ihres Kindesalters, infolge geistiger Behinderung, psychischer Störung, Rausch oder ähnlicher Zustände die Fähigkeit mangelt, vernunftgemäss zu handeln. 
considera normal, de modo que é a incapacidade de julgamento que deve ser provada. ${ }^{860}$ Considerando que o legislador foi bastante sucinto ao se referir à capacidade de julgamento, coube à jurisprudência traçar as linhas do conceito. ${ }^{861}$

Nesse sentido, da redação legal de que capacidade de julgamento é a capacidade de agir de forma consciente, extraem-se dois elementos. ${ }^{862}$ Em primeiro lugar se entende a capacidade de entender o significado, finalidade e efeitos de um determinado tratamento médico e formar para si uma vontade livre. Esses aspectos referem-se ao elemento intelectual. Num segundo momento, entende-se a capacidade de se conduzir conforme esse entendimento, livre de qualquer tipo de influência, o que se refere ao elemento da vontade.

Considerando esses entendimentos das nações coirmãs, a doutrina da Alemanha também questionou se na definição de capacidade de consentimento deveria estar presente, ao lado do elemento cognitivo, também o elemento da vontade. Sobre essa

${ }^{860}$ Art. 8, E. Beweisregeln, I. Beweislast: Wo das Gesetz es nicht anders bestimmt, hat derjenige das Vorhandensein einer behaupteten Tatsache zu beweisen, der aus ihr Rechte ableitet.

${ }^{861}$ GLEIXNER-EBERLE, Elisabeth. Die Einwilligung in die medizinische Behandlung Minderjähriger. Op. Cit., p. 147

${ }^{862}$ PETERMANN, Franck Thomas. Urteilsfähigkeit, Generelle Aspekte, Urteilsfähigkeit als Ehevoraussetzung, zum Testieren, zum willentlichen Sterben sowie Screening. Zürich: Tools, 2008. pp. 32-34. 
temática não há um consenso. Alguns, quando tratam da capacidade de consentimento, mencionam apenas o aspecto intelectual. ${ }^{863}$ Outros, entretanto, consideram tanto o aspecto intelectual como o da vontade. $^{864}$

Explica-se que o elemento subjetivo, que diz respeito à vontade, expressa-se pelo termo "capacidade de comando", que significa agir de forma autônoma e sem influência de terceiro. ${ }^{865}$ A capacidade de comando pode se mostrar ausente em casos como dependência de medicamento ou drogas, ${ }^{866}$ ou em razão de imaturidade advinda da idade e a consequente influência maior por parte da família e da

${ }^{863}$ DÖLL, Yves. In ERMANN, Bürgeliches Gesetzbuch. Op. Cit., p. 5139; LAUFS, §66 Die Art und Weise der Aufklärung. LAUFS, Adolf; UHLENBRUCK, Wilhelm. Handbuch des Arztrechts. Op. Cit., p. p. 529.

${ }^{864}$ DEUTSCH, Erwin; SPICKHOFF, Andreas. Medizinrecht. Azrtrecht, Arzneimittelrecht, Medizinproduktrecht und Transfusionsrecht. Op. Cit., p. 741; HEIDE, Jochen. Medizinische Zwangsbehandlung, Rechtsgrundlagen und verfassungsrechtliche Grenzen der Heilbehandlung gegen den Willen des Betroffenen. Op. Cit., p. 152; ODENWALD, Steffen. Die Einwilligunsfähigkeit im Strafrecht unter besonderer Hervorhebung ärztlichen Handels. Op. Cit., pp. 27-29; KUHLMANN, Jens-Michael. Einwilligung in die Heilbehandlung alter Menschen. Op Cit., p. 30.

${ }^{865}$ HEIDE, Jochen. Medizinische Zwangsbehandlung, Rechtsgrundlagen und verfassungsrechtliche Grenzen der Heilbehandlung gegen den Willen des Betroffenen. Op. Cit., p. 152. O termo alemão é Steuerungsfähigkeit. ${ }^{866}$ Ibidem, p. 152. 
sociedade. ${ }^{867}$ Algumas leis especiais da Alemanha fazem referência expressa a ambos os elementos.

A Gesetz über Medizinprodukte (Medizinproduktegesetz $M P G)$ - Lei sobre Produtos Médicos, em seu $\$ 20^{868}$ trata dos pressupostos para a realização de um experimento clínico, dentre ${ }^{867}$ GLEIXNER-EBERLE, Elisabeth. Die Einwilligung in die medizinische Behandlung Minderjähriger. Op. Cit., p. 283.

${ }^{235} \S 20$ Allgemeine Voraussetzungen zur klinischen Prüfung (1) Mit der klinischen Prüfung eines Medizinproduktes darf in Deutschland erst begonnen werden, wenn die zuständige Ethik-Kommission diese nach Maßgabe des § 22 zustimmend bewertet und die zuständige Bundesoberbehörde diese nach Maßgabe des $\S 22 \mathrm{a}$ genehmigt hat. Bei klinischen Prüfungen von Medizinprodukten mit geringem Sicherheitsrisiko kann die zuständige Bundesoberbehörde von einer Genehmigung absehen. Das Nähere zu diesem Verfahren wird in einer Rechtsverordnung nach $\S 37$ Absatz 2a geregelt. Die klinische Prüfung eines Medizinproduktes darf bei Menschen nur durchgeführt werden, wenn und solange

1. die Risiken, die mit ihr für die Person verbunden sind, bei der sie durchgeführt werden soll, gemessen an der voraussichtlichen Bedeutung des Medizinproduktes für die Heilkunde ärztlich vertretbar sind (...)

(2) Eine Einwilligung nach Absatz 1 Nr. 2 ist nur wirksam, wenn die Person, die sie abgibt, 1. geschäftsfähig und in der Lage ist, Wesen, Risiken, Bedeutung und Tragweite der klinischen Prüfung einzusehen und ihren Willen hiernach zu bestimmen, und 2. die Einwilligung selbst und schriftlich erteilt hat.

(4) Auf eine klinische Prüfung bei Minderjährigen finden die Absätze 1 bis 3 mit folgender Maßgabe Anwendung:

4. Die Einwilligung wird durch den gesetzlichen Vertreter oder Betreuer abgegeben. Sie ist nur wirksam, wenn dieser durch einen Arzt, bei für die Zahnheilkunde bestimmten Medizinprodukten auch durch einen Zahnarzt, über Wesen, Bedeutung und Tragweite der klinischen Prüfung aufgeklärt worden ist. Ist der Minderjährige in der Lage, Wesen, Bedeutung und Tragweite der klinischen Prüfung einzusehen und seinen Willen hiernach zu bestimmen, so ist auch seine schriftliche Einwilligung erforderlich. 
eles o consentimento do paciente. Quando se trata de um paciente maior, o Abs. $2 N r .1$ afirma que o consentimento é eficaz quando a pessoa apresenta capacidade de agir e está em condições de compreender a essência, riscos, significado e extensão do experimento, bem como determinar sua vontade de acordo esse entendimento.

No caso de pacientes menores, o Abs. $4 N r .4$ estabelece que, se o menor estiver em condição de compreender a essência, riscos, significado e extensão do experimento clínico e determinar sua vontade de acordo com esse entendimento, então seu consentimento deve ser tomado por escrito, juntamente com o consentimento dado por seus representantes legais ou tutor. Dispositivos semelhantes encontram-se na Gesetz über den Verkehr mit Arzneimitteln (Arzneimittelgesetz - AMG) - Lei de Medicamentos. ${ }^{869}$

Diante desse contexto, importante trazer à baila a concepção de capacidade de consentimento formulado por AMELUNG, que foi o primeiro doutrinador da Alemanha a tratar do assunto. ${ }^{870} \mathrm{O}$ referido autor tentou desenvolver e concretizar a fórmula dada pelo BGH

${ }^{869}$ AMG, $\S 40$ Abs. 1 Nr. 3 corresponde à MPG, $\$ 20$ Abs. 1 Nr. 4; e AMG, $\S 40$ Abs. 4 Nr. 3 corresponde a MPG, $\$ 20$ Abs. 4 Nr. 4.

${ }_{870}$ GLEIXNER-EBERLE, Elisabeth. Die Einwilligung in die medizinische Behandlung Minderjähriger. Op. Cit., p. 284. 
sobre a capacidade de consentimento. ${ }^{871}$ De acordo com o doutrinador, as exigências para se reconhecer a capacidade de consentir são, em primeiro lugar, a capacidade para entendimento dos fatos e do processo causal; em segundo, a capacidade para avaliação e, por fim, a capacidade de autodeterminação. ${ }^{872}$

Dessa forma, AMELUNG define a capacidade de consentir de modo negativo: "1. Incapaz de consentir é quem, em razão da menoridade, limitação intelectual ou doença psicológica, não consegue compreender: a) qual o valor ou qual o grau que os bens e interesses têm para ele no processo de decisão; b) quais consequências ou riscos advém da decisão; ou c) quais os meios que existem para alcançar os objetivos almejados, que menos the importunem. 2. O mesmo vale quando o menor, o incapaz intelectual ou deficiente mental, ainda que tenham o necessário discernimento, não estejam em condição de se determinar de acordo com ele".

Sustenta-se que a concepção de AMELUNG abarca tanto o elemento cognitivo, no item " 1 ", quando se refere à capacidade de entendimento e valoração, bem como ao elemento da vontade, no

${ }^{871}$ AMELUNG, Knust. Über die Einwilligungsfähigkeit (Teil I). Zeitschrift für die gesamte Strafrechtswissenschaft. v. 104 (3), pp. 525-558, janeiro de 1992.

${ }^{872}$ Ibidem, pp. 525-558. 
item "2", que trata da capacidade de se autodeterminar conforme aquele entendimento. ${ }^{873}$

A proposta de AMELUNG foi bem aceita pela doutrina. ${ }^{874}$ Sustenta-se que representantes da psiquiatria forneceram a AMELUNG algumas ponderações que o ajudaram a melhorar a definição. ${ }^{875}$ Assim, a capacidade de consentimento passou a ser definida do seguinte modo $^{876}$ :

1. Incapaz de consentir é quem, em razão da menoridade, limitação intelectual ou doença mental não consegue alcançar:

- qual o valor ou grau os bens e interesses têm para ele na decisão de consentir,

- a quais fatos a decisão se refere,

- quais consequências ou riscos advém da decisão de consentir,

${ }^{873}$ GLEIXNER-EBERLE, Elisabeth. Die Einwilligung in die medizinische Behandlung Minderjähriger. Op. Cit., p. 284.

874 BELLING, Detlev; EBERL, Christina; MICHILIK, Frank. Das Selbstbestimmungsrecht Minderjähriger bei medizinischen Eingriffen. Berlin: Luchterhand, 1994. pp. 127-130; LINK, Ihna. Schwangerschaftsabbruch bei Minderjährigen. Op. Cit., pp. 186-188; GLEIXNER-EBERLE, Elisabeth. Die Einwilligung in die medizinische Behandlung Minderjähriger. Op. Cit., p. 284. Além disso, a leitura do $\$ 173$ ABGB demonstra que o legislador austríaco tomou a definição de Amelung (cf. infra sobre o §173 ABGB).

${ }^{875}$ GLEIXNER-EBERLE, Elisabeth. Die Einwilligung in die medizinische Behandlung Minderjähriger. Op. Cit., p. 285.

876 AMELUNG, Knut. Die Einwilligung zwischen medizinischer Erfahrung, amerikanischer Ethik unf kulturellem Gedächtnisverlust; Bemerkingen zu Vollmann, Aufklärung und Einwilligung in der Psychiatrie. Frankfurt: Springer, 2000. pp. 520-521. 
- quais os meios que existem para alcançar os objetivos almejados, que menos the importunem.

2. O mesmo vale quando o menor, o incapaz intelectual ou doente mental, ainda que tenham a necessária inteligência, não estejam em condição de se determinar de acordo com ela.

Nesse contexto, conclui-se que a fórmula deduzida do julgamento do Bundesgerichtshof e a concepção de AMELUNG foram imperiosas para se alcançar um entendimento sobre a capacidade de consentimento dos menores. Dessa forma, pode-se definir capacidade de consentimento como a capacidade de compreender a essência, importância e extensão da intervenção médica e se determinar de acordo com esse entendimento.

\subsubsection{Avaliação da capacidade de consentimento no caso}

\section{$\underline{\text { concreto }}$}

Diante da ausência de uma regulamentação específica de limites de idade para a capacidade de consentimento, a avaliação da capacidade de consentimento cabe ao médico, que deverá averiguar a existência dessa capacidade sob os três aspectos da capacidade de discernimento, julgamento e comando. ${ }^{877}$ Para tanto, devem ser

877 ULSENHEIMER, Klaus. §139 Die fahrlässige Körperverletzung. In LAUFS, Adolf; UHLENBRUCK, Wilhelm. Handbuch des Arztrechts. Op. Cit., p. 1249. A partir de agora far-se-á referência apenas à expressão 
consideradas as circunstâncias concretas do menor, como constituição psíquica e física, idade, grau de escolaridade, tradições culturais e religiosas. No caso de pacientes menores, essa determinação da concreta capacidade de consentimento é cercada por dificuldades. ${ }^{878}$

Em primeiro lugar, atribuir aos médicos a incumbência de aferir caso a caso a presença dos pressupostos da capacidade de consentimento, impõe a eles um risco de avaliar de forma errada essa capacidade e, com isso, ter que arcar com o ônus advindo da responsabilidade civil e penal. ${ }^{879}$ Diante do risco de se verem processados por esse motivo, aliado à insegurança jurídica da inexistência de regras sobre limites rígidos de idade, normalmente os profissionais têm a tendência de negar a capacidade de consentimento de menores e se resguardam com a tomada de consentimento dos representantes legais. ${ }^{800}$ Há na doutrina, inclusive, quem sustente que o médico deve agir com reserva no

"capacidade de consentimento", considerando que seu conceito abrange também o conteúdo das outras capacidade declinadas.

${ }^{878}$ GLEIXNER-EBERLE, Elisabeth. Die Einwilligung in die medizinische Behandlung Minderjähriger. Op. Cit., p. 288.

879 ULSENHEIMER, Klaus. $§ 139$ Die fahrlässige Körperverletzung. In LAUFS, Adolf; UHLENBRUCK, Wilhelm. Handbuch des Arztrechts. Op. Cit., pp. 1261-1262.

${ }^{880}$ GOLBS, Ulrike. Das Vetorecht eines einwilligunsunfähigen Patienten. Baden-Baden: Nomos, 2006. p. 85. 
reconhecimento da capacidade de consentimento do menor, limitando-se a procedimentos insignificantes. ${ }^{881}$

A doutrina ainda se divide no que diz respeito a se reconhecer ao médico uma margem de liberdade para avaliar a capacidade de consentimento do paciente menor. Enquanto alguns sustentam que ao profissional deve ser conferida uma margem ampla de avaliação, diante da insegurança jurídica sobre o tema, ${ }^{882}$ outros entendem que essa margem deve ser bem limitada, uma vez que a capacidade de consentimento levará a decisões que interferirão diretamente em bens jurídicos personalíssimos, que são $o$ direito de autodeterminação e a integridade corporal do paciente. ${ }^{883}$ Outros doutrinadores, ainda, negam ao médico essa possibilidade de aferir a capacidade de consentimento dos menores no caso concreto, sob o fundamento de que os médicos poderiam aproveitar essa liberdade de avaliação e aplicar sua própria visão paternalista. ${ }^{884}$

881 HUBER. Peter. In Münchener Kommentar zum Bürgerlichen Gesetzbuch. Op. Cit., p. 798.

${ }^{882}$ WÖLK, Florian. Der minderjährige Patient in der ärztlichen Behandlung. Op. Cit., pp. 80, 82.

${ }^{883}$ KUHLMANN, Jens-Michael. Einwilligung in die Heilbehandlung alter Menschen. Op Cit., p. 87.

${ }^{884}$ ODENWALD, Steffen. Die Einwilligunsfähigkeit im Strafrecht unter besonderer Hervorhebung ärztlichen Handels. Op. Cit., p. 113. 
Muitas vezes, após essa avaliação da existência da capacidade de consentimento por parte dos médicos, será ela reexaminada pelo Poder Judiciário. É a chamada avaliação ex-post. ${ }^{885}$

Defende a doutrina que a averiguação da capacidade em pacientes menores deve ser feita por um exame cuidadoso e individual, pois a menoridade é um motivo forte para uma avaliação cautelosa. O principal critério norteador é a maturidade intelectual ou espiritual do jovem, ou seja, sua base para uma decisão livre. ${ }^{886}$

Por isso, é possível que o mesmo paciente seja considerado capaz em relação a uma determinada intervenção e incapaz, em relação à outra. Por consequência não é muito adequado estabelecer limites fixos e gerais de idade por causa do processo do desenvolvimento da maturidade. ${ }^{887}$ Mesmo assim, cristalizaram-se, na prática, alguns degraus conforme a idade. Mas também a esse respeito há divergência.

De início, vê-se na doutrina a orientação dominante pela idade de 14 anos, abaixo da qual o menor seria considerado incapaz de

885 REIPSCHLÄGER, Christiane. Die Einwilligung Minderjähriger in ärztliche Heileingriffe und die elterliche Personensorge. Op. Cit., p. 61. ${ }^{886}$ DUTTGE, Gunnar. Patientenautonomie und Einwilligungsfähigkeit. Op. Cit., pp. 79-80.

${ }^{887}$ LINK, Ihna. Schwangerschaftsabbruch bei Minderjährigen. Op. Cit., pp. 178-180; ULSENHEIMER, Klaus. $\$ 139$ Die fahrlässige Körperverletzung. In LAUFS, Adolf; UHLENBRUCK, Wilhelm. Handbuch des Arztrechts. Op. Cit., pp. 1249-1250. 
consentir. ${ }^{888}$ Há quem defenda que, após completar 16 anos, parte-se da existência dessa capacidade. Para as idades entre 14 e 16 anos não existe uma regra, ficando uma zona cinzenta, a qual requer uma avaliação orientada, sobretudo, pela complexidade e periculosidade da intervenção, bem como pela sua urgência. Nesse sentido, quanto mais se trata de um tratamento de rotina ou de uma intervenção urgente e a idade do jovem se aproxima da maioridade, tanto mais pode se atribuir a competência de decisão e compreensão a esse jovem. $^{889}$

Outros sustentam que a partir de 14 anos e antes de completar 18 o médico deve fazer essa avaliação sobre a personalidade do menor com vista à intervenção planejada e concreta. ${ }^{890}$ Outros, ainda, consideram a idade de 14 anos apenas como uma linha ${ }^{888}$ DUTTGE, Gunnar. Patientenautonomie und Einwilligungsfähigkeit. In: WISERMANN, Claudia; SIMON, Alfred. Patientenautonomie. Op. Cit., p. 80; LINK, Ihna. Schwangerschaftsabbruch bei Minderjährigen. Op. Cit., pp. 178-180; ULSENHEIMER, Klaus. $\$ 139$ Die fahrlässige Körperverletzung. In LAUFS, Adolf; UHLENBRUCK, Wilhelm. Handbuch des Arztrechts. Op. Cit., pp. 1249-1250; LAUFS, § 66 Die Art und Weise der Aufklärung. Aufklärungsformulare. In LAUFS, Adolf; UHLENBRUCK, Wilhelm. Handbuch des Arztrechts. Op. Cit., pp. 529-530; ODENWALD, Steffen. Die Einwilligunsfähigkeit im Strafrecht unter besonderer Hervorhebung ärztlichen Handels. Op. Cit., pp. 128-129.

${ }^{889}$ DUTTGE, Gunnar. Patientenautonomie und Einwilligungsfähigkeit. In: WIESERMANN, Claudia; SIMON, Alfred. Patientenautonomie. Op. Cit., p. 80 .

${ }^{890}$ LAUFS, § 66 Die Art und Weise der Aufklärung. Aufklärungsformulare. In LAUFS, Adolf; UHLENBRUCK, Wilhelm. Handbuch des Arztrechts. Op. Cit., pp. 529-530. 
orientadora para estabelecer a capacidade de consentimento e não como um limite pré-fixado. ${ }^{891}$ Ainda, existe posição no sentido de considerar como mínima a idade de 16 anos. ${ }^{892}$ Já houve projetos de lei que fracassaram tentando fixar a idade mínima para a capacidade de consentimento em 14 ou 16 anos. ${ }^{893}$

A orientação seguida pelos Tribunais alemães, até o momento, é no sentido de que quanto mais próximo o menor estiver da maioridade, mais se aceita sua capacidade de consentir. ${ }^{894}$ Nesse passo, alguns doutrinadores defendem o estabelecimento de limites concretos de idade, sob o argumento da dificuldade da avaliação promovida pelo médico. Os limites rígidos de idade representariam um critério mais fácil de aferição, o médico seria aliviado do risco de uma avaliação errônea e a insegurança jurídica seria afastada. ${ }^{895}$

Essa concepção da idade de 14 anos, seja considerando-a como um limite pré-estabelecido, seja como uma linha orientadora, apoia-

891 TAUPITZ, Jochen, Empfehlen sich zivilrechtliche Regelungen zu Absicherung der Patientenautonomie am Ende des Lebens?, A 60.

${ }^{892}$ KNAUF, Christian. Mutmassliche Einwilligung und Stellvertretung bei ärztliche Eingriffen na Einwillgungsunfähigen, Zugleich ein Beitrag zur Patientenverfügung. Baden-Baden: Nomos, 2005. p. 167.

${ }^{893}$ GLEIXNER-EBERLE, Elisabeth. Die Einwilligung in die medizinische Behandlung Minderjähriger. Op. Cit., p. 291.

${ }^{894}$ Ibidem, p. 288.

${ }^{895}$ ROUKA, Stella. Das Selbstbestimmungsrecht des Mnderjährigen bei ärztlichen Eingriffe. Op. Cit., pp. 139-141; 
se na psicologia do desenvolvimento, ${ }^{896}$ bem como em algumas leis especiais.

No âmbito do Direito Civil alemão, citam-se: $§ 5$ Satz 1 RelErzG: o menor de 14 anos pode determinar seu credo religioso; ${ }^{897} \S 1746$ Abs. 2 BGB: o menor de 14 anos pode revogar a concordância dada na adoção; ${ }^{898} § 60$ FamFG: processo em direito de família; reconhece-se direito de ação ao menor que completa 14

${ }^{896}$ Bundesärztekammer, $\overline{\text { DÄB1 1994, A3204, A } 3207 .}$

${ }^{897}$ Gesetz über die religiöse Kindererziehung (Lei sobre Educação religiosa dos filhos), §5: Nach der Vollendung des vierzehnten Lebensjahrs steht dem Kind die Entscheidung darüber zu, zu welchem religiösen Bekenntnis es sich halten will.

898 § 1746 (2) Hat das Kind das 14. Lebensjahr vollendet und ist es nicht geschäftsunfähig, so kann es die Einwilligung bis zum Wirksamwerden des Ausspruchs der Annahme gegenüber dem Familiengericht widerrufen. Der Widerruf bedarf der öffentlichen Beurkundung. Eine Zustimmung des gesetzlichen Vertreters ist nicht erforderlich. 
anos; ${ }^{899} \S 19$ StGB determinação da culpabilidade, ${ }^{900} \S 1$ Abs. 2 JGG: início da responsabilidade penal 14 anos. ${ }^{901}$

Para alguns, o limite de idade de 14 anos não deve servir como um rígido limite, pois o direito alemão não reconhece limites rígidos de idade para a determinação da capacidade de consentimento, mas sim como uma linha de orientação. ${ }^{902}$ Também a Áustria se posicionou pela idade de 14 anos, conforme se observa no $\$ 173$ do ABGB. Entretanto, a norma austríaca não fixou um limite de idade. Trata-se mais de uma presunção relativa, que serve de linha orientadora para a avaliação da capacidade de consentimento.

899 Familienverfahrensgesetz (Lei processual de direito de família) $\$ 60$ Beschwerderecht Minderjähriger: Ein Kind, für das die elterliche Sorge besteht, oder ein unter Vormundschaft stehender Mündel kann in allen seine Person betreffenden Angelegenheiten ohne Mitwirkung seines gesetzlichen Vertreters das Beschwerderecht ausüben. Das Gleiche gilt in sonstigen Angelegenheiten, in denen das Kind oder der Mündel vor einer Entscheidung des Gerichts gehört werden soll. Dies gilt nicht für Personen, die geschäftsunfähig sind oder bei Erlass der Entscheidung das 14. Lebensjahr nicht vollendet haben.

${ }^{900} \S 19$ Schuldunfähigkeit des Kindes: Schuldunfähig ist, wer bei Begehung der Tat noch nicht vierzehn Jahre alt ist.

901 Jugendgerichtsgesetz (Lei do juizado de menores) § 1Persönlicher und sachlicher Anwendungsbereich

(2) Jugendlicher ist, wer zur Zeit der Tat vierzehn, aber noch nicht achtzehn, Heranwachsender, wer zur Zeit der Tat achtzehn, aber noch nicht einundzwanzig Jahre alt ist.

${ }_{902}$ GLEIXNER-EBERLE, Elisabeth. Die Einwilligung in die medizinische Behandlung Minderjähriger. Op. Cit., p. 290. 
Nos termos do $§ 173$, ao qual se referiu supra, o menor capaz de discernimento e julgamento pode consentir sozinha em tratamentos médicos. Na dúvida, presume-se a existência da capacidade de discernimento e julgamento nos menores a partir de 14 anos. ${ }^{903}$ Mas, se essa capacidade faltar, será necessária a concordância dos representantes legais ou tutor. Em princípio, menores que não completaram 14 anos são considerados incapazes. No entanto, a norma não exclui a possibilidade de os considerar como capazes no caso concreto. ${ }^{904}$

Importante observar que a norma do $§ 173$ é dividida em três partes, quais sejam, $a, b$ e $c$. Conforme dispõe a parte $a$, o menor capaz de discernimento e julgamento pode consentir sozinha em tratamentos médicos. A parte $b$ dispõe que, quando o menor capaz de discernimento e julgamento consentir em um tratamento que, em regra, cause danos graves ou duradouros na integridade corporal, o tratamento somente poderá ser executado quando também os representantes legais concordarem. Ou seja, o legislador previu uma ${ }^{903}$ HENNIG, Lysann. Tattoos, PIercings, Schönheitsoperationen. Op. Cit., p. 172. A lei usa o termo mündige Minderjährige. Minderjährige são os menores e Mündigkeit é um termo específico, que no Direito austríaco se refere à idade de 14 anos, a partir da qual o menor possui capacidade para determinados atos da vida civil, nos termos do $\$ 21$ Abs. 2 ABGB. Cf., GLEIXNER-EBERLE, Elisabeth. Die Einwilligung in die medizinische Behandlung Minderjähriger. Op. Cit., pp. 13-14.

${ }^{904}$ GLEIXNER-EBERLE, Elisabeth. Die Einwilligung in die medizinische Behandlung Minderjähriger. Op. Cit., pp. 291-293. 
limitação à capacidade do menor, que, embora seja capaz de discernimento e julgamento, não poderá consentir sozinho em um tratamento que possa the causar danos graves ou duradouros ${ }^{905}$.

Num primeiro momento, o legislador traçou uma orientação baseada num fortalecimento do direito de autodeterminação do menor. Mas, depois, também estabeleceu uma responsabilidade dos pais em relação a este. Observe-se que a norma austríaca contém uma graduação, sendo que na primeira parte ela estabelece uma presunção de capacidade dos menores a partir de 14 anos. Porém, na segunda parte, dispõe que, em casos graves, esses menores não podem consentir sozinhos. Disso se infere que a norma caminha de um tratamento simples para um tratamento que cause danos graves ou duradouros. Se o caso for de um dano simples, como, por exemplo, uma vacinação ou dose de medicamento, basta o consentimento do menor. Como as consequências de uma cirurgia estética, na maior parte das vezes, são duradouras e dificilmente podem ser afastadas, trata-se, nesse caso, de um tratamento médico que deve ser classificado na segunda parte da norma, de modo que é necessário, na Áustria, do consentimento dos pais. ${ }^{906}$

${ }^{905}$ HENNIG, Lysann. Tattoos, Piercings, Schönheitsoperationen. Op. Cit., pp. 172-173.

${ }_{906}$ HENNIG, Lysann. Tattoos, Piercings, Schönheitsoperationen. Op. Cit., p. 173. 
Especificamente em relação a tratamentos e cirurgias estéticas, a Áustria fixou a idade mínima de 16 anos, proibindo, expressamente, a realização desses procedimentos em pessoas com idade inferior a essa. Nesse sentido, o $§ 7$ (1) da Ästhetische Operationgesetz, 80. Bundesgesetz de 14 de agosto de 2012 (Lei de Execução de Tratamentos e Operações Estéticas): ${ }^{907}$

Besonderer Schutz bestimmter Personengruppen

§7. (1) Eine ästhetische Behandlung oder Operation na Personen, dia das 16. Lebensjahr noch nicht vollendet haben, ist unzulässig.

(2) Eine ästhetische Behandlung oder Operation darf na Personen, dia das 16. Lebensjahr vollendet und das 18. Lebensjahr noch nicht vollendet haben, nur durchgeführt werden, wenn

1. die Einwilligung durch die Erzihungsberechtigten nach entsprechender umfassender ärztiche Aufklärung gemäss $§ \quad 5$ nachweislich und schriftlich gemäss $§ 6$ Abs. 2 erteil wurde und

2. die Einwilligung durch die Patientin (den Patienten), die (der) nach entsprechender umfassender ärztliche Aufklärung ( $§ 5)$ in der Lage ist Wesen, Bedeutung, Tragweite und Risiken der ästhetischen Behandlung oder Operation einzusehen bestimmen, nachweislich und schriftlich gemäss $\S 6$ Abs. 2 erteilt wurde.

${ }^{907}$ Cf. anexo VI. 
Além disso, outros países proibiram expressamente a cirurgia e procedimentos estéticos para menores.

A Itália, por meio da Lei $n^{\circ} 86$ de 5 de junho de $2012^{908}$, proibiu implante mamário em menores de 18 anos apenas para fins estéticos. Nos termos do referido diploma legal:

Art. 2. Limiti di eta' 1. L'impianto di protesi mammaria a soli fini estetici e' consentito soltanto su coloro che abbiano compiuto la maggiore eta'. Il divieto di cui al primo periodo non si applica nei casi di gravi malformazioni congenite certificate da un medico convenzionato con il Servizio sanitario nazionale o da una struttura sanitaria pubblica.

Também a Colômbia criou tal proibição, por meio da recente Ley No. 1799 de 25 de julho de 2016 "por medio de la cual se prohíben los procedimientos médicos y quirúrgicos estéticos para menores de edad y se dictan otras disposiciones". 909

Nesse sentido:

"Artículo 3. : Prohibición. Se prohíbe la realización de procedimentos médicos y chirúrgicos estéticos em pacientes menores de 18 años. El consentimento de los padres no constituye excepción válida a la presente prohibición.

${ }^{908}$ Cf. anexo VII.

${ }^{909}$ Cf. anexo VIII. 
Art. $4^{\circ}$ : Excepciones. La anterior prohibición no aplica a cirugías de nariz y de orejas, cirugías reconstructivas y/o iatrogénicas de otras cirugías, peelings químicos y mecânicos superficiales, y depilacion láser. Tampoco aplica a cirugías motivadas por patologias físicas o psicológicas debidamente acreditadas por los respectivos professionales de salud."

Na Alemanha, já houve tentativa de regulamentar por lei a proibição de cirurgia estética em menores, mas foi uma tentativa que não vingou. No projeto da Lei dos Direitos do Paciente muito se discutiu a respeito, mas nada foi regulamentado. ${ }^{910}$ HENNING oferece uma sugestão de regulamentação de cirurgias estéticas em menores. ${ }^{911}$

Em outros países a questão da capacidade de consentimento de menores se posiciona da seguinte forma: ${ }^{912}$ Bélgica: 18 anos, entretanto a literatura apoia um consenso conjunto a partir de $15 \mathrm{ou}$ 16 anos. Dinamarca: a partir de 15 anos, desde seja capaz de discernimento. Inglaterra: a partir de 16 anos, também em caso de capacidade de discernimento, mas há, em todo caso, possibilidade de ${ }^{910}$ Ibidem, p. 414.

911 Tattoos, Piercings, Schönheitsoperationen. Op.Cit., pp. 179-195.

912 TAUPITZ, Jochen. Empfehlen sich zivilrechtliche Regelungen zu Absicherung der Patientenautonomie am Ende des Lebens?, A 55, A 56. 
correção pelo Tribunal. Grécia: julgamento de cada caso entre 10 e 18 anos. Canadá: em algumas províncias em princípio a partir de 16 anos. Países Baixos: a partir de 16 anos, entre 12 e 16 anos julgamento caso a caso, reconhecendo-se o direito de veto dos menores. Áustria: julgamento a cada caso a partir de 14 anos. Portugal: a partir de 14 anos, desde que capaz de julgamento. Suécia: avaliação caso a caso. Suíça: entre 10 e 15 anos a capacidade de julgamento pode ser aceita de forma crescente e a partir de 15 anos ela deve ser presumida. Espanha: julgamento caso a caso até 18 anos. África do Sul: conforme o conselho de um projeto de lei sobre decisões de terminalidade da vida (End of Life Decisions Bill) a partir de 14 anos, desde que "assistidos por seus pais ou guardiães". Turquia: maioridade, que ocorre com 18 anos, ou por meio de casamento (para as mulheres com a conclusão de 15 anos e para os homens com a conclusão de 17 anos) ou com a conclusão de 15 anos por meio de declaração judicial. USA: em parte é presumida pela necessária maturidade a partir de 14 anos, em parte é estabelecida pela emancipação: casamento ou vida separada dos pais e independência financeira. Noruega: a partir de 16 anos. Polônia: a partir de 13 anos para medidas de rotina.

No Brasil, como salientado supra, não existe uma regulamentação legal, nem jurisprudência ou doutrina a respeito da 
capacidade de consentimento. Entretanto, julga-se importante expor como a legislação apresenta algumas situações diferentes sobre idade mínima para a prática de determinados atos do tráfego jurídico:

a) $\mathrm{O}$ art. $7^{\circ}$, XXXIII da Constituição Federal considera menor o trabalhador entre 16 a 18 anos. $\mathrm{O}$ contrato de aprendizagem pode ser celebrado a partir de 14 anos (art. 403 da Consolidação das Leis do Trabalho - CLT).

b) Outra função que pode ser exercida por menores é o estágio. Alunos que estiverem frequentando cursos de nível superior, profissionalizante de $2^{\mathrm{o}}$ grau, ou escolas de educação especial podem ser contratados como estagiários. O estágio não cria vínculo empregatício de qualquer natureza (art. $3^{\circ}$ caput da lei do Estágio Lei $\mathrm{n}^{\mathrm{o}} 11.788$ de 2008$)^{913}$ e o estagiário poderá receber bolsa, ou outra forma de contraprestação que venha a ser acordada, devendo o

${ }^{913}$ Art. $3^{-}$O estágio, tanto na hipótese do $\S 1^{\underline{0}}$ do art. $2^{\underline{0}}$ desta Lei quanto na prevista no $\S 2^{-}$do mesmo dispositivo, não cria vínculo empregatício de qualquer natureza, observados os seguintes requisitos: I - matrícula e freqüência regular do educando em curso de educação superior, de educação profissional, de ensino médio, da educação especial e nos anos finais do ensino fundamental, na modalidade profissional da educação de jovens e adultos e atestados pela instituição de ensino; II - celebração de termo de compromisso entre o educando, a parte concedente do estágio e a instituição de ensino; III - compatibilidade entre as atividades desenvolvidas no estágio e aquelas previstas no termo de compromisso. 
estudante, em qualquer hipótese, estar segurado contra acidentes pessoais (art. $9^{\circ}$, IV, da referida lei do Estágio). ${ }^{914}$

c) $\mathrm{O}$ atleta não profissional em formação, maior de quatorze anos de idade, poderá receber auxílio financeiro da entidade de prática desportiva formadora, sob a forma de bolsa de aprendizagem livremente pactuada mediante contrato formal, sem que seja gerado vínculo empregatício entre as partes (art. $29, \S 4^{\circ}$ da lei do Desporto - Lei $n^{\circ} 9.615$ de 1998). ${ }^{915}$

d) Direitos garantidos aos menores pela CLT:

- Ao menor é devido, no mínimo, o salário mínimo federal, inclusive ao menor aprendiz é garantido o salário mínimo hora (art. $428 \S 2^{\circ}$ da CLT), uma vez que sua jornada de trabalho será de no máximo 6 horas diárias, ficando vedadas prorrogação e compensação de jornada (art. 432 da CLT).

${ }^{914}$ Art. $9^{\circ}$ As pessoas jurídicas de direito privado e os órgãos da administração pública direta, autárquica e fundacional de qualquer dos Poderes da União, dos Estados, do Distrito Federal e dos Municípios, bem como profissionais liberais de nível superior devidamente registrados em seus respectivos conselhos de fiscalização profissional, podem oferecer estágio, observadas as seguintes obrigações: (...) IV - contratar em favor do estagiário seguro contra acidentes pessoais, cuja apólice seja compatível com valores de mercado, conforme fique estabelecido no termo de compromisso; (...).

$915 \S 4^{\underline{0}} \mathrm{O}$ atleta não profissional em formação, maior de quatorze e menor de vinte anos de idade, poderá receber auxílio financeiro da entidade de prática desportiva formadora, sob a forma de bolsa de aprendizagem livremente pactuada mediante contrato formal, sem que seja gerado vínculo empregatício entre as partes. 
- $\quad$ A jornada do menor aprendiz pode chegar ao limite de 8 horas diárias desde que tenha completado o ensino fundamental, computadas as horas destinadas à aprendizagem teórica (art. $432 \S 1^{\circ}$ da CLT).

- $\quad \mathrm{O}$ menor empregado tem direito a frequentar as aulas (Art. 427 da CLT).

- O empregado estudante, menor de 18 (dezoito) anos, terá direito a fazer coincidir suas férias com as férias escolares (art. 136, $\S 2^{\circ}$ da CLT).

- É proibido ao empregador fracionar o período de férias dos empregados menores de 18 (dezoito) anos (art. 134, $\S 2^{\circ}$ da CLT).

- São proibidos de trabalhar no horário das $22 \mathrm{~h}$ às $05 \mathrm{~h}$, considerado como horário noturno (art. 404 da CLT).

- É licito ao menor firmar recibos de pagamentos, mas a rescisão deverá ter a representação dos pais ou responsáveis legais (art. 439 da CLT).

- Mesmo que o menor fique afastado para cumprimento de serviço militar e não receba nenhum vencimento da empresa, deverá ter seu FGTS depositado mês a mês (art. 15, $§ 5^{\circ}$ da lei do FGTS, lei $\mathrm{n}^{\mathrm{o}} 8.036$ de 1990). 
d) Menor de 18 anos pode ser sócio em sociedade limitada (conforme acréscimo do $\S 3^{\circ}$ promovido pela lei. 12.399 de 2011 no art. 974 do Código Civil). ${ }^{916}$

- Requisitos:

1. O Menor deve ser representado ou assistido (art. 973, $\S 3^{\circ}$, III do CC).

2. O capital social deve estar integralizado, já que na sociedade limitada, há solidariedade entre os sócios pela parte que faltar para integralizar o capital social (art. 1.052 do CC).

3. O menor não pode exercer a administração em hipótese alguma (art. $973, \S 3^{\circ}, \mathrm{I}$ do CC), porque o administrador, ainda que o capital esteja integralizado, responde civilmente pela prática de algum ato ilícito. Se, por exemplo, o administrador esquecer a expressão "limitada" na firma ou denominação, sua responsabilidade será ilimitada (art. $1.158, \S 3^{\circ}$ do CC). Dentre outros motivos, o menor não emancipado, ainda não pode ser administrador da sociedade limitada ex vi dos arts. 1.016 e 1.017 do Código Civil. O administrador pode responder civilmente por culpa

916 § 3o O Registro Público de Empresas Mercantis a cargo das Juntas Comerciais deverá registrar contratos ou alterações contratuais de sociedade que envolva sócio incapaz, desde que atendidos, de forma conjunta, os seguintes pressupostos: I - o sócio incapaz não pode exercer a administração da sociedade; II - o capital social deve ser totalmente integralizado; III - o sócio relativamente incapaz deve ser assistido e o absolutamente incapaz deve ser representado por seus representantes legais. 
no desempenho de suas funções (art. 1.016, CC, com remissão ao art. 158 da LSA, dispositivo equivalente).

e) Menor tem o direito de ser ouvido pela Justiça após ser entregue aos cuidados da família que ao adotou, assim como tem o direito de preferência para que seja adotado pela mesma família que o irmão (art. $28, \S 1^{\circ}$ e $4^{\circ} \S$ do Estatuto da Criança e do Adolescente ECA).

- A colocação em família substituta far-se-á mediante guarda, tutela ou adoção, independentemente da situação jurídica da criança ou adolescente, no termo do ECA (art. 28 caput).

- $\quad \mathrm{O} \$ 1^{\circ}$ dispõe que sempre que possível, a criança ou o adolescente será previamente ouvido por equipe interprofissional, respeitado seu estágio de desenvolvimento e grau de compreensão sobre as implicações da medida, e terá sua opinião devidamente considerada (alteração feita pela lei no 12.010 de 2009).

f) Menor de 18 anos pode ter conta bancária:

- $\quad$ Existem várias situações em que uma pessoa menor de idade precisa ter uma conta bancária. Por isso, vários bancos não só permitem que os menores sejam correntistas como também oferecem serviços especiais para esse público. A questão é que para alguém com menos de 18 anos abrir uma conta é necessário que um responsável legal também assine o contrato. 
g) Em se tratando das medidas de proteção previstas no ECA:

- $\quad \mathrm{Na}$ aplicação das medidas levar-se-ão em conta as necessidades pedagógicas, preferindo-se aquelas que visem ao fortalecimento dos vínculos familiares e comunitários (art. 100 caput do ECA).

- Os princípio que regem a aplicação das medidas de proteção foram incluídos pela Lei $\mathrm{n}^{\circ} 12.010$ de 2009 através de parágrafo único no art. 100.

- Condição da criança e do adolescente como sujeitos de direitos: crianças e adolescentes são os titulares dos direitos previstos nesta e em outras Leis, bem como na Constituição Federal (art. 100, parágrafo único, I do ECA).

- Oitiva obrigatória e participação: a criança e ao adolescente, em separado ou na companhia dos pais, de responsável ou de pessoa por si indicada, bem como os seus pais ou responsável, têm direito a ser ouvidos e a participar nos atos e na definição da medida de promoção dos direitos e de proteção, sendo sua opinião devidamente considerada pela autoridade judiciária competente, observado o disposto nos $\S \S 1^{\circ}$ e $2^{\circ}$ do art. 28 da referida lei (art. 100, parágrafo único, XII do ECA). 
h) Menor pode votar - Maiores de 16 e menores de 18 anos

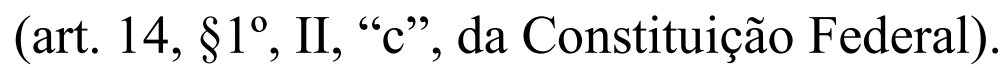

i) Menor pode casar (art. $5^{\circ}$, II e art. 1.550, II, ambos do $\mathrm{CC})$.

- Requisitos:

1. Menores entre 16 e 17 anos: Autorização do representante legal - assinatura do termo de consentimento (art. 1.517 combinado com o art. 1.519, ambos do CC).

2. Menores de 16 anos: Ordem judicial (arts. 1.520 e art. 1.553, ambos do CC).

j) Menor pode exercer emprego público efetivo (art. $5^{\circ}$, III do $\mathrm{CC})$.

k) Menor pode colar grau em curso superior (art. $5^{\circ}, \mathrm{IV}$, do CC).

1) Menor com 16 anos completos pode ter economia própria (art. $5^{\circ}, \mathrm{V}$, do CC).

m) Menores com mais de 16 anos podem ser admitidos como testemunha (art. 228, I, do CC e art. 446, $\S 4^{\circ}$ do Código de Processo Civil de $\left.2015^{917}\right)$.

n) Menor pode realizar mútuo (arts. 588 e 589 do CC).

- $\quad$ Requisitos previsto no art. 589:

${ }^{917} \S 4^{\circ}$ Sendo necessário, pode o juiz admitir o depoimento das testemunhas menores, impedidas ou suspeitas. 
I - se a pessoa, de cuja autorização necessitava o mutuário para contrair o empréstimo, o ratificar posteriormente;

II - se o menor, estando ausente essa pessoa, se viu obrigado a contrair o empréstimo para os seus alimentos habituais;

III - se o menor tiver bens ganhos com o seu trabalho. Mas, em tal caso, a execução do credor não lhes poderá ultrapassar as forças;

IV - se o empréstimo reverteu em benefício do menor;

$\mathrm{V}$ - se o menor obteve o empréstimo maliciosamente.

o) Menor pode realizar pacto antenupcial (art. 1.654 do CC)

- Requisito:

1. Aprovação de seu representante legal, salvo as hipóteses de regime obrigatório de separação de bens.

p) Menor pode ser instituído como herdeiro ou legatário (art. 1.733, $\S 2^{\circ}$ do CC)

- Observação:

1. Pode nomear curador especial para os bens deixados, ainda que o beneficiário se encontre sob o poder familiar, ou tutela.

q) Menor pode ser segurado facultativo a partir de 14 anos (art. 14 da lei $n^{\circ} 8.212$ de 1991 e art. 13 da lei $n^{\circ} 8.213$ de 1991)

r) Menor pode ter poupança em banco

s) Menor pode viajar para o exterior sozinho ou desacompanhado dos pais: 
- Requisitos (Resolução $n^{\circ} 131$ de 2011 do Conselho Nacional de Justiça - CNJ):

1. Autorização de ambos os pais com firma reconhecida

2. Autorização para viagem em repartição consular brasileira.

t) Menor a partir de 16 anos pode fazer testamento (art. 1.860, parágrafo único do $\mathrm{CC}$ ).

u) Menores podem ser herdeiros:

- Requisitos:

1. Desde que os menores de 16 anos estejam representados e os menores entre 16 e 18 estejam assistidos.

v) Maiores de 12 anos podem frequentar lan house e cybercafés - (lei estadual paulista $\mathrm{n}^{\circ} 12.228$ de 2006).

- Observações:

1. Se menor de 12 anos, deve estar acompanhado de pelo menos um dos pais ou representante legal.

2. Se menor entre 12 e 16 anos, precisa de autorização escrita de pelo menos um dos pais ou de representante legal.

3. Os menores de 18 anos podem frequentar apenas até a meia-noite. 
Diante desse contexto, o tema da determinação da capacidade de consentimento dos menores para tratamentos médicos permanece em aberto.

\subsubsection{Parâmetros para avaliar a capacidade de consentimento}

A doutrina aponta alguns parâmetros para avaliação da capacidade de consentimento.

\subsubsection{Tipo de tratamento}

Um critério utilizado na avaliação da capacidade de consentimento do menor é o tipo do tratamento a ser executado. Parte da doutrina se apoia sobre a gravidade do procedimento médico e a possibilidade de ser adiável ou não. ${ }^{918}$

Primeiramente, faz-se necessário esclarecer o que se entende por gravidade, já que não se trata de um conceito unívoco. A característica da gravidade do tratamento diz respeito, de modo geral, aos efeitos que o tratamento terá na saúde do paciente. A gravidade se refere ainda às dimensões e intensidade dos riscos, bem como ao perigo de dano à saúde. De forma mais afastada, mas ainda

${ }^{918}$ HUBER, Peter. In Münchner Kommentar. Op. Cit., §1626 BGB, Rn. 41; ULSENHEIMER, Klaus. §139 Die fahrlässige Körperverletzung. In LAUFS, Adolf; UHLENBRUCK, Wilhelm. Handbuch des Arztrechts. Op. Cit., pp. 1249-1250, Rn. 29. 
dentro da ideia de gravidade, estão as consequências, sobretudo aquelas a longo prazo que terão impacto na vida do paciente. ${ }^{919}$

Ao considerar o tipo de tratamento como parâmetro para sopesar a existência da capacidade de consentimento, a doutrina faz uma análise dentre os tratamentos insignificantes e graves. Alguns doutrinadores sustentam que apenas em relação a tratamentos insignificantes poder-se-ia concluir pela existência da capacidade. ${ }^{920}$ Porém, uma generalização como essa deve ser evitada, pois a capacidade de consentimento somente pode ser avaliada conforme as especificidades de cada caso concreto e da pessoa do menor. Não é possível abstrair tais aspectos e considerar unicamente a gravidade da medida. ${ }^{921}$

De qualquer forma, a gravidade do tratamento é considerada como critério na determinação da capacidade de consentimento. Esse ponto de vista corresponde ao entendimento sustentado pela jurisprudência alemã e doutrina dominantes, ou seja, de que as exigências para a capacidade de consentimento são tanto mais

919 REIPSCHLÄGER, Christiane. Die Einwilligung Minderjähriger in ärztliche Heileingriffe und die elterliche Personensorge. Op. Cit., p. 62. ${ }^{920}$ HUBER, Peter. In Münchner Kommentar. Op. Cit., §1626 BGB, p. 817, Rn 41; WAGNER, Gerhard. In Münchener Kommentar. v. 7. München: Beck, 2008. §823 BGB, Rn. 41.

${ }^{921}$ GLEIXNER-EBERLE, Elisabeth. Die Einwilligung in die medizinische Behandlung Minderjähriger. Op. Cit., p. 293. 
rígidas quanto grave for a medida médica a ser realizada. ${ }^{922}$ De outro lado, quanto mais simples ou insignificante for essa medida, menor rigor haverá na avaliação da capacidade de consentimento. ${ }^{923}$

Quando se parte da gravidade do procedimento, num primeiro momento não se considera exatamente a gravidade em si mesma e suas consequências. Considera-se, sim, o entendimento do processo de tratamento, das consequências e alternativas com ele relacionadas, bem como as exigências no sopesamento das vantagens e desvantagens no caso de se aceitar ou recusar sua execução. $^{924}$

Como resultado, em geral, a insignificância da medida médica é relacionada à facilidade de compreensão e avaliação dos prós e contras. ${ }^{925}$ Isso vale, também, para medidas mais graves, em que o nível de compreensão exigido é mais alto, uma vez que os esclarecimentos a serem prestados pelo médico também são mais abrangentes e complexos. Em outras palavras, as exigências da capacidade de entendimento são tanto maiores quanto mais 922 GOLBS, Ulrike. Das Vetorecht eines einwilligunsunfähigen Patienten. Op. Cit., pp. 80-81.

${ }^{923}$ AMELUNG, Knut Über die Einwilligungsfähigkeit (Teil II). Zeitschrift für die gesamte Strafrechtswissenschaft. v. 104 (3), pp. 821; 833, janeiro de 1992.

${ }^{924}$ GLEIXNER-EBERLE, Elisabeth. Die Einwilligung in die medizinische Behandlung Minderjähriger. Op. Cit., p. 294

${ }^{925}$ KUHLMANN, Jens-Michael. Einwilligung in die Heilbehandlung alter Menschen. Op Cit., p. 35. 
complexos forem os esclarecimentos e quanto maior a gravidade do procedimento, tanto maiores serão os esclarecimentos. ${ }^{926}$ Exige-se, nisso tudo, maior maturidade intelectual e moral do menor. ${ }^{927} \mathrm{O}$ mesmo entendimento se aplica para as consequências, ou seja, quanto mais graves forem as consequências, maiores serão as exigências para a capacidade de compreensão. ${ }^{928}$

Existe um posicionamento contrário, no sentido de que o menor deve decidir sozinho e, portanto, deve lhe ser reconhecida a necessária capacidade de consentimento também em casos que afetem sua configuração de vida. Entende-se que, mesmo em caso de dano grave à integridade corporal, existe uma tendência em se reconhecer ao menor amplo espaço de decisão, pois é ele quem vai sofrer diretamente as consequências da medida médica. Ainda, o significado dessa medida para a vida futura do menor contribui a que se reconheça sua capacidade de decidir sozinho a respeito. ${ }^{929}$

926 WÖLK, Florian. Der minderjährige Patient in der ärztlichen Behandlung. Op. Cit., pp. 80; 87; REIPSCHLÄGER, Christiane. Die Einwilligung Minderjähriger in ärztliche Heileingriffe und die elterliche Personensorge. Op. Cit., pp. 62-64.

${ }^{927}$ REIPSCHLÄGER, Christiane. Die Einwilligung Minderjähriger in ärztliche Heileingriffe und die elterliche Personensorge. Op. Cit., p. 65.

928 ULSENHEIMER, Klaus. §139 Die fahrlässige Körperverletzung. In LAUFS, Adolf; UHLENBRUCK, Wilhelm. Handbuch des Arztrechts. Op. Cit., Rn. 29, pp. 1249-1250.

${ }^{929}$ REUTER, Dieter. Kindesgrundrechte und elterliche Gewalt. Berlin: Duncker \& Humboldt, 1968. p. 212. 
Entretanto, não se pode deixar que um procedimento com caráter de alta infringência na integridade corporal do menor leve à admissão da capacidade de consentimento sem maiores reflexões. Decisiva é a questão de saber se o menor, em relação à gravidade da medida médica proposta, apresenta a necessária capacidade de entendimento, pela qual ele poderá compreender qual significado a doença e o tratamento têm na sua vida, bem como se possui capacidade para tomar uma decisão significativa sobre a medida em favor de um interesse seu. ${ }^{930}$

Derivando do aspecto da gravidade, parte da doutrina sustenta que a gravidade da medida médica pode estar relacionada à indicação. Dessa forma, quanto mais forte for a indicação, mais fácil será tomar uma decisão. ${ }^{931}$ Outros ainda mencionam o fator da necessidade do tratamento. ${ }^{932}$

A necessidade do tratamento está relacionada com sua indicação. Conforme visto supra as exigências do dever de informar em tratamentos sem indicação médica, principalmente em relação

930 RIXEN, Stephan. Das todkranke Kind zwischen Eltern und Arzt. Frankfurt: Springer, 1997. pp. 351-352.

${ }^{931}$ HEIDE, Jochen. Medizinische Zwangsbehandlung, Rechtsgrundlagen und verfassungsrechtliche Grenzen der Heilbehandlung gegen den Willen des Betroffenen. Op. Cit., p. 150.

932 REIPSCHLÄGER, Christiane. Die Einwilligung Minderjähriger in ärztliche Heileingriffe und die elterliche Personensorge. Op. Cit., pp. 6768 . 
aos riscos, são maiores e, por consequência, também as exigências para a capacidade de consentimento serão mais rígidas. ${ }^{933}$

É certo que as exigências sobre a capacidade de consentimento do menor serão tanto maiores quanto menor for a necessidade de um tratamento e quanto mais amplo for o esclarecimento. ${ }^{934} \mathrm{O}$ menor deve estar consciente de que o procedimento pode lhe causar danos que não estão relacionados com o sucesso almejado. Nessas situações, a capacidade de consentimento será analisada de forma mais rigorosa, pois quando um procedimento acarretar riscos desnecessários, a decisão em assumi-los exige maturidade e compreensão maiores do que no caso em que o procedimento se mostra necessário do ponto de vista médico. ${ }^{935}$ Nesse contexto, a capacidade de consentimento dos menores em relação às cirurgias estéticas deve ser avaliada com maior rigor, pois se trata de uma intervenção sem indicação médica e que acarreta riscos à saúde do menor. $^{936}$

Outros doutrinadores consideram o aspecto da urgência. Da mesma forma que gravidade, o termo urgência também não é 933 WÖLK, Florian. Der minderjährige Patient in der ärztlichen Behandlung. Op. Cit., pp. 80-87.

${ }_{935}^{934}$ Sobre extensão do esclarecimento, cf. capítulo 4, item 4.2.

935 WÖLK, Florian. Der minderjährige Patient in der ärztlichen Behandlung. Op. Cit., pp. 80-87.

${ }^{936}$ GLEIXNER-EBERLE, Elisabeth. Die Einwilligung in die medizinische Behandlung Minderjähriger. Op. Cit., p. 414. 
unívoco. Do ponto de vista jurídico, não há, entre um termo e outro, distinção instituída para aplicação ampla e genérica, nem na legislação, nem na doutrina ou na jurisprudência. No âmbito de aplicação da lei que rege os Planos de Saúde, os termos são distinguidos pelo art. 35-C, incisos I e II, com redação dada pela Lei $\mathrm{n}^{\mathrm{o}} 11.935$ de 2009. O inciso I conceitua emergência como sendo os casos que "implicarem risco imediato de vida ou de lesões irreparáveis para o paciente, caracterizado em declaração do médico assistente”. Já a urgência é conceituada no inciso II como sendo os casos "resultantes de acidentes pessoais ou de complicações no processo gestacional".

$\operatorname{COSTA}^{937}$ aponta que o Código de Ética Médica, instituído por meio da Resolução n ${ }^{0} 1.931$ de 2009 do Conselho Federal de Medicina, não estabelece parâmetros científicos seguros e definitivos sobre as diferenças entre urgência e emergência, utilizando tais termos sem qualquer preocupação com sua conceituação. Assim, fica reservado à anterior resolução $\mathrm{n}^{0} 1.451$ de

${ }^{937}$ A inconstitucionalidade da Resolução CONSUL $n^{0}$ 13, que limitou os atendimentos de urgência e emergência a 12 horas em ambulatório, 2010. Disponível em: <https:/jus.com.br/artigos/17327/a-inconstitucionalidade-daresolucao-consu-n-13-que-limitou-os-atendimentos-de-urgencia-eemergencia-a-12-horas-em-ambulatorio>. Acesso em: 02 nov. 2016. 
1995, ${ }^{938}$ também do Conselho Federal de Medicina, conceituar urgência e emergência. No art. $1^{\circ}$, parágrafo primeiro, da referida resolução fica estabelecido que emergência é "a constatação médica de condições de agravo à saúde que impliquem em risco iminente de vida ou sofrimento intenso, exigindo, portanto, tratamento médico imediato". Já urgência é definida no parágrafo segundo como "a ocorrência imprevista de agravo à saúde com ou sem risco potencial à vida, cujo portador necessita de assistência médica imediata".

A comunidade médica, por meio de consultas aos Conselhos Regionais de Medicina, reafirmou os parâmetros para uma situação médica ser considerada de urgência ou de emergência. Nesse sentido há o parecer do Dr. Moacyr Esteves Perche, ${ }^{939}$ aprovado em reunião ordinária do Conselho Regional de Medicina de São Paulo, em 24 de novembro de 1998 e o parecer elaborado pelo Dr. Ivan de Araújo Moura Fé ${ }^{940}$ para o Conselho Regional de Medicina do Ceará, datado de 23 de julho de 2001. Ambos reafirmam os conceitos da Resolução $\mathrm{n}^{\mathrm{o}} 1.451$, porém $\mathrm{o}$ primeiro parecerista admite a 938 Resolução disponível em: $<$ http://www.portalmedico.org.br/resolucoes/cfm/1995/1451_1995.htm>. Acesso em: 02 nov. 2016.

939

Parecer

disponível em:

$<$ http://www.portalmedico.org.br/pareceres/crmsp/pareceres/1998/55820_199 8.htm >. Acesso em 02 nov. 2016.

940

Parecer

disponível

em:

$<$ http://www.cremec.com.br/pareceres/2001/par1401.htm>. Acesso em 02 nov. 2016. 
dificuldade de uma distinção rigorosa entre os termos, observando que o médico deve proceder à triagem dos casos utilizando-se de análise criteriosa e bom senso para reconhecer o grau de seriedade envolvido em cada situação e as possíveis consequências de suas ações ou omissões.

Diante desse contexto, como critério para avaliação da capacidade de consentimento, será usado o termo urgência, considerando-se também a emergência.

Nesse caso, coloca-se a questão de saber se para medidas urgentes a capacidade de consentimento deve ser maior ou menor. De um lado, afirma-se que essa capacidade deveria ser maior, uma vez que as informações sobre a medida médica devem ser trabalhadas de forma mais rápida e sob forte pressão emocional e intelectual, de modo que a pessoa deverá ter uma alta capacidade de compreensão para processar todas essas informações num raciocínio lógico antes de tomar uma decisão. ${ }^{941}$ De outro lado, seria possível concluir por exigências menos rigorosas, já que a situação de urgência diminui a abrangência do dever de informar, cabendo ao

941 BELLING, Detlev; EBERL, Christina; MICHILIK, Frank. Das Selbstbestimmungsrecht Minderjähriger bei medizinischen Eingriffen. Op.Cit., p. 134; LINK, Ihna. Schwangerschaftsabbruch bei Minderjährigen. Op. Cit., p. 181; ROUKA, Stella. Das Selbstestimmungsrecht des Minderjährigen bei ärztlichen Eingriffen. Op. Cit., pp. 117-119. 
médico, dependendo do tempo disponível, esclarecer o paciente apenas sob os pontos essenciais do procedimento médico a ser tomado. Dessa forma, o paciente receberia menos informação e teria que raciocinar menos. ${ }^{942}$ Diante dessa dificuldade em relação à urgência, há quem defenda que ela não deve ser considerada como critério para avaliação da capacidade de consentimento. ${ }^{943}$

\subsubsection{Racionalidade objetiva}

Ao avaliar a capacidade de consentimento dos menores, a doutrina e jurisprudência alemãs consideram, também, o critério da racionalidade ou razoabilidade da decisão. ${ }^{944}$ Afirma-se que, quando a decisão do menor contraria toda a lógica médica, sendo, portanto, irracional ou irrazoável, essa situação é considerada como forte indício de ausência de capacidade de consentir por falta de

${ }^{942}$ ULSENHEIMER, Klaus. $\$ 139$ Die fahrlässige Körperverletzung. In LAUFS, Adolf; UHLENBRUCK, Wilhelm. Handbuch des Arztrechts. Op. Cit., p. 1598; WÖLK, Florian. Der minderjährige Patient in der ärztlichen Behandlung. Op. Cit., pp. 80-87.

${ }^{943}$ GLEIXNER-EBERLE, Elisabeth. Die Einwilligung in die medizinische Behandlung Minderjähriger. Op. Cit., p. 295.

944 REIPSCHLÄGER, Christiane. Die Einwilligung Minderjähriger in ärztliche Heileingriffe und die elterliche Personensorge. Op. Cit., p. 70; GLEIXNER-EBERLE, Elisabeth. Die Einwilligung in die medizinische Behandlung Minderjähriger. Op. Cit., p. 295, comentando que pelo julgamento do BGH de 10.02.1959, o Tribunal negou a capacidade de consentir de um menor, sob o argumento de que um menor sensato não toma uma decisão sozinho. 
maturidade e experiência. Nesse caso, seu consentimento não será suficiente para justificar o procedimento médico, sendo necessária a concordância de seus pais. ${ }^{945}$ Ao contrário, quando o consentimento do menor corresponder a um comportamento considerado normal, então ele será considerado capaz. Isso se justifica pelo fato de que um adulto teria o mesmo comportamento. ${ }^{946}$ Entretanto, o critério da razoabilidade deve ser tomado com discrição, pois como exposto no item 5.2.2 deste trabalho, nem sempre a razoabilidade objetiva caminha de mãos dadas com o direito de autodeterminação.

Se a capacidade de consentir fosse avaliada de acordo com a razoabilidade objetiva da decisão, o consentimento, que é um instrumento da autodeterminação da pessoa, poderia ser transformado em um instrumento de tutela jurídica. Na verdade, o direito de autodeterminação permite que as decisões sejam tanto racionais, como irracionais. Esse direito garantido constitucionalmente iria ruir se cada decisão irracional, embora querida por seu titular, fosse declarada ineficaz pela ausência de capacidade de consentir. ${ }^{947}$

${ }^{945}$ KUHLMANN, Jens-Michael. Einwilligung in die Heilbehandlung alter Menschen. Op Cit., p. 76.

946 REIPSCHLÄGER, Christiane. Die Einwilligung Minderjähriger in ärztliche Heileingriffe und die elterliche Personensorge. Op. Cit., p. 70.

${ }^{947}$ Ibidem, p. 73. 
É verdade que a falta de racionalidade numa decisão pode ser admitida como um indício de incapacidade de consentimento, servindo de razão para o médico provar de forma cuidadosa se o menor pode ser considerado capaz. ${ }^{948}$

Também, é certo que uma decisão a qual vai de encontro ao que se considera "objetivamente correto" tem maior chance de ser eficaz e de levar ao reconhecimento da capacidade de consentimento. ${ }^{949}$

Mas a interpretação de que a irrazoabilidade da decisão leva necessariamente à incapacidade de consentir contraria o princípio de que o titular do direito é livre em relação à sua personalidade, no que diz com sua integridade corporal e intelectual, para escolher seus critérios e viver e decidir de acordo com eles. ${ }^{950}$ A propósito, esse é o aspecto mais importante, ou seja, considerar se o menor está agindo conforme seu sistema interno de valores. ${ }^{951}$ Se esse aspecto é considerado para pacientes maiores, deve também valer para os

${ }^{948}$ KUHLMANN, Jens-Michael. Einwilligung in die Heilbehandlung alter Menschen. Op Cit., p. 76.

949 AMELUNG, Knut. Über die Einwilligungsfähigkeit (Teil II). Op. Cit. pp. $821 ; 830$.

${ }_{950}$ MORLOK, Martin. Selbstvertändnis als Rechtskriterium. Tübingen: J. C. B. Mohr, 1993. p. 78.

951 AMELUNG, Knut. Über die Einwilligungsfähigkeit (Teil I). Op. Cit. $525 ; 546$. 
menores. Assim, tanto para pacientes maiores como menores não se deve questionar sobre a razoabilidade da decisão. ${ }^{952}$

Visto sob outro ângulo, o fato de o paciente - seja maior ou menor - agir de forma racional, também não leva à conclusão necessária de que apresente capacidade de consentimento. A racionalidade da decisão não deve ser o único parâmetro para a avaliação da eficácia de tal decisão tomada pelo menor, pois há que se verificar se este compreendeu as circunstâncias que cercam o procedimento médico e se avaliou essas circunstâncias em relação à sua pessoa, ou se apenas está se deixando guiar pelos conselhos de seu médico. ${ }^{953}$

Se um paciente recusar um tratamento essencial à sua vida, há que se questionar o que está por trás dessa decisão, ou seja, os motivos de tal decisão, o que o levou a tomar esse tipo de decisão, sua história de vida, valores subjetivos, entre outros fatores. ${ }^{954}$ Há quem sustente que a avaliação desse sistema de valores em menores

952 GLEIXNER-EBERLE, Elisabeth. Die Einwilligung in die medizinische Behandlung Minderjähriger. Op. Cit., p. 296.

953 REIPSCHLÄGER, Christiane. Die Einwilligung Minderjähriger in ärztliche Heileingriffe und die elterliche Personensorge. Op. Cit., p. 73. ${ }^{954}$ GLEIXNER-EBERLE, Elisabeth. Die Einwilligung in die medizinische Behandlung Minderjähriger. Op. Cit., pp. 296-297, comentando uma decisão do Tribunal de Luzern, que respeitou a decisão de um jovem ao negar o tratamento de quimioterapia, sob o argumento de que, se essa decisão foi tomada em atenção ao sistema subjetivo de valores do paciente, então ela deve ser respeitada. 
é cercada de dificuldades, sobretudo pelo fato de uma pessoa menor estar em fase de desenvolvimento, de forma que esse sistema ainda não estará pronto. Ainda encontra muitos adeptos a concepção no sentido de que a adolescência é uma fase de grande perturbação psicológica, com períodos de alternância sempre ligados a crises emocionais. Entretanto, há pesquisas empíricas com jovens, cujos resultados contradisseram essas generalizações negativas e demonstraram que adolescentes, em sua maioria, não encontraram dificuldades na passagem para a idade adulta. ${ }^{955}$

No entanto, ainda que haja dificuldades na determinação do sistema de valores de menores, isso não deve levar à conclusão de que seu consentimento seria eficaz apenas se estivesse de acordo com um estado de "normalidade". Essa conclusão seria um contrassenso ao direito de autodeterminação, garantido constitucionalmente, conforme já declinado. ${ }^{956}$

Por fim, afirma-se que o fundamento para avaliação da racionalidade do consentimento do menor deve ser, prioritariamente, o processo interno de tomada de decisão no contexto de seu desenvolvimento e seu sistema de valor até então estabelecido. A subjetividade da decisão valorativa, que vem expressa na aceitação 955 REIPSCHLÄGER, Christiane. Die Einwilligung Minderjähriger in ärztliche Heileingriffe und die elterliche Personensorge. Op. Cit., p. 72. ${ }^{956}$ ROUKA, Stella. Das Selbstbestimmungsrecht des Minderjährigen bei ärztlichen Eingriffen. Op.Cit., p. 104. 
ou recusa do tratamento, não é passível de substituição. Diante desse panorama, os critérios de determinação da capacidade de consentimento devem ser outros que não pousem sobre aspectos subjetivos. $^{957}$

957 AMELUNG, Knut. Vetorechte beschränkt Einwilligungsfähiger in Grenzbereichen medizinischer Intervention. Berlin: Walter de Gruyter, 1995. p. 28. 


\section{CAPÍTULO 7 - O CONSENTIMENTO NAS INTERVENÇÕES MÉDICAS EM MENORES}

\subsection{Os menores incapazes de consentir}

\subsubsection{A concepção do consentimento como cuidado da pessoa}

A relação jurídica familiar entre o menor e seus pais se desenvolve no âmbito do poder familiar, que no Código Civil brasileiro é tratado entre os artigos 1.630 e 1.638. Melhor teria sido se o legislador, ao promulgar o Código em 2002, tivesse lançado mão da expressão "cuidado familiar" ao invés de "poder familiar", uma vez que a palavra "poder" infere a ideia de que a relação jurídica entre pais e filhos ocorre numa situação em que aqueles possuem poder sobre estes, acabando por subjugá-los à sua vontade e a tratá-los como objeto da relação. ${ }^{958}$

${ }^{958}$ VEIT, Bárbara. In BAMBERGER, Heinz Georg; ROTH, Herbert (Coord.). Kommentar zum Bürgerlichen Gesetzbuch. v. 3. 3 ed. München: Beck, 2012. Rn. 1, § 1626; HUBER, Peter. In Münchener Kommentar zum Bürgerlichen Gesetzbuch. v. 8. Op. Cit., p. 802; GLEIXNER-EBERLE, Elisabeth. Die Einwilligung in die medizinische Behandlung Minderjähriger. Op. Cit., pp. 303-304; REIPSCHLÄGER, Christiane. Die Einwilligung Minderjähriger in ärztliche Heileingriffe und die elterliche Personensorge. Op. Cit., p. 85. 
No entanto, essa não é a melhor conclusão que se poderia chegar para a relação familiar, pois esta se dá muito mais num contexto de cuidado e proteção do que de poder dos pais sobre os filhos. Além disso, a Constituição Federal de 1988 traz as ideias de liberdade, igualdade e responsabilidade, princípios estes que o constituinte coloca no próprio texto. Desse modo, a ordem jurídica brasileira enseja que, no relacionamento entre pais e filhos, haja o fomento de um ambiente saudável e pautado no equilíbrio. ${ }^{959}$

O conteúdo do poder familiar descrito no art. 1.634 do Código Civil demonstra justamente a obrigação de cuidado que os pais têm em relação aos filhos, quando determina que thes compete dirigir a criação e educação de seus filhos ${ }^{960}$ (inciso I); tê-los em sua companhia e guarda (inciso II); conceder-lhes ou negar-lhes consentimento para casarem (inciso III); nomear-lhes tutor, por testamento ou documento autêntico, se o outro dos pais não the sobreviver, ou o sobrevivo não puder exercer o poder familiar (inciso IV) e representá-los até os dezesseis anos, nos atos da vida

${ }^{959}$ FACHIN, Luiz Edson. Desafios e perspectivas do direito de família no Brasil Contemporâneo. In AZEVEDO, Antônio Junqueira de; TÔRRES, Heleno Taveira; CARBONE, Paulo (coord.). Princípios do novo Código Civil Brasileiro e outros temas: Homenagem a Tullio Ascarelli. São Paulo: Quartier Latin, 2008. p. 433.

${ }_{960}$ Quanto à educação dos filhos, é interessante o que afirma FACHIN, segundo o qual quem educa, num procedimento dialógico, também se renova (...). Nesse sentido, Ibidem, p. 433. 
civil, e assisti-los, após essa idade, nos atos em que forem partes, suprindo-lhes o consentimento (inciso V).

O legislador, ao dispor sobre o conteúdo do poder familiar, foi claro ao demonstrar o aspecto de cuidado que embasa a relação entre pais e filhos. A terminologia "cuidado paternal" corresponde muito mais ao reconhecimento de que os direitos dos menores dispostos no Código Civil e no Estatuto da Criança e do Adolescente não deveriam se expressar apenas por meio de prescrições legais, mas, também, por uma terminologia própria que indicasse seu real conteúdo. $^{961}$ Antes do advento do Código Civil de 2002, DUARTE $^{962}$ já anunciava que a antiga ideia do "pátrio poder" que indicava um feixe de direitos (com sentido autoritário) do pai sobre os filhos transforma-se num conjunto de deveres, os quais devem ser exercidos no interesse destes.

Dessa forma, o direito alemão alterou o termo "poder familiar" para "cuidado familiar" na reforma legislativa de 1980, justamente para sobressaltar o aspecto de cuidado e proteção que os pais têm em relação aos filhos e afastar a noção de poder como autoritarismo e força. ${ }^{963}$ Por essas razões, nesse trabalho optou-se por fazer

961 HUBER, Peter. In Münchener Kommentar zum Bürgerlichen Gesetzbuch. v. 8. Op. Cit., Rn. 4.

${ }_{962}$ Proteção Jurídica dos Bens de Incapazes. Op. Cit., p. 49.

${ }^{963}$ GLEIXNER-EBERLE, Elisabeth. Die Einwilligung in die medizinische Behandlung Minderjähriger. Op. Cit., pp. 303-304; REIPSCHLÄGER, 
referência à expressão "cuidado familiar" ao invés de "poder familiar".

Aliás, o conceito de cuidado familiar deve ir além do conteúdo de responsabilidade dos pais em relação aos filhos e do caráter obrigacional da posição jurídica aos pais. Mais do que isso, o cuidado familiar deve determinar claramente que, nas relações entre pais e filhos, deve-se atentar à idade, maturidade e discernimento, pois menoridade significa justamente necessidade de proteção compatível com essas condições. ${ }^{964}$ P65 $^{965}$

O cuidado familiar abrange a totalidade das relações entre pais e filhos menores. Ele decorre do direito dos pais estabelecido nos artigos 227 e 229, primeira parte da Constituição Federal ${ }^{966}$ e dos

Christiane. Die Einwilligung Minderjähriger in ärztliche Heileingriffe und die elterliche Personensorge. Op. Cit., p. 85.

964 HUBER, Peter. In Münchener Kommentar zum Bürgerlichen Gesetzbuch. v. 8. Op. Cit., Rn. 2; 6.

${ }^{965}$ Explica o doutrinador que, na língua alemã, o termo usado é Fürsorge, o qual expressa uma proteção no sentido de um agir ativo, e não apenas proteção. A qualificação do cuidado familiar como simples proteção do menor de perigos em geral mostra-se muito estreita para expressar o sentido real do cuidado familiar. Entretanto, como em português não existe um termo que corresponda a Fürsorge, o presente trabalho mencionará "proteção" ou "proteção e cuidado".

${ }^{966}$ Art. 227: É dever da família, da sociedade e do Estado assegurar à criança, ao adolescente e ao jovem, com absoluta prioridade, o direito à vida, à saúde, à alimentação, à educação, ao lazer, à profissionalização, à cultura, à dignidade, ao respeito, à liberdade e à convivência familiar e comunitária, além de coloca-los a salvo de toda forma de negligência, discriminação, exploração, violência, crueldade e opressão. 
direitos fundamentais das crianças e adolescentes. ${ }^{967}$ Trata-se de uma relação jurídica ambivalente, caracterizada pelo direito subjetivo dos pais, advindo da Carta Magna, quanto à criação e educação dos filhos e pelo direito fundamental das crianças em receber cuidado e proteção. ${ }^{968}$

No cuidado paternal, estão em primeiro plano a responsabilidade dos pais e o caráter de obrigação. Seu fundamento não é uma pretensão de poder dos pais, mas sim, a necessidade de proteção e ajuda dos filhos para que desenvolvam sua personalidade como pessoas competentes e autônomas no seio da sociedade. Conteúdo essencial do cuidado familiar é promover o desenvolvimento do menor, atuar conforme seu interesse e promover seu bem-estar. ${ }^{969}$

Art. 229: "Os pais têm o dever de assistir, criar e educar os filhos menores, e os filhos maiores têm o dever de ajudar e amparar os pais na velhice, carência ou enfermidade". Embora a redação da Carta refira-se apenas ao termo "dever", trata-se também de um direito fundamental dos pais, conforme explicado no corpo desse trabalho.

${ }^{967}$ PALANDT, Otto. Bürgerliches Gesetzbuch. v. 7.74 ed. München: Beck, 2015. p. 2030; RAKETE-DOMBEK, Ingeborg. Nomos Kommentar BGB: Familienrecht. v. 4.3 ed. Baden-Baden: Nomos, 2014. p. 1722.

${ }^{968}$ PALANDT, Otto. Bürgerliches Gesetzbuch. Op. Cit., p. 2030.

${ }^{969}$ Ibidem, p. 2030; ZIEGLER, Friederich. In PRÜTING, Hans; WEGEN, Gerhard; WEINREICH, Gerd. BGB Kommentar. §1626. 10 ed. Köln: Luchterhand, 2015. pp. 2526-2527; DÖLL, Yves. In Erman - Bürgeliches Gesetzbuch. Op. Cit., pp. 5136-5137; RAKETE-DOMBEK, Ingeborg. Nomos Kommentar BGB: Familienrecht. p. 1722. Nesse sentido, cf. ELIAS, Roberto João. Pátrio Poder: Guarda dos Filhos e Direito de Visita. São 
Embora o conceito de bem-estar seja difuso e indeterminado, pois não existe uma definição universal, é compreendido de forma ampla, como bem-estar corporal, espiritual e intelectual da criança e adolescente. $^{970}$

As prescrições do Código Civil sobre o direito de cuidado familiar representam a concretização desse direito garantido constitucionalmente pelos arts. 227 e 229 da Constituição Federal. Na Alemanha o art. 6 (2) da Constituição da República alemã declara que cuidado e educação dos filhos são o direito natural dos pais e sua primeira obrigação. ${ }^{971}$

Diante desse contexto dos diplomas constitucionais e das prescrições advindas do Código Civil, o direito de cuidado familiar é um direito natural dos pais, cabendo a eles, prioritariamente, especificar o conteúdo e o método da educação que almejam transmitir aos filhos. ${ }^{972}$ É direito dos pais definir o que é bom ou razoável para a vida atual e futura de seus filhos, pois os genitores

Paulo: Saraiva, 1999, p. 6; Idem. Pátrio Poder: Deveres e Direito para Proteção dos Filhos. Tese de Livre-Docência. São Paulo: Faculdade de Direito da Universidade de São Paulo, 1998. p. 57.

${ }^{970}$ DÖLL, Yves. In Erman - Bürgeliches Gesetzbuch. Op. Cit., p. 5197; OLZEN, Dirk. In Münchener Kommentar zum Bürgerlichen Gesetzbuch. v. 9. München: Beck, 2008. p. 996.

${ }^{971}$ Art. 6 (2) Pflege und Erziehung der Kinder sind das natürliche Recht der Eltern und die zuvörderst ihnen obliegende Pflicht. Über ihre Betätigung wacht die staatliche Gemeinschaft.

${ }^{972}$ PALANDT, Otto. Bürgerliches Gesetzbuch. Op. Cit., p. 2030. 
são os titulares da concretização e interpretação do bem-estar dos menores. ${ }^{973}$ Dessa forma, os pais transmitem à futura geração suas concepções próprias de vida, seus valores e ideias sobre política, religião, ética, estética, dentre outros. ${ }^{974}$ Disso decorre uma especial responsabilidade dos pais em relação a seus filhos menores e uma consequente proteção da criança na comunidade. ${ }^{975}$

De outro lado, o cuidado familiar representa um direito fundamental absoluto, ${ }^{976}$ e implica em responsabilidade a aquele que o viola. ${ }^{977}$ Não é passível de cessão, sendo irrenunciável. Isso não afasta a possibilidade de autorizar parentes, escolas, internatos para o exercício do cuidado familiar, podendo os pais voltar a exercê-lo a qualquer momento. ${ }^{978} \mathrm{Na}$ qualidade de direito absoluto, o cuidado familiar garante prioridade, autonomia e responsabilidade dos pais 973 COESTER, Michael. Elternautonomie und Staatsverantwortung bei der Pflege und Erziehung von Kindern. Zeitschrift für das gesamte Familienrecht. v. 43 (19), pp. 1181-1182, 1996.

${ }_{975}^{974}$ PALANDT, Otto. Bürgerliches Gesetzbuch. Op. Cit., p. 2030.

975 REIPSCHLÄGER, Christiane. Die Einwilligung Minderjähriger in ärztliche Heileingriffe und die elterliche Personensorge. Op. Cit., pp. 8687.

976 PALANDT, Otto. Bürgerliches Gesetzbuch. Op. Cit., p. 2030; DÖLL, Yves. In Erman - Bürgeliches Gesetzbuch. Op. Cit., p, 5137; ZIEGLER, Friederich. In PRÜTING, Hans; WEGEN, Gerhard; WEINREICH, Gerd. BGB Kommentar. Op. Cit., p. 2527.

977 ZIEGLER, Friederich. In PRÜTING, Hans; WEGEN, Gerhard; WEINREICH, Gerd. BGB Kommentar. Op. Cit., p. 2527.

978 DÖLL, Yves. In Erman - Bürgeliches Gesetzbuch. Op. Cit., p, 5137; ZIEGLER, Friederich. In PRÜTING, Hans; WEGEN, Gerhard; WEINREICH, Gerd. BGB Kommentar. Op. Cit., p. 2527. 
no cuidado de seus filhos. Essa exclusividade protege a família de qualquer ingerência alheia, seja de terceiros ou do próprio Estado. ${ }^{979}$ Ademais, o art. 226, caput, da Constituição Federal declara a família como base da sociedade e lhe garante especial proteção do Estado.

A família é reconhecida como instituição e espaço de vida autônomo e fechado, onde seus membros desenvolvem relações personalíssimas. ${ }^{980}$ Ela é um espaço de segurança para os menores e outros membros vulneráveis em várias situações da vida, como nos estados em que há falta de saúde física e mental, oferecendo suporte para sua sobrevivência. ${ }^{981}$ Além disso, a família é detentora de responsabilidade própria, do que deriva ao Estado a obrigação de respeitar essa união, bem como promover seu bem-estar. ${ }^{982}$

Visto nesse conjunto, o cuidado familiar não se limita a garantia de direito de defesa contra intervenções inadmissíveis do Estado, mas possibilita uma influência direta dos pais em relação a seus

979 REIPSCHLÄGER, Christiane. Die Einwilligung Minderjähriger in ärztliche Heileingriffe und die elterliche Personensorge. Op. Cit., pp. 9495.

${ }^{980}$ PALANDT, Otto. Bürgerliches Gesetzbuch. Op. Cit., p. 2030.

${ }^{981}$ NERY, Rosa Maria de Andrade. Instituições de Direito Civil. v. 5. São Paulo: Revista dos Tribunais, 2015. p. 385.

982 HUBER, Peter. In Münchener Kommentar zum Bürgerlichen Gesetzbuch. v. 8. Op. Cit., §1626, Rn. 9. 
filhos. ${ }^{983}$ Por consequência, a educação não pode ser completamente definida por meio de normas, pois ela decorre da direção de vida que os pais pretendem transmitir a seus filhos menores. Por ter a educação uma natureza individual, em razão da qualidade das pessoas envolvidas na relação, não é possível nem pertinente que o Estado estabeleça as regras a serem perseguidas. ${ }^{984}$

Se houvesse um controle dessa forma por meio do Estado, seria prejudicial ao fundamento da educação, que é a relação de confiança e autoridade que se estabelece entre pais e filhos. ${ }^{985}$ Como titulares do cuidado familiar, os pais possuem autonomia em definir o conteúdo da educação e do bem-estar dos filhos menores. ${ }^{986}$

O direito de criação e educação da pessoa do filho menor abrange um direito e dever amplo dos pais pelo bem-estar corporal, intelectual, espiritual e moral do filho, com a finalidade de realizar e desenvolver sua personalidade e levá-lo à maioridade, preparando-o, com o tempo, para se tornar uma pessoa que vive sua vida com

983 REIPSCHLÄGER, Christiane. Die Einwilligung Minderjähriger in ärztliche Heileingriffe und die elterliche Personensorge. Op. Cit., pp. 86; 95.

${ }^{984}$ Ibidem, pp. 87; 95.

${ }^{985}$ Ibidem, p. 87.

${ }^{986}$ Ibidem, p. 95. 
responsabilidade própria. ${ }^{987}$ Nesse sentido, os pais são os titulares da primazia na interpretação e concretização do bem-estar de seus filhos. $^{988}$

A criação dos filhos menores visa ao cuidado da existência corporal e significa principalmente acompanhamento do menor por meio de assistência à sua alimentação, saúde e vestimenta. ${ }^{989}$ A educação abrange, também, uma área que vai além de assegurar a existência do menor. $\mathrm{O}$ direito de educação tem por conteúdo principalmente o direito dos pais de definir o que é bom e razoável para a vida atual e futura da criança. ${ }^{990}$

7.1.2 O consentimento dos pais nos procedimentos médicos como objeto do cuidado familiar

Ao promover o bem-estar dos filhos menores, os pais têm que se preocupar com todos os aspectos nele compreendidos, ou seja, seu bem-estar físico, intelectual e espiritual. Isso significa empregar esforços para o restabelecimento de sua saúde e assumir a 987 DÖLL, Yves. In Erman - Bürgeliches Gesetzbuch. Op. Cit., §1631,p. 5163; HUBER, Peter. In Münchener Kommentar zum Bürgerlichen Gesetzbuch. v. 8. Op. Cit., §1626, Rn. 32

${ }^{988}$ COESTER, Michael. Elternautonomie und Staatsverantwortung bei der Pflege und Erziehung von Kindern. Op. Cit., pp. 1181-1182.

989 HUBER, Peter. In Münchener Kommentar zum Bürgerlichen Gesetzbuch. v. 8. Op. Cit., §1631, Rn 3.

${ }^{990}$ AMELUNG, Knut. Über die Einwilligungsfähigkeit (Teil II). Op. Cit., pp. 821 e 828. 
responsabilidade de acompanhá-los ao médico quando estiverem doentes, além de promoverem sua saúde no amplo sentido quando não estiverem doentes. Expressar o consentimento em tratamentos médicos necessários representa, portanto, conteúdo do cuidado familiar. $^{991}$

Quando um paciente menor não está em condições de compreender o significado e a abrangência do procedimento médico, ao invés de seu consentimento, os pais devem agir como seus representantes legais. ${ }^{992}$ Portanto, no caso dos pacientes menores incapazes de consentir, os titulares de tal capacidade são, em princípio, ambos os pais, pois cabe a eles o desempenho do cuidado familiar. Apenas o consentimento conjunto pode legitimar um procedimento médico. ${ }^{993}$

No exercício do cuidado familiar os pais devem agir em conformidade, buscando sempre um acordo, ${ }^{994}$ caso contrário deve-

${ }^{991}$ PALANDT, Otto. Bürgerliches Gesetzbuch. Op. Cit., p. 2031; HUBER, Peter. In Münchener Kommentar zum Bürgerlichen Gesetzbuch. v. 8. Op. Cit., Rn. 32; OLZEN, Dirk. In Münchener Kommentar zum Bürgerlichen Gesetzbuch. v. 9. Op. Cit., §1666, Rn. 80, p. 1006.

992 REIPSCHLÄGER, Christiane. Die Einwilligung Minderjähriger in ärztliche Heileingriffe und die elterliche Personensorge. Op. Cit., p. 110.

${ }^{993}$ KATZENMEIER, Christian. Arzthaftung. Op. Cit., p. 340.

${ }^{994} \$ 1627$ Ausübung der elterlichen Sorge: Die Eltern haben die elterliche Sorge in eigener Verantwortung und in gegenseitigem Einvernehmen zum Wohl des Kindes auszuüben. Bei Meinungsverschiedenheiten müssen sie versuchen, sich zu einigen. 
se recorrer ao Poder Judiciário. ${ }^{995}$ Entretanto, existem exceções ao princípio da representação conjunta, haja vista que, na falta ou impedimento de um dos pais, preleciona o caput do art. 1.631 do Código Civil brasileiro que o outro o exercerá com exclusividade.

Nessas situações pode ocorrer que um dos pais autorize o outro a agir por ele, o que pode ocorrer por meio de uma manifestação expressa ou tácita. Dessa forma, o consentimento é manifestado de forma eficaz por aquele genitor autorizado e apenas em relação a este o médico tem o dever de esclarecer. ${ }^{996}$

Quanto ao consentimento a ser manifestado pelos pais em tratamentos médicos de seus filhos menores, o Bundesgerichsthof (BGH) em um julgamento de 28.06.1988 estabeleceu três grupos de tratamentos médicos para verificar as exigências do genitor que se faz presente para expressar o consentimento. ${ }^{997}$ Em caso de intervenções insignificantes, consideradas de rotina, também chamadas "de bagatela", o médico deve confiar na autorização dada ao genitor presente sem necessidade de fazer ulteriores

995 Art. 1631, parágrafo único do Código Civil: "Durante o casamento e a união estável, compete o poder familiar aos pais; na falta ou impedimento de um deles, o outro exercerá com exclusividade. Parágrafo único: Divergindo os pais quanto ao exercício do poder familiar, é assegurado a qualquer um deles recorrer ao juiz para solução do desacordo".

${ }^{996}$ KATZENMEIER, Christian. Arzthaftung. Op. Cit., p. 340.

${ }^{997}$ DUTTGE, Gunnar. Patientenautonomie und Einwilligungsfähigkeit. Op. Cit., p. 81; GLEIXNER-EBERLE, Elisabeth. Die Einwilligung in die medizinische Behandlung Minderjähriger. Op. Cit., p. 307. 
questionamentos a respeito, desde que não sejam conhecidas circunstâncias contrárias. Em caso de doenças com riscos significativos de tratamento, o médico deve se certificar através de informação com o genitor presente, mas deve confiar que essa informação é verídica. Por fim, em casos graves, de terapias de risco, o médico deve buscar de forma ativa informação com o pai ausente se realmente concorda com o procedimento, para alcançar a necessária certeza.

A doutrina adotou esses três estágios. ${ }^{998}$ Sem dúvida, essa solução deve ser aceita, pois de um lado corresponde às necessidades práticas do quotidiano médico e atende aos interesses dos pais; de outro, defende o cuidado familiar em assuntos

998 ULSENHEIMER, Klaus. §139 Die fahrlässige Körperverletzung. In LAUFS, Adolf; UHLENBRUCK, Wilhelm. Handbuch des Arztrechts. Op. Cit., p. 1599, § 139, Rn. 47; LAUFS, Adolf. § 66 Die Art und Weise der Aufklärung. Aufklärungsformulare. In LAUFS, Adolf; UHLENBRUCK, Wilhelm. Handbuch des Arztrechts. Op. Cit., pp. 530-531; DIEDERICHSEN, Uwe. In PALANDT, Otto. Bürgerliches Gesetzbuch. Op. Cit., §1629, Rn. 10; KERN, Gerson. Fremdbestimmung bei der Einwilligung in ärztliche Eingriffe. Neue Juristische Wochenschrift. pp. 753 e 756, 1994; DEUTSCH, Erwin; SPICKHOFF, Andreas. Medizinrecht. Azrtrecht, Arzneimittelrecht, Medizinproduktrecht und Transfusionsrecht. Op. Cit., pp. 501-502; MICHEL, Margot. Rechte von Kindern in medizinischen Heilbehandlungen. Op. Cit., pp. 131-132. 
importantes, por meio da autorização e a responsabilização do genitor ausente. ${ }^{999}$

Entretanto, o consentimento dado pelos pais em tratamentos médicos de seus filhos menores, conquanto represente uma ação de cuidado, de outro lado pode representar uma relação de tensão com o direito de autodeterminação. Explica-se. A integridade corporal e a correspondente autodeterminação são bens jurídicos personalíssimos, que são realizados pelo consentimento esclarecido. Esse consentimento é o meio pelo qual o titular do bem jurídico realiza seu direito de autodeterminação, de forma que parece problemático ceder para outra pessoa a competência de decisão sobre esse bem jurídico. ${ }^{1000}$

A realização da autodeterminação do titular do bem jurídico por meio de uma determinação alheia resultante do exercício do cuidado familiar apresenta uma contradição em si mesma. Ou seja, a defesa do direito de autodeterminação somente é possível por meio de uma determinação alheia. De outro lado, existe consenso no sentido de

${ }^{999}$ GLEIXNER-EBERLE, Elisabeth. Die Einwilligung in die medizinische Behandlung Minderjähriger. Op. Cit., pp. 306-307.

1000 ROTHÄRMEL, Sonja; WOLFSLAST, Gabriele; FAGERT, Jörg M. Informed consent - ein kinderfeindliches Konzept?, Von der Benachteiligung minderjähriger Patienten durch das Informed ConsentKonzept am Beispiel der Kinder- und Jugendpsychiatrie. Frankfurt: Springer, 1999. pp. 293, 296. 
que a determinação alheia é inevitável para possibilitar tratamentos médicos em pessoas incapazes de consentimento. ${ }^{1001}$

Entretanto, a liberdade de decisão dos pais nos casos de tratamento médico de seu filho menor incapaz de consentimento é mais restrita do que a liberdade de uma pessoa capaz de consentimento em relação à sua própria saúde, pois aqueles devem agir sempre em prol do bem-estar dos menores. ${ }^{1002}$ Em outras palavras, ao aprovar ou recusar um determinado procedimento médico, os pais têm o dever de agir em proteção do filho e conforme ao seu bem-estar. ${ }^{1003}$

Como visto supra, a definição e o conteúdo do bem-estar da criança cabem aos pais no exercício do cuidado familiar. Eles podem e devem decidir sobre as intervenções médicas em seus filhos de maneira autônoma e responsável. ${ }^{1004}$

Nessa decisão, os pais devem avaliar cuidadosamente todas as circunstâncias que envolvem o procedimento, ou seja, extensão, riscos, ônus psíquico, e não apenas os benefícios médicos que ${ }^{1001}$ LINK, Ihna. Schwangerschaftsabbruch bei Minderjährigen. Op. Cit., p. 221.

1002 REIPSCHLÄGER, Christiane. Die Einwilligung Minderjähriger in ärztliche Heileingriffe und die elterliche Personensorge. Op. Cit., pp. 110111.

1003 KÖHLER, Michael. Medizinische Forschung in der Behandlung des Notfallpatienten. Neue Juristische Wochenschrift. pp. 853-854, 2002.

1004 REIPSCHLÄGER, Christiane. Die Einwilligung Minderjähriger in ärztliche Heileingriffe und die elterliche Personensorge. Op. Cit., p. 111. 
podem ser alcançados. Cabe aos pais decidir se o procedimento médico vale à pena, de modo que a função de cuidado e proteção se expressa nessa ponderação das vantagens e desvantagens da intervenção. ${ }^{1005}$

No contexto das intervenções médicas e na realização do cuidado familiar, ao atender o bem-estar do filho, cabe aos pais dar o consentimento para um procedimento quando este for indicado, no sentido de necessário. A necessidade do procedimento médico desempenha aqui um papel importante, ao ser considerada como pré-condição para o consentimento. ${ }^{1006}$

Em princípio, os pais são obrigados a tomar as providências médicas necessárias para manter a vida de seu filho ou evitar um dano grave à sua saúde. ${ }^{1007}$ Nas doenças com risco de vida, em que o tratamento médico representa a base central da existência da criança,

1005 OLZEN, Dirk. In Münchener Kommentar zum Bürgerlichen Gesetzbuch. v. 9. Op. Cit., §1666, p. 1007; REIPSCHLÄGER, Christiane. Die Einwilligung Minderjähriger in ärztliche Heileingriffe und die elterliche Personensorge. Op. Cit., p. 111.

${ }^{1006}$ KERN, Bernd-Rüdiger. Der Minderjährige als Blutspender. FamRZ. pp. 738-739, 1981.

${ }^{1007}$ Afirma-se que o princípio dos pais serem obrigados a consentir em toda medida indicada não vale de forma ilimitada. Algumas exceções são apontadas, tais como o consentimento para a finalização de medidas que mantém a vida artificialmente, quando o menor está sendo mantido por respiração e alimentação artificiais sem chance de voltar a si. Nesse sentido, cf. REIPSCHLÄGER, Christiane. Die Einwilligung Minderjähriger in ärztliche Heileingriffe und die elterliche Personensorge. Op. Cit., pp. 114115. 
deve-se escolher a medida médica da qual pode ser esperado o afastamento máximo do risco de vida. ${ }^{1008}$

O limite do poder de decisão dos pais é ultrapassado quando eles deixam de consentir em intervenções que podem salvar a vida do filho ou quando recusam outra medida necessária, como, por exemplo, uma vacinação em caso de viagem para uma área de risco. Trata-se de uma recusa abusiva do consentimento. ${ }^{1009}$

Nesses casos, os motivos pelos quais os pais agem assim, mesmo que mais nobres, não importam. A recusa de transfusão de sangue necessária para salvar a vida do filho, mesmo que por motivos religiosos, em princípio não é aceita. ${ }^{1010}$ Entretanto, se a medida médica contradisser concepções religiosas dos pais, estes não podem ser obrigados a dar um consentimento. Nesse caso, caberá ao juízo da Vara da Infância e Juventude decidir no lugar dos genitores. ${ }^{1011}$

Medidas diagnósticas não devem ser recusadas pelos pais quando forem consideradas inofensivas pelos conhecimentos ${ }^{1008}$ RIXEN, Stephan. Das todkranke Kind zwischen Eltern und Arzt. Op. Cit., pp. 351 e 353

${ }^{1009}$ PALANDT, Otto. Bürgerliches Gesetzbuch. Op. Cit., 1666, p. 2059; DÖLL, Yves. In Erman - Bürgeliches Gesetzbuch. Op. Cit., pp. 5136-5137, p. 5199 ;

1010 OLZEN, Dirk. In Münchener Kommentar zum Bürgerlichen Gesetzbuch. v. 9. Op. Cit., §1666, p. 1006.

1011 TAUPITZ, Jochen. Empfehlen sich zivilrechtliche Regelungen zu Absicherung der Patientenautonomie am Ende des Lebens? O. Cit., A 74. 
médicos. Em caso de medidas de riscos, que poderiam trazer altas chances de sucesso, há quem sustente que se houver recusa por parte dos pais, o Poder Judiciário deverá permiti-las, quando estes devessem também consentir com o tratamento planejado após a realização dessas medidas. ${ }^{1012}$

De outra parte, o consentimento para tratamentos médicos considerados não indicados é, via de regra, abusivo. Afirma-se que os pais não devem antecipar o futuro de seu filho por meio de uma decisão sobre intervenção médica que terá efeitos além da maioridade. $^{1013}$

Eles não têm o direito de se valer da possibilidade de expressarem seu consentimento em intervenções médicas que não sejam indicadas para o bem-estar psíquico do filho, tais como melhorar o desempenho do menor na prática esportiva ou realizar cirurgias estéticas. ${ }^{1014}$ Ao recusar uma cirurgia estética, os pais, em regra, não estão negligenciando o cuidado familiar, quando esse procedimento cirúrgico não tiver por escopo afastar um dano

1012 OLZEN, Dirk. In Münchener Kommentar zum Bürgerlichen Gesetzbuch. v. 9. Op. Cit., §1666, p. 1007.

${ }^{1013}$ KERN, Bernd-Rüdiger. Der Minderjährige als Blutspender. Op. Cit., pp. $738-739$

1014 BELLING, Detlev; EBERL, Christins; MICHLIK, Frank. Das Selbstbestimmungsrecht Minderjähriger bei medizinischen Eingriffen. Op. Cit., p. 125. 
psicológico que aflige seu filho. ${ }^{1015}$ Não se reconhece aos pais realizar suas ideias pessoais e formatar o corpo do filho para satisfazer interesses próprios. ${ }^{1016}$

A propósito, quando a decisão dos pais se tornar um perigo para a vida e incolumidade física da criança, o Poder Judiciário deve ser acionado para tomar as medidas necessárias em prol do bem-estar do menor. ${ }^{1017}$ Mas, se não houver tempo para acionar o tribunal, o médico poderá executar o tratamento apesar da recusa dos pais. ${ }^{1018}$ Trata-se de situações de negligência do cuidado familiar.

Alguns ${ }^{1019}$ sustentam que, nesse caso, o médico age de forma justificada pelo estado de necessidade ${ }^{1020}$ ou pela urgência ${ }^{1021}$.

1015 OLZEN, Dirk. In Münchener Kommentar zum Bürgerlichen Gesetzbuch. v. 9. Op. Cit., §1666, p. 1007.

1016 BELLING, Detlev; EBERL, Christins; MICHLIK, Frank. Das Selbstbestimmungsrecht Minderjähriger bei medizinischen Eingriffen. Op. Cit., p. 125.

1017 REIPSCHLÄGER, Christiane. Die Einwilligung Minderjähriger in ärztliche Heileingriffe und die elterliche Personensorge. Op. Cit., p. 113.

${ }^{1018}$ DIERKS, Christian; GRAF-BAUMANN, Toni; LENARD, Hans-Gerd. Therapieverweigerung bei Kindern und Jugendlichen. Frankfurt: Springer, 1995. p. 120.

1019 ULSENHEIMER, Klaus. §139 Die fahrlässige Körperverletzung. In LAUFS, Adolf; UHLENBRUCK, Wilhelm. Handbuch des Arztrechts. Op. Cit., p. 1600, §139 Rn. 49.

${ }^{1020} \$ 34$ Rechtfertigender Notstand: Wer in einer gegenwärtigen, nicht anders abwendbaren Gefahr für Leben, Leib, Freiheit, Ehre, Eigentum oder ein anderes Rechtsgut eine Tat begeht, um die Gefahr von sich oder einem anderen abzuwenden, handelt nicht rechtswidrig, wenn bei Abwägung der widerstreitenden Interessen, namentlich der betroffenen Rechtsgüter und des Grades der ihnen drohenden Gefahren, das geschützte Interesse das 
Outros justificam a intervenção com o dever médico de prestar socorro ou com a aceitação de um consentimento presumido do Tribunal. De qualquer forma, existe unanimidade de que o médico, diante de uma situação de perigo iminente, age de forma justificada quando desconsidera a recusa dos pais em dar o consentimento para uma medida médica necessária. ${ }^{1022}$

Nesse contexto, ainda que caiba aos pais prioritariamente dar ou recusar o consentimento para uma intervenção médica em prol do bem-estar do filho menor, a doutrina debate a questão de saber se este, ainda que incapaz de consentimento, deveria, ao menos, ser ouvido.

Na relação externa, que é aquela formada entre pais e médico, somente é importante o consentimento dos representantes legais, em regra, os pais. Mas na relação interna, que existe entre pais e filhos, é muito importante que os pais conversem com seu filho, o qual, mesmo sendo incapaz de consentimento, pode expressar seus

beeinträchtigte wesentlich überwiegt. Dies gilt jedoch nur, soweit die Tat ein angemessenes Mittel ist, die Gefahr abzuwenden.

${ }^{1021} \S 32$ Notwehr: (1) Wer eine Tat begeht, die durch Notwehr geboten ist, handelt nicht rechtswidrig. (2) Notwehr ist die Verteidigung, die erforderlich ist, um einen gegenwärtigen rechtswidrigen Angriff von sich oder einem anderen abzuwenden.

${ }^{1022}$ GLEIXNER-EBERLE, Elisabeth. Die Einwilligung in die medizinische Behandlung Minderjähriger. Op. Cit., p. 311. 
desejos e expressar um acordo com o procedimento médico planejado. ${ }^{1023}$

$\mathrm{O} \S 630$ (5) do $\mathrm{BGB}^{1024}$ dispõe sobre uma pretensão do paciente incapaz de receber informação condizente com seu entendimento sobre o procedimento médico, conforme seu estado de desenvolvimento e sua capacidade de entender. É primordial que os pais escutem seus filhos e considerem sua vontade, pois a integridade corporal é um bem jurídico personalíssimo e tem prioridade para a liberdade de seu titular. Ademais, as circunstâncias especiais em que o tratamento será desenvolvido são motivos para a integração do menor no processo de decisão. Isso significa que intervenções médicas contra a vontade do titular do bem jurídico devem ser evitadas, pois elas terão menores chances de sucesso, ao passo que intervenções que contam com o acordo também do menor têm maiores chances de sucesso. ${ }^{1025}$

Os pais não devem impor ao filho menor uma decisão, mas abordar com ele as circunstâncias do tratamento, todas as questões envolvidas sobre probabilidade de êxito e fracasso, tudo com o objetivo de chegarem a um acordo. Uma conversa nesse sentido ${ }^{1023}$ DÖLL, Yves. In Erman - Bürgeliches Gesetzbuch. Op. Cit., pp. 51365137.

${ }^{1024}$ Cf. nt. 170 supra.

1025 DÖLL, Yves. In Erman - Bürgeliches Gesetzbuch. Op. Cit., pp. 51365137. 
promoverá compreensão mútua e possibilitará aos pais tomarem conhecimento da vontade e argumentos do filho menor. ${ }^{1026}$

A capacidade de consentimento não surge de repente, mas se forma paulatinamente, por um processo de transição e desenvolvimento. Durante essa fase pode parecer inconveniente, sob certas circunstâncias, não considerar absolutamente nada da vontade do menor incapaz. Isso porque, mesmo que sua capacidade de consentimento ainda esteja em formação, em alguns casos ele já pode dispor de certa maturidade intelectual. ${ }^{1027}$

Sob esse contexto e dando um passo à frente, a doutrina também discute se ao menor incapaz deveria ser reconhecido um direito de veto contra o consentimento manifestado por seus pais. Colocada de outra forma, apresenta-se agora a questão de saber se deve ser conferida ao menor a capacidade de recusar uma intervenção médica consentida pelos pais. ${ }^{1028}$

1026 REIPSCHLÄGER, Christiane. Die Einwilligung Minderjähriger in ärztliche Heileingriffe und die elterliche Personensorge. Op. Cit., p. 112. ${ }^{1027}$ GLEIXNER-EBERLE, Elisabeth. Die Einwilligung in die medizinische Behandlung Minderjähriger. Op. Cit., p. 316.

${ }^{1028}$ ROTHÄRMEL, Sonja. Einwilligung, Veto, Mitbestimmung. Op. Cit., pp. 165-166. 


\subsubsection{Definição e pressupostos da capacidade de veto}

Por capacidade de veto entende-se o direito do paciente incapaz de consentir, de negar um procedimento médico indicado. ${ }^{1029}$ Dessa forma, ao menor incapaz de prestar seu consentimento, mas já capaz de apresentar um veto, seria reconhecida a possibilidade de revogação da eficácia do consentimento manifestado por seus pais. ${ }^{1030}$

Parte da doutrina considera que esse direito de veto não pode incidir sobre medidas médicas urgentes. ${ }^{1031}$ Outros, entretanto, alegam que até o momento não existe uma definição precisa de direito de veto, não ficando claro se, no caso de existir uma compreensão básica do menor, estaria ele apto a exercer um direito de veto. ${ }^{1032}$

1029 Ibidem, p. 174; TAUPITZ, Jochen. Empfehlen sich zivilrechtliche Regelungen zu Absicherung der Patientenautonomie am Ende des Lebens? Op. Cit., A 75-76; GOLBS, Ulrike. Das Vetorecht eines einwilligunsunfähigen Patienten. Op. Cit., pp. 128-129.

${ }^{1030}$ GLEIXNER-EBERLE, Elisabeth. Die Einwilligung in die medizinische Behandlung Minderjähriger. Op. Cit., p. 317.

1031 ULSENHEIMER, in DIERKS, Christian; GRAF-BAUMANN, Toni; LENARD, Hans-Gerd (coord.). Therapieverweigerung bei Kindern und Jugendlichen. Frankfurt: Springer, 1995, p. 88.

1032 ODENWALD, Steffen. Die Einwilligunsfähigkeit im Strafrecht unter besonderer Hervorhebung ärztlichen Handels. Op. Cit., p. 154; DUTTGE, Gunnar. Patientenautonomie und Einwilligungsfähigkeit. In: WIESERMANN, Claudia; SIMON, Alfred. Patientenautonomie. Op. Cit., p. 82. 
Em relação aos pressupostos para se reconhecer a capacidade de veto, paira grande incerteza, mas entende-se que estes devem ser menos rigorosos que aqueles necessários para se reconhecer a capacidade de consentimento. ${ }^{1033}$ Alguns doutrinadores sustentam que o pressuposto mínimo seria a capacidade natural ${ }^{1034}$ do menor em formular uma vontade, ${ }^{1035}$ o que pode ocorrer já com crianças desde a tenra idade. ${ }^{1036}$

Porém, esse entendimento que se pauta pela vontade natural no menor encontra objeções. Não seria suficiente a simples capacidade de vontade natural, exigindo-se que o menor fosse dotado de uma determinada capacidade de discernimento para compreender a necessidade do tratamento. ${ }^{1037}$ Nesse sentido, haveria, primeiramente, a fase da capacidade de veto, que depois se

${ }^{1033}$ GOLBS, Ulrike. Das Vetorecht eines einwilligunsunfähigen Patienten. Op. Cit., p. 198; ODENWALD, Steffen. Die Einwilligunsfähigkeit im Strafrecht unter besonderer Hervorhebung ärztlichen Handels. Op. Cit., p. 153.

${ }^{1034}$ Sobre definição de capacidade natural de vontade, cf. HEIDE, Jochen. Medizinische Zwangsbehandlung, Rechtsgrundlagen und verfassungsrechtliche Grenzen der Heilbehandlung gegen den Willen des Betroffenen. Op. Cit., p. 145.

${ }^{1035}$ GOLBS, Ulrike. Das Vetorecht eines einwilligunsunfähigen Patienten. Op. Cit., p. 140; WÖLK, Florian. Der minderjährige Patient in der ärztliche Behandlung. Op. Cit., pp. 80; 88.

${ }^{1036}$ A esse respeito, cf. item 6.3.1 (concepções não jurídicas da capacidade de consentir) desse trabalho.

${ }^{1037}$ ODENWALD, Steffen. Die Einwilligunsfähigkeit im Strafrecht unter besonderer Hervorhebung ärztlichen Handels. Op. Cit., p. 153. 
fortaleceria na capacidade de consentimento. Em outras palavras, o menor ainda não capaz de consentimento deve estar em condição de recusar com eficácia um procedimento médico que conta com o consentimento de seus pais. ${ }^{1038}$

Não existe uma normatização legal geral sobre o direito de veto para menores incapazes. No entanto, esse instituto não é de todo estranho para o direito alemão, pois há várias prescrições legais em que se reconhece o direito de veto para determinadas situações. ${ }^{1039}$

No que se refere a tratamentos médicos, o menor pode se opor a uma intervenção médica que lhe cause esterilização - §1905 Abs. 1 Nr. 1 BGB $^{1040}$ ou castração - $§ 3$ Abs. 3 Nr.1 KastrG (Gesetz über dir freiwillige Kastration und andere Behandlungsmethoden - Lei sobre a castração voluntária e outros métodos de tratamento). ${ }^{1041}$

1038 KATZENMEIER, §139, Rn. 47. In: LAUFS, Adolf; KERN, BerndRüdiger. Handbuch des Arztrechts. Op. Cit., p. 1599.

${ }^{1039}$ GOLBS, Ulrike. Das Vetorecht eines einwilligunsunfähigen Patienten. Op. Cit., pp. 198-223.

${ }^{1040} \S 1905$ Sterilisation (1) Besteht der ärztliche Eingriff in einer Sterilisation des Betreuten, in die dieser nicht einwilligen kann, so kann der Betreuer nur einwilligen, wenn 1. die Sterilisation dem Willen des Betreuten nicht widerspricht,

1041 § 3 Einwilligung

(3) Ist der Betroffene nicht fähig, Grund und Bedeutung der Kastration voll einzusehen und seinen Willen hiernach zu bestimmen, so ist die Kastration nur dann zulässig, wenn

1.der Betroffene mit ihr einverstanden ist, nachdem er in einer seinem Zustand entsprechenden Weise aufgeklärt worden ist und wenigstens verstanden hat, welche unmittelbaren Folgen eine Kastration hat (...) 
Ainda nos casos de estudos clínicos - $§ 40$ Abs. 4 Nr. 3 AMG ${ }^{1042}$ ou na doação de órgão post mortem - §2 Abs. 2 TPG (Gesetz über die Spende, Entnahme und Übertragung von Organen und Gewebe Transplantationgesetz - Lei sobre doação, retirada e transplante de órgãos e tecidos ou Lei de Transplantes). ${ }^{1043}$ Existe, também, o

1042 (4) Auf eine klinische Prüfung bei Minderjährigen finden die Absätze 1 bis 3 mit folgender Maßgabe Anwendung:

1.Das Arzneimittel muss zum Erkennen oder zum Verhüten von Krankheiten bei Minderjährigen bestimmt und die Anwendung des Arzneimittels nach den Erkenntnissen der medizinischen Wissenschaft angezeigt sein, um bei dem Minderjährigen Krankheiten $\mathrm{zu}$ erkennen oder ihn vor Krankheiten zu schützen. Angezeigt ist das Arzneimittel, wenn seine Anwendung bei dem Minderjährigen medizinisch indiziert ist.

2.Die klinische Prüfung an Erwachsenen oder andere Forschungsmethoden dürfen nach den Erkenntnissen der medizinischen Wissenschaft keine ausreichenden Prüfergebnisse erwarten lassen.

3.Die Einwilligung wird durch den gesetzlichen Vertreter abgegeben, nachdem er entsprechend Absatz 2 aufgeklärt worden ist. Sie muss dem mutmaßlichen Willen des Minderjährigen entsprechen, soweit ein solcher feststellbar ist. Der Minderjährige ist vor Beginn der klinischen Prüfung von einem im Umgang mit Minderjährigen erfahrenen Prüfer, der Arzt oder, bei zahnmedizinischer Prüfung, Zahnarzt ist, oder einem entsprechend erfahrenen Mitglied der Prüfgruppe, das Arzt oder, bei zahnmedizinischer Prüfung, Zahnarzt ist, über die Prüfung, die Risiken und den Nutzen aufzuklären, soweit dies im Hinblick auf sein Alter und seine geistige Reife möglich ist; erklärt der Minderjährige, nicht an der klinischen Prüfung teilnehmen zu wollen, oder bringt er dies in sonstiger Weise zum Ausdruck, so ist dies zu beachten. Ist der Minderjährige in der Lage, Wesen, Bedeutung und Tragweite der klinischen Prüfung zu erkennen und seinen Willen hiernach auszurichten, so ist auch seine Einwilligung erforderlich. Eine Gelegenheit $\mathrm{zu}$ einem Beratungsgespräch nach Absatz 2 Satz 2 ist neben dem gesetzlichen Vertreter auch dem Minderjährigen zu eröffnen.

$1043 \S 2$ Aufklärung der Bevölkerung, Erklärung zur Organ- und Gewebespende, Organ- und Gewebespenderegister, Organ- und 
direito de veto do menor incapaz de consentimento contra a retirada de medula óssea contra sua vontade - $\S 8$ a Nr. 4 da TPG. ${ }^{1044}$

Essas medidas são consideradas tão relevantes para a personalidade, que sua execução é inadmissível se aquele que não é habilitado para dar seu consentimento se opuser. Embora incapaz para consentir, o menor pode ser considerado capaz para vetar. Esses casos exigem respeito pelo indivíduo como sujeito e um consentimento expressado pelos seus representantes legais não terá força de superar eventual recusa por parte daquele que sofrerá a medida. ${ }^{1045}$

Gewebespendeausweise (2) Wer eine Erklärung zur Organ- und Gewebespende abgibt, kann in eine Organ- und Gewebeentnahme nach $\S 3$ einwilligen, ihr widersprechen oder die Entscheidung einer namentlich benannten Person seines Vertrauens übertragen (Erklärung zur Organ- und Gewebespende). Die Erklärung kann auf bestimmte Organe oder Gewebe beschränkt werden. Die Einwilligung und die Übertragung der Entscheidung können vom vollendeten sechzehnten, der Widerspruch kann vom vollendeten vierzehnten Lebensjahr an erklärt werden.

${ }^{1044} \S 8 \mathrm{a}$ Entnahme von Knochenmark bei minderjährigen Personen. 4. Der gesetzliche Vertreter ist entsprechend $\S 8$ Abs. 2 aufgeklärt worden und hat in die Entnahme und die Verwendung des Knochenmarks eingewilligt. § 1627 des Bürgerlichen Gesetzbuchs ist anzuwenden. Die minderjährige Person ist durch einen Arzt entsprechend $\S 8$ Abs. 2 aufzuklären, soweit dies im Hinblick auf ihr Alter und ihre geistige Reife möglich ist. Lehnt die minderjährige Person die beabsichtigte Entnahme oder Verwendung ab oder bringt sie dies in sonstiger Weise zum Ausdruck, so ist dies zu beachten.

1045 TAUPITZ, Jochen. Empfehlen sich zivilrechtliche Regelungen zu Absicherung der Patientenautonomie am Ende des Lebens? Op. Cit., A 75 . 
Além dessas situações há outras que não se relacionam com o tratamento médico. É o caso do menor de 14 anos que pode escolhe seu credo religioso e do menor de 12 que pode se opor a uma alteração de religião. ${ }^{1046}$

No âmbito internacional, o art. 17 Abs. 1 lit. "v" da Convenção de Biomedicina do Conselho da Europa ${ }^{1047}$ proíbe a pesquisa com incapazes de consentimento se houver recusa de sua parte.

AMELUNG e TAUPITZ foram os primeiros a analisar se, a partir dessas regulamentações, seria possível extrair um direito de veto geral dos menores incapazes de consentimento para o campo do Direito Médico. ${ }^{1048}$ Para TAUPITZ, o direito de veto significa pura defesa da dignidade. Dessa forma, o doutrinador indica a limitação

1046 TAUPITZ, Jochen. Empfehlen sich zivilrechtliche Regelungen zu Absicherung der Patientenautonomie am Ende des Lebens? Op. Cit., A 75.

1047 Artigo 17. ${ }^{\circ}$ Protecção das pessoas que careçam de capacidade para consentir numa investigação 1 - Nenhuma investigação pode ser levada a efeito sobre uma pessoa que careça, nos termos do artigo 5. ${ }^{\circ}$, de capacidade para nela consentir senão quanto estiverem reunidas as seguintes condições: (...) v) A pessoa em causa não tenha manifestado a sua oposição. Como já afirmamos supra, optamos por trazer a tradução portuguesa do referido diploma.

1048 AMELUNG, Knut. Vetorechte beschränkt Einwilligungsfähiger in Grenzbereichen medizinischer Intervention. Op. Cit., pp. 12-13; TAUPITZ, DJT 2000, A 75; GOLBS, Ulrike. Das Vetorecht eines einwilligunsunfähigen Patienten. Op. Cit., pp. 169-170; ROTHÄRMEL, Sonja. Einwilligung, Veto, Mitbestimmung. Op. Cit., pp. 166-167; ODENWALD, Steffen. Die Einwilligunsfähigkeit im Strafrecht unter besonderer Hervorhebung ärztlichen Handels. Op. Cit., pp. 151-152. 
da possibilidade de se exercer tal direito às situações de intervenções de especial relevância para a dignidade da pessoa humana, como as esterilizações e castrações. De outra parte, nega o direito de veto para casos de tratamento médico com finalidade de cura e restabelecimento da saúde. O referido doutrinador sustenta que não é concebível um direito de veto aos menores incapazes de consentimento contra a decisão tomada pelos pais em relação a um tratamento médico. Para ele, os pais têm o direito natural de criação e educação dos filhos e, antes disso, uma obrigação. ${ }^{1049}$

De outro lado, AMELUNG argumenta que o direito de veto pode ser considerado em dois grupos de reserva: o que preserva a dignidade e o que preserva a razão. Nesse sentido, as regras da esterilização e da castração buscam preservar a dignidade, ao passo que as regras da lei de medicamentos e de transplantes de órgãos buscam proteger a razão já existente ou que ainda virá a existir no incapaz de consentir. Sob essa concepção, o direito de veto poderia ser pensado, também, nos casos de tratamento de saúde nos quais o menor contasse com o consentimento de seus pais. ${ }^{1050}$

1049 TAUPITZ, Jochen. Empfehlen sich zivilrechtliche Regelungen zu Absicherung der Patientenautonomie am Ende des Lebens? Op. Cit., A 77.

1050 Vetorechte beschränkt Einwilligungsfähiger in Grenzbereichen medizinischer Intervention. Op. Cit., pp. 19-20. 
Entretanto, a almejada busca de unidade sobre um direito de veto a ser concebido de forma generalizada para o Direito Médico parece não ser possível. Observando as normas citadas, verifica-se que o direito de veto possui diferentes funções e objetivos, que não se coadunam entre si, de modo a prejudicar a formação de um conceito único. $^{1051}$

Ainda que realmente não seja possível chegar a um conceito geral de direito de veto, as ponderações de AMELUNG e TAUPITZ merecem apreciação, uma vez que podem servir como ponto de partida para a reflexão, de saber se é possível extrair um direito de veto para os menores a partir dessas normas. Toma-se em favor dessa tese a redação do $§ 1626$ (2) (1) do $\mathrm{BGB}^{1052}$ o qual dispõe que, na criação e educação, os pais devem considerar a capacidade e a necessidade crescentes da criança para agir de modo autônomo e responsável. $^{1053}$ Entretanto, há quem sustente que essa norma representa apenas uma diretriz para o direito de educação e não um ${ }^{1051}$ ROTHÄRMEL, Sonja. Einwilligung, Veto, Mitbestimmung. Op. Cit., p. 173

1052 §1626 BGB: (2) (1) “Elterliche Sorge, Grundsätze - (2) Bei der Pflege und Erziehung berücksichtigen die Eltern die wachsende Fähigkeit und das wachsende Bedürfnis des Kindes zu selbständigem verantwortungsbewusstem Handeln."

1053 TAUPITZ, Jochen. Empfehlen sich zivilrechtliche Regelungen zu Absicherung der Patientenautonomie am Ende des Lebens? Op. Cit., 77 A; GOLBS, Ulrike. Das Vetorecht eines einwilligunsunfähigen Patienten. Op. Cit., p. 223. 
autêntico direito de veto que pudesse significar o direito de decidir conjuntamente do menor com seus pais. ${ }^{1054}$

Por fim, alguns sustentam que o direito de veto dos menores é considerado garantia do princípio da dignidade da pessoa humana. ${ }^{1055}$ Mas, para outros, essa garantia poderia se referir apenas às intervenções médicas não indicadas ${ }^{1056}$. Para outros, ainda, o tratamento médico indicado, executado lege artis, não violaria a dignidade do menor, pois um tratamento que tem por escopo restabelecer a saúde do menor, não transforma este em mero objeto do tratamento. ${ }^{1057}$

Diante desse contexto, a doutrina discute quanto à aceitação de um direito de veto para menores incapazes de consentir. Debate, ainda, se tal direito deveria ser aceito de forma geral ou apenas em casos nos quais a recusa pelo tratamento não causará danos importantes à saúde do menor. ${ }^{1058}$

${ }^{1054}$ LINK, Ihna. Schwangerschaftsabbruch bei Minderjährigen. Op. Cit., p. 225 .

1055 WÖLK, Florian. Der minderjährige Patient in der ärztliche Behandlung. Op. Cit., pp. 80-88.

${ }^{1056}$ Nesse contexto incluem-se as cirurgias estéticas.

1057 ODENWALD, Steffen. Die Einwilligunsfähigkeit im Strafrecht unter besonderer Hervorhebung ärztlichen Handels. Op. Cit., p. 152.

${ }^{1058}$ DUTTGE, Gunnar. Patientenautonomie und Einwilligungsfähigkeit. In: WIESERMANN, Claudia; SIMON, Alfred. Patientenautonomie. Op. Cit., p. 82; GLEIXNER-EBERLE, Elisabeth. Die Einwilligung in die medizinische Behandlung Minderjähriger. Op. Cit., p. 322. 
De um lado, muitos apoiam a existência de tal direito ${ }^{1059}$ e ponderam se o menor, por meio do veto, poderia revogar o consentimento dado pelos pais. Afirma-se que o menor, mesmo sendo incapaz de consentimento, mas capaz para vetar, poderia recusar o tratamento de forma vinculante. ${ }^{1060}$ Mas essa questão não é pacífica e, muitas vezes, é deixada em aberto. ${ }^{1061}$

Alguns defensores do direito de veto limitam-no aos casos de medidas médicas não urgentes. ${ }^{1062}$ Se o procedimento puder ser adiado e puder produzir consequências a longo prazo, como ocorre com as cirurgias estéticas, então deve-se conceder ao menor o direito de veto. Isso se justifica pelo fato de o direito de cuidado

1059 TAUPITZ, Jochen. Empfehlen sich zivilrechtliche Regelungen zu Absicherung der Patientenautonomie am Ende des Lebens? Op. Cit., A 75-76; GOLBS, Ulrike. Das Vetorecht eines einwilligunsunfähigen Patienten. Op. Cit., pp. 128-129; KATZENMEIER, §139, Rn. 47. In: LAUFS, Adolf; KERN, Bernd-Rüdiger. Handbuch des Arztrechts. Op. Cit., p. 1599; ROTHÄRMEL, Sonja. Einwilligung, Veto, Mitbestimmung. Op. Cit., pp. 165-166.

${ }^{1060}$ ODENWALD, Steffen. Die Einwilligunsfähigkeit im Strafrecht unter besonderer Hervorhebung ärztlichen Handels. Op. Cit., pp. 151-152.

1061 ULSENHEIMER, Klaus. \$139 Die fahrlässige Körperverletzung. In LAUFS, Adolf; UHLENBRUCK, Wilhelm. Handbuch des Arztrechts. Op. Cit., p. $1598, \S 139$, Rn. 47

1062 ULSENHEIMER, in DIERKS, Christian; GRAF_BAUMANN, Toni; LENARD, Hans-Gerd. Therapieverweigerung bei Kindern und Jugendlichen. Op. Cit., p. 88. 
familiar dos pais se exaurir com a maioridade e várias intervenções médicas poderem ter eficácia para além dessa idade. ${ }^{1063}$

Outros, diferentemente, sustentam que o reconhecimento de um direito de veto é contrário à necessidade de proteção do menor. Se ele é incapaz para dar consentimento a uma determinada medida médica, então também não seria capaz de entender a necessidade dessa medida, recusando-a e opondo-se a um consentimento dado por seus pais. Reconhecer o direito de veto nesse sentido seria incoerente. ${ }^{1064}$

Ao se deparar com esse contexto, a melhor posição é aquela que não nega o direito de veto, mas o limita à relação interna entre pais e filhos. Explica-se. Diante do que já foi exposto, importante mencionar que mesmo os adeptos à existência do direito de veto reconhecem que não há um conceito formulado a seu respeito, nem esclarecimento de quais seriam seus pressupostos. Paira ainda muita indefinição.

Mesmo assim, o direito de veto não deve ser rechaçado totalmente, sendo adequado considerá-lo sob certas condições. Para

1063 WÖLK, Florian. Der minderjährige Patient in der ärztliche Behandlung. Op. Cit., pp. 80, 88.

1064 ROTHÄRMEL, Sonja; DIPPOLD, Ines; WIETHOFF, Katja (et al.). Patientenaufklärung, Informationsbedürfnis und Informationspraxis in der Kinder- und Jugendpsychiatrie und Psychotherapie. Göttingen: Vandenhoeck \& Ruprecht, 2006. p. 33; KUHLMANN, Einwilligung in die Heilbehandlung alter Menschen (cit.), pp. 215-216. 
tanto, doutrinadores partem da comparação entre o direito de veto e as chamadas situações de proteção do incapaz (tutela e curatela ${ }^{1065}$ ), para afirmar que, o desejo e o veto do curatelado são considerados nas decisões tomadas ou a serem tomadas pelo seu curador. ${ }^{1066}$ Dispõe o $\$ 1901$, Abs. 3, S. 1 do $\mathrm{BGB}^{1067}$ que o curador deve corresponder aos desejos do curatelado, desde que isso não se contraponha ao bem-estar deste último e for exigido do curador.

O Código Civil brasileiro dispõe, em seu art. 1,740, III, que "incumbe ao tutor, quanto à pessoa do menor, adimplir os demais deveres que normalmente cabem aos pais, ouvida a opinião do menor, se este já contar doze anos de idade". É certo, portanto, que o tutor deve ouvir o tutelado antes de tomar decisões que afetem sua pessoa, sendo claro que o menor, nesses casos, poderá se opor a uma determinada posição de seu tutor.

Conforme já exposto no item 7.1.1, o bem-estar do tutelado não pode ser definido de forma objetiva, mas considerando que se trata de direitos da personalidade, a aferição desse bem jurídico (bem1065 No direito alemão, tutela e curatela são figuras tratadas sob o termo Betreuungsrecht, unificando suas características principais e comuns, com enfoque diferente do direito brasileiro.

1066 TAUPITZ, Jochen. Empfehlen sich zivilrechtliche Regelungen zu Absicherung der Patientenautonomie am Ende des Lebens? Op. Cit., A 77; ROTHÄRMEL, Sonja. Einwilligung, Veto, Mitbestimmung. Op. Cit., pp. 194-195.

${ }^{1067}$ Der Betreuer hat Wünschen des Betreuten zu entsprechen, soweit dies dessen Wohl nicht zuwiderläuft und dem Betreuer zuzumuten ist. 
estar) deve se pautar pela maior autonomia possível da vontade do menor. ${ }^{1068}$

De outro lado, no que se refere à relação pais e filhos, admitir um direito de veto geral e com eficácia na relação externa entre pais e médicos, levaria a um conflito com o cuidado familiar. Esse direito, garantido constitucionalmente, deve perdurar até a maioridade do filho menor ou eventual emancipação. Ele não deve retroceder perante o menor incapaz, até porque um de seus fundamentos é o direito de proteção. ${ }^{1069}$

Assim, ao contrário do tutor, cabe aos pais um direito de determinação até que o filho se torne capaz para decidir sozinho. Essa maior proximidade e ligação entre pais e filhos em geral não ocorre na relação entre tutor e tutelado. ${ }^{1070}$

No direito tutelar, o veto concebível ao tutelado não produz efeitos externos, operando-se apenas na relação com o tutor. Por consequência, extrai-se a conclusão de que se nessa relação, na qual se verifica menor proximidade entre as partes, o direito de veto não

1068 TAUPITZ, Jochen. Empfehlen sich zivilrechtliche Regelungen zu Absicherung der Patientenautonomie am Ende des Lebens? Op. Cit., A 77.

1069 TAUPITZ, Jochen. Empfehlen sich zivilrechtliche Regelungen zu Absicherung der Patientenautonomie am Ende des Lebens? Op. Cit., A 75 - A 77

${ }^{1070}$ ROTHÄRMEL, Sonja. Einwilligung, Veto, Mitbestimmung. Op. Cit., p. 173. 
possui efeito vinculante sobre o consentimento do tutor, também não haverá na relação entre pais e filhos. ${ }^{1071}$

Diante desse contexto, não se pode reconhecer que a vontade do menor ao recusar uma determinada medida médica possa tornar ineficaz o consentimento dado por seus pais. Não se reconhece uma eficácia externa do veto do menor com o condão de limitar o poder de representação dos genitores. $\mathrm{Na}$ verdade, a vontade do menor somente será decisiva quando ele se tornar capaz de consentimento. ${ }^{1072}$

Reconhecer ao menor uma capacidade de veto antes de lhe reconhecer uma capacidade de consentimento, seria totalmente contraditório. Ademais, se a capacidade de veto tivesse maior alcance que a capacidade de consentir, também se chegaria ao paradoxo de que a capacidade de negar uma medida médica seria anterior à capacidade para aceitá-la. ${ }^{1073}$

Se o menor é incapaz de consentimento, cabe aos pais unicamente o direito de concedê-lo ou não ao tratamento médico. Essa competência de consentimento que substitui a vontade do menor provém do ato deste ainda não estar em condição de verificar

1071 SCHWAB, Dieter. In Münchener Kommentar zum Bürgerlichen Gesetzbuch. v. 9. Op. Cit., §1901 BGB Rn. 20 e $§ 1902$ BGB, Rn. 16. 1072 GLEIXNER-EBERLE, Elisabeth. Die Einwilligung in die medizinische Behandlung Minderjähriger. Op. Cit., p. 324.

${ }^{1073}$ Ibidem, p. 324. 
e sopesar as vantagens e desvantagens da realização ou não do tratamento. ${ }^{1074}$

É verdade que os pais devem exercer o cuidado familiar em consonância com o bem-estar de seu filho. Para tanto, ao conduzir a criação e educação, eles devem considerar a crescente necessidade e capacidade do menor em vista de uma conduta autônoma e responsável e conversar com seu filho sobre as questões atinentes ao cuidado familiar, conforme seu grau de amadurecimento, para buscar sempre uma decisão harmônica. ${ }^{1075}$

Sustenta DÖLL ${ }^{1076}$ que a disposição do legislador no $§ 1626$ do BGB no sentido de considerar a vontade da criança não significa que os pais estejam condicionados a decidir de acordo com essa vontade. $\mathrm{Na}$ verdade, o que buscou o legislador foi que as questões relacionadas às crianças devem ser resolvidas por meio de conversa entre elas e seus pais, com discussão das vantagens e desvantagens para somente após se tomar uma decisão, dentro do possível, harmônica. Entretanto, se isso não for possível, os pais devem ${ }_{1075}^{1074}$ Ibidem, p. 324.

1075 §1626 BGB: "Elterliche Sorge, Grundsätze - (2) Bei der Pflege und Erziehung berücksichtigen die Eltern die wachsende Fähigkeit und das wachsende Bedürfnis des Kindes zu selbständigem verantwortungsbewusstem Handeln. Sie besprechen mit dem Kind, soweit es nach dessen Entwicklungsstand angezeigt ist, Fragen der elterlichen Sorge und streben Einvernehmen an."

${ }^{1076}$ In Erman - Bürgeliches Gesetzbuch. Op. Cit., pp. 5136-5137 1626, Rn. 25, p. 2141. 
decidir inclusive contra a vontade do menor, conforme sua responsabilidade.

É essencial frisar que a vontade da criança é um dos aspectos a serem considerados no processo de tomada de decisão. Ela deve ser valorizada como um dos elementos da valoração do bem-estar do menor. ${ }^{1077}$ Se a vontade da criança for no sentido de vetar o procedimento, essa é apenas uma das circunstâncias a serem levadas em conta pelos pais. Estes ainda deverão analisar todas as outras circunstâncias que envolvem os tratamentos médicos, quais sejam, riscos, chances de sucesso, urgência da intervenção, entre outros. $\mathrm{Na}$ ponderação de todos esses aspectos, também se deve valorar a vontade da criança conforme sua maturidade. ${ }^{1078}$

Enquanto incapazes, apenas aos pais se reconhece a competência para decidir. Eles devem se orientar pelos critérios da gravidade, urgência e perigo do procedimento médico, bem como ponderar as consequências de uma eventual omissão do tratamento.

Todavia, o menor com crescente maturidade deve ser chamado para participar do processo de decisão de seus representantes legais.

1077 Sobre maiores detalhes sobre a relação entre a vontade da criança e seu bem-estar, cf. ZITELMANN, Maud, Kindeswohl und Kindeswillen im Spannungsfeld von Pädagogik und Recht, Votum, Münster, 2001, pp. 166171.

${ }^{1078}$ GLEIXNER-EBERLE, Elisabeth. Die Einwilligung in die medizinische Behandlung Minderjähriger. Op. Cit., p. 325. 
O objetivo de criação e educação dos filhos menores é proporcionarlhes o desenvolvimento para uma personalidade autorresponsável. Disso decorre que a vontade da criança deve ser observada na concretização de seu bem-estar. ${ }^{1079}$ Para tanto é essencial que o menor seja informado, ouvido e tenha oportunidade de expressar seus desejos. ${ }^{1080}$ Sua vontade séria e bem articulada deve ser considerada no processo de decisão dos pais, ainda que se trate de menor incapaz de consentir. ${ }^{1081}$

Os pais não devem impedir o esforço dos filhos em se tornarem autônomos, pois isso poderia até significar prejuízo ao seu bemestar. A criança não deve ser reduzida a objeto do poder de decisão dos pais. Isso contraria a dignidade e personalidade da criança. ${ }^{1082}$ Contraria, ainda, o próprio escopo do cuidado do poder familiar, que é fomentar o desenvolvimento de uma personalidade autorresponsável.

Por fim, a Lei dos Direitos do Paciente da Alemanha não fez referência expressa ao direito de veto dos menores. De uma leitura

1079 ZITELMANN, Kindeswohl und Kindeswille (cit.), pp. 166-170.

${ }^{1080}$ ROTHÄRMEL, Sonja. Einwilligung, Veto, Mitbestimmung. Op. Cit., pp. 195-196.

${ }^{1081}$ GLEIXNER-EBERLE, Elisabeth. Die Einwilligung in die medizinische Behandlung Minderjähriger. Op. Cit., p. 326.

1082 COESTER, Michael. Elternautonomie und Staatsverantwortung bei der Pflege und Erziehung von Kindern. Op. Cit., pp. 1181-1182. 
sistemática de seus parágrafos, conclui-se que o menor incapaz de consentimento deve ser informado de forma plena e compreensível. Entretanto, essa informação não é requisito de eficácia para o consentimento a ser dado pelos seus pais. ${ }^{1083}$

\subsection{Menores capazes de consentir}

Partindo da capacidade de consentimento de alguns menores, a doutrina discute sobre a possibilidade de esses celebrarem o contrato diretamente com o médico, sem necessidade do consentimento de seus pais. Sustentam os doutrinadores que reconhecer a capacidade de consentir dos menores de um lado e negar-lhes a possibilidade de celebrar o contato médico de outro, significaria uma violação de seu direito de autodeterminação. Entretanto, essa discussão ainda não tomou corpo e a jurisprudência alemã não reconhece essa possibilidade. ${ }^{1084}$ A competência para dispor de bens jurídicos

1083 GLEIXNER-EBERLE, Elisabeth. Die Einwilligung in die medizinische Behandlung Minderjähriger. Op. Cit., p. 325.

${ }^{1084}$ RUMETSCH, Virgilia. Medizinische Eingriffe bei Minderjährigen. Op. Cit., pp. 41-43; GLEIXNER-EBERLE, Elisabeth. Die Einwilligung in die medizinische Behandlung Minderjähriger. Op. Cit., p.383; BÖHMKER, Daniela. Die Entscheidungskompetenz des minderjährigen Patienten in der medizinischen Behandlung. Op. Cit., p. 36; REIPSCHLÄGER, Christiane. Die Einwilligung Minderjähriger in ärztliche Heileingriffe und die elterliche Personensorge. Op. Cit., pp. 188-189; ROUKA, Stella. Das 
personalíssimos somente encontra justificativa quando seu titular não apresenta capacidade de consentimento. ${ }^{1085}$

$\mathrm{Na}$ sequência da apresentação dos princípios que valem para o exercício do cuidado familiar em relação aos menores incapazes de consentimento, passa-se a abordar, agora, como essa competência na decisão para tratamentos médicos se altera, na medida em que o menor se torna cada vez mais capaz de tomar decisões autônomas e preenche as condições da capacidade de consentimento, por meio do avanço da idade e da aquisição de maturidade. Nesse ponto surge uma relação de tensão entre a capacidade de autodeterminação crescente do menor e o cuidado familiar no que diz respeito à determinação da competência para decidir sobre uma intervenção médica.

Considerando que o menor é o titular do bem jurídico atingido pela intervenção, a autorização dos pais sobre a realização dessa intervenção deve ser limitada, não sendo plausível forçar o menor a se submeter a uma medida contra sua vontade em vista de sua capacidade cada vez mais desenvolvida para alcançar uma decisão baseada na razão. ${ }^{1086}$ Admitir um direito unilateral dos pais, como

Selbstbestimmungsrecht des Minderjährigen bei ärztlichen Eingriffen. Op. Cit., pp. 148-149.

1085 REIPSCHLÄGER, Christiane. Die Einwilligung Minderjähriger in ärztliche Heileingriffe und die elterliche Personensorge. Op. Cit., p. 141.

${ }^{1086}$ Ibidem, p. 141. 
existe no caso dos menores incapazes de consentimento, seria inconciliável com a importância da integridade corporal como bem jurídico protegido pelo direito fundamental de liberdade. ${ }^{1087}$

Se o paciente menor for capaz de consentimento, conforme os critérios descritos para averiguar a existência dessa capacidade, a doutrina não é unânime em admitir a competência deste para decidir sozinho ou se ainda necessita do consentimento de seus pais. Sobre esse ponto existem três posições. A doutrina civil majoritária defende a competência do menor capaz de consentimento para consentir sozinho. ${ }^{1088}$ De acordo com essa posição, o tratamento médico é justificado pela decisão autônoma do menor, sem haver necessidade do consentimento conjunto de seus genitores. Nesse

1087 WÖLK, Florian. Der minderjährige Patient in der ärztliche Behandlung. Op. Cit., pp. 80-82.

1088 DEUTSCH, Erwin; SPICKHOFF, Andreas. Medizinrecht. Azrtrecht, Arzneimittelrecht, Medizinproduktrecht und Transfusionsrecht. Op. Cit., p. 789; TAUPITZ, Jochen. Empfehlen sich zivilrechtliche Regelungen zu Absicherung der Patientenautonomie am Ende des Lebens? Op. Cit., A 64 ss.; WÖLK, Florian. Der minderjährige Patient in der ärztliche Behandlung. Op. Cit., pp. 80 e 82; LINK, Ihna. Schwangerschaftsabbruch bei Minderjährigen. Op. Cit., p. 141; DÖLL, Yves. In Erman - Bürgeliches Gesetzbuch. Op. Cit., pp. 5136-5137§1626 BGB, Rn. 3, Rn. 16; HUBER, Peter. In Münchener Kommentar zum Bürgerlichen Gesetzbuch. v. 8. Op. Cit., §1626 BGB, Rn. 41, 42; 43; GOLBS, Ulrike. Das Vetorecht eines einwilligunsunfähigen Patienten. Op. Cit., pp. 88-90; ROUKA, Stella. Das Selbstbestimmungsrecht des Minderjährigen bei ärztlichen Eingriffen. Op. Cit., p. 142; BELLING, Detlev; EBERL, Christina; MICHILIK, Frank. Das Selbstbestimmungsrecht Minderjähriger bei medizinischen Eingriffen. Op. Cit., p.136. 
passo, o menor capaz de consentimento pode consentir num procedimento não desejado por seus pais ou recusar um procedimento por eles querido.

A doutrina dominante apoia-se no direito personalíssimo da integridade física. $\mathrm{O}$ consentimento em intervenções médicas atinge bens jurídicos da personalidade, os quais exigem a mais alta medida de autodeterminação. No campo dos direitos personalíssimos é desejável que esta prevaleça sobre a determinação alheia, a qual seria incompatível com a defesa desses bens jurídicos.

Contrariamente a essa posição, uma parte minoritária da doutrina defende a competência apenas dos pais, apesar dos menores serem capazes de consentimento. ${ }^{1089}$ Como consequência dessa concepção, sustenta-se que os pais, de um lado, por meio da recusa de seu consentimento, poderiam impedir a legitimidade de uma intervenção médica desejada pelo menor e, de outro lado, poderiam consentir em uma intervenção não querida pelo menor.

Os adeptos de tal concepção defendem que esse entendimento não feriria o direito da personalidade do menor, uma vez que este poderia recorrer ao Poder Judiciário caso entendesse que o consentimento dos pais fosse contrário ao seu bem-estar. Ademais,

${ }^{1089}$ WENDTLAND, Holger. In BAMBERGER, Heinz Georg; ROTH, Herbert (Coord.). Kommentar zum Bürgerlichen Gesetzbuch. v. 1. Op. Cit., §107, Rn. 2. 
acredita-se que não haveria interferência do direito de cuidado dos pais no direito de autodeterminação do menor, pois se houver abuso ou negligência por parte dos pais, excepcionalmente seria admitido um consentimento do menor capaz. ${ }^{1090}$

A terceira concepção defende uma competência cumulativa de consentimento do menor capaz de consentir e de seus pais. ${ }^{1091}$ Ainda que os adeptos dessa concepção concordem sobre a necessidade do consentimento cumulativo, eles se dividem quanto ao fundamento do entendimento.

Alguns defendem, em princípio, que o menor capaz de consentimento tem competência para decidir sozinho, mas, para determinadas intervenções, seria necessário também o consentimento de seus genitores. O critério para a exigência do consentimento complementar dos pais seria o grau de gravidade do

${ }^{1090}$ WENDTLAND, Holger. In BAMBERGER, Heinz Georg; ROTH, Herbert (Coord.). Kommentar zum Bürgerlichen Gesetzbuch. v. 1. Op. Cit., $\$ 107$, Rn. 2

1091 REIPSCHLÄGER, Christiane. Die Einwilligung Minderjähriger in ärztliche Heileingriffe und die elterliche Personensorge. Op. Cit., p. 154; NEBENDAHL, Mathias. Selbstbestimmungsrecht und rechtfertigende Einwilligung des Minderjährigen bei medizinischen Eingriffen. Frankfurt: Springer, 2009. pp.197 e 202; OLZEN, Dirk. In Münchener Kommentar zum Bürgerlichen Gesetzbuch. v. 9. Op. Cit., §1666, Rn. 78, p. 1005; DUTTGE, Gunnar. Patientenautonomie und Einwilligungsfähigkeit. Op. Cit., pp. 80-81. 
procedimento médico, que justificaria a necessidade de proteção do menor. $^{1092}$

Nesse sentido, FLUME ${ }^{1093}$ sustenta que, para intervenções insignificantes, bastaria o consentimento do menor capaz. Contudo, em caso de intervenções mais importantes, seria necessário o consentimento também de seus genitores, quando esse consentimento pudesse ser tomado sem perigo. Nesse caso, o consentimento dos pais tem prevalência sobre o do menor, caso aqueles não queiram a execução da intervenção médica. Porém, se a recusa representar uma negligência do dever de cuidado, então o Poder Judiciário deverá ser acionado. Em não havendo tempo para buscar uma medida judicial, o consentimento do menor deverá ser suficiente.

REIPSCHLÄGER ${ }^{1094}$ exige o consentimento dos pais juntamente com o do menor independentemente de a intervenção ser grave ou urgente, para haver uma transição segura entre a determinação alheia e a autodeterminação. Nesse sentido, o consentimento do menor somente produzirá efeitos quando houver,

1092 HUBER, Peter. In Münchener Kommentar zum Bürgerlichen Gesetzbuch. v. 8. Op. Cit., §1626 BGB, Rn. 41; DUTTGE, Gunnar. Patientenautonomie und Einwilligungsfähigkeit. Op. Cit., p. 81.

${ }^{1093}$ Allgemeiner Teil des bürgerlichen Rechts: Das Rechtsgeschäft. v. 2.4 ed. Berlin: Springer, 1992. pp. 219-220.

${ }^{1094}$ Die Einwilligung Minderjähriger in ärztliche Heileingriffe und die elterliche Personensorge. Op. Cit., pp. 155-157. 
também, o consentimento de seus pais. A autora parte da analogia do consentimento para pesquisas clínicas de medicamentos, de forma que essas pesquisas serviriam de modelo para procedimentos perigosos, em relação aos quais o menor necessitaria de maior proteção.

Essa concepção, portanto, julga necessária a cumulação de consentimentos para que a intervenção médica seja justificada. Tal exigência produz efeitos para a relação externa com o médico e significa que a licitude da intervenção depende de ambos os consentimentos. Assim, ainda que o menor não possa consentir sozinho numa intervenção, pode ele apresentar uma recusa perante uma intervenção desejada por seus pais, haja vista que ambos os consentimentos são requisitos da licitude do procedimento médico. $^{1095}$

Diante desse panorama, conclui-se que a melhor concepção é aquela defendida pela maioria da doutrina, ou seja, de reconhecer a competência do menor capaz de consentimento para decidir sozinho.

Existe aqui uma relação de tensão entre $\mathrm{o}$ direito de autodeterminação do menor e o direito de cuidado dos pais, ambos garantidos constitucionalmente. Paralelamente, ainda se fala na necessidade de proteção do menor.

1095 GLEIXNER-EBERLE, Elisabeth. Die Einwilligung in die medizinische Behandlung Minderjähriger. Op. Cit., p. 338. 
É verdade que o menor, em vista de sua imaturidade e falta de experiência, tome decisões que produzam efeitos sobre os quais ele não havia pensado. Sendo assim, um aspecto essencial a ser considerado no tema da competência de consentir é a necessidade de proteção do menor. ${ }^{1096}$ Sob esse aspecto, a concepção da dupla competência busca encontrar um equilíbrio entre o direito de autodeterminação, de um lado, e a necessidade de proteção, de outro, com a consequência de que o menor poderia recusar uma intervenção médica de forma eficiente, ainda que não pudesse nela consentir sozinho. ${ }^{1097}$

Disso se conclui que essa posição apresenta uma incoerência no sentido de reconhecer autodeterminação ao menor apenas no sentido negativo, pois somente a recusa da intervenção médica seria dotada de efeito vinculante. Ademais, essa posição peca por não garantir efetivamente proteção ao menor, uma vez que, ao reconhecer eficácia à sua recusa, esta também valeria em casos de intervenções vitais para a saúde do menor. ${ }^{1098}$

1096 Ibidem, p. 340.

1097 REIPSCHLÄGER, Christiane. Die Einwilligung Minderjähriger in ärztliche Heileingriffe und die elterliche Personensorge. Op. Cit., p. 149. 1098 NEBENDAHL, Mathias. Selbstbestimmungsrecht und rechtfertigende Einwilligung des Minderjährigen bei medizinischen Eingriffen. Op. Cit., pp. 197 e 204. 
Também a concepção da competência unilateral dos pais tem por escopo a proteção ao menor. Entretanto, pode-se argumentar sustentando que o menor capaz de consentimento não necessita mais da determinação alheia. Se ele é maduro o suficiente para que the seja reconhecida a capacidade de consentimento, a necessidade de proteção não mais se justifica. A autodeterminação alheia advém do princípio da assistência e deve valer até onde não se verifica a capacidade de autodeterminação. ${ }^{1099}$ Nesse passo, a doutrina discute como encontrar um equilíbrio entre o direito de autodeterminação e o direito de cuidado familiar, considerando que ambos são previstos na Constituição Federal.

Não há dúvida de que os menores são titulares dos direitos fundamentais, sendo certo que o legislador teve como objetivo fortalecer a posição do menor como titular desses direitos, os quais devem ser limitados apenas no que diz respeito à necessidade de proteção do menor fosse justificada.

O modelo de pessoa traçado na Constituição estabelece que se atribua mais consideração à crescente maturidade e capacidade de autodeterminação do menor. Como a capacidade de consentimento não corresponde necessariamente à capacidade de agir, pode

1099 WÖLK, Florian. Der minderjährige Patient in der ärztliche Behandlung. Op. Cit., pp. 80-84; GOLBS, Ulrike. Das Vetorecht eines einwilligunsunfähigen Patienten. Op. Cit., p. 89. 
acontecer que um menor capaz para consentir ainda não o seja para realizar os negócios da vida civil ou tenha capacidade de agir limitada, ou seja, em questões atinentes aos direitos da personalidade, o direito de autodeterminação encontra primazia. ${ }^{1100}$

Como exposto supra, ${ }^{1101}$ o cuidado familiar não revela um fim em si mesmo, não se trata de um direito egoísta dos pais, mas, sim, visa ao bem-estar do filho e é, por isso, um direito fiduciário, baseado na fides, ou seja, na confiança. Autorizações e consentimento dos pais existem e são necessárias apenas enquanto a capacidade da criança está em processo de desenvolvimento. ${ }^{1102}$

Assim, considerando que o direito de cuidado familiar deve ser exercido no interesse do menor, o qual deve ser conduzido à formação de uma personalidade autônoma, autodeterminada e responsável, deve-se concluir que o direito de cuidado familiar deve retroceder, à medida que o menor avança para a autodeterminação. ${ }^{1103}$

Dessa forma, direito de autodeterminação e direito de cuidado familiar estão em relação de proporcionalidade inversa: à medida em

${ }^{1100}$ GLEIXNER-EBERLE, Elisabeth. Die Einwilligung in die medizinische Behandlung Minderjähriger. Op. Cit., p. 343.

\footnotetext{
${ }^{1101}$ Item 7.1.1.

1102 GLEIXNER-EBERLE, Elisabeth. Die Einwilligung in die medizinische Behandlung Minderjähriger. Op. Cit., pp. 344-345.

1103 BELLING, Detlev; EBERL, Christina; MICHLIK, Frank. Das Selbstbestimmungsrecht Minderjähriger bei medizinischen Eingriffen. Op. Cit., p. 123; ULSENHEIMER, Klaus. §139 Die fahrlässige Körperverletzung. In LAUFS, Adolf; UHLENBRUCK, Wilhelm. Handbuch des Arztrechts. Op. Cit., Rn. 32, p. 1251.
} 
que o menor alcança maior maturidade e capacidade de autodeterminação, o cuidado familiar se distancia até se dissolver. A direção de vida inerente ao cuidado familiar deve se afastar quanto mais o menor ganha em autodeterminação. ${ }^{1104}$

Alguns sustentam que haveria uma situação de conflito entre a competência de consentimento dos pais e a competência de consentimento do menor. Mas essa observação é objetada com o argumento de que não há conflito, uma vez que se o menor é capaz de consentimento, apenas ele deve ser competente para expressá-lo e a autorização dos pais consentirem junto com ele ou por ele deve ser excluída. $^{1105}$

Entretanto, essa solução não se mostra como a mais adequada no caso dos tratamentos e cirurgias estéticas.

Como visto, por se tratarem de procedimentos sem indicação médica, com dever de informar rigoroso, principalmente se executados em pessoas menores, o dever de cuidado merece especial atenção. Nesse sentido, os países que regulamentaram a prática da cirurgia estética em menores trazem importantes diretrizes, o que se passa a expor.

$\mathrm{Na}$ Áustria, conforme visto, o art. 173 do ABGB presume capazes de consentimento os menores a partir de 14 anos. Por se 1104 BELLING, Detlev; EBERL, Christina; MICHLIK, Frank. Das Selbstbestimmungsrecht Minderjähriger bei medizinischen Eingriffen. Op. Cit., p. 156.

${ }^{1105}$ ROTHÄRMEL, Sonja. Einwilligung, Veto, Mitbestimmung. Op. Cit., p. 125. 
tratar de uma presunção relativa, a norma é aberta para considerar como capazes, até mesmo, pessoas abaixo de 14 anos, conforme o caso concreto, se preenchidos os requisitos para se reconhecer a capacidade de consentimento.

De outro lado, a 80. Bundesgesetz de 14 de agosto de 2012 da Áustria que entrou em vigor em $1^{\circ}$ de janeiro de 2013, proíbe expressamente, em seu $§ 7$ (1) a execução de cirurgia ou tratamento estético em pessoas menores de 16 anos.

A partir de 16 anos e antes que se complete 18 anos, é permitida a execução desses procedimentos sob rigorosas exigências. No $§ 7$ (2), dispõe ser necessário o consentimento das pessoas legitimadas ao dever de educação do menor, em regra, seus genitores, após terem sido exaustivamente esclarecidos pelo médico nos termos do $\S 6$ (2) da mesma lei. Além disso, requer-se também o consentimento do menor, o qual, após abrangente esclarecimento médico, esteja em condição de compreender a essência, significado, extensão e riscos do tratamento ou da cirurgia estética e de determinar sua vontade conforme esse entendimento. Em ambos os casos tanto esclarecimento como consentimento devem ser documentados e comprovados por escrito, conforme $\S 5$ (4) e $\S 6(2)$ da citada lei.

A Itália, por meio da Lei $n^{0} 86$ de 5 de junho de 2012, proibiu implante mamário em menores de 18 anos apenas para fins estéticos. 
Por fim, a Colômbia seguiu na mesma linha, pela Lei ${ }^{0} 1799$ de 25 de julho de 2016, proibindo a realização de procedimentos médicos e cirúrgicos estéticos em pacientes menores de 18 anos, excepcionando-se apenas cirurgias de nariz e orelhas. A lei colombiana chama a atenção para o fato de que nem mesmo o consentimento dos pais poderia constituir uma exceção válida para afastar a referida proibição e legitimar a realização de tais cirurgias em menores de 18 anos.

Esse contexto demonstra a rigidez com que os países estão tratando a questão da cirurgia estética em pessoas menores de idade, ainda que o menor seja considerado capaz de consentimento. A solução austríaca é exigir ambos os consentimentos, tanto dos representantes legais como do menor capaz e as soluções italiana e colombiana são no sentido de simplesmente proibir a prática de tais intervenções médicas. 


\section{CONCLUSÕES}

A temática do consentimento nas intervenções médicas representa um ponto essencial do Direito Médico. Trata-se de instituto jurídico fundamental e que deve ser reconhecido, pois a legitimidade das intervenções médicas, dentre elas, a cirurgia estética, depende do consentimento eficaz do paciente.

$\mathrm{O}$ consentimento tem por fundamento a garantia do direito de autodeterminação e autonomia do paciente, os quais são garantidos constitucionalmente e por meio de convenções internacionais e decorrem do princípio da dignidade da pessoa humana. Tem por pressuposto o esclarecimento médico que deve ser prestado sobre todas as circunstâncias que envolvem a intervenção, a fim de possibilitar ao paciente uma decisão responsável e autodeterminada.

Como visto, a relação médico-paciente é pautada na confiança e parceria, na qual o médico desempenha papel fundamental como profissional e conhecedor das regras técnicas. No caso da cirurgia estética, impera o entendimento de que o dever de esclarecimento médico deve ser o mais amplo possível, incluindo riscos remotos e chances de sucesso, uma vez que se trata de uma intervenção, cujo escopo é apenas melhorar a aparência do paciente. 
Em caso de paciente maior, o tema do consentimento nos tratamentos médicos não oferece grandes dificuldades, uma vez que a maioridade abre a possibilidade de realizar os mais diversos atos da vida civil, inclusive aqueles que dizem respeito às intervenções médicas, que atingem bens jurídicos personalíssimos.

Entretanto, a mesma facilidade não se observa quando se trata de paciente menor. Em relação a eles existem inúmeras dificuldades no que diz respeito ao consentimento a ser dado para a prática de uma intervenção médica. Menores também são titulares de bens jurídicos da personalidade, no caso, a vida, a integridade corporal e a saúde e em relação a eles também deve ser reconhecido o direito de autodeterminação.

Disso decorre que no Direito Médico deve-se reconhecer uma capacidade diferenciada, que é a chamada capacidade de consentimento.

$\mathrm{O}$ ordenamento jurídico brasileiro, assim como o alemão, não possui regulamentações sobre a capacidade de consentimento de menores para intervenções médicas. Conforme exposto, a capacidade de consentimento não deve se pautar pela capacidade de agir, cujas normas dadas pelo Direito Civil não devem ser aplicadas nem mesmo por analogia às questões médicas. 
Nesse sentido, a decisão de 5.12.1958 do Bundesgerichtshof $(B G H)$ na Alemanha foi um marco sobre a capacidade de consentimento dos menores nos tratamentos médicos, pois representou uma renúncia aos limites de idade da capacidade de agir. A partir de então, entendeu-se que a capacidade de consentimento deve ser autônoma e não deve ser determinada apoiando-se nas regulamentações do Código Civil. Além disso, essa decisão do BGH criou uma fórmula, pela qual capacidade de consentimento deve ser entendida como a capacidade de entender a essência, importância e extensão da intervenção médica e determinar-se de acordo com esse entendimento.

Essa fórmula foi bem aceita pela doutrina e jurisprudência alemãs porque ela não envolve todos os detalhes para se reconhecer a existência dessa capacidade, mas deixa certa margem de interpretação, consistindo, assim, uma norma aberta.

Diante da ausência de uma determinação legal dos limites de idade, a capacidade de consentir deve ser analisada em cada caso, conforme a maturidade concreta do menor. É certo que a ausência de limites rígidos de idade causa certa insegurança jurídica no que toca à avaliação da capacidade de consentimento dos menores, temendo os médicos incorrer numa avaliação errônea, o que lhes poderia acarretar alguma responsabilidade jurídica. 
Entretanto, de outro lado, a ausência de determinação legal de limites de idade para se reconhecer a capacidade de consentimento permite a análise de cada caso e, com isso, a concretização do direito de autodeterminação do menor, o qual poderá ser reconhecido como capaz para manifestar seu consentimento em relação a uma dada intervenção médica, independentemente de sua idade.

$\mathrm{Na}$ verdade, a avaliação da capacidade de consentimento não é tarefa fácil. Para tanto, a doutrina sugere alguns critérios, que não são exclusivos, mas devem servir como parâmetros para essa avaliação. Ademais, as concepções não jurídicas da capacidade de consentimento também devem ser consideradas pelos tribunais e classe médica, pois possibilitam uma ponderação mais ampla e completa.

As idades sugeridas de 14 ou 16 anos também não contam com unanimidade. Como visto, no Brasil, são vários os atos da vida civil que os menores podem praticar, principalmente a partir dos 16 anos, o que serve de indício para demonstrar que a capacidade de consentimento deve ser reconhecida antes mesmo de se chegar à maioridade.

Diante desse contexto, em que se deve reconhecer a capacidade de consentimento dos menores em relação às intervenções médicas, 
mister trazer uma reflexão a respeito das cirurgias meramente estéticas.

Como foi apresentado, o Brasil figura como um dos países onde mais se pratica esse tipo de cirurgia, inclusive entre menores. Por não haver uma regulamentação legal específica sobre o tema, por ora basta o consentimento dos pais, aliado ao entendimento médico, para que a cirurgia seja executada de forma legítima.

Temerária pelos efeitos, muitas vezes funestos dessas cirurgias, recentemente, em 25 de julho de 2016, a Colômbia aprovou uma lei que proíbe a cirurgia estética em menores de idade, ressalvando apenas a cirurgia de nariz e orelha. Ainda, ressaltou que nem mesmo o consentimento dos pais do menor é suficiente para afastar essa proibição legal.

A Áustria, país que reconhece a capacidade de consentimento dos menores em princípio a partir dos 14 anos, por meio de uma presunção que permite até mesmo o reconhecimento dessa capacidade para pessoas mais jovens, aprovou, em 2012, uma lei que pró́be a prática de cirurgia meramente estética em pessoas menores de 16 anos. Em relação àquelas entre 16 e 18 anos a lei exige diversas condições para que a cirurgia possa ser executada de forma regular. 
A Itália não ficou atrás e aprovou, também 2012, uma lei que proíbe implantes mamários em pessoas menores.

Esse cenário mundial acena a preocupação de alguns países com o crescimento desmedido de cirurgias estéticas em menores e a gravidade do tema, diante de possíveis consequências prejudiciais à sua saúde.

Se de um lado, deve-se reconhecer a capacidade de consentimento dos menores em relação às intervenções médicas, de outro, há mesmo que se fazer uma distinção entre as intervenções médicas tradicionais que promovem a saúde, daquelas intervenções que promovem pura e simplesmente a aparência e o embelezamento.

Nesse sentido, o maior rigor no dever de esclarecimento médico em relação às cirurgias estéticas, aliado ao maior rigor na avaliação da capacidade de consentimento dos menores por se tratar de intervenções sem indicação médica, de fato deve ser observado.

Entretanto, talvez o contexto mundial de prática de cirurgias estéticas demonstre que apenas maior rigidez em relação a esses aspectos não esteja sendo suficiente para evitar que pessoas menores se submetam a cirurgias que, ainda que the proporcionem o almejado sucesso, também lhes causarão danos à saúde, quiçá apenas psicológicos. 
Por se tratarem de pessoas em desenvolvimento, tanto psíquico como corporal, e por se tratar de uma intervenção médica que interferirá diretamente sobre ambos os aspectos, deixa-se aqui a reflexão para saber qual a melhor solução a ser adotada, tudo em prol da integral proteção que os menores devem receber, em prol, ainda, da garantia de um efetivo desenvolvimento de sua personalidade, pautado pelo seu bem-estar, para se tornarem pessoas autodeterminadas e responsáveis. 


\section{LISTA DE REFERÊNCIAS}

AGUIAR JR, Ruy Rosado de. Responsabilidade civil do médico. RT. São Paulo: Revista dos Tribunais. n. 718, pp. 33-53, agosto de 1995.

ALARCÃO, Rui de. A confirmação dos negócios anuláveis. Coimbra: Atlântida, 1971.

ALBERTINI, Ralph S., PHILLIPS, Katharine A. Thirty-three cases of body dysmorphic disorder in children and adolescents. Journal of the American Academy of Child \& Adolescent Psychiatry's, n. 38 (4), pp. 453-459, abril de 1999.

ALBUQUERQUE, Catarina. Os Direitos da Criança: as Nações Unidas, a Convenção e o Comité. In Boletim Documentação e Direito Comparado. nn. 83/84. Lisboa, Gabinete de Documentação e Direito Comparado, p. 27, 2000.

ALDERSON, Priscilla. Listening to children: ethics and social research. Barkingside: Barnardo's, 1995.

ALDERSON, Priscilla. Research with children: perspectives and practices, 2000. Trad. Port. A. François e F. Müller. As crianças como pesquisadoras: os efeitos dos direitos de participação sobre a metodologia de pesquisa. In Educação \& Sociedade. v. 26, n. 91. Campinas: Centro de Estudos Educação e Sociedade, p. 419, 2005.

ALDERSON, Priscilla. Children's consent to surgery. Buckingham: Open University Press, 1993. 
ALDERSON, Priscilla. Die Autonomie des Kindes - über die Selbstbestimmungsfähigkeit von Kindern in der Medizin. In WIESEMANN, Claudia; DÖRRIES, Andrea; WOLFSLAST, Gabriele; SIMON, Alfred (Coord.). Das Kind als Patient Ethische Konflikte zwischen Kindeswohl und Kindeswille. Frankfurt: Campus, 2003.

ALEXY, Robert. Theorie der grundrechte, 1986. Trad. esp. C. B. Pulido. Teoría de los derechos fundamentales. 2 ed. Madrid: Centro de Estudios Políticos y Constitucionales, 2014.

ALMEIDA COSTA, Mário Júlio. Direito das Obrigações. 7 ed. Coimbra: Almedina, 1999.

. Direito das obrigações. 9 ed., Coimbra: Almedina, 2001.

ALVES, Gláucia Correa R. Barcelos. Sobre a dignidade da pessoa. In MARTINS-COSTA, Judith (org.). A reconstrução do direito privado. São Paulo: Revista dos Tribunais, 2002.

AMARAL, Francisco. Direito Civil: Introdução. 7 ed. Rio de Janeiro: Renovar, 2008.

AMELUNG, Knut Über die Einwilligungsfähigkeit (Teil II). Zeitschrift für die gesamte Strafrechtswissenschaft. v. 104 (3), pp. 821; 833, janeiro de 1992 .

- Die Einwilligung zwischen medizinischer Erfahrung, amerikanischer Ethik unf kulturellem Gedächtnisverlust; Bemerkingen zu Vollmann, Aufklärung und Einwilligung in der Psychiatrie. Frankfurt: Springer, 2000. 
. Über die Einwilligungsfähigkeit (Teil I). Zeitschrift für die gesamte Strafrechtswissenschaft. v. 104 (3), pp. 525-558, janeiro de 1992.

Vetorechte beschränkt Einwilligungsfähiger in Grenzbereichen medizinischer Intervention. Berlin: Walter de Gruyter, 1995.

AMERICAN ACADEMY OF PEDIATRICS. Committee on Bioethics. Informed consent, parental permission, and assent in pediatric practice. Pediatrics. v. 95, pp. 314-317, fevereiro de 1995.

ANDRIGHI, Fátima Nancy. Responsabilidade civil na cirurgia estética. Brasília, 2006. p. 1. Disponível em: $<$ http://bdjur.stj.jus.br/jspui/bitstream/2011/2278/Responsabilidade_ Civil_Cirurgia.pdf $>$. Acesso em: 13 out. 2016.

ANTUNES VARELA, João de Matos. Das obrigações em geral. v. 1. 10 ed. Coimbra: Almedina, 2008.

ARZT, Gunther. Die Aufklärungspflicht des Arztes aus strafrechtlicher Sicht. In WIEGAND, Wolfgang (Coord.). Arzt und Recht. Bern: BJTP, 1985.

ÁVILA, Humberto Bergmann. Teoria dos princípios: Da definição à aplicação dos princípios jurídicos. 4 ed. São Paulo: Malheiros, 2005 .

AZEVEDO, Antônio Junqueira de. Estudos e pareceres de direito privado. São Paulo: Saraiva, 2004.

Negócio Jurídico: existência, validade e eficácia. 4 ed. São Paulo: Saraiva, 2010. 
BARTMANN, Peter. Selbstbestimmung und Selbsvertretung im Gesundheitswesen. In BARTMANN, Peter; HÜBNER, Ingolf (Coord.). Patientenselbsbestimmung. Paradigmenwechsel und Herausforderung in Gesundheitswesen. Neukirchen-Vluyn, 2002.

BEAUCHAMP, Tom L.; CHILDRESS, James F. Principles of Biomedical Ethics. 5 ed. New York: Oxford University Press, 2001.

BECHER, Eugen. Der Persönlichkeitsschutz beim ärztlichen Handeln. In WIEGAND, Wolfgang (Coord.). Arzt und Recht. Bern: BJTP, 1985.

BELINI, Marcelo Manechine. A razão áurea e a sequência de Fibonacci. Dissertação de mestrado apresentada ao Instituto de Ciências Matemáticas e de Computação da Universidade de São Paulo. Orientador: Prof. Assoc. Márcio Fuzeto Gameiro. São Carlos, 2015.

BELliNG, Detlev; EBERL, Christina; MICHILIK, Frank. Das Selbstbestimmungsrecht Minderjähriger bei medizinischen Eingriffen. Berlin: Luchterhand, 1994.

BENACCHIO, Marcelo. Responsabilidade civil do médico. In NERY, Rosa Maria de Andrade; DONNINI, Rogério (coord.). Responsabilidade civil: Estudos em homenagem ao professor Rui Geraldo Camargo Viana. São Paulo: Revista dos Tribunais, 2009. pp. 320-349.

BERRIOS, German E. The History of Mental Symptons: Descriptive Psychopathology Since Nineteenth Century. Cambridge: Cambridge University Press, 1996. p. 227. Disponível 
em: $<$ https://books.google.com.br/books?id=XSD_ucVR3E8C\&pg= PA277\&redir_esc $=\mathrm{y} \# \mathrm{v}=$ onepage \&q\&f$=$ false $>$.

BETTI, Emilio. Teoria generale del negozio giuridico. 2 ed. Torino: UTET, 1960.

BEVILAQUA, Clóvis. Código Civil dos Estados Unidos do Brasil comentado. v. 4. Rio de Janeiro: Francisco Alves, 1958.

BJORNSSON, Andri S., DIDIE, Elizabeth R., PHILLIPS, Katharine A., Body dysmorphic disorder. Dialogues in Clinical Neuroscience, Paris, n. 12(2), pp. 221-232, jun. 2010.

BLACK, Donald W.; GRANT, Jon E., DSM-5 Guidenbok, 2014. Trad. Port. Janisa S. Antoniazzi, Evelyn Tesche, Gabriel Rios Borges (et. all). Guia para o DSM-5: complemento essencial para o manual diagnóstico e estatístico de transtornos mentais. Disponível em

$<$ http://books.google.com/books?id=PJs7BgAAQBAJ\&pg=PA153>. Acesso em: 23 set. 2016

BÖHMKER, Daniela. Die Entscheidungskompetenz des minderjährigen Patienten in der medizinischen Behandlung. Frankfurt: Peter Lang, 2014.

BREDIN, Hugh; SANTORO-BRIENZA, Liberato. Philosophies of Art and Beauty: Introducing Aesthetics. Edinburgh: Edinburgh University Press, 2000.

BRÜCKNER, Sarah. Das medizinische Selbstbestimmungsrecht Minderjähriger. Marburg: Tectum, 2014. 
BUARQUE DE HOLANDA, Aurélio. Novo Dicionário Aurélio da Língua Portuguesa. 2 ed. Rio de Janeiro: Nova Fronteira, 1986.

. Mini Aurélio: o dicionário da língua portuguesa. 8 ed. Curitiba: Positivo, 2010.

BUCHER, Eugen. Die Ausübung der Persönlichkeitsrecht, insbesondere: Die Persönlichkeitsrechte des Patienten als Schranken der ärztlichen Tätigkeit. Zürich: Diss, 1956.

BUYX, Alena; HUCKLENBROICH, Peter. Wunscherfüllende Medizin und Krankheitsbegriff: Eine medizinische Analyse. In KETTNER, Matthias (coord.). Wunscherfüllende Medizin Ärztliche Behandlung im Dient von Selbstverwirklichung und Lebensplanung. Frankfurt: Campus, 2009.

CALDAS AULETE, Francisco Júlio. Dicionário contemporâneo da língua portuguesa. v. 1.3 ed. Lisboa: Sociedade Industrial de Tipografia, 1948.

. Dicionário contemporâneo da língua portuguesa. v. 2, 3 ed.. Lisboa: Sociedade Industrial de Tipografia, 1948.

CANÇADO TRINDADE, Antônio Augusto. Tratado de direito internacional dos Direitos Humanos. v. 1. 2 ed. Porto Alegre; Fabris, 2003.

CHAMMARD, Georges Boyer; MONZEIN, Paul. La responsabilité medicale. Paris: Presses Universitaires de France, 1974.

CHAVES, Antônio. Tratado de Direito Civil. v. 2. t. I. 3 ed. São Paulo: Revista dos Tribunais, 1984. 
COESTER, Michael. Elternautonomie und Staatsverantwortung bei der Pflege und Erziehung von Kindern. Zeitschrift für das gesamte Familienrecht. v. 43 (19), pp. 1181-1187, 1996.

COLUCCI, Camila Fernanda Pinsinato. Princípio do melhor interesse da criança: construção teórica e aplicação prática no direito brasileiro. Dissertação de mestrado (Orientador: Eduardo Tomasevicius Filho). São Paulo: Faculdade de Direito da Universidade de São Paulo, 2014.

COMPARATO, Fábio Konder. A afirmação histórica dos direitos humanos. 8 ed. São Paulo: Saraiva, 2013.

COMPARATO, Fábio Konder. Obrigações de meios, de resultado e de garantia. In TEPEDINO, Gustavo, FACHIN, Luiz Edson (org.). Doutrinas essenciais: Obrigações e contratos. v. 1. São Paulo: Revista dos Tribunais, 2011.

CORREA, Alexandre; SCIASCIA, Gaetano. Manual de direito romano. v. 1.1 ed. São Paulo: Saraiva, 1949.

COUTO E SILVA, Clóvis Veríssimo do. A obrigação como processo. Rio de Janeiro: FGV, 2006.

CRERAND, Canice E.; PHILlIPS, Katharine A.; MENARD, William; FAY, Christina. Nonpsychiatric Medical Treatment of Body Dysmorphic Disorder. Psychosomatics, n. 46(4), pp. 549-555, 2005.

Disponível

em:

$<$ http://www.psychosomaticsjournal.com/article/S0033-

3182(05)70040-2/pdf>. Acesso em: 23 set. 2016.

DANTAS, Eduardo; COLTRI, Marcos Vinícius. Comentários ao Código de Ética Médica. Rio de Janeiro: GZ, 2010. 
DERNBURG, Heinrich. Pandekten. v. 3. 6 ed., 1900. Trad. It. F. B. Cicala. Diritto delle Obrigazioni. Torino: Fratelli Bocca, 1903.

DEUTSCH, Erwin; SPICKHOFF, Andreas. Medizinrecht. Azrtrecht, Arzneimittelrecht, Medizinproduktrecht und Transfusionsrecht. 7 ed. Heidelberg: Springer, 2014.

DEUTSCHE AKADEMIE FÜR KINDER- UND JUGENDMEDIZIN. Begrenzung lebenserhaltender Therapie im Kindes- und Jugendalter. Disponível em: $<$ http://www.dakj.de $>$. Acesso em: 17 out. 2016.

DIERKS, Christian; GRAF-BAUMANN, Toni; LENARD, HansGerd. Therapieverweigerung bei Kindern und Jugendlichen. Frankfurt: Springer, 1995.

DOLLINGER, Jacob. Dignidade: o mais antigo valor da humanidade. In PIOVESAN, Flávia; GARCIA, Márcia (org.). Doutrinas essenciais: Direitos humanos. v. 1. São Paulo: Revista dos Tribunais, 2011.

DÖRRIES, Andrea. Zustimmung und Veto. Aspekte der Selbstbestimmung im Kindesalter. In WIESEMANN, Claudia; SIMON, Alfred. Patientenautonomie. Münster: Mentis, 2013.

DUARTE, Nestor. Proteção Jurídica dos Bens de Incapazes. Tese de Doutorado (orientador Yussef Said Cahali), Faculdade de Direito da Universidade de São Paulo, 1988.

DUTE, Jos. Landesbericht Niederlande. In FISCHER, Gerfried; LILIE, Hans (Coord.). Ärztliche Verantwortung im europäischen Rechtsvergleich. Köln: Verlag, 1999. 
DUTTGE, Gunnar. Patientenautonomie und Einwilligungsfähigkeit. In WIESEMANN, Claudia; SIMON, Alfred. Patientenautonomie. Münster: Mentis, 2013.

DWORKIN, Ronald. Life's dominion: An Argument about Abortion, Euthanasia, and Individual Freedom. New York: Vintage, 1994.

DWYER-HOLIGHAUS. Axel. Die Aufklärungspflicht des Arztes im Rechtsvergleich zwischen Deutschland und Italien. Leipzig: Leipziger Juristische Studien, 2005.

EHRLICH, Eugen. Die stillschweigende Willenserklärung. Berlin, 1983.

EISNER, Beate. Die Aufklärungspflicht des Arztes im schweizerischen Recht mit Hinweisen auf das Deutsche und amerikanische Recht. In KOTZUR, Joachim; NOACK, Herbert; WEBER, Ulrich (et al.) (Coord.). Jahrbuch Junger Zivilrechtswissenschaftler. München: Hannover, 1991.

ELIAS, Roberto João. Comentários ao Estatuto da Criança e do Adolescente. 4 ed. São Paulo: Saraiva, 2010

. Direitos Fundamentais da Criança e do Adolescente. São Paulo: Saraiva, 2005.

. Pátrio Poder: Deveres e Direitos para a Proteção dos Filhos. Tese de Livre-Docência da Faculdade de Direito da Universidade de São Paulo, 1998.

Pátrio Poder: Guarda dos Filhos e Direito de Visita. São Paulo: Saraiva, 1999. 
EMANUEL, Ezekiel J.; EMANUEL, Linda L. Four Models of the Physician-Patient-Relationship. Journal of the American Medical Association. v. 267, pp. 2221-2226, abril de 1992.

ENGISCH, Karl. Einführung in das juristische Denken, 1983. Trad. Port. J. Baptista Machado. Introdução ao pensamento jurídico. 6 ed. Lisboa: Calouste Gulbenkian, 1988.

ENNECERUS, Ludwig; NIPPERDEY, Hans Carl. Lehrbuch des bürgerlichen Rechts, Allgemeinet Teil des bürgerlichen Rechts; Zweiter Halbband: Entstehung, Untergang und Veränderung der Rechte, Ansprüche und Einreden, Ausübung und Sicherung der Rechte. 15 ed. Tübingen: Mohr, 1960.

ERMAN, Walter Alexander, Bürgerliches Gesetzbuch. v. 1, 14 ed. Köln: Dr. Otto hdt, 2014.

ETCOFF, Nancy. Nur die Schönsten überleben. Die Ästhetik des Menschen. München: Diederichs, 2001.

FACHIN, Luiz Edson. Desafios e perspectivas do direito de família no Brasil Contemporâneo. In AZEVEDO, Antônio Junqueira de; TÔRRES, Heleno Taveira; CARBONE, Paulo (coord.). Princípios do novo Código Civil Brasileiro e outros temas: Homenagem a Tullio Ascarelli. São Paulo: Quartier Latin, 2008.

FERREIRA FILHO, Manoel Gonçalves. Direitos humanos fundamentais. 11 ed. São Paulo: Saraiva, 2009.

- Princípios fundamentais do direito constitucional, São Paulo: Saraiva, 2009. 
FERRINI, Contardo. Manuale di Pandette. 3 ed. Milano: Società Editrice Libraria, 1908.

FLUME, Werner. Allgemeiner Teil des bürgerlichen Rechts: Das Rechtsgeschäft. v. 2. 4 ed. Berlin: Springer, 1992.

FOREMAN, David M. The family rule: a framework for obtaining ethical consent for medical interventions from children. Journal of Medical Ethics. v. 25 (6), pp. 491-500, dezembro de 1999.

FOSTER, Nestor José. Cirurgia plástica estética: obrigação de resultado ou obrigação de meios?. RT. São Paulo: Revista dos Tribunais. n. 738, p. 85, 1997.

FRANCKE, Robert. Ärztliche Berufsfreiheit und Patientenrechte: eine Untersuchung $\mathrm{zu}$ den verfassungsrechtlichen Grundlagen des ärztlichen Berufsrechts und des Patientenschutz. Stuttgart: Enke, 1994.

FRANCO, Talita. Princípios em cirurgia plástica. São Paulo: Atheneu, 2002.

GAUL, Charly. Kann Autonomie "fremdvertreten"werden? Philosophische, medizinische und juristische Überlegungen zur Einstellung lebenserhaltender Therapie bei Schwerstkranken unter Wahrung der Autonomie der Betroffenen. Ethik in der Medizin. n. 14, pp. 160-165, 2002.

GERNHUBER, Joachim; COESTER-WALTJEN, Dagmar. Familienrecht. 6 ed. München: Beck, 2010.

GESANG, Bernward. Perfektionierung des Menschen. Berlin: Walter de Gruyter, 2007. 
GIESEN, Dieter. Arzthaftungsrecht: Die zivilrechtliche Verantwortlichkeit des Arztes in rechtsvergleichender Sicht. Bielefeld: Gieseking, 1981.

GIOSTRI, Hildegard Taggesel, Algumas reflexões sobre as obrigações de meio e de resultado na avaliação da responsabilidade médica. Revista Trimestral de Direito Civil. Rio de Janeiro: Instituto Brasileiro de Direito Civil. v. 5. p. 103, 2001.

GIRINO, Franco. Studi in Tema di Stipulazione a Favore di Terzi. Milano: Giuffrè, 1965.

GLEIXNER-EBERLE, Elisabeth. Die Einwilligung in die medizinische Behandlung Minderjähriger. Frankfurt: Springer, 2014.

GOLBS, Ulrike. Das Vetorecht eines einwilligunsunfähigen Patienten. Baden-Baden: Nomos, 2006.

GOMES, Orlando. Contratos. 26 ed. Rio de Janeiro: Forense, 2008. 2010.

Introdução ao Direito Civil. 20 ed. Rio de Janeiro: Forense,

. Obrigações. 17 ed. Rio de Janeiro: Forense, 2008.

. Questões de direito civil. 5 ed. São Paulo: Saraiva, 1988.

GUILLOD, Olivier. Die Entscheidungsfreiheit des Patienten. Einige rechtliche Aspekte. In KERN, Gerson; MAZAL, Wolfgang (Coord.). Die Grenzen der Selbstbestimmung. Wien: Verlag, 2003. 
HAUPT, Günter. Über faktischen Vertragsverhältnisse. In Festschrift der Leipziger Juristenfakultät für Dr. Heinrich Siber zum 10. April 1940 II. Leipzig, 1943.

HAUSMANN, Christina. Einleitung. In GERBER, Jeni Regula; HAUSMANN, Christina (coord.). Die Rechte des Kindes: Das ONU-Übereinkommen und seine Auswirkungen auf die Schweiz. München: Genf 2001.

HEIDE, Jochen. Medizinische Zwangsbehandlung, Rechtsgrundlagen und verfassungsrechtliche Grenzen der Heilbehandlung gegen den Willen des Betroffenen. Berlin: Duncker \& Humbolt, 2001.

HENNIG, Lysann. Tattoos, Piercings, Schönheitsoperationen. Halle: Universitätsverlag Halle-Wittnberg, 2012.

HERGOVICH, Andreas (Coord.). Psychologie des Schönheit. Physische Attraktivität aus wissenschaftlicher Perspektive, Wien, WUV, 2002.

HESSE, Konrad. Grundzüge des Verfassungsrechts der Bundesrepublik Deutschland, 1995. Trad. port. L. A. Heck. Elementos de Direito Constitucional da República Federal Alemã. Porto Alegre: Sergio Antonio Fabris, 1998.

HILDT, Elisabeth. Prädikative genetische Diagnostik bei Kindern im Konflikt zwischen Autonomie und Fürsorge. In WIESERMANN, Claudia; SIMON, Alfred (coord.). Patientenautonomie. Theoretische Grundlagen. Praktische Anwendungen. Münster: Mentis, 2013. 
HIRATA, Alessandro. Relações contratuais fáticas (faktische Vertragsverhältnisse). Tese. São Paulo: Universidade de São Paulo, 2011.

HIRONAKA, Giselda Maria Fernandes Novaes. Cirurgia plástica e responsabilidade civil do médico: para uma análise jurídica da culpa do cirurgião plástico. Revista do Instituto de Estudos e Pesquisa (Divisão Jurídica). Bauru: ITE. n. 39, pp. 508-512, 2004.

HUBER, Peter. In Münchener Kommentar zum Bürgerlichen Gesetzbuch. v. 8. München: Beck, 2008.

JUEN, Thomas. Arzthaftungsrecht. Die zivilrechtliche Haftung des Arztes für den Behandlungsfehler - der Arzthaftungsprozess in Österreich. 2 ed. Wien: Manz, 2005.

KADUNC, Bogdana; PALERMO, Eliandre; ADDOR, Flavia (et. al.). Tratado de cirurgia dermatológica, cosmiatria e laser da Sociedade Brasileira de Dermatologia. Rio de Janeiro: Elvesier, 2013.

KARCHER, Eva. Methoden und Techniken von A-Z. In TASCHEN, Angelika (Coord.). Schönheitschirurgie. Köln: Verlag, 2005.

KATZENMEIER, Christian. Arzthaftung. München: Beck, 2002.

KERN, Bernd-Rüdiger. Der Minderjährige als Blutspender. FamRZ. pp. 738-739, 1981.

KERN, Gerson. Fremdbestimmung bei der Einwilligung in ärztliche Eingriffe. Neue Juristische Wochenschrift. pp. 753 e 756, 1994. 
KERN, Gerson. Vernunft - Gewissen - Heilbehandlung. In KERN, Gerson; MAZAL, Wolfgang (Coord.). Die Grenzen der Selbstbestimmung. Wien: Verlag, 2003.

KETTNER, Matthias (coord.). Wunscherfüllende Medizin: Ärztliche Behandlung im Dient von Selbstverwirklichung und Lebensplanung. Frankfurt: Campus, 2009.

KETTNER, Matthias; JUNKER, Iris, Konsequenzen der wunscherfüllenden Medizin für die Arzt-Patient-Beziehung, in KETTNER, Matthias (coord.). Wunscherfüllende Medizin: Ärztliche Behandlung im Dient von Selbstverwirklichung und Lebensplanung. Frankfurt: Campus, 2009.

KFORI NETO, Miguel. A responsabilidade civil do médico. In NERY JR., Nelson; NERY, Rosa Maria de Andrade (org.). Doutrinas essenciais: Responsabilidade civil. v. 5, São Paulo: Revista dos Tribunais, 2010. p. 623.

KNAUF, Christian. Mutmassliche Einwilligung und Stellvertretung bei ärztliche Eingriffen na Einwillgungsunfähigen, Zugleich ein Beitrag zur Patientenverfügung. Baden-Baden: Nomos, 2005.

KÖHLER, Michael. Medizinische Forschung in der Behandlung des Notfallpatienten. Neue Juristische Wochenschrift. pp. 853-854, 2002.

KOPPENOCK, Martin. Das Grundrecht auf bioetische Selbstbestimmung. Nomos: Baden-Baden, 1997.

KUBELLA, Kathrin. Patientenrechtegesetz. London: New York Springer, 2011. 
KUHLMANN, Jens-Michael. Einwilligung in die Heilbehandlung alter Menschen. Frankfurt: Peter Lang, 1996.

LAFER, Celso. A Internacionalização dos Direitos Humanos: Constituição, Racismo e Relações Internacionais. Barueri: Manole, 2005.

LARENZ, Karl. Allgemeiner Teil des deutschen Bürgerlichen Rechts. 7 ed. München: Beck, 1989.

- Die Begründung von Schuldverhältnissen durch sozialtypisches Verhalten, 1956. Trad. port. A. Hirata. O estabelecimento das relações obrigacionais por meio de comportamento social típico. Revista Direito GV. São Paulo: FGV. v. 3. n. 1, pp. 55-63, 2006.

. Methodenlehre der Rechtswissenschaft, 1991. Trad. Port. J. Lamego. Metodologia da ciência do direito. 3 ed. Lisboa: Calouste Gulbenkian, 1997.

LAUFS, Adolf; KATZENMEIER, Christian. Arzthaftungsrecht. München: Beck, 2015.

LAUFS, Adolf; KERN, Bernd-Rüdiger (coord.). Handbuch des Arztrechts. 4 ed. München: Beck, 2010. §616, Rn. 24.

LAUFS, Adolf; UHLENBRUCK, Wilhelm. Handbuch des Azrtrechts. 3. ed. München: Beck, 2002.

LE TOURNEAU, Philippe; CADIET, Loïc. Droit de la responsabilité et des contrats. Paris: Dalloz, 2002. 
LEVY, Maria de Lourdes; LARCHER, Victor; KURZ, Ronald. Informed consent/assent in children. Statement of the Ethics Working Group of the Confederation of European Specialists in Paediatrics (CESP). European Journal of Pediatrics. v. 162, pp. 629-633, setembro de 2003.

LINK, Ihna. Schwangerschaftsabbruch bei Minderjährigen. Eine vergleichende Untersuchung des deutschen und englischen Rechts. Frankfurt: Peter Lang, 2002.

LOPEZ, Teresa Ancona. Dano estético. 2 ed. São Paulo: Revista dos Tribunais, 1999.

. Das várias espécies de contratos - da locação de coisas; do empréstimo, da prestação de serviços; da empreitada; do depósito. In AZEVEDO, Antônio Junqueira (coord.). Comentários ao Código Civil. v. 7. São Paulo: Saraiva, 2003.

. Princípio da precaução e evolução da responsabilidade civil. São Paulo: Quartier Latin, 2010.

. Responsabilidade civil dos médicos. In CAHALI, Yussef Said (coord.), Responsabilidade civil: doutrina e jurisprudência. 2 ed., São Paulo: Saraiva, 1988. p. 321. pp. 315-337.

LORENZETTI, Ricardo Luis. Tratado de los contratos. t. 1. 2. ed. Buenos Aires: Rubinzal-Culzoni, 2007.

LORZ, Sigrid. Arzthaftung bei Schönheitsoperationen. Berlin: Dunckler \& Humblot, 2007.

LUTTEROTTI, Markus von; SPORKEN, Paul (coord.). Lexikon Medizin, Ethik, Recht. Freiburg: Herder, 1989. 
MAFFEIS MOREIRA, Marta Rodrigues. Contribuição ao estudo da responsabilidade civil do médico à luz do Direito Romano. São Paulo: Quartier Latin, 2016.

MALHADAS, Daisi, CONSOLIN DEZOTTI, Maria Celeste, MOURA NEVES, Maria Helena de (et. al.). Dicionário gregoportuguês. Cotia: Ateliê Editorial, 2006.

MARTIRE JUNIOR, Lybio. História da cirurgia plástica brasileira. São Paulo, 2005. Disponível em $<$ http://sbhm.webnode.com.br/products/historia-da-cirurgiaplastica>. Acesso em 27 set. 2016.

MEIRELLES, Rose M. Venceslau. O Princípio do melhor interesse da criança. In BODIN DE MORAES, Maria Celina (coord.). Princípios do direito civil contemporâneo. Rio de Janeiro: Renovar, 2006.

MELlo FRANCO, Vera Helena de. Contratos - Direito Civil e Empresarial. 2 ed. São Paulo: Revista dos Tribunais, 2011.

MELLO, Marcos Bernardes de. Teoria do Fato Jurídico: Plano da Eficácia. 5 ed. São Paulo: Saraiva, 2009.

. Teoria do Fato Jurídico: Plano da Existência. 14 ed. São Paulo: Saraiva, 2007.

MENEZES CORDEIRO, António Manuel da Rocha e. Da boa fé no direito civil. v. 1. Coimbra: Almedina, 2007.

MENGONI, Luigi. Obbligazioni 'di risultato' e obbligazioni 'di mezzi' - Studio critico. Estratto dalla Rivista del Diritto Commerciale. 52, n. 5-6, 7-8, 9-10, parte I. Milano: Francesco Vallardi. p. 1, nt. 2. 1954. 
MESSINEO, Francesco. Verbete Contratto irregolare (di fatto) e ad effetto irregolare. Enciclopedia del diritto. v. 10. Milano: Giuffrè, 1962. pp. 111-112.

MICHEL, Margot. Rechte von Kindern in medizinischen Heilbehandlungen. Basel: Helbing Lichtenhahn, 2009.

MÔNACO, Gustavo Ferraz de Campos. A proteção da criança no cenário internacional. Belo Horizonte: Del Rey, 2005.

MORAES SILVA, António. Diccionario da língua portugueza. v. 1. 8 ed.. Rio de Janeiro: Empreza Litteraria Fluminense, 1890.

MORAES, Wesley Aragão de. Salutogênese e caminhos iniciáticos: A espiritualidade como item de saúde in Arte Médica Ampliada. v. 34. n. 4. São Paulo: Associação Brasileira de Medicina Antroposófica, 2014.

MOREIRA ALVES, José Carlos. Direito Romano. 16 ed. Rio de Janeiro: Forense, 2012.

MORLOK, Martin. Selbstvertändnis als Rechtskriterium. Tübingen: J. C. B. Mohr, 1993.

MOTA PINTO, Carlos Alberto da. Cessão do contrato. São Paulo: Saraiva, 1985.

NAINI, Farhad. Facial Aesthetics: Concepts \& Clinical Diagnosis, 2011. Trad. Port. Sílvia Mariângela Spada (et. al.). Estética Facial: Conceitos e diagnósticos clínicos. Rio de Janeiro, Elsevier, 2014. 
NEBENDAHL, Mathias. Selbstbestimmungsrecht und rechtfertigende Einwilligung des Minderjährigen bei medizinischen Eingriffen. Frankfurt: Springer, 2009.

NERY JR, Nelson; NERY, Rosa Maria de Andrade. Código Civil Comentado [versão E-book].11 ed. São Paulo: Revista dos Tribunais, 2014.

NERY, Rosa Maria de Andrade. Instituições de Direito Civil. v. 5. São Paulo: Revista dos Tribunais, 2015.

ODENWALD, Steffen. Die Einwilligunsfähigkeit im Strafrecht unter besonderer Hervorhebung ärztlichen Handels. Frankfurt: Peter Lang, 2004.

OLZEN, Dirk. In Münchener Kommentar zum Bürgerlichen Gesetzbuch. v. 9. München: Beck, 2008.

PALANDT, Otto. Bürgerliches Gesetzbuch. v. 7.74 ed. München: Beck, 2015.

PALANGANA, Isilda Campaner. Desenvolvimento e aprendizagem em Piaget e Vigotsi: A relevância social [e-book]. 6 ed. São Paulo: Summus, 2015.

PANAGOPOULOU-KOUTNATZI, Fereniki. Die Selbstbestimmung des Patienten. Berlin: Duncker \& Humblot, 2009.

PAPALEO, João Cesar Guaspari. Contrato a Favor de Terceiro. Rio de Janeiro: Renovar, 2002. 
PELUZO, Cezar. (Coord.). Código Civil Comentado: doutrina e jurisprudência. 7 ed. Barueri: Manole, 2013.

PENTEADO, Luciano de Camargo. Doação com Encargo e causa contratual. 2 ed. São Paulo: Revista dos Tribunais, 2013.

PEREIRA, Caio Mário da Silva. Instituições de Direito Civil. v. 1. 24 ed. Rio de Janeiro: Forense, 2011.

. Instituições de direito civil. v. 2.25 ed. Rio de Janeiro: Forense, 2012.

. Instituições de Direito Civil. v. 3. 17 ed. Rio de Janeiro: Forense, 2014.

PERREZ, Meinrad. BAUMANN, Urs (Coord.). Lehrbuch klinische Psychologie: Psychotherapie. 5 ed., Bern: Huber, 2011, pp. 32-36.

PETERMANN, Franck Thomas. Urteilsfähigkeit, Generelle Aspekte, Urteilsfähigkeit als Ehevoraussetzung, zum Testieren, zum willentlichen Sterben sowie Screening. Zürich: Tools, 2008. PHILLIPS, Katharine A. Understanding Body Dysmorphic Disorder: An Essencial Guide. New York: Oxford University Press, 2009. $\quad$ pp. 50-51. Disponível em: $<$ https://books.google.com.br/books?id=uRTcOYgWj9cC\&pg=PA5 $0 \& \mathrm{dq}=$ muscle + dysmorphia\&redir_esc $=\mathrm{y} \# \mathrm{v}=$ onepage $\& \mathrm{q}=$ muscle $\% 2$ 0dysmorphia\&f=false $>$. Acesso em: 24 set.2016.

PHILLIPS, Katharine A.; DIDIE, Elizabeth (et. al.). Body Dysmorphic Disorder: Treating an Underrecognized. The American Journal of Psychiatry, n. 165(9), pp. 1111-1118, setembro de 2008. Disponível em: 
$<$ https://www.ncbi.nlm.nih.gov/pmc/articles/PMC2716131>. Acesso em 23 set. 2016.

PHILLIPS, Katharine A.; GRANT, Jon; SINISCALCHI, Jason; ALBERTINI, Ralph S. Surgical and Nonpsychiatric Medical Treatment of Patients With Body Dysmorphic Disorder. Psychosomatics, n. 42(6), pp. 504-510, novembro-dezembro de 2001. Disponível em: $<$ https://www.ncbi.nlm.nih.gov/pubmed/11815686>. Acesso em 23 set. 2016.

PHILLIPS, Katharine A.; MENARD, William; FAY, Christina; RISA, Weisberg. Demographic Characteristics, Phenomenology, Comorbidity, and Family History in 200 Individuals With Body Dysmorphic Disorder. Psychosomatics, n. 46(4), pp. 317-325, 2005. Disponível em: $<$ https://www.ncbi.nlm.nih.gov/pmc/articles/PMC1351257/>. Acesso em: 23 set. 2016.

- Clinical features of body dysmorphic disorder in adolescents and adults. Psychiatry Research, n. 141(3), pp. 305-314, março de 2006. Disponível em: $<$ https://www.ncbi.nlm.nih.gov/pmc/articles/PMC1592052/pdf/nihm s9381.pdf>. Acesso em: 23 set. 2016.

PIOVESAN, Flávia. Direitos humanos e o direito constitucional internacional. 9 ed. São Paulo: Saraiva, 2008.

Direitos humanos, o princípio da dignidade humana e a Constituição de 1988. In PIOVESAN, Flávia; GARCIA, Márcia (org.). Doutrinas essenciais: Direitos humanos. v. 1. São Paulo: Revista dos Tribunais, 2011. 
PIRES DE LIMA, Fernando Andrade; ANTUNES VARELA, João de Matos. Código Civil Anotado. v. 2. 4 ed. Coimbra: Coimbra, 2011.

PONTES DE MIRANDA, Francisco Cavalcanti. Tratado de Direito Privado: Parte Geral - Introdução. Pessoas Físicas e Jurídicas. t. 1.3 ed. Rio de Janeiro: Borsoi, 1970.

- Tratado de Direito Privado: Parte Especial - Direito das Obrigações. t. 26. $3^{\mathrm{a}}$ ed. Rio de Janeiro: Borsoi, 1971.

. Tratado de Direito Privado: Parte Especial - Direito das Obrigações. t. 43.3 ed. Rio de Janeiro: Borsoi, 1971.

- Tratado de Direito Privado: Parte Especial - Direito das Obrigações: Contrato de locação de Serviços. Contrato de trabalho. t. 47.3 ed. Rio de Janeiro: Borsoi, 1972.

POSCH, Waltraud. Körper machen Leute: Der Kult um die Schönheit. Frankfurt: Campus, 1999. pp. 37; 48-49.

PRÜTING, Hans; WEGEN, Gerhard; WEINREICH, Gerd. BGB Kommentar. §1626. 10 ed. Köln: Luchterhand, 2015.

RAKETE-DOMBEK, Ingeborg. Nomos Kommentar BGB: Familienrecht. v. 4 . 3 ed. Baden-Baden: Nomos, 2014.

RAMER, Paul; RENNHARD, Josef. Patientenrecht. Ein Ratgeber aus der Beobachterpraxis. 2 ed. Zürich: Beobachter-Buchverlag, 1998.

REIPSCHLÄGER, Christiane. Die Einwilligung Minderjähriger in ärztliche Heileingriffe und die elterliche Personensorge. Frankfurt: Peter Lang, 2004. 
REUTER, Dieter. Kindesgrundrechte und elterliche Gewalt. Berlin: Duncker \& Humboldt, 1968.

RIEDER, Heike. Genetische Untersuchungen und Persönlichkeitsrecht. Eine Auseinandersetzung mit dem Bundesgesetz über genetische Untersuchungen beim Menschen im medizinischen Bereich, München: Genf, 2006.

RIXEN, Stephan. Das todkranke Kind zwischen Eltern und Arzt. Frankfurt: Springer, 1997.

RODRIGUES PEREIRA, Lafayette. Direito das Cousas. Rio de Janeiro: Baptista de Souza, 1922.

ROSS, Lainie Friedman. Children, families, and health care decision-making. Oxford: Clarendon, 1998.

ROTHÄRMEL, Sonja; DIPPOLD, Ines; WIETHOFF, Katja (et al.). Patientenaufklärung, Informationsbedürfnis und Informationspraxis in der Kinder- und Jugendpsychiatrie und Psychotherapie. Göttingen: Vandenhoeck \& Ruprecht, 2006.

ROTHÄRMEL, Sonja; WOLFSLAST, Gabriele; FAGERT, Jörg M. Informed consent - ein kinderfeindliches Konzept?, Von der Benachteiligung minderjähriger Patienten durch das Informed Consent-Konzept am Beispiel der Kinder- und Jugendpsychiatrie. Frankfurt: Springer, 1999.

ROTHÄRMEL, Sonja. Einwilligung, Veto, Mitbestimmung. Baden-Baden: Nomos, 2004. 
ROUKA, Stella. Das Selbstbestimmungsrecht des Minderjährigen bei ärztlichen Eingriffen. Frankfurt: Peter Lang, 1994.

RÜDIGER, Margit; GROSSHANS, Lore. Schönheitsoperationen, Beauty nach Mass. München: GU, 2003. 2003 .

Schönheitsoperationen, Beauty nach Mass. München: GU,

RUMETSCH, Virgilia. Medizinische Eingriffe bei Minderjährigen. Eine rechtsvergleichende Untersuchung zum Schweizer und deutschen Recht. Helbing Lichtenhahn: Basel, 2013.

SANDEL, Michael. Justice, 2009. Trad. port. H. Matias e M. A. Máximo. Justiça: O que é fazer a coisa certa. 6 ed. Rio de Janeiro: Civilização Brasileira, 2012.

SANTARELLI ZULIANI, Ênio. Inversão do ônus da prova na ação de responsabilidade civil fundada em erro médico. RT. São Paulo: Revista dos Tribunais. n. 811, p. 49, maio de 2003.

SCHUCK, Martin. Strafrechtliche Bedeutung der Verletzung der ärztlichen Aufklärungslast unter besonderer Berücksichtigung der kosmetischen Chirurgie. Dissertação. München, 1980.

SCHWEIZER, Rainer J. Kommentierung von Art. 8, Art. 10 und Art. 13 BV. In: EHRENZELLER, Bernard; MASTRONARDI, Philippe; SCHWEIZER, Rainer J.; VALLERDER, Klaus A. (Coord.). Die schweizerische Bundesverfassung. Kommentar. 2 ed. Zürich: Genf, 2008. 
SCHWENZFEIER, Katja. Die kollisionsrechtliche Anknüpfung des Behandlungsverhältnisses im Rahmen einen kosmetischen Operation. Der Patient als Verbraucher?. Hamburg: D. Kovac, 2011.

SEGRE, Marco, O conceito de saúde. Disponível em $<$ http://www.scielo.br/scielo.php?script=sci_arttext\&pid=S003489101997000600016>. Acesso em 09 set. 2016.

SERPA LOPES, Miguel Maria de. Curso de direito civil. v. 1.3 ed. Rio de Janeiro: Freitas Bastos, 1960.

. Curso de direito civil. v. 2. $3^{\text {a }}$ ed. Rio de Janeiro: Freitas Bastos, 1961.

. Curso de direito civil. v. 3.3 ed. Rio de Janeiro: Freitas Bastos, 1960.

. Curso de direito civil. v. 5.3 ed. Rio de Janeiro: Freitas Bastos, 1961.

. Curso de Direito Constitucional Positivo. 38 ed. São Paulo: Malheiros, 2015.

. Direitos fundamentais: Conteúdo essencial, restrições e eficácia. 2 ed. São Paulo: Malheiros, 2014.

SIMON, Alfred; NAUCK, Friedemann. Patientenautonomie in der klinischen Praxis. In WIESERMANN, Claudia; SIMON, Alfred (coord.). Patientenautonomie. Theoretische Grundlagen. Praktische Anwendungen. Münster: Mentis, 2013. 
SPICKHOFF, Andreas. Die Eingriffsindikation im Wandel der Zeit - aus der Sicht eines Juristen, Life-style Medizin - von der medizinischen Indikation zum modischen Trend. Heidelberg: Springer, 2012.

SPICKHOFF, Andreas. Medizinrecht. 2 ed. München: Beck, 2014.

STEFFEN, Erich; DRESSLER, Wolf-Dieter, Arzthaftungsrecht. 9 ed. Köln: RWS, 2002.

STOCCO, Rui. Tratado de responsabilidade civil. 8 ed. São Paulo: Revista dos Tribunais, 2011.

STOCK, Christof. Die Indikation in der Wunschmedizin. Ein medizinrechtlicher Beitrag zur ethischen Diskussion über "Enhancement". Frankfurt am Main: Peter Lang, 2009.

TELLES JÚNIOR, Goffredo. Carta aos Brasileiros. In PIOVESAN, Flávia; GARCIA, Márcia (org.). Doutrinas essenciais: Direitos humanos. v. 1. São Paulo: Revista dos Tribunais, 2011.

TEPEDINO, Gustavo; MORAES, Maria Celina Bodin de ; BARBOZA, Heloisa Helena. Código Civil Interpretado conforme a Constituição da República. t. 2. Rio de Janeiro: Renovar, 2006.

TERRA, Márcia Regina. O desenvolvimento humano na teoria de Piaget. Campinas, [s.d.], Disponível em: $<$ http://www.unicamp.br/iel/site/alunos/publicacoes/textos/d00005.h tm>. Acesso em: 07 nov. 2016.

THEODORO JR., Humberto. Aspectos processuais da ação de responsabilidade por erro médico. RT. São Paulo: Revista dos Tribunais. v. 760, p. 42, fevereiro de 1999. 
TORRINHA, Francisco. Dicionário Latino Português. 2 ed. Porto: Gráficos Reunidos, 1942.

TRABUCCHI, Alberto. Istituzioni di diritto civile. 43 ed. Padova: Cedan, 2007.

TUNC, André. La distinction des obligations de résultat et des obliations de diligence. In Jalons - Dits et Écrits d'André Tunc, 1991. Trad. port. V. J. de Fradera. A distinção entre obrigações de resultado e obrigações de diligência. RT. São Paulo: Revista dos Tribunais, n. 778, pp. 755-763, agosto de 2000.

UNIVERSITY OF OXFORD. Oxford Advanced Learner's Dictionary. 6 ed. Oxford: University Press, 2004.

VAZ RODRIGUES, João. O Consentimento Informado para o Acto Médico no Ordenamento Jurídico Português: Elementos para o estudo da manifestação de vontade do paciente. Coimbra: Coimbra Editora, 2001.

VEIT, Bárbara. BAMBERGER, Heinz Georg; ROTH, Herbert (Coord.). Kommentar zum Bürgerlichen Gesetzbuch. v. 3. 3 ed. München: Beck, 2012.

VERGAMINI LUNA, Ana Cláudia; GIMENES ARCAS, Rita de Cássia. Responsabilidade civil do Estado e a atividade médica. in HIRONAKA, Giselda Maria Fernandes Novaes, DIAZ FALAVIGNA, Maria Clara Osuna, (coord.). Ensaios sobre responsabilidade civil na pós modernidade. 1 ed. Porto Alegre: Magister, 2007. 
VIEIRA DE ANDRADE, José Carlos. Os direitos fundamentais na constituição portuguesa de 1976. 3 ed. Coimbra: Almedina, 2004.

VOLTERRA, Edoardo. Istituzioni di Diritto Privato Romano. Roma: La Sapienza, 1988.

WAGNER, Gerhard. In Münchener Kommentar zum Bürgerlichen Gesetzbuch. v. 7. München: Beck, 2008.

WAGNER, Jörg. Der Begriff des Schönen in der Definition von Platon, Arstoteles und Seneca. Preetz: Bahnsen, 2000.

WALD, Arnold. Direito Civil: Direito das Obrigações e Teoria Geral dos Contratos. v. 2. 20 ed., São Paulo: Saraiva, 2011.

WENDTLAND, Holger. In BAMBERGER, Heinz Georg; ROTH, Herbert (Coord.). Kommentar zum Bürgerlichen Gesetzbuch. v. 1. München: Beck, 2012.

WENZEL, Frank. Handbuch des Fachanwalts Medizinrecht. Köln: Luchterhand, 2007.

WÖLK, Florian. Der minderjährige Patient in der ärztliche Behandlung. Frankfurt: Springer, 2001.

WORLD HEALTH ORGANIZATION. Women's Mental Health: An Evidence Based Review. Geneva, 2000. p.11. Disponível em: < http://apps.who.int/iris/bitstream/10665/66539/1/WHO_MSD_MDP _00.1.pdf $>$. Acesso em: 12 set. 2016.

WYTTENBACH, Judith. Grund- und Menschenrechtskonflikte zwischen Eltern, Kind und Sttat. Schutzpflichten des Staates 
gegenüber Kindern und Jugendlichen aus dem internationalen Menschenrechtsschutz und der Bundesverfassung (Art. 11 BV). München: Genf, 2006.

ZIEGLER, Friederich. In PRÜTING, Hans; WEGEN, Gerhard; WEINREICH, Gerd. BGB Kommentar. §1626. 10 ed. Köln: Luchterhand, 2015. 


\section{ANEXOS}

\section{ANEXO I}

\section{HOMOLOGAÇÃO DA PORTARIA QUE DISCIPLINA FUNCIONAMENTO DA COMISSÃO MISTA DE ESPECIALIDADES}

ORDINANCE OF APPROVAL TO DISCIPLINE MIXED SPECIALTIES COMMISSION OF OPERATION

*Conselho Federal de Medicina.

$C F M^{*}$

Palavras-chave $\neg$ Especialidades, áreas de atuação, registro, regulamentação, comissão mista.

Keywords $\neg$ Specialities, areas of expertise, registration, regulation, joint committee.

\section{RESUMO}

Dispõe sobre a homologação da Portaria CME $n^{0} 01 / 2016$, que disciplina o funcionamento da Comissão Mista de Especialidades (CME), composta pelo Conselho Federal de Medicina (CFM), pela Associação Médica Brasileira (AMB) e pela Comissão Nacional de Residência Médica (CNRM), que normatiza o reconhecimento e o registro das especialidades médicas e respectivas áreas de atuação no âmbito dos Conselhos de Medicina.

\section{RESOLUÇÃO CFM No 2.148/2016}

O CONSELHO FEDERAL DE MEDICINA, no uso das atribuições conferidas pela Lei $\mathrm{n}^{\mathrm{o}} 3.268$, de 30 de setembro de 1957 , regulamentada pelos Decretos $\mathrm{n}^{\circ} 44.045 / 1958$ e $\mathrm{n}^{\mathrm{o}} 6.821 / 2009$ e alterada pela Lei $\mathrm{n}^{\circ} 11.000$, de 15 de dezembro de 2004; 
CONSIDERANDO que cabem ao Conselho Federal de Medicina a normatização e a fiscalização do exercício da medicina;

CONSIDERANDO que o Conselho Federal de Medicina, como autarquia federal regida pela Lei $\mathrm{n}^{\mathrm{o}} 3.268 / 57$, possui autonomia administrativa e financeira, podendo dispor sobre sua organização interna;

CONSIDERANDO o disposto no Decreto $\mathrm{n}^{\circ}$ 8.516, de 10 de setembro de 2015, que regulamenta a formação do Cadastro Nacional de Especialistas, de que tratam os $\S \S 4^{\circ}$ e $5^{\circ}$ do art. $1^{\circ}$ da Lei ${ }^{\circ} 6.932$, de 7 de julho de 1981 , e o art. 35 da Lei ${ }^{\circ}$ 12.871, de 22 de outubro de 2013;

CONSIDERANDO, finalmente, o decidido em sessão plenária do dia 22 de julho de 2016;

\section{RESOLVE:}

Art. $1^{0} \neg$ Homologar a Portaria CME $n^{0} 01 / 2016$, anexa, que disciplina o funcionamento da Comissão Mista de Especialidades (CME), composta pelo Conselho Federal de Medicina (CFM), pela Associação Médica Brasileira (AMB) e pela Comissão Nacional de Residência Médica (CNRM).

Art. $2^{\circ} \neg$ Esta Resolução e a Portaria CME $n^{\circ}$ 01/2016 entrarão em vigor na data de sua publicação.

Brasília-DF, 22 de julho de 2016.

CARLOS VITAL TAVARES CORRÊA LIMA

Presidente

HENRIQUE BATISTA E SILVA

Secretário-geral

\section{ANEXO DA RESOLUÇÃO CFM No 2.148/2016}

PORTARIA CME No 01/2016

Regulamenta o funcionamento da Comissão Mista de Especialidades (CME), composta pelo Conselho Federal de Medicina (CFM), pela Associação 
Médica Brasileira (AMB) e pela Comissão Nacional de Residência Médica (CNRM), disciplinando o reconhecimento e o registro das especialidades médicas e respectivas áreas de atuação no âmbito dos Conselhos de Medicina, e dá outras providências.

A COMISSÃO MISTA DE ESPECIALIDADES (CME), no uso das atribuições que lhe confere o Decreto $\mathrm{n}^{\circ}$ 8.516, de 10 de setembro de 2015, e considerando o disposto nas Leis $\mathrm{n}^{\mathrm{o}} 6.932$, de 7 de julho de 1981, e $\mathrm{n}^{\mathrm{o}} 12.871$, de 22 de outubro de 2013, aprova o seguinte regulamento, que disciplina o seu funcionamento:

\section{CAPÍTULO I}

\section{DAS NORMAS ORIENTADORAS E REGULAMENTADORAS}

Art. $\mathbf{1}^{\mathbf{0}} \neg$ O Conselho Federal de Medicina (CFM), a Associação Médica Brasileira (AMB) e a Comissão Nacional de Residência Médica (CNRM) reconhecerão as mesmas especialidades e áreas de atuação.

$\S \mathbf{1}^{\mathbf{0}} \neg$ Define-se especialidade médica como núcleo de organização do trabalho médico que aprofunda verticalmente a abordagem teórica e prática de segmentos da dimensão biopsicossocial do indivíduo e da coletividade.

$\S \mathbf{2}^{\mathbf{0}} \neg$ Define-se área de atuação como modalidade de organização do trabalho médico, desenvolvida por profissionais capacitados para exercer ações médicas específicas, sendo derivada e relacionada com uma ou mais especialidades.

$\S \mathbf{3}^{\mathbf{0}} \neg$ Reconhecem-se como especialidades médicas aquelas consideradas raízes e aquelas que preenchem o conjunto de critérios abaixo relacionados:

1. Complexidade dos problemas de saúde e acúmulo de conhecimento em determinada área de atuação médica que transcenda $o$ aprendizado do curso médico e de uma área raiz em um setor específico;

2. Ter relevância epidemiológica e demanda social definida;

3. Ter complexidade que demande um conjunto de conhecimentos, habilidades e atitudes que exija um período mínimo de dois anos de formação;

4. Reunir conhecimentos que definam um núcleo de atuação própria que não possa ser englobado por especialidades já existentes.

$\S 4^{\mathbf{0}} \neg$ São critérios de exclusão para reconhecimento de especialidades:

1. Área que já esteja contida em uma especialidade existente; 
2. Processo que seja apenas meio diagnóstico e/ou terapêutico;

3. Área que esteja relacionada exclusivamente a uma doença ou problema de saúde isolado;

4. Área cuja atividade seja exclusivamente experimental;

5. Função ou atividade essencialmente vinculada ao conhecimento de legislação específica;

6. Área que seja apenas disciplina acadêmica.

$\S \mathbf{5}^{\mathbf{0}} \neg \mathrm{A} \mathrm{CNRM}$ somente autorizará programas de residência médica nas especialidades e áreas de atuação aprovadas pela CME.

$\S \mathbf{6}^{\mathbf{0}} \neg$ As especialidades médicas e áreas de atuação aprovadas pela CME terão sua certificação sob responsabilidade da AMB e/ou da CNRM.

$\S 7^{\mathbf{0}} \neg \mathrm{O}$ número de médicos e o tempo de existência de uma atividade não são parâmetros para reconhecimento ou exclusão de especialidade ou área de atuação.

Art. $\mathbf{2}^{\mathbf{0}} \neg$ É competência da CME a deliberação sobre assuntos relacionados a especialidades médicas e áreas de atuação, inclusive os oriundos das entidades que a compõem.

Art. $3^{\mathbf{o}} \neg$ Somente as entidades integrantes da CME são legitimadas para solicitar o reconhecimento de novas especialidades médicas e/ou áreas de atuação.

Parágrafo único. A deliberação e a decisão sobre pedido de reconhecimento de novas especialidades e/ou áreas de atuação deverão ser aprovadas por unanimidade pelos componentes da CME.

Art. $\mathbf{4}^{\mathbf{0}} \neg$ A extinção de qualquer especialidade médica e/ou área de atuação será efetivada após solicitação da AMB, do CFM ou da CNRM e com aprovação por unanimidade pelos componentes da CME.

Parágrafo único. A efetivação da extinção da especialidade médica e/ou área de atuação respeitará o tempo mínimo de duração do programa de residência médica.

Art. $\mathbf{5}^{\mathbf{0}} \neg$ A CME somente reconhecerá especialidade médica com tempo de formação mínimo de dois anos e área de atuação com tempo de formação mínimo de um ano, sendo obrigatória carga horária anual mínima de 2.880 horas.

$\S \mathbf{1}^{\mathbf{0}} \neg$ A matriz de competência, da qual decorre o tempo de formação de especialidade médica ou área de atuação para a residência médica, será aquela aprovada pela CNRM, respeitados os pré-requisitos necessários.

$\S \mathbf{2}^{\mathbf{0}} \neg$ A matriz de competência, da qual decorre o tempo de formação de especialidade médica ou área de atuação para a $\mathrm{AMB}$, em programas de 
formação credenciados por sociedades de especialidade, será aprovada pela CME e deverá manter similaridade com a matriz de competência aprovada pela CNRM, respeitados os pré-requisitos necessários.

$\S 3^{\mathbf{0}} \neg$ Cabe à CNRM autorizar e disciplinar ano opcional, desde que com o mesmo nome do programa de residência médica, para complementação da formação, mediante solicitação da instituição com a devida justificativa da necessidade de sua implantação e comprovação de sua capacidade, conforme requisitos necessários.

Art. $6^{\mathbf{0}} \neg \mathrm{A}$ AMB emitirá apenas títulos e certificados que atendam às determinações da CME.

Parágrafo único. Em seus editais de concurso para título de especialista ou certificado de área de atuação, a AMB deverá observar a matriz de competência e o tempo mínimo de formação na especialidade ou área de atuação determinados pela CME, conforme dispõe o caput e $\S 2^{\circ}$ do artigo $5^{\circ}$. Art. $7^{\mathbf{0}} \neg \mathrm{A}$ AMB, nos editais de titulação das suas associações filiadas, deverá prever a participação de médicos que não realizaram programas de especialização ou residência médica. Nesses casos, deverá exigir como único pré-requisito, de forma fundamentada, comprovação de atuação na área pelo dobro do tempo de formação do programa de residência médica, ficando vedada a cobrança de cumprimento de cursos ou treinamentos adicionais.

Art. $\mathbf{8}^{\mathbf{0}} \neg$ A atualização do rol de especialidades médicas e áreas de atuação reconhecidas, quando ocorrer, será feita por meio de Portaria da CME, que será homologada por resolução do Conselho Federal de Medicina, a qual será publicada no Diário Oficial da União.

Art. 9 $\neg$ A AMB deverá anualmente oferecer prova de título de especialista de todas as especialidades e áreas de atuação reconhecidas pela CME.

Art. $10 \neg$ Os exames da AMB para certificação de áreas de atuação comuns a duas ou mais especialidades serão únicos e sob a responsabilidade da AMB.

Art. $11 \neg$ Os Conselhos Regionais de Medicina (CRMs) deverão registrar apenas títulos de especialidade e certificados de áreas de atuação reconhecidos pela CME e emitidos pela $\mathrm{AMB}$ ou pela CNRM.

Art. $12 \neg$ A denominação dos registros de especialidade junto aos CRMs obedecerá aos seguintes critérios:

I- Documentos emitidos pela CNRM ou pela AMB previamente à Resolução CFM n ${ }^{\circ} 1.634 / 02$ e anexos, ou outra resolução posterior que a tenha revogado, poderão preservar, no registro, a denominação original; 
II - Documentos emitidos posteriormente à Resolução CFM $n^{0}$ 1.634/02 e anexos, ou outra resolução posterior que a tenha revogado, serão registrados de acordo com a denominação vigente no ato do registro. Se sofrerem alteração de especialidade para área de atuação, serão registrados por analogia.

Art. $13 \neg$ As solicitações de atualização dos títulos feitas por médicos às associações de especialidade deverão ser encaminhadas pelas associações à $\mathrm{AMB}$, que deverá atualizar a denominação anterior dos títulos ou certificados para a nomenclatura vigente, cabendo aos CRMs promover idêntica alteração no registro existente em seus cadastros.

Art. $14 \neg$ As especialidades médicas e as áreas de atuação devem receber registros independentes nos CRMs.

Art. $15 \neg$ As áreas de atuação receberão certificação, no âmbito da AMB, via associações de especialidade.

Art. $16 \neg$ As sociedades de especialidade ou de área de atuação reconhecidas ficam obrigadas a comprovar sua participação em centros de treinamento e formação, mediante relatório anual enviado à AMB.

Art. $17 \neg$ São proibidos aos médicos a divulgação e o anúncio de especialidades ou áreas de atuação que não tenham o reconhecimento da CME.

Parágrafo único. O médico só poderá fazer divulgação e anúncio de até duas especialidades e duas áreas de atuação, desde que registradas no CRM de sua jurisdição.

Art. $18 \neg$ A CME reunir-se-á ordinariamente no mínimo 6 (seis) vezes ao ano.

Parágrafo único. A CME poderá se reunir extraordinariamente mediante solicitação de qualquer um de seus membros.

Art. $19 \neg \mathrm{O}$ quórum mínimo para funcionamento da CME é de 3 (três) membros. No entanto, quando se tratar de deliberação sobre alteração da Portaria CME no 01/2016 ou da relação das especialidades médicas e/ou áreas de atuação, o quórum mínimo será obrigatoriamente com 1 (um) representante de cada ente integrante.

Art. $20 \neg$ As substituições dos membros da CME serão efetivadas após comunicado oficial das entidades à Comissão.

Parágrafo único. Será necessária publicação no Diário Oficial da União de Portaria do CFM com a nova designação.

Art. $21 \neg$ Os custos administrativos para funcionamento da CME correrão por conta do CFM, cabendo a cada entidade integrante, contudo, arcar com suas respectivas despesas logísticas. 
Art. $22 \neg$ A CME designará relator para a emissão de pareceres conclusivos a serem apreciados em reunião plenária da Comissão.

Art. $23 \neg$ As propostas para criação e reconhecimento de novas especialidades médicas ou áreas de atuação recusadas pela CME só poderão ser reapresentadas para nova avaliação após 5 (cinco) anos, contados a partir da data do indeferimento.

Art. $24 \neg$ A CME poderá, a seu critério, emitir resoluções, portarias, recomendações e normativas sobre suas atividades.

Brasília, 22 de julho de 2016.

MAURO LUIZ DE BRITTO RIBEIRO - CFM

MARIA DO PATROCÍNIO NUNES - CFM

ALDEMIR HUMBERTO SOARES - AMB

FÁBIO BISCEGLI JATENE - AMB

FRANCISCO ARSEGO DE OLIVEIRA - CNRM

FELIPE PROENÇO - CNRM

\section{EXPOSIÇÃO DE MOTIVOS DA RESOLUÇÃO CFM Nº 2.148/2016}

A Comissão Mista de Especialidades (CME), composta por representantes do Conselho Federal de Medicina (CFM), da Comissão Nacional de Residência Médica (CNRM) e da Associação Médica Brasileira (AMB), foi estabelecida por meio de convênio entre as entidades em 11 de abril de $2002 \mathrm{e}$ reconhecida pela Resolução CFM 1.634/2002.

Ao longo desses anos realizou importante trabalho de definição, uniformização e consolidação das especialidades e das áreas de atuação médica.

Em 10 de setembro de 2015 a Presidência da República editou o Decreto ${ }^{\circ}$ 8.516, que, além de criar o Cadastro Nacional de Especialistas, em seu artigo $4^{\circ}$ reconhece a CME, vinculada ao CFM, e determina que a ela compete definir as especialidades médicas no Brasil.

Neste mesmo artigo, em seu $\S 1^{\circ}$ assim define a composição da CME:

I - dois representantes da Comissão Nacional de Residência Médica, sendo um do Ministério da Saúde e um do Ministério da Educação;

II - dois representantes do Conselho Federal de Medicina; e

III - dois representantes da Associação Médica Brasileira. 
Já o $\S 2^{\circ}$ estabelece que os representantes da CME definirão as demais competências para sua atuação e as regras de seu funcionamento por meio de ato específico.

Os membros da CME, por unanimidade, estabeleceram que a Portaria CME $\mathrm{n}^{\mathrm{o}} 01 / 2016$, que disciplina seu funcionamento, fosse homologada pela plenária do CFM e publicada por meio de resolução, garantindo assim sua aplicabilidade e a continuidade dos trabalhos.

MAURO LUIZ DE BRITTO RIBEIRO

Relator

RESOLUÇÃO CFM nº 2.148/2016

Resolução aprovada na sessão plenária de 22 de julho de 2016. Publicada no D.O.U. em 3 de agosto de 2016, Seção I, p. 99. 


\section{ANEXO II}

\section{RESOLUÇÃO CFM No 2.149/2016}

(Publicada no D.O.U. de 03 de agosto de 2016, Seção I, p. 99)

Homologa a Portaria CME $n^{0}$ 02/2016, que aprova a relação de especialidades e áreas de atuação médicas aprovadas pela Comissão Mista de Especialidades.

O CONSELHO FEDERAL DE MEDICINA, no uso das atribuições conferidas pela Lei $\mathrm{n}^{\circ} 3.268$, de 30 de setembro de 1957, regulamentada pelos Decretos $\mathrm{n}^{\mathrm{o}} 44.045 / 1958$ e $\mathrm{n}^{\mathrm{o}} 6.821 / 2009$ e alterada pela Lei $\mathrm{n}^{\mathrm{o}}$ 11.000 , de 15 de dezembro de 2004;

CONSIDERANDO que cabem ao Conselho Federal de Medicina a normatização e a fiscalização do exercício da medicina;

CONSIDERANDO o disposto no Decreto $\mathrm{n}^{\circ}$ 8.516, de 10 de setembro de 2015, que regulamenta a formação do Cadastro Nacional de Especialistas, de que tratam os $\S \S 4^{\circ}$ e $5^{\circ}$ do art. $1^{\circ}$ da Lei $n^{\circ} 6.932$, de 7 de julho de 1981 , e o art. 35 da lei $\mathrm{n}^{\circ} 12.871$, de 22 de outubro de 2013;

CONSIDERANDO a Portaria CME $\mathrm{n}^{\mathrm{o}}$ 01/2016, homologada pela Resolução CFM n ${ }^{0}$ 2.148/2016, que disciplina o funcionamento da Comissão Mista de Especialidades (CME), composta pelo Conselho Federal de Medicina (CFM), pela Associação Médica Brasileira (AMB) e pela Comissão Nacional de Residência Médica (CNRM), que normatiza o reconhecimento e o registro das especialidades médicas e respectivas áreas de atuação no âmbito dos Conselhos de Medicina;

CONSIDERANDO, finalmente, o decidido em reunião plenária de 22 de julho de 2016; 


\section{RESOLVE:}

Art. $1^{\circ}$ Homologar a Portaria CME no 02/2016, anexa, que aprova a relação de especialidades e áreas de atuação médicas aprovadas pela Comissão Mista de Especialidades.

Art. $2^{\mathbf{0}}$ Revogam-se todas as disposições em contrário e em especial as

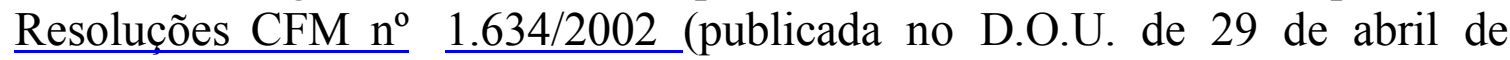
2002, Seção I, p. 81) e $\underline{n}^{0} 2.116 / 2015$ (publicada no D.O.U. de 4 de fevereiro de 2015, Seção I, p. 55).

Art. $3^{\circ}$ Esta resolução entra em vigor na data de sua publicação.

Brasília-DF, 22 de julho de 2016.

CARLOS VITAL TAVARES CORRÊA LIMA

Presidente

HENRIQUE BATISTA E SILVA

Secretário-geral 


\section{ANEXO DA RESOLUÇÃO CFM Nº 2.149/2016}

\section{PORTARIA CME No 02/2016}

A COMISSÃO MISTA DE ESPECIALIDADES (CME), no uso das atribuições que lhe confere o Decreto $\mathrm{n}^{\circ} 8.516$, de 10 de setembro de 2015, e considerando o disposto nas Leis $\mathrm{n}^{\circ}$ 6.932, de 7 de julho de 1981, e $\mathrm{n}^{\mathrm{o}} 12.871$, de 22 de outubro de 2013, resolve:

Art. $1^{0}$ Aprovar a seguinte relação de especialidades e áreas de atuação médicas.

\section{A) RELAÇÃO DAS ESPECIALIDADES MÉDICAS RECONHECIDAS}

1. Acupuntura

2. Alergia e imunologia

3. Anestesiologia

4. Angiologia

5. Cancerologia

6. Cardiologia

7. Cirurgia cardiovascular

8. Cirurgia da mão

9. Cirurgia de cabeça e pescoço

10. Cirurgia do aparelho digestivo

11. Cirurgia geral

12. Cirurgia pediátrica

13. Cirurgia plástica

14. Cirurgia torácica

15. Cirurgia vascular

16. Clínica médica

17. Coloproctologia

18. Dermatologia

19. Endocrinologia e metabologia

20. Endoscopia

21. Gastroenterologia

22. Genética médica

23. Geriatria

24. Ginecologia e obstetrícia

25. Hematologia e hemoterapia

26. Homeopatia 
27. Infectologia

28. Mastologia

29. Medicina de emergência

30. Medicina de família e comunidade

31. Medicina do trabalho

32. Medicina de tráfego

33. Medicina esportiva

34. Medicina física e reabilitação

35. Medicina intensiva

36. Medicina legal e perícia médica

37. Medicina nuclear

38. Medicina preventiva e social

39. Nefrologia

40. Neurocirurgia

41. Neurologia

42. Nutrologia

43. Oftalmologia

44. Ortopedia e traumatologia

45. Otorrinolaringologia

46. Patologia

47. Patologia clínica/medicina laboratorial

48. Pediatria

49. Pneumologia

50. Psiquiatria

51. Radiologia e diagnóstico por imagem

52. Radioterapia

53. Reumatologia

54. Urologia

\section{B) RELAÇÃO DAS ÁREAS DE ATUAÇÃO MÉDICAS RECONHECIDAS}

1. Administração em saúde

2. Alergia e imunologia pediátrica

3. Angiorradiologia e cirurgia endovascular

4. Atendimento ao queimado

5. Cardiologia pediátrica

6. Cirurgia bariátrica

7. Cirurgia crânio-maxilo-facial

8. Cirurgia do trauma 
9. Cirurgia videolaparoscópica

10. Citopatologia

11. Densitometria óssea

12. Dor

13. Ecocardiografia

14. Ecografia vascular com doppler

15. Eletrofisiologia clínica invasiva

16. Emergência pediátrica

17. Endocrinologia pediátrica

18. Endoscopia digestiva

19. Endoscopia ginecológica

20. Endoscopia respiratória

21. Ergometria

22. Foniatria

23. Gastroenterologia pediátrica

24. Hansenologia

25. Hematologia e hemoterapia pediátrica

26. Hemodinâmica e cardiologia intervencionista

27. Hepatologia

28. Infectologia hospitalar

29. Infectologia pediátrica

30. Mamografia

31. Medicina de urgência

32. Medicina do adolescente

33. Medicina do sono

34. Medicina fetal

35. Medicina intensiva pediátrica

36. Medicina paliativa

37. Medicina tropical

38. Nefrologia pediátrica

39. Neonatologia

40. Neurofisiologia clínica

41. Neurologia pediátrica

42. Neurorradiologia

43. Nutrição parenteral e enteral

44. Nutrição parenteral e enteral pediátrica

45. Nutrologia pediátrica

46. Pneumologia pediátrica

47. Psicogeriatria

48. Psicoterapia

49. Psiquiatria da infância e adolescência 
50. Psiquiatria forense

51. Radiologia intervencionista e angiorradiologia

52. Reprodução assistida

53. Reumatologia pediátrica

54. Sexologia

55. Toxicologia médica

56. Transplante de medula óssea

57. Ultrassonografia em ginecologia e obstetrician

\section{C) TITULAÇÕES DE ESPECIALIDADES MÉDICAS}

Título de especialista em ACUPUNTURA

Formação: 2 anos

CNRM: Programa de Residência Médica em Acupuntura

AMB: Concurso do Convênio AMB/Colégio Médico de Acupuntura

Título de especialista em ALERGIA e IMUNOLOGIA

Formação: 2 anos

CNRM: Programa de Residência Médica em Alergia e Imunopatologia

AMB: Concurso do Convênio AMB/Associação Brasileira de Alergia e Imunopatologia

Título de especialista em ANESTESIOLOGIA

Formação: 3 anos

CNRM: Programa de Residência Médica em Anestesiologia

AMB: Concurso do Convênio AMB/Sociedade Brasileira de Anestesiologia

Título de especialista em ANGIOLOGIA

Formação: 2 anos

CNRM: Programa de Residência Médica em Angiologia

AMB: Concurso do Convênio AMB/Sociedade Brasileira de Angiologia e Cirurgia Vascular

Título de especialista em CANCEROLOGIA/CANCEROLOGIA CLÍNICA

Formação: 3 anos

CNRM: Programa de Residência Médica em Cancerologia/Clínica

AMB: Concurso do Convênio AMB/Sociedade Brasileira de Cancerologia 
Título de especialista em CANCEROLOGIA/CANCEROLOGIA CIRÚRGICA

Formação: 3 anos

CNRM: Programa de Residência Médica em Cancerologia/Cirúrgica AMB:

Concurso do Convênio AMB/Sociedade Brasileira de Cancerologia

Título de especialista em CANCEROLOGIA/CANCEROLOGIA PEDIÁTRICA

Formação: 2 anos

CNRM: Programa de Residência Médica em Cancerologia/Pediátrica AMB: Concurso do Convênio AMB/Sociedade Brasileira de Cancerologia

Título de especialista em CARDIOLOGIA

Formação: 2 anos

CNRM: Programa de Residência Médica em Cardiologia

AMB: Concurso do Convênio AMB/Sociedade Brasileira de Cardiologia

Título de especialista em CIRURGIA CARDIOVASCULAR Formação: 4 anos

CNRM: Programa de Residência Médica em Cirurgia Cardiovascular

AMB: Concurso do Convênio AMB/Sociedade Brasileira de Cirurgia Cardiovascular

Título de especialista em CIRURGIA DA MÃO

Formação: 2 anos

CNRM: Programa de Residência Médica em Cirurgia da Mão

AMB: Concurso do Convênio AMB/Sociedade Brasileira de Cirurgia da Mão

Título de especialista em CIRURGIA DE CABEÇA E PESCOÇO Formação: 2 anos

CNRM: Programa de Residência Médica em Cirurgia de Cabeça e Pescoço AMB: Concurso do Convênio AMB/Sociedade Brasileira de Cirurgia de Cabeça e Pescoço

Título de especialista em CIRURGIA DO APARELHO DIGESTIVO Formação: 2 anos

CNRM: Programa de Residência Médica em Cirurgia do Aparelho Digestivo AMB: Concurso do Convênio AMB/Colégio Brasileiro de Cirurgia Digestiva 
Título de especialista em CIRURGIA GERAL

Formação: 2 anos

CNRM: Programa de Residência Médica em Cirurgia Geral

AMB: Concurso do Convênio AMB/Colégio Brasileiro de Cirurgiões

Título de especialista em CIRURGIA PEDIÁTRICA

Formação: 3 anos

CNRM: Programa de Residência Médica em Cirurgia Pediátrica

AMB: Concurso do Convênio AMB/Sociedade Brasileira de Cirurgia Pediátrica

Título de especialista em CIRURGIA PLÁSTICA

Formação: 3 anos

CNRM: Programa de Residência Médica em Cirurgia Plástica

AMB: Concurso do Convênio AMB/Sociedade Brasileira de Cirurgia Plástica

Título de especialista em CIRURGIA TORÁCICA

Formação: 2 anos

CNRM: Programa de Residência Médica em Cirurgia Torácica

AMB: Concurso do Convênio AMB/Sociedade Brasileira de Cirurgia Torácica

Título de especialista em CIRURGIA VASCULAR

Formação: 2 anos

CNRM: Programa de Residência Médica em Cirurgia Vascular

AMB: Concurso do Convênio AMB/Sociedade Brasileira de Angiologia e Cirurgia Vascular

Título de especialista em CLÍNICA MÉDICA

Formação: 2 anos

CNRM: Programa de Residência Médica em Clínica Médica

AMB: Concurso do Convênio AMB/Sociedade Brasileira de Clínica Médica

Título de especialista em COLOPROCTOLOGIA

Formação: 2 anos

CNRM: Programa de Residência Médica em Coloproctologia

AMB: Concurso do Convênio AMB/Sociedade Brasileira de Coloproctologia 
Título de especialista em DERMATOLOGIA

Formação: 3 anos

CNRM: Programa de Residência Médica em Dermatologia

AMB: Concurso do Convênio AMB/Sociedade Brasileira de Dermatologia

Título de especialista em ENDOCRINOLOGIA E METABOLOGIA Formação: 2 anos

CNRM: Programa de Residência Médica em Endocrinologia e Metabologia AMB: Concurso do Convênio AMB/Sociedade Brasileira de Endocrinologia e Metabologia

Título de especialista em ENDOSCOPIA

Formação: 2 anos

CNRM: Programa de Residência Médica em Endoscopia

AMB: Concurso do Convênio AMB/Sociedade Brasileira de Endoscopia Digestiva

Título de especialista em GASTROENTEROLOGIA

Formação: 2 anos

CNRM: Programa de Residência Médica em Gastroenterologia

AMB: Concurso do Convênio AMB/Federação Brasileira de Gastroenterologia

Título de especialista em GENÉTICA MÉDICA

Formação: 3 anos

CNRM: Programa de Residência Médica em Genética Médica

AMB: Concurso do Convênio AMB/Sociedade Brasileira de Genética Médica

Título de especialista em GERIATRIA

Formação: 2 anos

CNRM: Programa de Residência Médica em Geriatria

AMB: Concurso do Convênio AMB/Sociedade Brasileira de Geriatria e Gerontologia

Título de especialista em GINECOLOGIA E OBSTETRÍCIA Formação: 3 anos

CNRM: Programa de Residência Médica em Ginecologia e Obstetrícia AMB: Concurso do Convênio AMB/Federação Brasileira das Sociedades de Ginecologia e Obstetrícia 
Título de especialista em HEMATOLOGIA E HEMOTERAPIA Formação: 2 anos

CNRM: Programa de Residência Médica em Hematologia e Hemoterapia AMB: Concurso do Convênio AMB/Sociedade Brasileira de Hematologia e Hemoterapia

Título de especialista em HOMEOPATIA

Formação: 2 anos

CNRM: Programa de Residência Médica em Homeopatia

AMB: Concurso do Convênio AMB/Associação Médica Homeopática Brasileira

Título de especialista em INFECTOLOGIA

Formação: 3 anos

CNRM: Programa de Residência Médica em Infectologia

AMB: Concurso do Convênio AMB/Sociedade Brasileira de Infectologia

Título de especialista em MASTOLOGIA

Formação: 2 anos

CNRM: Programa de Residência Médica em Mastologia

AMB: Concurso do Convênio AMB/Sociedade Brasileira de Mastologia

Título de especialista em MEDICINA DE EMERGÊNCIA Formação: 3 anos

CNRM: Programa de Residência Médica em Medicina de Emergência AMB: Concurso AMB

Título de especialista em MEDICINA DE FAMÍLIA E COMUNIDADE Formação: 2 anos

CNRM: Programa de Residência Médica em Medicina de Família e Comunidade

AMB: Concurso do Convênio AMB / Sociedade Brasileira de Medicina de Comunidade

Título de especialista em MEDICINA DO TRABALHO Formação: 2 anos CNRM: Programa de Residência Médica em Medicina do Trabalho AMB: Concurso do Convênio AMB/Associação Nacional de Medicina do Trabalho

Título de especialista em MEDICINA DE TRÁFEGO Formação: 2 anos 
CNRM: Programa de Residência Médica em Medicina de Tráfego

AMB: Concurso do Convênio AMB/Associação Brasileira de Medicina de Tráfego

Título de especialista em MEDICINA ESPORTIVA

Formação: 2 anos

CNRM: Programa de Residência Médica em Medicina Esportiva

AMB: Concurso do Convênio AMB/Sociedade Brasileira de Medicina do Exercício e Esporte

Título de especialista em MEDICINA FÍSICA E REABILITAÇÃO

Formação: 3 anos

CNRM: Programa de Residência Médica em Medicina Física e Reabilitação AMB: Concurso do Convênio AMB/Sociedade Brasileira de Medicina Física e Reabilitação

Título de especialista em MEDICINA INTENSIVA

Formação: 2 anos

CNRM: Programa de Residência Médica em Medicina Intensiva

AMB: Concurso do Convênio AMB/Associação de Medicina Intensiva Brasileira

Título de especialista em MEDICINA LEGAL E PERÍCIA MÉDICA Formação: 3 anos

CNRM: Programa de Residência Médica em Medicina Legal e Perícia Médica

AMB: Concurso do Convênio AMB/Associação Brasileira de Medicina Legal e Perícias Médicas

Título de especialista em MEDICINA NUCLEAR

Formação: 3 anos

CNRM: Programa de Residência Médica em Medicina Nuclear

AMB: Concurso do Convênio AMB/Sociedade Brasileira de Medicina Nuclear

Título de especialista em MEDICINA PREVENTIVA E SOCIAL Formação: 2 anos

CNRM: Programa de Residência Médica em Medicina Preventiva e Social AMB: Associação Brasileira de Medicina Preventiva e Administração em Saúde 
Título de especialista em NEFROLOGIA

Formação: 2 anos

CNRM: Programa de Residência Médica em Nefrologia

AMB: Concurso do Convênio AMB/Sociedade Brasileira de Nefrologia

Título de especialista em NEUROCIRURGIA

Formação: 5 anos

CNRM: Programa de Residência Médica em Neurocirurgia

AMB: Concurso do Convênio AMB/Sociedade Brasileira de Neurocirurgia

Título de especialista em NEUROLOGIA

Formação: 3 anos

CNRM: Programa de Residência Médica em Neurologia

AMB: Concurso do Convênio AMB/Academia Brasileira de Neurologia

Título de especialista em NUTROLOGIA

Formação: 2 anos

CNRM: Programa de Residência Médica em Nutrologia

AMB: Concurso do Convênio AMB/Associação Brasileira de Nutrologia

Título de especialista em OFTALMOLOGIA

Formação: 3 anos

CNRM: Programa de Residência Médica em Oftalmologia

AMB: Concurso do Convênio AMB/Conselho Brasileiro de Oftalmologia

Título de especialista em ORTOPEDIA E TRAUMATOLOGIA

Formação: 3 anos

CNRM: Programa de Residência Médica em Ortopedia e Traumatologia

AMB: Concurso do Convênio AMB/Sociedade Brasileira de Ortopedia e Traumatologia

Título de especialista em OTORRINOLARINGOLOGIA

Formação: 3 anos

CNRM: Programa de Residência Médica em Otorrinolaringologia

AMB: Concurso do Convênio AMB/Associação Brasileira de Otorrinolaringologia e Cirurgia Cérvico-Facial

Título de especialista em PATOLOGIA

Formação: 3 anos

CNRM: Programa de Residência Médica em Patologia

AMB: Concurso do Convênio AMB/Sociedade Brasileira de Patologia 
Título de especialista em PATOLOGIA CLÍNICA/MEDICINA LABORATORIAL

Formação: 3 anos

CNRM: Programa de Residência Médica em Patologia Clínica/Medicina Laboratorial

AMB: Concurso do Convênio AMB/Sociedade Brasileira de Patologia Clínica/Medicina Laboratorial

Título de especialista em PEDIATRIA

Formação: 2 anos

CNRM: Programa de Residência Médica em Pediatria

AMB: Concurso do Convênio AMB/Sociedade Brasileira de Pediatria

Título de especialista em PNEUMOLOGIA

Formação: 2 anos

CNRM: Programa de Residência Médica em Pneumologia

AMB: Concurso do Convênio AMB/Sociedade Brasileira de Pneumologia e Tisiologia

Título de especialista em PSIQUIATRIA

Formação: 3 anos

CNRM: Programa de Residência Médica em Psiquiatria

AMB: Concurso do Convênio AMB/Associação Brasileira de Psiquiatria

Título de especialista em RADIOLOGIA E DIAGNÓSTICO POR IMAGEM

Formação: 3 anos

CNRM: Programa de Residência Médica em Radiologia e Diagnóstico por Imagem

AMB: Concurso do Convênio AMB/Colégio Brasileiro de Radiologia e Diagnóstico por Imagem

Título de especialista em DIAGNÓSTICO POR IMAGEM - atuação exclusiva: ULTRASSONOGRAFIA GERAL

Formação: 2 anos

AMB: Concurso do Convênio AMB/Colégio Brasileiro de Radiologia e Diagnóstico por Imagem

Título de especialista em DIAGNÓSTICO POR IMAGEM - atuação exclusiva: RADIOLOGIA ANGIORRADIOLOGIA 
Formação: 2 anos

AMB: Concurso do Convênio AMB/Colégio Brasileiro de Radiologia e Diagnóstico por Imagem

Título de especialista em RADIOTERAPIA

Formação: 3 anos

CNRM: Programa de Residência Médica em Radioterapia

AMB: Concurso do Convênio AMB/Sociedade Brasileira de Radioterapia

Título de especialista em REUMATOLOGIA

Formação: 2 anos

CNRM: Programa de Residência Médica em Reumatologia

AMB: Concurso do Convênio AMB/Sociedade Brasileira de Reumatologia

Título de especialista em UROLOGIA

Formação: 3 anos

CNRM: Programa de Residência Médica em Urologia

AMB: Concurso do Convênio AMB/Sociedade Brasileira de Urologia

\section{D) CERTIFICAÇÕES DE ÁREAS DE ATUAÇÃO}

\section{ADMINISTRAÇÃO EM SAÚDE}

Formação: 1 ano

CNRM: Opcional em qualquer programa de residência médica (PRM)

AMB: Concurso do Convênio AMB/Sociedade Brasileira de Administração de Saúde Requisito: título de especialista da AMB (TEAMB)

\section{ALERGIA E IMUNOLOGIA PEDIÁTRICA}

Formação: 2 anos

CNRM: Opcional em PRM em Alergia e Imunologia ou Pediatria AMB: Concurso do Convênio AMB

Requisitos:TEAMB em Alergia e Imunologia TEAMB em Pediatria

\section{ANGIORRADIOLOGIA E CIRURGIA ENDOVASCULAR}

Formação: 1 ano

CNRM: Opcional em PRM em Radiologia e Diagnóstico por Imagem, Cirurgia Vascular ou Angiologia

AMB: Concurso do Convênio AMB/Colégio Brasileiro de Radiologia e Diagnóstico por Imagem/Sociedade Brasileira de Angiologia e Cirurgia Vascular

Requisitos: TEAMB em Angiologia 
TEAMB em Cirurgia Vascular

TEAMB em Radiologia e Diagnóstico por Imagem

\section{ATENDIMENTO AO QUEIMADO}

Formação: 1 ano

CNRM: Opcional em PRM em Cirurgia Plástica

AMB: Concurso do Convênio AMB/Sociedade Brasileira de Cirurgia Plástica Requisito: TEAMB em Cirurgia Plástica

\section{CARDIOLOGIA PEDIÁTRICA}

Formação: 2 anos

CNRM: Opcional em PRM em Cardiologia ou Pediatria

AMB: Concurso do Convênio AMB/Sociedade Brasileira de Cardiologia/Sociedade Brasileira de Pediatria

Requisitos: TEAMB em Cardiologia

TEAMB em Pediatria

\section{CIRURGIA BARIÁTRICA}

Formação: 2 anos

CNRM: Opcional em PRM em Cirurgia do Aparelho Digestivo ou Cirurgia Geral

AMB: Concurso do convênio AMB/Colégio Brasileiro de Cirurgia Digestiva/Colégio Brasileiro de Cirurgiões.

Requisitos: TEAMB em Cirurgia do Aparelho Digestivo

TEAMB em Cirurgia Geral

\section{CIRURGIA CRÂNIO-MAXILO-FACIAL}

Formação: 1 ano

CNRM: Opcional em PRM em Cirurgia de Cabeça e Pescoço, Cirurgia Plástica ou Otorrinolaringologia

AMB: Concurso do Convênio AMB/Sociedade Brasileira de Cirurgia de Cabeça e Pescoço/Sociedade Brasileira de Cirurgia Plástica/Associação Brasileira de Otorrinolaringologia e Cirurgia Cérvico-Facial

Requisitos: TEAMB em Cirurgia de Cabeça e Pescoço

TEAMB em Cirurgia Plástica

TEAMB em Otorrinolaringologia

CIRURGIA DO TRAUMA

Formação: 1 ano

CNRM: Opcional em PRM em Cirurgia Geral 
AMB: Concurso do Convênio AMB/Colégio Brasileiro de Cirurgiões Requisito: TEAMB em Cirurgia Geral

\section{CIRURGIA VIDEOLAPAROSCÓPICA}

Formação: 1 ano

CNRM: Opcional em PRM em Cirurgia do Aparelho Digestivo ou Cirurgia Geral AMB: Concurso do Convênio AMB/Colégio Brasileiro de Cirurgia Digestiva/Colégio Brasileiro de Cirurgiões

Requisitos: TEAMB em Cirurgia do Aparelho Digestivo

TEAMB em Cirurgia Geral

CITOPATOLOGIA

Formação: 1 ano

CNRM: Opcional em PRM em Patologia AMB: Concurso AMB

Requisito: TEAMB em Patologia

\section{DENSITOMETRIA ÓSSEA}

Formação: 1 ano

CNRM: Opcional em PRM em Endocrinologia e Metabologia, Ginecologia e Obstetrícia, Medicina Nuclear, Ortopedia e Traumatologia ou Reumatologia

AMB: Concurso do Convênio AMB/Colégio Brasileiro de Radiologia e Diagnóstico por Imagem

Requisitos: TEAMB em Endocrinologia e Metabologia

TEAMB em Ginecologia e Obstetrícia

TEAMB em Medicina Nuclear

TEAMB em Ortopedia e Traumatologia

TEAMB em Reumatologia

DOR

Formação: 1 ano

CNRM: Opcional em PRM em Acupuntura, Anestesiologia, Clínica Médica, Medicina Física e Reabilitação, Neurocirurgia, Neurologia, Ortopedia, Pediatria ou Reumatologia

AMB: Concurso do Convênio AMB/Colégio Médico de Acupuntura/Sociedade Brasileira de Anestesiologia/Sociedade Brasileira de Clínica Médica/Sociedade Brasileira de Medicina Física e Reabilitação/Sociedade Brasileira de Neurocirurgia/Academia Brasileira de Neurologia/Sociedade Brasileira de Ortopedia e Traumatologia/Sociedade Brasileira de Pediatria/Sociedade Brasileira de Reumatologia

Requisitos:TEAMB em Acupuntura 
TEAMB em Anestesiologia

TEAMB em Clínica Médica

TEAMB em Medicina Física e Reabilitação

TEAMB em Neurocirurgia

TEAMB em Neurologia

TEAMB em Ortopedia

TEAMB em Pediatria

TEAMB em Reumatologia

\section{ECOCARDIOGRAFIA}

Formação: 1 ano

CNRM: Opcional em PRM em Cardiologia

AMB: Concurso do Convênio AMB/Sociedade Brasileira de Cardiologia

Requisitos: TEAMB em Cardiologia

TEAMB em Pediatria + certificado de atuação em Cardiologia Pediátrica

ECOGRAFIA VASCULAR COM DOPPLER

Formação: 1 ano

CNRM: Opcional em PRM em Radiologia, Cirurgia Vascular ou Angiologia

AMB: Concurso do Convênio AMB/Colégio Brasileiro de Radiologia e Diagnóstico por Imagem/Sociedade Brasileira de Angiologia e Cirurgia Vascular

Requisitos: TEAMB em Angiologia

TEAMB em Cardiologia + certificado de atuação em Ecocardiografia

TEAMB em Cirurgia Vascular

TEAMB em Diagnóstico por Imagem: atuação exclusiva Ultrassonografia Geral

TEAMB em Radiologia e Diagnóstico por Imagem

\section{ELETROFISIOLOGIA CLÍNICA INVASIVA}

Formação: 1 ano

CNRM: Opcional em PRM em Cardiologia

AMB: Concurso do Convênio AMB/Sociedade Brasileira de Cardiologia Requisito: TEAMB em Cardiologia

EMERGÊNCIA PEDIÁTRICA

Formação: 1 ano

CNRM: Opcional em PRM em Medicina de Emergência ou Pediatria 
AMB: Concursos AMB

Requisito: TEAMB em Medicina de Emergência

TEAMB em Pediatria

ENDOCRINOLOGIA PEDIÁTRICA

Formação: 2 anos

CNRM: Opcional em PRM em Endocrinologia e Metabologia ou Pediatria

AMB: Concurso do Convênio AMB/Sociedade Brasileira de Endocrinologia

e Metabologia/Sociedade Brasileira de Pediatria

Requisitos: TEAMB em Endocrinologia e Metabologia

TEAMB em Pediatria

\section{ENDOSCOPIA DIGESTIVA}

Formação: 1 ano

CNRM: Opcional em PRM em Endoscopia, Cirurgia do Aparelho Digestivo, Gastroenterologia, Coloproctologia ou Cirurgia Geral

AMB: Concurso do Convênio AMB/Sociedade Brasileira de Endoscopia Digestiva

Requisitos: TEAMB em Cirurgia do Aparelho Digestivo

TEAMB em Cirurgia Geral

TEAMB em Coloproctologia

TEAMB em Endoscopia

TEAMB em Gastroenterologia

\section{ENDOSCOPIA GINECOLÓGICA}

Formação: 1 ano

CNRM: Opcional em PRM em Ginecologia e Obstetrícia

AMB: Concurso do Convênio AMB/Federação Brasileira das Sociedades de Ginecologia e Obstetrícia

Requisito: TEAMB em Ginecologia e Obstetrícia

ENDOSCOPIA RESPIRATÓRIA

Formação: 1 ano

CNRM: Opcional em PRM em Cirurgia Torácica ou Pneumologia

AMB:Concurso do Convênio AMB/Sociedade Brasileira de

Pneumologiae Tisiologia/Sociedade Brasileira de Cirurgia Torácica

Requisitos: TEAMB em Cirurgia Torácica

TEAMB em Pneumologia

ERGOMETRIA

Formação: 1 ano 
CNRM: Opcional em PRM em Cardiologia

AMB: Concurso do Convênio AMB/Sociedade Brasileira de Cardiologia Requisito: TEAMB em Cardiologia

FONIATRIA

Formação: 1 ano

CNRM: Opcional em PRM em Otorrinolaringologia

AMB: Concurso do Convênio AMB/Associação Brasileira de Otorrinolaringologia Cirurgia Cérvico-Facial

Requisito: TEAMB em Otorrinolaringologia

GASTROENTEROLOGIA PEDIÁTRICA

Formação: 2 anos

CNRM: Opcional em PRM em Gastroenterologia ou Pediatria

AMB: Concurso do Convênio AMB/Federação Brasileira de Gastroenterologia/Sociedade Brasileira de Pediatria

Requisitos: TEAMB em Gastroenterologia

TEAMB em Pediatria

\section{HANSENOLOGIA}

Formação: 1 ano

CNRM: Opcional em PRM em Clínica Médica, Dermatologia, Infectologia, Medicina Preventiva e Social, Medicina de Família e Comunidade ou Neurologia AMB: Concurso AMB

Requisitos: TEAMB em Clínica Médica

TEAMB em Dermatologia

TEAMB em Infectologia

TEAMB em Medicina de Família e Comunidade

TEAMB em Medicina Preventiva e Social

TEAMB em Neurologia

\section{HEMATOLOGIA E HEMOTERAPIA PEDIÁTRICA}

Formação: 2 anos

CNRM: Opcional em PRM em Hematologia e Hemoterapia ou Pediatria

AMB: Concurso do Convênio AMB/Sociedade Brasileira de Hematologia e Hemoterapia/Sociedade Brasileira de Pediatria

Requisitos: TEAMB em Hematologia e Hemoterapia

TEAMB em Pediatria

HEMODINÂMICA E CARDIOLOGIA INTERVENCIONISTA 
Formação: 2 anos

CNRM: Opcional em PRM em Cardiologia

AMB: Concurso do Convênio AMB/Sociedade Brasileira de Cardiologia

Requisitos: TEAMB em Cardiologia

Pediátrica

TEAMB em Pediatria + certificado de atuação em Cardiologia

\section{HEPATOLOGIA}

Formação: 2 anos

CNRM: Opcional em PRM em Clínica Médica, Gastroenterologia ou Infectologia AMB: Concurso AMB

Requisitos: TEAMB em Clínica Médica

TEAMB em Gastroenterologia

TEAMB em Infectologia

\section{INFECTOLOGIA HOSPITALAR}

Formação: 1 ano

CNRM: Opcional em PRM em Infectologia

AMB: Concurso do Convênio AMB/Sociedade Brasileira de Infectologia Requisito: TEAMB em Infectologia

\section{INFECTOLOGIA PEDIÁTRICA}

Formação: 2 anos

CNRM: Opcional em PRM em Infectologia ou Pediatria

AMB: Concurso do Convênio AMB/Sociedade Brasileira de Infectologia/Sociedade Brasileira de Pediatria

Requisitos: TEAMB em Infectologia

TEAMB em Pediatria

\section{MAMOGRAFIA}

Formação: 1 ano

CNRM: Opcional em PRM em Ginecologia e Obstetrícia ou Mastologia

AMB: Concurso do Convênio AMB/Colégio Brasileiro de Radiologia e Diagnóstico por Imagem/Federação Brasileira das Sociedades de Ginecologia e Obstetrícia/Sociedade Brasileira de Mastologia

Requisitos: TEAMB em Diagnóstico por Imagem - atuação exclusiva: Ultrassonografia Geral

TEAMB em Ginecologia e Obstetrícia TEAMB em Mastologia

MEDICINA DE URGÊNCIA

Formação: 1 ano 
CNRM: Opcional em PRM em Clínica Médica

AMB: Concurso do Convênio AMB/Sociedade Brasileira de Clínica Médica Requisito: TEAMB em Clínica Médica

\section{MEDICINA DO ADOLESCENTE}

Formação: 1 ano

CNRM: Opcional em PRM em Pediatria

AMB: Concurso do Convênio AMB/Sociedade Brasileira de Pediatria Requisito: TEAMB em Pediatria

\section{MEDICINA DO SONO}

Formação: 1 ano

CNRM: Opcional em PRM em Clínica Médica, Neurologia, Otorrinolaringologia, Pediatria, Pneumologia ou Psiquiatria

AMB: Concurso do Convênio AMB/Academia Brasileira de Neurologia/Associação Brasileira de Otorrinolaringologia e Cirurgia Cérvico-Facial/Sociedade Brasileira de Pediatria/Sociedade Brasileira de Pneumologia e Tisiologia/Sociedade Brasileira de Psiquiatria/Sociedade Brasileira de Clínica Médica

Requisitos: TEAMB em Clínica Médica

TEAMB em Neurologia

TEAMB em Otorrinolaringologia

TEAMB em Pediatria

TEAMB em Pneumologia

TEAMB em Psiquiatria

\section{MEDICINA FETAL}

Formação: 1 ano

CNRM: Opcional em PRM em Ginecologia e Obstetrícia

AMB: Concurso do Convênio AMB/Federação Brasileira das Sociedades de Ginecologia e Obstetrícia

Requisito: TEAMB em Ginecologia e Obstetrícia

\section{MEDICINA INTENSIVA PEDIÁTRICA}

Formação: 2 anos

CNRM: Opcional em PRM em Medicina Intensiva ou Pediatria

AMB: Concurso do Convênio AMB/Associação de Medicina Intensiva Brasileira/Sociedade Brasileira de Pediatria Requisitos: TEAMB em Medicina Intensiva

TEAMB em Pediatria 


\section{MEDICINA PALIATIVA}

Formação: 1 ano

CNRM: Opcional em PRM em Anestesiologia, Cancerologia, Clínica Médica, Geriatria, Medicina de Família e Comunidade ou Pediatria, Cirurgia de Cabeça e Pescoço, Medicina Intensiva e Neurologia.

AMB: Concurso do Convênio AMB/Sociedade Brasileira de Anestesiologia/Sociedade Brasileira de Cancerologia/Sociedade Brasileira de Clínica Médica/Sociedade Brasileira de Geriatria e Gerontologia/Sociedade Brasileira de Medicina de Família e Comunidade/Sociedade Brasileira de Pediatria/Sociedade Brasileira de Cirurgia de Cabeça e Pescoço/Associação de Medicina Intensiva Brasileira/Academia Brasileira de Neurologia

Requisitos: TEAMB em Anestesiologia

TEAMB em Cancerologia

TEAMB em Clínica Médica

TEAMB em Geriatria

TEAMB em Medicina de Família e Comunidade

TEAMB em Pediatria

TEAMB em Cirurgia de Cabeça e Pescoço

TEAMB em Medicina Intensiva

TEAMB em Neurologia

MEDICINA TROPICAL

Formação: 1 ano

CNRM: Opcional em PRM em Infectologia

AMB: Concurso do Convênio AMB/Sociedade Brasileira de Infectologia Requisito: TEAMB em Infectologia

\section{NEFROLOGIA PEDIÁTRICA}

Formação: 2 anos

CNRM: Opcional em PRM em Nefrologia ou Pediatria

AMB: Concurso do Convênio AMB/Sociedade Brasileira de Nefrologia/Sociedade Brasileira de Pediatria

Requisitos: TEAMB em Nefrologia

TEAMB em Pediatria

\section{NEONATOLOGIA}

Formação: 2 anos

CNRM: Opcional em PRM em Pediatria

AMB: Concurso do Convênio AMB/Sociedade Brasileira de Pediatria Requisito: TEAMB em Pediatria 


\section{NEUROFISIOLOGIA CLÍNICA}

Formação: 1 ano

CNRM: Opcional em PRM em Medicina Física e Reabilitação, Neurologia ou Neurocirurgia AMB: Concurso AMB

Requisitos: TEAMB em Medicina Física e Reabilitação TEAMB em Neurocirurgia

TEAMB em Neurologia

TEAMB em Pediatria + certificado de atuação em Neurologia Pediátrica

\section{NEUROLOGIA PEDIÁTRICA}

Formação: 2 anos

CNRM: Opcional em PRM em Neurologia ou Pediatria

AMB: Concurso do Convênio AMB/Academia Brasileira de Neurologia/Sociedade Brasileira de Pediatria

Requisitos: TEAMB em Neurologia

TEAMB em Pediatria

\section{NEURORRADIOLOGIA}

Formação: 1 ano

CNRM: Opcional em PRM em Radiologia e Diagnóstico por Imagem, Neurologia ou Neurocirurgia

AMB: Concurso do Convênio AMB/Colégio Brasileiro de Radiologia e Diagnóstico por Imagem

Requisitos: TEAMB em Neurocirurgia

TEAMB em Neurologia

TEAMB em Radiologia e Diagnóstico por Imagem

\section{NUTRIÇÃO PARENTERAL E ENTERAL}

Formação: 1 ano

CNRM: Opcional em PRM em Nutrologia, Pediatria, Medicina Intensiva, Cirurgia do Aparelho Digestivo, Gastroenterologia ou Cirurgia Geral AMB: Concurso AMB

Requisitos: TEAMB em Cirurgia do Aparelho Digestivo TEAMB em Cirurgia Geral

TEAMB em Gastroenterologia TEAMB em Medicina Intensiva

TEAMB em Nutrologia

TEAMB em Pediatria

NUTRIÇÃO PARENTERAL E ENTERAL PEDIÁTRICA 
Formação: 2 anos

CNRM: Opcional em PRM em Nutrologia ou Pediatria AMB: Concurso AMB

Requisitos: TEAMB em Nutrologia

TEAMB em Pediatria

NUTROLOGIA PEDIÁTRICA

Formação: 2 anos

CNRM: Opcional em PRM em Nutrologia ou Pediatria

AMB: Concurso do Convênio AMB/Sociedade Brasileira de Pediatria/Associação Brasileira de Nutrologia

Requisitos: TEAMB em Nutrologia

TEAMB em Pediatria

PNEUMOLOGIA PEDIÁTRICA

Formação: 2 anos

CNRM: Opcional em PRM em Pediatria ou Pneumologia

AMB: Concurso do Convênio AMB/Sociedade Brasileira de Pediatria/ Sociedade Brasileira de Pneumologia e Tisiologia

Requisitos: TEAMB em Pediatria

TEAMB em Pneumologia

PSICOGERIATRIA

Formação: 1 ano

CNRM: Opcional em PRM em Psiquiatria

AMB: Concurso do Convênio AMB/Associação Brasileira de Psiquiatria

Requisito: TEAMB em Psiquiatria

PSICOTERAPIA

Formação: 1 ano

CNRM: Opcional em PRM em Psiquiatria

AMB: Concurso do Convênio AMB/Associação Brasileira de Psiquiatria Requisito: TEAMB em Psiquiatria

PSIQUIATRIA DA INFÂNCIA E ADOLESCÊNCIA

Formação: 1 ano

CNRM: Opcional em PRM em Psiquiatria

AMB: Concurso do Convênio AMB/Associação Brasileira de Psiquiatria

Requisito: TEAMB em Psiquiatria

PSIQUIATRIA FORENSE 
Formação: 1 ano

CNRM: Opcional em PRM em Psiquiatria

AMB: Concurso do Convênio AMB/Associação Brasileira de Psiquiatria Requisito: TEAMB em Psiquiatria

\section{RADIOLOGIA INTERVENCIONISTA E ANGIORRADIOLOGIA}

Formação: 1 ano

CNRM: Opcional em PRM em Angiologia, Cirurgia Vascular ou Radiologia e Diagnóstico por Imagem

AMB: Concurso do Convênio AMB/Colégio Brasileiro de Radiologia e Diagnóstico por Imagem/Sociedade Brasileira de Angiologia e Cirurgia Vascular

Requisitos: TEAMB em Angiologia

TEAMB em Cirurgia Vascular

TEAMB em Radiologia e Diagnóstico por Imagem

\section{REPRODUÇÃO ASSISTIDA}

Formação: 1 ano

CNRM: Opcional em PRM em Ginecologia e Obstetrícia

AMB: Concurso do Convênio AMB/Federação Brasileira das Sociedades de Ginecologia e Obstetrícia

Requisito: TEAMB em Ginecologia e Obstetrícia

\section{REUMATOLOGIA PEDIÁTRICA}

Formação: 2 anos

CNRM: Opcional em PRM em Reumatologia ou Pediatria

AMB: Concurso do Convênio AMB/Sociedade Brasileira de Pediatria/Sociedade Brasileira de Reumatologia

Requisitos: TEAMB em Pediatria

TEAMB em Reumatologia

\section{SEXOLOGIA}

Formação: 1 ano

CNRM: Opcional em PRM em Ginecologia e Obstetrícia

AMB: Concurso do Convênio AMB/Federação Brasileira das Sociedades de Ginecologia e Obstetrícia

Requisito: TEAMB em Ginecologia e Obstetrícia

TOXICOLOGIA MÉDICA

Formação: 1 ano

CNRM: Opcional em PRM em Clínica Médica ou Medicina Intensiva ou 
Pediatria ou Pneumologia

AMB: Concurso do Convênio AMB/Sociedade Brasileira de Clínica Médica/Associação de Medicina Intensiva Brasileira/Sociedade Brasileira de Pediatria/Sociedade Brasileira de Pneumologia e Tisiologia

Requisitos: TEAMB em Clínica Médica

TEAMB em Medicina Intensiva

TEAMB em Pediatria

TEAMB em Pneumologia

TRANSPLANTE DE MEDULA ÓSSEA

Formação: 1 ano

CNRM: Opcional em PRM em Hematologia e Hemoterapia

AMB: Concurso do Convênio AMB/Sociedade Brasileira de Hematologia e Hemoterapia

Requisito: TEAMB em Hematologia e Hemoterapia

ULTRASSONOGRAFIA EM GINECOLOGIA E OBSTETRÍCIA

Formação: 1 ano

CNRM: Opcional em PRM em Ginecologia e Obstetrícia

AMB: Concurso do Convênio AMB/Colégio Brasileiro de Radiologia e Diagnóstico por Imagem/Federação Brasileira das Sociedades de Ginecologia e Obstetrícia

Requisito: TEAMB em Ginecologia e Obstetrícia

Art. $2^{\circ}$ Revogam-se todas as disposições em contrário.

Brasília, 22 julho de 2016.

MAURO LUIZ DE BRITTO

CFM
MARIA DO PATROCÍNIO NUNES

CFM

\section{ALDEMIR HUMBERTO SOARES FÁBIO BISCEGLI JATENE AMB \\ AMB}

FRANCISCO ARSEGO DE OLIVEIRA FELIPE PROENÇO CNRM

CNRM 


\section{EXPOSIÇÃO DE MOTIVOS DA RESOLUÇÃO CFM N 2.149/2016}

O Decreto $\mathrm{n}^{\mathrm{o}} 8.516$, de 10 de setembro de 2015 , regulamenta a formação do Cadastro Nacional de Especialistas e estabelece a Comissão Mista de Especialidades (CME), vinculada ao CFM, à qual compete definir as especialidades médicas.

O citado Decreto prevê em seu artigo $4^{\circ}, \S 2^{\circ}$, que os representantes da CME definirão as demais competências para sua atuação e as regras de seu funcionamento por meio de ato específico.

Em cumprimento ao referido dispositivo, foi homologada, pela Resolução $\underline{\mathrm{CFM} \mathrm{n}^{\mathrm{o}}} \quad 2.148 / 2016$, a Portaria CME $\mathrm{n}^{\circ}$ 01/2016, que disciplina $\mathrm{o}$ funcionamento da Comissão Mista de Especialidades e normatiza o reconhecimento e o registro das especialidades médicas e respectivas áreas de atuação no âmbito dos Conselhos de Medicina.

Por conseguinte, a citada portaria, em seu artigo $8^{\circ}$, estabelece que "a atualização do rol de especialidades médicas e áreas de atuação reconhecidas, quando ocorrer, será feita por meio de Portaria da CME, que será homologada por resolução do Conselho Federal de Medicina, a qual será publicada no Diário Oficial da União".

Desta forma, a CME, por intermédio desta Resolução dá publicidade à Portaria CME $n^{\circ} 02 / 2016$, onde consta a relação de especialidades e áreas de atuação médicas aprovadas e reconhecidas por esta Comissão.

\section{MAURO LUIZ DE BRITTO RIBEIRO}

Relator 


\section{ANEXO III}

Íntegra da decisão: RECURSO ESPECIAL $\mathrm{N}^{\circ} 1.038 .260$ - ES (2008/0052647-3) RELATORA : MINISTRA ELIANA CALMON RECORRENTE : VAGNER FRANCO DA SILVEIRA ADVOGADO : OSMAR VELLOSO TOGNOLO E OUTRO(S) RECORRIDO : CONSELHO REGIONAL DE MEDICINA DO EST DO ESPIRITO SANTO ADVOGADO : RAPHAEL RABELO CUNHA MELO E OUTRO(S) EMENTA PROCESSUAL CIVIL E ADMINISTRATIVO VIOLAÇÃO DO ART. 535 DO CPC NÃO CARACTERIZADA CONSELHO DE MEDICINA - REGISTRO DE ESPECIALIDADE MÉDICA - "MEDICINA ESTÉTICA" - PODER REGULAMENTAR E FISCALIZATÓRIO. 1. Não ocorre ofensa ao art. 535, II, do CPC, se o Tribunal de origem decide, fundamentadamente, as questões essenciais ao julgamento da lide. 2. O Conselho de Medicina funciona como órgão delegado do Poder Público para tratar das questões envolvendo a saúde pública e as atividades dos profissionais médicos. Precedente do STF. 3. A simples existência de um curso de pós-graduação, ainda que reconhecido pelo MEC, não é capaz de qualificar-se, no universo científico, como nova especialidade médica. 4. As especialidades sujeitam-se aos processos dinâmicos da medicina, não podendo, por isso mesmo, ter caráter permanente ou imutável, dependendo das circunstâncias e necessidades, sofrendo mudanças de nomes, fusões ou extinções. 5. Hipótese em que o Conselho Federal de Medicina não reconheceu a "Medicina Estética" como especialidade médica negando, em conseqüência, o título de especialista ao profissional que concluiu curso de pós-graduação lato sensu. 6 . Não pode o Poder Judiciário invadir a competência dos Conselhos de Medicina, para obrigá-los a conferir o título de especialista, em ramo científico ainda não reconhecido como especialidade médica. 7. Recurso especial não provido. ACÓRDÃO Vistos, relatados e discutidos os autos em que são partes as acima indicadas, acordam os Ministros da Segunda Turma do Superior Tribunal de Justiça "A Turma, por unanimidade, negou provimento ao recurso, nos termos do voto do(a) Sr(a). Ministro(a)-Relator(a)." Os Srs. Ministros Castro Meira, Humberto Martins, Herman Benjamin e Mauro Campbell Marques votaram com a Sra. Ministra Relatora. Dr(a). OSMAR TOGNOLO, pela parte RECORRENTE: VAGNER FRANCO DA SILVEIRA Brasília-DF, 17 de dezembro de 2009 (Data do Julgamento) MINISTRA ELIANA CALMON Relatora RELATÓRIO A EXMA. SRA. MINISTRA ELIANA CALMON: Na origem, cuida-se de mandado de segurança impetrado pelo médico Vagner Franco da Silveira, com pedido de liminar, contra ato do Presidente da Comissão de Títulos de Especialista 
do CRM/ES e do Presidente do Conselho Regional de Medicina - ES, consubstanciado na negativa de registro da sua qualificação de especialista em "Medicina Estética" junto àquele Conselho, após ter concluído curso de pós-graduação, lato sensu, em "Medicina Estética", reconhecido pelo MEC, através da CAPES, junto à Escola de Medicina Fundação TécnicoEducacional Souza Marques, no Rio de Janeiro. O pedido foi negado administrativamente, com fundamento na Resolução 1.634/2002 do Conselho Federal de Medicina, por não haver previsão da especialidade "Medicina Estética". A segurança foi concedida pelo juiz de $1^{\circ}$ grau, mas reformada pelo Tribunal que a reviu em grau de remessa oficial e de recurso voluntário do Conselho Regional de Medicina, ficando assim ementado o aresto (fl. 510): PROCESSUAL CIVIL E ADMINISTRATIVO. LITISCONSÓRCIO PASSIVO. INEXISTÊNCIA. CURSO DE PÓS-GRADUAÇÃO LATO SENSU. ESPECIALIDADE EM MEDICINA ESTÉTICA. IMPOSSIBILIDADE. PROGRAMA DE RESIDÊNCIA MÉDICA CREDENCIADO PELA COMISSÃO NACIONAL DE RESIDÊNCIA MÉDICA. OBRIGATORIEDADE. LEIS $\mathrm{N}^{\circ} \mathrm{S}$ 3.268/57 E 6.932/81. SEGURANÇA DENEGADA. RECURSO E REMESSA PROVIDOS. - Não há falar em intimação do Conselho Federal de Medicina para integrar a lide por inexistir litisconsórcio necessário. A autoridade coatora, no Mandado de Segurança é aquela que tem poder para deferir ou indeferir pedido formulado pelo impetrante, in casu, o Conselho Regional de Medicina, uma vez que a pretensão autoral é dirigida à obtenção de seu registro como especialista em Medicina Estética. - Tem-se que a Lei $n^{\circ} 3.268 / 57$, ao regular a atuação dos Conselhos Regionais de Medicina, estipula, como pressuposto para o médico exercer qualquer especialização, o prévio registro do seu título ou diploma no MEC e a sua inscrição no Conselho Regional de Medicina, não sendo bastante e suficiente, para tal mister, a conclusão em curso de pós-graduação, lato sensu, que é a hipótese dos autos. - Por sua vez, a Lei $\mathrm{n}^{\circ}$ 6.932/81, que dispõe sobre a atividade do médico residente, prevê a obrigatoriedade da residência médica para que o profissional possa obter o título de especialista, devendo tais instituições médicas ser credenciadas pela Comissão Nacional de Residência Médica, conforme as normas insertas no art. $1^{\mathrm{o}}$ e $\S 1^{\circ}$ da mencionada lei. - Inexiste, nos autos, prova de que a Escola de Medicina Souza Marques tenha programa de Residência Médica credenciado pela Comissão Nacional de Residência Médica em conformidade com o estipulado no $\S 1^{\circ}$, do art. $1^{\circ}$, da Lei $n^{\circ} 6.932 / 81$. Assim, não tem o curso de pós-graduação, lato sensu, realizado pelo impetrante, o condão de habilitá-lo a se inscrever como especialista em Medicina Estética perante o Conselho Regional de Medicina. - Recurso e 
remessa providos. Segurança denegada. Opostos embargos declaratórios, restaram rejeitados (fls. 556-557): PROCESSUAL CIVIL. EMBARGOS DE DECLARAÇÃO. REGISTRO NO CONSELHO REGIONAL DE MEDICINA. ESPECIALIDADE EM MEDICINA ESTÉTICA. PROGRAMA DE RESIDÊNCIA MÉDICA CREDENCIADO PELA COMISSÃO NACIONAL DE RESIDÊNCIA MÉDICA. INEXISTÊNCIA DE PROVA PRÉ-CONSTITUÍDA. INEXISTÊNCIA DE VÍCIOS (CPC, ART. 535). MANUTENÇÃO DA DENEGAÇÃO DE SEGURANÇA. RECURSO NÃO PROVIDO. - Inexiste contradição quanto à aplicabilidade do art. 17 da Lei 3.268/57, uma vez que o acórdão não determinou que o impetrante estaria impedido de exercer a Medicina, tendo apenas deixado explicitado que os médicos só poderiam exercer legalmente a Medicina, em qualquer de seus ramos ou especialidades, após o prévio registro de seus títulos ou diploma no MEC e sua inscrição no Conselho Regional de Medicina, "não sendo bastante, para tal mister, a conclusão em curso de pós-graduação" (fl.478). - Igualmente, não há ontradição entre o relatório e fundamentação do voto, vez que ele consiste, tão-somente, em relatar o acontecido nos autos e os arrazoados das partes e como bem preleciona a doutrina: "O traço característico da contradição é representado, pois, pela incoerência, pela desarmonia do pensamento; as ideias contrapõem-se, sem que se possa conciliá-las. (...) É elementar que a contraditoriedade, capaz de ensejar os embargos declaratórios, tem de estar na sentença, ou no acórdão; (MANOEL ANTONIO TEIXEIRA FILHO in "Sistema do Recursos Trabalhistas", ed. LTr São Paulo, 1997, p. 350) E, em nenhum momento, o acórdão afirmou a existência unicamente da residência médica como modalidade de ensino de pós-graduação, ao fazer menção à Lei6.932/81. - Por outro lado, não há falar em omissão de análise de documento relevante, consubstanciado em registro no CRM de aluna que concluiu o mesmo curso de pós-graduação que o impetrante, vez que o paradigma não se refere à especialidade de Medicina Estética, fato afirmado pelo próprio recorrente, nas razões dos embargos, ao consignar que as especialidades são diferentes. Relativamente à omissão quanto à aplicabilidade da Lei 9.394/96, igualmente não prospera o recurso, vez que a matéria, Lei de Diretrizes e Bases da Educação, não é objeto do mandamus, que consiste no direito ao registro do título como especialista em Medicina Estética perante o Conselho Regional de Medicina, não sendo, também, necessária a análise de ser o curso reconhecido pelo MEC e ministrado por entidade por ele autorizada. - Quanto à alegação do embargante de que "o único fundamento para negar a inscrição do título de especialista obtido pelo impetrante foi de que este não se encaixaria em um rol descrito em uma 
resolução do Conselho Federal de Medicina (fls. 215/216), o que é, diga-se com respeito, um absurdo, como bem destacado pelo V. acórdão (...). Era, por todos os motivos, fundamental que o v. acórdão analisasse esses pontos, no que quedou omisso, justificando a oposição destes embargos", igualmente não merece prosperar o argumento, vez que a denegação da ordem se deu sob o fundamento de inexistência de prova pré-constituída de que a Escola de Medicina Souza Marques tenha programa de Residência Médica credenciado pela Comissão Nacional de Residência Médica em conformidade com a Lei6932/81. - Embargos de declaração não providos. Sustenta o recorrente, com fundamento na alínea "a" do permissivo constitucional, violação dos seguintes dispositivos legais: 1) art. 535, II, do CPC, por entender que não houve manifestação do acórdão recorrido sobre os arts. $9^{\circ}$, IX, e 48 da Lei de Diretrizes e Bases da Educação Nacional (Lei 9.394/1996); 2) art. 17 da Lei 3.268/1957, sob o fundamento de que esse dispositivo não limita o registro dos títulos que possuam residência médica: "Apenas exige o registro para que o profissional possa exercer sua profissão e mesmo apresentar-se como especialista em determinada área da medicina. Concluir, daí, como fez o acórdão, que apenas os títulos decorrentes de cumprimento de residência médica seriam idôneos para efetivação do registro é impor condição inexistente na lei, é criar restrição onde a lei não o fez." (fl. 567). 3) art. $1^{\circ}$ da Lei 6.932/1981, porquanto entendeu a Corte a quo que a residência médica seria a única forma de se obter especialização na área de medicina, e tal dispositivo legal não trata de especialização, mas somente de residência médica, "que regulamenta e qualifica como modalidade de curso de pós-graduação". Afirma que o procedimento adotado pelo CRM-ES não está amparado em lei e ressalta que o CRM-RJ registrou o certificado fornecido a outro profissional pela mesma fundação, sem residência médica, como especialista em Medicina do Trabalho. Dessa forma, indaga: por que seria essencial a residência para a "Medicina Estética"? Ressalta, ainda, a existência de várias outras especialidades médicas reconhecidas pelo Conselho Federal que independem da residência médica, como "Alergia e Imunologia Pediátrica" e "Diagnóstico por Imagem", conforme comprovado nos autos à fl. 265; e 4) art. 48 da Lei 9.394/1996, esse dispositivo garante validade em todo o território nacional aos diplomas de especialização obtidos em cursos autorizados pelo Ministério da Educação. Conclui, assim, que se o curso de especialização, de nível de pós-graduação, é reconhecido pelo MEC, os Conselhos Regionais têm obrigação de efetuar o registro, de forma a garantir ao profissional o direito de "se anunciar como especialista na área respectiva.". Em reforço a sua tese, cita o REsp 525.170/SC, da relatoria do Ministro Luiz Fux. Pede seja anulado o acórdão que decidiu os embargos 
declaratórios, mantendo-se a sentença. Após as contra-razões, admitido o especial, subiram os autos. É o relatório. VOTO A EXMA. SRA. MINISTRA ELIANA CALMON (Relatora): Preliminarmente, analiso a alegada afronta ao art. 535 do CPC. Para o recorrente o Tribunal a quo não se manifestou sobre art. 48 da Lei 9.394/1996, que confere validade nacional "aos diplomas de cursos superiores reconhecidos pelo MEC. Essa obrigatoriedade, por óbvio, alcança também os Conselhos de fiscalização profissional, entre os quais os de Medicina" (fl. 565). Entretanto, considero ter o Tribunal Regional solucionado a controvérsia de maneira sólida e fundamentada, como se pode constatar pelo trecho do voto proferido quando do julgamento dos embargos de declaração (fl. 555): Relativamente, à omissão quanto à aplicabilidade da Lei 9394/96, igualmente não prospera o recurso, vez que a matéria, Lei de Diretrizes e Bases da Educação, não é objeto do mandamus, que consiste no direito ao registro do título como especialista em Medicina Estética perante o Conselho Regional de Medicina, não sendo, também, necessária a análise de ser o curso reconhecido pelo MEC e administrado por entidade por ele autorizada. Finalmente, a alegação do embargante de que "o único fundamento para negar a inscrição do título de especialista obtido pelo impetrante foi de que este não se encaixaria em um rol descrito em uma resolução do Conselho Federal de Medicina (fls. 215/216), o que é, diga-se com respeito, um absurdo, como bem destacado pelo V. acórdão (...) Era, por todos os motivos, fundamental que o v. acórdão analisasses esses pontos, no que quedou omisso, justificando a oposição destes embargos", igualmente não merece prosperar o argumento, vez que denegação da ordem se deu sob o fundamento de inexistência de prova pré-constituída de que a Escola de Medicina Souza Marques tenha programada de Residência Médica credenciado pela Comissão Nacional de Residência Médica em conformidade com a Lei 6932/81. Assim, o fato de o julgador ter utilizado fundamento diverso do apresentado pela parte, não implica em omissão do julgado. Ultrapassado esse ponto, prequestionada implicitamente a matéria, passo à análise dos demais dispositivos tidos por violados. Afirma o recorrente ser o curso de especialização reconhecido pelo MEC, e como tal, tem o Conselho Regional obrigação de promover o registro dos diplomas expedidos após a conclusão do curso, de forma a garantir ao profissional o direito de anunciar-se como especialista na área respectiva. $O$ Tribunal de origem, para negar a segurança pleiteada, concluiu ser indispensável a existência de programa de residência médica, relativo ao curso de Medicina Estética, consoante se verifica do seguinte trecho do aresto recorrido (fl. 509): Por sua vez, a Lei $n^{0} 6.932 / 81$, que dispõe sobre a atividade do médico residente, prevê a obrigatoriedade da residência médica para que o 
profissional possa obter o título de especialista, devendo tais instituições médicas ser credenciadas pela Comissão Nacional de Residência Médica, conforme as normas insertas no art. $1^{\circ}$ e $\S 1^{\circ}$ da mencionada lei, verbis: "Art. $1^{\circ}$. A Residência médica constitui modalidade de ensino de pósgraduação, destinada a médicos, sob a forma de cursos de especialização, caracterizada por treinamento em serviço, funcionando sob a responsabilidade de instituições de saúde, universitárias ou não, sob a orientação de profissionais médicos de elevada qualificação ética e profissional". $\S 1^{\circ}$. As instituições de saúde de que trata este artigo somente poderão oferecer programas de Residência Médica depois de credenciadas pela Comissão Nacional de Residência Médica". Por tais razões, inexistindo prova de que a Escola de Medicina Souza Marques tenha programa de Residência Médica credenciado pela Comissão Nacional de Residência Médica em conformidade com o estipulado no $\S 1^{\circ}$, do art. $1^{\circ}$, da Lei $n^{\circ} 6.932 / 81$, não tem o curso de pós-graduação, lato sensu, realizado pelo impetrante, o condão de habilitá-lo a se inscrever como especialista em Medicina Estética perante o Conselho Regional de Medicina. (grifei). A partir de uma leitura atenta ao art. $1^{\circ}$ da Lei 6.932/1981, chego à conclusão diversa do posicionamento adotado pela Corte Regional. Vejamos. O art. $1^{\circ}$, cima transcrito, dispõe: "a residência médica constitui modalidade de ensino de pós-graduação, destinada a médicos, sob a forma de cursos de especialização" (grifei). Como se vê, não exige a lei, necessariamente, residência médica para os cursos de especialização. Assim, com base na interpretação literal da norma, não é possível, em face da ausência de residência médica, impedir o registro do diploma de curso de pósgraduação em "Medicina Estética", como curso de especialização, no Conselho Regional de Medicina. Todavia, ainda que se afaste esse fundamento, faz-se pertinente tecer algumas observações sobre a competência dos órgãos de classe da área médica, para também concluir pela denegação da ordem pleiteada A Lei 3.268/1957, ao tratar das atribuições do Conselho Federal e dos Conselhos Regionais de Medicina, dispõe que eles têm por finalidade supervisionar e julgar a ética profissional e disciplinar a classe médica: Lei 3.268/1957 Art. $1^{\mathrm{o}}$ : O Conselho Federal e os Conselhos Regionais de Medicina, instituídos pelo Decreto-lei $\mathrm{n}^{\mathrm{o}} 7.955$, de 13 de setembro de 1945, passam a constituir em seu conjunto uma autarquia, sendo cada um dêles dotado de personalidade jurídica de direito público, com autonomia administrativa e financeira. Art. $2^{\text {o: }}$ O Conselho Federal e os Conselhos Regionais de Medicina são os órgãos supervisores da ética profissional em tôda a República e ao mesmo tempo, julgadores e disciplinadores da classe médica, cabendo-lhes zelar e trabalhar por todos os meios ao seu alcance, pelo perfeito desempenho ético 
da medicina e pelo prestígio e bom conceito da profissão e dos que a exerçam legalmente. (grifei). E o art. 17, apontado pelo recorrente como violado, também dispondo sobre as atividades desenvolvidas pelos profissionais médicos, preceitua: Lei 3.268/1957 Art. 17: Os médicos só poderão exercer legalmente a medicina, em qualquer de seus ramos ou especialidades, após o prévio registro de seus títulos, diplomas, certificados ou cartas no Ministério da Educação e Cultura e de sua inscrição no Conselho Regional de Medicina, sob cuja jurisdição se achar o local de sua atividade. (grifei). Temos, portanto, a exigência para o exercício da medicina, "em qualquer de seus ramos ou especialidades", do prévio registro nos Conselhos Regionais de Medicina. Na hipótese em apreço, a controvérsia surgiu pelo fato de o Conselho Federal de Medicina não reconhecer a "Medicina Estética" como especialidade médica capaz de conferir o título de especialista ao profissional que concluiu curso de pósgraduação, lato sensu. A quaestio juris é a seguinte: o título de pósgraduação lato sensu, ainda que reconhecido pelo MEC, equipara-se aos títulos de especialização reconhecidos pelo CFM? Para respondermos a questão, necessário analisar a competência conferida aos órgãos da classe médica. A Constituição da República, em seu artigo 197, preceitua: Art. 197. São de relevância pública as ações e serviços de saúde, cabendo ao Poder Público dispor, nos termos da lei, sobre sua regulamentação, fiscalização e controle, devendo sua execução ser feita diretamente ou através de terceiros e, também, por pessoa física ou jurídica de direito privado. (grifei) É inquestionável que o Conselho de Medicina funciona como órgão delegado do Poder Público para tratar das questões envolvendo a saúde pública e as atividades dos profissionais médicos. Esse é o entendimento do Supremo Tribunal Federal, ao conferir a natureza jurídica autárquica aos órgãos de fiscalização de profissões regulamentadas, consoante precedente seguinte: DIREITO CONSTITUCIONAL E ADMINISTRATIVO. AÇÃO DIRETA DE INCONSTITUCIONALIDADE DO ART. 58 E SEUS PARÁGRAFOS DA LEI FEDERAL N ${ }^{\circ}$ 9.649, DE 27.05.1998, QUE TRATAM DOS SERVIÇOS DE FISCALIZAÇÃO DE PROFISSÕES REGULAMENTADAS. 1. Estando prejudicada a Ação, quanto ao $\S 3^{\circ}$ do art. 58 da Lei n ${ }^{\circ} 9.649$, de 27.05.1998, como já decidiu o Plenário, quando apreciou o pedido de medida cautelar, a Ação Direta é julgada procedente, quanto ao mais, declarando-se a inconstitucionalidade do "caput" e dos $\S$ $1^{\circ}, 2^{\circ}, 4^{\circ}, 5^{\circ}, 6^{\circ}, 7^{\circ}$ e $8^{\circ}$ do mesmo art. 58. 2. Isso porque a interpretação conjugada dos artigos $5^{\circ}$, XIII, 22, XVI, 21, XXIV, 70, parágrafo único, 149 e 175 da Constituição Federal, leva à conclusão, no sentido da indelegabilidade, a uma entidade privada, de atividade típica de Estado, que 
abrange até poder de polícia, de tributar e de punir, no que concerne ao exercício de atividades profissionais regulamentadas, como ocorre com os dispositivos impugnados. 3. Decisão unânime. (ADI 1717, Relator(a): Min. SYDNEY SANCHES, Tribunal Pleno, julgado em 07/11/2002, DJ 28-032003 PP-00061 EMENT VOL-02104-01 PP-00149). Temos, portanto, na voz do STF, que o art. $2^{\circ}$ da Lei 3.268/1957 foi recepcionado pela ordem constitucional vigente, outorgando aos Conselhos de Medicina 'julgar e disciplinar a classe médica'. Segundo o órgão dessa classe, a "Medicina Estética" não está incluída no rol de especialidades médicas, conforme dispõe a Resolução $n^{0} 1.666$ de 2003, do CFM. Pergunta-se então: como surge uma especialidade médica? Sobre o tema, a palavra doutrinária de André Luiz Nigre e Álvaro Henrique Teixeira de Almeida: (...) o processo normal e constituição de uma especialidade médica se dá em duas fases: (1) produz-se a autonomia de uma área da ciência e técnica médicas, que passa a ser monopólio de um grupo específico de profissionais; e (2) este grupo institucionaliza seu mecanismo de socialização de novos membros através de instituições docentes e titulações especializadas. (in Direito e Medicina: um estudo interdisciplinar. Rio de Janeiro: Lumen Juris, 2007, p. 42). Como se vê, a simples existência de um curso de pós-graduação não é capaz de fazer surgir, no universo científico, um novo ramo de especialidade médica, conforme regulamentado pelo órgão competente. Nesse diapasão, é importante destacar o disposto em outros atos normativos da classe médica, como por exemplo o art. $3^{\circ}$ da Resolução 1.634 de 2002, do CFM que afirma: Art. $3^{\circ}$ : Fica vedado ao médico a divulgação de especialidade ou área de atuação que não for reconhecida pelo Conselho Federal de Medicina ou pela Comissão Mista de Especialidades. Assim, interpretando as disposições das leis infraconstitucionais em harmonia com o preceito constitucional, concluo que o órgão da classe médica tem competência para criar e reconhecer especialidades médicas, após regular processamento na esfera administrativa. Entretanto, destaco que, conforme consta da disposição preambular do mencionado ato normativo do Conselho Federal de Medicina (Resolução 1.634/2002): "as especialidades sujeitam-se aos processos dinâmicos, não podendo ser permanentes ou imutáveis. A depender das circunstâncias e das necessidades podem sofrer mudanças de nomes, fusões ou extinções". Nada impede que, no futuro, os órgãos regulamentares e fiscalizadores da classe médica venham a atribuir outra qualificação aos cursos de "Medicina Estética". Por enquanto, entendo não ser possível ao Poder Judiciário invadir a competência - tanto constitucional como legal - dos Conselhos de Medicina, para obrigá-los a conferir o título de especialista, em ramo científico ainda não reconhecido 
como especialidade médica. Com essas considerações, nego provimento ao recurso especial. É o voto. 


\begin{abstract}
ANEXO IV
F00-F09 - Transtornos mentais orgânicos, inclusive os sintomáticos F00 - Demência na doença de Alzheimer (G30)

F01 - Demência vascular

F02 - Demência em outras doenças classificadas em outra parte

F03 - Demência não especificada

F04 - Síndrome amnésica orgânica não induzida pelo álcool ou por outras substâncias psicoativas

F05 - Delirium não induzido pelo álcool ou por outras substâncias psicoativas

F06 - Outros transtornos mentais devidos a lesão e disfunção cerebral e a doença física

F07 - Transtornos de personalidade e do comportamento devidos a doença, a lesão e a disfunção cerebral

F09 - Transtorno mental orgânico ou sintomático não especificado

F10-F19 - Transtornos mentais e comportamentais devidos ao uso de substância psicoativa

F10 - Transtornos mentais e comportamentais devidos ao uso de álcool

F11 - Transtornos mentais e comportamentais devidos ao uso de opiáceos

F12 - Transtornos mentais e comportamentais devidos ao uso de canabinóides

F13 - Transtornos mentais e comportamentais devidos ao uso de sedativos e hipnóticos

F14 - Transtornos mentais e comportamentais devidos ao uso da cocaína

F15 - Transtornos mentais e comportamentais devidos ao uso de outros estimulantes, inclusive a cafeína

F16 - Transtornos mentais e comportamentais devidos ao uso de alucinógenos

F17 - Transtornos mentais e comportamentais devidos ao uso de fumo

F18 - Transtornos mentais e comportamentais devidos ao uso de solventes voláteis

F19 - Transtornos mentais e comportamentais devidos ao uso de múltiplas drogas e ao uso de outras substâncias psicoativas

F20-F29 - Esquizofrenia, transtornos esquizotípicos e transtornos delirantes

F20 - Esquizofrenia

F21 - Transtorno esquizotípico

F22 - Transtornos delirantes persistentes

F23 - Transtornos psicóticos agudos e transitórios

F24 - Transtorno delirante induzido

F25 - Transtornos esquizoafetivos
\end{abstract}


F28 - Outros transtornos psicóticos não-orgânicos

F29 - Psicose não-orgânica não especificada

F30-F39 - Transtornos do humor [afetivos]

F30 - Episódio maníaco

F31 - Transtorno afetivo bipolar

F32 - Episódios depressivos

F33 - Transtorno depressivo recorrente

F34 - Transtornos de humor [afetivos] persistentes

F38 - Outros transtornos do humor [afetivos]

F39 - Transtorno do humor [afetivo] não especificado

F40-F48 - Transtornos neuróticos, transtornos relacionados com o "stress" e transtornos somatoformes

F40 - Transtornos fóbico-ansiosos

F41 - Outros transtornos ansiosos

F42 - Transtorno obsessivo-compulsivo

F43 - Reações ao "stress" grave e transtornos de adaptação

F44 - Transtornos dissociativos [de conversão]

F45 - Transtornos somatoformes

F48 - Outros transtornos neuróticos

F50-F59 - Síndromes comportamentais associadas a disfunções fisiológicas e a fatores físicos

F50 - Transtornos da alimentação

F51 - Transtornos não-orgânicos do sono devidos a fatores emocionais

F52 - Disfunção sexual, não causada por transtorno ou doença orgânica

F53 - Transtornos mentais e comportamentais associados ao puerpério, não classificados em outra parte

F54 - Fatores psicológicos ou comportamentais associados a doença ou a transtornos classificados em outra parte

F55 - Abuso de substâncias que não produzem dependência

F59 - Síndromes comportamentais associados a transtornos das funções

fisiológicas e a fatores físicos, não especificadas

F60-F69 - Transtornos da personalidade e do comportamento do adulto

F60 - Transtornos específicos da personalidade

F61 - Transtornos mistos da personalidade e outros transtornos da personalidade

F62 - Modificações duradouras da personalidade não atribuíveis a lesão ou doença cerebral

F63 - Transtornos dos hábitos e dos impulsos

F64 - Transtornos da identidade sexual

F65 - Transtornos da preferência sexual 
F66 - Transtornos psicológicos e comportamentais associados ao desenvolvimento sexual e à sua orientação

F68 - Outros transtornos da personalidade e do comportamento do adulto

F69 - Transtorno da personalidade e do comportamento do adulto, não especificado

F70- F79 Retardo mental

F70 - Retardo mental leve

F71 - Retardo mental moderado

F72 - Retardo mental grave

F73 - Retardo mental profundo

F78 - Outro retardo mental

F79 - Retardo mental não especificado

F80-F89 - Transtornos do desenvolvimento psicológico

F80 - Transtornos específicos do desenvolvimento da fala e da linguagem

F81 - Transtornos específicos do desenvolvimento das habilidades escolares

F82 - Transtorno específico do desenvolvimento motor

F83 - Transtornos específicos misto do desenvolvimento

F84 - Transtornos globais do desenvolvimento

F88 - Outros transtornos do desenvolvimento psicológico

F89 - Transtorno do desenvolvimento psicológico não especificado

F90-F98 - Transtornos do comportamento e transtornos emocionais que aparecem habitualmente durante a infância ou a adolescência

F90 - Transtornos hipercinéticos

F91 - Distúrbios de conduta

F92 - Transtornos mistos de conduta e das emoções

F93 - Transtornos emocionais com início especificamente na infância

F94 - Transtornos do funcionamento social com início especificamente durante a infância ou a adolescência

F95 - Tiques

F98 - Outros transtornos comportamentais e emocionais com início habitualmente durante a infância ou a adolescência

F99 - Transtorno mental não especificado

F99 - Transtorno mental não especificado em outra parte

Dentre as perturbações apresentadas no título existem subdivisões relevantes que especificam ainda mais as patologias apresentadas, as quais serão apresentadas em subitens (Ex: F00.1, F00.2, F00.3...). Merecem destaque ${ }^{1106}$ :

F00 Demência na doença de Alzheimer

${ }^{1106}$ Disponível em: http://www.medicinanet.com.br/pesquisa/cid10/cod/f99.htm. Acesso em 12/09/2016. 
F00 Demência na doença de Alzheimer

F00.0 Demência na doença de Alzheimer de início precoce

F00.1 Demência na doença de Alzheimer de início tardio

F00.2 Demência na doença de Alzheimer, forma atípica ou mista

F00.9 Demência não especificada na doença de Alzheimer

F01 Demência Vascular

F01 Demência vascular

F01.0 Demência vascular de início agudo

F01.1 Demência por infartos múltiplos

F01.2 Demência vascular subcortical

F01.3 Demência vascular mista, cortical e subcortical

F01.8 Outra demência vascular

F01.9 Demência vascular não especificada

F02 Demência em outras doenças classificadas em outra parte

F02 Demência em outras doenças classificadas em outra parte

F02.0 Demência da doença de Pick

F02.1 Demência na doença de Creutzfeldt-Jakob

F02.2 Demência na doença de Huntington

F02.3 Demência na doença de Parkinson

F02.4 Demência na doença pelo vírus da imunodeficiência humana (HIV)

F02.8 Demência em outras doenças especificadas classificadas em outra parte

F05 Delirium não induzido pelo álcool ou por outras substâncias psicoativas

F05 Delirium não induzido pelo álcool ou por outras substâncias psicoativas

F05.0 Delirium não superposto a uma demência, assim descrito

F05.1 Delirium superposto a uma demência

F05.8 Outro delirium

F05.9 Delirium não especificado

F06 Outros transtornos mentais devidos a lesão e disfunção cerebral e a doença física

F06 Outros transtornos mentais devidos a lesão e disfunção cerebral e a doença física

F06.0 Alucinose orgânica

F06.1 Estado catatônico orgânico

F06.2 Transtorno delirante orgânico (tipo esquizofrênico)

F06.3 Transtornos do humor (afetivos) orgânicos

F06.4 Transtornos da ansiedade orgânicos

F06.5 Transtorno dissociativo orgânico

F06.6 Transtorno de labilidade emocional (astênico) orgânico 
F06.7 Transtorno cognitivo leve

F06.8 Outros transtornos mentais especificados devidos a uma lesão e disfunção cerebral e a uma doença física

F06.9 Transtorno mental não especificado devido a uma lesão e disfunção cerebral e a uma doença física

F07 Transtornos de personalidade e do comportamento devidos a doença, a lesão e a disfunção cerebral

F07 Transtornos de personalidade e do comportamento devidos a doença, a lesão e a disfunção cerebral

F07.0 Transtorno orgânico da personalidade

F07.1 Síndrome pós-encefalítica

F07.2 Síndrome pós-traumática

F07.8 Outros transtornos orgânicos da personalidade e do comportamento devidos a doença cerebral, lesão e disfunção

F07.9 Transtorno orgânico não especificado da personalidade e do comportamento devido a doença cerebral, lesão e disfunção

F11 Transtornos mentais e comportamentais devidos ao uso de opiáceos

F11.0 Transtornos mentais e comportamentais devidos ao uso de opiáceos

F11.1 Transtornos mentais e comportamentais devidos ao uso de opiáceos - intoxicação aguda

F11.2 Transtornos mentais e comportamentais devidos ao uso de opiáceos - uso nocivo para a saúde

F11.3 Transtornos mentais e comportamentais devidos ao uso de opiáceos - síndrome de dependência

F11.4 Transtornos mentais e comportamentais devidos ao uso de opiáceos síndrome de abstinência com delirium

F11.5 Transtornos mentais e comportamentais devidos ao uso de opiáceos transtorno psicótico

F11.6 Transtornos mentais e comportamentais devidos ao uso de opiáceos síndrome

amnésica

F11.7 Transtornos mentais e comportamentais devidos ao uso de opiáceos transtorno psicótico residual ou de instalação tardia

F11.8 Transtornos mentais e comportamentais devidos ao uso de opiáceos outros transtornos mentais ou comportamentais

F11.9 Transtornos mentais e comportamentais devidos ao uso de opiáceos transtorno mental ou comportamental não especificado

F12 Transtornos mentais e comportamentais devidos ao uso de canabinóides

F12.0 Transtornos mentais e comportamentais devidos ao uso de canabinóides - intoxicação aguda - Causa óbito 
F12.1 Transtornos mentais e comportamentais devidos ao uso de canabinóides - uso nocivo para a saúde - Causa óbito

F12.2 Transtornos mentais e comportamentais devidos ao uso de canabinóides - síndrome de dependência - Causa óbito

F12.3 Transtornos mentais e comportamentais devidos ao uso de canabinóides - síndrome [estado] de abstinência - Causa óbito

F12.4 Transtornos mentais e comportamentais devidos ao uso de canabinóides - síndrome de abstinência com delirium - Causa óbito

F12.5 Transtornos mentais e comportamentais devidos ao uso de canabinóides - transtorno psicótico - Causa óbito

F12.6 Transtornos mentais e comportamentais devidos ao uso de canabinóides - síndrome amnésica - Causa óbito

F12.7 Transtornos mentais e comportamentais devidos ao uso de canabinóides - transtorno psicótico residual ou de instalação tardia - Causa óbito

F12.8 Transtornos mentais e comportamentais devidos ao uso de canabinóides - outros transtornos mentais ou comportamentais - Causa óbito

F12.9 Transtornos mentais e comportamentais devidos ao uso de canabinóides - transtorno mental ou comportamental não especificado Causa óbito

F13 Transtornos mentais e comportamentais devidos ao uso de sedativos e hipnóticos

F13.0 Transtornos mentais e comportamentais devidos ao uso de sedativos e hipnóticos - intoxicação aguda - Causa óbito

F13.1 Transtornos mentais e comportamentais devidos ao uso de sedativos e hipnóticos - uso nocivo para a saúde - Causa óbito

F13.2 Transtornos mentais e comportamentais devidos ao uso de sedativos e hipnóticos - síndrome de dependência - Causa óbito

F13.3 Transtornos mentais e comportamentais devidos ao uso de sedativos e hipnóticos - síndrome [estado] de abstinência - Causa óbito

F13.4 Transtornos mentais e comportamentais devidos ao uso de sedativos e hipnóticos - síndrome de abstinência com delirium - Causa óbito

F13.5 Transtornos mentais e comportamentais devidos ao uso de sedativos e hipnóticos - transtorno psicótico - Causa óbito

F13.6 Transtornos mentais e comportamentais devidos ao uso de sedativos e hipnóticos - síndrome amnésica - Causa óbito

F13.7 Transtornos mentais e comportamentais devidos ao uso de sedativos e hipnóticos - transtorno psicótico residual ou de instalação tardia - Causa óbito 
F13.8 Transtornos mentais e comportamentais devidos ao uso de sedativos e hipnóticos - outros transtornos mentais ou comportamentais - Causa óbito F13.9 Transtornos mentais e comportamentais devidos ao uso de sedativos e hipnóticos - transtorno mental ou comportamental não especificado Causa óbito

F14 Transtornos mentais e comportamentais devidos ao uso da cocaína F14.0 Transtornos mentais e comportamentais devidos ao uso da cocaína intoxicação aguda

F4.1 Transtornos mentais e comportamentais devidos ao uso da cocaína uso nocivo para a saúde

F14.2 Transtornos mentais e comportamentais devidos ao uso da cocaína síndrome de dependência

F14.3 Transtornos mentais e comportamentais devidos ao uso da cocaína síndrome (estado) de abstinência

F14.4 Transtornos mentais e comportamentais devidos ao uso da cocaína síndrome de abstinência com delirium

F14.5 Transtornos mentais e comportamentais devidos ao uso da cocaína transtorno psicótico

F14.6 Transtornos mentais e comportamentais devidos ao uso da cocaína síndrome amnésica

F14.7 Transtornos mentais e comportamentais devidos ao uso da cocaína transtorno psicótico residual ou de instalação tardia

F14.8 Transtornos mentais e comportamentais devidos ao uso da cocaína outros transtornos mentais ou comportamentais

F14.9 Transtornos mentais e comportamentais devidos ao uso da cocaína transtorno mental ou comportamental não especificado

F15 Transtornos mentais e comportamentais devidos ao uso de outros estimulantes, inclusive a cafeína

F15.0 Transtornos mentais e comportamentais devidos ao uso de outros estimulantes, inclusive a cafeína - intoxicação aguda - Causa óbito

F15.1 Transtornos mentais e comportamentais devidos ao uso de outros estimulantes, inclusive a cafeína - uso nocivo para a saúde - Causa óbito F15.2 Transtornos mentais e comportamentais devidos ao uso de outros estimulantes, inclusive a cafeína - síndrome de dependência - Causa óbito F15.3 Transtornos mentais e comportamentais devidos ao uso de outros estimulantes, inclusive a cafeína - síndrome [estado] de abstinência - Causa óbito

F15.4 Transtornos mentais e comportamentais devidos ao uso de outros estimulantes, inclusive a cafeína - síndrome de abstinência com delirium Causa óbito 
F15.5 Transtornos mentais e comportamentais devidos ao uso de outros estimulantes, inclusive a cafeína - transtorno psicótico - Causa óbito

F15.6 Transtornos mentais e comportamentais devidos ao uso de outros estimulantes, inclusive a cafeína - síndrome amnésica - Causa óbito

F15.7 Transtornos mentais e comportamentais devidos ao uso de outros estimulantes, inclusive a cafeína - transtorno psicótico residual ou de instalação tardia - Causa óbito

F15.8 Transtornos mentais e comportamentais devidos ao uso de outros estimulantes, inclusive a cafeína - outros transtornos mentais ou comportamentais - Causa óbito

F15.9 Transtornos mentais e comportamentais devidos ao uso de outros estimulantes, inclusive a cafeína - transtorno mental ou comportamental não especificado - Causa óbito

F16 Transtornos mentais e comportamentais devidos ao uso de alucinógenos

F16.0 Transtornos mentais e comportamentais devidos ao uso de alucinógenos - intoxicação aguda - Causa óbito

F16.1 Transtornos mentais e comportamentais devidos ao uso de alucinógenos - uso nocivo para a saúde - Causa óbito

F16.2 Transtornos mentais e comportamentais devidos ao uso de alucinógenos - síndrome de dependência - Causa óbitoF16.3 - Transtornos mentais e comportamentais devidos ao uso de alucinógenos - síndrome [estado] de abstinência - Causa óbito

F16.4 Transtornos mentais e comportamentais devidos ao uso de alucinógenos - síndrome de abstinência com delirium - Causa óbito

F16.5 Transtornos mentais e comportamentais devidos ao uso de alucinógenos - transtorno psicótico - Causa óbito

F16.6 Transtornos mentais e comportamentais devidos ao uso de alucinógenos - síndrome amnésica - Causa óbito

F16.7 Transtornos mentais e comportamentais devidos ao uso de alucinógenos - transtorno psicótico residual ou de instalação tardia - Causa óbito

F16.8 Transtornos mentais e comportamentais devidos ao uso de alucinógenos - outros transtornos mentais ou comportamentais - Causa óbito

F16.9 Transtornos mentais e comportamentais devidos ao uso de alucinógenos - transtorno mental ou comportamental não especificado Causa óbito

F17 Transtornos mentais e comportamentais devidos ao uso de fumo

F17.0 Transtornos mentais e comportamentais devidos ao uso de fumo intoxicação aguda - Causa óbito 
F17.1 Transtornos mentais e comportamentais devidos ao uso de fumo uso nocivo para a saúde - Causa óbito

F17.2 Transtornos mentais e comportamentais devidos ao uso de fumo síndrome de dependência - Causa óbito

F17.3 Transtornos mentais e comportamentais devidos ao uso de fumo síndrome [estado] de abstinência - Causa óbito

F17.4 Transtornos mentais e comportamentais devidos ao uso de fumo síndrome de abstinência com delirium - Causa óbito

F17.5 Transtornos mentais e comportamentais devidos ao uso de fumo transtorno psicótico - Causa óbito

F17.6 Transtornos mentais e comportamentais devidos ao uso de fumo síndrome amnésica - Causa óbito

F17.7 Transtornos mentais e comportamentais devidos ao uso de fumo transtorno psicótico residual ou de instalação tardia - Causa óbito

F17.8 Transtornos mentais e comportamentais devidos ao uso de fumo outros transtornos mentais ou comportamentais - Causa óbito

F17.9 Transtornos mentais e comportamentais devidos ao uso de fumo transtorno mental ou comportamental não especificado - Causa óbito

F18 Transtornos mentais e comportamentais devidos ao uso de solventes voláteis

F18.0 Transtornos mentais e comportamentais devidos ao uso de solventes voláteis - intoxicação aguda

F18.1 Transtornos mentais e comportamentais devidos ao uso de solventes voláteis - uso nocivo para a saúde

F18.2 Transtornos mentais e comportamentais devidos ao uso de solventes voláteis - síndrome de dependência

F18.3 Transtornos mentais e comportamentais devidos ao uso de solventes voláteis - síndrome (estado) de abstinência

F18.4 Transtornos mentais e comportamentais devidos ao uso de solventes voláteis - síndrome de abstinência com delirium

F18.5 Transtornos mentais e comportamentais devidos ao uso de solventes voláteis - transtorno psicótico

F18.6 Transtornos mentais e comportamentais devidos ao uso de solventes voláteis - síndrome amnésica

F18.7 Transtornos mentais e comportamentais devidos ao uso de solventes voláteis - transtorno psicótico residual ou de instalação tardia

F18.8 Transtornos mentais e comportamentais devidos ao uso de solventes voláteis - outros transtornos mentais ou comportamentais

F18.9 Transtornos mentais e comportamentais devidos ao uso de solventes voláteis - transtorno mental ou comportamental não especificado 
F19 Transtornos mentais e comportamentais devidos ao uso de múltiplas drogas e ao uso de outras substâncias psicoativas

F19.0 Transtornos mentais e comportamentais devidos ao uso de múltiplas drogas e ao uso de outras substâncias psicoativas - intoxicação aguda

F19.1 Transtornos mentais e comportamentais devidos ao uso de múltiplas drogas e ao uso de outras substâncias psicoativas - uso nocivo para a saúde F19.2 Transtornos mentais e comportamentais devidos ao uso de múltiplas drogas e ao uso de outras substâncias psicoativas - síndrome de dependência

F19.3 Transtornos mentais e comportamentais devidos ao uso de múltiplas drogas e ao uso de outras substâncias psicoativas - síndrome [estado] de abstinência

F19.4 Transtornos mentais e comportamentais devidos ao uso de múltiplas drogas e ao uso de outras substâncias psicoativas - síndrome de abstinência com delirium

F19.5 Transtornos mentais e comportamentais devidos ao uso de múltiplas drogas e ao uso de outras substâncias psicoativas - transtorno psicótico

F19.6 Transtornos mentais e comportamentais devidos ao uso de múltiplas drogas e ao uso de outras substâncias psicoativas - síndrome amnésica

F19.7 Transtornos mentais e comportamentais devidos ao uso de múltiplas drogas e ao uso de outras substâncias psicoativas - transtorno psicótico residual ou de instalação tardia

F19.8 Transtornos mentais e comportamentais devidos ao uso de múltiplas drogas e ao uso de outras substâncias psicoativas - outros transtornos mentais ou comportamentais

F19.9 Transtornos mentais e comportamentais devidos ao uso de múltiplas drogas e ao uso de outras substâncias psicoativas - transtorno mental ou comportamental não especificado

F20 Esquizofrenia

F20.0 Esquizofrenia paranóide

F20.1 Esquizofrenia hebefrênica

F20.2 Esquizofrenia catatônica

F20.3 Esquizofrenia indiferenciada

F20.4 Depressão pós-esquizofrênica

F20.5 Esquizofrenia residual

F20.6 Esquizofrenia simples

F20.8 Outras esquizofrenias

F20.9 Esquizofrenia não especificada

F21 Transtorno esquizotípico

F22 Transtornos delirantes persistentes

F22.0 Transtorno delirante 
F22.8 Outros transtornos delirantes persistentes

F22.9 Transtorno delirante persistente não especificado

F23 Transtornos psicóticos agudos e transitórios

F23.0 Transtorno psicótico agudo polimorfo, sem sintomas esquizofrênicos

F23.1 Transtorno psicótico agudo polimorfo, com sintomas esquizofrênicos

F23.2 Transtorno psicótico agudo de tipo esquizofrênico (schizophrenialike)

F23.3 Outros transtornos psicóticos agudos, essencialmente delirantes

F23.8 Outros transtornos psicóticos agudos e transitórios

F23.9 Transtorno psicótico agudo e transitório não especificado

F24 Transtorno delirante induzido

F25 Transtornos esquizoafetivos

F25.0 Transtorno esquizoafetivo do tipo maníaco

F25.1 Transtorno esquizoafetivo do tipo depressivo

F25.2 Transtorno esquizoafetivo do tipo misto

F25.8 Outros transtornos esquizoafetivos

F25.9 Transtorno esquizoafetivo não especificado

F28 Outros transtornos psicóticos não-orgânicos

F29 Psicose não-orgânica não especificada

F30 Episódio maníaco

F30.0 Hipomania

F30.1 Mania sem sintomas psicóticos

F30.2 Mania com sintomas psicóticos

F30.8 Outros episódios maníacos

F30.9 Episódio maníaco não especificado

F31 Transtorno afetivo bipolar

F31.0 Transtorno afetivo bipolar, episódio atual hipomaníaco

F31.1 Transtorno afetivo bipolar, episódio atual maníaco sem sintomas psicóticos

F31.2 Transtorno afetivo bipolar, episódio atual maníaco com sintomas psicóticos

F31.3 Transtorno afetivo bipolar, episódio atual depressivo leve ou moderado

F31.4 Transtorno afetivo bipolar, episódio atual depressivo grave sem sintomas psicóticos

F31.5 Transtorno afetivo bipolar, episódio atual depressivo grave com sintomas psicóticos

F31.6 Transtorno afetivo bipolar, episódio atual misto

F31.7 Transtorno afetivo bipolar, atualmente em remissão F31.8 Outros transtornos afetivos bipolares

F32 Episódios depressivos 
F32.1 Episódio depressivo moderado

F32.2 Episódio depressivo grave sem sintomas psicóticos

F32.3 Episódio depressivo grave com sintomas psicóticos

F32.8 Outros episódios depressivos

F32.9 Episódio depressivo não especificado

F33 Transtorno depressivo recorrente

F33.0 Transtorno depressivo recorrente, episódio atual leve - Causa óbito

F331 Transtorno depressivo recorrente, episódio atual moderado - Causa óbito

F33.2 Transtorno depressivo recorrente, episódio atual grave sem sintomas psicóticos - Causa óbito

F33.3 Transtorno depressivo recorrente, episódio atual grave com sintomas psicóticos - Causa óbito

F33.4 Transtorno depressivo recorrente, atualmente em remissão - Causa óbito

F33.8 Outros transtornos depressivos recorrentes - Causa óbito

F33.9 Transtorno depressivo recorrente sem especificação - Causa óbito

F34 Transtornos de humor [afetivos] persistentes

F34.0 Ciclotimia

F34.1 Distimia

F34.8 Outros transtornos do humor [afetivos] persistentes

F34.9 Transtorno do humor [afetivo] persistente não especificado

F38 Outros transtornos do humor [afetivos]

F38.0 Outros transtornos do humor [afetivos] isolados

F38.1 Outros transtornos do humor [afetivos] recorrentes

F38.8 Outros transtornos especificados do humor [afetivos]

F40.1 Fobias sociais

F40.2 Fobias específicas (isoladas)

F40.8 Outros transtornos fóbico-ansiosos

F40.9 Transtorno fóbico-ansioso não especificado

F41 Outros transtornos ansiosos

F41.0 Transtorno de pânico [ansiedade paroxística episódica]

F41.1 Ansiedade generalizada

F41.2 Transtorno misto ansioso e depressivo

F41.3 Outros transtornos ansiosos mistos

F41.8 Outros transtornos ansiosos especificados

F41.9 Transtorno ansioso não especificado

F42 Transtorno obsessivo-compulsivo

F42.0 Transtorno obsessivo-compulsivo com predominância de idéias ou de ruminações obsessivas 
F42.1 Transtorno obsessivo-compulsivo com predominância de comportamentos compulsivos [rituais obsessivos]

F42.2 Transtorno obsessivo-compulsivo, forma mista, com ideias obsessivas e comportamentos compulsivos

F42.8 Outros transtornos obsessivo-compulsivos

F42.9 Transtorno obsessivo-compulsivo não especificado

F43 Reações ao "stress" grave e transtornos de adaptação

F43.0 Reação aguda ao "stress"

F43.1 Estado de "stress" pós-traumático

F43.2 Transtornos de adaptação

F43.8 Outras reações ao "stress" grave

F43.9 Reação não especificada a um "stress" grave

F44 Transtornos dissociativos [de conversão]

F44.0 Amnésia dissociativa

F44.1 Fuga dissociativa

F44.2 Estupor dissociativo

F44.3 Estados de transe e de possessão

F44.4 Transtornos dissociativos do movimento

F44.5 Convulsões dissociativas

F44.6 Anestesia e perda sensorial dissociativas

F44.7 Transtorno dissociativo misto [de conversão]

F44.8 Outros transtornos dissociativos [de conversão]

F44.9 Transtorno dissociativo [de conversão] não especificado

F45 Transtornos somatoformes

F45.0 Transtorno de somatização

F45.1 Transtorno somatoforme indiferenciado

F45.2 Transtorno hipocondríaco

F45.3 Transtorno neurovegetativo somatoforme

F45.4 Transtorno doloroso somatoforme persistente

F45.8 Outros transtornos somatoformes

F45.9 Transtorno somatoforme não especificado

F48 Outros transtornos neuróticos

F48.0 Neurastenia

F48.1 Síndrome de despersonalização-desrealização

F48.8 Outros transtornos neuróticos especificados

F48.9 Transtorno neurótico não especificado

F50 Transtornos da alimentação

F50.0 Anorexia nervosa

F50.1 Anorexia nervosa atípica

F50.2 Bulimia nervosa

F50.3 Bulimia nervosa atípica 
F50.4 Hiperfagia associada a outros distúrbios psicológicos

F50.5 Vômitos associados a outros distúrbios psicológicos

F50.8 Outros transtornos da alimentação

F50.9 Transtorno de alimentação não especificado

F51 Transtornos não-orgânicos do sono devidos a fatores emocionais

F51.0 Insônia não-orgânica

F51.1 Hipersonia não-orgânica

F51.2 Transtorno do ciclo vigília-sono devido a fatores não-orgânicos

F51.3 Sonambulismo

F51.4 Terrores noturnos

F51.5 Pesadelos

F51.8 Outros transtornos do sono devidos a fatores não-orgânicos

F51.9 Transtorno do sono devido a fatores não-orgânicos não especificados

F52 Disfunção sexual, não causada por transtorno ou doença orgânica

F52.0 Ausência ou perda do desejo sexual

F52.1 Aversão sexual e ausência de prazer sexual

F52.2 Falha de resposta genital

F52.3 Disfunção orgásmica

F52.4 Ejaculação precoce

F52.5 Vaginismo não-orgânico

F52.6 Dispareunia não-orgânica

F52.7 Apetite sexual excessivo

F52.8 Outras disfunções sexuais não devidas a transtorno ou à doença orgânica

F52.9 Disfunção sexual não devida a transtorno ou à doença orgânica, não especificada

F53 Transtornos mentais e comportamentais associados ao puerpério, não classificados em outra parte

F53.0 Transtornos mentais e comportamentais leves associados ao puerpério não classificados em outra parte

F53.1 Transtornos mentais e comportamentais graves associados ao puerpério não classificados em outra parte

F53.8 Outros transtornos mentais e comportamentais associados ao puerpério não classificados em outra parte

F53.9 Transtorno mental e comportamental associado ao puerpério, não especificado

F54 Fatores psicológicos ou comportamentais associados a doença ou a transtornos classificados em outra parte

F55 Abuso de substâncias que não produzem dependência 
F59 Síndromes comportamentais associados a transtornos das funções fisiológicas e a fatores físicos, não especificadas

F60 Transtornos específicos da personalidade

F60.0 Personalidade paranoica

F60.1 Personalidade esquizoide

F60.2 Personalidade dissocial

F60.3 Transtorno de personalidade com instabilidade emocional

F60.4 Personalidade histriônica

F60.5 Personalidade anancástica

F60.6 Personalidade ansiosa [esquiva]

F60.7 Personalidade dependente

F60.8 Outros transtornos específicos da personalidade

F60.9 Transtorno não especificado da personalidade

F61 Transtornos mistos da personalidade e outros transtornos da personalidade

F62 Modificações duradouras da personalidade não atribuíveis a lesão ou doença cerebral

F62.0 Modificação duradoura da personalidade após uma experiência catastrófica

F62.1 Modificação duradoura da personalidade após doença psiquiátrica

F62.8 Outras modificações duradouras da personalidade

F62.9 Modificação duradoura da personalidade, não especificada

F63 Transtornos dos hábitos e dos impulsos

F63.0 Jogo patológico

F63.1 Piromania

F63.2 Roubo patológico [cleptomania]

F63.3 Tricotilomania

F63.8 Outros transtornos dos hábitos e dos impulsos

F63.9 Transtorno dos hábitos e impulsos, não especificado

F64 Transtornos da identidade sexual

F64.0 Transexualismo

F64.1 Travestismo bivalente

F64.2 Transtorno de identidade sexual na infância

F64.8 Outros transtornos da identidade sexual

F64.9 Transtorno não especificado da identidade sexual

F65 Transtornos da preferência sexual

F65.0 Fetichismo

F65.1 Travestismo fetichista

F65.2 Exibicionismo

F65.3 Voyeurismo

F65.4 Pedofilia 
F65.5 Sadomasoquismo

F65.6 Transtornos múltiplos da preferência sexual

F65.8 Outros transtornos da preferência sexual

F65.9 Transtorno da preferência sexual, não especificado

F66 Transtornos psicológicos e comportamentais associados ao desenvolvimento sexual e à sua orientação

F66.0 Transtorno da maturação sexual

F66.1 Orientação sexual egodistônica

F66.2 Transtorno do relacionamento sexual

F66.8 Outros transtornos do desenvolvimento psicossexual

F66.9 Transtorno do desenvolvimento sexual, não especificado

F68 Outros transtornos da personalidade e do comportamento do adulto

F68.0 Sintomas físicos aumentados por fatores psicológicos

F68.1 Produção deliberada ou simulação de sintomas ou de incapacidades, físicas ou psicológicas [transtorno fictício]

F68.8 Outros transtornos especificados da personalidade e do comportamento do adulto

F69 Transtorno da personalidade e do comportamento do adulto, não especificado

F70 Retardo mental leve

F71 Retardo mental moderado

F72 Retardo mental grave

F73 Retardo mental profundo

F78 Outro retardo mental

F79 Retardo mental não especificado

F80 Transtornos específicos do desenvolvimento da fala e da linguagem

F80.0 Transtorno específico da articulação da fala

F80.1 Transtorno expressivo de linguagem

F80.2 Transtorno receptivo da linguagem

F80.3 Afasia adquirida com epilepsia [síndrome de Landau-Kleffner]

F80.8 Outros transtornos de desenvolvimento da fala ou da linguagem

Balbucio

F80.9 Transtorno não especificado do desenvolvimento da fala ou da linguagem

F81 Transtornos específicos do desenvolvimento das habilidades escolares

F81.0 Transtorno específico de leitura

F81.1 Transtorno específico da soletração

F81.2 Transtorno específico da habilidade em aritmética

F81.3 Transtorno misto de habilidades escolares

F81.8 Outros transtornos do desenvolvimento das habilidades escolares 
F81.9 Transtorno não especificado do desenvolvimento das habilidades escolares

F82 Transtorno específico do desenvolvimento motor

F83 Transtornos específicos misto do desenvolvimento

F84 Transtornos globais do desenvolvimento

F84.0 Autismo infantil

F84.1 Autismo atípico

F84.2 Síndrome de Rett

F84.3 Outro transtorno desintegrativo da infância

F84.4 Transtorno com hipercinesia associada a retardo mental e a movimentos estereotipados

F84.5 Síndrome de Asperger

F84.8 Outros transtornos globais do desenvolvimento

F84.9 Transtornos globais não especificados do desenvolvimento

F88 Outros transtornos do desenvolvimento psicológico

F89 Transtorno do desenvolvimento psicológico não especificado

F90 Transtornos hipercinéticos

F90.0 Distúrbios da atividade e da atenção

F90.1 Transtorno hipercinético de conduta

F90.8 Outros transtornos hipercinéticos

F90.9 Transtorno hipercinético não especificado

F91 Distúrbios de conduta

F91.0 Distúrbio de conduta restrito ao contexto familiar

F91.1 Distúrbio de conduta não-socializado

F91.2 Distúrbio de conduta do tipo socializado

F91.3 Distúrbio desafiador e de oposição

F91.8 Outros transtornos de conduta

F91.9 Transtorno de conduta não especificado

F92 Transtornos mistos de conduta e das emoções

F92.0 Distúrbio depressivo de conduta

F92.8 Outros transtornos mistos da conduta e das emoções

F92.9 Transtorno misto da conduta e das emoções não especificado

F93 Transtornos emocionais com início especificamente na infância

F93.0 Transtorno ligado à angústia de separação

F93.1 Transtorno fóbico ansioso da infância

F93.2 Distúrbio de ansiedade social da infância

F93.3 Transtorno de rivalidade entre irmãos

F93.8 Outros transtornos emocionais da infância

F94 Transtornos do funcionamento social com início especificamente durante a infância ou a adolescência

F94.1 Distúrbio reativo de vinculação da infância 
F94.2 Transtorno de fixação da infância, com desinibição)

F94.8 Outros transtornos do funcionamento social na infância

F94.9 Transtorno do funcionamento social da infância não especificado

F95 Tiques

F95.0 Tique transitório

F95.1 Tique motor ou vocal crônico

F95.2 Tiques vocais e motores múltiplos combinados [doença de Gilles de la Tourette]

F95.8 Outros tiques

F95.9 Tique não especificado

F98 Outros transtornos comportamentais e emocionais com início habitualmente durante a infância ou a adolescência

F98.0 Enurese de origem não-orgânica

F98.1 Encoprese de origem não-orgânica

F98.2 Transtorno de alimentação na infância

F98.3 Pica do lactente ou da criança

F98.4 Estereotipias motoras

F98.5 Gagueira [tartamudez]

F98.6 Linguagem precipitada

F98.8 Outros transtornos comportamentais e emocionais especificados com início habitualmente na infância ou adolescência

F98.9 - Transtornos comportamentais e emocionais não especificados com início habitualmente na infância ou adolescência

F99 - Transtorno mental não especificado em outra parte 


\section{ANEXO V}

\section{BGH Urt. v. 05. Dezember 1958 - VI ZR 266/57, BGHZ 29, 33}

\section{Leitsätze:}

1. Die Einwilligung eines Minderjährigen zu einem Eingriff in seine körperliche Unversehrtheit (Operation) ist rechtswirksam, wenn der Minderjährige nach seiner geistigen und sittlichen Reife die Bedeutung und Tragweite des Eingriffs und seiner Gestattung zu ermessen vermag.

2. Das elterliche Recht der Personensorge steht der Einwilligung jedenfalls dann nicht entgegen, wenn die elterliche Zustimmung aus besonderen Gründen nicht zu erlangen ist.

Wesentliche Aussagen:

Ein Minderjähriger kann selbst in die Vornahme einer Operation wirksam einwilligen, wenn er nach seiner Verstandesreife dazu in der Lage ist. Bei der Einwilligung zu einem Eingriff in die körperliche Integrität handelt es sich gerade nicht um Zustimmung zu einem Rechtsgeschäft nach $§ 183$ BGB, sondern um eine Gestattung oder Ermächtigung zur Vornahme tatsächlicher Handlungen, die in den Rechtskreis des Gestattenden eingreifen. Das Leben und die körperliche Unversehrtheit zu den Rechtsgütern, die zwar Dritten gegenüber Schutz genießen, selbst aber nicht Gegenstand eines Rechts ihres Trägers sind. Über sie kann der Mensch nicht verfügen wie über eine ihm gehörige Sache oder ein ihm zustehendes dingliches Recht. Die Vorschriften der $\S \S 107 \mathrm{ff}$ BGB, die rechtsgeschäftliche Willenserklärungen betreffen, sind daher auf die Einwilligung $\mathrm{zu}$ einem ärztlichen Eingriff nicht unmittelbar anzuwenden. Zwar besteht eine gewisse Rechtsähnlichkeit, weil es sich um eine Willensäußerung des Minderjährigen handelt, die bedeutsame Rechtsfolgen nach sich ziehen kann. Eine analoge Anwendung erscheint jedoch nur insoweit geboten, als es der Zweck des Gesetzes: der Schutz des Minderjährigen, verlangt. Der Minderjährige kann aber eines besonderen gesetzlichen Schutzes entbehren, wenn er nach seiner geistigen und sittlichen Reife die Bedeutung und Tragweite des Eingriffs und seiner Gestattung zu ermessen vermag. Ist der Minderjährige hierzu in der Lage, kann er in einen ärztlichen Eingriff wirksam einwilligen mit der Folge, dass der Eingriff als rechtmäßig zu erachten ist. Der zivilrechtliche Behandlungsvertrag ist nach $§ 107$ BGB allerdings weiterhin von der Genehmigung des Vertreters abhängig.

Die Einwilligung des Patienten reicht nicht weiter als seine Vorstellung von den möglichen nachteiligen Folgen des Eingriffs, die er mit der 
Einwilligung auf sich nimmt. Eine wirksame Einwilligung setzt daher voraus, dass der Patient Wesen, Bedeutung und Tragweite des ärztlichen Eingriffs, insbesondere den Grad der Gefährlichkeit in seinen Grundzügen erkannt hat. Der Patient muss aber, soll seine Einwilligung wirksam sein, auch ohne besondere Nachfrage beim Arzt, wenigstens über die nach ärztlicher Erfahrung typischen und die nicht äußerst selten eintretenden gesundheitsschädigenden Folgen des Eingriffs ins Bild gesetzt werden.

\section{Sachverhalt:}

Der am 30. April 1929 geborene Kläger begab sich Anfang Januar 1950 wegen einer Schilddrüsenerkrankung, an der er bereits seit längerer Zeit litt, als Privatpatient in die Behandlung des Beklagten. Dieser wies ihn am 3. Januar 1950 in das W Krankenhaus in B ein, dessen Chefarzt er ist. Am 14. Januar 1950 nahm er mit Einwilligung des Klägers eine Schilddrüsenoperation vor. Der Beklagte hatte auf Bitten des Klägers davon Abstand genommen, den operativen Eingriff von der Einwilligung des gesetzlichen Vertreters abhängig zu machen, da der Kläger erklärte, seine in der sowjetisch besetzten Zone lebenden Eltern könnten schweren Belästigungen ausgesetzt werden, wenn man dort Kenntnis davon erlange, dass er in die Bundesrepublik geflüchtet sei.

Der Kläger hat vorgetragen, der Beklagte habe sich bei der Operation verschiedene Kunstfehler zuschulden kommen lassen, die schwerwiegende gesundheitliche Schäden zur Folge gehabt hätten. Insbesondere sei der nervus recurrens verletzt worden und dadurch eine Stimmbandnervenlähmung (Posticusparese) eingetreten. Daher habe er seine Stimme verloren und leide dauernd an starken Atembeschwerden. Der Eingriff sei aber auch deswegen rechtswidrig durchgeführt worden, weil es an

der erforderlichen Einwilligung des gesetzlichen Vertreters gefehlt habe. Zudem habe der Beklagte ihn selbst über die möglichen Folgen der Operation nur unzureichend aufgeklärt.

Der Kläger verlangt mit der Klage Ersatz seines Vermögensschadens in Höhe von 7.088 DM, Zahlung eines ins richterliche Ermessen gestellten Schmerzensgeldes für die Zeit bis zur Rechtshängigkeit sowie Feststellung der Verpflichtung des Beklagten zum Ersatz aller weiteren Schäden aus der Operation.

Der Beklagte hat Klageabweisung beantragt. Er hat bestritten, dass ihm ein Kunstfehler unterlaufen sei, und daß er es an der erforderlichen Sorgfalt habe fehlen lassen. Er meint, eine Einwilligung des gesetzlichen Vertreters sei unter den obwaltenden Umständen nicht erforderlich 
gewesen, zumal der Kläger bereits ein Vierteljahr nach der Operation volljährig geworden sei. Über die Tragweite und die möglichen Folgen der Operation habe er den Kläger ausreichend belehrt.

Das Landgericht hat die Zahlungsansprüche dem Grunde nach für gerechtfertigt erklärt und die begehrte Feststellung getroffen. Es hat ausgeführt, dem Beklagten sei zwar ein Kunstfehler nicht nachzuweisen, der von ihm vorgenommene Eingriff sei aber rechtswidrig, weil die Einwilligung des gesetzlichen Vertreters gefehlt habe. Ein Minderjähriger könne zwar unter gewissen Voraussetzungen in die Vornahme einer Operation rechtswirksam einwilligen. Der Kläger habe aber nicht über die geistige und sittliche Reife verfügt, um die Schwere und Gefährlichkeit des Eingriffs zu ermessen; seine Einwilligung sei daher nicht wirksam gewesen. Das habe der Kläger auch erkannt; er habe daher schuldhaft gehandelt. Die schwere Atemnot und der Stimmverlust des Klägers seien durch die Operation verursacht. Der Beklagte müsse daher für sie einstehen.

Das Oberlandesgericht hat auf die Berufung des Beklagten die Klage abgewiesen.

Mit der Revision verfolgt der Kläger seine Klageanträge weiter. Der Beklagte bittet um Zurückweisung der Revision.

Entscheidungsgründe

Die Revision muss Erfolg haben.

Das Berufungsgericht erachtet einen Kunstfehler oder eine Fahrlässigkeit des Beklagten bei der Durchführung der Operation nicht für nachgewiesen. Es hält auch die vom Kläger über die Atembeschwerden und den Stimmverlust hinaus als Operationsfolgen geltend gemachten Gesundheitsschäden nicht für erwiesen. Insoweit wird das Urteil von der Revision nicht angegriffen. Streit besteht nur mehr darüber, ob der Beklagte die Operation ohne wirksame Einwilligung vorgenommen hat, ob ihm dies als Verschulden zuzurechnen ist, und ob die Atembeschwerden des Klägers und der Verlust der Stimme durch die Operation verursacht sind.

Das Berufungsgericht geht ohne Rechtsirrtum davon aus, dass der Kläger, obwohl noch minderjährig, in die Vornahme der Operation wirksam einwilligen konnte und die Zustimmung des gesetzlichen Vertreters nicht erforderlich war.

In der Rechtsprechung der Zivilsenate des Reichsgerichts, der Erman (Anm. $1 \mathrm{zu} \S 107 \mathrm{BGB}$ ) und Soergel (8. Aufl. Anm. $3 \mathrm{zu} \S 107$ BGB) folgen (ebenso Enneccerus-Nipperdey Allg. Teil des Bürgerlichen Gesetzbuches $1955 \S 151$ II e), wird die Auffassung vertreten, dass die 
Berechtigung des Arztes zur Vornahme einer Operation grundsätzlich durch die Zustimmung des gesetzlichen Vertreters bedingt ist und die persönliche Einwilligung des Minderjährigen auch dann nicht genügt, die Rechtswidrigkeit des Eingriffs auszuschließen, wenn dieser "eine gewisse Verstandesreife erlangt hat". ( RG JW 1911, 748 = WarnR 1911, 398; RGZ 68, $431 ; 168,206)$. Dem vermag der erkennende Senat nicht zu folgen, und zwar aus folgenden Erwägungen:

Bei der Einwilligung $\mathrm{zu}$ einem Eingriff in die körperliche Integrität handelt es sich nicht um eine Einwilligung im Sinne des $\S 183$ BGB , nicht um die Zustimmung zu einem Rechtsgeschäft, also nicht um eine rechtsgeschäftliche Willenserklärung, sondern um eine Gestattung oder Ermächtigung zur Vornahme tatsächlicher Handlungen, die in den Rechtskreis des Gestattenden eingreifen. (Larenz, Schuldrecht 2. Aufl. § 66 e 1). Wie das Reichsgericht in der grundlegenden Entscheidung RGSt 41,392

(395) hierzu ausgeführt hat, gehört das Leben und die körperliche Unversehrtheit wie auch die Ehre zu den sog. Rechtsgütern, die zwar Dritten gegenüber Rechtsschutz genießen, selbst aber nicht Gegenstand eines Rechts ihres Trägers sind. Über sie kann der Mensch nicht verfügen wie über eine ihm gehörige Sache, ein ihm zustehendes dingliches Recht oder ein Rechtsverhältnis. Die Vorschriften der $\S \S 107 \mathrm{ff}$ BGB , die rechtsgeschäftliche Willenserklärungen betreffen, sind daher auf die Einwilligung $\mathrm{zu}$ einem ärztlichen Eingriff nicht unmittelbar anzuwenden.

Einer analogen Anwendung steht zwar entgegen der in RGRK, 10. Aufl. § 106 BGB Anm. 2 vertretenen Meinung nicht das Fehlen des Erfordernisses der Rechtsähnlichkeit entgegen. Die Rechtsähnlichkeit ergibt sich daraus, dass es sich um eine Willensäußerung des Minderjährigen handelt, die bedeutsame Rechtsfolgen nach sich ziehen kann. Eine analoge Anwendung erscheint jedoch nur insoweit geboten, als es der Zweck des Gesetzes: der Schutz des Minderjährigen, verlangt. Der Minderjährige kann aber eines besonderen gesetzlichen Schutzes entraten, wenn er nach seiner geistigen und sittlichen Reife die Bedeutung und Tragweite des Eingriffs und seiner Gestattung zu ermessen vermag. Ist der Minderjährige hierzu in der Lage, kann er in einen ärztlichen Eingriff wirksam einwilligen mit der Folge, dass der Eingriff als rechtmäßig zu erachten ist. Ebenso im Ergebnis Staudinger, 11. Aufl. § 107 BGB Anm. 11; RGRK aaO.; OLG München, NJW 1958, 633 ; Engisch, Die rechtliche Bedeutung der ärztlichen Operation, Jena 1958, S. 14; desgl. die Strafsenate des Reichsgerichts und des Bundesgerichtshofs in ständiger Rechtsprechung ( RGSt 41, 392 ; 60, 34, 
70, 107; BGHSt 4, 88 ) sowie das strafrechtliche Schrifttum (Maurach, Deutsches Strafrecht Allgem. Teil, 2. Aufl. $§ 28$ I 2 b; LK Mezger) Bem. 10 e vor $\S 51 \mathrm{StGB}$; Schönke/Schröder, 8. Aufl. Bem. III 6 b vor $\S 51 \mathrm{StGB}$ ). Dem Bestimmungsrecht des Minderjährigen über seine körperliche Unversehrtheit in dem vorstehend abgegrenzten Rahmen steht das elterliche Personensorgerecht ( $\S 1626$ Abs. 2 BGB ) jedenfalls dann nicht entgegen, wenn, wie im vorliegenden Falle die Einholung der elterlichen Zustimmung undurchführbar ist und der Minderjährige unmittelbar vor der Vollendung des 21. Lebensjahres steht. Für ganz besonders gelagerte Fälle lässt auch die oben angeführte Entscheidung RG Warn. 1911, 398 die Möglichkeit einer Ausnahme von dem Erfordernis der Zustimmung des gesetzlichen Vertreters offen.

Nur zur Klarstellung sei noch vermerkt, dass die Rechtswirksamkeit des ärztlichen Behandlungsvertrages mit den daran geknüpften zivilrechtlichen Folgen gemäß $\S 107$ BGB von der Einwilligung des gesetzlichen Vertreters abhängig bleibt.

Dass der Kläger nach seiner geistigen Veranlagung und Entwicklung sowie seiner sittlichen Reife fähig war, die Erheblichkeit und möglichen Folgen der Operation zu ermessen, hat das Berufungsgericht ohne Rechtsirrtum bejaht.

Dagegen wird die Annahme des Berufungsgerichts, der Beklagte habe den Kläger über die möglichen schädlichen Folgen der Operation hinreichend belehrt, den Grundsätzen, die der erkennende Senat in fester Rechtsprechung im Anschluss an das Reichsgericht über Bedeutung und Ausmaß der ärztlichen Belehrungspflicht entwickelt hat, nicht gerecht. ( BGH NJW 1956, 1106 und die dort angeführten Urteile des Reichsgerichts). Die Einwilligung des Patienten reicht nicht weiter als seine Vorstellung von den möglichen nachteiligen Folgen des Eingriffs, die er mit der Einwilligung auf sich nimmt. Eine wirksame Einwilligung setzt daher voraus, dass der Patient Wesen, Bedeutung und Tragweite des ärztlichen Eingriffs, insbesondere den Grad der Gefährlichkeit in seinen Grundzügen erkannt hat. Zwar wird nicht immer eine bis in alle Einzelheiten gehende Aufklärung erforderlich sein, der Patient muss aber, soll seine Einwilligung wirksam sein, auch ohne besondere Nachfrage beim Arzt, wenigstens über die nach ärztlicher Erfahrung typischen und die nicht äußerst selten eintretenden gesundheitsschädigenden Folgen des Eingriffs ins Bild gesetzt werden.

Nach dem Gutachten von Prof. Dr. H vom 11. August 1955 kommt es bei Kropfoperationen mit einer Häufigkeit bis zu $7 \%$ der Fälle, ohne dass dem Operateur ein Kunstfehler zur Last zu legen wäre, zu einer einseitigen oder doppelseitigen Schädigung des nervus recurrens, die eine 
Posticuslähmung und damit schwere Atemnot und eine mehr oder weniger stark ausgeprägte Heiserkeit zur Folge haben kann. Das Gutachten Dr. Jatho führt aus, bei doppelter Posticuslähmung könne zufolge Erstarrung des motorischen Stimmbandapparates keine Stimme mehr zustande kommen. Der Beklagte selbst trägt vor, es sei bekannt, dass nach Kropfoperationen einseitige und doppelseitige Nervenschädigungen aufträten. Er hat aber nach der Feststellung des Berufungsgerichts dem Kläger lediglich erklärt, es handele sich um einen schwerwiegenden Eingriff, dessen Erfolg nicht sicher sei; es sei durchaus möglich, dass die Atemnot durch die Operation nicht behoben werden könne, und die Operation stelle die einzige Möglichkeit dar, den Beschwerden des Klägers, vor allem der Schilddrüsenvergiftung abzuhelfen.

Diese Aufklärung lässt einen hinreichend klaren Hinweis auf die oben aufgeführten naheliegenden und nicht seltenen schwerwiegenden Folgen der Operation vermissen. Es fehlt vor allem jeder Hinweis auf die Möglichkeit des Verlusts der Stimme, der nach der Behauptung des Klägers auch tatsächlich eingetreten ist. Schon aus diesem Grunde muss die dem Kläger erteilte Aufklärung als unzureichend erachtet werden. Aber auch die Äußerung des Beklagten, es sei nicht sicher, ob der Kläger durch die Operation von seiner Atemnot befreit werde, kann nicht als hinreichende Aufklärung über die Möglichkeit der über den Verlust der Stimme hinausgehenden Folgen einer Nervenschädigung erachtet werden.

Die unzureichende Belehrung des Klägers hat zur Folge, dass seine Einwilligung nicht wirksam, die Vornahme der Operation daher rechtswidrig war. Da die mangelhafte Aufklärung dem Beklagten als Fahrlässigkeit zuzurechnen ist, muss er auch für die gesundheitsschädigenden Folgen der Operation einstehen, die nicht auf einen ärztlichen Kunstfehler zurückzuführen sind.

Das Berufungsgericht nimmt an, dem Kläger sei durch die Operation überhaupt kein gesundheitlicher Schaden entstanden. Es führt hierzu aus, auf Grund des Gutachtens Dr. H stehe heute zwar eine doppelseitige Posticuslähmung, die zu schweren Atemstörungen Anlass gebe, außer Frage. Durch die Zeugenaussage des Oberarztes Dr. M sei aber in einer jeden Zweifel ausschließenden Weise erwiesen, daß die beim Kläger seit der Operation vorhandenen schweren Atemstörungen in demselben Ausmaß bereits vor der Operation bestanden hätten. Es könne daher dahingestellt bleiben, ob der Sachverständige mit Recht eine Zerrung des nervus recurrens durch die Operation annehme.

Diese Erwägungen sind, wie der Revision zuzugeben ist, rechtlich nicht bedenkenfrei. Zunächst lassen sie den vom Kläger behaupteten und vom 
Beklagten nicht ernstlich bestrittenen Verlust der Stimme nach der Operation außer Betracht. Dass dieser Verlust einen Schaden für den Kläger bedeutet, bedarf keiner weiteren Ausführung.

Aber auch die Feststellung, dass die Atembeschwerden sich nach der Operation nicht verschlimmert haben, gibt zu prozessualen Bedenken Anlass, wie die Revision zu Recht rügt. Zwar hat sich das Urteil mit den Aussagen der Ärzte, die den Kläger kurz vor der Operation behandelt und keine stärkere Atemnot festgestellt haben, auseinandergesetzt. Es hat aber das Nachtragsgutachten von Dr. H, das das Vorliegen starker Atembeschwerden und einen hörbaren Stridor für die Zeit vor der Operation verneint, überhaupt nicht erwähnt. Das lässt die Möglichkeit offen, dass das Berufungsgericht bei der Beweiswürdigung dieses Gutachten nicht berücksichtigt hat, was als Prozessverstoß zu erachten ist.

Das Berufungsgericht stellt nicht fest, dass schon vor der Operation beim Kläger eine Posticuslähmung vorgelegen hat. Es gründet seine Annahme, der Kläger habe durch die Operation keinen Schaden erlitten, ausschließlich darauf, dass seine Atembeschwerden vor der Operation ebenso stark gewesen seien wie nachher. Es übersieht dabei, dass nach dem eigenen Vorbringen des Beklagten die Atembeschwerden des Klägers vor der Operation auf einer Reihe möglicher anderer Ursachen beruhen konnten, insbesondere Pressung der Luftröhre durch einen Tauchkropf, Schwellung des Kehlkopfes, Störung durch einen Fremdkörper, Hysterie. Atembeschwerden, die auf diesen Ursachen beruhten, waren aber möglicherweise einer erfolgreichen Heilbehandlung nicht in demselben Maße unzugänglich und daher nicht so schwerwiegend wie die für die Zeit nach der Operation festgestellte Posticuslähmung. Die Feststellung allein, dass die Atembeschwerden des Klägers vor und nach der Operation gleich stark gewesen sind, reicht danach, wie die Revision mit Recht rügt, zur Verneinung eines Schadens des Klägers nicht aus.

Der Rechtsstreit war nach alledem zu weiteren Erörterungen an das Berufungsgericht zurückzuverweisen.

Bei der erneuten Verhandlung ist es dem Kläger unbenommen, den vom Berufungsgericht übergangenen Beweisantrag auf Vernehmung der Eheleute $\mathrm{W} \mathrm{zu}$ wiederholen, bei denen er nach seinem Vorbringen in der Zeit vor und nach der Operation gewohnt hat. Die Aussagen dieser Zeugen sind möglicherweise geeignet, den Beweiswert der Zeugenaussage Dr. M in Frage $\mathrm{zu}$ stellen. Die in den Vorinstanzen vom Kläger weiter beantragte Vernehmung des Zeugen Dr. S erscheint dagegen nicht erforderlich, da der Beklagte im Schriftsatz vom 7. Juli 1956 zugibt, dass die Diagnose

"Posticusparese" erst nach der Entlassung des Klägers aus dem 
Krankenhaus in die Krankenblätter eingetragen worden ist und zwar auf Grund eines Befundes der Hals- Nasen- und Ohrenklinik in M. ... Damit gesteht er praktisch das zu, was der Kläger durch Dr. S beweisen will. 


\section{ANEXO VI}

\section{BUNDESGESETZBLATT}

\section{FÜR DIE REPUBLIK ÖSTERREICH}

Jahrgang 2012 Ausgegeben am 14. August 2012 Teil I

80. Bundesgesetz: Durchführung von ästhetischen Behandlungen und Operationen sowie Änderung des Ärztegesetzes 1998

(NR: GP XXIV RV1807 AB 1822 S. 167. BR: 8763 AB 8784 S. 812.)

80. Bundesgesetz, mit dem das Bundesgesetz über die Durchführung von ästhetischen Behandlungen und Operationen erlassen und das Ärztegesetz 1998 geändert wird

Der Nationalrat hat beschlossen:

\section{Artikel 1}

\section{Bundesgesetz über die Durchführung von ästhetischen Behandlungen und Operationen (ÄsthOpG)}

\section{Inhaltsverzeichnis}

$\S 1$ Ziel und Geltungsbereich

$\S 2$ Allgemeines

$\S 3$ Begriffsbestimmungen

$\S 4$ Qualifikation

$\S 5$ Ärztliche Aufklärung

$\S 6$ Einwilligung

$\S 7$ Besonderer Schutz bestimmter Personengruppen

$\S 8$ Werbebeschränkung und Provisionsverbot

$\S 9$ Operationspass

$\S 10$ Information des Krankenversicherungsträgers

$\S 11$ Strafbestimmungen

$\S 12$ Übergangsbestimmung

$\S 13$ Inkrafttreten

$\S 14$ Vollziehung

\section{Ziel und Geltungsbereich}

$\S$ 1. (1) Dieses Bundesgesetz dient dem vorbeugenden Schutz der Gesundheit und körperlichen Unversehrtheit von Patientinnen (Patienten) sowie dem Schutz vor Komplikationen und unerwünschten Folgen bei der Durchführung von ästhetischen Behandlungen und Operationen ohne medizinische Indikation.

(2) Ästhetische Behandlungen und Operationen ohne medizinische Indikation sind dann von diesem Bundesgesetz erfasst, wenn sie ärztliche 
Tätigkeiten gemäß § 2 Abs. 2 Ärztegesetz 1998, BGBl. I Nr. 169/1998, sind und dürfen diesfalls vorbehaltlich Abs. 3 und 4 nur nach Maßgabe dieses Bundesgesetzes durchgeführt werden.

(3) Auf Tätigkeiten, für die die Gewerbeordnung 1994, BGBl. I Nr. 194/1994, gilt, ist dieses Bundesgesetz nicht anzuwenden.

(4) Auf Tätigkeiten, für die das Zahnärztegesetz, BGBl. I Nr. 126/2005, gilt, ist dieses Bundesgesetz nicht anzuwenden.

\section{Allgemeines}

$\S$ 2. Soweit in diesem Bundesgesetz auf Bestimmungen anderer Bundesgesetze verwiesen wird, sind diese in ihrer jeweils geltenden Fassung anzuwenden.

\section{Begriffsbestimmungen}

§ 3. (1) Im Sinne dieses Bundesgesetzes bedeuten die Begriffe:

1. „Ästhetische Operation“ (ästhetische Chirurgie, ästhetisch-chirurgischer Eingriff, kosmetische Chirurgie, kosmetische Operation, Schönheitschirurgie, Schönheitsoperation): eine operativ-chirurgische Behandlung zur Herbeiführung einer subjektiv wahrgenommenen Verbesserung des optischen Aussehens oder der Verschönerung des menschlichen Körpers oder der ästhetischen Veränderung des körperlichen Aussehens einschließlich der Behandlung altersbedingter äußerlicher Veränderungen des Körpers ohne medizinische Indikation;

2. „Ästhetische Behandlung“: eine Behandlung mit anderen als operativchirurgischen Methoden wie insbesondere mittels Arzneimitteln und minimal-invasiver Methoden zur Herbeiführung einer subjektiv wahrgenommenen Verbesserung des optischen Aussehens oder der Verschönerung des menschlichen Körpers oder der ästhetischen Veränderung des körperlichen Aussehens einschließlich der Behandlung altersbedingter äußerlicher Veränderungen des Körpers ohne medizinische Indikation;

3. „Eingriff“: eine ästhetische Operation;

4. „Medizinische Indikation“: ein auf aktuellen medizinischwissenschaftlichen Erkenntnissen beruhender Grund, eine ästhetische Behandlung oder Operation durchzuführen. Sie liegt vor, wenn die ästhetische Behandlung oder Operation unter Berücksichtigung der Lebensverhältnisse der Patientin (des Patienten) nach objektiven Kriterien notwendig ist, um Lebensgefahr oder die Gefahr einer Beeinträchtigung des Gesundheitszustands der Patientin (des Patienten) abzuwenden oder einen anatomischen oder funktionellen Krankheitszustand zu beseitigen und die Gefahr oder der Krankheitszustand nicht auf eine gelindere für die Patientin (den Patienten) zumutbare Weise abgewendet oder beseitigt werden kann. 
(2) Die Tätigkeiten des Piercens und Tätowierens fallen nicht unter die Begriffe ,ästhetische Operation“, ,ästhetische Behandlung“" und „Eingriff“ gemäß Abs. $1 \mathrm{Z} 1$ bis 3.

\section{Qualifikation}

§ 4. (1) Ästhetische Operationen im Sinne des $\S 3$ Abs. $1 \mathrm{Z} 1$ sind jedenfalls Auflagerungsplastik, Bauchstraffung (Abdominoplastik), Brauenkorrektur, Bruststraffung (Mastopexie), Brustvergrößerung (Mammaaugmentation) und Brustverkleinerung (Mammareduktion), Eigenfetttransfer (Lipofilling), Facelift (Rhytidektomie), Fettabsaugung (Liposuction), Gesäß-Modellierung, Gesichtsimplantate, Halslift, Kinnplastik (Genioplastik), Körperstraffung (Bodylift), Korrektur abstehender Ohren (Otoplastik), Lippenvergrößerung und Lippenaufpolsterung (Lippenaugmentation), Nasenkorrektur (Rhinoplastik), Oberarmstraffung (Brachioplastik), Oberlidkorrektur und Unterlidkorrektur (Blepharoplastik), Oberschenkelstraffung (Dermolipektomie), Penisvergrößerung, Stirnlift, Vaginoplastik und Labienplastik.

(2) Ästhetische Behandlungen im Sinne des $\S 3$ Abs. 1 Z 2 sind als ärztliche Tätigkeiten gemäß $\S 2$ Abs. 2 Ärztegesetz 1998 jedenfalls Anwendungen von Arzneimitteln wie insbesondere Botulinumtoxin sowie physikalische Anwendungen wie insbesondere Photorejuvenation (Laser Skin Resurfacing, Laserpeeling, Faltenlaserung, Thermage und vergleichbare Anwendungen), wobei die Ausnahme für solche Tätigkeiten, die aufgrund der Gewerbeordnung 1994 erbracht werden, unberührt bleibt (§ 1 Abs. 3).

(3) Eine ästhetische Operation darf von folgenden Ärztinnen (Ärzten) durchgeführt werden:

1. zur selbständigen Berufsausübung berechtigte Fachärztinnen (Fachärzte) für Plastische, Ästhetische und Rekonstruktive Chirurgie,

2. weitere zur selbständigen Berufsausübung berechtigte Fachärztinnen (Fachärzte) unter Berücksichtigung des $\S 31$ Abs. 3 Ärztegesetz 1998, soweit sie durch Verordnung der Österreichischen Ärztekammer gemäß Abs. $5 \mathrm{Z} 2$ dazu berechtigt sind, und

3. zur selbständigen Berufsausübung berechtigte Ärztinnen (Ärzte) für Allgemeinmedizin, soweit sie hinsichtlich bestimmter Eingriffe über eine Anerkennung durch die Österreichische Ärztekammer verfügen. Diese Anerkennung setzt den Nachweis von Ärztinnen (Ärzten) gemäß Z 1 und 2 gleichwertigen Kenntnissen, Erfahrungen und Fertigkeiten voraus.

Sonstigen Ärztinnen (Ärzten) ist die Durchführung ästhetischer Operationen vorbehaltlich Abs. 4 verboten. 
(4) Turnusärztinnen (Turnusärzte) sind zur Durchführung ästhetischer Behandlungen und Operationen nur im Zusammenhang mit ihrer Ausbildung zur Ärztin für Allgemeinmedizin (zum Arzt für Allgemeinmedizin) oder zur Fachärztin (zum Facharzt) im Rahmen des $\S 3$ Abs. 3 Ärztegesetz 1998 berechtigt.

(5) Die Österreichische Ärztekammer hat im übertragenen Wirkungsbereich durch Verordnung gemäß § 117c Abs. 2 Z 10 Ärztegesetz 1998 Bestimmungen über

1. weitere über Abs. 1 hinausgehende ästhetische Operationen,

2. weitere Fachärztinnen (Fachärzte), die unter Berücksichtigung des $\S 31$ Abs. 3 Ärztegesetz 1998 zur Durchführung bestimmter ästhetischer Operationen im Sinne dieses Bundesgesetzes berechtigt sind (Abs. 3 Z 2), und

3. die von Ärztinnen (Ärzten) für Allgemeinmedizin nachzuweisenden gleichwertigen Kenntnisse, Erfahrungen und Fertigkeiten, die diese zur Durchführung bestimmter ästhetischer Operationen im Sinne dieses Bundesgesetzes berechtigen (Abs. 3 Z 3), einschließlich des Verfahrens zur Anerkennung der entsprechenden Nachweise bei Gleichwertigkeit entsprechend den Grundsätzen des $\S 14$ Abs. 5 und 6 Ärztegesetz 1998, jedoch unbeschadet der Zuständigkeit des Präsidenten der Österreichischen Ärztekammer, zu erlassen.

(6) Die Österreichische Ärztekammer hat im eigenen Wirkungsbereich nach Meldung der gemäß Abs. 3 berechtigten Ärztinnen (Ärzte) auf ihrer Website für Patientinnen (Patienten) gut sichtbar und allgemein zugänglich zu verlautbaren:

1. jene Fachärztinnen (Fachärzte) für Plastische, Ästhetische und Rekonstruktive Chirurgie, die ästhetische Operationen im Sinne dieses Bundesgesetzes durchführen,

2. jene Fachärztinnen (Fachärzte) gemäß Abs. 5 Z 2, die zur Durchführung bestimmter ästhetischer Operationen berechtigt sind, einschließlich der diesen zugeordneten ästhetischen Operationen sowie

3. jene Ärztinnen (Ärzte) für Allgemeinmedizin, die auf Grund nachgewiesener gleichwertiger Kenntnisse, Erfahrungen und Fertigkeiten gemäß Abs. 5 Z 3 zur Durchführung bestimmter ästhetischer Operationen berechtigt sind.

(7) Ärztinnen (Ärzte) gemäß Abs. 3 sind verpflichtet, zur Information über die neuesten Entwicklungen und Erkenntnisse der medizinischen Wissenschaft im Bereich der von ihnen angebotenen und durchgeführten ästhetischen Behandlungen und Operationen spezielle fachspezifische Fortbildungen $\mathrm{zu}$ absolvieren. Näheres ist von der Österreichischen 
Ärztekammer durch Verordnung gemäß $§ 117 b$ Abs. 2 Z 9 lit. a Ärztegesetz 1998 zu bestimmen.

(8) Die Patientin (Der Patient) ist von der behandelnden Ärztin (vom behandelnden Arzt) über deren (dessen) berufsrechtliche Qualifikation gemäß Abs. 3 und auf Nachfrage über die von dieser (diesem) absolvierten fachspezifischen Fortbildungen zu informieren.

(9) Das Anführen eines Hinweises

1. „Ästhetische Chirurgie“ und

2. „Ästhetische Medizin“"

ist ausschließlich Ärztinnen (Ärzten) gemäß Abs. 3 entsprechend der jeweiligen berufsrechtlichen Qualifikation erlaubt. Die Verwendung sonstiger Hinweise im Zusammenhang mit dem Anbieten oder der Durchführung von ästhetischen Operationen im Sinne des $\S 3$ Abs. 1 Z 1ist unzulässig.

\section{Ärztliche Aufklärung}

§ 5. (1) Die Ärztin (Der Arzt) hat vor der Durchführung einer ästhetischen Operation die Patientin (den Patienten) klar und verständlich über

1. die Methode des Eingriffs,

2. Wesen, Bedeutung und Tragweite des Eingriffs,

3. im Rahmen des Eingriffs angewendete Arzneimittel und deren Nebenwirkungen sowie Medizinprodukte einschließlich Implantate und deren Funktionsfähigkeit und Lebensdauer,

4. alternative Behandlungsmöglichkeiten,

5. das in Aussicht gestellte Ergebnis des Eingriffs und möglicher Abweichungen,

6. mit dem Eingriff verbundene Unannehmlichkeiten, mögliche Folgen, wie Narbenbildung, und Komplikationen einschließlich der Beeinträchtigung von Organfunktionen, allenfalls unter Zuhilfenahme von beispielhaften Fotografien, sowie deren Behandlungsmöglichkeiten,

7. die erforderliche Nachbehandlung einschließlich der voraussichtlichen

Dauer der Arbeitsunfähigkeit und mögliche Spätfolgen, allfällig erforderliche Nachfolgeoperationen einschließlich den Hinweis, dass diese Unfähigkeit der Arbeitsaufnahme als keine Arbeitsunfähigkeit im sozialversicherungs- und arbeitsrechtlichen Sinn gelten könnte,

8. sämtliche bekannte Gefahren des Eingriffs und

9. sämtliche im Zusammenhang mit dem Eingriff stehende Kosten einschließlich zu erwartender Folgekosten (Abs. 6 bis 9)

umfassend mündlich und schriftlich in einer für medizinische Laiinnen (Laien) verständlichen Sprache aufzuklären. Ein allfälliger Verzicht auf diese ärztliche Aufklärung ist rechtsunwirksam. 
(2) Entsteht im Rahmen der ärztlichen Aufklärung der Verdacht, dass bei der Patientin (dem Patienten) eine krankheitswertige psychische Störung vorliegt, deren Folge der Wunsch nach der ästhetischen Operation ist, so ist von der behandelnden Ärztin (vom behandelnden Arzt) vor Durchführung des Eingriffs eine Abklärung allfälliger psychischer Störungen einschließlich Beratung durch eine klinische Psychologin (einen klinischen Psychologen) oder eine Fachärztin (einen Facharzt) für Psychiatrie und Psychotherapeutische Medizin zu veranlassen.

(3) In den Fällen des $\S 7$ sind zusätzlich die Erziehungsberechtigten oder erforderlichenfalls die Sachwalterin (der Sachwalter) im Sinne des Abs. 1 aufzuklären.

(4) Die erfolgte ärztliche Aufklärung ist schriftlich in gut lesbarer Form zu dokumentieren und von der Patientin (dem Patienten) sowie in den Fällen des $\S 7$ zusätzlich von den Erziehungsberechtigten oder erforderlichenfalls der Sachwalterin (dem Sachwalter) durch deren (dessen) Unterschrift zu bestätigen.

(5) Die Ärztin (Der Arzt) hat im Rahmen ihrer (seiner) Dokumentationspflicht eine Fotodokumentation über

1. den Status vor dem geplanten Eingriff und

2. das Ergebnis des durchgeführten Eingriffs anzulegen.

(6) Im Rahmen der ärztlichen Aufklärung über die Kosten der ästhetischen Operation (Abs. 1 Z 9) ist die Patientin (der Patient) insbesondere auch darüber zu informieren, dass die Behandlungskosten nicht von einem inländischen Träger der Sozialversicherung oder der Krankenfürsorge übernommen werden und dass diese von der Patientin (vom Patienten) zu tragen sind.

(7) Die ärztliche Aufklärung über die von der Patientin (vom Patienten) zu tragenden Kosten der ästhetischen Operation (Abs. 1 Z 9) hat in Form eines schriftlichen Kostenplans zu erfolgen, sofern

1. im Hinblick auf die Art und den Umfang der Behandlung wesentliche Kosten (Abs. 8) anfallen,

2. die Kosten die in der jeweils geltenden privatärztlichen Honorarordnung der entsprechenden Ärztekammer festgelegte Honorarhöhe übersteigen oder

3. dies die Patientin (der Patient) verlangt.

(8) Wesentliche Kosten im Sinne des Abs. 7 Z 1 sind 70\% der von Statistik Austria gemäß volkswirtschaftlicher Gesamtrechnung laut ESVG 1995 ermittelten Nettolöhne und Gehälter, nominell, monatlich je Arbeitnehmerin (Arbeitnehmer). Die Österreichische Ärztekammer hat im übertragenen Wirkungsbereich die wesentlichen Kosten ein Mal jährlich bis längstens 1. Oktober jeden Jahres auf ihrer Website auszuweisen. 
(9) Die Ärztin (Der Arzt) hat gegebenenfalls die Inhalte der jeweils geltenden privatärztlichen Honorarordnung der entsprechenden Ärztekammer in einer für die Patientinnen (Patienten) gut sichtbaren Form zugänglich zu machen und eine schriftliche Ausfertigung der Patientin (dem Patienten) auszuhändigen.

\section{Einwilligung}

§ 6. (1) Eine ästhetische Operation darf nur durchgeführt werden, wenn die Patientin (der Patient) nach umfassender ärztlicher Aufklärung (§ 5) ihre (seine) Einwilligung nachweislich dazu erteilt hat. Bei einer ästhetischen Operation ist überdies eine Frist von zumindest zwei Wochen zwischen der abgeschlossenen ärztlichen Aufklärung und der Einwilligung einzuhalten. Der Bundesminister für Gesundheit kann durch Verordnung für Personen ohne Wohnsitz in Österreich, die nur zum Zweck der Vornahme einer ästhetischen Operation nach Österreich einreisen, eine kürzere Frist, die zumindest eine Woche zu betragen hat, bestimmen. Dabei ist auf den mit der Reise verbundenen Aufwand, insbesondere die Wegstrecke, Bedacht zu nehmen.

(2) Die Einwilligung der Patientin (des Patienten) gemäß Abs. 1 ist schriftlich zu dokumentieren. Die Einwilligung muss datiert und mit der Unterschrift der Patientin (des Patienten) und der behandelnden Ärztin (des behandelnden Arztes) versehen werden. Sofern die Patientin (der Patient) dazu nicht in der Lage ist, muss die Einwilligung vor einer (einem) von der Patientin (dem Patienten) beizustellenden unabhängigen Zeugin (Zeugen) abgegeben werden, die (der) die Einwilligung durch ihre (seine) Unterschrift zu bestätigen hat. Eine Kopie der unterfertigten schriftlichen ärztlichen Aufklärungs-und Einwilligungsunterlagen ist der Patientin (dem Patienten) auszuhändigen.

(3) Eine ästhetische Operation darf frühestens an dem, dem Tag des Vorliegens der gemäß Abs. 1 und 2 zu erteilenden Einwilligung folgenden Tag, erfolgen.

\section{Besonderer Schutz bestimmter Personengruppen}

§ 7. (1) Eine ästhetische Behandlung oder Operation an Personen, die das 16. Lebensjahr noch nicht vollendet haben, ist unzulässig.

(2) Eine ästhetische Behandlung oder Operation darf an Personen, die das 16. Lebensjahr vollendet und das 18. Lebensjahr noch nicht vollendet haben, nur durchgeführt werden, wenn

1. die Einwilligung durch die Erziehungsberechtigten nach entsprechender umfassender ärztlicher Aufklärung gemäß $\S 5$ nachweislich und schriftlich gemäß $\S 6$ Abs. 2 erteilt wurde und

2. die Einwilligung durch die Patientin (den Patienten), die (der) nach entsprechender umfassender ärztlicher Aufklärung (§ 5) in der Lage ist, 
Wesen, Bedeutung, Tragweite und Risiken der ästhetischen Behandlung oder Operation einzusehen und ihren (seinen) Willen danach zu bestimmen, nachweislich und schriftlich gemäß $§ 6$ Abs. 2 erteilt wurde.

Bei einer ästhetischen Operation hat zusätzlich vor Durchführung des Eingriffs nachweislich eine Abklärung allfälliger psychischer Störungen einschließlich Beratung durch eine klinische Psychologin (einen klinischen Psychologen), eine Fachärztin (einen Facharzt) für Psychiatrie und Psychotherapeutische Medizin oder eine Fachärztin (einen Facharzt) für Kinder- und Jugendpsychiatrie $\mathrm{zu}$ erfolgen. Das Vorliegen einer krankheitswertigen psychischen Störung schließt die Durchführung des Eingriffs aus, sofern im Rahmen der erfolgten Abklärung festgestellt wurde, dass der Wunsch nach dem Eingriff Folge dieser Störung ist.

(3) Eine ästhetische Behandlung oder Operation darf an Personen, denen infolge einer psychischen Krankheit oder geistigen Behinderung zur Vertretung hinsichtlich medizinischer Behandlungen eine Sachwalterin (ein Sachwalter) bestellt ist, nur dann durchgeführt werden, wenn die Einwilligung durch die Patientin (den Patienten), sofern sie (er) nach entsprechender umfassender ärztlicher Aufklärung (§ 5) in der Lage ist, Wesen, Bedeutung, Tragweite und Risiken der ästhetischen Behandlung oder Operation einzusehen und ihren (seinen) Willen danach zu bestimmen, nachweislich und schriftlich gemäß $\S 6$ Abs. 2 erteilt wurde. Ist die Patientin (der Patient) nicht einsichts- und urteilsfähig, so ist die Einwilligung durch die Sachwalterin (den Sachwalter) nach entsprechender umfassender ärztlicher Aufklärung ( $§ 5$ ) nachweislich und schriftlich zu erteilen.

(4) Wird die Einwilligung durch Personen, die das 16. Lebensjahr vollendet und das 18. Lebensjahr noch nicht vollendet haben, oder denen infolge einer psychischen Krankheit oder geistigen Behinderung zur Vertretung hinsichtlich medizinischer Behandlungen eine Sachwalterin (ein Sachwalter) bestellt ist, bis spätestens eine Woche vor dem Behandlungsoder Operationstermin widerrufen, so darf der Patientin (dem Patienten) dadurch kein finanzieller Nachteil entstehen.

(5) Eine ästhetische Behandlung oder Operation an Personen, die das 16. Lebensjahr vollendet und das 18 . Lebensjahr noch nicht vollendet haben, oder denen infolge einer psychischen Krankheit oder geistigen Behinderung zur Vertretung hinsichtlich medizinischer Behandlungen eine Sachwalterin (ein Sachwalter) bestellt ist, darf frühestens vier Wochen nach Vorliegen der zu erteilenden Einwilligungen (Abs. 2 und 3) durchgeführt werden.

\section{Werbebeschränkung und Provisionsverbot}


§ 8. (1) Die Ärztin (Der Arzt) hat sich im Zusammenhang mit der Durchführung ästhetischer Behandlungen oder Operationen jeder diskriminierenden, unsachlichen, unwahren oder das Standesansehen beeinträchtigenden Anpreisung, Werbung oder der Selbstanpreisung durch reklamehaftes Herausstellen ihrer (seiner) Person oder ihrer (seiner) Leistungen $\mathrm{zu}$ enthalten. Fachliche Informationen über eigene Tätigkeitsgebiete einschließlich Hinweise auf wissenschaftliche Arbeiten stellen keine Werbung im Sinne dieses Bundesgesetzes dar.

(2) Für ästhetische Behandlungen oder Operationen im Sinne dieses Bundesgesetzes darf insbesondere nicht geworben werden:

1. mit Angaben, dass die ästhetische Behandlung oder Operation ärztlich, zahnärztlich oder anderweitig fachlich empfohlen oder geprüft ist oder angewendet wird,

2. mit Hinweisen auf die besondere Preisgünstigkeit der ästhetischen Behandlung oder Operation oder dem Anbieten kostenloser Beratungsgespräche,

3. durch Werbevorträge,

4. mit Werbemaßnahmen, die sich ausschließlich oder überwiegend an Minderjährige richten und

5. mit Preisausschreiben, Spielen, Verlosungen oder vergleichbaren Verfahren.

Bei der Verwendung von Fotografien, die mittels Bildbearbeitungsprogrammen verändert wurden, sind diese als verändert und nicht der Realität entsprechend zu kennzeichnen.

(3) Die Ärztin (Der Arzt) darf sich oder einer (einem) Anderen keine Vergütungen für die Zuweisung von Patientinnen (Patienten) an sie (ihn) oder durch sie (ihn) versprechen, geben, nehmen oder zusichern lassen. Rechtsgeschäfte, die gegen dieses Verbot verstoßen, sind nichtig. Leistungen aus solchen Rechtsgeschäften können zurückgefordert werden.

(4) Die Vornahme der gemäß Abs. 1 bis 3 verbotenen Tätigkeiten ist auch Gruppenpraxen gemäß § 52a Ärztegesetz 1998 sowie sonstigen physischen und juristischen Personen untersagt.

(5) Die Anpreisung oder Werbung im Sinne der Abs. 1 und 2 durch ein Unternehmen mit Sitz außerhalb des Geltungsbereichs dieses Gesetzes ist unzulässig.

(6) Die Abs. 1 und 2 sind auch auf die entgeltliche Vermittlung von ästhetischen Behandlungen oder Operationen durch Dritte anzuwenden.

(7) Die Österreichische Ärztekammer, die Ärztekammern in den Bundesländern und die gesetzlich eingerichteten Patientenvertretungen sind berechtigt, Ansprüche auf Unterlassung wettbewerbswidrigen Verhaltens (insbesondere gemäß $\S 14$ des Bundesgesetzes gegen den unlauteren 
Wettbewerb 1984 - UWG, BGB1. Nr. 448/1984) vor den Gerichten geltend zu machen.

\section{Operationspass}

§ 9. (1) Für jede Patientin (jeden Patienten), an der (dem) beabsichtigt ist, eine oder mehrere ästhetische Operationen durchzuführen, ist im Rahmen der ersten ärztlichen Konsultation ein Operationspass anzulegen.

(2) Der Operationspass gemäß Abs. 1 hat insbesondere folgende Angaben zu enthalten:

1. Vornamen und Familien- oder Nachname, Geburtsdatum und gegebenenfalls Sozialversicherungsnummer der Patientin (des Patienten),

2. Name und Qualifikation ( $§ 4$ Abs. 3) der behandelnden Ärztin (des behandelnden Arztes),

3. Datum und Grund der ersten sowie aller folgenden ärztlichen Konsultationen sowie gegebenenfalls der Abklärung gemäß $\S 5$ Abs. 2 oder $\S 7$ Abs. 2,

4. Datum der ästhetischen Operation,

5. Art der ästhetischen Operation und

6. gegebenenfalls Bezeichnung, Art und Typ, Loscode oder Seriennummer des Implantats samt Name und Anschrift des Herstellers und des Vertreibers.

(3) Die Österreichische Ärztekammer hat im übertragenen Wirkungsbereich durch Verordnung gemäß § 117c Abs. 2 Z 10 Ärztegesetz 1998 nähere Bestimmungen über Form und Inhalt des Operationspasses zu erlassen.

(4) Die Eintragungen im Operationspass sind von der behandelnden Ärztin (dem behandelnden Arzt) mit ihrer (seiner) Unterschrift zu bestätigen.

(5) Der Operationspass ist der Patientin (dem Patienten) nach der ersten ärztlichen Konsultation zu übergeben. Die Übergabe des Operationspasses an die Patientin (den Patienten) ist von der Ärztin (dem Arzt) schriftlich zu dokumentieren und von der Patientin (dem Patienten) durch ihre (seine) Unterschrift zu bestätigen.

(6) Jede weitere ärztliche Konsultation und durchgeführte ästhetische Operation ist in der Folge ebenfalls in dem von der Patientin (dem Patienten) vorzulegenden Operationspass von der Ärztin (dem Arzt) schriftlich zu dokumentieren und von der Patientin (dem Patienten) durch ihre (seine) Unterschrift zu bestätigen. Abs. 2 Z 2 bis 6 ist anzuwenden.

(7) Hinsichtlich Personen gemäß $\S 7$ ist auch für ästhetische Behandlungen ein Operationspass anzulegen. Abs. 1 bis 6 sind anzuwenden.

\section{Information des Krankenversicherungsträgers}

§ 10. Bei Verdacht, dass eine fehlerhaft durchgeführte ästhetische Behandlung oder Operation im Sinne dieses Bundesgesetzes zu einer 
Erkrankung oder sonstigen Komplikation geführt hat, haben nachbehandelnde Ärztinnen (Ärzte), die die ästhetische Behandlung oder Operation durchgeführt haben, sowie sonstige nachbehandelnde Ärztinnen (Ärzte) die entsprechenden Informationen an den gesetzlichen Krankenversicherungsträger, die Krankenfürsorgeanstalt oder den gesetzlichen Pensionsversicherungsträger zur Prüfung eines allfälligen Regressanspruches zu übermitteln, sofern es sich bei der Nachbehandlung um eine sozialversicherungsrechtlich erstattungsfähige Leistung handelt.

\section{Strafbestimmungen}

$\S$ 11. (1) Wer einer oder mehreren in den $\S \S 4,5,6,7,8,9$ Abs. 1 und 4 bis 6 sowie $\S 10$ enthaltenen Anordnungen oder Verboten zuwider handelt, begeht, sofern die Tat nicht den Tatbestand einer in die Zuständigkeit der Gerichte fallenden strafbaren Handlung bildet, eine Verwaltungsübertretung und ist mit einer Geldstrafe bis zu 15000 Euro zu bestrafen. Der Versuch ist strafbar.

(2) Sofern

1. aus der Tat gemäß Abs. 1 eine schwerwiegende Gefahr für Leib und Leben oder die Gesundheit eines Menschen entstanden ist oder

2. die Täterin (der Täter) bereits zwei Mal wegen einer Verwaltungsübertretung gemäß Abs. 1 bestraft worden ist, ist die Täterin (der Täter) mit einer Geldstrafe bis zu 25000 Euro zu bestrafen.

\section{Übergangsbestimmung}

$\S$ 12. (1) Vor Inkrafttreten dieses Bundesgesetzes begonnene oder vertraglich vereinbarte ästhetische Behandlungen und Operationen, die im Zeitpunkt des Inkrafttretens noch nicht abgeschlossen sind, sowie in unmittelbarem Zusammenhang mit diesem Eingriff stehende unbedingt erforderliche Nachbehandlungen sind von der Anwendung dieses Bundesgesetzes ausgenommen.

(2) Nachweisverfahren gemäß $§ 4$ Abs. 3 Z 3 betreffend Ärztinnen (Ärzte) für Allgemeinmedizin, die bereits vor dem 1. Jänner 2013 ästhetische Operationen vorgenommen haben, sind bis längstens 1. Juli 2013 abzuschließen. Entsprechende Anträge können bereits vor Inkrafttreten dieses Gesetzes, längstens aber bis zum Ablauf des 31. Jänner 2013 gestellt werden. Bis zum Abschluss dieses Verfahrens ist die jeweilige Ärztin (der jeweilige Arzt) berechtigt, die bisher durchgeführten Eingriffe weiterhin vorzunehmen.

(3) Verordnungen auf Grundlage dieses Bundesgesetzes können bereits vor seinem Inkrafttreten ( $\S 13)$ erlassen werden. Sie dürfen frühestens mit Inkrafttreten dieses Bundesgesetzes in Kraft treten.

\section{Inkrafttreten}


$\S$ 13. Dieses Bundesgesetz tritt mit 1. Jänner 2013 in Kraft.

\section{Vollziehung}

$\S$ 14. Mit der Vollziehung dieses Bundesgesetzes ist die Bundesministerin für Gesundheit (der Bundesminister für Gesundheit) betraut.

\section{Artikel 2}

\section{Bundesgesetz, mit dem das Ärztegesetz 1998 geändert wird}

Das Bundesgesetz über die Ausübung des ärztlichen Berufes und der Standesvertretung der Ärzte (Ärztegesetz 1998 - ÄrzteG 1998), BGB1. I Nr. 169/1998, zuletzt geändert durch das Bundesgesetz BGBl. I Nr. 50/2012, wird wie folgt geändert:

1. Am Ende des § 43 Abs. $4 Z 4$ wird der Punkt durch einen Beistrich ersetzt und danach wird folgende $Z 5$ angefügt:

„5. Hinweise gemäß $§ 4$ Abs. 9 des Bundesgesetzes über die Durchführung von ästhetischen Behandlungen und Operationen (ÄsthOpG), BGBl. I Nr. 80/2012.“

1a. § 91 Abs. 2 werden folgende Sätze angefügt:

„Zur Unterstützung im Zusammenhang mit der Einhebung der Kurienumlage kann sich die Kurienversammlung eines Dritten bedienen. Die Betrauung eines Dritten ist in der Umlagenordnung zu regeln."

2. Am Ende des $\S 117 b$ Abs. 1 Z $22 a$ entfällt das Wort "sowie“, am Ende $\operatorname{der} Z 23$ wird das Wort ,sowie“ angefügt, wobei der Punkt durch einen Beistrich ersetzt wird und danach wird folgende Z 24 angefügt:

„24. Verlautbarungen gemäß $§ 4$ Abs. 6 ÄsthOpG.“

3. Am Ende des $\$ 117$ c Abs. 1 Z 5 wird der Punkt durch einen Strichpunkt ersetzt und danach wird folgende $Z 6$ angefügt:

„6. Durchführung von Verfahren gemäß $§ 4$ Abs. 3 Z 3 ÄsthOpG.““

4. Am Ende des $\$ 117$ c Abs. 2 Z 8 entfällt das Wort „sowie“, am Ende der Z 9 wird nach dem Klammerausdruck das Wort „sowie“ angefügt, wobei der Punkt entfällt und danach wird folgende $Z 10$ angefügt:

„10. Verordnung über Qualifikationen und einen Operationspass für ästhetische Operationen (§ 4 Abs. 5 und $\S 9$ ÄsthOpG).“

5. Im $\S 122 \mathrm{Z} 6$ wird der Ausdruck, §117c Abs. $2 \mathrm{Z} 1$ bis 9“ durch den Ausdruck ,§ $117 \mathrm{c}$ Abs. $2 \mathrm{Z} 1$ bis 10“ ersetzt.

6. $\S 125$ Abs. 4 zweiter Satz lautet wie folgt:

„Er entscheidet mit Bescheid als erste und letzte Instanz in den Verfahren gemäß $\S 15$ Abs. 6, § 27 Abs. 10 und 11 und $\S 59$ Abs. 3 ÄrzteG 1998 sowie gemäß $\S 4$ Abs. 3 Z 3 ÄsthOpG.“

7. $\$ 130$ Abs. 1 werden folgende Sätze angefügt:

„Die Bestellung eines zweiten gleichrangigen Kammeramtsdirektors ist zulässig. Wenn ein zweiter Kammeramtsdirektor bestellt wird, hat zumindest ein Kammeramtsdirektor rechtskundig zu sein.“ 
8. Nach $\S 230$ wird folgender $\$ 231$ samt Überschrift angefügt: „Schlussbestimmung zur Ärztegesetz-Novelle BGBI. I Nr. 80/2012 $\S$ 231. $\S 130$ Abs. 1 in der Fassung der Ärztegesetz-Novelle BGBl. I Nr. 80/2012 tritt mit 1. April 2012 in Kraft.“

Fischer

Faymann 


\section{ANEXO VII}

\section{LEGGE 5 giugno 2012, n.86}

Istituzione del registro nazionale e dei registri regionali degli impianti protesici mammari, obblighi informativi alle pazienti, nonche' divieto di intervento di plastica mammaria alle persone minori. (12G0106) (G.U. Serie Generale n. 148 del 27 giugno 2012)

La Camera dei deputati ed il Senato dela Repubblica
hanno approvato;

\section{IL PRESIDENTE DELLA REPUBBLICA}

Promulga

la seguente legge:

Art. 1

Registro degli impianti protesici mammari

1. Il Ministero della salute, le regioni e le province autonome di Trento e di Bolzano istituiscono, rispettivamente, il registro nazionale e $\mathrm{i}$ registri regionali degli impianti protesici mammari effettuati in Italia, nell'ambito della chirurgia plastica, ricostruttiva ed estetica.

2. I registri di cui al comma 1 si inquadrano nel campo del monitoraggio clinico ed epidemiologico delle attivita' di chirurgia plastica, ricostruttiva ed estetica.

3. I registri di cui al comma 1 sono istituiti a fini di:

a) monitoraggio clinico del soggetto sottoposto a impianto, allo scopo di prevenire le complicanze e migliorare la gestione clinicoassistenziale degli eventuali effetti indesiderati ed esiti a distanza;

b) monitoraggio epidemiologico, a scopo di studio e ricerca scientifica in campo clinico e biomedico e di programmazione, gestione, controllo e valutazione dell'assistenza sanitaria.

4. Per il raggiungimento delle finalita' di cui al comma 3 , i registri raccolgono dati relativi agli impianti protesici di cui al comma 1 , con particolare riguardo alle informazioni concernenti la tipologia e durata degli impianti, con informazioni dettagliate circa il materiale di 
riempimento utilizzato ed etichettatura del prodotto, gli effetti collaterali ad essi connessi nonche' l'incidenza dei tumori mammari e delle malattie autoimmuni.

5. I registri regionali raccolgono i dati e trattano l'informazione in modo da perseguire gli obiettivi di cui alle lettere a) e b) del comma 3; il registro nazionale raccoglie $i$ dati $e$ tratta l'informazione per perseguire le finalita' di cui alla lettera $b$ ) del comma 3.

6. I dati personali oggetto di trattamento sono raccolti, nel rispetto della normativa vigente in materia di protezione dei dati personali, in conformita' ai principi di liceita', proporzionalita', necessita' e indispensabilita' del trattamento dei dati personali.

Accedono ai registri regionali per l'inserimento e la consultazione dei dati individuali e nominativi, per le finalita' di cui alla lettera a) del comma 3, i medici e gli altri professionisti sanitari che prendono in cura il soggetto sottoposto all'impianto, al momento dell'impianto stesso e nell'eventualita' di effetti indesiderati o esiti a distanza, previa autorizzazione del titolare del registro regionale. Il trattamento dei dati raccolti nel registro nazionale e nei registri regionali per le finalita' di cui alla lettera b) del comma 3 e' consentito, rispettivamente, al Ministero della salute e alle regioni e alle province autonome di Trento e di Bolzano nei limiti delle competenze loro attribuite dalla legge, senza l'utilizzo dei dati identificativi dei soggetti, secondo livelli di accesso, modalita' e criteri di organizzazione ed elaborazione dei dati definiti con il regolamento di cui al comma 8. L'accesso ai dati dei registri per le finalita' di ricerca scientifica in campo clinico e biomedico e' altresi' consentito agli interessati che ne facciano richiesta, nel rispetto della normativa vigente in materia di protezione dei dati personali e delle misure e regole stabilite con il regolamento di cui al comma 8.

1. Entro sei mesi dalla data di entrata in vigore della presente legge, con regolamento adottato, ai sensi dell'articolo 17, comma 3, della legge 23 agosto 1988, n. 400, con decreto del Ministro della salute, previa intesa in sede di Conferenza permanente per i rapporti tra lo Stato, le regioni e le province autonome di Trento e di Bolzano, acquisito il parere del Garante per la protezione dei dati personali, ai sensi dell'articolo 154, comma 4, del codice in materia di protezione dei dati personali, di cui al decreto legislativo 30 giugno 2003, n. 196, si provvede a disciplinare:

a) i tempi e le modalita' di raccolta dei dati nel registro nazionale, istituito presso la Direzione generale dei farmaci e dispositivi medici del Ministero della salute, e gli obblighi informativi delle regioni e 
delle province autonome di Trento e di Bolzano nei confronti del registro nazionale;

b) i tipi di dati sensibili e le operazioni eseguibili;

c) i soggetti che possono avere accesso ai dati del registro nazionale e dei registri regionali, anche in relazione al loro diverso livello di aggregazione;

d) le modalita' di trasmissione tra le regioni dei dati raccolti fuori della regione di residenza del soggetto sottoposto a impianto;

e) le garanzie e le misure di sicurezza da adottare nel trattamento dei dati personali, nel rispetto dei diritti del soggetto sottoposto all'impianto;

f) la definizione e le relative modalita' di attribuzione di un codice identificativo univoco del soggetto, che non consenta l'identificazione diretta dell'interessato, fatto salvo quanto previsto dall'articolo 4, comma 2.

\section{Art. 2}

\section{Limiti di eta'}

1. L'impianto di protesi mammaria a soli fini estetici $\mathrm{e}^{\prime}$ consentito soltanto su coloro che abbiano compiuto la maggiore eta'. Il divieto di cui al primo periodo non si applica nei casi di gravi malformazioni congenite certificate da un medico convenzionato con il Servizio sanitario nazionale o da una struttura sanitaria pubblica.

2. L'inosservanza del divieto di cui al comma 1 e' punita con l'applicazione della sanzione amministrativa del pagamento di una somma pari a 20.000 euro a carico degli operatori sanitari che provvedono all'esecuzione dell'impianto. Gli operatori sanitari che provvedono all'esecuzione dell'impianto sono altresi' sottoposti alla sospensione dalla professione per tre mesi.

\section{Art. 3}

\section{Requisiti per l'applicazione di protesi mammarie}

1. L'applicazione di protesi mammarie per fini estetici e' riservata a coloro che sono in possesso del titolo di specializzazione in chirurgia plastica o a chi, alla data di entrata in vigore della presente legge, ha svolto attivita' chirurgica equipollente nei precedenti cinque anni o e' in possesso del titolo di specializzazione in chirurgia generale, 
ginecologia e ostetricia o

chirurgia toracica.

\section{Art. 4}

\section{Modalita' di custodia e di accesso ai registri}

1. I registri regionali sono custoditi presso le unita' organizzative delle regioni e delle province autonome competenti, come individuate da provvedimenti regionali e provinciali.

2. I dati individuali sono obbligatoriamente e tempestivamente comunicati ai registri regionali dai soggetti di cui all'articolo 1, comma 7, operanti nelle strutture sanitarie pubbliche e private autorizzate dove sono effettuati interventi di plastica mammaria o dove sono seguiti le complicanze a distanza o gli effetti non desiderati, mediante l'attribuzione di un codice identificativo univoco del soggetto sottoposto all'impianto, che non consenta l'identificazione diretta dell'interessato. Qualora, per il verificarsi di incidenti correlati allo specifico tipo o modello di protesi impiantata, occorra risalire all'identita' dell'interessato, la decodificazione dei predetti dati avviene con le modalita' definite dal regolamento di cui all'articolo 1, comma 8, nel rispetto della normativa vigente in materia di protezione dei dati personali.

3. Salvo che il fatto non costituisca reato, i soggetti di cui all'articolo 1, comma 7, operanti nelle strutture pubbliche e private, che omettono di raccogliere, aggiornare e trasmettere i dati ai registri, sono puniti con la sanzione amministrativa del pagamento di una somma da euro 500 a euro 5.000 .

4. Ciascuna struttura sanitaria di cui al comma 2 compila per ogni impianto protesico mammario una scheda informativa, contenente informazioni dettagliate circa il materiale di riempimento utilizzato nella protesi, la durata dell'impianto, gli effetti collaterali dell'intervento e la presenza di eventuali controindicazioni, fermo restando il dovere del medico di raccogliere il consenso informato sottoscritto dal paziente previa visione della scheda informativa contenente informazioni riguardanti $\mathrm{i}$ benefici, $\mathrm{i}$ rischi $\mathrm{e}$ gli eventuali effetti collaterali correlati all'impianto protesico. Le regioni e le province autonome di Trento e di Bolzano verificano la coerenza tra le informazioni contenute nelle schede informative e lo stato attuale delle conoscenze ottenute dal repertorio nazionale dei dispositivi medici e dalle evidenze della letteratura scientifica.

5. Entro sei mesi dalla data di entrata in vigore della presente legge, 
le regioni e le province autonome di Trento e di Bolzano definiscono i criteri per la compilazione della scheda informativa e per lo svolgimento delle verifiche di cui al comma 4.

Art. 5

\section{Relazione al Parlamento}

Ogni due anni il Ministro della salute trasmette al Parlamento una relazione sui dati raccolti nel registro nazionale e nei registri regionali, relativamente alle finalita' di cui all'articolo 1, comma 3, lettera b), della presente legge.

Art. 6

\section{Disposizioni Finanziarie}

Dall'attuazione delle disposizioni della presente legge non devono derivare nuovi o maggiori oneri a carico della finanza pubblica.

Le amministrazioni interessate provvedono agli adempimenti previsti dalla presente legge con le risorse umane, finanziarie e strumentali disponibili a legislazione vigente.

La presente legge, munita del sigillo dello Stato, sara' inserita nella Raccolta ufficiale degli atti normativi della Repubblica italiana. E' fatto obbligo a chiunque spetti di osservarla e di farla osservare come legge dello Stato.

Data a Roma, addi' 5 giugno 2012

\section{NAPOLITANO}

Monti, Presidente de 1Consiglio dei Ministri

Balduzzi, Ministro della salute

Visto, il Guardasigilli: Severino 


\section{ANEXO VIII}

LEY No: 179925 JUL 2016

\section{POR MEDIO DE LA CUAL SE PROHÍBEN LOS PROCEDIMIENTOS MÉDICOS V QUIRÚRGICOS ESTÉTICOS PARA MENORES DE EDAD V SE DICTAN OTRAS DISPOSICION ES.}

\section{EL CONGRESO DE COLOMBIA}

\section{DECRETA:}

Artículo $1^{\circ}$. Objeto. La presente ley tiene por objeto prohibir los procedimientos médicos y quirúrgicos estéticos para pacientes menores de edad y establecer el régimen sancionatorio a quienes violen esta prohibición.

Artículo $2^{\circ}$. Definición. Para todos los efectos de la presente ley se entenderá por procedimientos médicos y quirúrgicos estéticos todo procedimiento médico o quirúrgico de corrección de alteraciones de la norma estética con la finalidad de obtener una mayor armonía facial y corporal,así como también de tratamentos médicos de embellecimiento y de rejuvenecimiento.

Artículo $3^{\circ}$. Prohibición. Se prohíbe la realización de procedimientos médicos y quirúrgicos estéticos en pacientes menores de 18 anos. EI consentimiento de los padres no constituye excepción válida a la presente prohibición.

Artículo $4^{\circ}$. Excepciones. La anterior prohibición no aplica a cirugías de nariz y de orejas, cirugías reconstructivas y/o iatrogénicas de otras cirugías, peelings químicos y mecánicos superficiales, y depilación láser. Tampoco aplica a cirugías motivadas por patologías físicas o psicológicas debidamente acreditadas por los respectivos profesionales de salud. En los casos de cirugías motivadas por patologías físicas o psicológicas, el cirujano deberá solicitar un permiso especial a la entidad territorial de salud para la realización dei procedimiento.

Parágrafo. EI Ministerio de Salud deberá establecer los trámites y 
documentos requeridos para la expedición dei permiso de que trata el inciso anterior, en um plazo no mayor a seis (6) meses contados a partir de la expedición de la presente ley.

Artículo 5․ Restricciones Publicitarias. Prohíbase la promoción publicitaria dirigida a menores de edad de procedimientos médicos y quirúrgicos estéticos.

Prohíbase el uso de modelos menores de edad en campanas de promoción de cirugías estéticas, consultorios y clínicas de cirugía estética, y procedimientos estéticos de cualquier tipo.

Prohíbase la difusión de aquellas campanas a las que se refiere el inciso anterior, que previa la entrada en vigencia de la presente ley utilizan la imagen de modelos menores de edad.

Artículo $6^{\circ}$. Deber de denuncia. Los profesionales de la salud,centros de salud, padres de familia y los ciudadanos que tengan conocimiento de posibles violaciones a la presente ley deberán denunciarias ante las autoridades competentes.

Artículo $7^{\circ}$. Sanciones. EI incumplimiento parcial o total de lo contenido en la presente ley, por personas naturales, jurídicas o establecimientos contratantes, implicará una multa mínima de $500 \mathrm{smlv}$ para cada una de las partes; la pérdida de la licencia médica, si es profesional de la salud, y el cierre definitivo dei centro de salud, si es reincidente.

Artículo $\mathbf{8}^{\circ}$. Solidaridad Los profesionales de la salud y centros de salud responderán solidariamente por las sanciones derivadas dei incumplimiento de la presente ley y por todo dano ocasionado a los pacientes, como consecuencia de la realización de estos procedimientos.

Artículo 9. Poder Sancionatorio. Se faculta a los entes territoriales de salud, para que gradúen e impongan las sanciones que surjan dei incumplimiento de la presente ley por parte de los profesionales de la salud y centros de salud.

Los valores recaudados por concepto de la imposición de multas y sanciones harán parte dei presupuesto de la entidad,y serán destinados para la creación y promoción y divulgación de campanas de educación sobre los riesgos de las cirugías plásticas estéticas. 
Artículo 10. Las disposiciones establecidas en la presente ley se aplicarán sin perjuicio de las normas establecidas en el Código de Ética Médica y demás reglamentos que rijan el ejercicio profesional de la medicina.

Artículo 11. Vigencias y derogatorias. La presente ley empezará a regir a partir de la fecha de su promulgación y deroga las disposiciones que le sean contrarias.

EL PRESIDENTE DELH. S A REPUBLICA

LUIS FERNANDO VELASCO CHAVES

EL SECRETARIO GENERAL DEL H. SENADO DE LA REPUBLICA

GREGORIO ELJACH PACHECO

EL PRESIDENTE DE LA H. CÁMARA DE REPRESENTANTES

ALFREDO RAFAEL DE UQUE ZULETA

EL SECRETARIO GENERAL DE LA H. CÁMARA DE REPRESENTANTES

JORGE HUMBERTO MANTILLA SERRANO 


\section{LEY No. 1799}

POR MEDIO DE LA CUAL SE PROHÍBEN LOS PROCEDIMIENTOS MÉDICOS Y QUIRÚRGICOS ESTÉTICOS PARA MENORES DE EDAD Y SE DICTAN OTRAS DISPOSICIONES.

\section{REPÚBLICA DE COLOMBIA - GOBIERNO NACIONAL PUBLÍQUESE Y CÚMPLASE}

Dada en Bogotá, D.C., a los 25JUL2016

EL MINISTRO DE SALUD Y PROTECCIÓN SOCIAL,

\section{ALEJANDRO GAVIRIA URIBE}

EL SECRETARIO GENERAL DEL MINISTERIO DE TECNOLOGÍAS, DE LA INFORMACIÓN Y LAS COMU A IONES, ENCARGADO DE LAS FUNCIONES DEL DESPACHO D L MI ISTRO DE TECNOLOGÍAS, DE LA INFORMACIÓN Y LAS COMUNI ACIO ES, 